Catching Our Breath: Next Steps for Reducing Urban Ozone

$$
\text { July } 1989
$$$$
\text { OTA-O-412 }
$$

NTIS order \#PB90-130451

GPO stock \#052-003-01158-1
CATCHING OUR BREATH

Next Steps for Reducing Urban Ozone

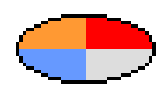




\section{Recommended Citation:}

U.S. Congress, Office of Technology Assessment, Catching Our Breath: Next Steps for Reducing Urban Ozone, OTA-O-412 (Washington, DC: U.S. Government Printing Office, July 1989).

Library of Congress Catalog Card Number 89-600715

For sale by the Superintendent of Documents

U.S. Government Printing Office, Washington, DC 20402-9325

(order form can be found in the back of this report) 


\section{Foreword}

More than a decade has passed since the last major set of amendments to the Clean Air Act. Deadlines for meeting the health-based air quality standard for ozone, the major component of urban smog, have come and gone. While some progress has been made, most metropolitan areas still do not meet the air quality goals first set by Congress in 1970 .

This report on urban ozone was requested by the Senate Committee on Environment and Public Works, the House Committee on Energy and Commerce, and its Subcommittee on Health and the Environment in anticipation of the upcoming reauthorization of the Clean Air Act. Of the air pollutants that the Act covers, ozone has been the most difficult to bring under control; it may well be the most expensive.

One of the key findings of our study is that, once again, we cannot achieve the ozone standard in all areas with currently available technology. We can make considerable progress-about two-thirds of the reductions needed, enough to bring about half of the cities into compliance with the standard-but we cannot get all the way there.

We thus conclude that an effective ozone control strategy must include measures to achieve both near-term emissions reductions using today's control methods and, just as important, measures to ensure that we can continue to make progress post-2000, when many areas will still exceed the standard. Our report presents options in both categories.

Substantial assistance was received from many organizations and individuals during the course of this study. We would like to express our thanks to our advisory panel, contractors, workshop participants, and the many reviewers who provided advice and information throughout the course of this assessment. Special thanks goes to the many individuals at the Environmental Protection Agency who answered our numerous requests for data, models, and technical assistance. OTA, however, remains solely responsible for the contents of this report.

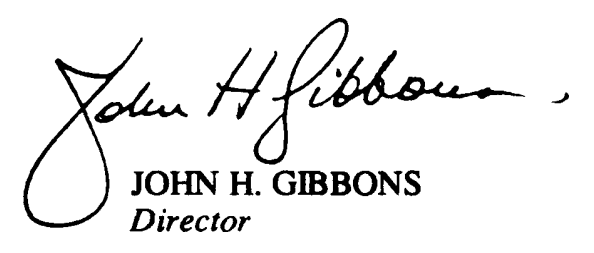




\title{
Catching Our Breath: Next Steps for Reducing Urban Ozone Advisory Panel
}

\author{
Clifford S. Russell, Chairman
}

Vanderbilt University

S. William Becker

State and Territorial Air Pollution Program

Administrators/Association of LQcal Air

Pollution Control Officials

Kelly M. Brown

Ford Motor Co.

George D. Carpenter

Procter \& Gamble

Kenneth L. Demerjian

State University of New York

Robert Frank

The Johns Hopkins University

Fran Du Melle

American Lung Association/American Thoracic Association

David Hawkins

Natural Resources Defense Council

Principal Contractors

Beryl Benderly

Sierra Research, Inc.

E.H. Pechan \& Associates

Lawrence J. Folinsbee

Additional Contributors

Alliance Technologies Corp.
Richard A. Liroff

The Conservation Foundation

Jennifer Ann Logan

Harvard University

Vincent J. Marchesani

ICI Americas, Inc.

Richard B. Stewart

University of Chicago

William Sylte

California Air Resources Board

Leonard Weinstein

Cornell University

James A. Woodman

North Carolina State University

Stanley L. Zwicker

McClaren Environmental Engineering (formerly Union Oil)

Raymond J. Kopp

Alan J. Krupnick

Perry J. Sampson

NOTE: OTA appreciates and is grateful for the valuable assistance and thoughtful critiques provided by the advisory panel members. The panel does not, however, necessarily approve, disapprove, or endorse this report. OTA assumes full responsibility for the report and the accuracy of its contents. 


\title{
OTA Project Staff-Catching Our Breath: Next Steps for Reducing Urban Ozone
}

John Andelin, Assistant Director, OTA

Science, Information, and Natural Resources Division

Robert W. Niblock, Oceans and Environment Program Manager

\author{
Robert M. Friedman, Project Director \\ Jana B. Milford, Analyst \\ Richard D. Rapoport, Analyst \\ Nancy B. Szabo, Analyst
}

Contributing Staff
Jonathan Chudnoff $\quad$ Theo Colburn Kathryn Harrison

Administrative Staff

Kathleen A. Beil Sally W. Van Aller 


\section{Workshop for State and Local Pollution Control Officials January 13,1987}

Bill Becker

State and Territorial Air Pollution Program Administrators/Association of Local Air Pollution Control Officials

Eli Bell

Texas Air Quality Board

Mike Bradley

Northeast States for Coordinated Air Use Management

John Elston

New Jersey Bureau of Air Pollution Control

George Ferreri

Maryland Air Management Administration

James Hambright

Pennylvania Bureau of Air Quality Control

Michael Hayes

Illinois Division of Air Pollution Control

James Lents

South Coast Air Quality Management District, California
Bruce Maillet

Massachusetts Division of Air Quality Control

Robert Miller

Michigan Air Quality Division

Donald Moline

Toledo, Ohio, Environment Services Division

Nick Nikkala

Missouri Division of Air Pollution Control

John Paul

Dayton, Ohio, Regional Air Pollution Control Agency

William W. Sylte

California Air Resources Board

Don Theiler

Wisconsin Bureau of Air Management

\section{Workshop for Current and Former EPA Staff}

\section{J uly $\mathbf{1 6 , 1 9 8 7}$}

Alex Cristofaro

Office of Policy Analysis, EPA

Louis Gitto

Air Management Division, Region 1, EPA

William Hathaway

Air Management Division, Region 6, EPA

David Hawkins

Natural Resources Defense Council

Tom Helms

Office of Air Quality Planning and Standards, EPA

David Howekamp

Air Management Division, Region 9, EPA

David Kee

Air Management Division, Region 5, EPA

Joseph Lees

Office of Air and Radiation, EPA
Phil Lorang

Office of Mobile Sources, EPA

William Pedersen

Verner, Liipfert, Bernhard, McPherson, \& Hand

John Rasnic

Office of Air Quality Planning and Standards, EPA

Paul Stolpman

Office of Policy Analysis and Review, EPA

John Thillman

Office of Air Quality Planning and Standards, EPA

John Topping

Topping \& Swillinger

Michael Walsh

Consultant

Peter Wyckoff

Office of General Counsel, EPA 


\section{Workshop for Industry and Government \\ September 30, 1987}

Walter Barber

Chemical Waste, Inc.

David Baron

Arizona Center for Law in the Public Interest

Donald Deieso

New Jersey Department of Environmental Management and Control

Gerald Emison

Office of Air Quality Planning and Standards, EPA

Frank Friedman

Occidental Petroleum

Sam Leonard

General Motors

Gladys Meade

American Lung Association of California
Robert Miller

Michigan Air Quality Division

Brad Raffle

Conoco Inc.

Phil Reed

Skadden, Arps, Slate, Meagher \& Flom

Jim Tozzi

Multinational Business Services

Richard Wilson

Office of Mobile Sources, EPA

Tom Zosel

3M Company 


\section{Reviewers and Contributors}

Gary Agid

California Air Resources Board

Steve Albu

California Air Resources Board

David Aldorfer

General Motors Corp.

Paul Allen

California Air Resources Board

Jeffrey Alson

EPA

Thomas Austin

Sierra Research, Inc.

John Bachmann

EPA

John Bailar

McGill University

Alan Basala

EPA

William Battye

Alliance Technologies Corp.

Keith Baugues

EPA

Eli Bell

Texas Air Control Board

Mark Berger

University of Kentucky

Bruce Bertelsen

Manufacturers of Emission Controls Association

John Blodgett

Congressional Research Service

Robert Boisselle

Massachusetts Department of Environmental Quality Engineering

Mike Bradley

Northeast States for Coordinated Air Use Management

Philip Bromberg

University of North Carolina, Chapel Hill

Donald Buist

Ford Motor Co.
Frank Bunyard

EPA

Tom Cackette

California Air Resources Board

William Chameides

Georgia Technical University

Raymond Conner

National Paint \& Coatings

Association

Greg Cooper

New Jersey Department of Environmental Protection

Alex Cristofaro

EPA

Greg Dana

Automobile Importers of America

Jan Demmy

Alliance Technologies Corp.

Carmen Difiglio

U.S. Department of Energy

Douglas Dockery

Harvard School of Public Health

Ralph Engel

Chemical Specialties Manufacturers Association

Lawrence Follinsbee

Combustion Engineering

A. Myrick Freeman III

Resources for the Future

Henry Gong

University of California, Los Angeles

Kenneth Gross

General Motors Corp.

David Gushee

Congressional Research Service

Jack Hackney

University of Southern California

Marcel Halberstadt

Motor Vehicle Manufacturers Association

Jane Hall

California State University at Fullerton
James Hambright

Pennsylvania Department of

Environmental Resources

Gary Hawthorn

EPA

Milan Hazucha

University of North Carolina, Chapel Hill

Walter Heck

Agricultural Research Service

Charles Hudson

Navistar International

Teiji Iida

Toyota Motor Corp.

Michael Jackson

Acurex Corp.

Michael Jackson

Pulmonary Medicine Associates

Jay Jacobson

Boyce Thompson Institute for Plant Research

Christopher James

Rhode Island Department of Environmental Management

Arthur Johnson

University of Pennsylvania

Pam Johnson

EPA

Bruce Jordan

EPA

Mario Jorquera

Maryland Air Management Administration

Patrick Kinney

Health Effects Institute

Erica Laich

E.H. Pechan \& Associates

Michael Lebowitz

University of Arizona

Allen Lefohn

A.S.L. \& Associates

Sam Leonard

General Motors Corp. 
Morton Lippman

New York University Medical Center

Phil Lorang

EPA

Matthew Low

TLI Systems

Bruce Madriaga

EPA

Tom McCurdy

EPA

William McDonnell

EPA

Dave McKee

EPA

Barry McNutt

U.S. Department of Energy

Michael Meyer

Georgia Institute of Technology

Ned Meyer

EPA

Ralph Morris

Systems Applications Inc.

Howard Padgham

Chrysler Motors Corp.

James Pasek

General Motors Corp.
John Paul

Dayton Ohio Regional Air Pollution Control Agency

Norm Possiel

EPA

James Raub

EPA

John Rawlings

North Carolina State University

Glen Reid

Johnson Matthey

Walter Retzsch

American Petroleum Institute

Harvey Richmond

EPA

Molly Ross

U.S. Department of the Interior

Phil Roth

Michael Rusin

American Petroleum Institute

Ted Russell

Carnegie Mellon University

Kenneth Schere

EPA

Sandy Sillman

University of Michigan
John Skelly

The Pennsylvania State University

Mark Smith

Alliance Technologies Corp.

Robert Stricter

American Petroleum Institute

C. Robert Taylor

Auburn University

Michael Walsh

Norman Whittlesey

Washington State University

Jim Wilson

E.H. Pechan \& Associates

Richard Wilson

EPA

David Wooley

New York State Attorney General's Office

Elaine Wright

General Motors Corp.

Terry Yosie

American Petroleum Institute

Steve Ziman

Chevron

Tom Zosel

3M Company 


\section{Contents}

Page

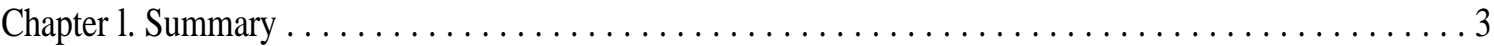

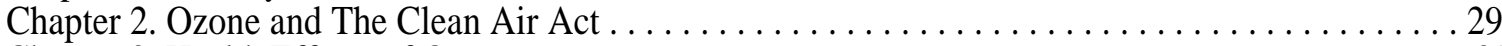

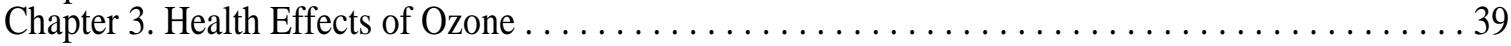

Chapter 4. Effects of Ozone on Crops and Forests . . . . . . . . . . . . . . . . . . . . . . . . . . 79

Chapter 5. LoweringOzone: Effect of Controlling Volatile Organic Compounds and

Nitrogen Oxides . . . . . . . . . . . . . . . . . . . . . . . . . . . . . . . . . . . . 97

Chapter 6. Controlling Emissions of Volatile Organic Compounds . . . . . . . . . . . . . . 113

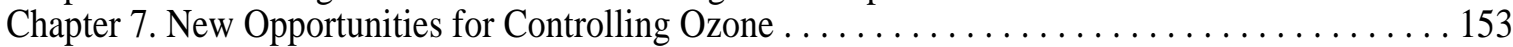

Chapter 8. Policy Options . . . . . . . . . . . . . . . . . . . . . . . . . . . . . . . . . . . 195

Appendix A. Parameters Used To Calculate Volatile Organic Compound Emissions Reduction

Potential and Associated Costs of Control for Stationary Sources . . . . . . . . . . . . . . . 235 
Chapter 1

\section{Summary}




\section{CONTENTS}

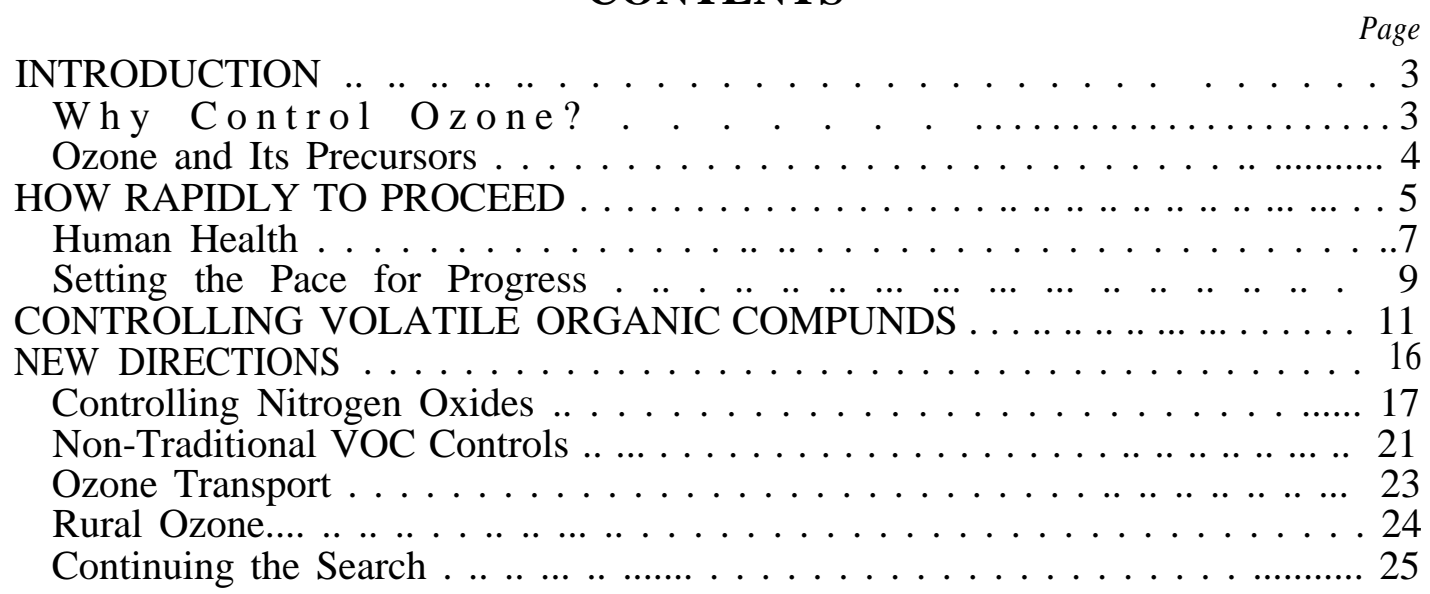

\section{Figures}

Figure

1-1. Areas Classified as Nonattainment for Ozone Based on 1983-85 Data ........ 6

1-2. Areas Where Ozone Concentrations Exceeded O.12 ppm at Least One Hour Per Year on Average, From 1983-85. .. .. .. . . . . . . . . . . . .. 7

1-3. Likelihood of Adverse Effects From Ozone While Exercising . . . . . . . . . . . . . 9

1-4. Summary of Estimated Nationwide Volatile Organic Compound (VOC) Emissions by Source Category, by Year. . . . . . . . . . . . . . . . . . . . . 12

1-5. VOC Emissions in Nonattainment Cities, by Source Category, in $1985 \ldots \ldots \ldots$. . . 13

1-6. Estimates of Possible Shortfalls and Excesses in Emissions Reductions Needed to Attain the Ozone Standard in 1994 as a Percentage of 1985 Emissions . . . . . . . . . . 14

1-7. VOC Emissions Reductions in 1994 Compared to 1985 Emissions,

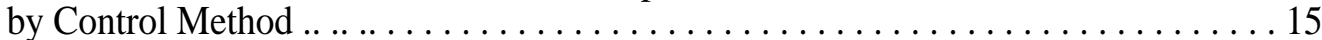

1-8. Estimated Cost-Effectiveness of VOC Emission Control Methods in 1994 in

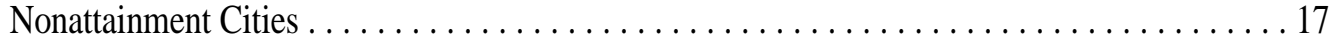

1-9. Cumulative Annual Cost of, and Percent Emissions Reductions From, VOC Control Methods ........................................ 18

1-10. Summary of Estimated Nationwide Nitrogen Oxides $\left(\mathrm{NO}_{\mathrm{x}}\right)$ Emissions by

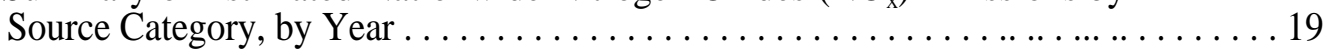

1-n. $\mathrm{NO}_{\mathrm{x}}$ Emissions Reductions in 1994 Compared to 1985 Emissions, by Control Method . . . . . . . . . . . . . . . . . . . . . . . . . . . . . . . . 20

1-12. Total Solvent Use Covered by Existing Regulations in 1985, by Source Category ............................. 22

1-13. Estimated Daily 7-hour Average Ozone Concentrations During the

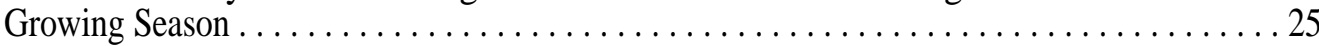

\section{Tables}

Table

1-1. Options for Amending the Clean Air Act Overall Requirements . . . . . . . . . . . 11

1-2. Options for Amending the Clean Air Act Currently Available Control Methods . . . 16

1-3. Options for Amending the Clean Air Act: New Directions.. . . . . . . . . . . . . 18 


\section{INTRODUCTION}

Within the next year or two, Congress must reauthorize-and, some believe, rethink-the Clean Air Act. The mechanism established in 1970 to assure the Nation's air quality has notably failed to control a major pollutant, ozone, in much of the country. Today, almost two decades after the Act's original passage, about 100 urban areas still violate the ozone standard; indeed, the intense heat of summer 1988 added an estimated 28 new names to the list of "nonattainment" cities. Currently available control methods are not adequate to bring all of these cities into compliance. This third attempt to craft an ozone control program thus raises several controversial issues: how great a threat ozone poses to human health, agricultural production and environmental welfare; what technical measures to take against this hard-tocontrol pollutant; how to alter deadlines, sanctions, and planning mechanisms; how to deal with the cities that cannot meet the standard with any existing or near-term means; and finally, how to encourage development of new control methods so that continued progress can be made. This report aims to assist Congress in grappling with these issues.

Since 1970, a Federal-State partnership has been in place to handle ozone control, with the Environmental Protection Agency (EPA) setting nationally uniform standards and the States, with the Agency's help and approval, working to meet them. Based on ozone's known health effects, the standard is currently set at a peak, l-hour average ozone concentration of 0.12 parts per million (ppm). Any area experiencing concentrations exceeding the standard more than once per year, on average, is declared a "nonattainment" area. EPA updates the nonattainment list annually, as data become available. In
1987, the list included cities housing about half of the American population; 1988's number promises to be substantially higher.

\section{Why Control Ozone?}

The $0.12 \mathrm{ppm}$ national standard for ozone derives from solid evidence of the health effects of short-term exposure above that level. Excessive ozone is harmful to people. Some healthy adults and children begin to experience coughing, painful breathing, and temporary loss of some lung function after about an hour or two of exercise at the peak concentrations found in nonattainment cities.

Does the current standard adequately protect people who are exposed for long periods or at high exercise levels? Experts are unsure. Several studies over the past 5 years have shown temporary loss of some lung function after an hour or two of exposure at concentrations between 0.12 and $0.16 \mathrm{ppm}$, among moderately to heavily exercising children and adults. And despite the current standard's emphasis on a 1-hour peak, real-life exposures to near daily maximum levels can last much longer; ozone levels can stay high from mid-morning through late afternoon. With exposure during 6 hours of heavy exercise, temporary loss of some lung function can appear with ozone levels as low as $0.08 \mathrm{ppm}$.

Potentially more troubling and less wellunderstood are the effects of long-term, chronic exposure to summertime ozone concentrations found in many cities. Regular out-of-doors work or play during the hot, sunny summer months in the most polluted cities might, some medical experts believe, cause biochemical and structural changes in the lung, paving the way for chronic respiratory diseases. To date, though, evidence of a possible connection between 
irreversible lung damage and repeated exposure to summertime ozone levels remains inconclusive.

Clear evidence shows that ozone damages economically, ecologically, and aesthetically important plants. When exposed to ozone, major annual crops produce reduced yields. Some tree species suffer injury to needles or leaves, lowered productivity, and in severe cases, individual trees can die. Important tree species are seriously affected in large areas of the country. In the most heavily affected forested areas, such as the San Bernardino National Forest in California, ozone has begun altering the natural ecological balance of species.

How serious are these damages and risks? What will it cost to avoid them? And how does the cost compare to the benefits potentially gained? These are questions that scientists cannot confidently answer. Deciding how to act in the absence of full information falls to Congress and the Nation.

\section{Ozone and Its Precursors}

Ozone is produced when its precursors, volatile organic compounds (VOCs) and nitrogen oxides $\left(\mathrm{NO}_{\mathrm{x}}\right)$, combine in the presence of sunlight. VOCs, a broad class of pollutants encompassing hundreds of specific compounds, come from manmade sources including automobile and truck exhaust, evaporation of solvents and gasoline, chemical manufacturing, and petroleum refining. In most urban areas, such manmade sources account for the great majority of VOC emissions, but in the summer in some regions, natural vegetation may produce an almost equal quantity. $\mathrm{NO}_{\mathrm{x}}$ arises primarily from fossil fuel combustion. Major sources include highway vehicles, and utility and industrial boilers. Ozone control efforts have traditionally focused on reducing local VOC emissions, partly because the relevant technologies were thought to be cheaper and more readily available. In addition, under some conditions at some locations, reducing $\mathrm{NO}_{\mathrm{x}}$ can have the counterproductive impact of increasing ozone concentrations above what they would be if VOCs were controlled alone.

Through past efforts, the Nation has made some progress. According to EPA estimates, while VOC emissions have remained relatively constant over the last decade, they are about 40 percent lower than they would have been without existing controls. The major existing mechanism for regulating air quality is a State Implementation Plan (SIP). Subject to EPA review, each State prepares a document analyzing its particular inventory of precursor emissions and establishing the reductions necessary to meet the ozone standard. SIPS also establish the programs intended to achieve those reductions, mainly by limiting the amount of precursors that various commercial and industrial establishments, vehicles and the like are allowed to discharge into the atmosphere. The process of developing a SIP is both technically and politically challenging. It not only requires an accurate analysis of the State's existing and anticipated stationary and mobile source emissions, but also a broad consensus on the means the public will accept to reduce them. Changes in customary practices in industry, manufacturing, commerce, fuel use, and transportation may be entailed. Finally, in addition to State-implemented controls, emissions from new motor vehicles are regulated by EPA.

Despite these regulatory mechanisms, however, large areas of the country have missed each of several 5- and 10-year deadlines set by Congress-first the original deadline of 1975 , and again in 1982 and 1987. Why haven't past programs worked?

During a series of workshops held by OTA to answer this question, many State and local officials and other participants called the past deadlines unrealistic. They argued that the deadlines forced a short-term focus in both developing plans and implementing programs, even though the worst nonattaimnent cities 
clearly needed decades of concerted effort to overcome their ozone problems. Inadequate timeframes, these critics argued, encouraged States to cheat on their SIPS, and EPA to play along with them.

Many officials also blamed incomplete or inadequate inventories of local pollution sources and overly optimistic forecasts of future emissions for the failure of certain control strategies. Few regulators, for example, anticipated the general rise in gasoline volatility, which increased VOC evaporation. Many also underestimated the growth in automobile use that occurred. In addition, some of the mathematical models used for planning proved inaccurate, causing miscalculations of the quantities of controls needed.

Many States also had difficulty enforcing regulations on stationary emissions sources, controlling emissions growth, and preventing ozone or its precursors from blowing in from neighboring areas. Finally, many of the workshop participants noted a widespread "lack of political will" to take steps necessary to meet the ozone standard, both in EPA and many States.

Looking ahead, clearly we still do not have all the answers. If we are willing to use and pay for currently available technology, we can make significant advances over the next 5 to 10 years, achieving about two-thirds of the reductions we need. This should bring about half of all current nonattainment areas into compliance. But we cannot, by the year 2000, get the entire Nation to the goal that Congress established in 1970.

In facing this reality, Congress will have to address several major issues, which fill the remainder of this summary. The next section considers the question of how hard Congress should push for ozone reductions. How should we balance the severity of the health effects against the difficulty of the task, especially for those cities with no practical possibility of achieving the needed reductions with currently available technology? The third section explores the currently available means-and costs----of controlling VOCs. The last section looks into the technological and regulatory future, examining new directions and long-term efforts toward VOC reductions as well as approaches that are largely untried, including $\mathrm{NO}_{\mathrm{x}}$ controls and efforts to reduce upwind emissions. Finally, the last section considers means of reducing ozone in rural areas.

\section{HOW RAPIDLY TO PROCEED}

The central issue facing Congress is how to balance the urgency of the ozone problem against the difficulty of the solution. In a number of areas, meeting the goal will exact substantial financial and social costs. Though experts disagree about the level of danger that ozone actually poses to the population, a large portion of the American people live in places where ozone concentrations far exceed those known to be completely safe. Clearly, therefore, the societal goal set by Congress in the Clear Air Act Amendments of 1970, achieving air quality necessary "to protect the public health. . . with an adequate margin of safety, "weighs in on the side of prompt and effective action.

Equally clear, however, is the fact that in the worst areas, even the most costly and stringent of available measures will not lower emission levels sufficiently to meet the standard. Achieving that goal is a long-range project, well beyond the 5- and 10-year horizons of existing law. It will require both new technologies and lifestyle changes in the most affected communities, including changes in transportation, work, and housing patterns. In other, less polluted nonattainment areas, the standard can be met with less cost and disruption.

About 100 nonattainment areas dot the country from coast to coast, with "design values"a measure of peak ozone concentrationsranging from $0.13 \mathrm{ppm}$ to as high as $0.36 \mathrm{ppm}$. Figure 1-1 summarizes the data for the 3-year period 1983-85. Generally, the higher the design 
Figure 1-1-Areas Classified as Nonattainment for Ozone Based on 1983-85 Data

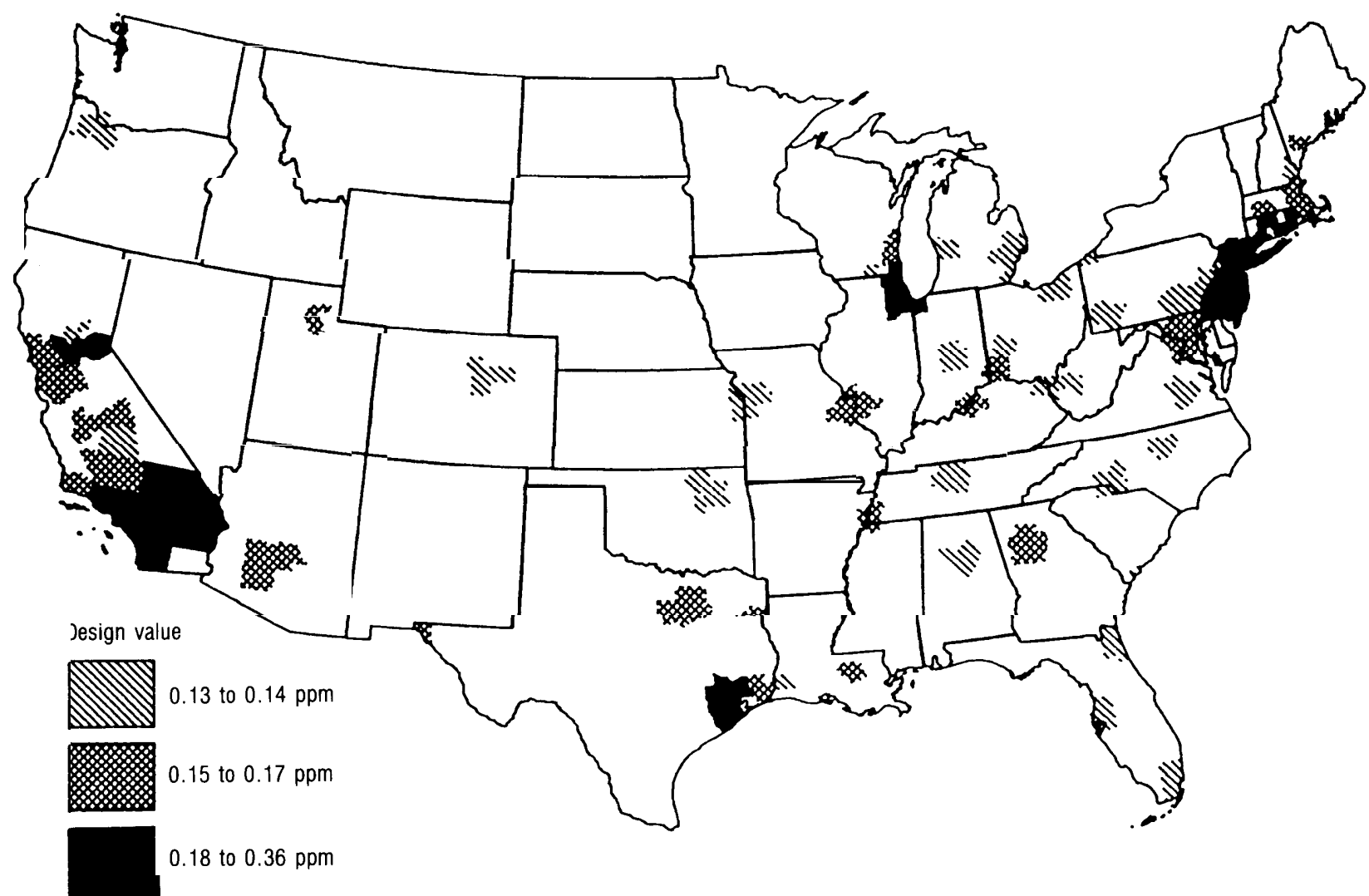

The shading indicates the fourth highest daily maximum I-hour average ozone concentration, or "design value," for each area.

SOURCE: U.S. Environmental Protection Agency

value, the stricter the emission controls needed to meet the standard. Half the areas are fairly close to attainment, with design values up to 0.14 or $0.15 \mathrm{ppm}$; for these places, reaching the standard is probably feasible with existing technologies. However, the remaining areas, including the Nation's worst violator, Los Angeles, present much more serious and challenging problems, with design values in excess of $0.16 \mathrm{ppm}$.

About half of all Americans live in areas that exceed the standard at least once a year. As shown in figure 1-2, 130 of the 317 urban and rural areas for which we have data exceeded $0.12 \mathrm{ppm}$ for at least one hour between 1983 and 1985. Sixty of them had concentrations that high for at least 6 or more hours per year. A number of areas topped the standard for 20 or more hours, with the worst-Los Angelesaveraging 275 hours per year.

Ozone in a city's air, however, does not necessarily equal ozone in people's lungs. Concentrations vary with time of day and exact location. People vary in the amount of time they spend indoors, where concentrations are lower. And the more actively someone exercises, the more ozone he or she inhales. Each year, nationwide, an estimated 34 million people are actually exposed to ozone above $0.12 \mathrm{ppm}$ at low exercise levels, and about 21 million are exposed during moderate exercise, on average about 9 hours per year. About 13 million people 
Figure 1-2-Areas Where Ozone Concentration s Exceeded $0.12 \mathrm{ppm}$ at Least One Hour Per Year on Average,

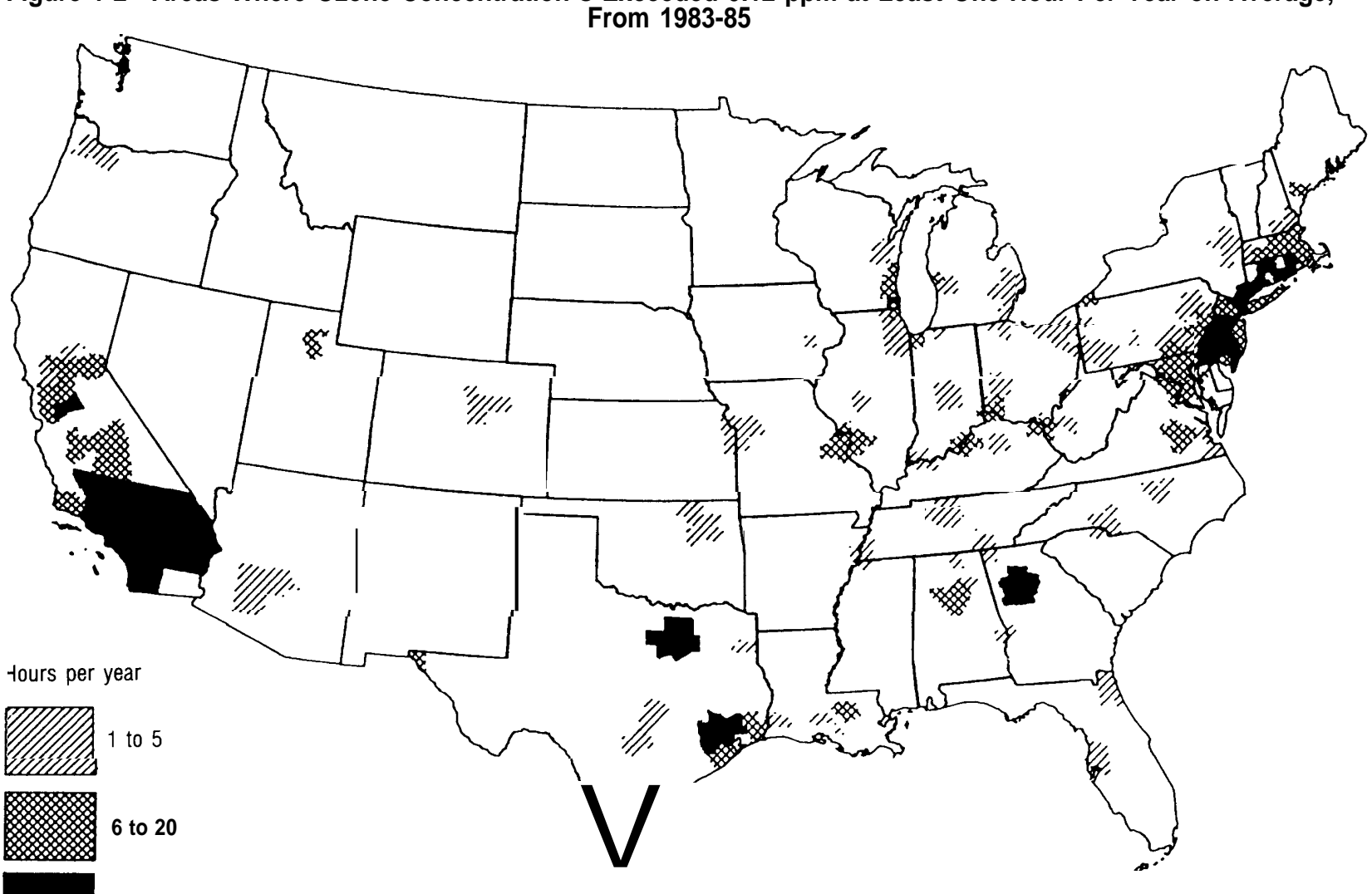

more than 20

Data from all monitors located in each area were averagedin constructing the map. The shading indicates the number of hours that a concentration of $0.12 \mathrm{ppm}$ was exceeded. One hundred thirty million people reside in the areas shown.

SOURCE: U.S. Environmental Protection Agency, Storage and Retrieval of Aerometric Data, data base, processed by E.H. Pechan \& Assoc., 1987.

are exposed to ozone above $0.12 \mathrm{ppm}$ during heavy exercise, each of them for about 6 hours each year, on average. At each exercise level, one-quarter of these people live in the Los Angeles area.

It is important to remember that people have varying lifestyles, not "average" ones. Those exposed to high concentrations at high ozone levels of exercise include some who choose to be outside and some who have no choice, the latter including workers doing physical labor such as construction. About 5 percent of adult men work outdoors most of the time, and an additional 10 percent do so part of the time.
Children play outdoors for about 3 to 4 hours each day, on average, during the summer months when school is out and ozone concentrations are high.

\section{Human Health}

Ozone's most perceptible short-term effects on human health are respiratory symptoms such as coughing and painful deep breathing. It also reduces people's ability to inhale and exhale normally, affecting the most commonly used measures of lung function (e.g., the maximum amount of air a person can exhale in one second or the maximum he or she can exhale after 
taking a deep breath). As the intensity of exercise rises, so does the amount of air drawn into the lungs, and thus the dose of ozone. The more heavily one exercises at a given level of ozone concentration, and the longer the exercise lasts, the larger the potential effect on lung function.

At what point do these short-term effects become so severe that the public needs protection? The Clean Air Act mandates control of pollutants that produce "an adverse effect on public health or welfare," but scientists differ on whereto place this threshold. They agree that permanent respiratory injury or disabling illness would definitely fall into the "adverse" category, but not on whether mild to moderate symptoms and smaller, reversible changes in lung function that produce no disability should be considered adverse, as well. Thus, many Members of Congress and staff have heard conflicting opinions on the seriousness of the problem. Some people say it affects only a few asthmatic joggers who lack the sense to stay indoors on hot, smoggy summer afternoons. Others see it as a major public health danger threatening over 100 million Americans.

Medical concern centers as much-or even more---on chronic damage as on short-term effects, although research to date has yielded only limited understanding of chronic risks. Some researchers see links between the acute effects produced by short-term exposure and certain mechanisms that could produce chronic effects or lasting injury. Animal studies, for example, reveal biochemical and structural changes in lung tissue that could, if duplicated in humans, produce permanent, irreversible damage. Ozone exposure appears to reduce, at least temporarily, the lungs' ability to ward off infection, possibly paving the way for disease. In addition, animal studies have shown a tendency toward 'stiffening" of the lung, a step in premature aging. As yet, though, evidence for chronic effects in humans at concentrations present in nonattainment cities remains inconclusive.

EPA identifies two subgroups of people who may be at special risk for adverse effects: athletes and workers who exercise heavily outdoors and people with preexisting respiratory problems. Also problematic are children, who appear to be less susceptible to (or at least less aware of) acute symptoms and thus may spend more time outdoors in high ozone concentrations. Most laboratory studies have shown no special effects in asthmatics, but epidemiologic evidence suggests that they suffer more frequent attacks, respiratory symptoms, and hospital admissions during periods of high ozone. In addition, about 5 to 20 percent of the healthy adult population appear to be "responders," who for no apparent reason are significantly more sensitive than average to a given dose of ozone.

Results from a preliminary model developed for OTA illustrate that at the summertime ozone levels found in many cities, some people who engage in moderate exercise for extended periods can experience adverse effects. For example, on a summer day when ozone concentrations average $0.14 \mathrm{ppm}$, a construction worker on an 8-hour shift might experience a temporary decrease in lung function that most scientists consider harmful. On those same summer days, children playing outdoors for half the day would also risk effects on lung function that some scientists consider adverse. (See figure 1-3.) And some heavy exercisers, for example runners and bicyclists, would notice adverse effects in about 2 hours. Even higher levels of ozone, which prevail in a number of areas, would, of course, have swifter and more severe impacts on health.

So what would Americans gain by meeting the standard nationwide? In terms of acute effects, the Nation would avoid several hundred 
Figure 1-3-Likelihood of Adverse Effects From Ozone While Exercising

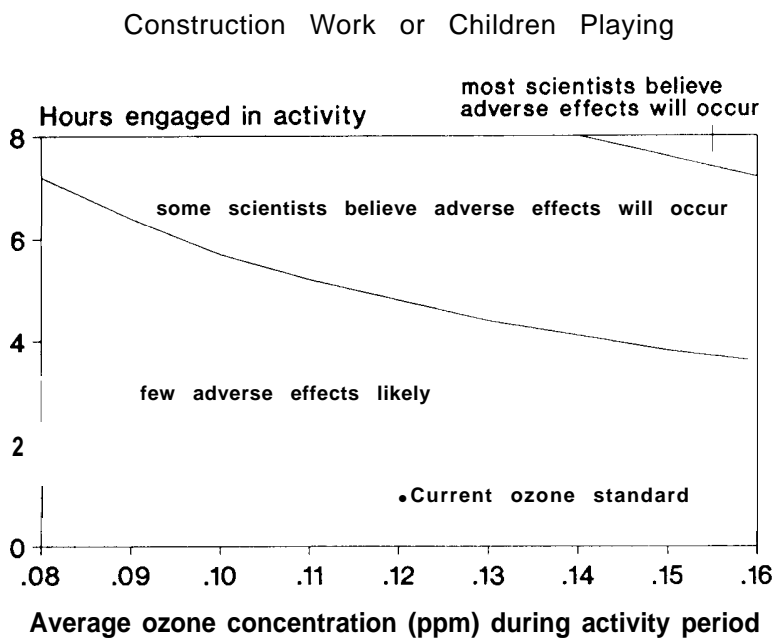

Competitive Sports or Bicycling

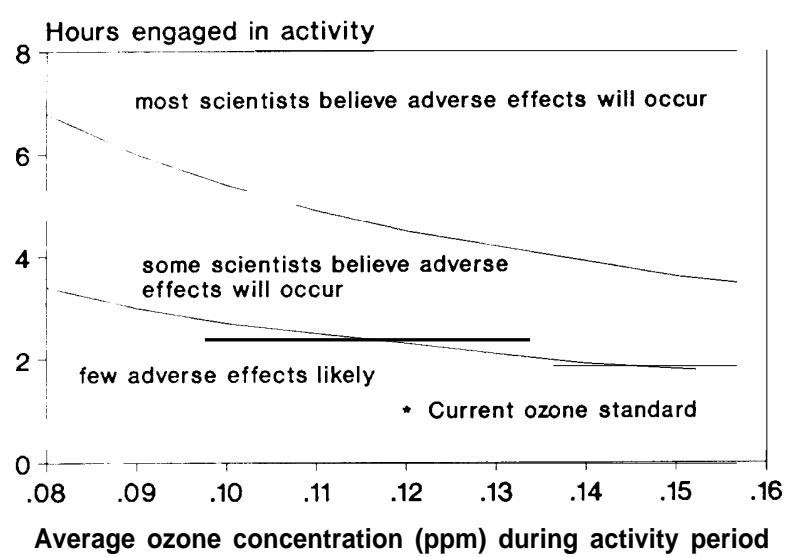

The likelihood of experiencing adverse effects depends on 1) the ozone concentration, 2) the vigorousness of the activity, and 3) the number of hours engaged in that activity. The figure on the left shows the number of hours to reach an adverse effect under moderate exercise conditions (e.g., construction work or children playing). The figure on the right shows that fewer hours are needed under heavy exercise (e.g., competitive sports or bicycling). The current one-hour ozone standard is shown for comparison.

SOURCE: OTA, based on work for OTA by Lawrence J. Folinsbee, Environmental Monitoring and Services

million episodes of such respiratory symptoms as coughing, chest pain and shortness of breath. Some people in the worst areas would experience dozens fewer incidents of respiratory symptoms each year, while many in other areas would experience no change. About 8 to 50 million days of restricted activity might also be eliminated. These are days when someone feels ill enough to limit the day's activities, if not necessarily to stay in bed or home from work. Most of the benefit would be concentrated in high ozone areas such as southern California and the Northeast corridor cities.

The economic value of eliminating those short-term effects might total between $\$ 0.5$ and $\$ 4$ billion, according to rough estimates that incorporate assumptions about what people would be willing to pay to be free of ozone's acute symptoms. Unfortunately, we cannot estimate the value of the lowered risk of long-term, chronic effects, Whether these effects exist, and what their magnitude may be, is still unknown.
They might be either large or small. This uncertainty must also be factored into congressional decisions about attainment.

\section{Setting the Pace for Progress}

From a policy standpoint the Nation's nonattainment areas fall along a "continuum of possibility. " At one end are those that can confidently expect to achieve the standard within a 5-year timeframe using existing controls. At the other extreme are those where attainment is a far-off prospect, requiring 15 to 20 or more years and extensive control technology development. In between fall those that will face differing degrees of difficulty and need intermediate amounts of time to meet the Clean Air Act's goals.

For the first group, those close to attainment, both EPA and the State and local air regulators, STAPPA/ALAPCO (the State and Territorial Air Pollution Program Administrators and the Association of heal Air Pollution Control Officials) suggest 5 years as an appropriate 
planning and implementation period. For the intermediate group, additional time for planning, modeling, and control technology development and implementation will increase chances of success. Under the 1977 Clean Air Act Amendments, Congress permitted these areas 10 years, 5 more than the original deadline. Assuming incentives that encourage development of new control methods, a number of these cities should succeed in meeting the goal within 8 to 10 years after Congress amends the Act. The worst nonattainment areas, however, especially Los Angeles, are likely to require 20 years or more. For these extremely challenging cases, Congress may wish to set a long-term deadline such as 20 years, or discard deadlines altogether and impose interim requirements instead.

Naturally, the areas with the most difficult control problems are also those with the most urgent health risks. Thus, even if these worst areas cannot meet a fixed deadline, they need to move toward attainment at a reasonable rate. To monitor progress, Congress may wish to specify either interim air quality standards, area-wide emission schedules, source-specific control methods, or some combination of these approaches.

Interim air quality standards are the most direct way of gauging progress, but have the disadvantage of requiring averages of several years of data. Furthermore, they may inappropriately penalize States making sincere efforts against insurmountable odds. Interim air quality standards thus are better suited as triggers to undertake corrective measures, for example, identifying those plan elements that need improvement or revision. A second option, areawide schedules specifying a rate of progress in lowering emissions (e.g., reductions of 10 to 15 percent each 3-year period) work well with market-based approaches and allow States to choose the most feasible and cost-effective control methods, which may vary from place to place. Finally, States lacking the expertise or political clout to design and enforce new regulations may prefer a third option, a federally prescribed list of controls that they must carry out. Source-specific controls remove the burden of designing control strategies from the States by outlining exactly what each State must do. But they also shift the responsibility for finding new ways to reduce emissions from industry to the EPA.

Improved data collection and planning will most benefit the States facing the most difficult challenges. Better planning techniques, including development of detailed emissions inventory development and air quality modeling, can help States determine the control measures they need to impose. At minimum, the modest planning exercises that EPA has proposed as basic should benefit all areas. "Enhanced planning" methods such as state-of-the-art modeling and comprehensive evaluation of control options may be needed in the worst areas. Using advanced planning techniques could prove expensive, costing the Nation as much as an additional $\$ 100$ million per year for the first few years. Such costs, however, are modest in comparison to the costs of control. Congress may wish to assist the States to cover this cost, either by increasing Federal grants to the States under the existing program, or by requiring emission fees that would raise the needed funds from pollution sources.

Changing the Act's deadline provisions also raises the issue of sanctions for failure to comply. Few people disagree with imposing sanctions on States that fail to prepare or carry out reasonable plans. But what should happen to those fulfilling all the requirements of their plans and still falling short because of the uncertainty inherent in predicting air quality or for other unforeseeable technical reasons? Many people believe that States should not bear the brunt of failures beyond their control, whether due to reasonable scientific and technical errors, pollution transported into their area from upwind, poor EPA performance, or the inability to find reductions adequate to maintain a schedule or meet a deadline. Others argue, however, that 
deadlines or requirements without sanctions will neither be taken seriously nor provide the incentive for "forcing" the development of new control technologies.

These 'overall" policy decisions that Congress must make when amending the Clean Air Act are summarized in table 1-1.

\section{CONTROLLING VOLATILE ORGANIC COMPOUNDS}

Since 1970, reducing VOC emissions has been the backbone of our national ozone control strategy, and even now, additional progress is still possible in this area. Congress, therefore, may wish to mandate additional VOC controls directly, rather than leaving the choice to the States or the EPA. This section presents an overview of the possibilities available with today's technology.

Total manmade VOC emissions, according to OTA estimates, will remain about the same for about a decade. Substantially lower emissions from cars and trucks should offset sizable increases from stationary sources, as shown in figure 1-4. But total emissions will begin rising again by around 1995 to 2000, assuming that State and EPA regulations remain unchanged.

Today, as shown in figure $1-5$, emissions from mobile sources, surface coatings such as paints, and other organic solvent evaporation

\section{Table 1-1-Options for Amending the Clean Air Act: Overall Requirements}

\section{Deadlines:}

Decision 1: How manyv categories of nonattainment areas, each with its own deadline and other requirements, should be established?

- Option 1: Two categories-those that can attain the standard with currently available controls and those that cannot.

- Option 2: Three or more categories, including more than one category of areas that cannot attain with currently available controls.

Decision 2: What deadline should be set for those areas that can attain the standard with currently available control methods'?

Option 1: Maintain the Act's current 5-year schedule from start of planning to attainment.

- Option 2: Require detailed inventories, modeling, and planning and tallow 5 to 7 years.

Decision 3: What deadline(s) should be set for those areas that cannot attain the standard with currently available controli methods?

Option 1: 8 to 10 years for the "best" of the areas that cannot attain with currently available control measures; at least 20 years for the "worst" (Los Angeles).

Option 2: Eliminate deadlines.

\section{interim requirements:}

Decision: What interim requirements are needed to ensure continuing progress towards attainment?

Option 1: interim air quality targets.

Option 2: Areawide emission reduction schedules.

Option 3: Source-specific controls.

- Option 4: Some combination of the above options.

Penalties and corrective actions in the event of failure:

Decision 1: For what kinds of failures should States be penalized?

Option 1: Sanctions for failing to make "sufficient" efforts.
Option 2: Sanctions for failing to identify enough controls to meet a congressionally specified reduction schedule.

- Option 3: Sanctions for failing to attain the standard by the required date.

Decision 2: What types of sanctions should be adopted?

- Option 1: Sanctions that limit growth in nonattainment areas, for example, a ban on construction of new sources of pollution or a moratorium on hookups to publicly owned drinking water distribution systems or sewage treatment systems.

- Option 2: Limits on Federal assistance, for example, withholding Federal highway funds (except those for safety, mass transit, and transportation improvement projects related to air quailty) or sewage treatment grants.

Decision 3: What types of corrective actions should be adopted?

Option 1: Planning requirements.

Option 2: Source-specific controls.

Option 3: Market-based control programs, for example, emissions fees or marketable emissions permits.

\section{Stats and local planning requirements:}

Decision 1: What types of planning should be required and where?

Option 1: Minimal requirements for all nonattainment areas.

- Option 2: Enhanced efforts in areas with the worst ozone problems or a typical conditions.

Decision 2: Who pays for enhanced State and local planning activities?

Option 1: Increase funding for section 105 grants or make special, separate appropriations for ozone nonattainment area planning.

Option 2: Develop a nationwide user-fee program (administered by EPA) or a fee requirement (administered by the States) on nonattainment area emissions. 


\section{Figure 1-4-Summary of Estimated Nationwide Volatile Organic Compound (VOC) Emissions by Source Category, by Year}

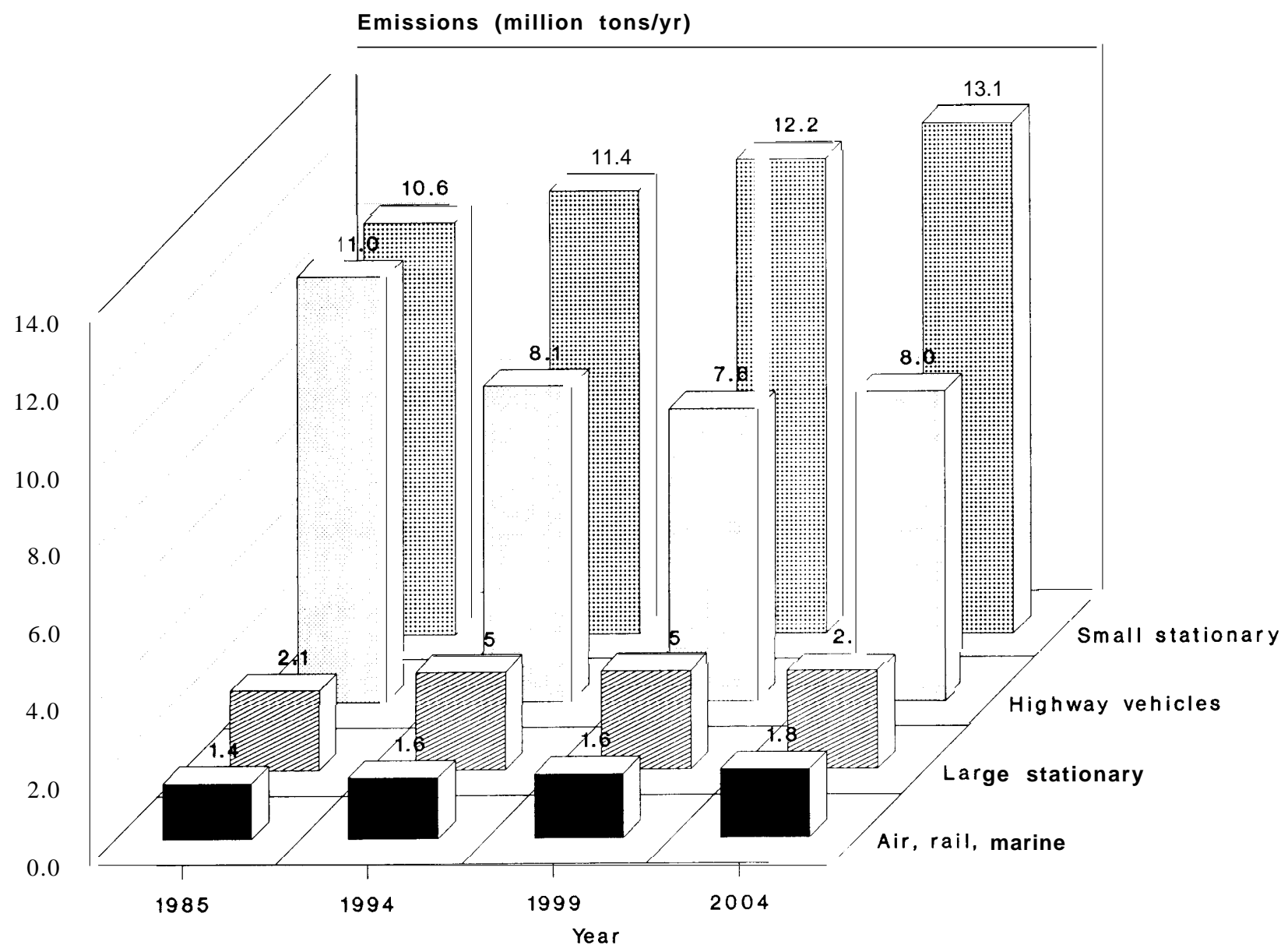

The numbers directly above the boxes are the total emissions within the source category. For example, emissions from highway vehicles in 1994 are 8.1 million tons per year, nationwide. Assumes no regulations other than those in place in 1987. The estimates that we present are representative of the emissions on atypical nonattainment day, multiplied by 365 days per year, rather than estimates of true annual emissions. For convenience, throughout the report, we refer to these estimates as annual emissions rather than as "nonattainment-dayequivalent-annual-emissions." Note that the baseline does not include reductions due to the recently promulgated limit on gasoline volatility of 10.5 psi Reid vapor pressure (RVP). Stationary sources that emit more than 50 tons per year of VOC are included in the large" Category.

SOURCE: Office of Technology Assessment, 1989.

together account for about two-thirds of all manmade VOCs. Highway vehicles alone contribute about 40 to 45 percent of the total, The next largest category of emissions, evaporation of organic solvents, involves such diverse ac- tivities as decreasing metal parts and drycleaning, and products such as insecticides. Next come surface coatings, which include inks, paints, and various similar materials used in painting cars, finishing furniture, and other 
Figure 1-5-VOC Emissions in Nonattainment Cities, by Source Category, in 1985



Stationary sources that emit more than 50 tons per year of VOC are included in the large" categories

SOURCE: OTA, from EPA's National Emissions Data System (NEDS) and National Add Precipttation Assessment Program emissions inventories.

products. These sources vary in size from huge industrial installations to a person painting a chair. About 45 percent of all VOC emissions originate in small stationary sources producing less than 50 tons per year; they include vapors from solvents and paints, gasoline evaporating while being pumped, emissions from printers and autobody repair shops, and the like.

How close can nonattainment cities come to achieving adequate reductions of these many different kinds of VOC emissions? We have analyzed about 60 currently available control methods that together deal with sources producing about 85 percent of current VOC emissions. We believe that the potential exists, using these controls, to lower summertime VOC emissions in nonattainment cities in the year 1994 by about 35 percent of the 1985 level. A reduction of this size would equal approximately two-thirds of all the reductions needed, on average, to allow nonattainment cities to meet the standard. According to our analysis, if all currently available controls are applied, total VOC emissions in the nonattainment cities will fall by about 3.8 million tons per year by 1994; the exact figure could be as low as 1.5 million tons or as high as 5.0 million tons, depending on the accuracy of our assumptions.

All cities, however, would not reach the same level of air quality after implementing these reductions, as shown in figure 1-6. If those with current design values (peak ozone concentrations) of $0.14 \mathrm{ppm}$ were to implement all the VOC control methods we analyzed, they could achieve ozone levels at, or even below the standard. Cities with current design values of $0.16 \mathrm{ppm}$ or higher would still fall short, and in some cases far short, of the needed reductions.

Each of the 60 control methods analyzed contributes to the 35-percent reduction from 1985 levels that we foresee happening in nonattainment cities, as shown in figure 1-7. The most productive method, yielding 12 percent in reductions on a hot summer day, requires changing the composition of the Nation's motor fuels. Less volatile gasoline would curtail evaporation from vehicles' fuel tanks (including socalled "running losses" while the vehicle is moving) and would lower exhaust emissions. An additional 6 percent in reductions could come from stricter controls on facilities that treat, store, and dispose of hazardous wastes (TSDFs). Another 4 percent could come from applying all "reasonably available control technology" (RACT-level) controls now found in any State's ozone control plan to all nonattainment areas' sources larger than 25 tons. About 40 types of sources, such as petroleum refineries, chemical manufacturers, print shops, and drycleaners, would be included.

A 2-percent reduction would come from enhanced programs to inspect cars and trucks and require maintenance of faulty pollution controls. This is over and above the reductions achieved

\footnotetext{
In our analysis, we assume that gasoline volatility is reduced to 9 pounds per square inch (psi) ReidVapor Pressure (RVP), nationwide during the 5 -month summertime period when ozone concentrations most often exceed the standard.
} 


\section{Figure 1-6-Estimates of Possible Shortfalls and Excesses in Emissions Reductions Needed to Attain the Ozone Standard in 1994 as a Percentage of 1985 Emissions}

As a percentage of 1985 emisslons

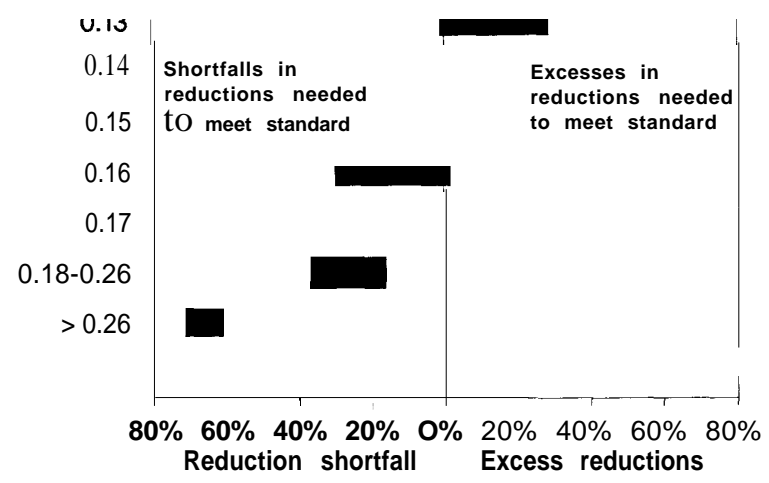

The bars shown above represent ranges of uncertainty associated with our method of estimating the VOC reductions needed to attain the standard in each city. Because of the uncertainty associated with estimating the emissions reductions required to attain the ozone standard, the reduction target we chose for each city could be too low or too high. Therefore, the adoption of all additional controls in an individual city may result in either a shortfall or an excess in the emissions reductions required to meet the standard. For this reason, we present estimates for both undercontrol and overcontrol.

SOURCE: Office of Technology Assessment, 1989.

by the inspection and maintenance programs in operation today. Modifying the nozzles of gas station pumps to trap escaping vapors (installing "Stage II gasoline vapor recovery systems") would yield another 2-percent reduction. Installing devices to do the same job on individual vehicles as they fuel up ("onboard technology") would produce about the same reductions 8 to 10 years later, as newer cars that have the devices replace older ones that do not. (The two methods together would yield only slightly greater reductions than either method alone.) Adopting new "control technique guidelines" for smaller categories of stationary sources, such as autobody refinishing and wood furniture coating shops, coke oven byproduct plants, and bakeries, would account for an additional 1 percent. Another 0.5-percent reduction can be had in the worst nonattainment areas by requiring businesses that operate fleets of 10 or more vehicles ${ }^{2}$ in those areas to substitute methanol for gasoline. Limits on the solvent content in architectural coatings such as paints and stains would lower emissions by 0.5 percent. Finally, more stringent standards for tailpipe emissions from gasoline-powered cars and light-duty trucks ${ }^{3}$ would lower emissions by 1.5 percent by 2004 as new cars and trucks enter the Nation's vehicle fleet.

Some of these controls can be implemented by the States in nonattainment areas alone, others are better suited to Federal implementation nationwide. The congressional options mentioned above, as well as several additional ones discussed in chapter 8 , are summarized in table 1-2.

As we could not identify VOC controls capable of achieving the final third of the reductions needed to attain the standard in all nonattainment cities, we could not estimate the ultimate price to the Nation of bringing ozone under control. We can, however, estimate the cost of bringing about half of the cities into

2 We assume that over the next ten years, methanol-fueled cars will run on a blend of 85 percent methanoand 15 percent gasoline.

${ }^{3}$ The emission standards used in our analysis are as follows: (in grams of pollutant emitted per mile travelled [g/mile] fOr non-methane hydrocarbons [NMHC] and $\mathrm{NO}_{\mathbf{X}}$ )

Passenger cars-NMHC: $0.25 \mathrm{~g} / \mathrm{mile}$; $\mathrm{NO}_{\mathrm{x}}: 0.4 \mathrm{~g} / \mathrm{mile}$

Lightduty gasoline trucks (by truck weight)--

(less than 3,750 lbs) NMHC: $0.34 \mathrm{~g} / \mathrm{mile} ; \mathrm{NO}_{\mathbf{x}}: 0.46 \mathrm{~g} / \mathrm{mile}$

$(3,750$ to $6,000 \mathrm{lbs})$ NMHC: $0.43 \mathrm{~g} / \mathrm{mile} ; \mathrm{NO}_{\mathrm{x}}: 0.80 \mathrm{~g} / \mathrm{mile}$

(6,000 to $8,500 \mathrm{lbs}) \mathrm{NMHC}: 0.55 \mathrm{~g} / \mathrm{mile}$; $\mathrm{NO}_{\mathrm{X}}$ : $1.15 \mathrm{~g} / \mathrm{mile}$

We assume that these standards can be met during 50,000 miles of controlledtest driving (certification testing) forpassenger cars, and $120,000 \mathrm{miles}$ for light-duty trucks; however, voC emission rates after 50,000 miles (for cars) and 120,000 miles (for trucks) of actual use by vehicle owners would likely exceed these standards. We assume that new standards go into effect in 1994 for both passenger cars and light-duty trucks. 
Figure 1-7-VOC Emissions Reductions in 1994 Compared to 1985 Emissions, by Control Method

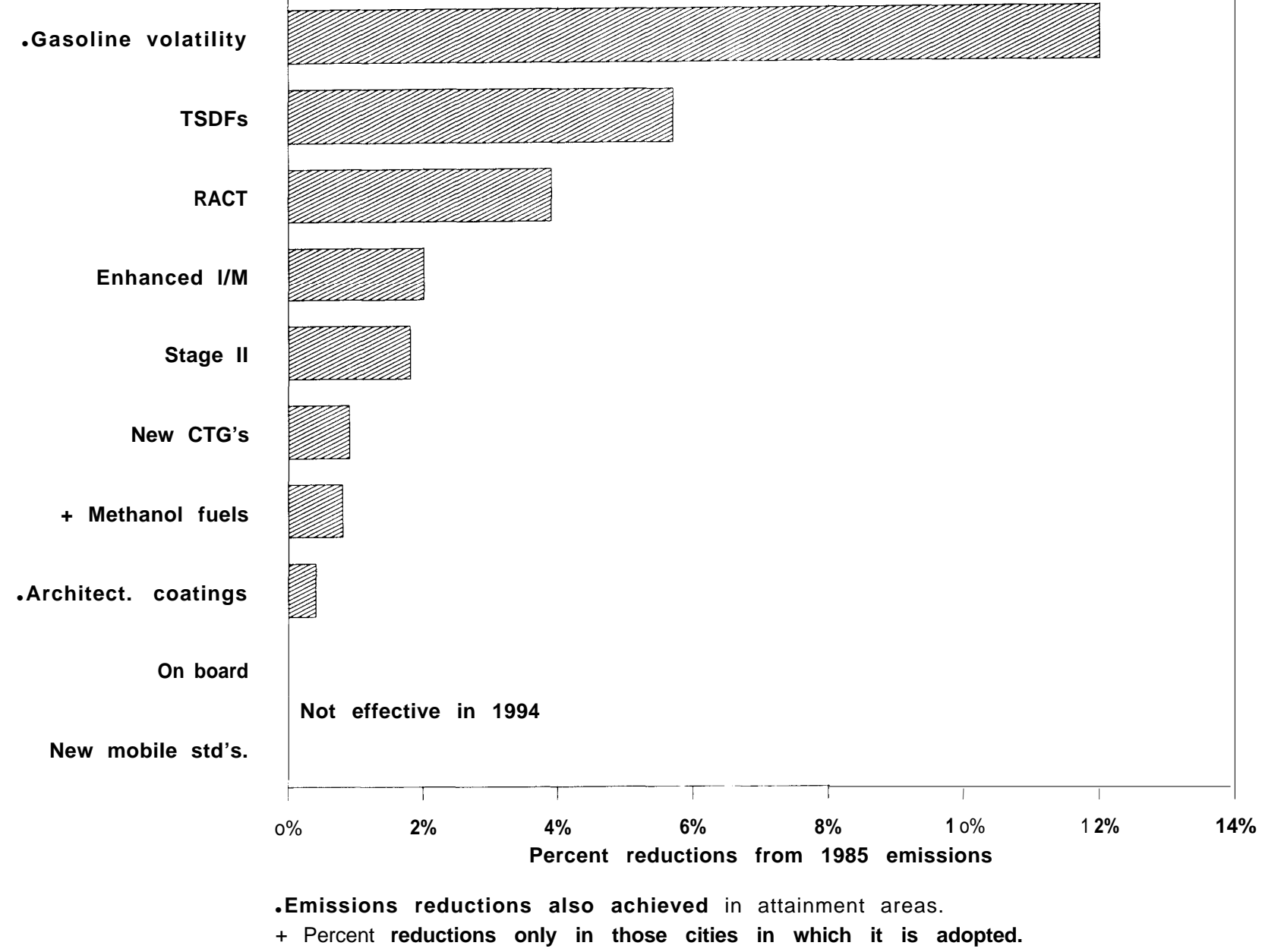

Strategy Descriptions

Gasoline volatility controls which limit the rate of gasoline evaporation.

TSDF = controls on hazardous waste treatment, storage, and disposal facilities

RACT = "Reasonable Available Control Tehnology" on all existing stationary sources that emit more than 25 tons per year of VOC.

Enhanced inspection and maintenance (i/M) programs for cars and light-duty trucks.

Stage ii control devices on gas pumps to capture gasoline vapor during motor vehicle refueling.

New CTGs = new Control Technique Guidelines for several categories of existing stationary sources for which no current regulations exist. Methanol fuels as a substitute for gasoline as a motor vehicle fuel.

Federal Controls on architectural surface coatings.

Onboard controls on motor vehicles to capture gasoline vapor during refueling.

New highway-vehicle emission standards for passenger cars and light-duty gasoline trucks.

SOURCE: Office of Technology Assessment, 1989.

compliance, and of substantially improving the air quality of the rest. Applying all these controls in all nonattainment cities would cost these cities between $\$ 4.2$ and $\$ 7.1$ billion per year in 1994 and between $\$ 6.6$ and $\$ 10$ billion annually by 2004 . Because some controls would apply nationwide, rather than just in nonattainment areas, the national price tag would total about $\$ 8.8$ to $\$ 13$ billion in 2004 .

Some of these controls simultaneously reduce other air pollutants in addition to VOCs. Enhanced motor vehicle inspection and mainte- 
Table 1-2-Options for Amending the Clean Air Act: Currently Available Control Methods

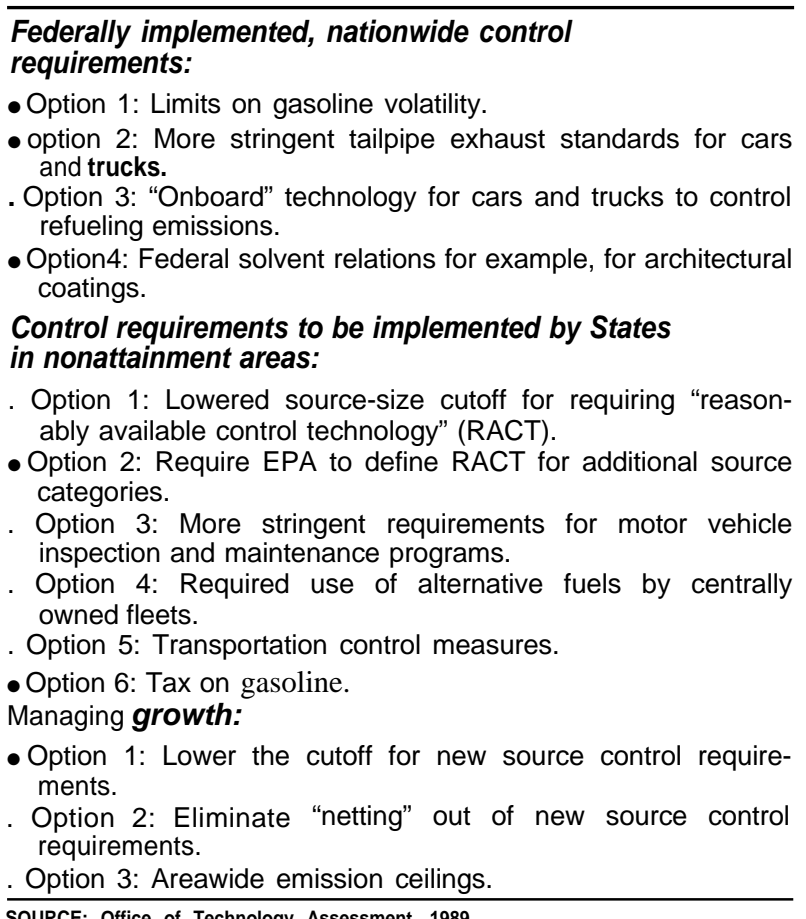

SOURCE: Office of Technology Assessment, 1989.

nance programs also reduce nitrogen oxides and carbon monoxide. More stringent highway vehicle standards apply to nitrogen oxides, too. About $\$ 2.5$ billion of the total nationwide cost in 2004 can be assigned to nitrogen oxide control, the benefit of which will be discussed later. About $\$ 1.5$ billion per year can be assigned to control of carbon monoxide.

Depending on the method used, the cost of eliminating a ton of VOC emissions varies considerably. By far the cheapest is limiting gasoline volatility, at about $\$ 120$ to $\$ 750$ per ton of VOC reduction; by far the most expensive is replacing gasoline with methanol, at $\$ 8,700$ to $\$ 51,000$ per ton of reductions. (See figure 1-8.) As shown in figure 1-9, the cheaper methods can provide reductions equal to about 30 percent of the 1985 levels. As more reductions are re- quired, though, more and more expensive methods must come into play, and the cost of additional reductions rises steeply.

Most of the control methods we analyzed cost between $\$ 1,000$ and $\$ 5,000$ per ton of VOC reductions obtained. We estimate that in 1994 , if controls costing more than $\$ 5,000$ per ton of reductions were excluded from consideration, total annual costs for the nonattainment areas would drop to about $\$ 2.7$ to $\$ 5.1$ billion per year, a drop of about 30 to 35 percent. There would be a corresponding loss in reductions of about 2 percent of 1985 emissions.

Were all the analyzed controls applied, the remaining emissions in nonattainment areas would come mainly from highway vehicles (25 to 30 percent) and small stationary sources (55 percent), many of which do not lend themselves to traditional forms of regulation. Solventcontaining consumer and commercial products, for example, along with architectural surface coatings, individually emit small amounts of VOCs, but in aggregate they amount to about 10 percent of the remaining inventory.

\section{NEW DIRECTIONS}

Obviously, local controls on VOC emissions cannot completely solve the Nation's ozone problem. New control methods will be needed, but looking beyond the traditional controls raises challenging new technical and political issues. One promising approach for some areas is controlling $\mathrm{NO}_{\mathrm{x}}$, both locally and in areas upwind of certain nonattainment cities. Indeed, some cities will not be able to attain the ozone standard unless the areas from which they receive windblown ozone or precursors, which may themselves comply with the standard, further reduce their emissions. In addition, rural areas, many of which are affected by high VOC emissions from vegetation, transport of pollutants from other areas, or both, call for strategies different from those used in cities. And finally, while we can take preliminary steps in each of these nontraditional approaches over the next 
Figure 1-8-Estimated Cost-Effectiveness of VOC Emission Control Methods in 1994 in Nonattainment Cities

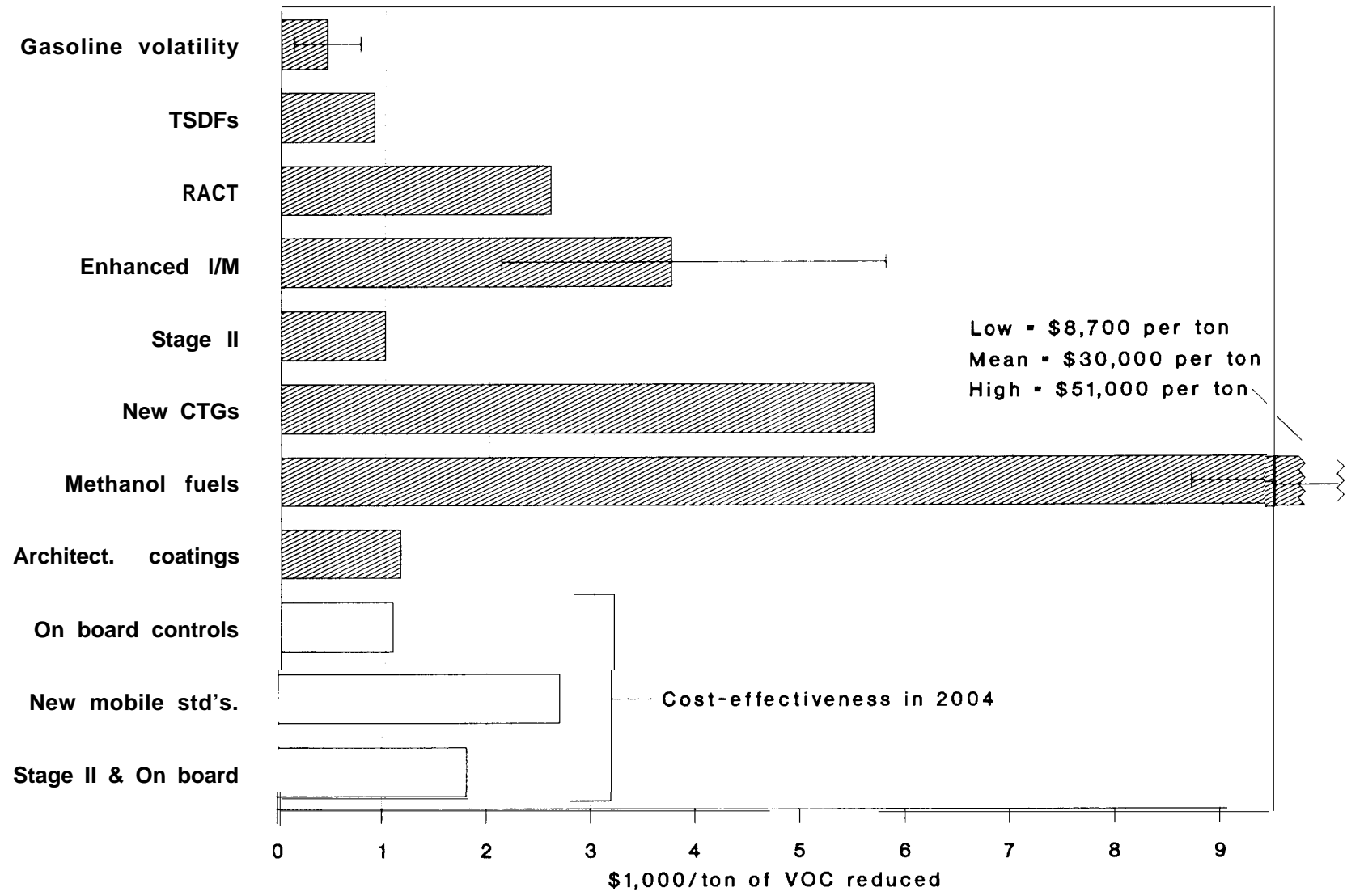

The cost-effectiveness of enhanced inspection and maintenance $(1 / \mathrm{M})$ programs and new mobile standards include only the cost of VOC control. Since Onboard controls and new mobile standards do not take affect until after 1994, we present the cost-effectiveness in 2004. The thick horizontal bars represent the average cost-effectiveness in nonattainment cities. The thin horizontal lines for gasoline volatility, methanol fuels, and $\mathbf{I} / \mathbf{M}$ programs represent ranges of uncertainty associated with assumptions we used to estimate total annual costs. The very large uncertainty associated with the methanol fuels is due to the uncertainty of methanol prices relative to gasoline prices. We were unable to estimate cost-effectiveness uncertainty for other control methods. See figure 7 for a description of control methods.

SOURCE: Office of Technology Assessment, 1989.

decade, additional research will greatly help in the search for productive new directions for ozone control after the year 2000. Congressional options for pursuing these new approaches to controlling ozone are summarized in table 1-3.

\section{Controlling Nitrogen Oxides}

Historically, ozone control efforts have concentrated on VOC emission reductions both because methods were thought to be cheaper and more available and because in some cases reducing $\mathrm{NO}_{\mathrm{x}}$ may actually be counterproduc- tive. The precise local balance of VOCs and $\mathrm{NO}_{\mathrm{x}}$ varies from place to place, even within the same metropolitan area, and from day to day. Where the concentration of $\mathrm{NO}_{x}$ is high relative to VOCs, for example, in urban or industrial centers with high $\mathrm{NO}_{\mathrm{x}}$ emissions, reducing VOC emissions can effectively cut ozone because production is limited by the quantity of available VOCs. In these cases, reducing $\mathrm{NO}_{x}$ may actually increase ozone concentrations.

$\mathrm{NO}_{\mathrm{x}}$ reductions work best where the relative concentration of VOCs is high and the produc- 


\section{Figure 1-9-Cumulative Annual Cost of, and Percent Emissions Reductions From, VOC Control Methods}

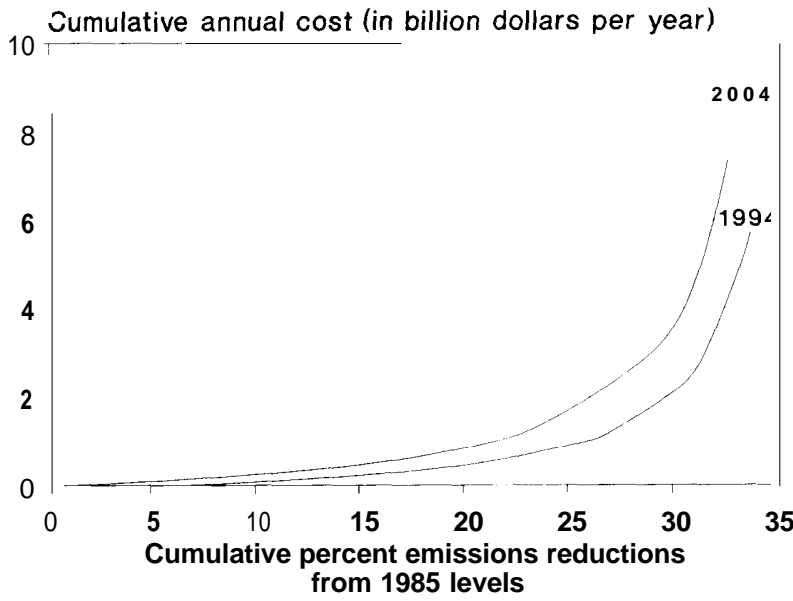

Control methods are ranked by cost-effectiveness, that is, the total cost of control per ton of VOC reduced. For example, the most cost-effective controls (e.g., gasoline volatility) are located in the lower left portion of the curve. In this figure, the costs of enhanced $\mathrm{l} / \mathrm{M}$ programs and new highway-vehicle standards include the VOC control costs and the cost of $\mathrm{NO}_{x}$ and carbon monoxide control (1/M programs, only).

SOURCE: Office of Technology Assessment, 1989.

tion of ozone is thus " $\mathrm{NO}_{\mathrm{x}}$-limited." This occurs in some cities and in most rural areas. As an air mass moves away from industrial districts and out over suburban or rural areas downwind of pollutant emission centers, conditions tend to become more $\mathrm{NO}_{\mathrm{x}}$-limited because $\mathrm{NO}_{\mathrm{x}}$ disappears from the air through chemical and physical processes more rapidly than do VOCs.

Two types of sources, highway vehicles and electric utility boilers, account for two-thirds of $\mathrm{NO}_{\mathrm{x}}$ emissions. Highway vehicles contribute about a third of the national total, led by passenger cars with 17 percent and heavy-duty diesel trucks with 9 percent. In the southern California cities with design values above 0.26 , highway vehicles account for about two-thirds of local $\mathrm{NO}_{\mathrm{x}}$ emissions; in most nonattainment cities, they contribute about 30 to 45 percent.

Under current regulations, total $\mathrm{NO}_{\mathrm{x}}$ emissions will increase steadily between 1985 and 2004, rising by about 5 percent by 1994 and by
Table 1-3-Options for Amending the Clean Air Act: New Directions

\section{Controls on emissions of nitrogen oxides in} nonattainment areas:

- Option 1: Congressionally mandated $\mathrm{NO}_{x}$ controls.

. Option 2: Presumptive $\mathrm{NO}_{x}$ controls on stationary sources, with EPA authority to exempt areas under specified situations

- Option 3: Requirements to analyze $\mathrm{NO}_{x}$ controls under certain situations.

\section{Long-term control VOC strategies:}

. Option 1: Lowering emissions from solvents, either through traditional "engineering" approaches or through market-based mechanisms.

- Option 2: Transportation control measures.

- Option 3: Requirements for widespread use of alternative fuels in nonattainment areas that are far from meeting the standard.

\section{Controls in upwind areas:}

- Option 1: Enlarge nonattainment areas to include the entire extended metropolitan area.

- Option 2: Congressionally specified $\mathrm{NO}_{x}$ controls in designated "transport regions" or nationwide.

- Option 3: Strengthen the interstate transport provisions of the Clean Air Act.

- Option 4: Provide EPA with clear authority to develop regional control strategies based on regional-scale modeling.

Reducing ozone in attainment (rural) areas:

. Option 1. Specify a deadline for EPA reconsideration of the ozone secondary standard and a schedule for Option by the States.

- Option 2. Congressionally specified $\mathrm{NO}_{x}$ controls.

Research:

Decision 1: What areas of research deserve increased funding?

- Improving the planning process, developing new control methods, and further evaluating the risks from ozone.

Decision 2: Who pays for the research?

Option 1: General revenues.

- Option 2: User fees.

SOURCE: Office of Technology Assessment, 1989

about 25 percent by 2004. (See figure 1-10.) As newer, cleaner cars replace older ones, highway emissions will decline until the mid- 1990s, only to rise again as miles traveled increase. Stationary sources, however, will increase their emissions steadily.

We analyzed the potential for emissions reductions and costs of using three currently available $\mathrm{NO}_{\mathrm{x}}$ control categories in nonattainment areas. First was placing "reasonably available" control technology (RACT) on existing stationary sources emitting more than 100 tons per year; these include both electric utility boilers and other large stationary sources such as 
Figure I-I O-Summary of Estimated Nationwide Nitrogen Oxides $\left(\mathrm{NO}_{\mathrm{x}}\right)$ Emissions by Source Category, by Year

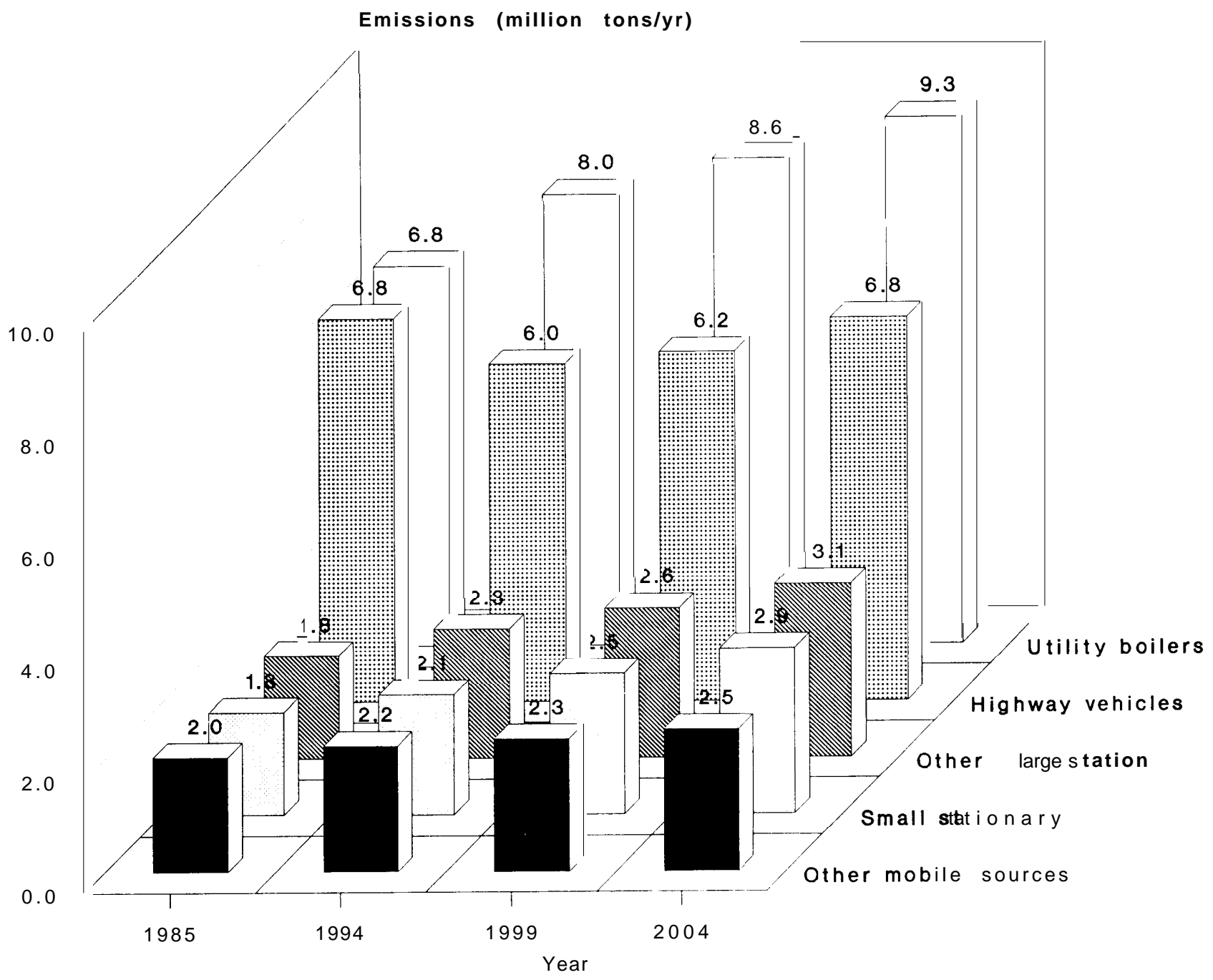

The numbers directly above the boxes are the total emissions within the source category. For example, emissions from highway vehicles in 1994 are 6.0 million tons per year, nationwide. Assumes no new laws or regulations.

SOURCE: OTA, based on work by E.H. Pechan and Associates

stationary engines, gas turbines, industrial boilers, and process heaters. Second was an enhanced inspection and maintenance (I/M) program for highway vehicles, and third, more stringent emission standards for gasoline highway vehicles. ${ }^{4} \mathrm{We}$ estimate that these measures could reduce $\mathrm{NO}_{\mathrm{x}}$ emissions in nonattainment cities by 1.2 million tons per year in 1994 , about 17 percent below 1985 levels, and by 2 million tons per year in 2004, about 28 percent below 1985 levels. As shown in figure 1-11, the largest reductions would come from controls on electric

${ }^{4}$ The emission standards used in our analysis were listed in the previous section on VOC controls. 
Figure 1-11-NO Emissions Reductions in 1994 Compared to 1985 Emissions, by Control Method

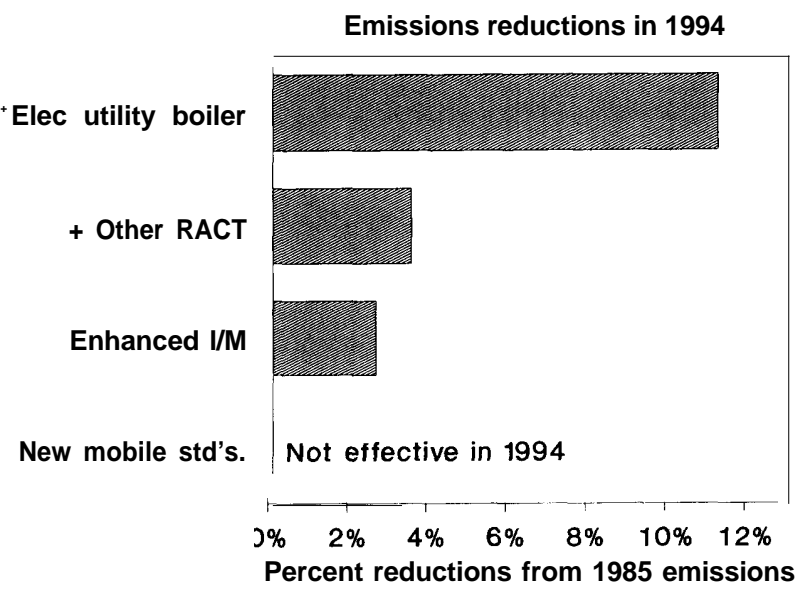

+ Controls on sources emitting more than $\mathbf{1 0 0}$ tons per year. Strategy Descriptions:

Elecric utility boiler and other RACT = moderately stringent controls on all existing stationary sources that emit more than 100 tons per year of $\mathrm{NO}_{x}$. Considered to be "reasonably available control technologies."

Enhanced inspection and maintenance (I/M) programs for cars and light-duty trucks.

New highway-vehicie emission standards for passenger cars and light-duty gasoline trucks.

SOURCE: OTA, based on work by E.H. Pechan and Associates

utility boilers. In addition to reductions in nonattainment cities, new highway-vehicle emission standards would eliminate 800,000 tons per year in attainment areas by 2004 .

What would $\mathrm{NO}_{\mathrm{x}}$ controls cost? Of the three strategies analyzed, only one, RACT-level controls on large stationary sources, was not included in the cost of "traditional" control methods presented in the previous section. Over and above the controls presented there, the $\mathrm{NO}_{\mathrm{x}}$ controls would cost about $\$ 0.5$ billion per year in 1994 and about $\$ 0.7$ billion in 2004. About $\$ 2.5$ billion of the nonattainment area control costs in 2004 cited earlier can be assigned to $\mathrm{NO}_{\mathrm{x}}$ reductions from enhanced I/M programs and more stringent highway vehicle standards.

The impacts of controlling $\mathrm{NO}_{\mathrm{x}}$ emissions in nonattainment areas will be mixed. The high degree of local variation complicates the task of deciding whether or not to mandate controls on $\mathrm{NO}_{\mathrm{x}}$. Preliminary analyses indicate that in most southern cities (from Texas east), $\mathrm{NO}_{\mathrm{x}}$ reductions would help reduce ozone concentrations; in most isolated Midwestern cities, however, they might have the opposite effect. Recent results from EPA's Regional Oxidant Model (ROM) simulating ozone formation and transport throughout the Northeast over a 2-week period, indicate that throughout this region, results will be mixed. Overall, a one-third cut in NO, emissions on top of a 50-percent reduction in regionwide VOC emissions resulted in modest ozone benefits for most nonattainment cities, compared to a case where VOC emissions were controlled alone. However, this cut in $\mathrm{NO}_{x}$ emissions increased population exposure to ozone at concentrations above the standard in some cities (e.g., Pittsburgh), decreased population exposure in some (e.g., Hartford), and resulted in negligible changes in others (such as New York). Further regional and city-by-city modeling is necessary to verify these conclusions.

Congress might wish to require studies to determine which areas would indeed benefit from $\mathrm{NO}_{\mathrm{x}}$ controls. On the other hand, it may instead wish to require such controls everywhere, but allow for exemptions in places where they are useless or counterproductive in reducing ozone.

NO, emissions affect more than just nonattainment area ozone concentrations, further complicating the decision about whether to mandate controls. $\mathrm{NO}_{\mathrm{x}}$ emissions contribute to acid deposition and are a major determinant of elevated ozone concentrations in agricultural and forested regions. Though $\mathrm{NO}_{\mathrm{x}}$ reductions can have either a beneficial or detrimental effect on peak ozone concentrations in nonattainment areas, they will most likely lower both acid deposition and regional ozone concentrations. 


\section{Non-Traditional VOC Controls}

Another approach to lowering ozone is developing new methods, both technical and regulatory, of controlling VOCs. By 1994, between 25 and 30 percent of the VOC emissions remaining after currently available controls are applied will come from highway vehicles. About 55 percent of the remaining total will come from small stationary sources that individually emit less than 25 tons per year. Over half of this latter category will come from surface coatings and other organic solvent evaporation. Efforts to further reduce VOC emissions must focus on these sources.

\section{Solvents}

Solvents are used in a wide variety of industrial, commercial, and home uses, from cleaning and decreasing heavy equipment to washing paintbrushes and removing spots from garments. They appear in thousands of commercial and consumer products such as personalcare products, adhesives, paints, and cleaners used daily throughout the country. They are used by manufacturers to paint or otherwise coat cars, appliances, furniture, and many other products in facilities that range from the huge to the tiny.

At present, only about one-quarter of total solvent use is covered by regulations, mostly in industrial applications. Currently available control methods could be applied to about an additional quarter of the total, mainly by controlling solvent and coating use by small to mid-sized industrial and commercial sources. As indicated in figure 1-12, however, all existing regulations, whether applied or not, cover less than half of solvent use. In trying to further reduce solvent emissions, regulators face the challenge of encouraging development of an enormous variety of new products, manufacturing processes and control methods. For that reason, alternative, innovative approaches must be seriously considered.
One more traditional approach to controlling these ubiquitous emissions is applying existing controls to smaller-sized commercial and industrial sources. This is no easy task for regulators, however, because hundreds of thousands of firms in nonattainment areas individually use small quantities of solvents. Another approach is to place limits on the permissible VOC content of certain products and processes; those that exceed the limit after a specified date would be banned from sale. These two strategies are variations on established "engineering" techniques of regulating users.

Also possible are so-called market-based approaches that do not directly regulate the user but make the polluting products or processes either more expensive or unobtainable, thus harnessing producers' and users' self-interest in the cause of finding substitutes. This would encourage manufacturers to reformulate solvents and users to seek non-solvent alternatives. Either emission fees or marketable emission permits could be established to discourage use of products high in VOCs by making it more profitable to use substitutes.

\section{Transportation Control Measures}

Reducing solvent emissions will pose technological challenges. In contrast, a technologically simple, if politically difficult, way to lower VOC emissions now exists: cutting the use of motor vehicles, especially private cars. The 1977 Amendments to the Clean Air Act required urban areas to implement transportation control measures (TCMs) necessary to meet ozone and carbon monoxide standards. Experience shows, though, that TCMs require considerable local initiative and political will because they aim to change the everyday habits and private decisions of hundreds of thousands of people. Involuntary TCMs have proven politically infeasible and voluntary ones difficult to sustain. Success requires long lead times, high priority given to air quality concerns in urban transportation and land-use planning, a high degree of 
Figure 1-12-Total Solvent Use Covered by Existing Regulations in 1985, by Source Category

16

Solvent use (million tons/year)

Source size

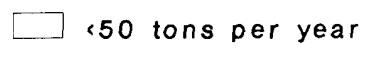

1.2

W $>50$ tons per year

0.8

architectural coating

0.6

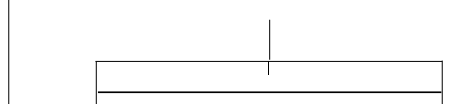

0.4

0.0

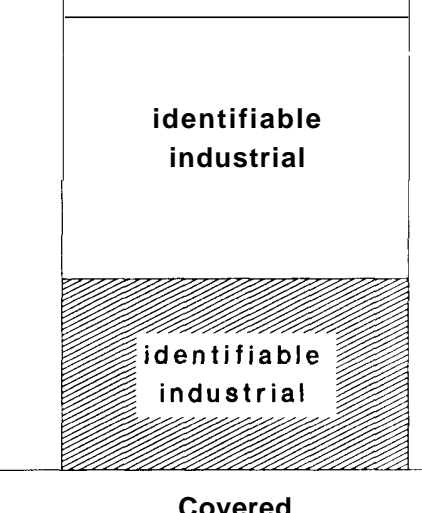



Regs not applied consumer and commercial products

We show solvent use that is (1 ) covered by existing regulations in place as of 1985, (2) not covered in a particular nonattainment area, but for which regulations do exist in other areas, and (3) not covered and for which no regulations exist as of 1985. The identifiable industrial category includes solvent use by 14 major industrial users, including rubber and plastics manufacturing, paper coating, printing, metal decreasing, and auto refinishing.

SOURCE: OTA, baaed on the National Acid Precipitation Assessment Program 1985 emission inventory and Environmental Protection Agency, Summary of State VOC Regulatons, EPA450/2-S5-003.

public support and participation and, in some cases such as mass transit development, major capital expenditures. Possible tactics include requiring staggered work hours; encouraging carpools through inducements like priority parking places, dedicated highway lanes and reduced tolls; constructing attractive and economical mass transit systems; limiting available parking places; and encouraging employers to locate closer to residential areas, which would cut distances workers have to travel.

During the 1984 Olympics, Los Angeles demonstrated that some TCMs, such as increased transit service and modified work and delivery schedules, can yield worthwhile benefits with little lead time. But the real payoff from 
a TCM strategy comes in the long term. The transportation and land use control measures outlined in the 1988 Los Angeles area Air Quality Management Plan are expected to reduce vehicle VOC emissions by a few percent in the mid-1990s, but with additional legal authority and highway funding, Los Angeles hopes to achieve reductions of about 30 percent by 2010 , compared to projected levels without TCMs. Growth management measures aimed at matching new jobs with nearby housing account for almost half the reductions projected for 2010, but will have only negligible impact before 2000. An additional 15 percent of the reductions by 2010 will come from new freeway construction intended to reduce congestion.

Neither of these measures will be easy: growth management will require coordination of zoning laws and other development policies among dozens of municipalities. The proposed freeway construction will require additional revenue, and, if it were to encourage vehicle use more than anticipated, would be less effective than planned.

\section{Alternative Motor Vehicle Fuels}

Fueling vehicles that now use gasoline with either methanol or compressed natural gas (CNG) is another technically feasible option that would produce only modest reductions in the near term but that could, with advances in automotive technology and an infrastructure to support delivery of fuels, ultimately result in quite substantial air quality benefits. Methanol cars likely to be available over the next 10 years will run on a blend of 85 percent methanol and 15 percent gasoline (or straight gasoline if necessary). VOC emissions from these vehicles would be about 30 percent lower in ozoneproducing potential than comparable use of low-volatility gasoline.

Over the long term, assuming advances in vehicle technology and widespread availability of methanol so that straight (100 percent) methanol can be exclusively used, the ozone- producing potential of dedicated methanol vehicles may be up to 90 percent lower than current gasoline vehicles. Several technical problems must first be addressed, however, including difficulty starting vehicles on straight methanol in cold weather and safety concerns related to the fuel's acute toxicity and invisible flame.

The ozone-producing potential of dedicated CNG vehicles would also be up to 90 percent lower than current gasoline vehicles. The distance they can travel before they must be refueled is about half that of gasoline, however, even with a considerably larger fuel tank.

Moreover as we have seen, use of alternative fuels, especially methanol, is potentially a very expensive control measure. The actual marginal cost over gasoline depends, of course, on future fuel prices, which are notoriously difficult to predict. Widespread use of alternative fuels would require development of both commercially available vehicles and a considerable supply infrastructure, neither of which now exist. Requiring use of CNG or methanol in selected cities, and only in commercial fleets of vehicles that are fueled at a central location, would be a way of gaining some experience with alternative fuels and beginning to reap some air quality benefits, while holding down infrastructure costs.

\section{Ozone Transport}

In many places, even those with good control of their local emissions, reducing ozone is complicated by the "transport" of pollutants, as ozone or precursors originating elsewhere are carried in by the wind. "Plumes" of elevated ozone have been tracked 100 miles or more downwind of some cities: New York's, for example, can extend all the way to Boston. Over half of the metropolitan areas that failed to attain the ozone standard between 1983 and 1985 lie within 100 miles downwind of other nonattainment cities. In such cases, VOC (and sometimes $\mathrm{NO}_{\mathrm{x}}$ ) reductions in the upwind cities could probably improve air quality in their downwind 
neighbors. Indeed, reductions in certain areas that are themselves already meeting the standard might also aid certain downwind nonattainment areas.

The significance of transported pollutants varies substantially from region to region and day to day. During severe pollution episodes lasting for several days, for example, industrial or urban $\mathrm{NO}_{\mathrm{x}}$ or ozone pollution can contribute to high ozone levels hundreds of miles away. In certain heavily populated parts of the country, pollution transport is a significant, and a very complex, problem. The northeast corridor, from Maine to Virginia, contains 21 nonattainment areas in close proximity; California, 8 ; the gulf coast of Texas and Louisiana, 7; and the Lake Michigan area, 5. Over the next 2 to 5 years proposed or ongoing modeling studies in these four major transport regions could provide information about the quantities of pollutants that are transported and the potential effectiveness of different control strategies.

Congress may wish to mandate direct controls on transported pollutants, possibly by enlarging nonattainment areas to include entire consolidated metropolitan areas or even larger regions. Designing effective strategies, however, requires very detailed information. As an alternative, Congress might wish to provide EPA the clear authority to develop regional control strategies based on regional modeling.

\section{Rural Ozone}

Excessive ozone and precursor pollutant transport affect more than just cities and suburbs. Both crops and trees in rural areas are sensitive to ozone concentrations well below the human health-based standard.

Light flecks, dark stipples, yellow spots, premature aging, and leaf loss mark annual crops injured by ozone; reduced growth rates and yields may occur even without visible injury. Crop losses increase as ozone concentrations rise. At concentrations found in rural areas throughout much of the United States, ozone depresses yields of economically important crops such as soybeans and cotton by between a few and 20 percent. Ozone concentrations during the day, averaged over the entire growingseason, exceed $0.04 \mathrm{ppm}$ in California, parts of the Midwest, throughout the South, and up the east coast. (See figure 1-13.) We estimate that the Nation could realize between $\$ 0.5$ billion and $\$ 1$ billion in benefits from a nationwide drop in ozone concentrations amounting to 25 percent of the difference between current levels and estimated background levels.

In the forests of the San Bernardino Mountains east of Los Angeles, and throughout the Eastern United States, sensitive strains of trees are seriously affected by ozone. However, the impacts of ozone on trees and forest ecosystems are not yet well enough understood to allow us to estimate the economic benefits from a reduction of ozone damage to trees in National and State parks, forests, and commercial timberlands.

Strong evidence links ozone to damage of ponderosa and Jeffrey pines in the San Bemar.dino National Forest. Incense cedar and white fir may replace these ozone-sensitive trees as the dominant species. Sensitive strains of eastern white pines in the Great Smoky Mountains and Acadia National Parks show symptoms of ozone injury. Scientists are concerned that ozone may be contributing to declines of red spruce in some high-elevation Appalachian forests and to reduced growth rates of yellow pines in some southern forests.

Congress may wish to specify a deadline for EPA reconsideration of revising the "secondary" standard, which protects vegetation, and a schedule for subsequent adoption by the States. Currently, the secondary standard is identical to the health-based standard and is generally thought to be poorly designed for protecting vegetation. Another option is for Congress to directly specify regional or national 
Figure 1-13-Estimated Daily 7-hour Average Ozone Concentrations During the Growing Season

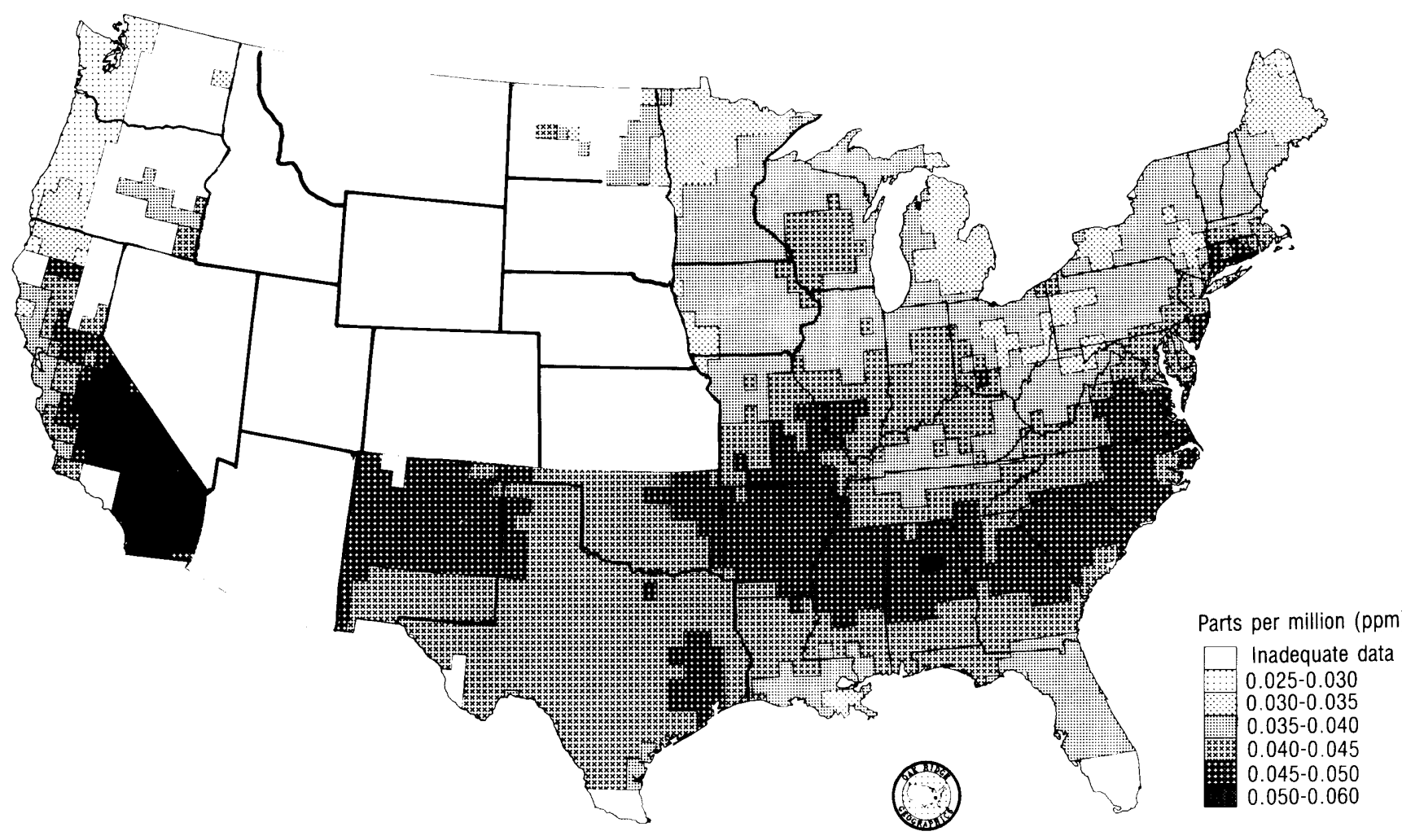

Location of Rural Ozone Monitors

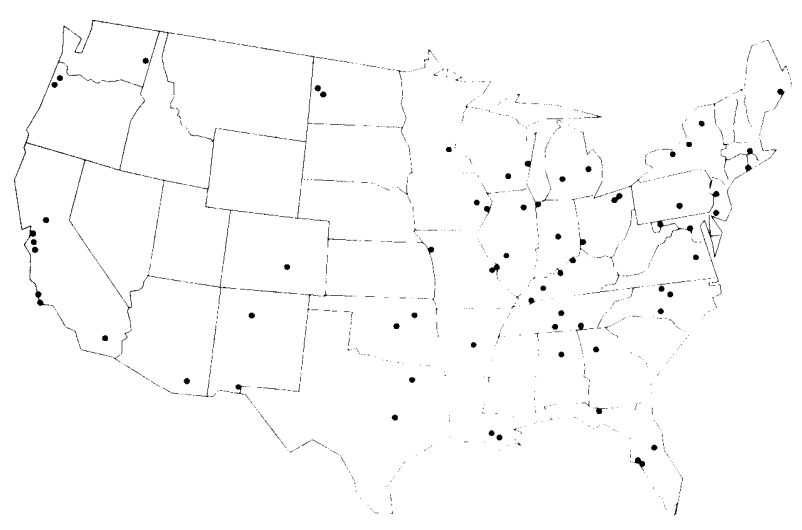

$\mathrm{NO}_{\mathrm{x}}$ controls, for example, stricter vehicle emission standards, in order to help lower ozone in rural areas. Theory suggests that $\mathrm{NO}_{\mathrm{x}}$ controls in southern and eastern rural areas will produce greater benefits than VOC controls.
Daily 7-hour daytime ozone concentrations are averaged over the months April through October and the years 1978-82. The lower map shows the location of rural ozone monitors in 1984.

SOURCE: a) Adaptod from Olson. R.J., Allison, L.J., and McCollough, I.L., Addnet Notebook: Documentation of the Acid Deposition Data Network (ADDNET) Data Base Supporting the National Acid Precipitation Assessment Program, Environmental Sciences Division publication no. 2755 (Oak Ridge, TN: Oak Ridge National Laboratory, August 1987). b) Adapted trom National Acid Precipitation Assessment Program, Interim Assessment: The Causes and Effects of Acidic Deposition, vol. III (Washington, DC: October 1987).

\section{Continuing the Search}

Ozone is probably the least understood of the six "criteria" pollutants that the Clean Air Act seeks to control and, not surprisingly, the most intractable to date. A modest investment in 
research today will pay off in better decisions and better results 10 years from now. Research should focus on improving the planning process, developing new control methods, and further evaluating the magnitude of the risks from ozone.

Planning-related research would provide better VOC emissions inventories and air quality models, which would permit more accurate plans and effective programs. Current VOC emissions inventories are quite poor. Emissions are not actually measured, but are estimated using models. Today's VOC models are far less accurate than, for example, those used for sulfur dioxide or $\mathrm{NO}_{\mathrm{x}}$. Only the 10 percent of emissions from large stationary sources such as refineries and chemical plants are individually surveyed and their emissions estimates reasonably accurate. The 40 to 45 percent from highway vehicles are estimated from a recently updated model that some still believe to be inadequate. Another 25 to 30 percent of emissions, those from diverse uses like solvents, drycleaning, and surface coatings, can be estimated nationally from sales figures; in any given nonattainment area, however, they can only be crudely guessed. Emissions from vegetation, which may figure crucially in the inventories of some nonattainment areas, are also very poorly understood. The air quality models used by most States to prepare their control plans are a good deal less accurate than the very best "state-of-the-art" versions now available. More EPA attention to the operational aspects of modeling-developing tools for the average
State agency, rather than for the expert modellercould improve most States' ability to understand the effectiveness of alternative emissions controls.

Developing solvent substitutes, cleaner fuels and methods of trapping and destroying VOCs from small sources also deserve high priority. At present, though, EPA's annual budget for new and cheaper VOC control measures is less than one-tenth of one percent of the projected cost of control. In fiscal year 1989, EPA spent about $\$ 3.8$ million on methods to lower mobile source emissions, the vast majority on one program, methanol-fueled vehicles. EPA spent only $\$ 0.4$ million on research to develop new control methods for stationary sources of VOC.

This level of funding does not seem well matched to the magnitude of the shortfall in reductions needed to attain the standard after applying all currently available technology. Moreover, putting the majority of the research emphasis on but one new control strategy-use of methanol fuels - seems very risky.

And finally, an intelligent approach to ozone requires a broader understanding of its effects. Regulatory efforts now focus primarily on one category of effects, temporary loss of some lung function resulting from exposure to short-term peaks. We cannot evaluate ozone's true risks, however, without knowing much more about the chronic effects of long-term exposure. We also need to know the full nature and extent of ozone's "welfare" effects, especially those on forests. 
Chapter 2

\section{Ozone and The Clean Air Act}




\section{CONTENTS}

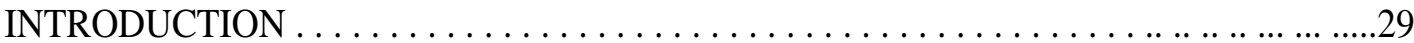

EVOLUTION OF OZONE CONTROL UNDER THE CLEAN AIR ACT... . . . . . . . 29 STATE IMPLEMENTATION PLAN DEVELOPMENT AND

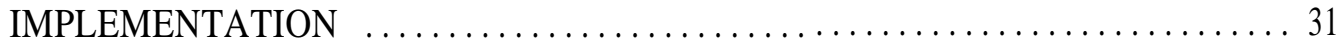

FAILURE TO MEET THE OZONE STANDARD FOLLOWING THE

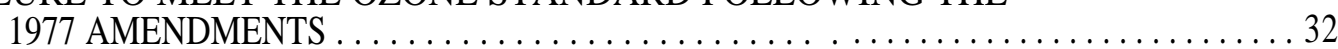

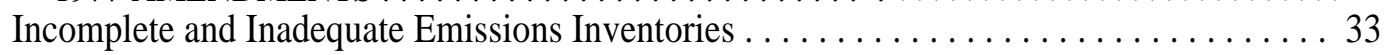

Underestimates of the Extent of Control Required To Attain the Standard . . . . . . . . 33

States Had Difficulty Issuing Stationary Source Regulations . . . . . . . . . . . . . 34

Poor Control Over Emissions Growth . . . . . . . . . . . . . . . . . . . . . . . . . . . 34

Inability To Control "Transported" Ozone and Precursors . . . . . . . . . . . . . . 35

Lack of Leadership and Political Will To Solve the Problem . . . . . . . . . . . . . . . . 35

Unreasonable Deadlines . . . . . . . . . . . ........................... 36

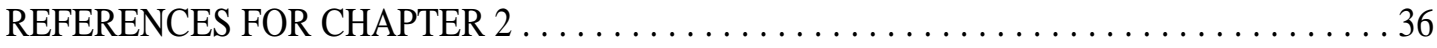




\section{INTRODUCTION}

The goal of the Clean Air Act is to "protect and enhance the quality of the Nation's air resources." To implement that goal, the 1970 Clean Air Act Amendments required EPA to establish National Ambient Air Quality Standards (NAAQS) to define the level of air quality that is expected to be maintained throughout the Nation. Of the six "criteria" pollutants for which standards have been established, we have been least successful in our efforts to attain the standard for ozone. Nationwide, about 100 areas still violate the ozone standard.

This upcoming reauthorization of the Clean Air Act will be the third time that Congress will specify a mechanism to achieve the goal specified in 1970 . To provide context for the remainder of the report, in this chapter we first review the Framework for meeting the ozone standard that was established in the 1970 and 1977 Clean Air Act Amendments and then briefly discuss the State implementation planning (SIP) process. The last section presents some of the reasons why efforts to meet the standard following the 1977 Amendments failed.

\section{EVOLUTION OF OZONE CONTROL UNDER THE CLEAN AIR ACT}

The 1970 and 1977 Clean Air Act Amendments established a partnership between the States and the Federal Government. EPA sets nationally uniform air quality standards; and the States, with the Agency's assistance, are responsible for meeting them. The requirement that the States develop "State Implementation Plans" (SIPS) and submit them to EPA for review allows for Federal oversight of the States' efforts to achieve and maintain the required level of air quality. In addition to the SIP process, the 1970 Clean Air Act Amendments established two mandatory control programs, one applying to new motor vehicles and the other to new stationary sources. EPA is responsible for setting standards for new motor vehicles. EPA also issues regulations for new stationary sources, but the program is implemented by the States. The 1977 Amendments added three additional control programs, requiring ozone and carbon monoxide nonattainment areas to apply retrofit controls on existing stationary sources and more stringent emissions limits on new stationary sources, and to develop motor vehicle inspection and maintenance programs.

As defined in the Clean Air Act, "primary" air quality standards represent the maximum allowable concentration of each criteria pollutant that protects against adverse health effects. The primary standards are required to be set at a level that "protects the public health" with an "adequate margin of safety," without regard to the economic or technical feasibility of attainment. Secondary standards are established to protect against adverse impacts on human comfort and welfare, including impacts on visibility, vegetation, animals, wildlife, materials, and property. The States, together with EPA, are responsible for ensuring that the primary air quality standards are met "as expeditiously as practicable," within the deadlines specified in the Act. The secondary standards are to be attained in a "reasonable" period of time.

Primary and secondary standards for oxidants ${ }^{2}$ were first set by EPA in 1971. In 1979, EPA revised the standards to the current definition. Both the primary and secondary standards for ozone are currently defined as a daily maximum, 1-hour average concentration of 0.12 parts per million (ppm). not to be exceeded more than once per year, on average.

In the Clean Air Act Amendments of 1970, Congress set 1975 as the deadline for meeting the primary air quality standards. The States were required to develop and carry out SIPS, estimating the emissions reductions required to attain the NAAQS, and establishing control programs to achieve the required reductions. In addition, EPA

${ }^{1}$ The six "criteria" pollutants for which the Environmental protection Agency has been explicitly required to establish NAAQS are ozone, lead, sulfur dioxide, particulate, nitrogen dioxide, and carbon monoxide.

${ }^{2}$ Photochemical oxidants are a group of chemicall related pollutants. From the standpoint of health and welfare effects, ozone is the most important of these pollutants. Ozone typically comprises over 90 percent of the total mass of" photochemical oxidants measured in urban air. 


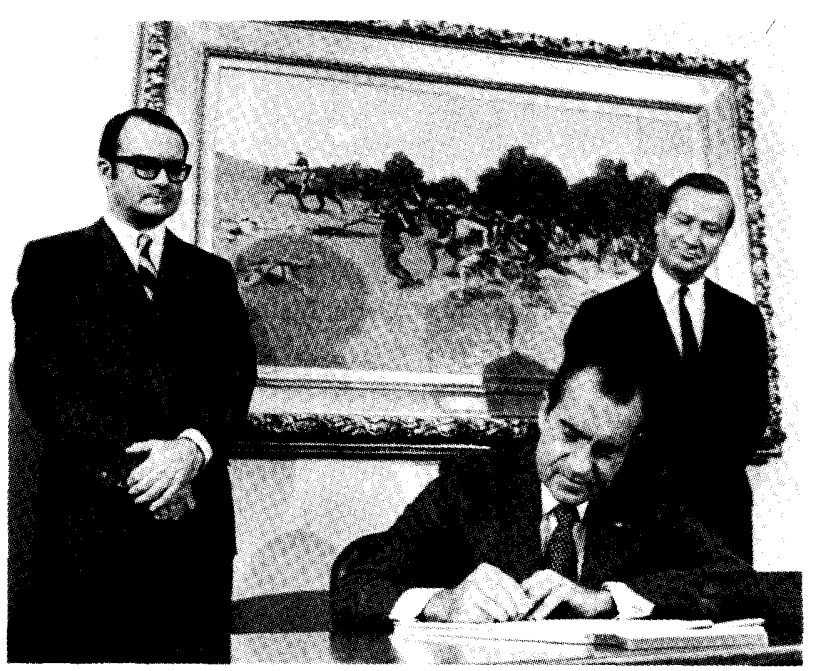

President Richard M. Nixon signs the Clean Air Act Amendments of 1970 .

was required to develop New Source Performance Standards (NSPS) that would be imposed on new or modified stationary sources with the potential to emit more than 100 tons per year of any of the criteria pollutants or of volatile organic compounds (VOCs), one of the two principal precursors of ozone. To enforce the NSPS, the States were required to include construction permit programs in their SIPS. EPA was also required to enforce a specified schedule for reducing emissions from motor vehicles.

By 1977, 2 years after the original deadline, 78 areas were still violating the ozone standard then in place (no more than one exceedance per year of a l-hour average oxidant concentration of $0.08 \mathrm{ppm}$ ). The widespread failure to attain the ozone standard by 1977 has been attributed to the fact that mobile source emissions reductions that the States and EPA were counting on to reduce ozone were not fully realized [3], and that few controls were required on existing stationary sources of VOCs [1]. Due to waivers granted by the EPA Administrator and an extension given by Congress, the schedule specified in the Clean Air Act for tightening motor vehicle emissions limits had not been met. For example, while new car VOC emissions rates were about 60 percent lower in 1977 than in 1970, according to the schedule specified in the Act, a 90-percent reduction should have been achieved. Transportation control measures such as gas rationing, restricted parking, and restricted freeway lanes generally met with strong resistance; and in 1974 Congress enacted legislation that prohibited EPA from requiring many types of transportation control measures.

In 1977, the deadline for meeting the ozone standard was moved back to 1982 . Severe nonattainment areas that did not expect to be able to meet the 1982 deadline could obtain an extension to 1987. Responding to the failure to meet the goals of the 1970 Clean Air Act, the 1977 Amendments included a new and more aggressive control program. New SIPS were to be developed and submitted to EPA in 1979, and again in 1982, for areas seeking extensions of the attainment deadline to 1987. A new schedule was established for imposing emissions limits for new motor vehicles. Existing stationary sources in nonattainment areas would have to be retrofit with emissions controls. A new source could only be constructed in a nonattainment area if it would operate at the "lowest achievable emissions rate" and if emissions reductions could be obtained from other sources to offset the emissions from the proposed source. Transportation control measures would have to be considered. Severe nonattainment areas would have to implement automobile inspection and maintenance programs.

By 1983, 17 areas that had not asked for extensions to 1987 were still violating the ozone standard (which had by that time been revised to its current definition, a daily peak l-hour average concentration of $0.12 \mathrm{ppm}$ not to be exceeded more than once per year, on average). Following its interpretation of the Act, EPA proposed to ban construction of major stationary sources in these areas. However, Congress then prohibited the Agency from using appropriated funds to impose construction moratoriums in areas with approved SIPS. Consequently, the areas that had not met the 1982 deadline were simply required to submit revised SIPS demonstrating how they would attain the standard by 1987 . By the end of 1987, no final action had been taken to approve or disapprove any of these SIPs. Since 1983, the Agency's policy on sanctions has been to restrict their imposition to areas with deficient SIPs or areas that have failed to carry out their SIP commitments in good faith. 
In addition to the 17 areas that were supposed to meet the 1982 deadline but failed to do so, approximately 40 ozone nonattainment areas had obtained deadline extensions prior to 1982. These areas were to have submitted SIPS in 1982 that would demonstrate attainment by 1987 . EPA promulgated approvals and disapprovals for most of these SIPS in 1983 or 1984. Sanctions were imposed in some areas to spur correction of SIP deficiencies. In July of 1987, EPA proposed construction bans for 11 ozone nonattainment areas that still did not have adequate SIPS.

Some progress has been made since 1977 in reducing emissions of VOCs, one of the two principal sets of precursors of ozone. EPA estimates that nationwide, emissions of VOCs have decreased by about 10 percent over the last decade. The decline in VOC emissions is due primarily to a 30-percent decline in mobile source emissions, which has occurred because of significant reductions in vehicle emissions rates, despite a 25 -percent increase in vehicle-miles traveled [4]. Stationary source VOC emissions have increased by about 3 percent since 1977.

Emissions of nitrogen oxides $\left(\mathrm{NO}_{\mathrm{x}}\right.$, the other principal set of precursors of ozone) are estimated to have declined by less than 2 percent [4].

Despite the progress that has been made in reducing VOC emissions, more than 60 areas still violate the current ozone standard. In November of 1987, EPA proposed a “post-1987" policy for addressing ozone and carbon monoxide nonattainment. Then, on December 11, 1987, Congress extended the deadline for attainment once again, this time to August 1988. The legislation precluded the imposition of the construction bans EPA had proposed in July.

\section{STATE IMPLEMENTATION PLAN DEVELOPMENT AND IMPLEMENTATION}

The principal regulatory mechanism by which the air quality standards are to be met and maintained is the State-level process of developing and implementing State Implementation Plans (SIPS). Through the SIP process, the States determine the emissions reductions required to meet the air quality standard and then set up programs to achieve the required reductions. EPA is responsible for reviewing the SIPS to ensure that they will lead to attainment, and also provides guidance to the States on several aspects of SIP development. In addition to deadlines for attainment of the standards, Congress has also specified deadlines for SIP development.

Developing and implementing a State Implementation Plan for ozone involves a series of steps that are carried out primarily at the State and local levels:

- First, the extent and severity of the local air quality problem is determined by monitoring ambient ozone concentrations. An area is classified "nonattainment" for ozone if peak 1-hour average concentrations measured at any monitor exceed $0.12 \mathrm{ppm}$ more than 1 day per year, averaged over 3 years.

- A critical piece of information required to develop a strategy for meeting the ozone standard is an inventory of $\mathrm{VOC}$ and $\mathrm{NO}_{\mathrm{x}}$ emissions that covers both stationary and mobile sources. The first step is to estimate current emissions of both precursors. The second is to forecast the changes in emissions that are anticipated to occur in the future without additional local control efforts. Such changes include increases or decreases due to anticipated changes in population, motor vehicle use and industrial activity, and also reductions due to control programs which will be implemented at the Federal level.

- The next step is to use a mathematical model to predict how much emissions will have to be reduced (in addition to the reductions that will be achieved through federally implemented control programs) to meet the ozone standard by the congressionally specified deadline. The predicted control requirement becomes the emissions reduction target for the area.

- The three preceding steps are technically challenging. The fourth step is difficult not only from a technical standpoint, but also from a political standpoint. Each nonattainment area must develop a control strategy that allocates the required emissions reductions among sources in the area, and then design programs to carry out the strategy. A control strategy typically includes imposition of emission lim- 
its or control technology requirements on stationary sources, with permitting and source inspection and monitoring programs to ensure compliance. Control strategies may include measures to encourage people to cut back on driving. Retrofit controls on some categories of stationary sources, new source construction permitting programs and motor vehicle inspection and maintenance programs have been specified by Congress as mandatory components of SIP control strategies for ozone.

- Once an ozone control strategy has been developed, the regulations contained in the SIP must be approved through the State regulatory process, and in some cases, by the State legislature. This step alone can be timeconsuming. State rulemaking processes typically take from 6 to 11 months [2].

- Once a SIP has been approved at the State level, it is sent to EPA for review. The Agency ensures that the SIP has made the required "attainment demonstration," i.e., that the control measures the State has committed to implementing will provide the level of emissions reductions predicted to be required to meet the standard. The Agency also ensures that the SIP includes all of the control programs that Congress requires. If the States are delinquent in their submittals or submit deficient SIPS, the Agency is required to impose specified sanctions and may impose others at its discretion.

- The first six steps can be regarded as SIP development. What remains is to carry out the regulatory programs contained in the SIP. This includes operating inspection, monitoring, and enforcement programs for both stationary and mobile sources. As SIP implementation progresses, the impact of the SIP is assessed by tracking emissions, and ultimately through monitoring ambient ozone concentrations.

- Finally, the control strategy is revised, if necessary, to resolve problems identified by EPA during its review process, or to compensate for inaccurate predictions of emissions trends or of the efficacy of control measures, or, finally, if the ozone standard is not attained.

EPA participates in SIP development by providing guidance to the States on monitoring, emissions inventory development, modeling, and on the cost and reduction potential of alternative control measures. Most States rely heavily on EPA as a source of this information. For ozone, the "control technique guidelines" (CTGs) issued by EPA on retrofit control strategies for existing sources of VOCs have been particularly critical. States have not only relied on the CTGs to help identify potential VOC control measures but also to facilitate promulgation of State-level regulations. For example, the existence of a CTG for a particular source can provide leverage in convincing State legislators that the source ought to be controlled.

EPA is responsible for reviewing the SIPs to ensure that they will lead to attainment by the specified deadline and that they contain the required control programs. This process involves repeated interaction between EPA, its Regional offices, and the States.

\section{FAILURE TO MEET THE OZONE STANDARD FOLLOWING THE 1977 AMENDMENTS}

More than 10 years have now gone by since the passage of the last major set of amendments to the Clean Air Act, which called for a new and more aggressive control program to attain the ozone standard throughout the country by 1987 . While ozone concentrations have been lowered in many nonattainment areas, about 100 areas still exceed the standard. OTA sponsored two workshops involving State and local air pollution control agency officials and current and former EPA staff, respectively, to explore the reasons why this decade-long effort has not resulted in more areas attaining the standard.

Before each of the workshops, participants were asked to complete a questionnaire that suggested possible problems associated with the development and implementation of the ozone control strategy pursued since the late 1970s. The results of the questionnaires formed the basis for further discussion.

Participants at each workshop tended to agree on a few problems that they saw as most significant. However, the problems emphasized by EPA and State regulators were quite different. State and local respondents emphasized the problems of transport of 
ozone and ozone precursors, inadequate air quality models, States' inability to promulgate regulations without EPA support, and inadequate EPA performance. EPA respondents most often cited emissions growth, inaccurate emissions inventories, unreasonable deadlines in the Act, and "lack of political will" to solve the ozone problem.

Many of the key problems identified in the OTA workshops were similar to those discussed in a recent General Accounting Office (GAO) report [5]. The GAO investigators also identified problems stemming from inaccurate emissions inventories, flawed modeling, and ineffective EPA oversight. In addition, they found that some control measures planned by States were not implemented or were poorly enforced.

In this section, we will summarize the reasons for continued nonattainment most often suggested by participants in the OTA workshops and in the GAO report. Our discussion begins with "planning" problems, such as inadequate inventories and poor modeling, and continues with the more difficult administrative and political problems, such as the slow pace of issuing control regulations and poor control over emissions growth.

\section{Incomplete and Inadequate Emissions Inventories}

An early and extremely important step in developing an ozone control strategy is to estimate current emissions of ozone precursors and to project future emissions in the absence of additional controls. Both EPA and State participants at the OTA workshops suggested that incomplete or inaccurate emissions inventories were a very serious problem. Respondents were particularly concerned that emissions projections made in the past have been too low, thus leading to underestimation of the reductions needed to ensure attainment by 1987 . State respondents emphasized that when current SIPs were developed, regulators did not anticipate the gradual increase in gasoline volatility and hence evaporative emissions that has since occurred. EPA participants stressed that in many areas, growth in automobile use has been much higher than originally expected, and as a result automobile emissions have exceeded expectations.
The GAO investigators agreed that the ozone plans they reviewed often understated VOC emissions. For example, they found that 'the plan for the Los Angeles area estimated that vehicle mileage would increase 14 percent for the planning period, but the mileage actually increased during the 1979 to 1985 period by 26 percent" [5].

\section{Underestimates of the Extent of Control Required To Attain the Standard}

The next step in devising a control strategy is to estimate the extent of emissions reductions necessary. Ozone is formed by a complex series of reactions involving volatile organic compounds (VOCs) and nitrogen oxides $\left(\mathrm{NO}_{\mathrm{x}}\right)$ in the presence of sunlight. In order to control ozone formation, one must decide how much to reduce emissions of VOCs or $\mathrm{NO}_{\mathrm{x}}$, or both. To do so, regulators have relied on atmospheric models that describe the relationship between VOC and $\mathrm{NO}_{\mathrm{x}}$ emissions and ambient ozone levels. Since each nonattainment area is unique due to a different mix of sources and different meteorological conditions, relying on computer models to predict control requirements allowed regulators to tailor control programs to each area's local circumstances.

State and local participants at the OTA workshops suggested that inaccuracy and misuse of atmospheric models were among the most significant problems that contributed to continued nonattainment. They suggested that, due to incomplete scientific understanding of ozone formation, available atmospheric models were (and still are) too inaccurate to derive accurate estimates of the emissions reductions needed to ensure attainment. State participants suggested that state-of-the-art models, which they believe are accurate to within 30 percent at best, are not sufficient to ensure compliance with a standard that allows only 3 exceedances over a 3 -year period.

State participants suggested that a second problem with models was that delegation of responsibility for applying models to the States provided them with ample opportunities to cheat in developing their implementation plans, a practice known as "gaming. "States were able to choose favorable model assumptions and inputs to arrive at the least stringent predictions of emission reduction requirements. 
Many State participants were also concerned that available models do not adequately account for transport of ozone and its precursors. Finally, State workshop participants questioned whether $\mathrm{NO}_{x}$ emission reductions may have been needed in addition to the VOC reductions, which EPA has exclusively encouraged.

In contrast to State and local workshop participants, EPA participants were relatively comfortable with available air quality models. They suggested that uncertainties in modeling are no greater than the uncertainties associated with many other steps of devising and enforcing an ozone control strategy. EPA respondents were also much less concerned than their State and local counterparts with whether $\mathrm{NO}_{\mathrm{x}}$ reductions were needed, although they did suggest that $\mathrm{NO}_{\mathrm{x}}$ controls might be beneficial in a few areas. However, some EPA participants, 1ike their State counterparts, were concerned that available models do not adequately account for transport.

The GAO investigators pointed out the problems that resulted from the use of modeling with incorrect or inadequate data when preparing SIPS. For example, they pointed out that Houston's 1982 SIP indicated that they needed a 41-percent reduction to attain the standard, but that the analysis relied on some poor quality atmospheric data. When the same analysis was performed by EPA with more accurate data, a 71-percent reduction was predicted to be required [5].

\section{States Had Difficulty Issuing Stationary Source Regulations}

Once the magnitude of overall reductions needed has been established, State regulators must decide which sources or source categories will be required to lower emissions, and by how much. EPA provides States with technical guidance concerning the availability and cost of various control measures for new and existing sources. For 29 categories of existing sources of VOCs, the agency issued CTGs that presumptively define the level of controls that EPA considers "reasonably available" (the level of control required for existing sources under the Act). The actual regulations limiting emissions from both new and existing sources were issued by the States. States were required to include regulations corre- sponding to the CTGs in their SIPS, plus any additional regulations needed to achieve the standard.

State workshop participants pointed out that in many cases reductions due to CTGs alone were not sufficient to attain the standard. They argued that they were unable to promulgate the additional regulations necessary to achieve the requisite VOC emission reductions. First, they suggested that many State regulators face legislative prohibitions or political pressure not to adopt particular control measures unless they are clearly forced to do so by EPA. Second, they suggested that State agencies often do not have the resources or technical expertise needed to develop new regulations on their own. State participants complained that EPA stopped issuing CTGs in recent years, leaving them without a clear Federal directive to issue particular regulations and without the resources to develop their own regulations. They also argued that it is more resource efficient for EPA to develop regulations or CTGs once than for each State to duplicate the activity.

In their own defense, some EPA participants suggested that the Agency stopped issuing CTGs in the face of resistance from the Office of Management and Budget (OMB). One participant suggested that after OMB reviewed them, the most recent group of CTGs were "so watered down that it may have been better not to issue them." Other EPA participants argued that budget limitations were much more significant than OMB review.

The GAO report provides some specific examples of areas that did not implement all of the measures they needed to attain the standard. The report states that in Los Angeles, about half of the stationary source control measures committed to in their SIP were not implemented as of 1986. GAO concludes that "in general, the measures had not been implemented either because the control technology was not fully developed or the local air quality board considered the measures too costly given the expected reductions" [5].

\section{Poor Control Over Emissions Growth}

In order to meet the air quality standard, nonattainment areas needed to both reduce existing emissions and ensure that new sources of emissions were offset by additional reductions from existing 
sources. EPA respondents most often cited emissions growth as the most important reason for the widespread failure to attain the ozone standard. As suggested above, growth in automobile use was seen as particularly problematic. Although many areas experienced a net decrease in mobile source emissions as a result of more stringent tailpipe emission standards, the reductions were often less than anticipated due to higher than expected automobile use. Workshop participants also stressed that the increasing number of automobiles will eventually reverse the downward trend in mobile source emissions nationwide unless more stringent tailpipe standards are adopted.

EPA respondents were sharply divided over the effectiveness of regulatory measures intended to offset new stationary source emissions. Only 'm new sources, those that emit more than 100 tons per year, have been subject to new source review, which requires them to obtain emissions reductions from existing sources to offset their emissions, and to install the most stringent control technology available. New sources larger than 100 tons per year can avoid new source review by obtaining offsetting reductions to limit the net emissions increase to less than that of a "major" source, a practice called "netting." About half of EPA respondents felt that too many sources have been exempt from new source review. However, others suggested that current new source review adequately counteracts emissions growth or results in only insignificant emissions increases.

Most State and local workshop participants were dissatisfied with new stationary source controls. They distrust emissions trading, since they feel that most emissions reductions used in "netting" or offsets would have occurred anyway. State participants argued that such reductions should have been "credited toward cleaner air" rather than used to facilitate new emissions.

\section{Inability To Control “Transported” Ozone and Precursors}

State and local participants complained about the difficulty of achieving adequate emissions reductions when the geographic characteristics of the problem do not correspond to State boundaries. State and local respondents suggested that many nonattainment areas monitor high levels of ozone precursors and even nonattainment levels of ozone in air masses entering their areas. They argued that emissions in upwind attainment and nonattainment areas contribute significantly to some cities' air quality problems and to elevated ozone levels in rural areas. EPA respondents also ranked transport as a serious problem, although they did not rank it as highly as did State respondents.

\section{Lack of Leadership and Political Will To Solve the Problem}

State and local workshop participants complained that EPA has not demonstrated sufficient leadership orand commitment to solve the problem. They suggested that EPA "dragged its feet" on decisions to issue Federal regulations for fuel volatility, automobile refueling emission controls, and more stringent tailpipe standards. Participants suggested that EPA's indecision discouraged States from developing their own regulations for those particular sources or for other categories that would deliver small benefits in comparison. As discussed above, the States argued that they were often unable to promulgate additional stationary source regulations because EPA stopped issuing CTGs.

In response to these criticisms, EPA respondents suggested several areas in which the States did not require the measures that they should have, citing inadequate automobile inspection and maintenance programs and incomplete SIP implementation as examples. Although they acknowledged that some Federal regulations have been delayed, most EPA respondents suggested that earlier issuance of those regulations would not have had a large effect on the overall nonattainment problem.

The GAO report concluded that both State implementation and enforcement of control programs and EPA oversight have not been as effective as they should have been. From their discussions with State and local officials, the GAO investigators concluded that at the local level there has been "a general reluctance to implement control measures that will have a negative impact on economic development or change lifestyles" [5]. Agreeing with comments made by EPA participants at our workshops, GAO 
pointed out a number of specific examples of weak implementation, inspection, and enforcement at the State and local level.

\section{Unreasonable Deadlines}

Finally, many EPA respondents suggested that Although the Act delegates primary responsibility the deadlines Congress specified in the 1977 Amendfor developing SIPS and promulgating the necessary ments were simply unreasonable. They argued that regulations to the States, EPA is responsible for widespread failure to attain the standard by Decemreviewing SIPS and overseeing their implementationber 31, 1987, does not reflect insufficient progress as The GAO report was critical of EPA's oversightmuch as unrealistic expectations. While some sugrole. In two of the three urban areas they studied,gested that the deadline was only unreasonable for EPA did not enforce requirements that the States Los Angeles, others felt that it was unrealistic for stick to their declared schedules of annual emissions many areas. Participants at both workshops argued reductions. All three areas had problems with theifhat unreasonable deadlines were counterproducSIPS. Even though EPA was aware of deficiencies, tive. They suggested that overly stringent deadlines it did not call for SIP revisions in two of the areas and encouraged States to cheat on their SIPS and EPA to waited until July 1987 to disapprove the SIPplay along with them.

submitted by the third area.

EPA participants at our workshops agreed with many of the criticisms of EPA's performance, but stated that they faced serious constraints on their ability to administer the Act. Questionnaire respondents cited inadequate budgets, OMB interference, and lack of political support. Some suggested that there was never really the "political will" to take the steps necessary to solve the ozone problem. Although many EPA participants cited "lack of political will" as a problem, they disagreed over whose will was lacking. Some suggested that there was an implicit understanding between the States and EPA not to push for more aggressive control measures since they felt that they had reached the limits of public acceptability. Others suggested that past efforts were not at all aggressive; administrative will, not public support, was lacking. Some argued that the change in Administration in 1981 lead to weaker EPA implementation of the Clean Air Act.

\section{REFERENCES FOR CHAPTER 2}

1. Hawkins, D., Natural Resources Defense Council, personal communication, March 1988.

2. Pacific Environmental Services, Inc., Study of the 1979 State Implementation Plan Submittals, prepared for the National Commission on Air Quality (Elmhurst, IL: December 1980).

3. Stewart, R. B., and Krier, J. E., Environmental Law and Policy, 2nd ed. (Indianapolis, IN: Bobbs-Merrill Co., Inc., 1978).

4. U.S. Environmental Protection Agency, National Air Quality and Emissions Trends Report, 1985, EPA-4501 4-87-001 (Research Triangle Park, NC: 1987).

5. U.S. General Accounting Office, Air Pollution: Ozone Attainment Requires Long-Term Solutions To Solve ComplexProblems, GAO/RCED-88-40(Gaithersburg, MD: Jan. 26, 1988). 
Chapter 3

\section{Health Effects of Ozone}




\section{CONTENTS}

\begin{tabular}{|c|c|}
\hline Page & Page \\
\hline INTRODUCTION & 3-5. Areas Where Ozone Concentrations \\
\hline A PRIMER ON THE HEALTH EFFECTS & Exceeded O.14 ppm at Least One Hour Per \\
\hline OF OZONE $\ldots \ldots \ldots \ldots \ldots \ldots \ldots \ldots$ & Year on Average, From $1983-85 \ldots \ldots \ldots 56$ \\
\hline Major Issues & 3-6. Areas Where Ozone Concentrations \\
\hline The Acute Effects of Ozone ... ... ... ...... 43 & Exceeded $0.18 \mathrm{ppm}$ at Least One Hour Per \\
\hline Chromic Effects: The Development of & Year on Average, From 1983-85 \\
\hline Respiratory Disease .. .. .. .. ... . & 3-7. Profile of Ozone Concentrations as They \\
\hline The Possibie Link Between Acute and & Change Over the Day at a Single Monitoring \\
\hline Chronic Effects .... . & Site \\
\hline $\begin{array}{l}\text { Potentially Susceptible Members of } \\
\text { the Population } \ldots \ldots \ldots \ldots .+\ldots . . . \ldots . .9 .49\end{array}$ & $\begin{array}{l}\text { 3-8. Contour Map of the Variation in Daily Peak } \\
\text { Ozone Concentrations Predicted for the }\end{array}$ \\
\hline Possible Synergistic Effects of Ozone & New York City Area.... \\
\hline $\begin{array}{l}\text { and Acid Aerosols } \ldots \ldots \ldots \ldots \ldots \ldots \\
\text { EXPOSURE TO OZONE } \ldots \ldots \ldots \ldots \ldots \ldots\end{array}$ & 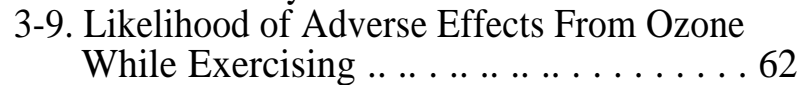 \\
\hline
\end{tabular}

Areas Failing To Meet the Standard . . . . . . . 52

Frequency and Magnitude of Exceedances. . 53

Factors Influencing Exposure to Ozone . . . . 55

Population Exposure Estimates . . . . . . . . . . 58

EXTRAPOLATION OF EFFECTS OF

MULTIPLE-HOUR EXPOSURES

TO OZONE ....................6 60

SELECTED NATIONWIDE HEALTH

BENEFITSFROM CONTROLLING

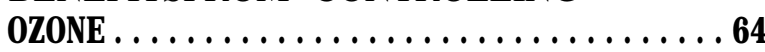

How the Estimates Are Calculated ....... . 65

Selected Health Benefits of Lowered Ozone Concentrations . . . . . . . . . . . . . 66

Assigning a Dollar Value to Health Improvements From Lowered Ozone

Levels .. ... ... ... . . . . . ... ... . . . . . . . . . 68

REFERENCES FOR CHAPTER . . . . . . . . 70

\section{Figures}

Figure Page

3-1. Acute Effects of Ozone Exposure . . . . . . . 44

3-2. Percent Decreases in Group Mean Lung

Function During 2-hr Ozone Exposures

With Different Levels of Intermittent

Exercise .. ...................... . . 45

3-3. Areas Classified as Nonattainment for

Ozone Based on 1983-85 Data .... ..... 53

Tables
Table
3-i. Gradation of Individual Physiological
Response to Acute Ozone Exposure. . . . 43
3-2. Areas Classified as Nonattainment for
Ozone Based on 1983-85 and 1985-87
Data ......................... 54
3-3. Estimated Exposures to Ozone
Concentrations Above O.12 ppm ......... 59
3-4. Population Residing in Areas Where the
Indicated Concentration is Exceeded at Least
One Period Per Year, for Each Averaging
Time ................................ 63

3-5. Number of Cities Where Ozone

Concentrattions Exceed O.14 ppm for 2-, 4-, and 8-hr Periods for the Specified Number of Days Per Year, on Average, and Population Residing in Those Cities ............. 64

3-6. Avoided Episodes of Respiratory Symptoms ... . . . . ............... . . 67

3-7. Avoided Episodes of Respiratory Symptoms ..................... 67

3-8. Avoided Days of Adverse Consequences. 68

3-9. Avoided Days of Adverse Consequences . 69

3-10. Dollar Value of Selected Health Benefits. 69

3-4. Areas Where Ozone Concentrations

Exceeded O.12 ppm at Least One Hour Per

Year on Average, From 1983-85 . . . . . . . 55 


\section{INTRODUCTION}

Ozone has been shown to cause immediate, short-term changes in lung function and increased respiratory symptoms among healthy adults and children who exercise moderately or heavily during periods of elevated ozone concentrations. Decreases in lung function and pronounced symptoms such as coughing and pain when breathing deeply have been experienced by people exposed to ozone for 1 to 2 hours at ozone levels comparable to peak levels found in many nonattainment cities. Short-term effects have also been observed at concentrations lower than the l-hour ozone standard (0.12 parts per million (ppm)) when exposures last for longer periods (about 6 hours). The implications of these effects are unclear at this time.

In addition to short-ten-n effects, ozone has been suspected of playing a role in the development of chronic lung diseases and in increasing the rate at which the adult lung ages. While not dismissing the short-term effects of ozone, many health professionals appear more concerned that repeated exposure to ozone over a lifetime may result in permanent impairment of the lungs. Some studies suggest that there may be some persistent effects associated with long-term exposure to ozone, although our understanding of such effects is currently limited. Some new research provides evidence that exposure to ozone for several hours at concentrations equal to or below $0.12 \mathrm{ppm}$ is associated with inflammation of the lungs, a suspected intermediary step in the progression from acute to chronic health effects.

In this chapter, we present four different perspectives on the effects of ozone on human health. First, we present a descriptive summary of the acute and chronic effects that ozone is known or suspected to cause. The second section presents nationwide estimates of population exposure to ozone at concentrations that exceed the standard. About 35 million people-one-quarter of the people who live in nonattainment areas-are exposed to ozone concentrations above the standard, on average, about
9 hours per year. About 13 million people are exposed to concentrations above the standard while exercising at moderate levels of exertion.

Next, we present an assessment of the lung function effects that may be occurring in exercising populations exposed for several hours at concentrations common on days when the ozone standard is exceeded. For example, on a summer day when the ozone level averages $0.14 \mathrm{ppm}$, a construction worker on an 8-hour shift or a child who plays outdoors for about 4 hours would be at risk of adverse effects on lung function. People exercising more vigorously-e.g., athletes engaged in competitive sports-could expect to experience potentially adverse effects after about 2 hours.

Finally, we attempt to quantify some of the health improvements that would result from lowering ozone concentrations. If ozone concentrations were lowered enough to meet the standard in all areas, several hundred million incidents of respiratory symptoms, such as coughing or pain on deep breathing, might be avoided each year. Some people living in the worst nonattainment areas would experience dozens fewer incidents of respiratory symptoms each year, while many people living in other nonattainment areas would experience no change. Also eliminated would be about 8 million to 50 million days each year when someone's activities are restricted because they are feeling ill from exposure to ozone. By asking people what they would be willing to pay to avoid a day of coughing or restricted activity, for example, it is possible to get a rough feel for the economic value of the health improvements listed above. The uncertainties are quite large due to the many assumptions that must be made, but about $\$ 0.5$ billion to $\$ 4$ billion per year is a reasonable range for the portion of health benefits that we were able to evaluate. We could not estimate benefits associated with changes in lung function, or the effect of repeated exposure to ozone over a lifetime (e.g., possible premature aging of the lungs or permanent lung impairment). 


\section{A PRIMER ON THE HEALTH EFFECTS OF OZONE ${ }^{1}$}

Human exposure to ozone primarily affects the lungs. Ozone has been shown to cause immediate, short-term changes in lung function and increased respiratory symptoms, and has been suspected of playing a role in the long-term development of chronic lung diseases. The immediate or "acute" effects may include some breathing difficulty and coughing, but such effects appear to be reversible, usually disappearing after a few hours. Ozone has also been suspected of playing a role in initiating asthma attacks.

Although the short-term effects are important, many health professionals are more concerned that repeated exposure to ozone over a lifetime may result in permanent impairment of the lung. Since ozone damages the tissues lining the airways of the lung, it has been hypothesized that ozone exposure could contribute to the accelerated aging of the lung, retardation of lung development in children, or the development of pulmonary fibrosis, a chronic lung disease. However, research is just beginning to shed light on questions about the possible long-term effects of ozone exposure. We are not yet able to confirm or dismiss many of the concerns about these effects.

\section{Major Issues}

The debate over health effects from ozone has centered around four major issues:

1. what are the lowest ozone concentrations at which health effects are observed?

2. what constitutes an "adverse health effect" from ozone exposure?

3. what are the effects of exposure to ozone over a long period of time? and

4. who appears to be most susceptible to ozone's ill effects?

All of these issues play an important role in the standard-setting process. ${ }^{2}$ Determining the lowest level at which health effects are observed is a crucial frost step. Studies conducted both in the laboratory and in the ambient environment generate data which help scientists define the lowest observable effects level. Once this level has been determined, a margin of safety is built into the standard to protect the groups most sensitive to the pollutant. The margin of safety is designed to protect these populations against health effects that research has not yet identified. Deciding which effects are to be considered "adverse" and determining which populations may be most sensitive to ozone are essential to setting an "adequate" margin of safety. Information about adverse effects helps policymakers define an upper bound on this margin; information on sensitive populations assists in defining a lower bound. Finally, studies of the long-term effects of exposure to a pollutant also provide input to the standardsetting process. These four major issues are discussed briefly below.

ISSUE 1: What are the lowest ozone concentrations at which health effects are observed?

The lowest concentration at which effects from ozone have been observed has been revised downward during the last 15 years, as more information has become available. In the early 1970s the threshold for responses to oxidants ${ }^{3}$ was presumed to be $0.25 \mathrm{ppm}$. This was based on limited data, however [87]. In 1977, new ozone studies showed lung function effects to heavily exercising people at concentrations as low as $0.15 \mathrm{ppm}$ [16]. During the last 5 years or so, the health effects database for ozone has greatly expanded. Scientists now believe that the duration of exposure to ozone and the intensity of exercise during exposure play a major role in determining responses at lower levels of ozone. A number of new human studies show that temporary loss of some lung function occurs in moderately to heavily exercising children and young adults exposed for 1 to 2 hours to ozone concentrations between 0.12 and $0.16 \mathrm{ppm}[60,5,70,71]$. Significant acute effects have been observed during prolonged periods of exposure (6.6 hours) at moderate exercise levels, at concentrations as low as 0.08

\footnotetext{
${ }^{1}$ The following summary of the health effects of ozone is based on a report prepared by Lawrence J. Folinsbee for the Office of Technology Assessment (see ref. [25a]).

${ }^{2}$ The air quality standard for ozone is currently under review by the EnvironmentaProtection Agency.

${ }^{3}$ Photochemical oxidants are a group of chemically related pollutants, From the standpoint of health and welfare effects, ozone is the most important photochemical oxidant. Ozone typically comprises over 90 percent of the total mass of photochemical oxidants measured in urban air.
} 


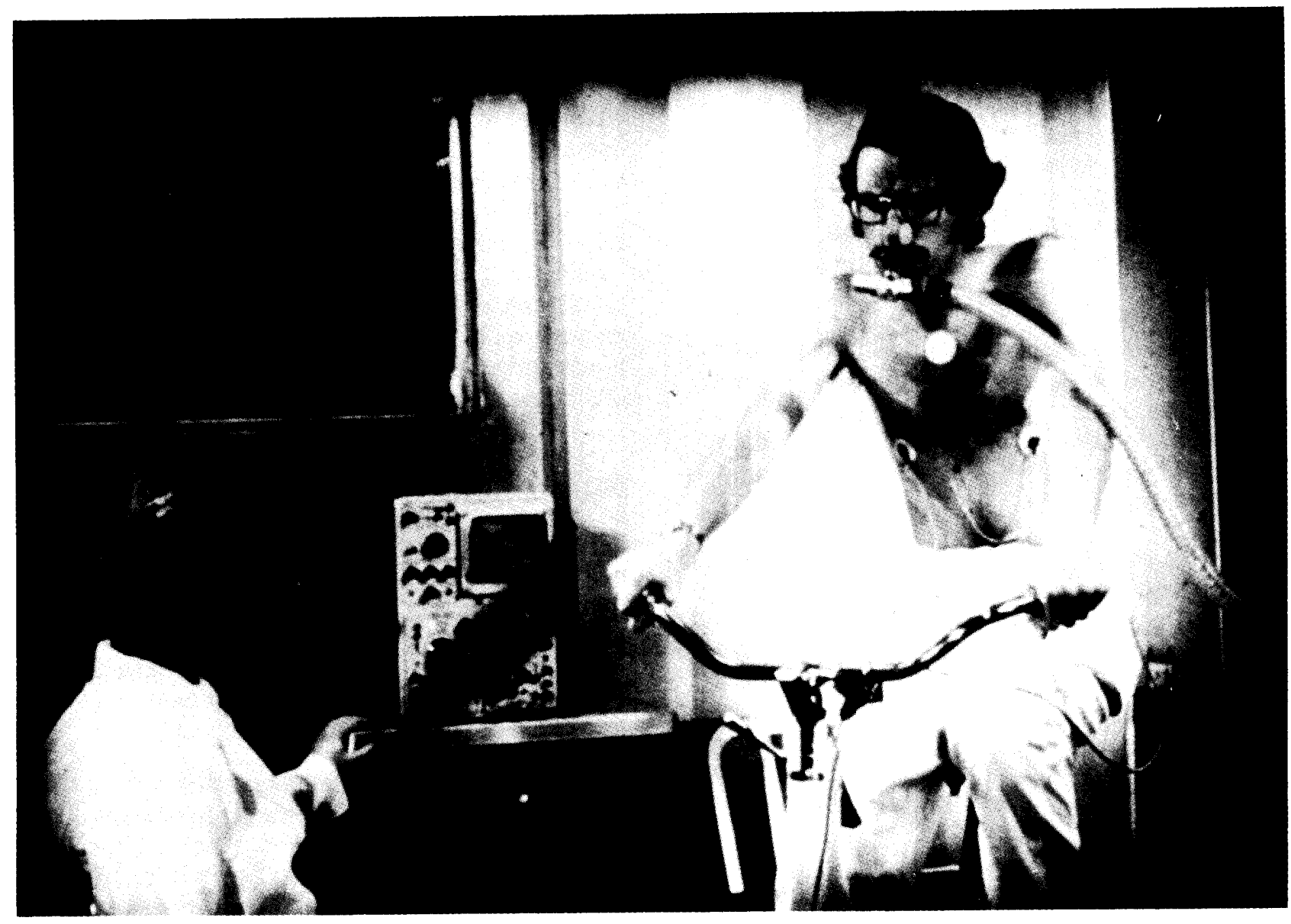

Photo credit: South Coast Air Quality Management District

Much of our understanding of the short-term effects of ozone comes from laboratory studies such as the one shown here. Volunteers breathe filtered air with known concentrations of ozone added, typically for an hour or two while exercising. Both before the experiment begins and after it is over, this volunteer's lung function was measured by having him exhale as rapidly as possible into a test device. Some healthy adults experience some temporary loss of lung function after an hour or two of heavy exercise at ozone concentrations about equal to the standard.

ppm [28,39]. This information is of crucial importance as EPA considers revising the ozone standard from its current level of $0.12 \mathrm{ppm}$ for a l-hour averaging time. Consideration of both the concentration and averaging time are considered by EPA as it reviews the standard. Some argue that the averaging time of the standard should be extended to more accurately reflect atmospheric evidence that ozone concentrations may remain elevated for up to 8 hours, not just rise and fall rapidly around a sharp peak concentration. In addition, others argue that lowering the concentration level of the l-hour standard to below $0.12 \mathrm{ppm}$ should provide some protection from prolonged exposure effects observed below that level.

\section{ISSUE 2: What is an adverse health effect?}

The Clean Air Act directs EPA to set air quality standards for pollutants that may produce "an adverse effect on public health or welfare." A great deal of discussion has been conducted within the scientific and medical community as to what constitutes an "adverse health effect," especially with regard to the effect on lung function of inhaling 
ozone at levels equal to or below the National Ambient Air Quality Standard. There is general agreement that permanent respiratory injury or episodes of pollutant-induced respiratory illness that interfere with normal activity would be considered "adverse" [23]. However, it is less clear that acute, reversible changes in lung function or increases in the incidence of respiratory symptoms, neither of which may be associated with disability, constitute an adverse health effect.

The broad continuum of effects and the diversity of scientific opinion make it difficult to precisely define what is and is not an adverse health effect. Moreover, perceptions of what is a medically significant health effect can vary greatly among physicians and patients.

The EPA staff recommends, and most members of EPA's Clean Air Science Advisory Committee (CASAC) agree, that the threshold for an individual's adverse respiratory response to acute ozone exposure should include all of the following "moderate" responses: (See also table 3-1.)

- 10 to 20 percent decrement in $\mathrm{FEV}_{1}$ (i.e., loss of lung function) in individuals (with complete recovery after 6 hours);

- mild-moderate cough, shortness of breath, pain when inhaling deeply; and

- a few individuals (i.e., some with preexisting respiratory disease or heavily exercising healthy individuals) choose to discontinue activity.

Most members of the medical community would consider a 10 percent or greater group mean loss in lung function to be sufficient to warrant concern about damage to the lung, especially if one considers that some individuals in these groups are likely to experience greater than average decrements in lung function. In addition, lung function losses which may not be harmful for people with normal, healthy lungs may be more significant for individuals with preexisting lung disease. Certainly effects that could be incapacitating and could interfere with normal activity (e.g., asthma attacks) should be considered adverse.
ISSUE 3: What are the implications of long-term human exposure to ambient ozone levels?

Perhaps the most important health concern with respect to ozone is the potential for irreversible damage to the lung from repeated exposure to ozone over a long period of time. This is especially critical when one considers that a significant percentage of the U.S. population is living in areas that may experience recurrent episodes of ozone concentrations at or near the national standard. (For further discussion of population exposure to ozone in nonattainment areas, see the following section in this chapter.)

Ozone can cause temporary loss of some lung function and increased respiratory symptoms in healthy individuals exercising heavily (e.g., competitive sports) at concentrations as low as $0.12 \mathrm{ppm}$. However, while the effects of short-term exposure to this level of ozone appear to be reversible, it is not known if repeated exposure to ozone levels in the range of 0.08 to $0.20 \mathrm{ppm}$ results in extended or, possibly, permanent changes in lung function, structure, state of growth or aging of the lung.

Both animal and human repeated-exposure studies as well as some epidemiologic studies have attempted to address concerns about the implications of long-term ("chronic") exposure to these low concentrations of ozone. Together, these studies have yielded preliminary evidence that there may, in fact, be some persistent effects associated with chronic exposure. To date, the most compelling evidence suggesting that ozone plays a role in the initiation or triggering of respiratory disease processes has come primarily from animal toxicology studies and human epidemiology studies. This research has also provided scientists with some initial clues about the possible link between acute reversible effects and chronic irreversible effects.

ISSUE 4: Are there any subpopulations which are particularly susceptible to ozone's ill effects?

In response to the Clean Air Act's mandate that EPA set air quality standards for pollutants, "allowing an adequate margin of safety ... to protect the

${ }^{4} \mathrm{FEV}_{1}$ - or the volume of air exhaled in the first second of a forcedexpiration-isonemeasure of pulmonary function that may indicate airway obstruction in the lungs. 
Table 3-I-Gradation of Individual Physiological Response to Acute Ozone Exposure

\begin{tabular}{|c|c|c|c|}
\hline $\begin{array}{l}\text { Gradation of } \\
\text { response }\end{array}$ & Moderate & Severe & Incapaciting \\
\hline $\begin{array}{l}\text { Change in lung function } \\
\text { (FEV }_{1}, \text { FVC) } \ldots \ldots \ldots .10^{\circ} 10\end{array}$ & $10-20 " / 0$ & $20-40 \%$ & $>40 \%$ \\
\hline $\begin{array}{l}\text { Duration of effect } \ldots \ldots, \text {. Complete recovery } \\
\text { in }<30 \mathrm{~min}\end{array}$ & $\begin{array}{l}\text { Complete recovery } \\
\text { in }<6 \mathrm{hr}\end{array}$ & $\begin{array}{l}\text { Complete recovery } \\
\text { in } 24 \mathrm{hr}\end{array}$ & $\begin{array}{l}\text { Recovery in } \\
>24 \mathrm{hr}\end{array}$ \\
\hline Symptoms . . . . . . . . Mild to moderate & $\begin{array}{l}\text { Mild to moderate } \\
\text { cough, pain on } \\
\text { deep inspiration, } \\
\text { shortness of breath }\end{array}$ & $\begin{array}{l}\text { Repeated cough, } \\
\text { moderate to severe } \\
\text { pain on deep inspiration } \\
\text { and shortness of breath; } \\
\text { breathing distress }\end{array}$ & $\begin{array}{l}\text { Severe cough, } \\
\text { pain on deep } \\
\text { inspiration, and } \\
\text { shortness of breath; } \\
\text { obvious distress }\end{array}$ \\
\hline Limitation of activity . . . . None & $\begin{array}{l}\text { Few individuals } \\
\text { choose to discontinue } \\
\text { activity }\end{array}$ & $\begin{array}{l}\text { Some individuals choose } \\
\text { to discontinue activity }\end{array}$ & $\begin{array}{l}1 \text { Many individuals } \\
\text { choose to discontinue } \\
\text { activity }\end{array}$ \\
\hline
\end{tabular}

public health," the EPA has sought to identify those subpopulations, if any, which are shown to be more sensitive to ozone exposure than the general population.

EPA has identified two major groups at increased risk of developing adverse health effects from exposure to ozone: 1) a subgroup of the general population with preexisting disease (e.g., asthma, chronic obstructive pulmonary disease); and 2) those individuals who exercise or work outdoors [98]. The first group is of concern because their respiratory systems are already compromised, placing them at greater risk than individuals without preexisting disease exposed to the same ozone dose. The second group is at risk because by exercising or working in an outdoor environment, they are increasing the dose of ozone to their lungs. To date, neither of these groups as a whole has been clearly shown to be more sensitive to ozone than the rest of the population, although some individuals within these groups appear to be more sensitive. In general, people with pre-existing respiratory disease have not been studied at ozone concentrations and exercise levels as high as those used for healthy subjects. The strongest evidence for a population "at-risk" exists for healthy, heavily exercising individuals.

Studies have also shown that there is a subpopulation of otherwise healthy individuals who consistently respond more significantly to the same dose of ozone than do their cohorts. These ozone-sensitive individuals are called "responders." The EPA estimates that from 5 to 20 percent of the healthy population may represent a subgroup of responders who are at abnormally high risk for the acute effects of ozone exposure [98]. The factors that would account for such individual variability in sensitivity are unknown at this time. Whether these susceptible individuals are also at increased risk for the development of chronic, irreversible effects from ozone is also unknown. (Susceptible populations are discussed at greater length towards the end of this section. )

\section{The Acute Effects of Ozone}

A great deal of research has been conducted on the acute or short-term health effects from ozone exposure. The primary acute effects investigated are: impairment of lung function, inflammation of the deep lung, respiratory symptoms, and limitations on activity. These acute effects of ozone exposure are summarized in figure 3-1, along with the ozone level at which they begin. The figure is divided into two sections: the upper section describes effects that occur with 1- to 3-hour exposures, the lower section those that occur with 4-to 8-hour exposures. The tail of the arrow indicates the concentration at which an effect may begin. At the lowest concentrations at which effects are seen, the exposures are typically accompanied by very heavy exercise for 3 hours or 
Figure 3-I-Acute Effects of Ozone Exposure

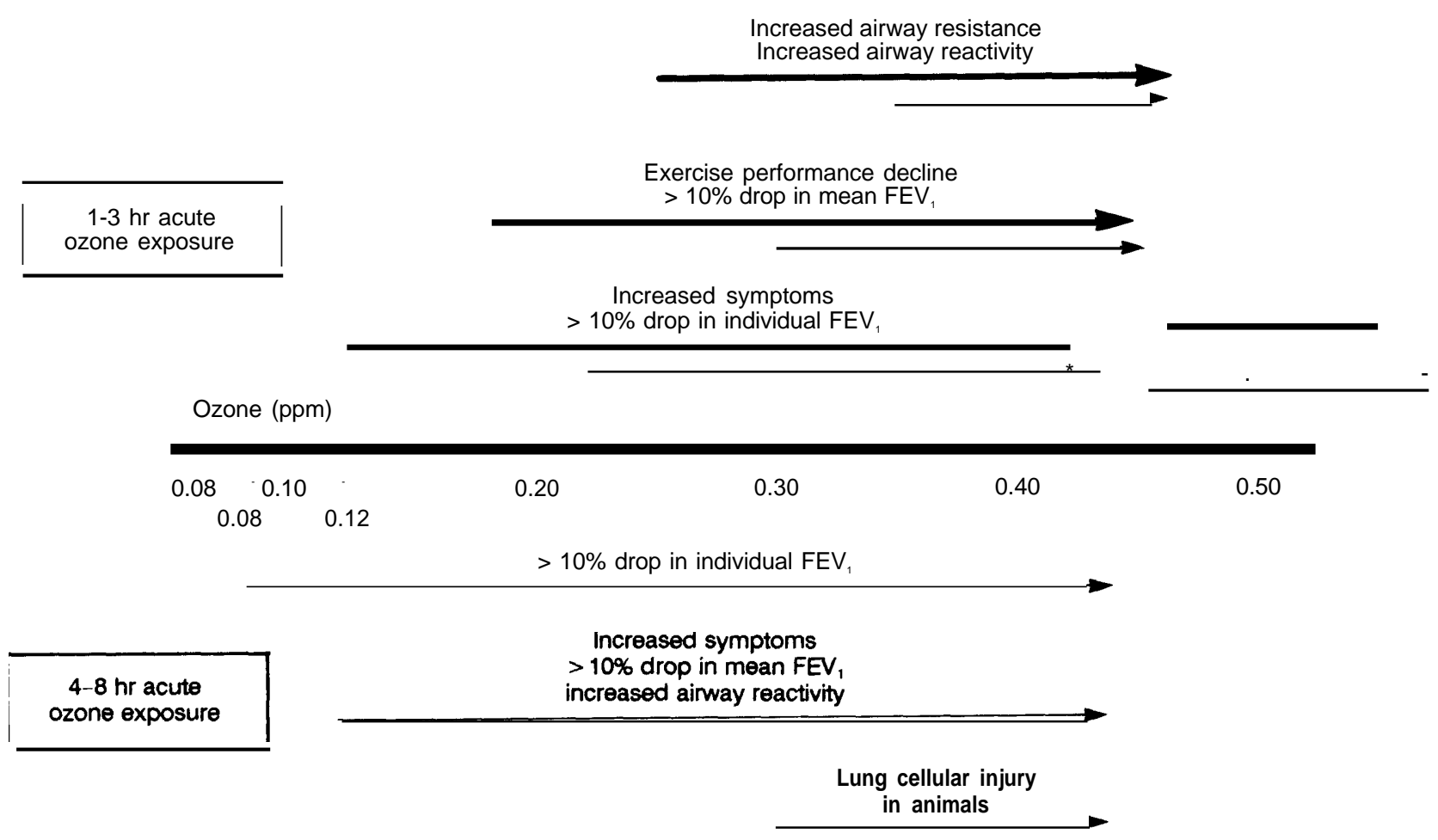

Effects above the ozone concentration line are from 1 to 3 hour exposures to ozone. Effects below the line are from 4 to 8 hour exposures. $\mathrm{FEV}_{1}$ (forced expiatory volume in 1 second) is a measure of lung function. The bolder arrows indicate the range of concentrations at which effects occur from exposure while exercising heavily; the lighter arrows indicate the concentrations at which effects occur while exercising moderately. Effects begin at the concentration indicated by the tail (left side) of the arrow.

SOURCE: L.J. Folinsbee, "A Summary of the Health Effects of Ozone," contractor report for OTA, June 30, 1988.

less. With moderate exercise, effects occur at low concentrations if exposures are prolonged (6 or more hours). The more adverse responses, such as cell damage shown in laboratory animal studies, occur at the higher concentrations.

\section{Lung Function Effects}

Ozone has well-documented, short-term, reversible effects on lung function. In studies of people exposed to ozone, the most commonly measured lung function effects are changes in "one-second forced expiatory volume" $(\mathrm{FEV}$,$) and "forced vital$ capacity" (FVC). Ozone can cause decreases in both of these measures of lung function.
Changes in lung function depend on the dose of ozone which is ultimately delivered to the lung. A number of factors influence dose, including the concentration of ozone in the air, duration of exposure, and the average volume of air breathed per minute, referred to as the ventilation rate. The ventilation rate increases with exercise. Figure 3-2 describes the dose-response relationship between ozone and $\mathrm{FEV}_{1}$. As this diagram shows, an increase in exercise intensity at any given ozone concentration results in a decrease in group mean $\mathrm{FEV}_{1}$. It is important to point out that this figure illustrates the average effect of exercise on groups, and that a great deal of variability in response exists among individual. Many studies have, in fact, shown that there

${ }^{5} \mathrm{FEV}_{1}$ is the maximum amount of air that can be exhaled from the lungs in 1 second; FVC is the maximum amount of air that can be exhaled from the lungs after taking a full deep breath. 
Figure 3-2-Percent Decreases in Group Mean Lung Function During 2-hr Ozone Exposures With Different Levels of Intermittent Exercise

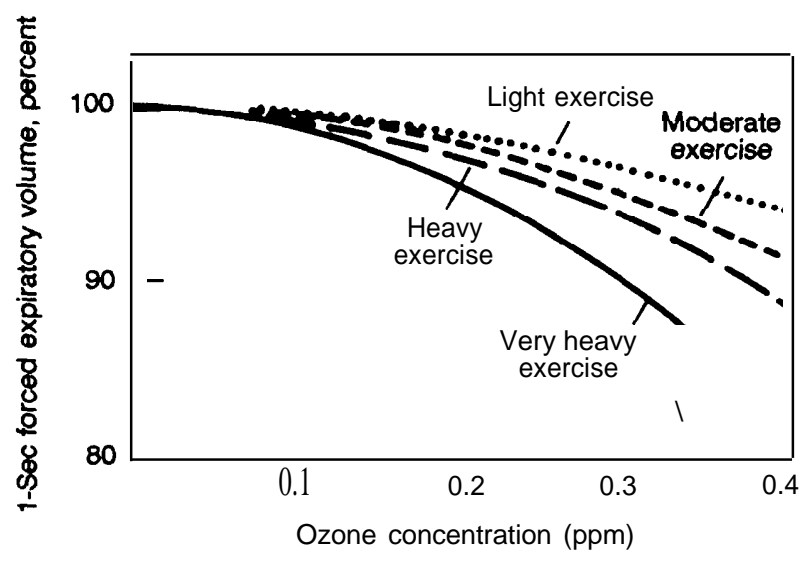

An increase in exercise intensity at any given ozone concentration results in a larger group average loss of lung function (FEV forced expiatory volume in 1 second). The lung function changes shown in the graph are for 1- to 2-hour exposures. Note that some individuals may experience decreases as much as three times greater than the group average.

SOURCE: U.S. Environmental Protection Agency, office of Air Quality Planning and Standards, Review of the National Ambient Air Quality Standards for Ozone Preliminary Assessmemt of Sciontific and Technical Information, Draft Staft Paper (Washington, DC: November 1988).

can be a large difference between the average change in lung function for a group and changes experienced by some individuals within a group.

Prior to 1980, there was very little information on lung function changes from controlled exposures to ozone concentrations below $0.30 \mathrm{ppm}$. This was mainly because under the conditions of rest or mild exercise employed in most of these studies, there was little, if any effect observed from 11 to 2-hour exposures to ozone levels less than $0.30 \mathrm{ppm}$. However, a number of studies, using higher exercise levels, have since shown clear responses to ozone levels between 0.12 to 0.24 ppm [70,26,3,35]. Average decreases in group mean $\mathrm{FEV}_{1}$ ranged from 6 to 22 percent. For comparison, the range of lung function decrease due to the normal aging of the lung ranges from about 0.5 to 1 percent per year in adult males between the ages of about 30 to 70 years old [19]. While the lung function changes due to acute ozone exposure appear to be temporary, the changes due to normal lung aging are permanent. Furthermore, the mechanism initiating these permanent changes in aging lungs is quite different from that at work in lungs acutely exposed to ozone.

At ozone concentrations equal to or exceeding the current ambient air quality standard for ozone, some investigators have seen small (4 to 6 percent) but statistically significant group mean decreases in $\mathrm{FVC}$ and $\mathrm{FEV}_{1}$ under conditions of heavy exercise [70,35], while others have not $[85,52,60]$. Because of the variability in observed changes in lung function among different studies, it is difficult to draw any definite conclusions about changes in lung function in the range of 0.08 to $0.16 \mathrm{ppm}$ ozone for 1- or 2-hour exposure periods. The most substantial responses in this range of ozone concentration occur under conditions of moderate or heavier exercise and durations of exposure longer than 1 or 2 hours. For example, Folinsbee and coworkers recently observed 7- to 13-percent decreases in group mean $\mathrm{FEV}_{1}$ in subjects performing moderate exercise for 6.6 hours at ozone levels of between 0.08 and 0.12 ppm $[28,39]$. Folinsbee, under contract to OTA, used these and other laboratory data to extrapolate the effects of multiple-hour exposures to ozone at concentrations typical of summertime conditions present in a number of U.S. cities [25 b]. A discussion of this analysis, including the lung function impacts one could expect from "typical" exercise scenarios, is presented in the third section of this chapter.

All of the lung function effects mentioned above were observed in human chamber studies. Some scientists believe, however, that chamber studies underestimate the effects from ozone exposure that may occur in populations exposed to ozone in the ambient air while engaged in normal recreational activity. The effects of ozone on lung function have also been evaluated in the ambient environment through field studies. Many of these studies have been of children in summer camp, but some have been of healthy adults engaged in outdoor exercise $[89,63]$. The decreases in lung function observed in these studies have been greater than those seen in

IIn a study by Folinsbee et al. [28], the average group change in $\mathrm{FEV}_{1}$ at $0.12 \mathrm{ppm}$ of ozone was 13 percent, with individual changes ringing from $-47.6 \%$ to +3.5 percent. Gong et al. [35] showed an average change in lung function of -5.6 percent in a group exposed to $0.12 \mathrm{ppm}$ of ozone, with individual responses varying from -30 percent to +10 percent. In a study by McDonnell et al, [70], while the average group decrease in FEV ${ }_{1}$ was $<5$ percent, individual responses ranged from a 17 -percent decrease in $\mathrm{FEV}_{1}$ to no change in this measure of lung function. 
human chamber studies in controlled indoor environments. Some scientists have postulated that the presence of other pollutants in the ambient environment, as well as other cofactors such as temperature and humidity, have contributed to this increased effect. With regard to the more significant lung function effects observed in summer camp children, some have proposed that this is the result of their greater cumulative daily exposure to ozone. These children may be exposed to ozone outdoors practically all day long, as opposed to children in chambers who may be exposed to ozone for 1 to 2 hours, with periods in clean air both before and after ozone exposure.

A current controversy surrounding impairment of lung function from ozone exposure involves the definition of an "adverse" loss in lung function. Group mean decreases in either FEV, or FVC of greater than 10 percent are clearly significant enough to be considered adverse, especially in light of the fact that some individual within these groups experience decrements in lung function greater than the average. There is less consensus, however, as to whether or not temporary and infrequently occurring changes of less than 10 percent, in and of themselves, represent an adverse health effect for a healthy young adult. Some health professionals would consider such changes to be adverse if they restrict activity or limit performance [23]. Shortterm, reversible loss of lung function could have adverse effects in individuals whose lung capacity is already reduced. However, there is no universal agreement among scientists as to the implications of such "small" changes.

\section{Symptom Responses}

Symptoms experienced by people exposed to ozone are also important markers of the effects of ozone. The major respiratory symptoms-coughing and pain when breathing deeply-typically are observed at about the same ozone exposure levels as are changes in lung function indices; heavy exercise for 1 to 3 hours at concentrations as low as $0.12 \mathrm{ppm}$ have been shown to cause such symptoms in healthy young adults [70,3,52]. Pronounced symptoms such as repeated coughing or pain when taking a deep breath will almost always be associated with substantial (greater than 10 percent) lung function changes. Folinsbee and coworkers' recent study [28] demonstrated a significant correlation at $0.12 \mathrm{ppm}$ between discomfort on deep breathing and changes in lung function (FVC) within individuals. However, most other studies that have looked for such an association have not seen it at this concentration.

Adults perceive symptoms of ozone exposure at low concentrations $(0.12 \mathrm{ppm})$ [70] but children apparently do not $[71,4,5]$. While children are certainly capable of sensing breathing discomfort, their lack of response from these low-level exposures could be the result of a higher "threshold" of perception for symptoms. It has been suggested that the weak symptom responses of children may put them at greater risk from ozone exposure because they may not try to avoid being exposed if they are unable to perceive the effects. Further research is needed on the sensitivity of children to the symptoms of ozone exposure.

The last section of this chapter presents the results of a health benefits study conducted for OTA [49]. This study estimates the benefits of controlling ozone with respect to symptoms avoided and restricted activity. The benefits of reducing lung function effects and the risk of developing chronic respiratory diseases were not estimated.

\section{Chronic Effects: The Development of Respiratory Disease}

In understanding how ozone may contribute to the development of respiratory disease, information about the mechanism of effect is vital. Because such effects are difficult to observe in humans, however, scientists often turn to animal studies for this information. Until very recently, little information has been available on the underlying changes (e.g., biochemical and structural effects) occurring in the lungs that may mark the beginnings of respiratory disease. Because scientists cannot easily observe the changes induced by ozone exposure that may be occurring at the cellular level in the human lung, they have tended to investigate other types of responses. Both human chamber and epidemiology studies have been used to examine some of these responses, including: symptoms produced by exposure, the magnitude of decline in lung function, and the related disability or peformance decreases that may occur in exposed individuals. These responses, 
while important in their own right, may also reflect changes at the cellular level that contribute to the development of chronic respiratory disease.

\section{Animal Studies}

Animal studies serve two distinct purposes: 1) providing information on the basic mechanism at work in the lungs in response to ozone exposure, and 2) providing a better understanding of the possible effects of chronic exposure to ozone.

Animal studies have shown that ozone exposure can cause biochemical and structural changes in the lung. Some of these changes are suspected of playing a role in the development of chronic lung diseases (e.g., pulmonary fibrosis), although there is no scientific consensus regarding the significance of these observed effects. Studies of animals exposed repeatedly to relatively high levels of ozone $(0.50$ $\mathrm{ppm}$ ) have revealed that it may be responsible for at least temporarily reducing the ability of the lungs to clear foreign material and thus ward off infection [29], and for causing lung inflammation [104]. Generally speaking, extended exposure to either high or low concentrations of ozone will tend to retard lung clearance. There is some evidence that acute exposure to low concentrations of ozone may actually enhance clearance. ${ }^{7}$ Several studies, however, have shown an increased response to bacterial infection in animals exposed to ozone levels as low as 0.08 to $0.10 \mathrm{ppm}$ for several hours $[73,22]$. Continuous exposure to ozone (at $0.50 \mathrm{ppm}$ ) has also been shown to alter the course of viral infection in mice by leading to structural changes in the lungs that increase the likelihood that fibrosis ${ }^{8}$ will occur [41].

One type of structural change in the lungs that some scientists believe may be linked to the development of lung fibrosis is the deposition of collagen-a structural protein that contributes to "stiffening" of the lungs [53,11].9 Repeated, intermittent exposure of monkeys to ozone concentra- tions as low as $0.25 \mathrm{ppm}$ has been shown to result in increased lung collagen content [91], although it is not certain whether such increases alone are great enough to cause fibrosis. Injury to the periphery of the lungs has been demonstrated in rats exposed to ozone at the current standard level of $0.12 \mathrm{ppm}$ [15]. Ozone has also been shown to damage certain lung cells in animals at levels as low as 0.25 ppm [14]. However, the long-term health consequences of this cell damage are not known.

While many of these studies offer important insights about the effects of exposure to ozone, the inherent uncertainties in extrapolating from animal data make it difficult to assess risk to humans from these studies. For example, uncertainties about: 1) how the distribution of dose within the respiratory system compares among animals and humans, and 2 ) whether, for a specified dose to a target site, responses in the two species would be quantitatively and qualitatively equivalent, make dose-response comparisons a difficult task.

\section{Epidemiologic Studies}

Epidemiologic studies have also been used to investigate the potential link between ozone exposure and respiratory disease. These studies involve large groups of people who are exposed to oxidant air pollution (mostly ozone) in their daily life and who may experience a variety of adverse responses from this exposure. One question that has received considerable attention is whether regular exposure to oxidant air pollution causes an increased rate of loss of lung function with age. Part of the normal aging process of the lung involves loss of "usable lung volume," perhaps related to the changes in elasticity of the lung known to occur with aging. If breathing ozone over along period of time causes an acceleration of the lung aging process, we would expect to see a more rapid age-related decline in lung volume in people who reside continuously in oxidantpolluted areas. One epidemiologic study of populations living in southern California suggests that

\footnotetext{
${ }^{7}$ Some scientists believe that short-term exposure to ozone does not allow enough time for the cilia (a defense mechanism of the lungs against foreign material) to be damaged, which tends to occur when the lungs are exposed to ozone for a prolonged period. Cilia normally act to clear out foreign material in the lungs, and some suspect that short-term exposure to ozone may increase the liquid flow of mucus in the lungs, stimulating the cilia to react to clear the lungs.

8Pulmonary fibrosis results fro the formation of excessive amounts of protein fibers that stiffen the $\mathrm{hmg}$. If this Stiffening is severe enough, it can produce debilitating disease.

${ }^{9}$ In addition to its suspected role $_{\text {in }}$ the development of fibrosis, lung stiffening is associated with breathing difficulty and subsequent limitation of work performance.
} 
respiratory function is affected by chronic exposure to ozone. The study showed an association between an accelerated loss of lung function over an extended period of time (5 years) and residing in a high oxidant community [17]..$^{10}$ The evidence is far from conclusive, however, and the question of what impact ozone may have on lung function over a lifetime requires further evaluation before a definitive answer can be reached.

\section{Susceptibility and Adaptation From Repeated Exposure to Ozone}

Chamber studies of humans show two notable responses to repeated ozone exposure: 1) when an individual is exposed to ozone on two consecutive occasions separated by less than 48 hours, the second exposure generally causes greater lung function effects than the first one $[27,10]$; and 2) with continued exposure, these effects begin to diminish in intensity and after 4 or 5 days the pulmonary function effects are undetectable [40,50,58]. This gradual loss of functional response has been called "adaptation."

The adaptive responses of individuals who live in areas with high ozone levels, however, might be different from the responses of subjects exposed to ozone for only a few consecutive days in a laboratory setting. Recent preliminary evidence indicates that people who live in Los Angeles may become less sensitive to ozone during the "smog season" but regain their sensitivity during the relatively smogfree winter season [61]. In this study, "adaptation" did not disappear rapidly, as in the chamber exposures, but appeared to persist for at least 2 to 3 months after the end of the smog season. Although this suggests that processes other than those observed in a chamber may be involved in long-term adaptation to ozone exposure, further evaluation is needed.

Though measurable lung function changes and symptom responses may lessen for a period during repeated exposure, other changes within the lungs may still be ongoing. For example, research on animals shows that some lung injury, in the form of effects on host defense systems [33], increased susceptibility to disease [34], and lung inflammation
[46], may continue during an "adaptive" period when lung function changes and symptom responses are reduced. Therefore, individuals who, through adaptation, experience fewer or less severe symptoms, may be at increased risk for longer-term damage because of these other, ongoing effects. Since these individuals may believe that they are able to tolerate exercise outdoors during peak ozone episodes because they experience fewer symptoms, they may receive potentially greater tissue damage over the long-term.

\section{The Possible Link Between Acute and Chronic Effects}

New research examining the effects from prolonged exposure to ozone at levels equal to or below the standard are providing scientists with preliminary information on the possible links between acute and chronic effects. Prolonged exposure to ozone at concentrations equal to or below the ozone standard can be associated with inflammation of the lungs, a suspected intermediary step in the progression from acute to chronic health effects [46,21]. However, questions about the degree of tissue injury occurring, and, if it occurs repeatedly, whether this injury leads to chronic health effects, remain unanswered. Not only has tissue injury in the lungs been demonstrated at $0.12 \mathrm{ppm}$, but the elasticity of the lungs also appears to have been affected. This latter effect is believed to accelerate the normal aging process of the lungs $[13,6]$.

\section{Human Chamber Studies}

Prolonged acute exposures (up to 6.6 hours) of humans in controlled laboratory settings to ozone concentrations similar to those found in many nonattainment cities ( 0.12 to $0.18 \mathrm{ppm})$ have produced several effects, including: progressively larger changes in respiratory function and symptoms with time [28], increased responsiveness of the airways of individuals to inhaled substances [72], and increased membrane permeability $[43,46]$. The relationship between these changes in the lung and the progressive development of chronic structural and functional damage is not known. Some health professionals postulate that the link between acute and chronic effects is the lung inflammation ob-

\footnotetext{
10While the Detels et al, study [17] does not provide scientists with quantitative dose-response data, its results showing an association between living in a high oxidant area and increased lung function losses, contribute to our understanding of the potential long-term effects of ozone exposure.
} 
served in the animal and human subjects of shortterm ozone studies. Before this inflammatory response disappears, some suggest that it may induce other, persistent changes in the lung or, with additional exposure or a concurrent infection, might culminate in chronic degenerative respiratory effects. Airway inflammation occurs during the development of a number of respiratory diseases, most notably asthma and chronic bronchitis.

\section{Potentially Susceptible Members of the Population}

Implicit in the Clean Air Act's directive that EPA set air quality standards with an "adequate margin of safety" is the desire to protect the most sensitive groups in the population. This desire has been echoed more explicitly in the legislative history of the Act [94].

At present, scientists postulate that about 5 to 20 percent of the healthy population may represent a subgroup of "responders" [98] who may be significantly more responsive than the general population to the same dose of ozone. Some also consider people with pre-existing respiratory disease (e.g., asthma, chronic bronchitis), individuals who exercise heavily or work outdoors, and children as potential "at-risk" groups.

The strongest evidence for increased responsiveness exists for people who exercise intensively outdoors, since the dose of ozone they receive is much higher than average due to their increased breathing rate. Because individuals with preexisting lung disease already have compromised respiratory systems, there is concern that lung function changes and other respiratory effects may be more serious for these people than for the normal, healthy population. However, limited data make it difficult to confirm the susceptibility of people with preexisting respiratory disease.

\section{Athletes and Outdoor Workers}

Both epidemiologic and chamber studies have indicated that athletes may be at substantial risk of experiencing decreases in work performance and temporary loss of some lung function when exercis- ing for approximately 1 hour at ozone concentrations as low as $0.20 \mathrm{ppm}[26,35,85]$. Outdoor workers exposed to ozone for prolonged periods may also be at increased risk. New research shows that volunteers performing the equivalent of a day of heavy manual labor while exposed to $0.12 \mathrm{ppm}$ ozone experience significant loss in lung function (13 percent group mean decrease in $\mathrm{FEV}_{1}$ ) and pronounced symptoms (e.g., cough, pain when inhaling deeply) [28]. This research suggests that extended periods of heavy exercise while exposed to ozone may be harmful to respiratory health and physical performance, not only during periods of high ozone concentrations (greater than $0.20 \mathrm{ppm}$ ), but also at levels found in many nonattainment cities $(0.12$ to $0.18 \mathrm{ppm})$.

\section{Asthmatics}

Results of studies on asthmatics are mixed. A number of epidemiologic studies of asthmatics have suggested that ozone exposure may be associated with increased asthma attacks, hospital admissions for asthma, temporary loss of some lung function, and symptoms (See ref. [103,9,38,36]. Asthmatics have also participated in studies in which lung function and symptoms were assessed before and after breathing ozone in a controlled laboratory environment. These studies have typically shown that the lung function and symptom responses of asthmatics to a specific low concentration level of ozone do not differ from the responses of healthy non-asthmatics $[44,62,57] .11$

It is unclear why asthmatics have generally failed to exhibit increased sensitivity to many of the effects of ozone in chamber studies. However, these have been group analyses; there may be a subpopulation of asthmatics more sensitive than a subgroup of "normals" to ozone inhalation. For example, moderate to severe asthmatics have not been studied in these controlled environments. Chamber studies of asthmatics have only recently been conducted at the higher exercise and ozone concentration levels that have yielded the most significant responses in non-asthmatics. The discrepancy between results in epidemiologic and chamber studies may also be due to interaction between ozone and other environ-

\footnotetext{
${ }^{11}$ While the weight of the evidence suggests that asthmatics are no more sensitive to ozone than healthy, non-asthmatics, one recent clinical study suggests that asthmatics may be slightly more sensitive to the effects of ozone on airway narrowing, which occurs at somewhat higher ozone concentrations than the changes in $\mathrm{FEV}_{1}[47]$.
} 
mental factors (i.e., other pollutants, high temperatures, and humidity) in the field. Factors operating in the ambient environment may not have been replicated in clinical studies. The question of whether asthmatics may be somewhat more adversely affected by ozone inhalation is not yet resolved.

\section{People With Chronic Obstructive Pulmonary Disease}

People with chronic obstructive pulmonary disease (COPD) (e.g., chronic bronchitis, emphysema), many of whom are former smokers, are also of concern as an "at-risk" subgroup because they already have poor lung function. Like asthmatics, relatively small decrements in lung function could be adverse for them, compared to healthy individuals, who may not be affected by such changes. Several different laboratory studies have been conducted on COPD patients exposed to ozone $[51,58,59,88,42]$, but none have found them to experience significant reductions in lung function measures (FVC, FEV ${ }_{1}$ ) even at concentrations as high as $0.30 \mathrm{ppm}$ for 1 to 2 hours. It would be necessary to study these individuals over longer periods of exposure and at higher exercise levels (unobtainable by many COPD patients) in order to adequately evaluate their risk from ozone exposure. Out of concern for their health, studies of patients with COPD, like those with asthma, have not been performed under such conditions to date.

\section{Children}

Concern for children as a potentially susceptible subgroup has been raised for several reasons:

1. their lungs are not fully developed until adulthood, increasing their risk for damage from ozone exposure;

2. they are more likely than the average adult to be exercising outdoors when ozone levels are high (summertime); and

3. their higher metabolic rates tend to lead to higher ventilation rates during exercise, which may give them a greater dose of ozone than exercising adults.

The critical question regarding children exposed to ozone is whether repeated exposure will influence their lung maturation. Relatively low concentrations of ozone (at or around the standard) do appear to have an adverse impact on the lung function of active children $[71,63]$. On the basis of both controlled exposure studies and field studies of ambient pollutant exposure, however, children $d o$ not appear to have lung function effects that are different than those experienced by adults. However, children appear to experience fewer symptoms than adults when exposed to concentrations as low as $0.12 \mathrm{ppm}[71,3,52]$. It is unclear at this time why children have weaker symptom responses. Some scientists have suggested that this lack of significant symptom response may put them at greater risk because it would fail to deter them from future ozone exposure.

\section{The Elderly}

Concern over the elderly as a possible "ozonesensitive" subgroup has been largely because of a general belief that the most frail members of any population may be at an overall greater risk from numerous environmental stresses than the population at large. However, it is commonly accepted that these individuals are the least likely to be exercising outdoors where they might be exposed to ozone. A subgroup of healthy, older adults may be at risk because they may participate in outdoor activities where they might be exposed to ozone. The limited evidence available at this time, however, does not indicate that age plays a significant role in their response to ozone. While lung function effects have been observed in this subpopulation, several studies suggest that healthy older adults may, in fact, be less susceptible to the acute lung function effects of ozone than healthy young adults $[20,82]$. The extent to which pulmonary function changes reflect other events occurring in the lungs of older adults who are exposed to ozone is unknown.

\section{Possible Synergistic Effects of Ozone and Acid Aerosols ${ }^{12}$}

Some scientists are concerned that ozone and acid particulate and vapors may interact to affect human health. This has been prompted by research indicating that both pollutants affect a similar target in the lungs, may be enhanced by exercise, and reach peak concentrations at the same time of the year. Some laboratory findings suggest that the response of

12This section is based largely on EPA's "Acid Aerosolsissue paper" [99]. 


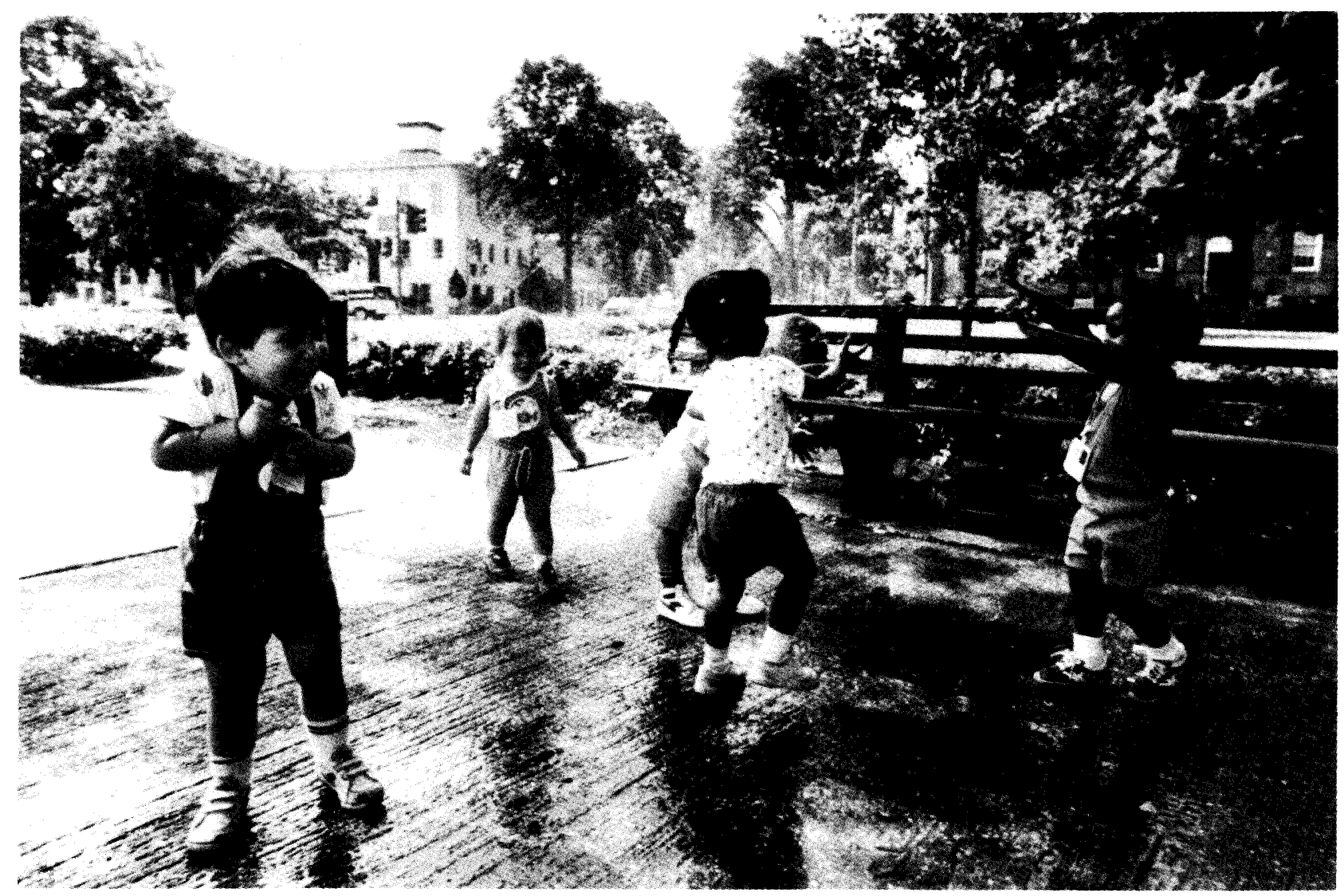

Photo credit: Steve Delaney

Many health scientists are worried about the effects of ozone on children at play during high ozone episodes found in many nonattainment cities. The critical unknown is whether repeated exposure will influence their lung maturation.

subjects exposed to ozone in conjunction with acid aerosols is greater than when exposed to ozone alone [75].

The two types of acid particulate that are receiving the most attention are ammonium bisulfate and sulfuric acid. There is evidence to suggest that both acids are respiratory irritants and that their "target zone," owing to their small size, is the periphery of the lungs, similar to that for ozone. In addition, exercise seems to exacerbate the effects of inhaled sulfuric acid [100], as has been shown to be the case with the impact of ozone exposure. Moreover, on the east coast, airborne sulfates are most acidic in the summertime, the time of year when peak ozone levels tend to occur.
Possible interaction between ozone and some acid aerosols is believed by some scientists to affect lung clearance mechanisms, lung function, and acute respiratory hospital admissions. Recent studies of animals exposed to sulfuric acid show persistent impairment of lung clearance, as does research currently underway with ozone [86]. ${ }^{14}$ Disturbance of lung clearance mechanisms is believed by some scientists to promote the inception or progression of chronic respiratory disease, but there is no proven connection at this time. Given the recent concern about chronic health effects from exposure to ozone alone, and the possibility of synergism between ozone and certain acid aerosols, this new information is of particular concern.

13011 the west coast,nitricacid, which is in vapor form under most ambient conditions, has shown a correspondence with ozone concentrations.

${ }^{14}$ Work on 4-, 8-, and 12-month exposures is in progress at this time. 
Short-term loss of some lung function in children exposed to ozone ( 0.12 to $0.18 \mathrm{ppm}$ ) in the ambient environment has led some researchers to postulate that other pollutants, in particular, acid sulfates, may have contributed to this enhanced effect [62]. One epidemiologic study has shown a significant correlation between ozone, sulfates, temperature, and respiratory disease admissions to the hospital during the summer months [9].

Research suggests that the acidity of an aerosol is related to its toxicological potency, and is an important factor in determining whether the aerosol will interact synergistically with ozone [99,54]. There is some evidence that much lower concentrations of sulfuric acid-the more acidic aerosolthan ammonium sulfate $\left(0.04 \mathrm{mg} / \mathrm{m}^{3} \mathrm{v} .5 .0 \mathrm{mg} / \mathrm{m}^{3}\right.$, respectively) $[102,101]$ are needed to produce a synergistic effect. Evidence from field studies shows temporary effects on lung function of summer camp children from elevated levels of sulfuric acid $(>0.04$ $\left.\mathrm{mg} / \mathrm{m}^{3}\right)$ and ozone $(>0.13 \mathrm{ppm})[79,80]$. Concentrations of sulfuric acid up to $0.04 \mathrm{mg} / \mathrm{m}^{3}$ have been observed in urban areas in the United States [99]. Preliminary evidence from animal studies, however, indicates effects only at much higher levels than the human studies. Effects on the rat lung do not appear until sulfuric acid concentrations reach $0.5 \mathrm{mg} / \mathrm{m}^{3}$, in combination with $0.12 \mathrm{ppm}$ of ozone [102].

While our understanding of the relationship between ozone and acid aerosols is limited at this time, the apparent correlation between atmospheric concentrations of ozone and acid particulate and their respective health effects, as well as the general lack of data on acids in the ambient environment, indicate a need for additional research on pollutant mixtures.

\section{EXPOSURE TO OZONE}

As discussed above, ozone has been shown to cause short-term decreases in lung function and increased respiratory symptoms in people engaged in moderate to heavy exercise when ozone concentrations exceed the standard. There is also concern about persistent health effects associated with longterm exposure to ozone. This section presents information on the number of areas throughout the
United States where the ozone standard is not met, and the population that lives in those areas. To get a sense of the frequency with which people may be exposed to elevated ozone levels and the magnitude of these exceedances, the number of times that areas fail to meet the standard is also presented. Because living in an area where ozone levels have been measured above the standard does not guarantee that a person will actually be exposed at those levels, we look at the various factors that influence exposure to ozone.

\section{Areas Failing To Meet the Standard}

$A \boldsymbol{n}$ area is designated "nonattainment" for ozone if concentrations exceeding $0.125 \mathrm{ppm}$ (l-hour average) are measured on more than 3 days over a 3 -year period at any monitoring site in the area (i.e., the area has an "expected exceedance" rate greater than once per year, averaged over 3 years).

Figure 3-3 shows the metropolitan statistical areas (MSAs) and grouped or "consolidated" metropolitan statistical areas (CMSAs) that were classified as ozone nonattainment areas based on 1983-85 monitoring data. Areas that were designated nonattainment for the 1983-85 period, as well as the 1985-87 period, are listed in table 3-2. As indicated in the table, several non-MSA areas were also designated nonattainment but are not shown on the map.

EPA updates the list of nonattainment areas every year as data for a new season become available. Based on the 1983-85 data, 76 urban areas (encompassing 104 individual MSAs plus the 10 non-MSA areas) were designated nonattainment. In contrast, 70 areas were designated nonattainment based on the 1985-87 period (18 areas were dropped in and 12 areas were added). The difference is partially attributable to differences in weather between the two periods. We focus on the nonattainment list from the 1983-85 period for consistency with other parts of our assessment. The list for the most recent 3 -year period at the time of publication (1986-88) is not yet available.

The shading in figure 3-3 indicates the 1983-85 "design value" for each area. The design value is a

${ }^{15}$ The non-MSA areas are Dover, DE; Seaford, DE; Iberville Parish, LA; Pointe Coupee Parish, LA; St. James Parish, LA; Acadia National Park, ME; Gardiner County, ME; Hancock County, ME; York County, ME; and Northampton County, VA. 
Figure 3-3-Areas Classified as Nonattainment for Ozons Based on 1083-85 Data

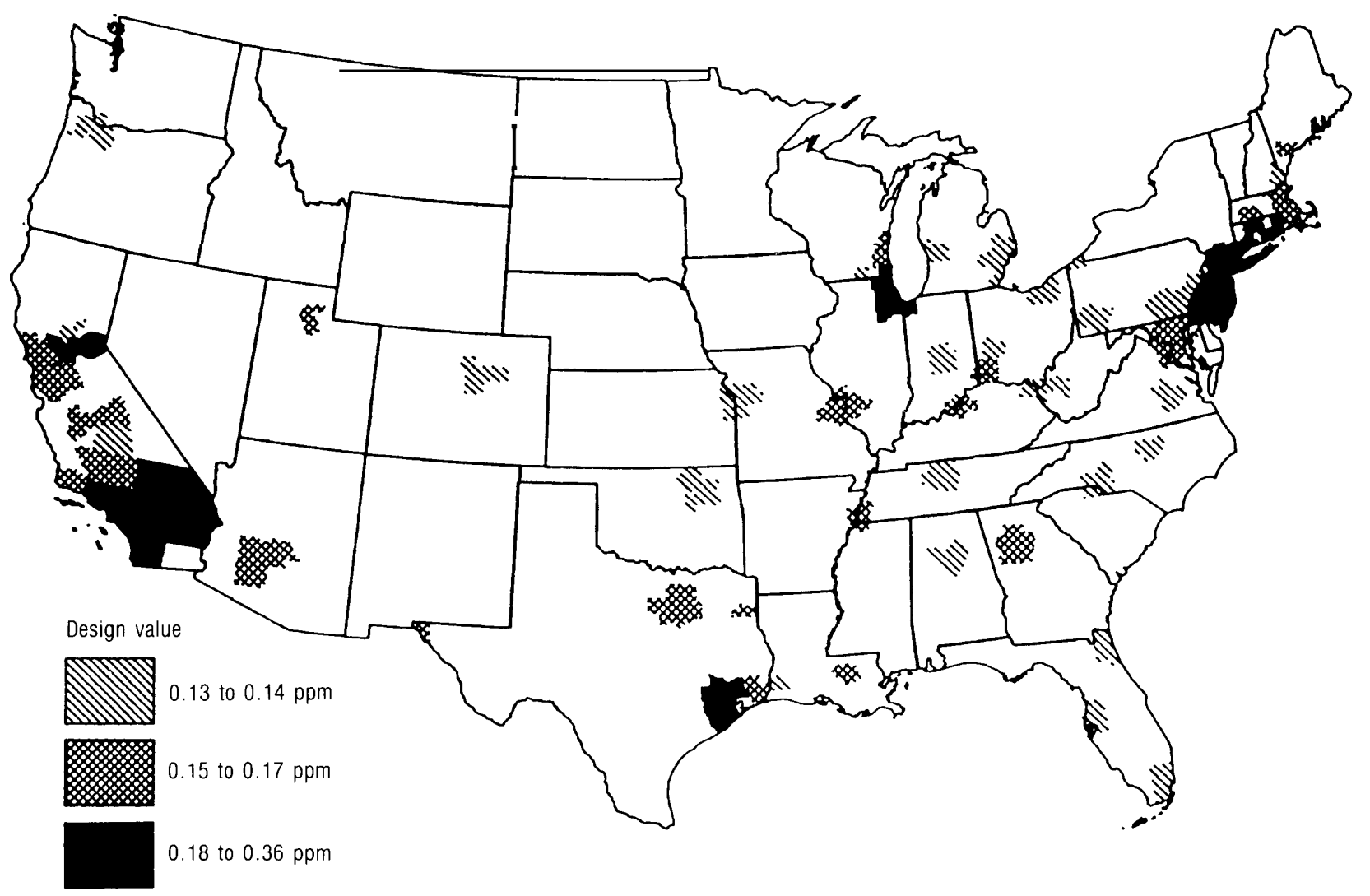

The shading indicates the fourth highest daily maximum 1-hour average ozone concentration, or "design value," for each area. SOURCE: U.S. Environmental Protoction Agency

measure of the highest 1-hour average ozone concentrations in the area and is the fourth highest of all of the daily peak 1-hour average ozone concentrations observed within the area over the most recent 3 -year period. Areas with design values of $0.13 \mathrm{ppm}$ or higher are violating the ozone standard. On average, the higher the design value, the greater the level of emissions control required to prevent violations of the standard. For the 1983-85 period, 39 areas had design values of 0.13 or 0.14 ppm, 27 areas had design values of 0.15 to $0.17 \mathrm{ppm}$, and 10 areas had design values of $0.18 \mathrm{ppm}$ or more. The highest design value for any area was $0.36 \mathrm{ppm}$, for Los Angeles, CA.

\section{Frequency and Magnitude of Exceedances}

Figures 3-4 through 3-6 show the areas throughout the contiguous United States where ozone concentrations exceeded $0.12,0.14$, and $0.18 \mathrm{ppm}$, respectively, at least 1 hour per year, averaged over the years 1983 to 1985 . By averaging data from all of the monitors in each area, the maps indicate the number of hours each concentration level was typically exceeded. ${ }^{16}$ The data shown were obtained from EPA [84]. The all-monitor average statistics are assumed to be more representative of air quality throughout each area than data for the peak monitor (the monitor where the highest concentrations were recorded) would be. Note that more areas would be

\footnotetext{
${ }^{16}$ The number of monitors in each area ranges from 1 to 18 (in Los Angeles). The average number of monitors in each area is three.
} 
Table 3-2-Areas Classified as Nonattainment for Ozone Based on 1983-85 and 1985-87 Data

\begin{tabular}{|c|c|c|c|}
\hline \multirow[b]{2}{*}{ Area name } & Design value (ppm) & \multirow[b]{2}{*}{ Area name } & Design value (ppm) \\
\hline & $1985-87$ & & $1985-87$ \\
\hline $1983-85$ design value of 0.13 to $0.14 \mathrm{ppm}$ & & Tulsa, OK & 0.12 \\
\hline Acadia National Park, ME* $\ldots \ldots \ldots .13$ & ---- & Visalia-Tulare-Porterville, CA & 0.15 \\
\hline 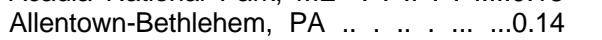 & 0.13 & York, PA ........... & \\
\hline Birmingham, $\mathrm{AL}^{* *} \ldots \ldots \ldots \ldots \ldots . .13$ & 0.15 & Yuba City, CA . & \\
\hline Charleston, WV . & & $1983-\& \mathrm{~J}$ design value of 0.15 to $0.17 \mathrm{ppm}$ & \\
\hline Charlotte-Gastonia-Rock Hill, NC-SC .. .0.13 & 0.13 & Atlanta, GA . . . . . . . . . . . . . . & 0.17 \\
\hline Cleveland, $\mathrm{OH}^{\star *} \ldots \ldots \ldots \ldots \ldots \ldots .14$ & 0.13 & Bakersfield, CA. & 0.16 \\
\hline Dayton-Springfield, $\mathrm{OH} \ldots \ldots \ldots \ldots . . . .13$ & $\cdots$ & Baltimore, MD . . & 0.17 \\
\hline Denver-Boulder, CO ${ }^{\star *} \ldots \ldots \ldots \ldots . . .13$ & --- & Baton Rouge, LA ....... & 0.14 \\
\hline 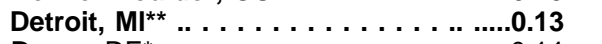 & 0.13 & Beaumont-Pod Arthur, TX ..... & 0.13 \\
\hline Dover, $\mathrm{DE}^{\star} \ldots \ldots \ldots \ldots \ldots \ldots \ldots .14$ & --- & Boston, MA ${ }^{* *} \ldots \ldots \ldots \ldots$ & 0.14 \\
\hline$\ldots \ldots \ldots \ldots .0 .13$ & --- & Cincinnati, $\mathrm{OH}-\mathrm{KY}-\mathrm{IN}^{* *} \ldots \ldots$ & 0.14 \\
\hline$\ldots \ldots \ldots \ldots 0.14$ & -- & Dallas-Ft. Worth, $\mathrm{TX}^{\star *} \ldots$ & 0.16 \\
\hline Grand Rapids, Ml & 0.13 & El Paso, TX ........ & 0.16 \\
\hline Hancock County, ME* $\ldots \ldots \ldots \ldots .13 \ldots$ & 0.13 & Fresno, CA. & 0.17 \\
\hline $\begin{array}{llll}\text { Harrisburg-Lebanon-Carlisle, PA } & . . & \ldots . .0 .13\end{array}$ & & Longview-Marshall, TX & \\
\hline Huntington-Ashland, WV-KY-OH,$\ldots . .0 .14$ & 0.14 & Louisville, KY-IN . . & 0.16 \\
\hline 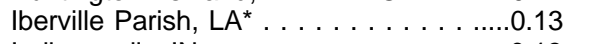 & 0.13 & Knox County, ME* & 0.15 \\
\hline 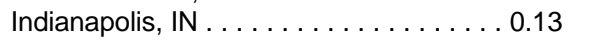 & 0.13 & Memphis, TN-AR-MS & 0.13 \\
\hline Jacksonville, FL . & 0.16 & Milwaukee, $\mathrm{WI}{ }^{* *}$. & 0.17 \\
\hline Janesville-Beloit, WI . . . . . . . . ....0.13 & & Modesto, CA. & 0.15 \\
\hline Jefferson County, NY* . . . . . . . . . --- & 0.13 & New Bedford, MA. & 0.14 \\
\hline 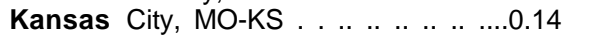 & - & Phoenix, AZ. & 0.14 \\
\hline Kennebec County, ME* ...........--- & 0.12 & Portland, ME & 0.14 \\
\hline Kent County, DE* $\ldots \ldots \ldots \ldots \ldots \ldots \ldots$ & 0.13 & Salt Lake City-Ogden, UT. & 0.15 \\
\hline Kewaunee County, $\mathrm{WI}^{\star} \ldots \ldots \ldots \ldots \ldots \ldots$...- & 0.13 & Santa Barbara-Santa Maria-Lompoc, CA.. 0.16 & 0.14 \\
\hline Kings County, $\mathrm{CA}^{*} \ldots \ldots \ldots \ldots \ldots \ldots \ldots$ & 0.13 & Seaford, $D^{*} \ldots \ldots \ldots \ldots \ldots \ldots \ldots .15$ & \\
\hline Lake Charles, LA. . . . . . . . . . . . ....0.14 & & St. Louis, MO-IL** & 0.16 \\
\hline Lancaster, PA . . . . . . . . . . . . . ....0.13 & --- & Stockton, CA ... & 0.14 \\
\hline$\ldots \ldots \ldots \ldots \ldots{ }^{---}$ & 0.13 & Washington, DC-MD-VA & 0.15 \\
\hline Lincoln County, ME* .............--- & 0.13 & Worcester, MA ......... & 0.13 \\
\hline $\begin{array}{llllll}\text { Miami-Hialeah, } \mathrm{FL}^{* *} & \ldots . & . . & \ldots & \ldots & \ldots . .0 .13\end{array}$ & 0.15 & York County, ME* & 0.15 \\
\hline Montgomery, AL . . . . . . . . . . --- & 0.14 & San Francisco, $\mathrm{CA}^{* \star} \ldots$ & 0.14 \\
\hline Muskegon, Ml . . . . . . . . . . . . ....0.14 & 0.17 & $1983-65$ design value 0.18 to 0.26 ppm & \\
\hline $\begin{array}{l}\text { Nashville, TN } \ldots \ldots \ldots \ldots \ldots \ldots \ldots \ldots .0 .14 \\
\text { Norfolk, VA }\end{array}$ & 0.14 & Atlantic City, NJ .... & 0.14 \\
\hline 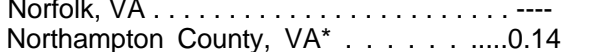 & 0.13 & Chicago, IL $\mathrm{L}^{* *}$. & 0.17 \\
\hline & 0.13 & Greater Connecticut ${ }^{* *}$ & 0.17 \\
\hline Pittsburgh, $\mathrm{PA}^{* *} \ldots \ldots$ & 0.13 & Houston, $\mathrm{TX}^{\star *}$ & 0.20 \\
\hline Pointe Coupee Parish, LA* . . . . . ....0.13 & & New York, NY-NJ-CT* . & 0.19 \\
\hline Portland, OR-WA** & 0.15 & Philadelphia, PA-NJ ${ }^{\star *} \ldots \ldots \ldots \ldots \ldots . .0 .18$ & 0.16 \\
\hline Portsmouth-Dover-Rochester, NH-ME. .0 .13 & 0.13 & Providence, $R^{*} \ldots \ldots$. . . . . ....0.18 & 0.16 \\
\hline Raleigh-Durham, NC ..............- & 0.13 & Sacramento, CA. & 0.17 \\
\hline Reading, PA.. & & San Diego, CA.... . . . . . . . . . ....0.21 & 0.18 \\
\hline Richmond-Petersburg VA . . . . . .....0.13 & 0.13 & 1983-85design value $0.27 \mathrm{ppm}$ or higher & \\
\hline St. James Parish, LA ${ }^{*} \ldots \ldots \ldots \ldots \ldots .13$ & & Los Angeles-Long Beach, CA** . .....0.36 & 0.35 \\
\hline Tampa-St. Petersburg-Clearwater, FL** .0 .13 & 0.13 & & \\
\hline
\end{tabular}

"non-MSA area. "mult-MSA consolidated area. ---in attainment.

SOURCE: U.S. Environmental Protection Agency.

expected to show exceedances of the specified concentrations if data for the peak monitor in each area were used.

Of the 317(urbanandnonurban) areas for which we have ozone data, figure 3-4 shows the 130 areas where a concentration ofO.12 ppm was exceeded at least 1 hour per year, on average, between 1983 and 1985.1 ${ }^{7}$ Sixty of those are a shad concentrations equal to or greater than $0.12 \mathrm{ppm}$ for60r more hours per year, The Dallas, Houston, and Atlanta areas and

${ }^{17}$ If data for the peak monitor in each area had been used instead of the all monitor average statistics, 146 areas would be indicated ashavingozone concentrations greater thanor equal to $0.12 \mathrm{ppm}$ at least 1 hour per year. 
Figure 3-4-Areas Where Ozone Concentrations Exceeded 0.12 ppm at Least One Hour Per Year on Average, From 1983-85

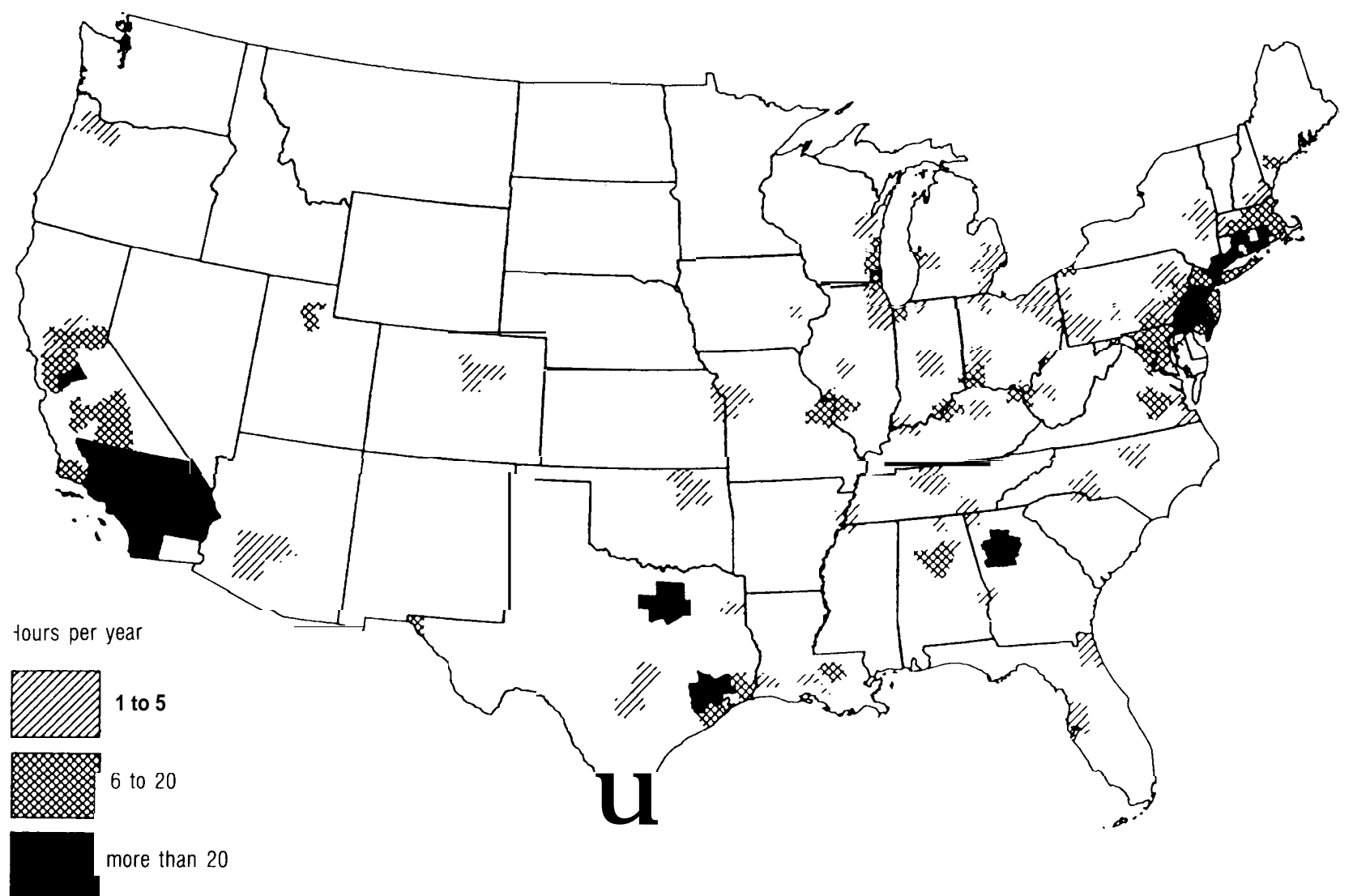

Data from all monitors located in each area were averaged in constructing the map. The shading indicates the number of hours that a concentration of $0.12 \mathrm{ppm}$ was exceeded. One hundred thirty million people reside in the areas shown.

SOURCE: U.S. Environmental Protection Agency, Storage and Retrieval of Aerometric Data, database, processed by E.H. Pechan \& Associates, 1987.

parts of California, New York, New Jersey, and Connecticut all recorded concentrations greater than or equal to $0.12 \mathrm{ppm}$ more than 20 hours per year. The maximum number of hours that monitored ozone concentrations exceeded $0.12 \mathrm{ppm}$ in any one area was 275 hours per year.

Figure 3-5 shows the 60 areas where the allmonitor average statistics indicate that ozone concentrations reached $0.14 \mathrm{ppm}$ at least 1 hour per year between 1983 and 1985. Twenty-four of these areas recorded ozone concentrations of at least $0.14 \mathrm{ppm}$ for 6 or more hours per year. Seven areas, namely the Houston area and parts of Connecticut and southern California, recorded concentrations of $0.14 \mathrm{ppm}$ or higher more than 20 hours per year.
Figure 3-6 shows the 18 areas where concentrations were as high as $0.18 \mathrm{ppm}$ for 1 or more hours per year between 1983 and 1985. The all-monitor average statistics indicate that concentrations exceeded 0.18 ppm 6 or more hours per year in Houston and in two areas in Connecticut. Concentrations reached $0.18 \mathrm{ppm}$ more than 20 hours per year in three areas in southern California.

\section{Factors Influencing Exposure to Ozone}

Just because an individual lives in an area where ozone concentrations of $0.14 \mathrm{ppm}$ (for example) have been measured does not mean that he or she has been exposed to ozone concentrations at that level, or that if exposed, he or she would experience 
Figure 3-5-Areas Where Ozone Concentrations Exceeded 0.14 ppm at Least One Hour Per Year on Average,

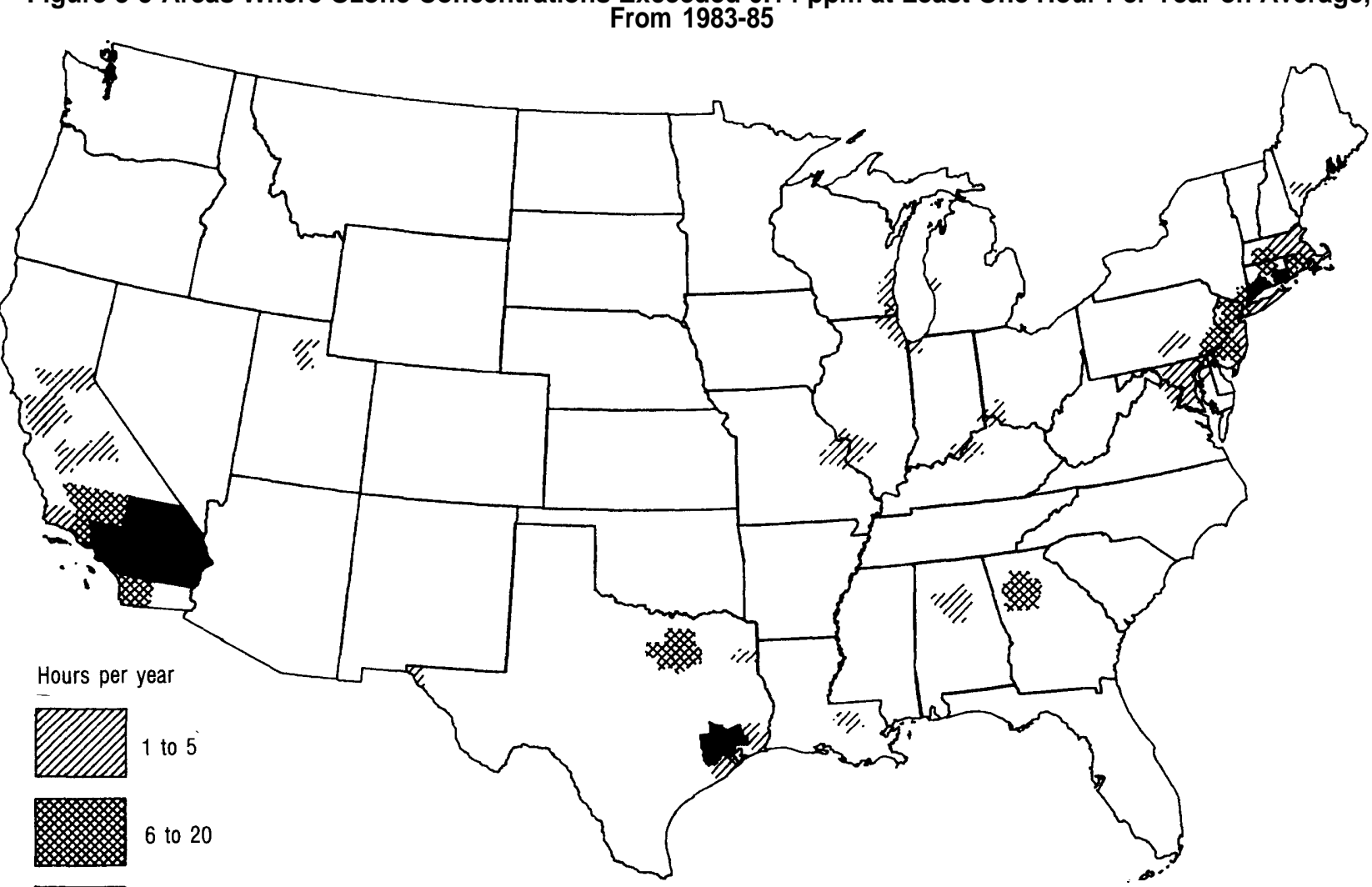

more than 20

Data from all monitors located in each area were averaged in constructing the map. The shading indicates the number of hours that a concentration of $0.14 \mathrm{ppm}$ was exceeded. Eighty-six million people reside in the areas shown.

SOURCE: U.S. Environmental Protection Agency, Storage and Retrieval of Aerometric Data, database, processed by E.H. Pechan \& Associates, 1987.

adverse health effects. This section discusses some of the factors that determine what a specified measured ozone concentration means for human health. The factors that need to be kept in mind include:

1. how outdoor ozone concentrations vary over time and location within a city;

2. where people are and for how longespecially how much time they spend outdoors v. indoors, where concentrations are lower;

3. people's activity levels - which determine their breathing rate and the depth of the breaths they take, and thus the amount of ozone they inhaled over a given period of time; and
4. person-to-person variability in how sensitive people are to ozone.

At urban locations, ozone concentrations usually peak during the early to mid-afternoon, after building up throughout the morning. At suburban and rural locations, the peak concentrations usually occur later in the afternoon or early evening. Figure 3-7 shows a profile of ozone concentrations as they change over the day at a single monitoring site. The profile is typical of a suburban area downwind of the center of a major city. Especially at suburban and rural locations, ozone concentrations often stay within 10 to 20 percent of the peak l-hour average concentration for several hours. 
Figure 3-6-Areas Where Ozone Concentrations Exceeded $0.18 \mathrm{ppm}$ at Least One Hour Per Year on Average, From 1983-85

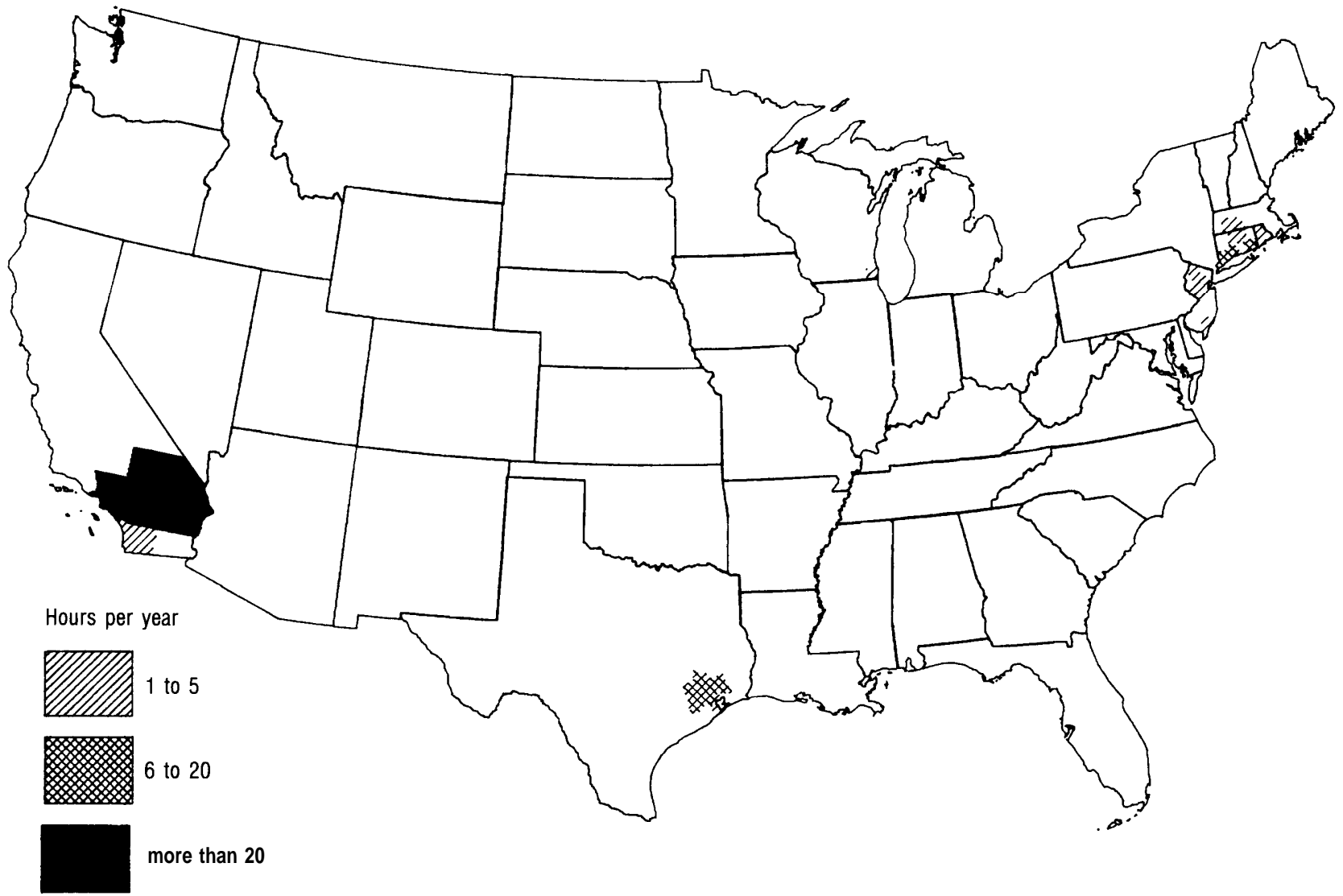

Data from all monitors located in each area were averaged in constructing the map. The shading indicates the number of hours that a concentration of $0.18 \mathrm{ppm}$ was exceeded. Twenty-five million people reside in the areas shown.

SOURCE: U.S. Environmental Protection Agency, Storage and Retrieval of Aerometric Data, database, processed by E.H. Pechan \& Associates, 1987.

The first step in relating measured ozone concentrations to potential health effects is to estimate from the monitor readings the pollutant concentrations to which people have actually been exposed. Figure 3-8 shows a contour map of how peak ozone concentrations on a given day vary across the New York City metropolitan area. The diagram shows ozone concentrations predicted using a model, with meteorological conditions and emissions of July 16, 1980 as inputs. As shown in the example, at any one time, outdoor ozone concentrations can vary by a factor of two or more across an urban area. However, as shown in figure 3-8, ozone concentrations tend to vary smoothly over large areas, and not to show sharp, localized peaks. ${ }^{18}$

People who are outdoors during the afternoon when ozone concentrations reach their peak are apt to be exposed to higher ozone concentrations than people who are indoors. In air-conditioned buildings, indoor ozone concentrations are typically about 30 percent of those measured outdoors at the same location [76]. Ozone concentrations inside buildings with open windows instead of airconditioning are estimated to be about 60 percent of

${ }^{18}$ One exception to this general rule is that in the plumes of large $\mathrm{NO}_{\mathrm{x}}$ sources, up to about a mile downwind of the source, ozone concentrations can be much lower than in the surrounding air. This is because extremely high concentrations of $\mathrm{NO}_{\mathbf{x}}$ without comparably high VOC concentrations destroy ozone faster than it is produced. However, as the $\mathrm{NO}_{\mathbf{x}}$ plume disperses, $\mathrm{VOC}$ and $\mathrm{NO}_{\mathbf{x}}$ levels come into balance and net ozone production results, 
Figure 3-7-Profile of Ozone Concentrations as They Change Over the Day at a Single Monitoring Site

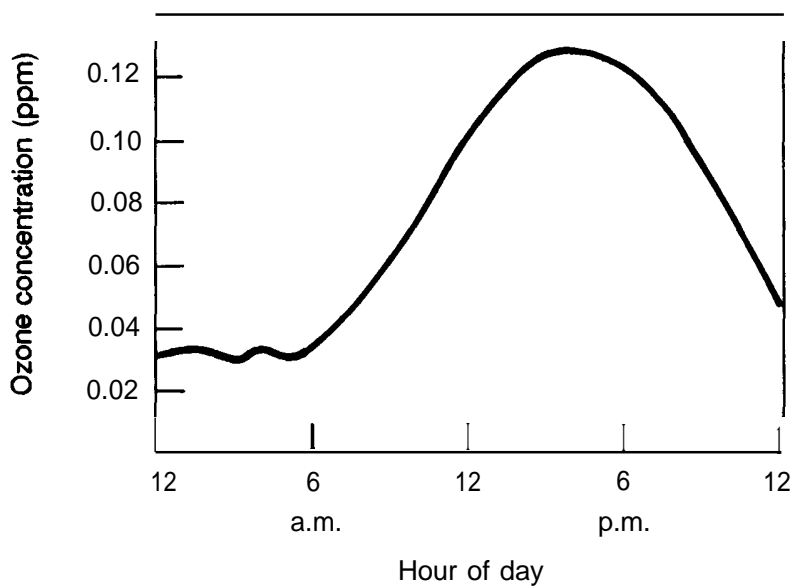

The profile is typical of a suburban area downwind of a strong source area or city center.

SOURCE: Adapted from U.S. Environmental Protection Agency, Environmental Criteria and Assessment Office, Air Qualty Criteria for Ozone and Other Photochemical Oxidants, vol. I (Washington, DC: August 1966).

outdoor concentrations [76]. Most people spend 80 to 90 percent of their time indoors. Note, however, that some people work or recreate outdoors most of the day. About 5 percent of adult men work mostly outdoors. An additional 10 percent work outside part of the time. The proportion of women who work outside is thought to be somewhat lower [77].

Two factors determine the total amount of ozone an individual inhales over a given period of time: 1) the ozone concentrations to which the person is exposed; and 2) the depth and rate at which the individual is breathing. The depth and rate at which someone breathes is determined by the level of exercise he or she is performing. Since the amount of air and thus the amount of ozone inhaled increases with increasing physical exertion, people who are exercising or doing vigorous labor outdoors are more likely to experience health effects due to elevated ozone concentrations than people who are sitting, standing, or walking at a leisurely pace. As examples, recreational jogging, swimming and bicy -
Figure 3-8-Contour Map of the Variation in Daily Peak Ozone Concentrations Predicted for the New York City Area

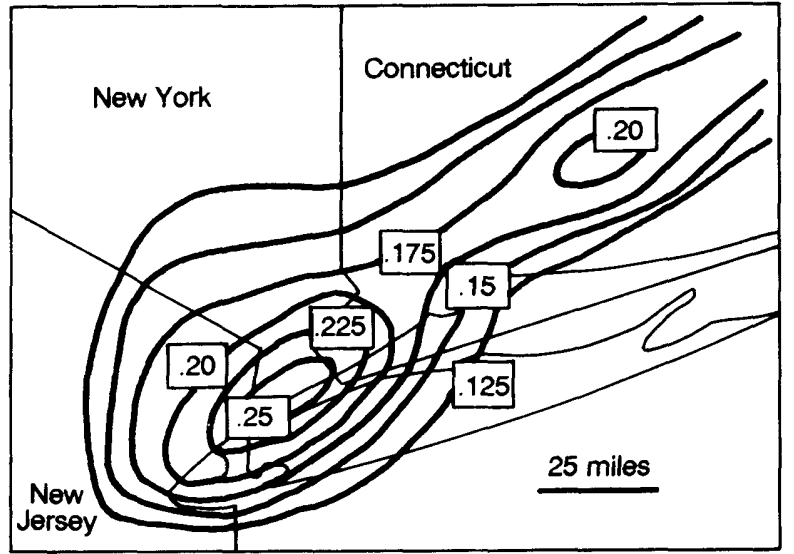

The map was prepared with results from an urban-scale ozone model, with meteorological conditions and emissions of July 16, 1980. As shown, ozone concentrations typically vary smoothly over a large area and do not show localized peaks. Ozone concentrations in parts per million.

SOURCE: Adapted from S.T. Rae, Application of the Urban Airshed Model to the New York Motropolitan Area, EPA 450/4-67-011 (Research Triangle Park, NC: U.S. Environmental Protection Agency, May 1987).

cling can constitute heavy exercise. Those who compete in these sports are likely to be attaining very heavy exercise levels.

As discussed in the section on health effects, clinical and epidemiologic studies have shown that different people respond differently to ozone even when they are exposed to the same concentrations over the same time period and are breathing at the same rate. From 5 to 20 percent of the population of healthy adults are thought to be very sensitive to ozone. The reasons for their heightened sensitivity have not been established.

\section{Population Exposure Estimates}

Based on 1984 census estimates [92] and the data presented in figures 3-4 to 3-6, approximately 130 million people live in areas where ozone concentrations are expected to equal or exceed $0.12 \mathrm{ppm}$ at least 1 hour per year. ${ }^{20}$ Eighty-six million people live in areas where concentrations reach at least 0.14 ppm at least 1 hour per year; 25 million where

\footnotetext{
${ }^{19} \mathrm{~A} 1984$ Gallup survey indicated that about 18 percent of adult Americans jog at least once per week [31]. Four out of every 1,000 adults $(() .4$ percent) run more than 6 miles at least once per week [32].

20EPA defines nonattainment areas as areas where ozone concentrations equal or exceed (). $125 \mathrm{ppm}$ at least 1 hour per year. Over 12 million people live in areas that are included in Figure 24, with the $0.12 \mathrm{ppm}$ cutoff, but are excluded with EPA's $0.125 \mathrm{ppm}$ cutoff.
} 
Table 3-3-Estimated Exposures to Ozone Concentrations Above $0.12 \mathrm{ppm}$

\begin{tabular}{|c|c|c|c|}
\hline Exercise level & $\begin{array}{c}\text { People exposed } \\
\text { per year }\end{array}$ & $\begin{array}{c}\text { Percent of people living } \\
\text { in areas exceeding } 0,12 \mathrm{ppm}\end{array}$ & $\begin{array}{l}\text { Hours of exposure per } \\
\text { person exposed per year }\end{array}$ \\
\hline 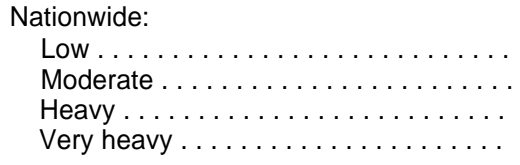 & $\begin{array}{l}34 \text { million } \\
21 \text { million } \\
13 \text { million } \\
80 \text { thousand }\end{array}$ & $\begin{array}{l}26 \% \\
16 \% \\
10 \% \\
<0.1 \%\end{array}$ & $\begin{array}{l}8.8 \mathrm{hr} \\
8.6 \mathrm{hr} \\
5.7 \mathrm{hr} \\
4.1 \mathrm{hr}\end{array}$ \\
\hline 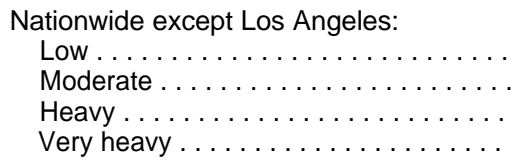 & $\begin{array}{l}24 \text { million } \\
16 \text { million } \\
10 \text { million } \\
60 \text { thousand }\end{array}$ & $\begin{array}{l}20 \% \\
13 \% \\
8 \% \\
<0.1 \%\end{array}$ & $\begin{array}{l}3.7 \mathrm{hr} \\
4.6 \mathrm{hr} \\
3.2 \mathrm{hr} \\
2.1 \mathrm{hr}\end{array}$ \\
\hline 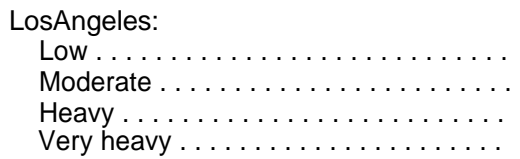 & $\begin{array}{l}9.7 \text { miilion } \\
4.6 \text { million } \\
3.0 \text { miilion } \\
20 \text { thousand }\end{array}$ & $\begin{array}{l}97 \% \\
46 \% \\
30 \% \\
0.2 \%\end{array}$ & $\begin{array}{l}22 \mathrm{hr} \\
24 \mathrm{hr} \\
14 \mathrm{hr} \\
\mathrm{IO} \mathrm{hr}\end{array}$ \\
\hline
\end{tabular}

These estimates are based on hourly ozone data for the period 1983-85, and take into account people's activity patterns (e.g. time commuting, time indoors at work, etc.) and location throughout the day. The estimates are broken down according to people's exercise levels. Those exercising at the higher levels are most apt to be susceptible to health impacts. The total number of people residing in areas where ozone concentrations exceeded $0.12 \mathrm{ppm}$ at least 1 hour per year, on average during 1983-85, was approximately 130 million.

SOURCE: OTA, using data from T.R McCurdy, Ottice of Air Quality Planning and Standards, U.S. Environmental Protection Agency, National Estimates of Exposure to Ozone Under Anemative National Standerds (Research Triangle Park, NC: December 1986).

concentrations reach at least $0.18 \mathrm{ppm}$; and 10 million live in the Los Angeles and Anaheim, CA MSAs where ozone concentrations reach or exceed $0.25 \mathrm{ppm}$.

Of the 130 million people who live in areas where ozone concentrations reach or exceed $0.12 \mathrm{ppm}, 43$ percent (62 million) live in areas where concentrations reach 0.12 ppm 6 or more hours per year; 34 percent (44 million) in areas where concentrations reach $0.12 \mathrm{ppm}$ at least 20 hours per year, and almost 10 percent (12 million) in areas (Los Angeles, Riverside and Anaheim, CA) where ozone concentrations reach $0.12 \mathrm{ppm}$ more than 100 hours each year. As with the maps presented above, it is important to note that the preceding estimates are based on the average of all of the monitors in each area, not the "peak" monitor.

The population statistics presented above might be considered the number of people "potentially" exposed to ozone-people who, if they were outside at the "right" time and location, would be exposed to ozone concentrations above the level at which the current ozone standard is set. Table 3-3 presents estimates of actual exposures: the number of people who do happen to be in the right place at the right time to be exposed to concentrations above $0.12 \mathrm{ppm}$ for at least an hour; and for each person who is exposed, the average number of times each year that exposures occur. The numbers given in table 3-3 were calculated by combining EPA's exposure estimates [69] with the number of people that we have estimated live in areas where ozone concentrations are expected to exceed $0.12 \mathrm{ppm}$ more than 1 hour per year.

The numbers given in table 3-3 are broken down by the exercise levels at which the exposures were estimated to have occurred. Recall that people exercising at higher levels are expected to be more susceptible to health impacts, Nationwide, 34 million people are estimated to be exposed each year at low exercise levels; 21 million at moderate exercise levels; 13 million at heavy exercise levels; and approximately 80,000 during very heavy exercise. ${ }^{21}$ In each exercise category, these numbers represent about 25 percent of the people who achieve that exercise level some time during the year. Thus, since everyone is exercising at a low level at some time (e.g., when they are walking leisurely on a flat surface), about 25 percent of the people who live in

\footnotetext{
${ }^{21}$ The corresponding ventilation rates for these exercise levels are: low $=\geq 25$ liters/minute (I/rein); moderate $=26$ to $43 \mathrm{l} / \mathrm{rein}$; high =44 to $63 \mathrm{l} / \mathrm{min}$; and very high $=\geq 64 \mathrm{t} / \mathrm{rein}[68]$.
} 
areas where ozone concentrations exceed $0.12 \mathrm{ppm}$ are estimated to be exposed to concentrations at or above this level. By far the most people are exposed at low or moderate exercise levels. Fewer people are exposed at the highest exercise level, because relatively few people engage in very heavy exercise. Of the nationwide totals, 9.7 million, 4.6 million, 3 million, and 20,000 of the people exposed at low, moderate, heavy, and very heavy levels, respectively, are residents of the Los Angeles area.

On a nationwide basis, people who are exposed to ozone concentrations of $0.12 \mathrm{ppm}$ at moderate exercise levels are estimated to be exposed an average of about 9 hours per year; people exposed at heavy levels an average of 5.7 hours per year; and people exposed at very heavy exercise levels an average of 4.1 hours per year. However, the national averages mask considerable variability among urban areas. In particular, the national figures are skewed by the high incidence of exposures in the Los Angeles area. In Los Angeles, the average numbers of hours people are exposed at low, moderate, heavy, and very heavy exercise levels are estimated to be $22,24,14$, and 10 hours per year per person exposed, respectively. For the rest of the country, with the Los Angeles estimates subtracted out, the estimated numbers of hours of exposure are, respectively, 3.7, 4.6, 3.2, and 2.1 hours per year for people exposed at low, moderate, heavy, and very heavy exercise levels.

\section{EXTRAPOLATION OF EFFECTS OF MULTIPLE-HOUR EXPOSURES TO OZONE}

A carpenter spends the day hauling lumber and hammering away at the frame of a two-story house. A group of elementary school children are packed off to spend the summer at camp, where they will swim, hike, and compete in games of basketball, tennis, and the like. A high school cross-country track team begins practicing in August for their upcoming fall season, engaging in vigorous, daily routines of sprinting and long runs around the school track. Are these people at risk for adverse health effects from exposure to ozone? What conditions would make them at risk? Could their lung function be harmed by exercising outdoors when the ozone level is high? How many people like them might be harmed by working or playing in ozone contaminated environments?

In this next section we take a closer look at the effects of ozone on people performing various activities, examining the role that exercise and ozone concentration play in the time it takes for an "adverse" health effect to occur.

While data exist on the lung function effects expected from exposure to ozone above the current l-hour standard of $0.12 \mathrm{ppm}$, there is little information available on effects for longer periods of exposure and at lower ozone levels. Information about the health effects that might be experienced under such conditions is needed to assist scientists and policy makers in determining the adequacy of the current standard for protecting public health and in determining how quickly areas should be required to meet the ozone standard.

To begin to address these issues, an OTA contractor $^{22}$ developed a model to extrapolate the results of 1- to 2-hour exposure studies to conditions of multiple-hour exposures (up to 8 hours) at ozone concentrations typically measured during summertime in many U.S. cities ( 0.08 to $0.16 \mathrm{ppm})$. This extrapolation model predicts the average changes in lung function (measured by $\mathrm{FEV}_{1}$ and $\mathrm{FVC}$ ) $^{23}$ for people exercising at different intensities under these conditions. Data were selected nom a number of exposure studies ${ }^{24}$ and applied to a regression model that expresses the dose of ozone that an exposed individual would receive, and then predicts a response in terms of lung function changes. Dose is assumed to be affected by: the ozone concentration in the air one is breathing, the effect of exercise intensity on one's inhalation rate, how long one is exposed to ozone, and how much of the exposure

${ }^{22}$ This section is based on an OTA contractor report by Lawrence J.Folinsbee [25b].

${ }^{23}$ Forced expiratory volumein 1 sec $\cdot$ nd $\left(\mathrm{FEV}_{1}\right)$ and forced vital capacity $(\mathrm{FVC})$ are common measures of lungfunction that can be affected by exposure to ozone. FEV $_{1}$ is the maximum amount of air that can be exhaled from the lungs in 1 second; FVC is the maximum amount of air that can be exhaled from the lungs after taking a full deep breath.

${ }^{24}$ Model parameters were estimated from exposure studies conducted at low ozone concentrations. The primary criterion for selecting studies to include was that the exposures occurred at ozone concentrations that were within or close to the ozone concentration region of interest (i.e., $<0.20 \mathrm{ppm}$ ). 
period one is exercising. This model can be used to predict changes in lung function in exercising populations. ${ }^{25}$ It is important to note that the predicted losses in lung function in the model are group mean changes, and that some individuals may experience $\mathrm{FEV}_{1}$ or $\mathrm{FVC}$ losses greater or less than the average changes for the whole group. ${ }^{26}$

Given the limited time available to develop this model and the number of simplifying assumptions that had to be made, ${ }^{27}$ the model results must be considered approximate. When more data applicable to multi-hour exposures at low ozone concentrations become available, such a model can be improved.

Two alternative activity scenarios illustrate how exercise can affect lung function, given various ozone concentrations. The first scenariorepresenting a moderate level of exercisecorresponds to activity intensities and patterns of typical construction workers, and children playing outdoors on a summer day. The second scenario corresponds to a more vigorous activity level, for example, people engaged in active sports or biking. ${ }^{28}$ Figure 3-9 illustrates how the level of outdoor activity could affect the time it takes before an "adverse" change in lung function might occur, given average ozone concentrations of 0.08 to 0.16 ppm. With respect to "adverse" effects, we assumed that most scientists would not consider group mean decreases in $\mathrm{FEV}_{1}$ of less than 5 percent to be an adverse effect; some scientists would call group mean decreases of 5 to 10 percent an adverse effect; and most scientists would call decreases of 10 percent or greater an adverse effect. The lower line on these figures represents a 5 percent cutoff; the upper line represents a 10 percent cutoff. These ranges apply to healthy people rather than to persons with preexisting respiratory disease. This definition of "adverse" is consistent with the definition presented by EPA in its most recent review of the ozone standard. ${ }^{30}$

Figure 3-9 shows that as one undertakes more vigorous exercise, fewer hours of ozone exposure are required to produce an adverse effect on lung function, given the same ozone concentration. For example, in the graph to the right in figure 3-9, when average ozone concentrations are $0.14 \mathrm{ppm}$, a 5-percent loss of lung function would be anticipated

${ }^{25}$ For example, under Folinsbee's model, the $\%$ change in $F E V=0_{3} X$ SVE X ExpDur X ActRat X -0.0367, where $O_{3}$ is ozone concentration, $S$ VE is specific ventilation (ratio of ventilation to vital capacity, or $\mathbf{L} / \mathrm{min} / \mathbf{L}$ of forced vital capacity), ExpDur is exposure duration, and ActRat is activity ratio (fraction of total exposure duration during which individual is exercising). The last number is the slope of the relationship between dose rate and rate of change of $\mathrm{FEV}_{1}$. See Table 4 in [25b] for the complete range of predicted lung function changes.

${ }^{26}$ For example, ${ }_{n}$ a study $b_{y}$ Folinsbee [28], an average decrease of 13 percent in FEV was experienced by a group exposed to $0.12 \mathrm{ppm}$ Of OZOne over a 6.6-hour period; individual variability ranged from losses as high as 47.6 percent to positive changes of 3.5 percent.

${ }^{27}$ In order to make generalized extrapolations across data ranges for which minimal information exists, the following assumptions were made: 1) changes in lung function area linear function of exposure duration; 2) the influence of ozone concentration on function changes over the concentration range of interest is approximately linear; 3 ) there is no threshold concentration for response; 4) the influence of ozone at low concentrations on people breathing at rest cannot be demonstrated and thus only the ozone exposure accompanied by exercise is relevant; 5) the effects of ozone on the lungs are a function of the size of the lungs, and more specifically, the surface area of the lungs affected by ozone; and 6) within the concentration range of interest, ozone's effects are proportional to the estimated dose of ozone breathed during exercise.

28For both of these exercise scenarios, we used the following formula, based on Folinsbee's analysis, to determine the hours to reach an adverse effect: number of hrs to reach adverse effect= $100 / 60 \mathrm{X} \mathrm{FEV}_{1}$ decr $/\left(\mathrm{O}_{3}\right.$ X SVE X ActRat X -0.0367). At the moderate exercise level, we assigned an SVE, or specific ventilation rate, of "6" (about 33 liters/min) to be consistent with EPA's definition of a typical ventilation rate experienced at a moderate (or "medium") level of exercise (26to434rnin). An activity ratio of 0.66 was applied, because it was assumed that a typical construction worker would be working about 40 minutes of every hour, with 20 minutes of rest time interspersed. At the heavy exercise level, the SVE was " 10 " (about 55 1/rein), which is in line with EPA's definition of heavy exercise (44 to 63 1/rein). At heavy exercise levels, we assumed an activity ratio of 0.84 , or 10 minutes of rest for every 50 minutes of exercise.

${ }^{29}$ It is important ${ }^{t}$. point out that these ozone levels are not peak concentrations, but represent what an average ozone level would be during the period of exposure.

30EPA staff recommends the following definition for an "adverse" response [98]: Individual lung function loss of 10 to 20 percent for Up to 6 hewS. with accompanying symptoms and curtailment of some activity. We use group mean lung function losses of 5 to 10 percent as a surrogate for individual losses on the order of 10 to 20 percent, i.e., the most sensitive members of the population. Studies have shown that when groups experience losses of between about 5 percent and 10 percent, a number of individuals within these groups maybe experiencing lung function losses up to two and three times this much. Using data presented in a risk assessment prepared for EPA [37], we compared group mean lung function changes to the EPA estimates of the percent of the population with lung function losses of greater than 10 and 20 percent. A 5 percent group mean decrease in FEV we consider a response that "some scientists would consider adverse", is roughly equivalent to 10 to 20 percent of the population (the most sensitive individuals) experiencing equal to or greater than a 10 percent decrease in FEV , according to EPA's risk assesment. Furthermore, a 10 percent group mean loss in $\mathrm{FEV}_{1}$, which we describe as a response that "most scientists would consider adverse", is about the same as 20 percent of the population (most sensitive members) experiencing lung function losses of equal to or greater than 20 percent, 
Figure 3-9-Likelihood of Adverse Effects From Ozone While Exercising

Construction Work or Children Playing



Average ozone concentration (ppm) during activity period
Competitive Sports or Bicycling

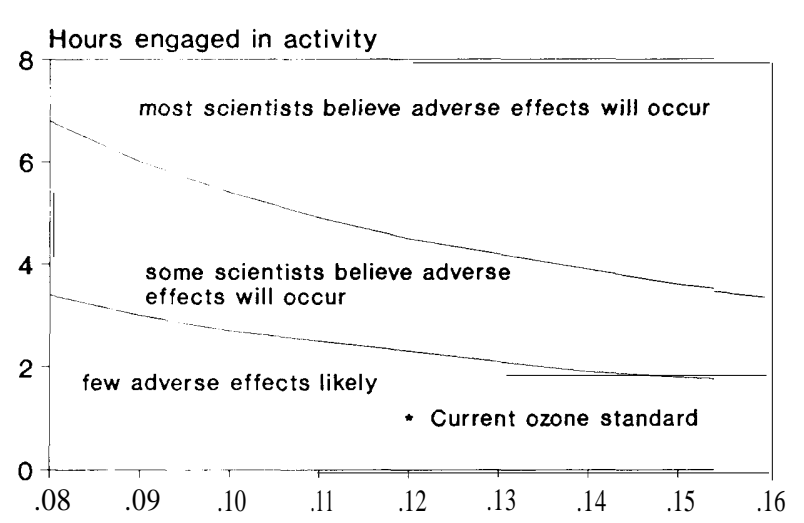

Average ozone concentration (ppm) during activity period

The likelihood of experiencing adverse effects depends on 1) the ozone concentration, 2) the vigorousness of the activity, and 3) the number of hours engaged in that activity. The figure on the left shows the number of hours to reach an adverse effect under moderate exercise conditions (e.g., construction work or children playing). The figure on the right shows that fewer hours are needed under heavy exercise (e.g., competitive sports or bicycling). The current one-hour ozone standard is shown for comparison.

SOURCE: OTA, based on work for OTA by Lawrence J. Folinsbee, Environmental Monitoring and Services.

for groups engaged in strenuous exercise-such as biking or playing tennis-for 2 hours. At the same ozone concentration $(0.14 \mathrm{ppm})$, a 10 percent lung function loss would be expected to occur after about 4 hours of strenuous exercise. Looking at a more moderate level of exercise, e.g. construction work as shown in the graph to the left in figure 3-9, we see that it takes about twice as much time-or 4 hours-to reach lung function losses of 5 percent at $0.14 \mathrm{ppm}$ than with more rigorous exercise. On a typical summer day, one might expect children to be outside playing for about 4 hours, the time it takes to experience what some scientists believe would be adverse lung function effects (5 percent average decreases). After about 8 hours-not an unlikely workday for construction workers-people exercising at a moderate level when ozone concentrations are $0.14 \mathrm{ppm}$ may, on the average, have as great as 10 percent lung function losses.

Note also on these two figures that the level where adverse effects appear likely to occur (e.g., where some or most scientists become concerned about adverse effects) gets closer to the NAAQS for ozone as exercise intensity increases from moderate to heavy levels. In other words, the ozone standard is less protective of people who choose to work outdoors or exercise more vigorously than people who lead less active lifestyles.

Not only is it important to realize how one's activity level might affect the amount of time it would take to produce an "adverse" health effect, but also, within a given activity level, how ozone concentration affects the number of hours until adverse effects occur. At a moderate level of activity-construction work or the equivalent in outdoor exercise-we see that at $0.16 \mathrm{ppm}$ of ozone, it takes about $31 / 2$ hours to produce $\mathrm{FEV}_{1}$ decreases of 5 percent; at 0.13 ppm it takes about $41 / 2$ hours; and at $0.10 \mathrm{ppm}$, approximately $51 / 2$ hours. For a group of construction workers to average 10 percent decreases in lung function-the point at which few scientists disagree that the effects are adverse-it would take about 7 hours at $0.16 \mathrm{ppm}$ and 9 hours at $0.13 \mathrm{ppm}$.

Table 3-4 indicates the population residing in areas where ozone levels equal or exceed average concentrations ranging from 0.08 to $0.16 \mathrm{ppm}$ for 
between 1 to 8 hours, on at least 1 day per year. ${ }^{3}$ Table 3-5 presents the number of cities and population living in those cities where the ozone concentration exceeds $0.14 \mathrm{ppm}$ for 2-,4-, and 8-hour periods for at least 1,2,5, and 10 days a year. The estimates given in tables 3-4 and 3-5 represent "potentially" exposed people-they would not actually have been exposed unless they were outside when the recorded ozone episodes occurred. (And they would probably not be affected by their exposure unless engaged in some kind of exercise.) While we do not have precise data on the number of exercising people actually exposed, we can make some general statements about the percentage of individuals living in these areas who may be exposed to these ozone conditions while working or exercising outdoors.

First of all, we know that a significant portion of the U.S. population is living in areas where ozone levels are within the ranges discussed so far. For example, table 3-5 shows that 45 million people live in 24 cities where the 4-hour average ozone concentrations exceed $0.14 \mathrm{ppm}$ for at least once per year. About one-third of this population lives in 14 cities where these conditions occur at least five times a year; one-quarter live in areas where these conditions occur at least 10 times a year. About 18 million people live in 10 cities in which 8-hour average ozone levels exceed $0.14 \mathrm{ppm}$ at least once per year.

Second, we know that within these potentially exposed populations, some portion will actually be exposed because of their outdoor activity. One subpopulation that has been defined as potentially "at risk" for adverse effects from exposure to ozone is peopIe who work outdoors. Looking at construction workers, we see that they could experience adverse health effects under conditions found in many areas around the United States. As mentioned above, a moderate level of exercise like construction work in areas where 7-hour average ozone concentrations exceeded $0.16 \mathrm{ppm}$ would produce what most scientists would consider to be an adverse effect (10 percent group mean decrease in $\mathrm{FEV}_{1}$ ). We estimate that a few percent, or about 0.4 million of the 18 million people residing in areas in which these ozone conditions occur, would be exposed at

\section{Table 34-Population Residing in Areas Where the Indicated Concentration is Exceeded at least One Period Per Year, for Each Averaging Time}

\begin{tabular}{|c|c|c|c|c|c|c|c|}
\hline \multirow[b]{2}{*}{$\begin{array}{l}\text { Averaging } \\
\text { time (hours) } \\
\end{array}$} & \multicolumn{7}{|c|}{$\begin{array}{l}\text { Population (millions) in areas } \\
\text { exceeding concentrations of }\end{array}$} \\
\hline & $\begin{array}{l}.08 \\
\mathrm{ppm}\end{array}$ & $\begin{array}{r}.10 \\
\mathrm{ppm}\end{array}$ & $\begin{array}{c}.12 \\
\mathrm{ppm}\end{array}$ & $\begin{array}{l}.14 \\
\mathrm{ppm}\end{array}$ & $\begin{array}{l}.16 \\
\mathrm{ppm}\end{array}$ & $\begin{array}{l}.18 \\
\mathrm{ppm}\end{array}$ & $\begin{array}{l}.20 \\
\mathrm{ppm}\end{array}$ \\
\hline $1 \ldots \ldots$ & 160 & 150 & 110 & 65 & 41 & 21 & 17 \\
\hline $2 \ldots$ & 160 & 140 & 98 & 54 & 22 & 18 & 15 \\
\hline 4 & 160 & 130 & 75 & 45 & 18 & 16 & 12 \\
\hline $6 \ldots \ldots \ldots$ & 160 & 120 & 60 & 23 & 17 & 12 & 9.7 \\
\hline $8 \ldots \ldots \ldots$ & 150 & 93 & 45 & 18 & 12 & 9.7 & 1.8 \\
\hline
\end{tabular}

least once per year while engaged in construction work. ${ }^{32}$ Average lung function decreases of 5 percenta change of concern to some scientists-might be seen in people exercising at moderate levels when ozone concentrations exceed $0.14 \mathrm{ppm}$ for four hours. We estimate that a few percent of the 45 million people living in the 24 cities where these conditions occur-or about one million peoplewould be exposed at least once per year while engaged in construction work. About one-third of this population would be exposed at least five times a year in the six cities where these conditions occur.

Active children exposed to ozone under comparable conditions might also experience adverse lung function effects. For example, kids exercising moderately (at approximately the same relative intensity as construction workers) for 4 hours when the ozone concentration is $0.14 \mathrm{ppm}$ would be expected to average about a 5-percent decrease in their lung function. As mentioned above, this is the point at which some scientists become concerned about adverse health effects. Since children between 5 and 14 years of age constitute about 14 percent of the total U.S. population, [93] about 6 million kids live in the 24 cities where ozone concentrations exceed $0.14 \mathrm{ppm}$ at least once a year. About 2 million children live in the six cities where similar ozone levels occur at least five times a year.

Finally, it is important to reemphasize that under any of the above-mentioned scenarios, some portion of the population will be more sensitive to ozone

\footnotetext{
31Data are for the period 1983-85.

32This estimate ("a few percent") of adversely affected construction workers is based on the following information. First, an estimated 5 percent of adult men work outdoors full-time, and another 10 percent work outdoors part of the time [77]. We assume that a smaller fraction of women work outdoors and that about 1.5 percent of the U.S. population (mostly men) are employed in nonsupervisory construction jobs [92].
} 
Table 3-5-Number of Cities Where Ozone Concentrations Exceed $0.14 \mathrm{ppm}$ for 2-,4-, and 8-hr Periods for the Specified Number of Days Per Year, on Average, and Population Residing in Those Cities

\begin{tabular}{|c|c|c|c|c|c|c|}
\hline \multirow[b]{2}{*}{ Days per year } & \multicolumn{2}{|c|}{ 2-hr } & \multicolumn{2}{|c|}{ 4-hr } & \multicolumn{2}{|c|}{ 8-hr } \\
\hline & $\begin{array}{l}\text { Population } \\
\text { (millions) }\end{array}$ & Cities & $\begin{array}{l}\text { Population } \\
\text { (millions) }\end{array}$ & Cities & $\begin{array}{l}\text { Population } \\
\text { (millions) }\end{array}$ & Cities \\
\hline $\begin{array}{l}>1 \ldots \ldots \\
>2 \ldots \ldots \ldots \\
>5 \ldots \ldots \ldots\end{array}$ & $\begin{array}{l}\ldots 54 \\
\ldots 34 \\
\ldots 19 \\
\ldots 13\end{array}$ & $\begin{array}{r}33 \\
21 \\
9 \\
4\end{array}$ & $\begin{array}{l}45 \\
21 \\
14 \\
12\end{array}$ & $\begin{array}{r}24 \\
12 \\
3\end{array}$ & $\begin{array}{l}18 \\
13 \\
10 \\
10\end{array}$ & $\begin{array}{r}10 \\
5 \\
2 \\
2\end{array}$ \\
\hline
\end{tabular}

SOURCE: OTA, baaed on EPA SARDAD 1983-85 monitoring data.

than indicated by the group mean responses we have considered. EPA has labeled these people as "responders," and estimates that from 5 to 20 percent of the healthy population in the United States are in this more sensitive group. Therefore, while Folinsbee's model has allowed us to predict group mean lung function decreases, about 5 to 20 percent of the exposed population discussed above would experience significantly larger lung function changes under the ozone exposure conditions considered here.

\section{SELECTED NATIONWIDE HEALTH BENEFITS FROM CONTROLLING OZONE}

This section looks at expected nationwide reductions in some types of health effects from reducing ozone levels in all nonattainment areas. ${ }^{33}$ Estimates are made of the number of incidents of various respiratory symptoms and days when ozone exposure may limit a person's activity, under three scenarios: 1) current ozone levels, 2) ozone levels after all reasonably available volatile organic compound (VOC) control methods are applied, and 3) ozone levels assuming that the standard is attained in all areas. The "benefit" of control is the difference between the nationwide health effects from current ozone levels and the health effects after control. A rough approximation of the economic value of these health improvements is also given.

We estimate that if ozone concentrations were lowered enough to meet the standard in all areas, several hundred million incidents of respiratory symptoms, such as coughing or pain on deep breathing, might be avoided each year. Among the approximately 115 million people living in nonattainment areas, some in the worst areas would experience dozens fewer incidents of respiratory symptoms each year while many in other areas would experience no change. About 8 million to 50 million "restricted activity days" might also be eliminated. These are days when someone feels ill enough to limit a day's worth of activitiesdisrupting most of the day's activities, but generally not spending the day in bed or staying home from work.

By asking people what they would be willing to pay to avoid a day of coughing or a day of restricted activity, it is also possible to get a rough feel for the economic value to individuals of the health improvements listed above. As will be discussed below, the uncertainties are quite large due to the many assumptions that must be made, but about $\$ 0.5$ billion to $\$ 4$ billion per year is a reasonable range for the portion of health benefits that we were able to evaluate. Under some assumptions, benefits are less than $\$ 0.1$ billion per year and under others, up to about $\$ 10$ billion per year.

Keep in mind, however, that we could only quantitatively estimate some of the benefits. We did estimate such acute health effects as the number of times per year when people experience respiratory symptoms, such as coughing or pain on deep breathing; days when someone's daily activities are restricted; and days with asthma attacks. We did not estimate benefits associated with changes in lung function because we had no method for assigning a value to this effect. (We did, however, include shortness of breath, a symptom of lung function changes perceptible by people without medical

\footnotetext{
${ }^{33}$ This section is based on results presented in an OTA contractor report by Alan J. Krupnick and Raymond J. Kopp [49].
} 
measuring devices.) And, even though many health professionals are concerned that repeated exposure to ozone over a lifetime may result in premature aging of the lungs, along with the possibility of permanent lung impairment, current understanding does not allow us to quantity the lowered risk of chronic effects.

We also did not include health benefits of lowering VOC emissions that are not related to lowered ozone concentrations. Probably the most significant omission in this regard is that some VOCs are carcinogenic. A preliminary EPA assessment estimated that nationwide, about 2,000 cancers per year might result from exposure to toxic air pollutants [97]. About half of the risk from the 20 chemicals considered in the study, about 1,000 cancers per year, comes from VOCs. The specific chemicals or groups of chemicals posing the greatest aggregate risk include benzene, butadiene, formaldehyde, gasoline vapors, and emissions from hazardous waste treatment, storage, and disposal facilities. Another EPA study concluded that about 250 to 400 deaths per year might be due to exposure to three VOCs from mobile sources: benzene, butadiene, and formaldehyde $[12,67,74]$. These estimates of cancer risks from exposure to VOC should be regarded as rough estimates due to uncertainties about how carcinogenic these chemicals truly are, and to the simplistic method of estimating human exposure. Nonetheless, reducing VOC emissions to lower ozone concentrations will also lead to lower risks of cancer from exposure to these chemicals.

\section{How the Estimates Are Calculated}

To calculate the aggregate benefits from lowering ozone concentrations in nonattainment areas, several steps are followed. First "concentrationresponse" relationships are developed, that is, equations that describe the "response" (e.g., cough incidents or days of restricted activity days) from exposure to ozone at different concentrations. Next data are obtained on ozone levels in nonattainment areas. For this analysis we obtained 3 years of data on daily maximum hourly ozone concentrations measured at each of several hundred monitors in EPA's nationwide data base. Using the concentrationresponse relationships, we then calculate the effects of ozone on the population of each nonattainment county from the concentrations measured each day during the ozone seasons of 1983 through $1985 .{ }^{34}$

Then, using a simplified air quality model (called EKMA and discussed in chapter 4), we estimated ozone concentrations after controls have been adopted. We modeled two control scenarios: 1) air quality levels after sufficient controls have been adopted to meet the ozone standard in all areas, and 2) air quality levels after VOC emissions in nonattainment areas have been lowered by 35 percentcontrols about equivalent to adopting all currently available control measures. (The emissions control aspect of this scenario is discussed in chapter 6.) We then calculate the effects of ozone-again county-by county and day-by-day-at these lower ozone concentrations. The diference between the before and after estimates (either avoided episodes of respiratory symptoms or avoided days of selected adverse consequences) are displayed in a series of tables.

If desired, one can take the aggregate estimates of effects and assign dollar values to the avoided symptom incidents and restricted activity days. These values are taken from interviews where people are asked what they would be willing to pay to avoid such effects as a day of coughing or an asthma attack. As one might imagine, the range of responses is quite large, thus the dollar values must be treated as more uncertain than the estimates of adverse effects avoided.

Two types of studies are used to estimate the concentration-response relationships: clinical and epidemiologic. In clinical studies, people are exposed in laboratories to carefully monitored ozone concentrations, typically while exercising on a stationary cycle or treadmill. Researchers measure changes in lung function as well as ask the volunteers to describe any respiratory symptoms they may be experiencing. In the epidemiologic studies used in this analysis, volunteers fill out daily or biweekly diaries of their health status. These are later compared to concentrations measured at nearby ozone monitors, after controlling for many other factors such as age, sex, smoking status, occupation, daily temperatures, and concentrations of other air pollutants.

\footnotetext{
${ }^{34}$ For counties with more than one ozone monitor, we averaged the readings from all monitors. For counties with no ozone monitors, we averaged the readings from all monitors operating within the metropolitan area.
} 
Each type of study has advantages and disadvantages for estimating the health benefits from lowering ozone concentrations. The clinical studies provide excellent data on how individuals respond to very specific exposure conditions (typically 1 to 2 hours of exposure while exercising vigorously). However, one is left with the difficult task of extrapolating the effects of ozone under typical daily routines-adults exercising and walking to work, children playing, and so on.

The epidemiologic studies directly produce data on effects of interest-respiratory symptoms and restricted activity-while engaged in typical day-today activities, but the relationship to ozone exposure is more difficult to establish. First, the effects data must be statistically compared to ozone levels that are often only rough indicators of actual exposure. Second, because several other factors that affect respiratory health must be considered simultaneously (e.g., smoking status, temperature) it is quite difficult to isolate the effect of ozone alone.

Keep in mind that none of the studies we used estimate the risks of chronic effects from longer term exposure to ozone. Whether there are chronic effects from exposure over many years and, if so, the magnitude, is still uncertain.

\section{Selected Health Benefits of Lowered Ozone Concentrations}

As mentioned above, we used two types of studies to estimate the effects from exposure to ozone: clinical studies and epidemiologic studies. Using a clinical study, we estimated three types of symptoms: the number of incidents of coughing, shortness of breath, and chest discomfort (i.e., pain on deep breathing) [70]. From the epidemiologic studies, we estimated the number of days when respiratory illness restricted normal activities [78], days with any type of respiratory-related symptom (e.g., coughing, wheezing, chest discomfort, sore throat, etc.) [49], and days of asthma attacks [38].

Table 3-6 presents our estimates of the total number of incidents of respiratory symptoms avoided from adopting the two control scenarios mentioned above. Two sets of estimates based on clinical studies are shown. The lower estimates assume that the only people who might be affected by ozone are those who engage in heavy exercise outdoors. The higher estimates assume that people exercising at light and moderate exercise levels can also be affected by ozone, but with proportionally lower effects at the lower exercise levels .35 The time spent outdoors at each exercise level is estimated from EPA data [76].

Taking into consideration uncertainty about who will be affected, we estimate that meeting the standard in all areas would eliminate about 110 to 350 million cough incidents each year, and about 60 to 200 million incidents each of shortness of breath and chest pain. Our scenario that reduces VOC emissions by 35 percent would eliminate about 40 to 130 million coughing episodes per year and about 20 to 70 million incidents each of shortness of breath and chest pain. As shown in the table, the range is even greater when one considers possible errors due statistical estimation of the concentration-response function from clinical data.

These health benefits may be easier to conceptualize when expressed on a per-person basis, or more accurately, the type of response one might expect within a group of 100 people. Among every 100 people, averaged across all nonattainment areas, meeting the standard would eliminate about 100 to 300 cough episodes per year. The improvement, averaging about one to three fewer cough episodes per person per year, can be compared to an average of about eight cough days per person per year [24]. The number of symptom episodes avoided would vary from individual to individual, of course, for several reasons. First, not everyone is active outdoors. Second, among every 100 people, about 5 to 20 are much more sensitive than the average for unknown reasons. In addition, the average improvement varies considerably from nonattainment area to nonattainment area, depending on the severity of the ozone problem.

In table 3-7, we report the per-person improvement in areas by a measure of peak ozone concentra-

\footnotetext{
${ }^{35}$ Many clinical studies have shown adverse effects fro ${ }_{\mathrm{m}}$ ozone under heavy and very heavy exercise conditions. At least one has shown effects under moderate exercise over multi-hour time periods, supporting the hypothesis that the effects of ozone are due as much to "dose' '-the total amount of ozone inhaled-as to concentration and exercise level. Limiting our analysis to only heavy exercisers is a fairly conservative assumption; extrapolating effects to all exercise levels (including light) is a reasonable extrapolation, but no clinical data exist to support it.
} 
Table 3-6-Avoided Episodes of Respiratory Symptoms (millions of episodes per year)

\begin{tabular}{|c|c|c|c|c|}
\hline & \multicolumn{2}{|c|}{ From meeting the standard } & \multicolumn{2}{|c|}{ From a $350 /$. vOC reduction } \\
\hline & Midpoint & Range & Midpoint & Range \\
\hline $\begin{array}{l}\text { Cough: } \\
\quad \text { Affecting heavy exercisers only } \ldots \ldots \ldots \ldots \ldots \ldots \\
\text { Affecting all exercisers } \ldots \ldots \ldots \ldots \ldots \ldots\end{array}$ & $\begin{array}{l}110 \\
350\end{array}$ & $\begin{array}{c}(78-130) \\
(250-440)\end{array}$ & $\begin{array}{r}39 \\
130\end{array}$ & $\begin{array}{c}(29-49) \\
(100-160)\end{array}$ \\
\hline $\begin{array}{l}\text { Shortness of breath: } \\
\quad \text { Affecting heavy exercisers only } \ldots \ldots \ldots \ldots \ldots \ldots \ldots \\
\text { Affecting all exercisers } \ldots \ldots \ldots \ldots \ldots \ldots \ldots\end{array}$ & $\begin{array}{r}61 \\
200\end{array}$ & $\begin{array}{c}(43-77) \\
(140-250)\end{array}$ & $\begin{array}{l}22 \\
72\end{array}$ & $\begin{array}{l}(16-27) \\
(51-89)\end{array}$ \\
\hline $\begin{array}{l}\text { Pain on deep breathing: } \\
\text { Affecting heavy exercisers only } \ldots \ldots \ldots \ldots \ldots \ldots \\
\text { Affecting all exercisers } \ldots \ldots \ldots \ldots \ldots \ldots \ldots\end{array}$ & $\begin{array}{r}60 \\
200\end{array}$ & $\begin{array}{c}(42-78) \\
(140-260)\end{array}$ & $\begin{array}{l}22 \\
72\end{array}$ & $\begin{array}{l}(15-28) \\
(51-93)\end{array}$ \\
\hline
\end{tabular}

Table 3-7-Avoided Episodes of Respiratory Symptoms (episodes per 100 people per year)

\begin{tabular}{|c|c|c|c|c|}
\hline & \multicolumn{2}{|c|}{ From meeting the standard } & \multicolumn{2}{|c|}{ From a $35 \%$ VOC reduction } \\
\hline & $\begin{array}{c}\text { Heavy } \\
\text { exercisers only }\end{array}$ & $\begin{array}{c}\text { All } \\
\text { exercisers }\end{array}$ & $\begin{array}{c}\text { Heavy } \\
\text { exercisers only }\end{array}$ & $\begin{array}{c}\text { All } \\
\text { exercisers } \\
\end{array}$ \\
\hline $\begin{array}{l}\text { Cough: } \\
\text { All area average } \ldots \ldots \ldots \ldots \ldots \ldots \ldots \\
\text { Peak }<0.14 \text { ppm } \ldots \ldots \ldots \ldots \ldots \ldots \ldots \\
\text { Peak } 0.14 \text { to } 0.18 \ldots \ldots \ldots \ldots \ldots \ldots \\
\text { Peak } 0.18 \text { to } 0.27 \ldots \ldots \ldots \ldots \ldots \ldots \ldots \\
\text { Peak }>0.27 \ldots \ldots \ldots \ldots \ldots\end{array}$ & $\begin{array}{r}96 \\
17 \\
63 \\
150 \\
430\end{array}$ & $\begin{array}{r}310 \\
55 \\
210 \\
490 \\
1410\end{array}$ & $\begin{array}{r}36 \\
12 \\
24 \\
50 \\
140\end{array}$ & $\begin{array}{r}120 \\
39 \\
79 \\
170 \\
470\end{array}$ \\
\hline $\begin{array}{l}\text { Shortness of breath: } \\
\text { All area average } \ldots \ldots \ldots \ldots \ldots \ldots \ldots \\
\text { Peak }<0.14 \text { ppm } \ldots \ldots \ldots \ldots \ldots \ldots \ldots \\
\text { Peak } 0.14 \text { to } 0.18 \ldots \ldots \ldots \ldots \ldots \\
\text { Peak } 0.18 \text { to } 0.27 \ldots \ldots \ldots \ldots \ldots \ldots \ldots \\
\text { Peak }>0.27 \ldots \ldots \ldots \ldots \ldots \ldots\end{array}$ & $\begin{array}{r}55 \\
10 \\
38 \\
88 \\
240\end{array}$ & $\begin{array}{r}180 \\
33 \\
120 \\
290 \\
780\end{array}$ & $\begin{array}{r}20 \\
7 \\
14 \\
29 \\
74\end{array}$ & $\begin{array}{r}65 \\
24 \\
46 \\
95 \\
240\end{array}$ \\
\hline $\begin{array}{l}\text { Pain on deep breathing: } \\
\text { All area average } \ldots \ldots \ldots \ldots \ldots \ldots \ldots \\
\text { Peak }<0.14 \text { ppm } \ldots \ldots \ldots \ldots \ldots \ldots \\
\text { Peak } 0.14 \text { to } 0.18 \ldots \ldots \ldots \ldots \\
\text { Peak } 0.18 \text { to } 0.27 \ldots \ldots \ldots \ldots \ldots \ldots \\
\text { Peak }>0.27 \ldots \ldots \ldots \ldots \ldots \ldots\end{array}$ & $\begin{array}{r}54 \\
10 \\
36 \\
85 \\
\mathbf{2 4 0}\end{array}$ & $\begin{array}{r}189 \\
32 \\
120 \\
280 \\
790\end{array}$ & $\begin{array}{r}20 \\
7 \\
14 \\
28 \\
79\end{array}$ & $\begin{array}{r}65 \\
23 \\
45 \\
93 \\
260\end{array}$ \\
\hline
\end{tabular}

tions, We use the fourth highest concentration observed over the 3 -year period in each county (i.e., the equivalent of a county-level "design value") rather than characterize an entire metropolitan area by a single concentration. In those areas where peak ozone concentrations are close to the standard (between 0.12 and $0.14 \mathrm{ppm}$ ), meeting the standard would eliminate about 15 to 55 cough episodes per year among every 100 people. In those areas with the worst ozone problems, meeting the standard would eliminate 400 to 1,400 cough episodes per year among every 100 people.
Table 3-8 presents the benefits estimated using the epidemiologic studies. Meeting the standard in all areas would eliminate about 25 million days per year of restricted activity and about 50 million days with respiratory-related symptoms. About 2 million days of asthma attacks would also be eliminated. Our scenario that reduces VOC emissions by 35 percent would eliminate about 8 million restricted activity days per year, about 18 million symptom days, and about 0.6 million asthma attack days.

Note that in the tables we have disaggregate restricted activity days and symptom days into 
Table 3-8-Avoided Days of Adverse Consequences (millions of days per year)

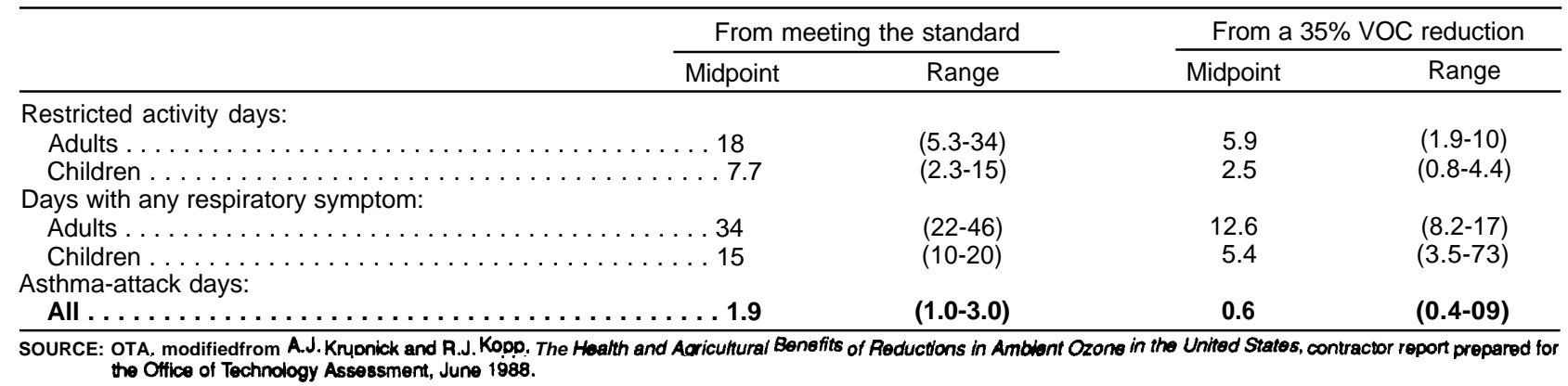

improvements among adults and improvements among children. The epidemiologic studies that we relied on found effects in adults only. his might be because children are less likely to perceive symptoms than adults, or might only indicate that children are less likely to report symptoms. The estimates given in the text assume that children and adults are affected in similar ways.

In table 3-9, we once again express these improvements on a per-person basis. Among every 100 people (adults and children), averaged across all nonattainment areas, meeting the standard would eliminate about 45 days with respiratory symptoms each year. About half ( 25 days) would also be days of restricted activity. Among every 100 asthmatics, meeting the standard would eliminate about 60 asthma-attack days each year. Improvements from lowering VOC emissions by 35 percent would average about 8 fewer restricted activity days and 15 fewer days with respiratory symptoms among every 100 people. Among every 100 asthmatics, we would expect to see 20 fewer asthma-attack days. These improvements can be compared to a current total of about 130 respiratory-related restricted activity days [95] and 800 cough days each year among every 100 people [24]. Among 100 asthmatics, one would expect about 1000 asthma-attack days each year [49]. Each of these totals is the number of days of poor respiratory health from all causes, not just air pollution.

Again, there is considerable variation from area to area. For example, in those areas where peak ozone concentrations are close to the standard (between 0.12 and $0.14 \mathrm{ppm}$ ), meeting the standard would eliminate about 8 days with respiratory symptoms each year, and 3 days of restricted activity, among every 100 people. In those areas with the worst ozone problems, meeting the standard would eliminate about 200 days with respiratory symptoms, and 120 days of restricted activity, among every 100 people.

Note that the epidemiologic studies predict lower benefits than the clinical studies, that is, the epidemiologic studies predict fewer health effects from exposure to ozone than the clinical studies. Several reasons are possible. First, people may be less likely to exercise outdoors on days with high ozone concentrations due to both the pollution and high temperatures. If so, one would expect that fewer people would actually be affected than the number predicted from laboratory studies. Second, there is considerable variation among similar types of studies. For example, EPA compares data from the McDonnell study (which we used) to a similar study by Kulle and concludes that the McDonnell study predicts about twice as many people would experience at least mild cough after exercising heavily for two hours at ozone concentrations in the range of 0.12 to $0.20 \mathrm{ppm}$ [98]. There are too few epidemiologic studies to be able to get a feel for how variable they might be. All we can conclude is that the difference between the results predicted by the clinical and epidemiologic studies falls within the range of uncertainty of this type of analysis.

\section{Assigning a Dollar Value to Health Improvements From Lowered Ozone Levels}

Although it is extremely difficult to assign a dollar value to the health improvements described above, table 3-10 presents our best guesses, based on the limited information available in the economic literature. These are derived by simply multiplying our 
Table 3-9-Avoided Days of Adverse Consequences (days per 100 people per year)

\begin{tabular}{|c|c|c|c|c|}
\hline & \multicolumn{2}{|c|}{ From meeting the standard } & \multicolumn{2}{|c|}{ From a $35 \%$ VOC reduction } \\
\hline & Midpoint & Range & Midpoint & Range \\
\hline $\begin{array}{l}\text { Restricted activity days: } \\
\text { All area average } \ldots \ldots \ldots \ldots \ldots \ldots \\
\text { Peak }<0.14 \text { ppm } \ldots \ldots \ldots \ldots \ldots \ldots \\
\text { Peak } 0.14 \text { to } 0.18 \ldots \ldots \ldots \ldots \ldots \\
\text { Peak } 0.18 \text { to } 0.27 \ldots \ldots \ldots \ldots \ldots \\
\text { Peak }>0.27 \ldots \ldots \ldots \ldots \ldots \ldots\end{array}$ & $\begin{array}{r}23 \\
3 \\
13 \\
34 \\
120\end{array}$ & $\begin{array}{c}(7-44) \\
(I-6) \\
(4-23) \\
(11-61) \\
(32-240)\end{array}$ & $\begin{array}{r}2 \\
5 \\
11 \\
32\end{array}$ & $\begin{array}{c}(2-13) \\
(2-8) \\
(4-19) \\
(10-57)\end{array}$ \\
\hline $\begin{array}{l}\text { Days with any respiratory symptom: } \\
\text { All area average } \ldots \ldots \ldots \ldots \ldots \ldots \\
\text { Peak }<0.14 \text { ppm } \ldots \ldots \ldots \ldots \ldots \\
\text { Peak } 0.14 \text { to } 0.18 \ldots \ldots \ldots \ldots \\
\text { Peak } 0.18 \text { to } 0.27 \ldots \ldots \ldots \ldots \ldots \\
\text { Peak }>0.27 \ldots \ldots \ldots \ldots\end{array}$ & $\begin{array}{r}44 \\
8 \\
30 \\
69 \\
195\end{array}$ & $\begin{array}{c}(29-60) \\
(5-11) \\
(19-40) \\
(45-94) \\
(130-260)\end{array}$ & $\begin{array}{r}16 \\
6 \\
11 \\
23 \\
64\end{array}$ & $\begin{array}{c}(11-22) \\
(4-8) \\
(7-15) \\
(15-31) \\
(42-87)\end{array}$ \\
\hline $\begin{array}{r}\text { Asthma-attack days (per } 100 \text { asthmatics) } \\
\text { All area average } \ldots \ldots \ldots \ldots \ldots \ldots \ldots \\
\text { Peak }<0.14 \text { ppm } \ldots \ldots \ldots \ldots \ldots \ldots \\
\text { Peak } 0.14 \text { to } 0.18 \ldots \ldots \ldots \ldots \ldots \ldots \\
\text { Peak } 0.18 \text { to } 0.27 \ldots \ldots \ldots \ldots \ldots \ldots \ldots \\
\text { Peak }>0.27 \ldots \ldots \ldots \ldots \ldots \ldots\end{array}$ & $\begin{array}{r}58 \\
\\
35 \\
86 \\
280\end{array}$ & $\begin{array}{c}(31-89) \\
(5-13) \\
(20-51) \\
(48-130) \\
(145-449)\end{array}$ & $\begin{array}{r}19 \\
6 \\
13 \\
27 \\
78\end{array}$ & $\begin{array}{c}(11-28) \\
(4-9) \\
(7-18) \\
(15-39) \\
(44-110)\end{array}$ \\
\hline
\end{tabular}

SOURCE: OTA, modified from A.J. Krupnick and A.J.Kopp, The Health and Agricuhural Benefits of Reductions in Amblent Ozone in the United States, contractor report prepared for the Oftico of Technology Assossment, June 1968.

Table 3-10-Dollar Value of Selected Health Benefits (millions of dollars par year)

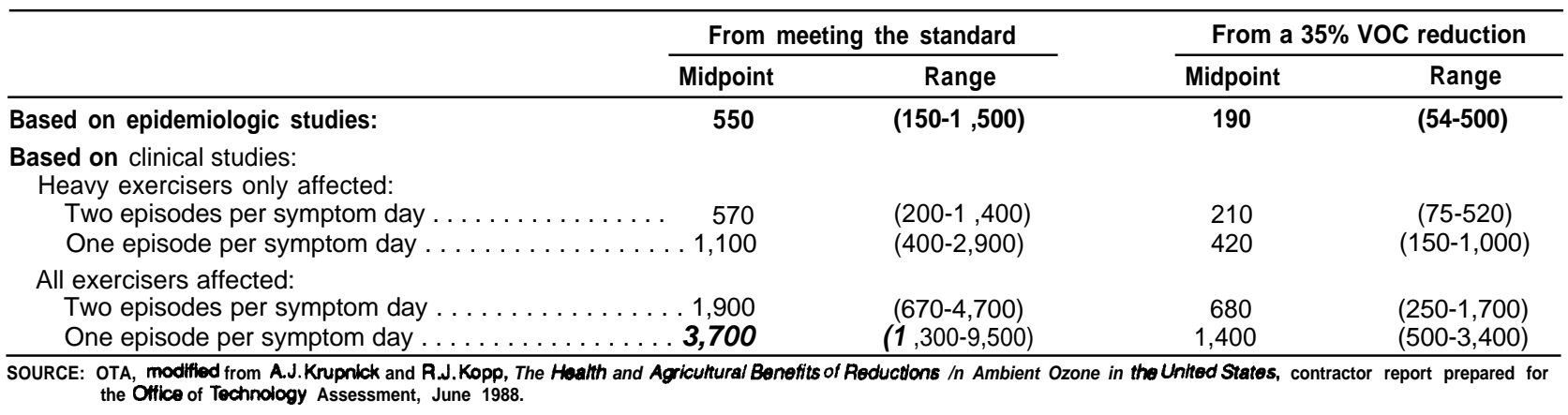

estimates of the number of days of improved respiratory health by a dollar value for each day of adverse health effects. A range of dollar values are available from four studies where people were directly asked how much they would be willing to pay to avoid a day of respiratory symptoms $[90,18,83,66]$.

The estimates in table 3-10 assume the following dollar value of each health effect: People would be willing to pay $\$ 5$ to avoid each day of respiratory symptoms, with a range of $\$ 2.50$ to $\$ 10$. People would be willing to pay $\$ 18$ to avoid each day of restricted activity, ranging from $\$ 11$ to $\$ 30$. And people would be willing to pay $\$ 25$ to avoid each day of asthma attacks, with a range of $\$ 9$ to $\$ 41$. These were chosen as reasonably representative estimates of the "typical" responses found in the available studies, but keep in mind that the range of individual responses in the studies was enormous.

For example, in one of the studies [18], the arithmetic average response for the value of a cough day was about $\$ 11$. However, half the survey respondents replied $\$ 1$ or lower. For shortness of breath, the average response was about $\$ 8$, but over half of the respondents replied that they would be willing to pay nothing. In addition, these average values do not include very high responses (e.g., one respondent valued a cough day at $\$ 10,000$ ).

With these limitations in mind, let us turn to table 3-10. From epidemiologic studies, we were able to quantify the following health benefits from lowering 
ozone concentrations: avoided days with respiratory symptoms, avoided days of restricted activity, and avoided days of asthma attack. We estimate that the economic value of these health improvements from meeting the standard would be about $\$ 550$ million per year, ranging from about $\$ 150$ million to $\$ 1.5$ billion per year. ${ }^{36}$ The economic value of these health improvements from a 35-percent reduction in VOC emissions would be about $\$ 190$ million per year, ranging up to about $\$ 500$ million per year.

From the clinical studies, we are able to estimate the number of avoided episodes of three types of respiratory symptoms: coughing, shortness of breath, and pain on deep breathing. Dollar benefits based on these studies range from values about equal to those stated above, to several times as much.

Our "best" estimates from the clinical studies of the economic value of the respiratory symptoms avoided from meeting the standard range from about $\$ 570$ million to $\$ 3.7$ billion per year. Under alternative reasonable assumptions, benefits range from about $\$ 200$ million per year to about $\$ 9.5$ billion per year. The higher estimate assumes: 1) a somewhat higher probability of experiencing respiratory symptoms from exposure to ozone, and 2) that people would be willing to pay $\$ 10$ to avoid a day of respiratory symptoms.

Our "best" estimates of the value of respiratory symptoms avoided from a 35-percent reduction in VOC emissions range from about $\$ 210$ million per year to about $\$ 1.4$ billion per year. Under alternative assumptions, our estimates range from $\$ 50$ million to $\$ 3.4$ billion per year. Again, the higher estimate assumes a somewhat higher responsiveness to ozone and that people would be willing to pay $\$ 30$ to avoid a day of restricted activity.

We have no way of judging which of the estimates presented in the table are more likely. Neither approach-using epidemiologic studies or clinical studies - seems clearly superior for this type of benefits assessment. For meeting the standard, about $\$ 0.5$ billion to $\$ 3.7$ billion per year is the range of our "best" estimates for the portion of health benefits that we were able to evaluate. From lowering VOC emissions by 35 percent, about $\$ 0.2$ billion to $\$ 1.4$ billion per year is a reasonable range for the portion of health benefits that we were able to evaluate. In either case, the benefits could reasonably be lower or about $2 \frac{1}{2}$ times greater, depending primarily on the value one assigns to a day of respiratory illness.

Again, none of the studies we used estimate the risks of chronic effects from longer term exposure to ozone. As discussed in an earlier section, many health professionals appear to be particularly concerned over the possibility of permanent damage to the lung from exposure to ozone over many years. We were not able to quantify these risks and include them in our benefits estimates.

\section{REFERENCES FOR CHAPTER 3}

1. Abraham, W. M., Januszkiewicz, A. J., Mingle, M., Welker, M., Wanner, A., and Sackner, M. A., "Sensitivity of Bronchoprovocation and Tracheal mucous Velocity in Detecting Airway Responses to $\mathrm{O}_{3}, " J$. Appl.Physiol., 1980, 48:789-793.

2. American Thoracic Society, "Guidelines as to What Constitutes an Adverse Respiratory Health Effect, with Special Reference to Epidemiologic Studies of Air Pollution," Am. Rev. Respir.Dis., 1985, 131:666-668.

3. Avol, E. L., Linn, W. S., Venet, T. G., Shamoo, D. A., and Hackney, J. D., "Comparative Respiratory Effects of Ozone and Ambient Oxidant Pollution Exposure During Heavy Exercise," JAPCA, 1984, 34:804-809.

4. Avol, E. L., Linn, W. S., Shamoo, D. A., Valencia, L. M., Anzar, U.T., Venet, T. G., and Hackney, J. D., "Respiratory effects of Photochemical Oxidant Air Pollution in Exercising Adolescents, " Am. Rev. Respir. Dis., 1985, 132:619-622.

5. Avol, E. L., Linn, W. S., Sharnoo, D. A., Valencia, L. M., Venet, T. G., Trim, S. C., and Hackney, J. D., "Short-term respiratory Effects of Photochemical Oxidant in Exercising Children, "JAPCA,1987, 37: 158-162.

6. Bartlett, D. Jr, Faulkner, C.S. II, and Cook, K., "Effect of Chronic Ozone Exposure on Lung Elasticity in Young Rats," J. Appl.Physiol., 1974, 37: 92-96.

7. Bates, D. V., and Sizto, R., "Relationship Between Air Pollutant Levels and Hospital Admissions in Southern Ontario," Can. J. Pub. Health, 1983, 74: 117-122.

\footnotetext{
${ }^{36}$ In our analysis, we assume that on days of restricted activity, respiratory symptoms will al so be felt. We thereforeassume that the estimate that people are willing to pay to avoid a day of restricted activity includes the amount they are will to pay to avoid a day of respiratory symptoms. Our estimates of economic value have been adjusted to reflect this overlap.
} 
8. Bates, D. V., and Sizto, R., "A Study of Hospital Admissions and Air Pollutants in Southern Ontario," 1986, In: Lee, S. D., Schneider, T., Grant, L. D., Verkerk, P. J.,(eds.), Aerosols: Research, Risk Assessment, and Control Strategies: Proceedings of the 2nd US-Dutch International Symposium (Williamsburgh, VA, Chelsea, MI: Lewis Publishers, Inc., May 1985), pp. 767-777.

9. Bates, D. V., and Sizto, R., "Air Pollution and Hospital Admissions in Southern Ontario: The Acid Summer Haze Effect, " Environ. Res., 1987, 43:317-331.

10. Bedi, J. F., Dreschsler-Parks, D. M., and Horvath, S. M., 'Duration of Increased Pulmonary Function Sensitivity to an Initial Ozone Exposure, " Am. Ind.Hyg. Assoc. J., 1985, 46:731-734.

11 Bhatnagar, R. S., Hussain, M. Z., Sorense, K. R., Mustafa, M.G., von Dohlen, F. M., and Lee, S. D., "Effect of Ozone on Lung Collagen Biosynthesis, " in Lee, S. D., Mustafa, M. G., and Mehlman, M.A. (eds.), an international symposium on the biomedical effects of ozone and related photochemical oxidants, Advances in modern epidemiological toxicology: vol. 5 (Pinehurst, NC., Princeton, NJ: Princeton Scientific Publishers, Inc., March 1982), pp. 311-321.

12. Carey, P. M., Air Toxics Emissions From Motor Vehicles, Tecnical Report EPA-AA-TSS-PA-865, Office of Mobile Sources, Environmental Protection Agency, September 1987.

13. Costa, D. L., Kutzman, R. S., Lehmann, J. R., Popehoe, E. A., and Drew, R. T., "A Subchronic Multi-dose Ozone Study in Rats," (1983) In: Lee SD, Mustafa MG, Mehlman MA, Eds. International Symposium on the Biomedical Effects of Ozone and Related Photochemical Oxidants; (Pinehurst, NC, Princeton, NJ: Princeton Scientific Publishers Inc. March 1982), pp. 369-393. (Advances in Modem Environmental Toxicology: V. 5).

14. Crapo, J. D., Barry, B. E., Chang, L-Y., and Mercer, R.R., "Alterations in Lung Structure Caused by Inhalation of Oxidants," J. Toxicol. Environ. Health, 1984, 13:301-321.

15. Crapo, J, D., Ying, H., Chang, L-Y., and Mercer, R. M., "Assessment of Lung Injury Caused by Oxidant Air Pollutants Using Electron Microscopic Morphometric Techniques, " presented at 80th Annual Meeting of APCA, New York, NY, June 21-26, 1986; Session 99, "Extrapolation of animal toxicological data to man, " pp. 1-10.

16. Delucia, A.J., and Adams, W. C., "Effects of Ozone Inhalation During Exercise on Pulmonary
Function and Blood Biochemistry," J. Appl. Physiol.Respir. Environ. Exercise Physiol., 1977, 43:75-81.

17. Detels, R., Tashkin, D. P., Sayre, J. W., Rokaw, S. N., Coulson, A. H., Massey, F. J., and Wegman, D. H., "The UCLA Population Studies of Chronic Obstructive Respiratory Disease, " Chest, October 1987, 92:594-603.

18. Dickie, M., Gerking, S., Brookshire, D., Coursey, D., Schulze, W., Coulson, A., and Tashkin, D., "Reconciling Averting Behavior and Contingent Value Benefit Estimates of Reducing Symptoms of Ozone Exposure" Improving Accuracy and Reducing Costs of Environmental Benefits Assessments (Washington DC: EPA 1987).

19. Dockery, D. W., Ware, J. H., Ferris, B. G., Glicksberg, D. S., Fay, M. E., Spiro, A., and Speizer, F. E., "Distribution of Forced Expiatory Volume in One Second and Forced Vital Capacity in Healty White Adult Never-smokers in Six U.S. Cities, " Am. Rev. Resp. Dis., 1985, 131:51 1-520.

20. Drechsler-Parks, D. M., Bedi, J, F., and Horvath, S. M., "Pulmonary Function Response of Older Men and Women to Ozone Exposure," Exp. Gerontology, 1987, 22:91-101.

21. Driscoll, K. E., Yollmuth, T. A., and Schlesinger, R. B., "Acute and SubChronic Ozone Inhalation in the Rabbit: Responses to Aveolar Macrophages," J. Tox. and Environ., 1987,12:27-43.

22. Ehrlich, R., Findlay, J. C., Feners, J. D., and Gardner, D. E., "Health Effects of Short-term Inhalation of Nitrogen Dioxide and Ozone Mixtures, "Environ. Res., 1977, 14:223-231.

23. Ferris, B.G. et al., "Guidelines as to What Constitutes an Adverse Respiratory Health Effect, With Special Reference to Epidemiologic Studies of Air Pollution," Am. Rev. Respir.Dis., 1985, $131: 666-668$.

24. Flesh, R. D., Riha, M, L., and Miller, M. F., "Effects of Short-term Intermittent Air Pollutants on Incidence and Severity of Acute Respiratory Disease: Data Collection and Quality Assurance. Project Summary, " U.S. Environmental Protection Agency, EPA-600/S 1-81-065.

25a. Folinsbee, L. J., "A Summary of the Health Effects of Ozone," contractor report for OTA, June 30, 1988.

25b. Folinsbee, L. J., "Extrapolation of the Effects of Exposure to Ozone for Durations Up to Eight Hours and Ozone Concentrations Up to 0.16 ppm, " contractor report for OTA, June 20, 1988.

26. Folinsbee, L.J., Bedi, J. F., and Horvath, S. M., "Pulmonary Function Changes After $1 \mathrm{~h}$ Continu- 
ous Heavy Exercise in 0.21 ppm Ozone, " J. Appl. Physiol., 1984, 57:984-988.

27. Folinsbee, L.J., and Horvath, S.M., "Persistence of the Acute Effects of Ozone Exposure," Aviat. Space Environ. Med., 1986, 57:1136-1143.

28. Folinsbee, L. J., McDonnell, W. F., and Horstman, D. H., "Pulmonary Function and Symptom Responses After 6.6 Hour Exposure to $0.12 \mathrm{ppm}$ Ozone With Moderate Exercise, " JAPCA, 1988, 38:28-35.

29. Foster, W.M., Costa, D.L., and Langenback, E. G., "Ozone Exposure Alters Tracheobranchial Mucociliary Function in Humans," J. Appl. Physical., 1987, 63:996-1002.

30. Friedman, Robert D., Sensitive Populations and Environmental Standards_An Issue Report (Washington, DC: The Conservation Foundation, 1981).

31. Gallup Poll,"Percentage of Americans Who Exercise Daily Up 12 Points Since 1982/ Popularity of Jogging Continues to Increase," The Gallup Opinion Index, vol. 226, July, 1984, pp.9-11.

32. Gallup Poll, "As Runners Extend Distances, Percent Reporting They Jog Levels Off; Half of Americans Exercise Regularly, "The Gallup Opinion Index, 1983.

33. Gardner, D.E., Lewis, T.R., Alpert, S. M., Hurst, D. J., and Coffin, D. L., "The Role of Tolerance in Pulmonary Defense Mechanisms, " Arch.Environ. Health, 1972, 25:432-438.

34. Gardner, D. E., and Graham, J.A., "Increased Pulmonary Disease Mediated Through Altered Bacterial Defenses," 1977. In: Sanders, C. L., Schneider, R.P., Dagle, G. E., and Ragen, H.A. (eds.), Pulmonary Microphage and Epithelial Cells: Proceedings of the Sixteenth Annual Hanford Biology Symposium (Richland, VA, Washington, DC: Energy Research and Development Administration, September 1976), pp. 1-21.

35. Gong, H., Bradley, M. S., Simmons, D. P., and Tashkin, "Impaired Exercise Performance and Pulmonary Function in Elite Cyclists During Low-level Ozone Exposure in a Hot Environmerit," Am. Rev. Respir. Dis., 1986, 134:726-733.

36. Gong, H., "Relationship Between Air Quality and the Respiratory Status of Asthmatics in an Area of High Oxidant Pollution in Los Angeles County," California Air Resources Board Find Report, April 1987.

37. Hayes, S.R., Rosenbaum, A. S., Wallsten, T. S., Whitfield, R. G., and Winkler, R. L., Assessment of Lung Fuction and Symptom Health Risks Associated with Attainment of Alternative Ozone NAAQS-
Draft Final Report, EPA 68-02-4313 (Washington, DC: U.S. Environmental Protection Agency, Sept. 18, 1987).

38. Holguin, A.H., Buffler, P. A., Contant, C.F., Stock, T. H., Kotchmar, D., Hsi, B.P., Jenkins, D. E., Gehan, B.M., Noel, L. M., and Mei, M., "The Effects of Ozone on Asthmatics in the Houston Area," Air Pollution Control Association Transactions on Ozone/Oxidants Standards, Houston, TX, November 1984, pp. 262-280.

39. Horstman, D. H., McDonnell, W. F., AbdulSalaam, S., Folinsbee, L.J., and Ives, P.J., "Current U.S. EPA Research Concerning More Prolonged Exposure of Humans to Low Ozone Concentrations," presented at the 81st annual meeting of APCA, Dallas, TX, June 19-24, 1988..

40. Horvath, S.M., Gliner, J. A., and Folinsbee, L.J., "Adaptation to Ozone: Duration of Effect," $\mathrm{Am}$. Rev. Respir. Dis., 1981,123:496-499.

41. Jakab, G. J., "InfluenzaVirus, OzoneandFibrogenesis, " Part 2 of two parts (abstract), Amer. Rev. Respir. Dis. 137:4:166, April 1988.

42. Kehrl, H.R., Hazucha, M. J., Solic, J. J., and Bromberg, P. A., "Responses of Subjects with Chronic Obstructive Pulmonary Disease After Exposures to $0.30 \mathrm{ppm}$ Ozone," Am. Rev. Respir. Dis., 1985, $131: 719-724$.

43. Kehrl, H.R., Vincent, L. M., Kowalsky, R.J., Horstman, A. H., O'Neil, J. J., McCartney, W. H., and Bromberg, P.A., "OzoneExposure Increases Respiratory Epitheilial Permeability in Humans, "Am. Review of Respir.Dis., 1987, 135: 1124-1128.

44. Koenig, J. Q., Covert, D. S., Marshall, S. G., Belle, G. V., and Pierson, W. E., "The Effects of Ozone and Nitrogen Dioxide on Pulmonary Function in Healthy and in Asthmatic Adolescents," Am. Rev. Respir. Dis., 1987, 136:1 152-1157.

45. Koren, H, S., Devlin, R. B., Graham, D. E., Mann, R., Horstman, D. H., Kozumbo, W. J., Becker, S., McDonnell, W. F., and Bromberg, P.A., "OzoneInduced Inflammation in the Lower Airways of Human Subjects," Am. Rev. Respir. Dis., 1989, 139:407-415.

46. Koren, H. S., Graham, D., Becker, S., and Devlin, R., "Modulation of the Inflammatory Response in Human Lung Exposed to Ambient Levels of Ozone," in Atmospheric Ozone Research and Its Policy Implications (cd.) Schneider, T., Lee, S.D., Welters, G.J.R., and Grant, L.D. (Amsterdam: Elsevier, 1989), pp. 745-753.

47. Kreit, J. W., Gross, K. B., Moore, T. B., Lorenzen, T.J., D'Arch, J., and Eschenbacher, W. L., “'Ozone- 
Induced Changes in Pulmonary Function and Bronchial Responsiveness in Asthmatics," J. Appl. Physiol., 1989, 66(1):217-222.

48. Krupnick, A., Barrington, W., and Ostro, B., "Ambient Ozone and Acute Health Effects: Evidence From Daily Data," Discussion Paper 89-01, Resources for the Future, Washington, DC, 1989.

49. Krupnick, A.J. and Kopp, R. J., "The Health and Agricultural Benefits of Reductions in Ambient Ozone in the United States, " contractor report for OTA, June 1988.

50. Kulle, T.J., Sauder, L. R., Kern, H. D., Farrell, B.P., Bermel, M. S., and Smith, D. M., "Duration of pulmonary Function Adaptation to Ozone in Humans," Am. Ind. Hyg. Assoc. J., 1982, 43:832837.

51. Kulle, T.J., Milman, J.H., Sauder, L.R., Kerr, H. D., Farrell, B.P., and Miller, W. R., 'Pulmonary Function Adaptation to Ozone in Subjects With Chronic Bronchitis," Environ. Res., 1984, 34:55-63.

52. Kulle, T. J., Sauder, L.R., Hebel, J. R., and Chatharn, M. D., "Ozone Response Relationships in Healthy Non-Smokers, "Am. Rev. Respir. Dis., 1985, 132:36-41.

53. Last, J. A., Greenberg, D. B., and Castleman, W. L., "Ozone-Induced Alterations in Collagen Metabolism of Rat Lungs," Toxicol. Appl. Pharmacol., 1979, 51:247-258.

54, Last, J. A., Hyde, D.M., and Chang, D.P.Y., "A Mechanism of Synergistic Lung Damange by Ozone and Respirable Aerosol," Exp. Lung Res., 1984, 7:223-235.

55. Last, J. A., and Warren, D. L., "Synergistic Interaction of Ozone and Respirable Aerosols on Rat Lungs; III. Ozone and Sulfuric Acid Aerosol, ” Toxicol.Appl.Pharmacol., 1987, 88:203-216.

56. Linn, W. S., Buckley, R., Speir, C., Blessey, R., Jones, M., Fischer, D., and Hackney, J.D., "Health Effects of Ozone Exposure in Asthmatics," Am. Rev. Respir.Dis., 1978, 117:835-843.

57. Linn, W. S., Jones, M.P., Bachmayer, E.A., et al., "Short Term Respiratory Effects of Polluted Air: A Laboratory Study of Volunteers in a High Oxidant Community," Am. Rev. Respir. Dis., 1980, 121:243-252.

58. Linn, W. S., Fischer, D. A., Medway, D.A., Anzar, U.T., Spier, C.E., Valencia, L. M., Venet, T.G., and Hackney, J. D., "Short Term Respiratory Effects $\mathrm{O}_{3}$ Exposure in Volunteers With Chronic Obstructive Pulmonary Disease, " Am. Rev. Respir. Dis. 125:658-663, 1982.

59. Linn, W. S., Shamoo, D. A., Venet, T. G., Spier, C.E., Valencia, L, M., Anzar, U.T., and Hackney,
J.D., "Response to Ozone in Volunteers With Chronic Obstructive Pulmonary Disease, " Arch. Environ. Health 38:278-283, 1983.

60. Linn, W. S., Avol, E.L., Shamoo, C. E., Speir, L. M., Valencia, T.G., Venet, D.A., Fischer, J.D., and Hackney, J., "A Dose Response Study of Healthy, Heavily Exercising Men Exposed to Ozone at Concentrations Near the Ambient Air Quality Standard, " Toxicol. Indust. Health 2:99112,1986

61. Linn, W. S., Avol, E.L., Shamoo, D.A., Peng, R-C, Valencia, L. M., Little, D.E., and Hackney, J.D., "Repeated Laboratory Ozone Exposures of Volunteer Los Angeles Residents: An Apparent Seasonal Variation in Response," Toxicol.Indust. Health 4:505-520, 1988.

62, Lioy, P, J., Vollmuth, T. A., and Lippmann, M., "Persistence of Peak Flow Decrement in Children Following Ozone Exposures Exceeding the National Ambient Air Quality Standard," J. Air Pollut. Control Assoc., 1985, 35:1068-1071.

63. Lippmann, M., Lioy, D.J., Leikauf, G., Green, K. B., Baxter, D., Morandi, M., Pasternack, B., Fife, D., and Speizer, F.E., Adv. in Modern Environ, Toxicol.5:423-446, 1983.

64. Lippmann, M., Lioy, P. J., Leikauf, G., Green, K. B., Baxter, D., Morandi, M., and Pasternack, B. S., "Effects of Ozone on the Pulmonary Function of Children," In: Lee, S. D., Mustafa, M. G., and Mehlman, M.A. (eds.), International Symposium on the Biomedical Effects of Ozone and Related Photochemical Oxidants (Princeton, NJ: Princeton Scientific Publishers, Inc., March 1982), pp. 423-446.

65. Lippmann, M., "Health Significance of Pulmonary Function Tests, " Presented at the 80th Annual Meeting of APCA. New York, NY, June 21-26, 1987.

66. Loehman, E.T., et al., "Distributional Analysis of Regional Benefits and Air Quality Control," Journal of Environmental and Economic Management 6:222-243, 1979.

67. Mathtech, Inc., "Methodology for Estimating Costs of Carcinogenic Emissions From Mobile Sources," report prepared for U.S. Environmental Protection Agency, Office of Air Quality Planning and Standards, September 1988.

68. McCurdy, T.R., Office of Air Quality Planning and Standards, U.S. Environmental Protection Agency, National Estimates of Exposure to Ozone Under Alternative National Standards (Research Triangle Park, NC: December 1986).

69. McCurdy, T.R., Office of Air Quality Planning and Standards, U.S. Environmental Protection 
Agency, Research Triangle Park, NC, personal communication, February 1988.

70. McDonnell, W.F., Horseman, D. H., Hazucha, M. J., Seal, E., Haak, E. D., Sallam, S. A., and House, D.E., "pulmonary Effects of Ozone Exposure During Exercise: Dose Response Characteristics," J. Appl.Physiol. 54, 5:1345-1352, 1983.

71. McDonnell, W.F., Chapman, R. S., Leigh, M. W., Strope, G.L., and Collier, A. M., "Respiratory Responses of Vigorously Exercising Children to 0.12 ppm Ozone Exposure," Am. Rev. Respir. Dis. 132:875-879, 1985.

72. McDonnell, W. F., Hortsman, D. H., AbdulSalaam, S., Raggio, L.J., and Green, J.A., "The Respiratory Responses of Subjects With Allergic Rhinitis to Ozone Exposure and Their Relationship to Nonspecific Airway Reactivity, "Toxicol. Industr. Health 3:507-517, 1987.

73. Miller, F.J., Illing, J.W., and Gardner, D. E., "Effect of Urban Ozone Levels on LaboratoryInduced Respiratory Infections," Toxicol.Lett. 2:163-169, 1978.

74. Morton, B., "Addendum to 'Methodology for Estimating Costs of Carcinogenic Emissions From Mobile Sources,"' U.S. Environmental Protection Agency, Office of Air Quality Planning and Standards, Apr. 5, 1989.

75. Osebold, J. W., Gershwin, L.J., and Ace, Y. C., "Studies on the Enhancement of Allergic Lung Sensitization by Inhalation of Ozone and Sulfuric Acid Aerosol," J. Environ. Pathol.Toxicol. 3:221234, 1980.

76, Paul, R. A., Johnson, T., Pope, A., Ferdo, A., and Biller, W. F., National Estimates of Exposure to Ozone Under Alternative National Standards, draft report to U.S. Environmental Protection Agency by PEI Associates, Inc. (Research Triangle Park, NC: December 1986).

77. Pope, A., Development of Activity Patterns To Determine Population Exposure to Ozone, EPA 68-02-4309 (Research Triangle Park, NC: U.S. Environmental Protection Agency, May 1986).

78. Portney, P.R., and Mullahy, J., "UrbanAirQuality and Acute Respiratory Illness, "Journal of Urban Economics 20:21-38, 1986.

79. Raizenne, M. E., Hargreave, F., Sears, M., Spengler, J., Stern, B., and Burnett, R., "Exercise and Lung Function Responses During an Air Pollution Episode in Young Females With Airway Hyperresponsiveness to Methacholine," Am, Rev. Respir.Dis. 135:A343, 1987.

80. Raizenne, M, E., Stem, B., Burnett, R., Franklin, C.A., and Spengler, J. D., "Acute Lung Function Reponses to Ambient Aerosol Exposures in Chil- dren," In: International Symposium on Health Effects of Acid Aerosols: Addressing Obstacles in the Emerging Data Base (Research Triangle Park, NC: October 1987, also Environ. Health Perspect., in press.

81. Rae, S.T., Application of the Urban Airshed Model to the New York Metropolitan Area, EPA 45 0/4-87011 (Research Triangle Park, NC: U.S. Environmental Protection Agency, May 1987).

82. Reisenauer, C. S., Koenig, J. Q., McManus, M. S., Smith, M. S., Kusic, G., and Pierson, W.E., "Pulmonary Response to Ozone Exposures in Healthy Individuals Aged 55 Years or Greater," JAPCA 38:51-55, January 1988.

83. Rowe, R. D., and Chestnut, L. G., Energy and Resource Consultants, Inc., Report to EPA, Oxidants and Asthmatics in Los Angeles: A Benefits Analysis, EPA-23 O-O7-85-O1O (Washington, DC: 1985).

84. SAROAD, Storage and Retrieval of Aerometric Data, database, data files for 1983, 1984 and 1985 (Research Triangle Park, NC: U.S. Environmental Protection Agency, 1987).

85. Schlegle, E. S., and Adams, W. C., "Reduced Exercise Time in Competitive Simulations Consequent to Low Level Ozone Exposure," Med. Sci. Sports Exercise 18:408-414, 1986.

86. Schlesinger, R.B., Naumann, B. D., and Chen, L. C., "Physiological and Histological Alterations in the Bronchial Mucociliary Clearance System of Rabbits Following Intermittent Oral or Nasal Inhalation of Sulfuric Acid Mist," J. of Toxicol. and Environ. Health 12441-465, 1983.

87. Schoettlin, C. E., and Landau, E., "Air Pollution and Asthmatic Attacks in the Los Angeles Area," Public Health Rep. 76:545-548,1961.

88. Solic, J.J., Hazucka, M.J., and Bromberg, P.A., "Acute Effects of 0.2 ppm Ozone in Patients With Chronic Obstructive Pulmonary Disease," Am. Rev. Respir. Dis. 125:664-669, 1982.

89. Specktor, D. M., Lippmann, M., Lioy, P. J., Thurston, G. D., Citak, K., James, D. J., Bock, N., Speizer, F. E., and Hayes, C., Am. Rev. Respir. Dis. 137:313-320, 1988.

90. Tolley, G. S., et al., "Valuation of Reductions in Human Health Symptoms and Risk," final report to EPA, Grant \#CR-81053-01-0, 1986.

91. Tyler, W. S., Tyler, N. K., Last, J. A., Gillespie, M.J., and Barstow, T.J., "Comparison of Daily and Seasonal Exposures of Young Monkeys to Ozone," Toxicology 50:131-144, 1988.

92. U.S. Department of Commerce, Bureau of the Census, Detailed Population Characteristics, Uni- 
ted States Summary, 1980 Census of Population (Washington, DC: March 1984).

93. U.S. Department of Commerce, State and Metropolitan Area Data Book, 1986, Files on Diskette (Washington, DC: 1986).

94. U. S. Congress, Senate Committee on Public Works, Senate Report No. 91-1196, 91st Cong., 2d sess. 11 (1970), reprinted in A Legislative History of the Clean Air Act Amendments of 1970, Ser. No. 93-18, 93d Cong., 2d sess. 411 (1974).

95. U.S. Department of Health and Human Services, National Center for Health Statistics, "National Health Interview Survey: United States 1979," April 1981, table 3, p. 15.

96. U.S. Environmental Protection Agency, Environmental Criteria and Assessment Office, Air Quality Criteria for Ozone and Other Photochemical Oxidants, Vol. I of V (Washington, DC: August 1986).

97. U.S. Environmental Protection Agency, Office of Policy, Planning, and Analysis, Unfinished Business: A Comparative Assessment of Environmental Problems, Appendix 1, Report of the Cancer Risk Work Group, (Washington, DC: February 1987).

98. U.S. Environmental Protection Agency, Office of Air Quality Planning and Standards, Review of the National Ambient Air Quality Standards for Ozone Preliminary Assessment of Scientific and Technical Information, Draft Staff Paper (Washington, DC: November 1988).
99. U.S. Environmental Protection Agency, Office of Health and Environmental Assessment, Acid Aerosols Issue Paper, Review Draft (Washington, DC: February 1988).

100. Utell, M.J., Morrow, P. E., Bauer, M.A., Hyde, R. W., and Schrek, R. M., "Modifiers of Responses to Sulfuric Acid Aerosols in Asthmatics, "Aerosols: Formation and Reactivity (London: Pergamon Press, 1986).

101. Warren, D.L., Guth, D,J., and Last, J. A., "Synergistic Interaction of Ozone and Respirable Aerosols on Rat Lungs; II. Synergy Between Ammonium Sulfate Aerosol and Various Concentrations of Ozone," Toxicol. Appl. Pharmacol.84:470-479, 1986.

102. Warren, D.L., and Last, J.A., "Synergistic Interaction of Ozone and Respirable Aerosols on Rat Lungs: III. Ozone and Sulfuric Acid Aerosol," Toxicol. Appl.Pharmacol.88:203-216, 1988.

103. Whittemore, A. S., and Kom, E. L., "Asthma and Air Pollution in the Los Angeles Area," Am. J. Public Health 70:687-696, 1980.

104. Wright, E. S., Kehrer, J.P., White, D. M., and Smiler, K. L., "Effects of Chronic Exposures to Ozone on Collagen in Rat Lung, "Toxicol.Appl. Pharmacol.92:445-452, 1988. 
Chapter 4

\section{Effects of Ozone on Crops and Forests}




\section{CONTENTS}

Page

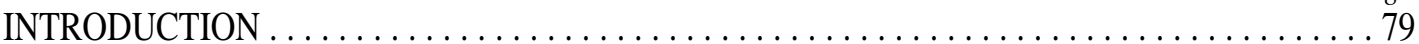

CONCENTRATIONS OF OZONE IN RURAL AREAS . . . . . . . . . . . . . . . . . . 79

POTENTIAL EFFECTS OF OZONE ON FORESTS $\ldots \ldots \ldots \ldots \ldots \ldots \ldots \ldots \ldots \ldots \ldots$

Ponderosa and Jeffrey Pine Trees in the San Bernardino National Forest and

Other Locations in California....... . . . . . . . . . . . . . . . . . . . . . . 81

Sensitive Strains of White Pine Trees in the Eastern United States . . . . . . . . . . . . 82

Red Spruce Trees at High-Elevation Sites in the Eastern United States . . . . . . . . . . 82

Yellow Pine Trees in the Southeastern United States . . . . . . . . . . . . . . . . . . . . . . . . 84

Sugar Maple Trees in Pennsylvania, New York, New England, and

Southeastern Canada . . . . . . . . . . . . . . . . . . . . . . ....................... 84

European Forests . . . . . . . . . . . . . . . . . . . . . . . . . . . . . . . . . . . . . 85

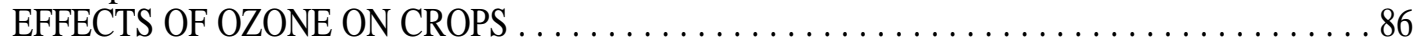

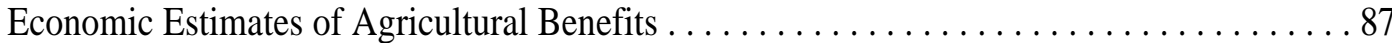

Agricultural Benefits of Reducing Ozone By 10 to 50 Percent. . . . . . . . . . . . . . 88

REFERENCES FOR CHAPTER . . . . . . . . . . . . . . . . . . . . . . . 91

Figure

\section{Figures}

4-1. Estimated Daily 7-hour Average Ozone Concentrations During the

Growing Season . . . . . . . . . . . . . . . . . . . . . . . . . . . . . . . . . . . 80

4-2. Major Forested Areas and Dominant Tree Types of the United States . . . . . . . . . 82

4-3. 1984 Crop Production at the State Level . . . . . . . . . . . . . . . . . . . . . . . . . 88

4-4. Dose-Response Functions for Corn Used in the Two Agricultural Benefits

Analyses Performed for OTA . . . . . . . . . . . . . . . . . . . . . . . . . 90

\section{Tables}

Table

4-1. Yield Losses Predicted to Occur for Seasonal Average 7-hour Mean

Page

Ozone Concentrations of 0.04 and $0.06 \mathrm{ppm}$

4-2. Estimates of Agricultural Benefits That Would Result Under Market Conditions, If Ozone Concentrations Were To Be Reduced Nationwide by the Indicated Amounts Relative to a Background Concentration of 0.03 ppm, . 


\section{INTRODUCTION}

At concentrations that occur in rural areas throughout the southern and eastern halves of the United States, ozone reduces yields of economically important crops by from 1 to 20 percent, compared to yields that would be expected if natural background concentrations were not exceeded [10]. Analyses performed for OTA show that annual agricultural benefits in the range of $\$ 500$ million to $\$ 1$ billion (1986\$) would be expected to result from increased productivity of major crops, if ozone concentrations throughout the country were reduced by 25 percent of the difference between current and background levels $[1,21]$. These benefits include lower prices for consumers, and increased profits for crop producers in at least some parts of the country. Crop producers in California, the South, and the Northeast would be most apt to benefit from nationwide reductions in ozone, as current concentrations are highest in these areas.

Severe damage to ponderosa and Jeffrey pines in southern California forests, and foliar injury and growth reductions in sensitive strains of eastern white pine, have been clearly linked to exposure to ozone. Ozone has been hypothesized as partially responsible for declines of other tree species that have been observed in the Eastern United States, southern Canada, and Europe. In several cases, the location and timing of the declines suggest that air pollutants might have played a role. In controlled experiments, ozone has been shown to produce foliar injury and/or reduce growth rates in young trees of numerous species.

The forest-related benefits of reducing ozone concentrations cannot currently be estimated. Exposureresponse information for major annual crops was developed through research coordinated by an 8year program, the National Crop Loss Assessment Network. Research on exposure-response relationships for trees is being conducted under the National Acid Precipitation Assessment Program, and a new 10 -year effort was established by the Forest Ecosys- tems and Atmospheric Pollution Research Act of the 100th Congress. However, developing exposureresponse information for trees is more difficult and takes longer than for crops, due to the comparatively slow growth and long lifetimes of trees, and to complicating factors in their natural settings.

This chapter first shows the magnitude of ozone concentrations at rural locations across the United States. Then, current understanding of the effects of ozone on trees is reviewed, and the major cases in which ozone has been suggested as a cause of decline are discussed. Finally, the effects of ozone on crops are reviewed, and new estimates of the agricultural benefits of reducing ozone presented.

\section{CONCENTRATIONS OF OZONE IN RURAL AREAS}

Figure 4-1 shows estimated daily 7-hour average (9 a.m. to 4 p.m.) ozone concentrations averaged over the months April to October and the years 1978-82 [28]. ${ }^{1}$ For comparison, the natural background value of the statistic shown is estimated to be on the order of 0.030 parts per million (ppm), although this value is highly uncertain [23]. Figure 4-1 was prepared by interpolating data from over 300 selected monitors, generally including suburban monitors but excluding those at urban sites. Because this chapter addresses the effect of ozone on crops and forests, figure 4-1 also shows where rural monitors are located [26]. There are fewer than 100 ozone monitors located at rural sites across the United States, and a number of States do not have any. Because the reliability of a concentration estimate is extremely sensitive to the density of monitoring sites in the area, no estimates are shown for most Western States,

Ozone concentrations vary from one growing season to another as a consequence of year-to-year differences in weather patterns. An analysis of ozone data from the years 1978-83, for forested subregions of the Eastern United States, gives an indication of

${ }^{1}$ Recent studies have suggested that for many crops, a measure of cumulative exposure to ozone would be a better measure of exposure than the 7-hour seasonal average ozone concentration [44]. However, the 7-hour seasonal average concentration has been reported most often. 
Figure 4-1-Estimated Daily 7-hour Average Ozone Concentrations During the Growing Season

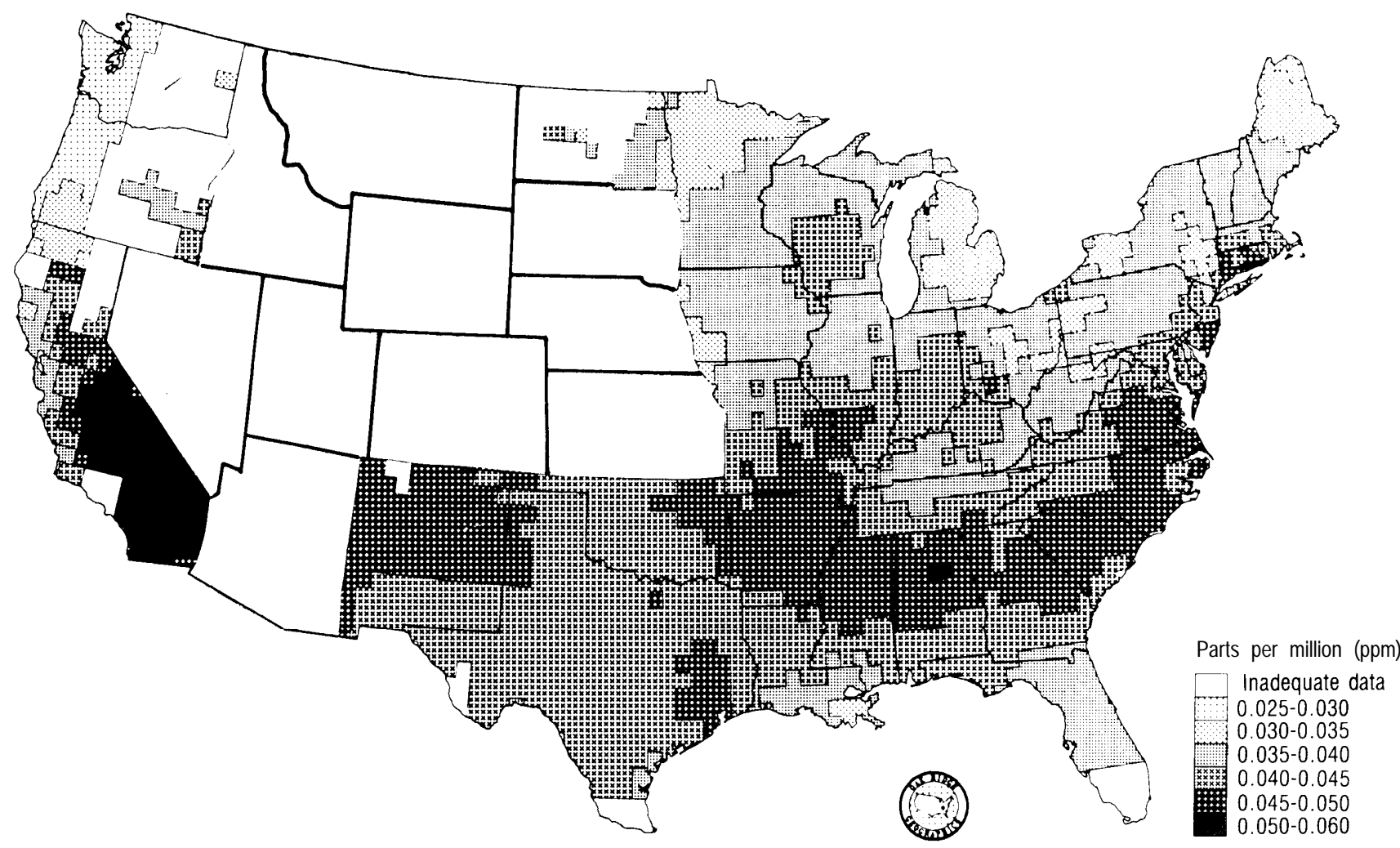

Location of Rural Ozone Monitors

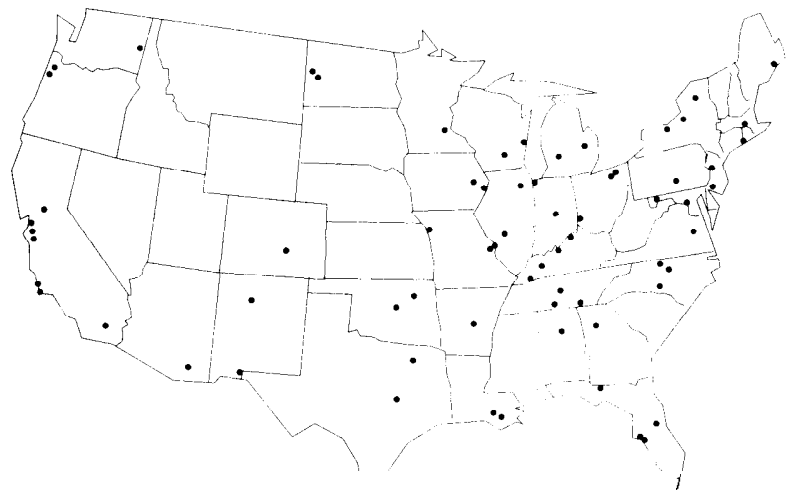

how much April to October, daily 7-hour average concentrations change from one year to the next [32]. Data from major cities were excluded from the analysis. As examples, during the 6-year period concentrations averaged over sites in the upper Great Lakes region (northeastern Minnesota, northern Wisconsin, and northern Michigan) ranged year to
Daily 7-hour daytime ozone concentrations are average over the months April through October and the years 1978-82. The lower map shows the location of rural ozone monitors in 1984.

SOURCE: a) Adapted from R.J. Olson, L.J. Allison, and I.L. McCullough, Addnet Notebook: Documentation of the Acid Deposition Data Network (ADDNET) Data Base Supporting the National Add Precipitation Assessment Program, Environmental Sciences Division publication no. 2755 (Oak Ridge, TN: Oak Ridge National Laboratory, August 1987). b) Adapted from National Acid Precipation Assessment Program, Interim Assessment: The Causes and Effects of Acidic Deposition, vol. III (Washington, DC: October 1987).

year from 0.035 to $0.043 \mathrm{ppm}$; and concentrations averaged over sites in Pennsylvania, New York and western Maryland ranged year to year from 0.036 to $0.042 \mathrm{ppm}$. Concentrations for individual sites varied more than these multi-state averages: concentrations at Whiteface Mountain, NY, ranged from 0.037 to $0.049 \mathrm{ppm}$, for example. 


\section{POTENTIAL EFFECTS OF OZONE ON FORESTS}

Exposure to ozone has been suggested as a factor in several confirmed or reported cases of tree species decline in the United States, Canada, and Europe. In two cases-the decline of ponderosa and Jeffrey pines in the San Bernardino Mountains east of Los Angeles, and the decline of sensitive strains of eastern white pine trees throughout the Eastern United States-exposure to ozone has been established as a primary cause.

Ozone-induced injury in trees shows up primarily as foliar injury, including leaf or needle discoloration and premature loss. In advanced cases, needles or leaves and then branches of injured trees die back. For example, ozone injury to eastern white pine needles appears as a "chlorotic" or yellow mottle, with needles ultimately dying back from the tips. Reduced growth rates may precede or follow foliar injury. Increased susceptibility to diseases and other stresses may result from reduced photosynthesis and decreased allocation of carbohydrates to tree roots [34]. Ultimately trees may die prematurely. All of these effects have been observed in forests of the San Bernardino Mountains as a result of exposure to high concentrations of ozone originating from $\mathrm{NO}_{x}$ and VOC emissions in the Los Angeles basin. In addition to trees, ozone injures a variety of other plants that occur in forest ecosystems. Examples include wild grape, blackberry, milkweed and poison ivy [30,42].

Some of the symptoms of exposure to ozone can also have other causes. And inmost cases of decline, it is likely that multiple stresses contribute, so it is difficult to sort out primary causes and even tougher to predict the gains that might be made if one stress is mitigated. Controlled exposure studies indicate that seedlings of many species are sensitive to ozone. However, the responses observed in studies conducted to isolate the effects of ozone do not always match symptoms observed in natural environments. Moreover, for the most part, programs to monitor air pollution levels at forest sites where injury has been observed, and controlled studies of the effects of ozone on mature trees, are only now being initiated. So, although exposure to ozone has been suggested as an explanation for several declines, in most of these cases scientists have not yet established whether or not ozone is in fact, an important contributor.

Figure 4-2 shows the major forested areas of the United States, and identifies the dominant types of trees in each area. Comparing figure 4-2 with figure 4-1 indicates that elevated ozone concentrations are generally present in the western conifer region of California, and the eastern hardwood and southeastern yellow pine regions. Below, we discuss whether ozone is contributing to major declines in each of these areas of the United States, as well as to widespread damage in Central European forests.

\section{Ponderosa and Jeffrey Pine Trees in the San Bernardino National Forest and Other Locations in California}

Ozone is generally held to be the principal cause of visible injury and accelerated mortality of ponderosa and Jeffrey pine trees in the San Bernardino and San Gabriel Mountains of southern California. White fir, incense cedar, and California black oak trees have also been affected, but are less sensitive than the pines. The symptoms observed in the forests have been duplicated in controlled exposure studies. At some sites in the San Bernardino National Forest east of Los Angeles, daytime (14 hour) average ozone concentrations of $0.10 \mathrm{ppm}$ are typical during June, July, and August [26]. The decline of ponderosa and Jeffrey pine there has been so severe that if current trends persist, incense cedar and white fir are expected to replace them as dominant species [25].

The National Park Service has reported extensive ozone injury in national parks in California [42]. Average summer, daytime ozone concentrations at some sites along the western slopes of the Sierra Nevada, including a site in western Sequoia National Park, range from 0.060 to $0.085 \mathrm{ppm}$ [31]. Over 75 percent of the ponderosa and Jeffrey pine trees surveyed at the western border of Sequoia National Park in 1984 showed foliar injury attributed to ozone [42], with associated growth reductions in Jeffrey pine trees [31]. Foliar symptoms that match symptoms of ozone exposure have been observed on giant sequoia seedlings in Sequoia National Park, as well [41]. Injury to ponderosa and Jeffrey pines has also been documented in Yosemite National Park [42]. 
Figure 4-2-Major Forested Areas and Dominant Tree Types of the United States

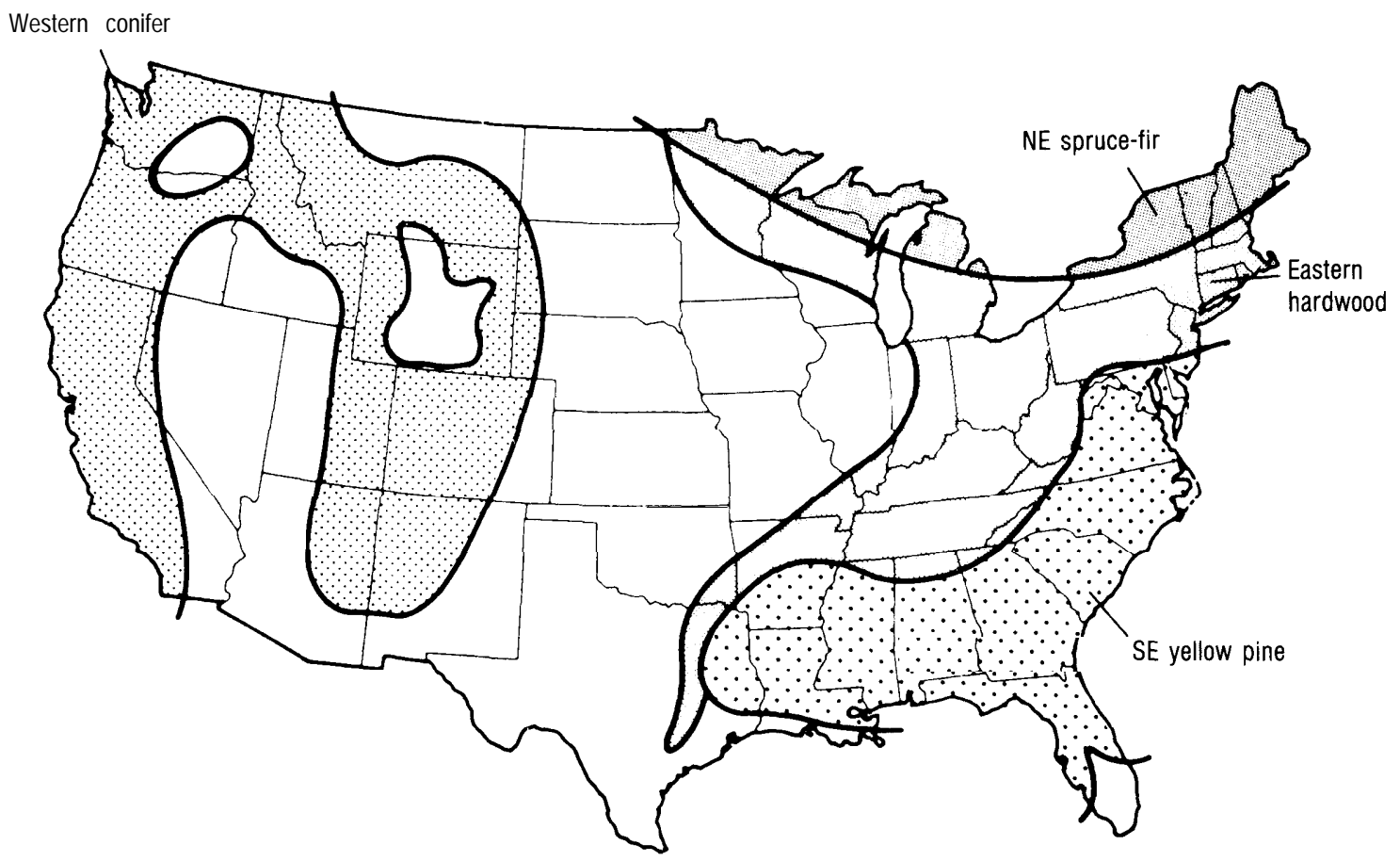

SOURCE: National AcidPrecipitation Assessment Program, interim Assessment: The Causes and Effects of Acidlc Deposition, vol. IV (Washington, DC: October 1987).

\section{Sensitive Strains of White Pine Trees in the Eastern United States}

Foliar injury, reduced growth rates, and increased mortality due to exposure to ozone are apparent in some eastern white pine trees throughout the Eastern United States.* Symptoms of ozone injury have been observed in some eastern white pine trees in Acadia and Great Smoky Mountains National Parks [42]. Controlled exposure studies and field studies support the hypothesis that concentrations of ozone observed throughout the East are high enough to injure the most sensitive white pine trees (as with other species of trees, not all strains of white pine are equally sensitive to ozone) [45]. Reductions in growth rates have been shown to be positively correlated with the degree of foliar injury in individual trees [5]. Preliminary evidence in Great Smoky Mountains National Park suggests that the most sensitive strains of eastern white pine may be disappearing [42]. However, considering all eastern white pines, not just sensitive strains, regionwide reductions in productivity have not been observed [4].

\section{Red Spruce Trees at High-Elevation Sites in the Eastern United States}

Reductions in radial growth rates, dieback, and increased mortality have been observed in red spruce trees at high-elevation sites in the northern Appalachian Mountains of New York and New England and the southern Appalachians of North Carolina, Tennessee, Virginia, and West Virginia [26]. ${ }^{3}$ The populations of red spruce trees in some highelevation forests in the Northeast have declined by 40 percent to over 70 percent since the mid 1960 s, and the decline is continuing [16]. Red spruce mortality in the southern Appalachians is much lower, within normal limits for high-elevation forests [9]. Different foliar symptoms are observed in northern and southern trees, suggesting that different factors must be involved. Less severe foliar injury,

${ }^{2}$ The eastern white pine ecosystem comprises about 10 percent of the forested area in the Northeast, and lessthan 1 percent in the Scutheast [39].

3. "High-elevation" refers t. sites above about 2,500 feet in the Northeast and above about 5,800 feet in the Southeast. 


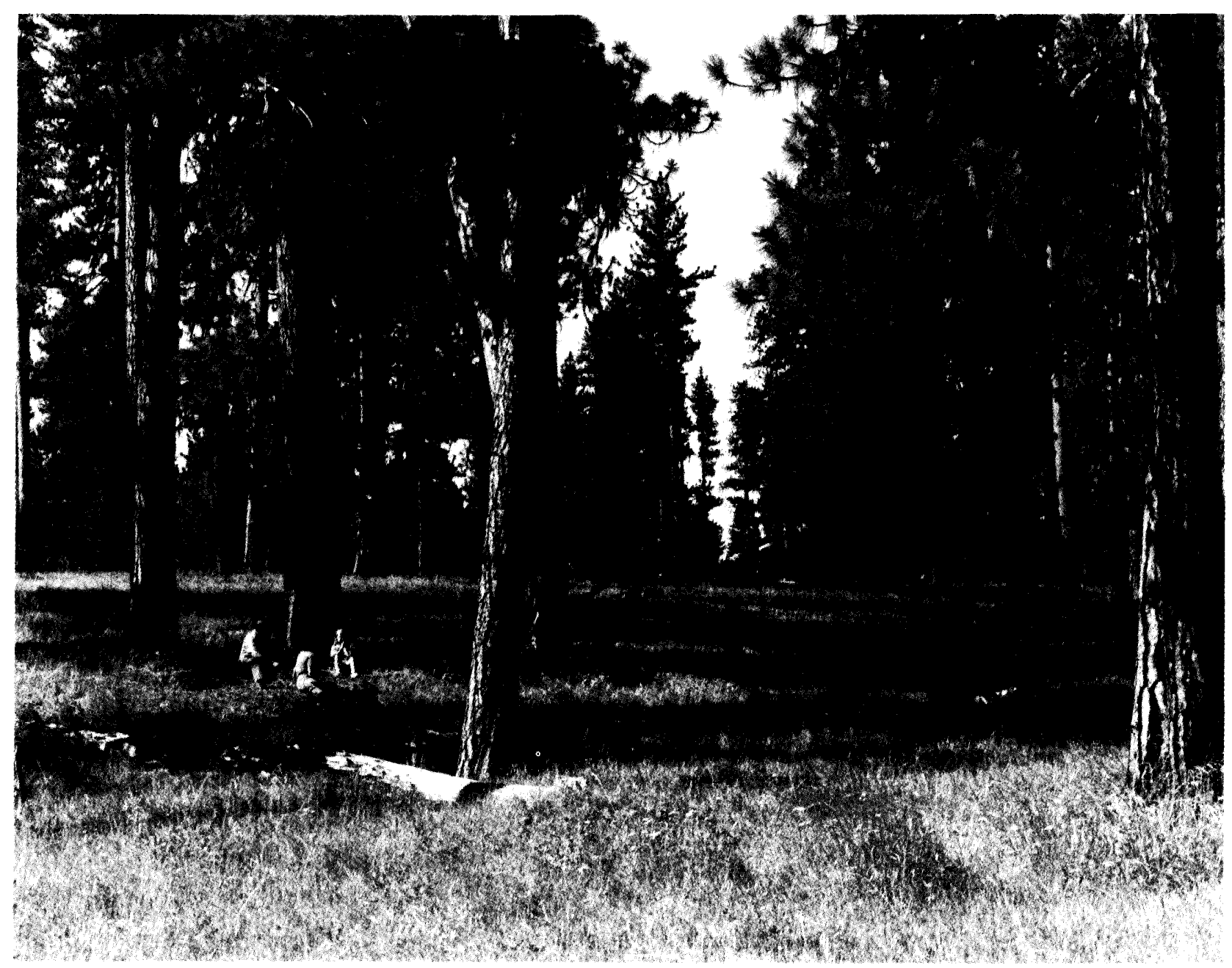

Photo credit: U.S. Depertmenf of Agriculture

Above photograph shows a stand of ponderosa pine trees. Ozone is generally held to be the principal cause of visible injury and accelerated mortality of ponderosa andeffrey pine trees in the San Bernardino and San Gabriel Mountains of southern California.

mortality, and growth reductions have also been observed in red spruce trees at low elevations in the Northeast [26]. The growth reductions observed at most low-elevation sites are thought by some scientists to be consistent with natural-trends associated with aging [12].

It is not clear which stresses are responsible for the decline of high-elevation red spruce, and it is likely that more than one factor is involved. Scientists have noted that soil and climate conditions at high elevations are often marginal for red spruce. They suggest that under these marginal conditions, im- creased pollution levels, winter damage and/or drought that have occurred since the 1960s could be pushing the trees into decline [16].

Heavy mortality from pest infestation (by the balsam woolly adelgid) and unexplained reductions in growth rates have occurred in Fraser fir trees that are mixed with red spruce at high-elevation sites in the southern Appalachians [12,9]. Although the balsam woolly adelgid does not affect red spruce directly, it has been suggested that heavy Fraser fir mortality leaves co-occurring red spruce more ex- 
posed to harsh climatic conditions at high elevations [9]. Balsam woolly adelgid infestation is not a particularly severe problem in the Northeast.

Air pollution has been considered as a possible cause of red spruce decline in high-elevation forests because no insects and diseases are ubiquitous (although various pathogens are present at different sites), and because the affected forests are exposed to high concentrations of ozone and other gaseous air pollutants, and to strongly acidic cloud water. However, the question of whether exposure to high pollutant levels has actually damaged red spruce is still under study. In the Eastern United States, water carried by the clouds intercepted by high-elevation forests is up to 100 times more acidic than "clean" rainwater, and some high-elevation sites are shrouded in clouds up to 40 percent of the time [26]. For two reasons, forests at high elevations are also likely to be exposed to more ozone than nearby low-elevation forests. First, nighttime and early morning ozone concentrations are often much greater at high-elevation sites in rural or remote areas than concentrations measured at adjacent sites at lower elevations. ${ }^{4}$ Second, the frequent presence of clouds and consequent high humidity enhances ozone uptake through leaves and needles [26].

\section{Yellow Pine Trees in the Southeastern United States}

The southeastern part of the United States is a major timber-producing region, containing 20 percent of the Nation's commercial softwood. More importantly, the region typically contributes about half of the Nation's annual growth in softwood stocks [40]. To illustrate the importance of southern softwood, hypothetical simulations have been performed with a model used by the U.S. Forest Service to project future timber resources. The simulations suggest that a 15-percent reduction in growth rates throughout the Southeast would reduce softwood stocks in the contiguous United States by almost 10 percent after 25 years, and by about 15 percent in 45 years, compared to a base case with no growth rate reductions [8]. The study estimated that a 15-percent reduction in growth rates of eastern softwoods would cost the Nation about $\$ 500$ million per year. (The Southeast accounts for about 60 percent of the softwood trees grown in the East.)

Southern softwood production is dominated by yellow pine varieties such as loblolly and shortleaf. In Florida, Georgia, North Carolina, South Carolina, and Virginia, radial growth rates of yellow pine trees in natural stands (which comprise about 70 percent of the yellow pine forests in these States) have been reduced by up to 50 percent compared to rates observed in the late 1950s [38]. The causes of the widespread growth reductions, which have occurred without visible injury, have not been definitely established. However, drought, the natural aging of the stands, and increased competition from hardwoods, are all thought to be involved. Root rot pathogens have been shown to cause growth reductions in loblolly pine [7], in some cases without apparent symptoms. Exposure to air pollution may be a contributing stress. Recent studies using controlled exposures have shown that ozone injures needles and reduces growth of loblolly pine seedlings $[11,35,19,36,37]$. However, additional research is needed to determine whether ozone is involved in the reductions in growth rates that have been observed in mature trees in the field.

\section{Sugar Maple Trees in Pennsylvania, New York, New England, and Southeastern Canada}

Dieback of tree crowns and elevated mortality rates became apparent in stands of sugar maple and associated hardwoods at some locations in southeastern Canada in the late 1970s. A 1985 survey indicated that 40 percent of the area of the sugar maple forests in Quebec had some foliar injury, with associated growth reductions in cases of moderate to severe injury [26]. Injury to sugar maples has been noticed more recently in the Northeastern United States. Pest infestation or disease are apparent causes in all of the cases in this country, although some of the cases in Canada have not been explained [26]. Air pollution has been suggested as a contributing factor. Recent experiments conducted in chambers have indicated that exposure to ozone reduced growth rates of sugar maple seedlings without

\footnotetext{
${ }^{4} \mathrm{After}$ sunset, when ozone production ceases, ground-level ozone concentrations fall off as the pollutant is deposited onto vegetation or the ground. In layers of air hundreds of yards above the ground, however, deposition is not a factor, and ozone concentrations can remain high. Where ridges or hill tops intercept pollution carried aloft, high-elevation forests can be exposed to high concentrations of ozone at night.
} 


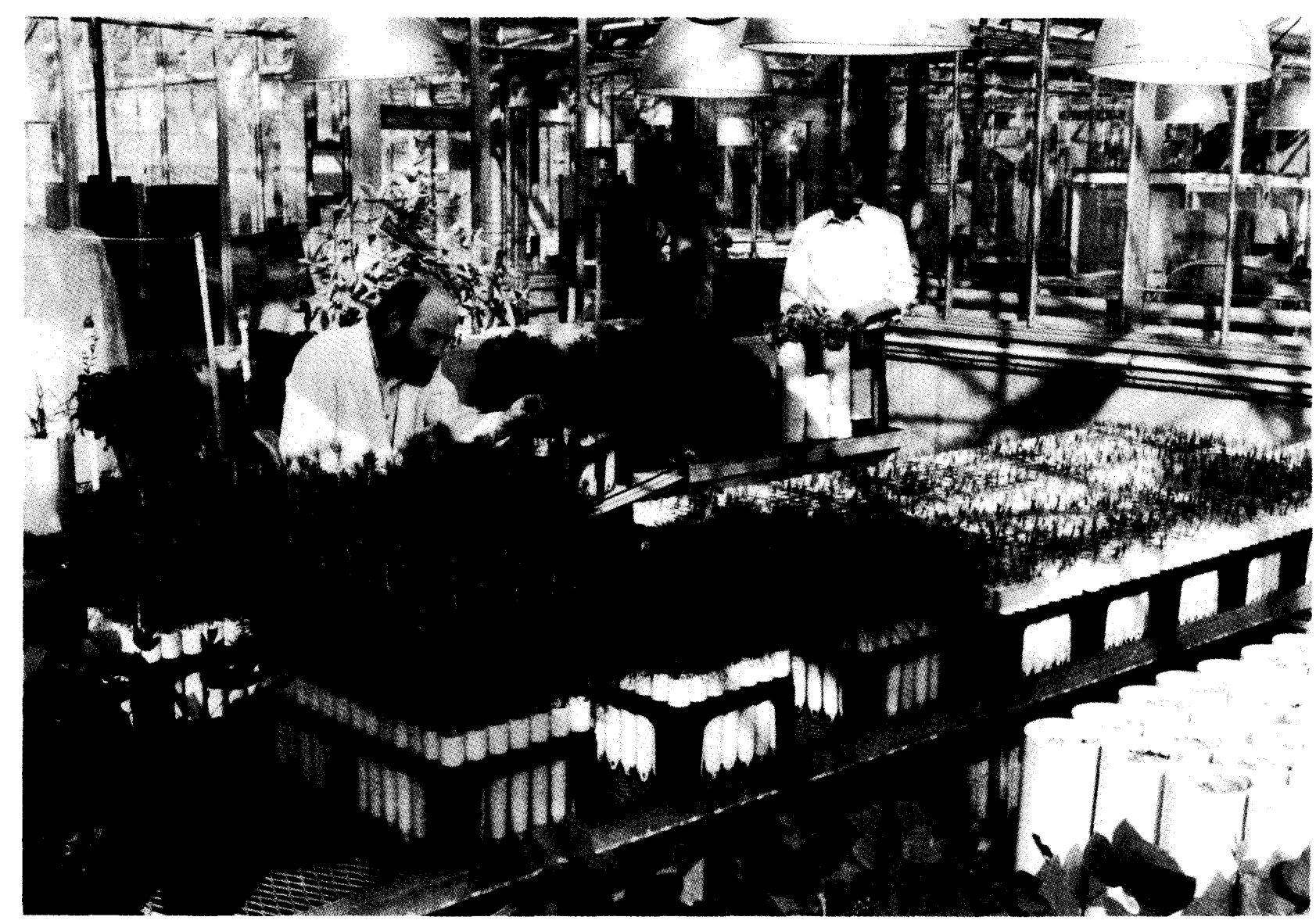

Photo credit: Grady Neely, Environmemal Research Laboratory, U.S. Environmental Protection Agency, Corvallis, OR

Two scientists inspecting yellow-poplars and slash pine for sensitivity to, and symptoms of damage from, ozone exposure uilder controlled experimental conditions.

observable foliar injury [15]. However, no reduction in regionwide average growth rates of sugar maples has been observed in the United States [13].

\section{European Forests}

Forest survey data indicate that 15 percent of the conifers in 17 European countries have lost more needles than normal (i.e., more than 25 percent), and that 17 percent of the deciduous trees have lost more leaves than normal (i.e., more than 10 percent) [27]. Although damage to trees in Europe is popularly attributed to air pollution, other factors are understood to contribute, including climate, soil conditions, and stand aging.

At least in West Germany, the country with the longest forest survey record, the extent of damage appears to have stabilized. Since 1984, the overall percentage of trees in West Germany with more than 25 percent foliar loss has held constant at about 18 percent. In fact, the condition of some species, and of trees in some regions, has improved [6].

The most significantly affected species in central Europe is Norway spruce, which comprises about 40 percent of central European forests. Needle chlorosis associated with magnesium deficiency in foliage and soils is the most prominent symptom observed in Nonway spruce growing at high elevations, while thinning of tree crowns is the main symptom observed at lower elevations [33]. Poor soil conditions and magnesium deficiency have also been observed in association with chlorosis in Norway spruce at some sites in the United States [17]. 


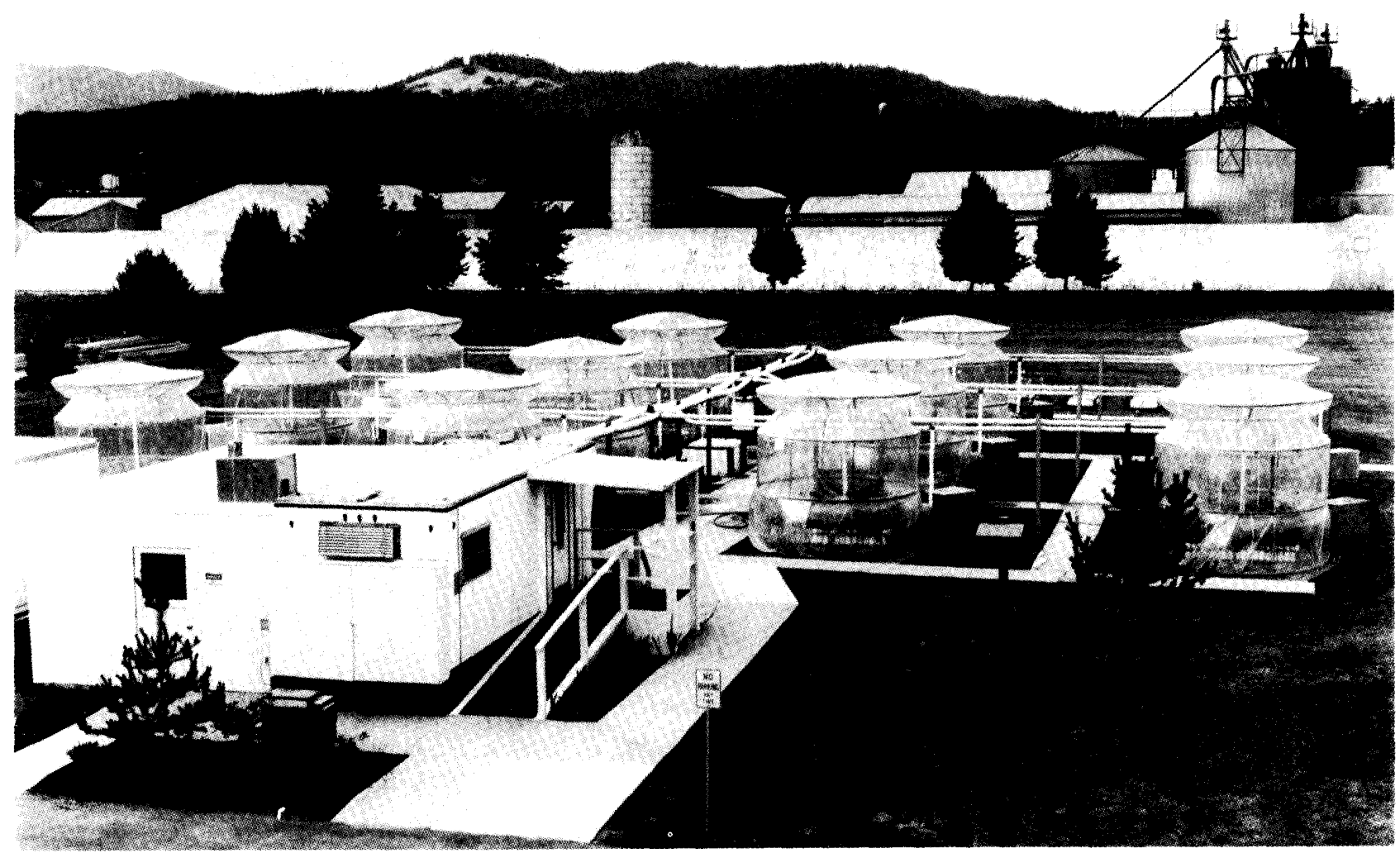

Photo credit: Grady Neely, Environmental Research Laboratory, US. Environmental Protection Agency, Corvallis, OR

Outdoor exposure chambers are used to study the effects of ozone on various crop and tree species under controlled experimental conditions.

One hypothesis that has been suggested to explain the chlorotic symptoms of high-elevation Norway spruce was that chronic exposure to ozone might damage cell membranes, exacerbating nutrient losses, which might also be occurring due to the leaching action of acidic deposition. If uptake from the soil was inadequate to replenish essential nutrients, damage might result [33]. However, laboratory studies testing this hypothesis have not reproduced the symptoms observed in the field, and some scientists now discount it [6].

\section{EFFECTS OF OZONE ON CROPS}

In annual crops, visible symptoms of exposure to ozone typically include light flecks, dark stipples, and yellow spots or patches on leaves. Chronic exposure to ozone can induce premature aging and loss of foliage. The minimum concentrations of ozone that produce acute foliar injury in susceptible plants exposed for 4 hours range from 0.04 to 0.09 ppmn, depending on the plant species [14]. Among other environmental factors, light conditions, temperature, relative humidity, and soil water content affect how plants respond to ozone exposures.

For field and cash crops, the most important responses to ozone are reduced growth rates and yields. These effects may occur without the visible injury usually associated with exposure to ozone, but they are often accompanied by premature loss of foliage. Reduced growth and yields result primarily from reduced photosynthesis and transport of carbohydrates within plants. Table 4-1 displays reductions in yields predicted to occur for various crops exposed over the growing season to average daily 7-hour mean ozone concentrations of 0.04 and 0.06 ppm [43]. The predictions are from the National Crop Loss Assessment Network (NCLAN), an 8 -year study in which crops were grown in the field 


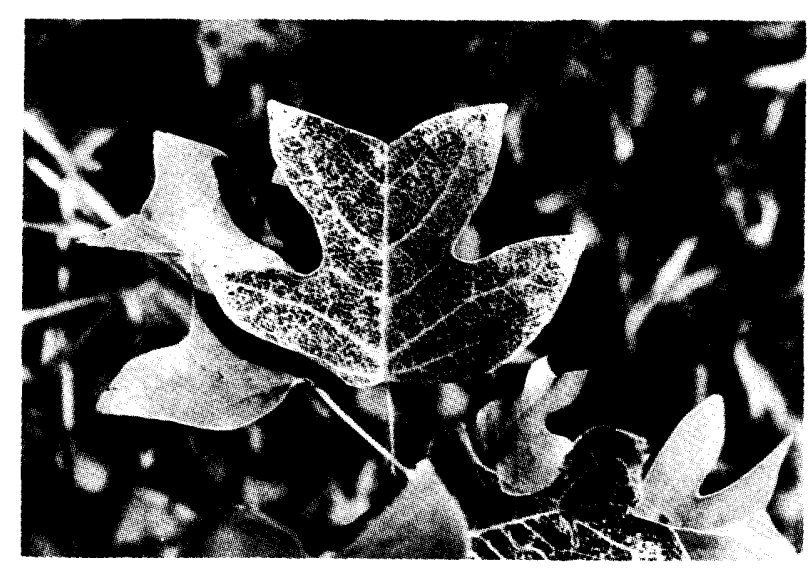

Photo credit: U.S. Department of Agriculture

Dark pigmented stipple on upper surface and general chlorosis of yellow-poplar leaves exposed to ozone.

either in ambient air, air that had been filtered to remove ozone, or air to which extra ozone had been added. The reductions shown in the table are relative to the yields obtained for crops exposed to assumed background ozone concentrations. The range of reductions given for each crop indicates differences among varieties. In addition to the major crops listed in table 4-1, yield reductions have been seen with a wide variety of other crops including alfalfa, clover, sorghum, barley, dry bean, root crops, tomatoes, spinach, lettuce, and other produce.

Figure 4-3 shows State-level production of each of the four crops listed in table 4-1. As shown in figure 4-1, daytime, growing-season average concentrations of $0.04 \mathrm{ppm}$ were widely exceeded over the 1978-82 period, and a few locations saw concentrations higher than $0.06 \mathrm{ppm}$. Due to year-toyear variability in weather, concentrations at a given site would be higher in some years and lower in others, if data for individual years were shown [32]. Elevated ozone concentrations throughout the South may damage cotton. The major soybean-producing regions of the Mississippi and Ohio River valleys and corn-producing regions throughout the eastern half of the United States are also exposed. Unfortunately, only scant ozone data are available for most areas where wheat is grown.
Table 4-I-Yield Losses Predicted to Occur for Seasonal Average 7-hour Mean Ozone Concentrations of 0.04 and 0.06 ppm

\begin{tabular}{|c|c|c|}
\hline Crop & $\begin{array}{l}0.04 \text { ppm ozone } \\
\text { percent yield reduction }\end{array}$ & $\begin{array}{l}0.06 \text { ppm ozone } \\
\text { percent yield reduction }\end{array}$ \\
\hline Cotton & 4.6 to 16 & 16 to 35 \\
\hline Wheat ........ & 0.0 to 29 & 0.9 to 51 \\
\hline Soybeans & 1.7 to 15 & 5.3 to 24 \\
\hline Corn ...... & 0.0 to 1.4 & 0.3 to 5.1 \\
\hline \multicolumn{3}{|c|}{$\begin{array}{l}\text { NOTE: As shown in figure } 4-1 \text {, the } 0.04 \mathrm{ppm} \text { level exceeded overlarge portions of the } \\
\text { southern and Eastern United States. The } 0.06 \mathrm{ppm} \text { level is more extreme, with } \\
\text { few areas having multi-year averages that reach it. }\end{array}$} \\
\hline \multicolumn{3}{|c|}{$\begin{array}{l}\text { SOURCE: U.S. Environmental Protection Agency, Office of Air Quality Planning and } \\
\text { Assessment "Review of the National Ambient Air Quality Standards for } \\
\text { Ozone Preliminary Assessment of Scientific and Technical Information," } \\
\text { draft staff paper (Research Triangle Park, NC: November 1987). }\end{array}$} \\
\hline
\end{tabular}

\section{Economic Estimates of Agricultural Benefits}

By using relationships between ozone levels and crop yields estimated from the NCLAN experiments, together with models of the Nation's agricultural economy, it is possible to estimate how much crop producers and consumers would benefit from reducing ozone. If ozone concentrations were reduced, crop yields would increase and prices fall, benefiting consumers (and some livestock producers). Crop producers' profits could either rise or fall, depending on whether local yield increases reduced their unit production costs enough to offset the lower prices they would receive. Crop producers in areas where ozone concentrations are currently highest would benefit the most from nationwide reductions, or conversely continue to incur the largest losses if concentrations are not reduced.

In this section we present estimates of the agricultural benefits of a range of plausible reductions in ozone, based on models developed by two different groups of researchers $(21,1)$. At present, it is not possible to reliably predict the impact that VOC and $\mathrm{NO}_{\mathrm{x}}$ control measures would have on ozone concentrations in rural areas. So, for the purposes of this analysis, we assume that currently available control measures could reduce rural ozone concentrations by some amount between 10 and 50 percent of the way to an estimated background concentration of $0.030 \mathrm{ppm}$.

The two models used to estimate agricultural benefits for this report use different exposure-

\footnotetext{
${ }^{5}$ This estimate is based on surface measurements at rural cites in Canada [23]. The appropriate concentration to use for background is very uncertain, so calculations were performed to investigate the sensitivity of the benefits estimates to this parameter.
} 
Figure 4-3-1984 Crop Production at the State Level
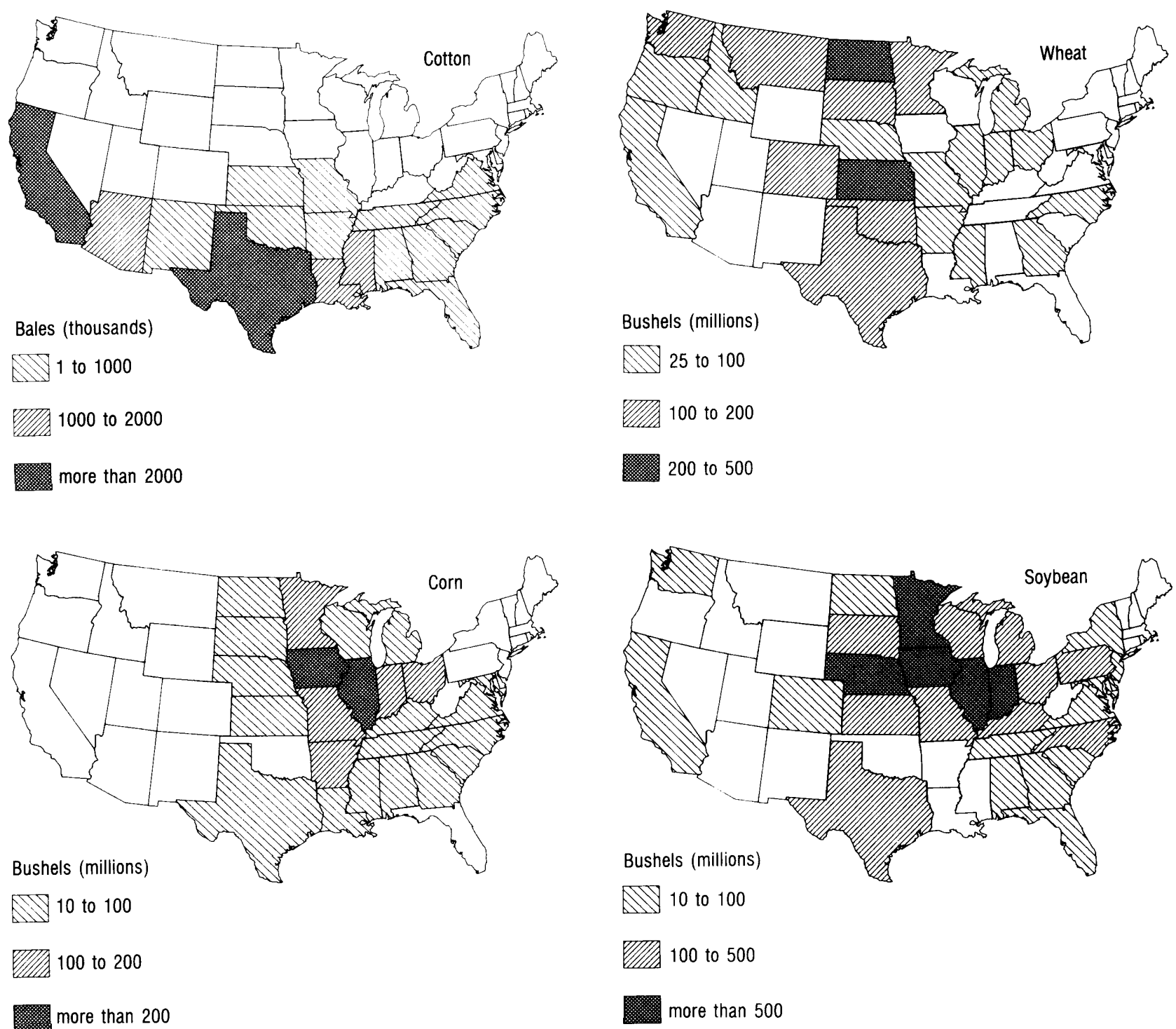

SOURCE: U.S. Department of Agriculture, Agricultural Statistics 1965 (Washington, DC: U.S. Government Printing Office, January 1980).

response functions (mathematical expressions of the relationship between ozone concentrations and crop yields) and economic parameters, and base case ozone concentrations from different years. They also adopt different assumptions about how farmers will change the number of acres of each crop that they plant in order to optimize their operations, as crop prices decline in response to higher yields and increased production.

\section{Agricultural Benefits of Reducing Ozone By 10 to 50 Percent}

Estimates of agricultural benefits associated with reductions in ozone of 10,25 , and 50 percent of the difference between base levels and background, are given in table 4-2. Both sets of estimates include benefits associated with corn, soybean, wheat, cotton, barley, alfalfa, and sorghum production and 
Table 4-2-Estimates of Agricultural Benefits That Would Result Under Market Conditions, if Ozone Concentrations Ware To Be Reduced Nationwide by the indicated Amounts Relative to a Background Concentration of $0.03 \mathrm{ppm}$

\begin{tabular}{|c|c|}
\hline $\begin{array}{l}\text { Ozone } \\
\text { reduction }\end{array}$ & $\begin{array}{l}\text { Krupnick and Kopp Adams and Glyer } \\
(\$ \text { millions [19861) (\$ millions [19861) }\end{array}$ \\
\hline $10 \%$ & 230 \\
\hline $5 \%$ & 990 \\
\hline $0 \%$. & 1910 \\
\hline \multicolumn{2}{|c|}{$\begin{array}{l}\text { SOURCES: A.J. Krupnick and R.J. Kopp, The Health and Agricultural Benefits of } \\
\text { Reductions in Ambient Ozone in the United States, contractor repor } \\
\text { prepared for the Office of Technology Assessment, June 1988. R.M } \\
\text { Adams and J.D. Glyer, An Assessment of the Agricultural Benefits of } \\
\text { Tropospheric Ozone Reductions Using Office of Technology Assessmen } \\
\text { (OTA) Assumptions, contractor report prepared for the Office of Technol- } \\
\text { ogy Assessment, August 1988. }\end{array}$} \\
\hline
\end{tabular}

consumption. Krupnick and Kopp's estimates also include benefits for oats and peanuts. Adams and Glyer's estimates additionally include benefits for grass-legume hay and rice. Crops that are important in limited areas, like citrus fruit and produce grown in Florida and California, were not included.

As shown in table 4-2, the estimates of total benefits range from $\$ 230$ million per year for a 10 percent reduction in ozone to about $\$ 1.9$ billion per year for a 50 percent reduction. ${ }^{7}$ In all cases, corn, soybeans, wheat, and cotton account for over 90 percent of the total benefits. At each reduction level, Adams and Glyer's estimates of total benefits are almost double Krupnick and Kopp's estimates. An important result predicted by Krupnick and Kopp is that on a nationwide basis, crop producers might suffer a net loss due to lower prices, if ozone concentrations are reduced. Adams and Glyer's model lumps livestock producers (who benefit from reduced feed prices) together with crop producers, and predicts that together they would benefit. It is not possible to separate crop producers from livestock producers, in Adams and Glyer's model.

Underlying the nationwide estimates are benefits to crop producers that vary by region. The largest improvements in yields in both analyses occur in
California, the South, and the Northeast, where ozone concentrations in agricultural areas are currently highest. Accordingly, crop producers in these areas would benefit the most from reducing ozone. For the 25-percent reduction scenario, for example, in Adams and Glyer's analysis, corn yields increase by about 3 percent or more in California and in some Northeastern States, whereas in some Midwestern States, corn yields increase by half a percent or less.

The first reason for the discrepancy between Adams and Glyer's and Krupnick and Kopp's results is the different changes in yields that are predicted in the two analyses, due to their use of different baseline ozone concentrations and different exposureresponse functions. Comparing them on a State-byState basis, for the 25-percent reduction scenario, the yield changes for corn tend to be about 3 times larger, for cotton and wheat about 2 times larger, and for soybeans about 2.5 times larger, in Adams and Glyer's analysis than in Krupnick and Kopp's. Baseline ozone concentrations were generally higher (uncertainties in the baseline ozone concentrations are discussed in a subsequent section), and crop yields more sensitive to ozone (as shown for corn in figure 4-4), in Adams and Glyer's analysis than in Krupnick and Kopp's.

The exposure-response functions used by Krupnick and Kopp were estimated by averaging results from NCLAN experiments conducted through 1982. Additional experiments conducted by NCLAN through 1986 were also averaged into the exposure-response functions used by Adams and Glyer. Some of the crop varieties used in the later experiments were apparently more sensitive to changes in ozone concentrations than those tested earlier [20]. Incorporating the more recent data, the exposure-response functions used by Adams and Glyer represent a broader sample of the crop varieties grown in the United States than those used by Krupnick and Kopp. However, it is not clear how

6Yield losses due to ozone at current levels may be significant for some of these crops. For example, yield reductionsof almost 20percent are estimated for California oranges, grapes, and lemons, compared to yields with 12-hour seasonal average ozone concentrations of $0.025 \mathrm{ppm}$ [29].

${ }^{7}$ Previous analyses have estimated that if ozone concentrations in rural areas were reduced by a straight 25 percent, without adjusting for background ozone, total benefits would be on the order of $\$ 2$ billion per year [3,18,2]. The estimates of the benefits of reductions above a 0.030 ppm background given here are roughly consistent with previous estimates, since ozone is reduced by smaller absolute amounts in our scenarios. For example, for an initial ozone concentration of $0.045 \mathrm{ppm}$, the change in the ozone concentration corresponding to a straight 25-percent reduction would be three times larger than that corresponding to a reduction of 25 percent of the way to a background concentration of $0.030 \mathrm{ppm}$.

${ }^{8}$ Adams and Glyer [ 1 ] used base case ozone concentrations averaged over the period 19 81-83. Krupnick and Kopp [21] used concentrations averaged over the period 1979-82. 


\section{Figure 4-4-Dose-Response Functions for Corn Used in the Two Agricultural Benefits Analyses Performed for OTA}

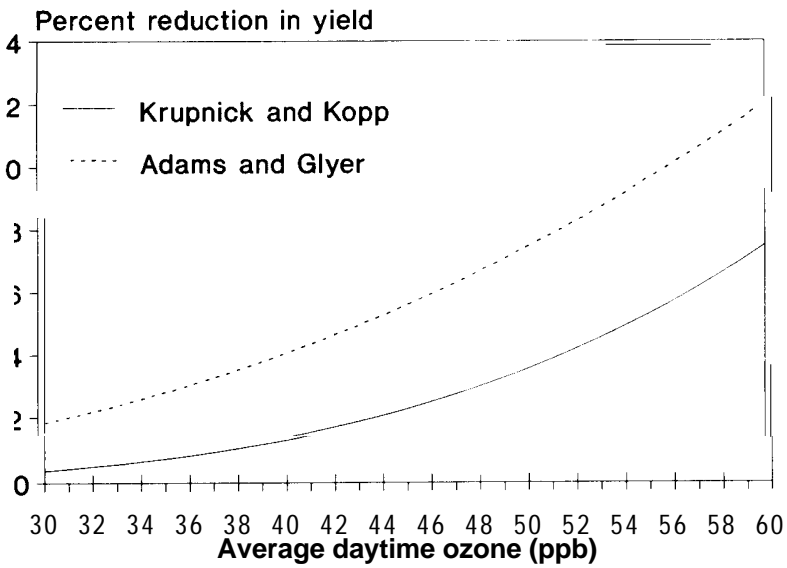

The dose-response function used by Krupnick and Kopp was estimated from experiments conducted by the National Crop Loss Assessment Network through 1981. The function used by Adams and Glyer was estimated from experiments conducted through 1986.

SOURCE: A.J. Krupnick and R.J.Kopp, The Health and Agricultural Benefits of Roductions In Ambiont Ozono in tho Unilod Stmites, contractor roport prepared for the Office of Technology Assessment, June 19S8; and A.M. Adams and J.D. Glyer, An Assessment of the Agriculhural Benefits of Tropospheric Ozone Reductions Using Office of Technology Assessmen (OTA) Assumptions, contractor report prepared for the Office of Technology Assessment August 19SS.

well the exposure-response functions used by either group represent the average responses of the actual mix of varieties planted by farmers.

The structure and assumptions of the economic components of their models is also a reason for discrepancy between Adams and Glyer's and Kopp and Krupnick's results. First, Adams and Glyer's model is based on economic conditions for the 1981-83 period, whereas Krupnick and Kopp's model reflects the target price provisions established by the Food Security Act of 1985 for crops grown in 1986. Incorporating 1986 target prices into Adams and Glyer's analysis reduces their total benefits by about 10 percent, to $\$ 880$ million.

Finally, as ozone concentrations are reduced and crop prices tend to decline in response to higher yields, Adams and Glyer assume that farmers would change the number of acres sown with each crop to maximize their profits under the new conditions. Krupnick and Kopp assume that planted acreage would stay constant at 1986 (base case) levels. Krupnick and Kopp's assumption seems reasonable in the short term, before a steady trend in market prices is observable. So the prediction that producers would not gain from reducing ozone seems to be reasonable for the first few years after ozone concentrations are reduced. Adams and Glyer's assumption that farmers will eventually adjust their acreage seems more reasonable as a prediction of what would occur after several years if ozone concentrations remain low.

\section{Agricultural Benefits Under Current Price Support Programs}

In order to stabilize supplies and prices, and to supplement farmers' incomes, the Federal Government currently pays farmers the difference between the price they obtain on the market and a higher "target" price established by law, for several major crops. The target prices encourage surplus production, at some expense to society because the cost of producing the surplus exceeds its value. Increased yields due to reduced ozone can be viewed as adding to the surplus, and some economists argue that the benefits estimates presented in the previous section need to be adjusted for this effect. Given 1986 target prices, and adjusting the benefits estimates to account for the loss to society associated with surplus production, Krupnick and Kopp estimate that for corn, cotton, soybeans, and wheat, the benefits of the 25-percent reduction scenario would be $\$ 380$ million, about 20 percent lower than the benefits associated with those four crops when the cost of the surplus is not taken into account. However, others argue that subsidy programs could be adjusted to reflect the yield changes, so that surpluses would not necessarily increase above desirable levels [24].

\section{Sensitivity of Benefits to Uncertainty in Ozone Concentrations in Agricultural Areas}

An important source of uncertainty in agricultural benefits is the estimation of current ozone concentrations in areas across the country where crop production takes place. Baseline ozone concentrations are estimated by extrapolating from both suburban and rural monitors to agricultural areas. Unfortunately,

\footnotetext{
9In order to stabilizesuppliesandprices, and to supplement farmers' incomes, the Federal Government currently pays farmers the difference between the price they obtain on the market and a higher "target" price established by law, for several major crops.
} 
in many States, appropriate data are only available from one or two monitors, and significant errors are apt to be introduced by extrapolating from these data [22]. The natural background concentration of ozone is also uncertain, because it cannot be measured anywhere-areas that are similar to the continental United States are invariably affected by human activity. When the benefits of a 25 -percent reduction in ozone were recalculated with $0.005 \mathrm{ppm}$ either uniformly added to or subtracted from the baseline concentrations, the total benefits were correspondingly increased or reduced by about 50 percent. A similar degree of sensitivity to the assumed background ozone concentration was found.

\section{REFERENCES FOR CHAPTER 4}

1. Adams, R. M., and Glyer, J. D., An Assessment of the Agricultural Benefits of Tropospheric Ozone Reductions Using Office of Technology Assessment (OTA) Assumptions, contractor report prepared for the Office of Technology Assessment, August 1988.

2. Adams, R.M., Glyer, J.D., Johnson, S.L., and McCarl, 13. A., A Reassessment of the Economic Effects of Ozone on U.S. Agriculture (Corvallis, OR: Oregon State University, 1988).

3. Adams, R. M., Hamilton, S. A., and McCarl, B. A., The Economic Effects of Ozone on Agriculture, EPA report No. EPA-600/3-84-090 (Corvallis, OR: U.S. Environmental Protection Agency, 1984).

4. Bennett, J. F., Status of Eastern White Pine Project: A Progress Report (Research Triangle Park, NC: U.S. Department of Agriculture, 1987), as cited in NAPAP, 1987.

5. Benoit, L. F., Skelly, J. M., Moore, L. D., and Dochinger, L. S., "Radial Growth Reductions of Pinus Strobus L. Correlated With Foliar Ozone Sensitivity as an Indicator of Ozone-Induced Losses in Eastern Forests," Canadian J. Forest Research 12:673-678, 1982.

6. Blank, L. W., Roberts, T.M., and Skeffington, R.A., "Commentary: New Perspectives on Forest Decline," Nature 336:27-30, 1988.

7. Bradford, B., Alexander, S.A., and Skelly, J. M., "Determination of Growth Loss of Pinus Taeda L. Caused by Heterobasidion Annosus (Fr.) Bref.," European J. Forest Pathology 8:129-134,1978.

8. Darwin, R. F., Nesse, R.J., and Callaway, J. M., Economic Effects of Hypothetical Reduction in Tree Growth in the Northeastern and Southeastern United States (Richland, WA: Pacific Northwest Laboratory, August 1986).
9. Dull, C. W., Ward, J. D., Brown, H. D., Ryan, G. W., Clerke, W. H., and Uhler, R. J., Evaluation of Spruce and Fir Mortality in the Southern Appalachian Mountains, Protection Report R8-PR13 (U.S. Department of Agriculture, Forest Service Southern Region, October 1988).

10. Heck, W. W., Cure, W.W., Rawlings, J. O., Zaragoza, L.J., Heagle, A. S., Heggestad, H. E., Kohut, R.J., Kress, L. W., and Temple, P.J., "Assessing Impacts of Ozone on Agricultural Crops: II. Crop Yield Functions and Alternative Exposure Statistics," $J$. Air Pollution Control Association 34:810-817, 1984.

11. Heck, W. W., U.S. Department of Agriculture, personal communication, March 25, 1988.

12. Hertel, G.D., Spruce-Fir Research Cooperative Technical Report (U.S. Department of Agriculture, March 1988).

13. Hornbeck, J. W., Smith, R. S., and Federer, C. A., "Extended Growth Decreases in New England Are Limited to Red Spruce and Balsam Fir," Proceedings, International Symposium on Ecological Aspects of Tree-Ring Analysis (Palisades, NY: LamontDoherty Geological observatory, 1987), as cited in NAPAP, 1987.

14. Jacobson, J. S., "The Effects of Photochemical Oxidants on Vegetation," Ozon und Begleitsubstanzen irn Photochemishen Smog, VDI colloquium (Dusseldorf, West Germany: Verein deutscher Ingenieure (VDI) GmbH, 1976), pp. 163-173, as cited in U.S. EPA, 1987.

15. Jensen, K. F., and Dochinger, L. S., "Response of Eastern Hardwood Species to Ozone, Sulfur Dioxide and Acid Precipitation," paper 88-70.3, presented at the 81st Meeting of the Air Pollution Control Association (Dallas, TX: June 1988).

16. Johnson, A. H., and McLaughlin, S. B., "The Nature and Timing of the Deterioration of Red Spruce in the Northern Appalachian Mountains," Acid Deposition: Long-term Trends (Washington, DC: National Academy Press, 1986).

17. Ke, J., and Skelly, J.M., "An Evaluation of Norway Spruce in the Northeastern United States, " presented at the International Union of Forest Research Organizations Symposium (Interlaken, Switzerland: Oct. 20-21, 1988).

18. Kopp, R.J., Vaughan, W.J., and Hazilla, M., Agricultural Sector Benefits Analysis for Ozone: Methods Evaluation and Demonstration, EPA report No. EPA-450/5-84-O03 (Research Triangle Park, NC: U.S. Environmental Protection Agency, 1984).

19. Kress, L.W., Allen, H. L., Mudano, J. E., and Heck, W. W., "Response of Loblolly Pine to Acidic Pre- 
cipitation and Ozone, " paper 88-70.5, presented at the 81st Meeting of the Air Pollution Control Association (Dallas, TX: June 1988).

20. Kress, Lance, U.S. Department of Agriculture, personal communication, December 1988.

21. Krupnick, A.J., and Kopp, R.J., The Health and Agricultural Benefits of Reductions in Ambient Ozone in the United States, contractor report prepared for the Office of Technology Assessment, June 1988.

22. Lefohn, A. S., Knudsen, H. P., Logan, J. A., Simpson J., and Bhumralkar, C., "An Evaluation of the Kriging Method to Predict 7-h Seasonal Mean Ozone Concentrations for Estimating Crop Losses," J. Air Pollution Control Association 37:595-602,1987.

23. Logan, J. A., "Tropospheric Ozone: Seasonal Behavior, Trends, and Anthropogenic Influence, " J. Geophysical Research 90:10463-10482, 1985.

24. Madriaga, B., "Ambient Air Quality Standards for U.S. Agriculture: The Correct Welfare Measure Revisited," J. Environmental Management 27:421427, 1988.

25. McBride, J. R., Miller, P.R., and Laven, R. D., "Effects of Oxidant Air Pollutants on Forest Succession in the Mixed Conifer Forest Type of Southern California\%" Proceedings of the Symposium on Air Pollutants Effects on Forest Ecosystems (St. Paul, MN: Acid Rain Foundation, 1985), as cited in NAPAP, 1987.

26. National Acid Precipitation Assessment Program, Interim Assessment: The Causes and Effects of Acidic Deposition, vols. III and IV (Washington, DC: October 1987).

27. Nilsson, S., and Duinker, P., "The Extent of Forest Decline in Europe, " Environment 29:4-9 and 30-31, 1987.

28. Olson, R.J., Allison, L.J., and McCullough, I.L., Addnet Notebook: Documentation of the Acid Deposition Data Network (ADDNET) Data Base Supporting the National Acid Precipitation Assessment Program, Environmental Sciences Division publication No. 2755 (Oak Ridge, TN: Oak Ridge National Laboratory, August 1987),

29. Olszyk, D.M., Cabrera, H., and Thompson, C.R., "California Statewide Assessment of the Effects of Ozone on Crop Productivity," J. Air Pollution Control Association 38:928-931,1988.

30. The Pennsylvania State University, Department of Plant Pathology,

Diagnosing Injury to Eastern Forest Trees (University Park, PA: 1987).

31. Peterson, D. L., Arbaugh, M.J., Wakefield, V. A., and Miller, P.R., "Evidence of Growth Reduction in Ozone-Stressed Jeffrey Pine (Pinus Jeffreyi Grev. and Balf.) in Sequoia and Kings Canyon National Parks," J. Air Pollution Control Association 37:906912, 1987.

32. Pinkerton, J. E., and Lefohn, A. S., "The Characterization of Ozone Data for Sites Located in Forested Areas of the Eastern United States," J. Air Pollution Control Association 37:1005-1010,1987.

33. Prinz, B., "Causes of Forest Darnage in Europe," Environment 29:1 1-15 and 32-37, 1987.

34. Reich, P, B., and Arnundson, R. G., "Ambient Levels of Ozone Reduce Net Photosynthesis in Tree and Crop Species," Science 230:566-570, 1985.

35. Reinert, R. A., Shafer, S.R., Eason, G., Horton, S.J., Schoeneberger, M.M., and Wells, C., "Responses of Loblolly Pine Half-Sib Families to Ozone," paper 88-125.2, presented at the 81st Meeting of the Air Pollution Control Association (Dallas, TX: June 1988).

36. Shafer, S. A., Heagle, A. S., and Camberato, D. M., "Effects of Chronic Doses of Ozone on Field-grown Loblolly Pine: Seedlings Response in the First Year," J. Air Pollution Control Association 37:1 1791184, 1987.

37. Shafer, S. A., and Heagle, A. S., "Responses of Field Grown Loblolly Pine to Chronic Ozone During Multiple Growing Seasons," Canadian J. Forest Research, in press, 1989.

38. Sheffield, R. M., Cost, N. D., Bechtold, W.A., and McClure, J. P., Pine Growth Reductions in the Southeast, Research Bulletin SE-83 (U.S. Department of Agriculture, Forest Service Southeast Forest Experiment Station, 1985), as cited in NAPAP, 1987.

39. U.S. Department of Agriculture, An Assessment of the Forest and Range Lund Situation in the United States (Washington, DC: U.S. Government Printing Office, January 1980).

40. U.S. Department of Agriculture, Agricultural Statistics 1985 (Washington, DC: U.S. Government Printing Office, 1985).

41. U.S. Department of the Interior, testimony, Impacts of Air Pollution on National Park Units: Hearings Before the Subcommittee on National Parks and Recreation of the House Committee on Interior and Insular Affairs, 99th Cong., 1st sess., 535-538, 1985.

42. U.S. Department of the Interior, National Park Service, Air Quality in the National Parks, Natural Resources Report 88-1 (Denver, CO: July 1988).

43. U.S. Environmental Protection Agency, Office of Air Quality Planning and Assessment, Review of the National Ambient Air Quality Standards for Ozone Preliminary Assessment of Scientific and Technical [formation, draft staff paper (Research Triangle Park, NC: November 1987). 
44. U.S. Environmental Protection Agency, Office of Health and Environmental Assessment, Summary of Selected New Information on Effects of Ozone on Health and Vegetation: Draft Supplement to Air Quality Criteria for Ozone and Other Photochemical Oxidants, EPA report No. EPA/600/8-88-105A (Washington, DC: November 1988).
45. Woodman, J.N., and Cowling, E. B., "Airborne Chemicals and Forest Health," Environmental Science and Technology 21 :120-126, 1987. 
Chapter 5

\section{Lowering Ozone: Effect of Controlling Volatile Organic Compounds and Nitrogen Oxides}




\section{CONTENTS}

INTRODUCTION . . , . . . . . . . . . . . . . . . 97

THE RELATIONSHIPS OF VOLATILE ORGANIC COMPOUND AND

NITROGEN OXIDE EMISSIONS TO OZONE . . . . . . . . . . . . . . . . . . . . . . . 97

EFFECT OF CONTROLLING VOLATILE ORGANIC COMPOUNDS . . . . . . . . . . . 99

Local Volatile Organic Compound Reductions Required To Meet the Standard . . . . . 99

The Effect of Lowering Volatile Organic Compound Emissions by 35 Percent . . . . . 100

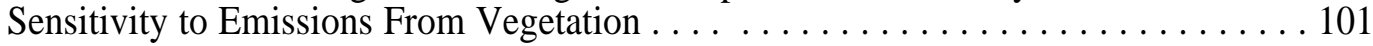

EFFECT OF CONTROLLING NITROGEN OXIDES . . . . . . . . . . . . . . . 101

Balance of Volatile Organic Compounds and Nitrogen oxides . . . . . . . . ...... 101

The Effects of Nitrogen Oxide Controls in Urban Areas . . . . . . . . . . . . . 102

Combined Volatile Organic Compound and Nitrogen Oxide Control in the

Northeast . . . . . . . . . . . . . . . . . . . . . . . . . . . . . . . . . . . . . . 102

RURAL OZONE, TRANSPORTED OZONE AND PRECURSORS . . . . . . . . . 106

Transported Ozone and precursors . . . . . . . . . . . . ......106

Regional Episodes . . . . . . . . . . . . . . . . . . . . . . . . 106

Reducing Rural Ozone ... ... . . . . . . . . . . . . . . . . . . . . . . . . 107

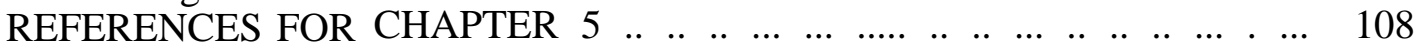

\section{Figures}

Figure

5-1. VOC Emissions Reductions Estimated To Be Required to Reduce Ozone From the Initial Peak Concentrations or 'Design Values" Show, Down to 0.12 ppm......100

5-2. Ozone Concentrations Predicted To Result When VOC Emissions Are Reduced by 35 Percent with No Change in $\mathrm{NO}_{\mathrm{x}}$ Emissions Levels... . . . . . . . . . . . . 101

5-3. Change in Peak Ozone Concentrations in the Los Angeles Basin, Predicted

to Result From Reducing $\mathrm{NO}_{\mathrm{x}}$ Emissions by 35 Percent Below 1982 Levels . . . . . 103

5-4. Region Covered by the U. S. Environmental Protection Agency's Regional

Oxidant Model (ROM)

\section{Tables}

Table

5-1. Predicted Effect of VOC-Alone and Combined VOC and $\mathrm{NO}_{\mathrm{x}}$ Control Strategies in Northeaster Cities, Over a 16-Day Period in July 1980

5-2. Predicted Effects of VOC-Alone and Combined VOC and $\mathrm{NO}_{\mathrm{x}}$ Controls in the Hartford, New York City, and Pittsburgh Areas, Over a 16-DayPeriodin July 1980 .

5-3, Predicted Effect of VOC-Alone and Combined VOC and $\mathrm{NO}_{\mathrm{x}}$ Control Strategies in Nonurban Areas of the Northeast, Over a 16-Day Period in July 1980 


\section{Lowering Ozone: Effect of Controlling Volatile Organic Compounds and Nitrogen Oxides}

\section{INTRODUCTION'}

Ozone is not emitted; rather it is produced in the atmosphere from reactions involving two " precursor" pollutants: volatile organic compounds (VOCs) and nitrogen oxides $\left(\mathrm{NO}_{\mathrm{x}}\right)$. To develop effective strategies for reducing ozone, an understanding of the complex relationship between ozone concentrations and VOC and $\mathrm{NO}_{\mathrm{x}}$ emission levels is needed. Unfortunately, our ability to predict the effectiveness of control strategies is limited by uncertainties in emissions inventories, especially for VOCs (see chapter 6); lack of atmospheric concentration data for VOCs, $\mathrm{NO}_{\mathrm{x}}$, and rural ozone; and deficiencies in air quality models that have been applied to most cities. Moreover, generalizations are difficult to make because of the fact that the relationship depends strongly on local conditions such as topography, and spatial distributions and types of emission sources, which vary from one city to another, and on meteorological conditions that vary from day-to-day.

The focus of efforts to reduce urban ozone has historically been on controlling local VOC emissions. We assume that this focus will be continued. However, as discussed in chapter 6 , we project that in many cities, currently available VOC control measures will fall short of providing the reductions needed to meet the ozone standard. In some cases, controlling $\mathrm{NO}_{\mathrm{x}}$ emissions in addition to VOCs might reduce ozone more than controlling VOC emissions alone. In other situations, however, a combined strategy of $\mathrm{NO}_{x}$ and VOC controls might actually reduce peak ozone less than reducing VOCs alone. For many cities, the modeling and data gathering needed to reliably predict whether $\mathrm{NO}_{x}$ controls would be helpful have yet to be done. Reducing emissions in upwind areas as well as locally might also help reduce peak ozone concentrations in some nonattainment cities. Some studies have indicated where controls in upwind areas might be important, but we cannot yet quantify how much they would help.
To date, no control efforts have been undertaken expressly to reduce ozone concentrations in rural areas. However, a few recent modeling studies have attempted to simulate rural conditions. The studies suggest preliminarily that outside of pollution plumes downwind of urban and industrial areas, reducing $\mathrm{NO}_{\mathrm{x}}$ emissions will generally be a more effective strategy for lowering ozone than reducing VOC emissions.

In this chapter, we first present an overview of the relationship between ozone levels and VOC and $\mathrm{NO}_{\mathrm{x}}$ emissions. We then present estimates of the amounts that VOC emissions need to be reduced to enable cities with different design values to meet the ozone standard, and the amount that ozone concentrations could be reduced in these cities using available VOC control measures. The question of whether reducing $\mathrm{NO}_{\mathrm{x}}$ emissions in addition to VOCs is likely to be beneficial or not is considered next. After that we look at the role of transported ozone and precursors. Finally, we discuss how VOC and $\mathrm{NO}_{\mathrm{x}}$ emission reductions might affect ozone in rural areas, where it can damage trees and annual crops.

\section{THE RELATIONSHIP OF VOLATILE ORGANIC COMPOUND AND NITROGEN OXIDE EMISSIONS TO OZONE}

Ozone is produced through chemical reactions involving nitrogen oxides and volatile organic compounds. 'Ozone concentrations tend to be highest on hot, sunny days for three reasons: 1) the chemical reactions depend on sunlight and temperature; 2) emissions from some sources increase with outdoor temperatures; and 3) stagnant air that tends to limit pollutant dispersal is often associated with high temperatures. Ozone concentrations exceeding the standard occur almost exclusively between May and September in most areas of the United States, although California and the gulf coast have longer seasons with high ozone [32]. The highest concen-

${ }^{1}$ Carbon monoxide and methane are also involved in ozone production. However, $\mathrm{NO}_{\mathrm{x}}$ and $\mathrm{VOCs}$ are most important in urban areas. 
trations are often observed after more than 1 day of hot, sunny conditions. Multi-day episodes can lead to concentrations that approach or even exceed the ozone standard over large areas of the Eastern United States, encompassing rural areas as well as cities [35,36,37]. Ozone levels observed at a given location can be influenced significantly by transported pollutants as well as local emissions. Plumes of elevated ozone concentrations have been observed 200 or more miles downwind of urban areas, under some circumstances [21,8,30].

Nitrogen oxides are products of fossil fuel combustion. On a nationwide basis, approximately 35 percent of $\mathrm{NO}_{\mathrm{x}}$ emissions are from highway vehicles, another 35 percent are from utilities, and 12 percent are from industrial fuel combustion. $\mathrm{NO}_{\mathrm{x}}$ emissions from natural sources are negligible [16]. About 60 percent of the $\mathrm{NO}_{x}$ in the Northeastern United States is emitted in nonattainment cities. In the South and Midwest, however, most of the $\mathrm{NO}_{\mathrm{x}}$ originates in rural areas or small cities, with only about 30 percent coming from nonattainment areas. $\mathrm{NO}_{\mathrm{x}}$ has an atmospheric lifetime in summer of about 6 to 10 hours [28] and thus is unlikely to be transported more than about 100 miles.

VOCs are a broad class of organic gases such as vapors from solvents and gasoline. In urban areas, approximately 45 percent of manmade VOCS are emitted from highway vehicles, about 25 percent from surface coatings and other organic solvent use, and smaller fractions from other categories including gasoline evaporation from gas stations, solid waste disposal, chemical manufacturing, and petroleum processing. The proportion of manmade VOC emissions originating in nonattainment cities rather than attainment areas varies from 60 percent in the Northeast to about 30 percent in the South. Evaporative emissions of VOCs tend to be especially high ins hot weather.

Individual VOCs differ substantially in how quickly they react in the atmosphere. In summer, the atmospheric lifetimes of common organic gases range from less than an hour to several days [1], and correspondingly, transport distances for various VOCs range from a few to hundreds of miles. The fastest reacting VOCs tend to produce the most ozone, however, so VOCs from distant sources tend to be less important than "fresh" emissions.
Along with manmade sources, trees and other plants also produce VOCs, with especially high emissions in hot weather. Estimates of VOC emissions from vegetation are extremely uncertain-a recent study suggests they might be either high or low by a factor of 3 or more due to questions about emission rate measurements and land use estimates [11]. If current estimates of vegetative emissions are correct, though, totaled over the contiguous 48 States, peak summertime emissions from vegetation exceed manmade VOC emissions by about a factor of 2 [11]. The national totals reflect the vast amount of rural area in the United States where, in summertime, vegetation is the dominant source of VOCs. Vegetative emissions are generally highest in the rural Southeast, but are also high in forested parts of the Southwest, Northwest, and Northeast. In summer in nonattainment areas, we estimate that ratios of manmade-to-vegetative VOC emissions range from about 1 to 1 , in wooded suburbs, to more than 20 to 1 , in densely developed urban cores [11,20]..

A useful way of thinking about how effective VOC and/or $\mathrm{NO}_{\mathrm{x}}$ reductions are likely to be in a given area is to look at the balance in concentrations of VOCs and $\mathrm{NO}_{\mathrm{x}}$ found in the ambient air, given existing emissions levels and pollutant transport from upwind. Generally, VOC reductions are effective and NO, reductions ineffective where the concentration of $\mathrm{NO}_{\mathrm{x}}$ is relatively high compared to the concentration of VOCs (i.e., ozone production is "VOC-limited"). Under such conditions, which are most likely to occur in high emissions areas such as urban or industrial centers, reducing $\mathrm{NO}_{\mathrm{x}}$ can actually increase ozone concentrations. Conversely, $\mathrm{NO}_{\mathrm{x}}$ reductions are most effective and VOC reductions least effective where the concentration of VOCs is relatively high compared to the concentration of $\mathrm{NO}$, (ozone production is $\mathrm{NO}_{\mathrm{x}}$-limited). Conditions tend to be increasingly $\mathrm{NO}_{\mathrm{x}}$-limited as a polluted air mass is transported out over suburban and rural areas downwind of high emissions regions, because chemical and physical processes tend to remove $\mathrm{NO}_{\mathrm{x}}$ more rapidly than VOCs. Although measurements are sparse, conditions in rural areas tend to be $\mathrm{NO}_{\mathrm{x}}$-limited $[1,31,10]$.

The relationship between ozone and its precursors is actually much more complicated than implied by the simple description of VOC-limited $\mathrm{v}$. $\mathrm{NO}_{\mathrm{x}^{-}}$ limited conditions. Atmospheric concentrations of 
ozone, VOCs and $\mathrm{NO}_{\mathrm{x}}$, vary from place-to-place and day-to-day, making it difficult to reliably predict the impact of $\mathrm{VOC}$ and/or $\mathrm{NO}_{\mathrm{x}}$ reductions in a given city. Computer models used to predict the effect of emissions changes on ozone levels usually include mathematical representations of VOC, NOx, and carbon monoxide emissions; chemical reactions among 30 or more chemical compounds; meteorological conditions including wind speed and direction, temperature, humidity, cloud cover, and atmospheric mixing; and pollutant concentrations at the start of the simulations and along the boundaries of the region being modeled. Various models differ greatly in how detailed their inputs are (e.g., whether they use emissions totaled over an urban area or require them to be "gridded," i.e., broken out for small subdivisions of the area).

The most detailed urban models perform reasonably well in replicating observed ozone concentrations over episodes lasting 1 to 3 days, provided that adequate emissions inventories, boundary and initial pollutant concentration data, and meteorological data are available [26]. Unfortunately, application of these models is time-consuming and expensive (costing on the order of $\$ 500,000$ ), and their use has been limited. To date, most cities have used EPA's Empirical Kinetic Modeling Approach (EKMA) model instead. ${ }^{2}$ EKMA was designed to minimize input requirements, and allows use of default values for many parameters. Consequently, it often oversimplifies the relationship between precursor emissions and ozone.

EPA has historically encouraged exclusive reliance on VOC emission controls to ensure compliance with the air quality standard for ozone. $\mathrm{NO}_{\mathrm{x}}$ emission controls have mostly been used only to the extent necessary to comply with the standard for nitrogen dioxide. Part of the reason for the emphasis on VOC controls is that laboratory (smog chamber) experiments and computer modeling studies have shown that reducing $\mathrm{NO}_{\mathrm{x}}$ emissions could increase ozone concentrations under some conditions found in urban areas. (See ref. [17,9,2] for reviews of some of these studies.) However, recent measurements of
VOC and $\mathrm{NO}_{\mathrm{x}}$ concentrations in a number of areas, new modeling analyses, and new estimates of the impact of VOC emissions from vegetation have elicited speculation that in rural areas [27,31] and in some cities $[3,7,5], \mathrm{NO}_{\mathrm{x}}$ controls may be more effective in reducing photochemical pollution than previously thought. In short, the issue of whether reducing $\mathrm{NO}_{\mathrm{x}}$ emissions would generally help lower ozone is still controversial.

\section{EFFECT OF CONTROLLING VOLATILE ORGANIC COMPOUNDS}

\section{Local Volatile Organic Compound Reductions Required To Meet the Standard}

This section presents estimates of local VOC emission reductions needed to reduce local peak 1-hour average ozone concentrations or "design values" down to 0.12 parts per million (ppm), the maximum concentration allowed under the ozone standard. For areas with design values up to 0.20 $\mathrm{ppm}$, the control requirements presented in figure 5-1 were estimated using EPA's EKMA model, with the Agency's default set of "typical" meteorological, emissions, and transport conditions [18]. A moderate amount of ozone ( $0.07 \mathrm{ppm})$ is assumed to be transported from upwind, and VOC emissions from vegetation are assumed to be negligible. NO, emissions were assumed to be unchanged from 1985 levels.

A key parameter in an EKMA calculation is a ratio of the VOC and $\mathrm{NO}_{\mathrm{x}}$ concentrations measured at a central location in a given city, and averaged over the period from 6 to 9 a.m. on the day when the city's highest ozone concentration occurred. This VOC-to$\mathrm{NO}_{\mathrm{x}}$ ratio is assumed to be a measure of the precursor balance that initially exists in the parcel of air that produces the peak ozone concentration later in the day. In figure 5-1, the range of VOC control requirements shown for each design value corresponds to the range of VOC-to- $\mathrm{NO}_{\mathrm{x}}$ ratios expected to prevail on most days, in most cities-from about 8:1 (8 ppb carbon to $1 \mathrm{ppb}$ NO.) to 15:1 [3]. For two

\footnotetext{
2The EKMA model consists of a single cell, or box, in which chemical reactions take place, and which is moved in a straight line at a constant velocity during the course of a day, The box leaves the center of a city at $8 \mathrm{a} . \mathrm{m}$. and arrives in the afternoon at the location where the peak ozone concentration was observed. En route, the contents of the box are diluted with comparatively clean air, and emissions are added as the box moves over sources. Problems with the model include its unrealistic treatment of the horizontal movement of the box and the mixing of freshly emitted pollutants into it; lack of spatial resolution; and sensitivity to difficult-to-measure starting concentrations of VOCs and $\mathrm{NO}_{\mathrm{x}}$.
} 


\section{Figure 5-1-VOC Emissions Reductions Estimated To Be Required To Reduce Ozone From the Initial Peak Concentrations or "Design Values" Shown, Down to $0.12 \mathrm{ppm}$} \\ high $\mathrm{VOC} / \mathrm{NO} \times$ ratio \\ $60 \%$ \\ $40 \%$ \\ $20 \%$ । \\ low $\mathrm{VOC} / \mathrm{NO}$ ratio \\ nn

$\begin{array}{lllllllll}0.12 & 0.13 & 0.14 & 0.15 & 0.16 & 0.17 & 0.18 & 0.19 & 0.20 \\ \text { Initial design value (ppm) }\end{array}$

Control requirements were estimated using EPA's standard "EKMA" model, with meteorological, emissions, and transport conditions set to approximate conditions in a typical area where transport from upwind cities is not the principal cause of nonattainment. The range of estimates shown for each design value corresponds to the range of $\mathrm{VOC}$ and $\mathrm{NO}_{x}$ ratios expected to prevail across different cities. The percentage reduction needed to meet the standard in an individual city will typically fall somewhere between the two curves shown.

SOURCE: Adaptod from E.L. Meyer, Jr., U.S. Environmental Protection Agency, personal communication, September 1987.

cities (or 2 days in the same city) with the same peak ozone concentration, the level of VOC control required to meet the standard will generally be highest for the city (or day) with the highest VOC-to- $\mathrm{NO}_{x}$ ratio, i.e., the most VOC-rich conditions. However, local conditions that deviate from the default values used in our calculations could lead to different results. For example, a higher level of pollution transported into a city from upwind could lead to a relatively high control requirement even if the city had a low VOC-to- $\mathrm{NO}_{\mathrm{x}}$ ratio.

To illustrate how to interpret figure 5-1, for a city with a design value of $0.16 \mathrm{ppm}$, with no change in $\mathrm{NO}_{\mathrm{x}}$ emissions levels, the model predicts that VOC reductions ranging from about 45 to 70 percent will be needed to meet the ozone standard. As used here, the EKMA model is intended to provide only rough estimates of control requirements. In our judgment, it seems reasonable that control requirements for most cities would fall within the ranges shown in figure 5-1. However, control requirements for individual nonattainment areas could deviate substantially from those presented here.

\section{The Effect of Lowering Volatile Organic Compound Emissions by 35 Percent}

As we will discuss in detail in chapter 6 , if all VOC controls we consider to be currently available were to be imposed, the total reductions in VOC emissions estimated for most areas by 1994 would be between 20 and 50 percent of 1985 levels, falling short of the amounts estimated to be required to attain the standard in many cities.

Figure 5-2 shows peak ozone concentrations predicted to result when VOC emissions are reduced by 35 percent (with $\mathrm{NO}_{\mathrm{x}}$ emissions unchanged), plotted against initial design values. The solid lines represent estimates of the range of peak ozone concentrations expected to result from a 35-percent reduction in VOC emissions with no change in $\mathrm{NO}_{\mathrm{x}}$ emissions. The dashed line represents "no change" in ozone concentrations, i.e., the final concentration is the same as the initial concentration or design value. Note that the ozone standard, $0.12 \mathrm{ppm}$, is at the bottom of the graph, so that the relative position of a control scenario line between the "no change" diagonal and the bottom of the graph indicates what fraction of the reduction in ozone that is needed to obtain the standard is predicted to be achieved. The range of reductions shown for each design value in figure 5-2 is based on the range of 6 to 9 a.m. VOC-to-NO $\mathrm{NO}_{\mathrm{x}}$ ratios expected in most cities.

As shown in figure 5-2, we predict that currently available VOC reductions would be sufficient to enable most areas with design values equal to 0.13 ppm to meet the standard. Some areas with design values equal to $0.14 \mathrm{ppm}$ are also predicted to be able to attain. Reducing VOC emissions by 35 percent is predicted to lower ozone concentrations in areas with design values higher than $0.15 \mathrm{ppm}$ by about one-third to two-thirds of the amounts needed to meet the standard. As with the control requirement calculations, the impact of VOC reductions in individual nonattainment areas could deviate substantially from the results shown in figure 5-2. 


\section{Figure 5-2-Ozone Concentrations Predicted To Result When VOC Emissions Are Reduced by 35 percent, With No Change in $\mathrm{NO}_{x}$ Emissions levels}

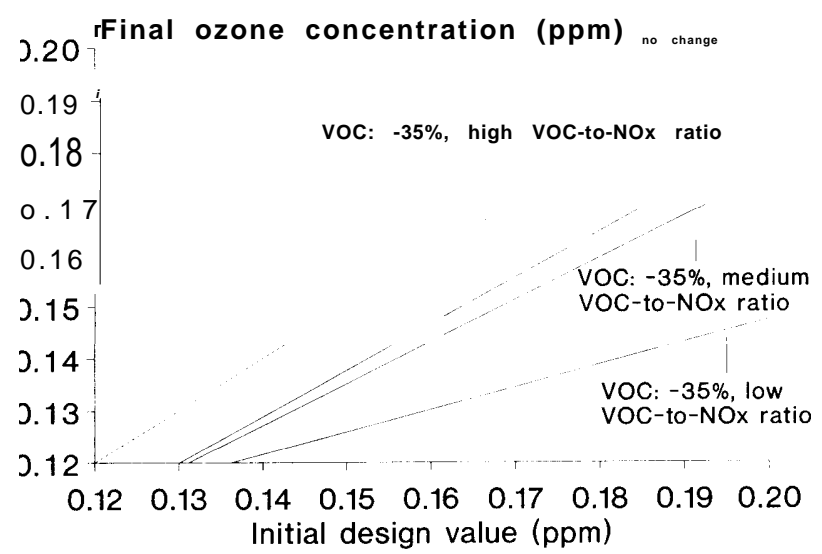

The three solid lines indicate the ozone concentrations predicted to result in cities with low, medium and high VOC to NO, ratios. The dashed line illustrates the "no control" ease, i.e., the final ozone concentrations are the same as the initial design values.

SOURCE: Adapted from E.L. Meyer, Jr., U.S. Environmental Protection Agency, personal communication, September 1987.

\section{Sensitivity to Emissions From Vegetation}

Figures 5-1 and 5-2 were generated using a model that assumes VOC emissions from vegetation are negligible. However, rough estimates suggest that the fraction of total VOC emissions in nonattainment areas that come from vegetation actually ranges from a few percent up to about 50 percent, with areas where the contribution appears to be greater than about 25 percent located almost exclusively in the Southeast. ${ }^{3}$ If they comprise a significant fraction of total VOCs, vegetative emissions can substantially reduce the apparent effectiveness of controlling manmade VOC emissions. In Atlanta, for example, where over 50 percent of the 11 -county nonattainment area is wooded, summertime emissions from vegetation are estimated to be about equal to manmade VOC emissions [7]. Neglecting emissions from vegetation, simulations with a version of EPA's EKMA model predict that a 40 percent reduction in manmade VOC emissions would be needed to attain the ozone standard in Atlanta. When vegetative emissions are considered, a 70-percent reduction in manmade VOCs is predicted to be required [7]. Although the Atlanta case is an extreme example, it suggests that for some cities, control requirements may exceed the range shown in figure 5-1, and reducing manmade VOC emissions by 35 percent may be less effective than indicated in figure 5-2.

\section{EFFECT OF CONTROLLING NITROGEN OXIDES}

In its post-1987 policy proposal, EPA has suggested that some areas may be required to consider reducing emissions of $\mathrm{NO}_{x}$ in addition to VOCs [33]. And, the State of California has promulgated new, more stringent limits on $\mathrm{NO}_{\mathrm{x}}$ emissions from motor vehicles, primarily to meet nitrogen dioxide and particulate matter (PM-1O) standards, but to help reduce ozone as well [6]. This section considers the option of controlling $\mathrm{NO}_{\mathrm{x}}$ emissions in addition to VOCS.

\section{Balance of Volatile Organic Compounds and Nitrogen Oxides}

The ratio of the average VOC and $\mathrm{NO}_{x}$ concentrations measured over the period from 6 to 9 a.m. at a downtown location is often used as a rough measure of the precursor balance that exists in the parcel of air that is expected to produce a city's peak ozone concentration later in the day. The higher the ratio of VOCs to $\mathrm{NO}_{\mathrm{x}}$, the more $\mathrm{NO}_{\mathrm{x}}$-limited is the air parcel, and the more likely it is that reductions in $\mathrm{NO}_{\mathrm{x}}$ will be beneficial. Conversely, the lower the ratio, the more likely it is that reducing $\mathrm{NO}_{-}$will be counterproductive. Because they depend on emissions, meteorology, topography, and upwind precursor levels, VOC-to-NO ${ }_{\mathrm{x}}$ ratios are expected to differ from one city to another. However, the actual balance can also vary significantly from day-to-day in a given city, as meteorological conditions and emissions vary, and can also depend significantly on monitor location.

As a screening method, EPA has suggested that cities for which the median ratio over the summer is 10:1 (10 ppb carbon per 1 ppb $\mathrm{NO}_{\mathrm{x}}$ ) or greater will be required to consider reducing $\mathrm{NO}_{\mathrm{x}}$ emissions in addition to VOCs. EPA has compiled 6 to 9 a.m.

\footnotetext{
${ }^{3}$ Based on average levels of VOC emissions from vegetation estimated for five regions of the United States [12] and manmade VOC emissions estimated for each nonattainment area.
} 
VOC-to-NO $\mathrm{NO}_{\mathrm{x}}$ ratios for about 40 cities, for summers between 1984 and 1987 [4]. Of the 40 cities, about one-third had median VOC-to- $\mathrm{NO}_{\mathrm{x}}$ ratios lower than $10: 1$, indicating that they would not be required to consider $\mathrm{NO}_{\mathrm{x}}$ controls. Most of these cities were located in the upper Midwest or Northeast. The remainder of the cities had median ratios higher than 10:1, with the highest VOC-to- $\mathrm{NO}_{\mathrm{x}}$ ratios generally observed in the South (Texas and east), where no cities consistently had VOC-to- $\mathrm{NO}_{\mathrm{x}}$ ratios less than 10:1.

VOC-to- $\mathrm{NO}_{\mathrm{x}}$ ratios give only a preliminary indication of the potential effect of controlling $\mathrm{NO}_{\mathrm{x}}$. The variability mentioned above is one limitation. A second is that there is no single ratio that clearly separates $\mathrm{NO}_{\mathrm{x}}$ and VOC-limited conditions, but rather a transition range extending from about 8:1 to 15: 1, encompassing the median ratios of most cities. Most importantly, additional factors such as the size of a city, its spatial distribution of emissions sources, and the reactivity of the mix of VOCs present also influence whether or not $\mathrm{NO}_{x}$ controls would be beneficial. As recommended by EPA, detailed air quality models are ultimately needed to reliably estimate the impacts of controls [33].

\section{The Effects of Nitrogen Oxide Controls in Urban Areas}

Over the past 15 years, urban-scale models have been used to predict the impacts of $\mathrm{NO}_{\mathrm{x}}$ controls for a half dozen United States cities (for example, see $[17,5,24,29])$. The conclusions of the studies have been mixed: compared to VOC control alone, adding $\mathrm{NO}_{\mathrm{x}}$ control was found to be counterproductive in some studies and beneficial in others. A key point from these studies is that in many urban areas, with both VOC and $\mathrm{NO}_{\mathrm{x}}$ reductions, peak ozone concentrations will be higher at some locations and lower at others than if VOC emissions were controlled alone. Thus a key question is whether controlling $\mathrm{NO}_{x}$ is beneficial or counterproductive for an area as a whole, not just at a single location. A Los Angeles-area study illustrates how complicated this question can be.

Figure 5-3 illustrates the complexity of reducing $\mathrm{NO}_{\mathrm{x}}$ emissions, as predicted using an urban-scale model, for a 1982 episode in the Los Angeles area [19]. The figure shows the predicted impact of uniformly reducing $\mathrm{NO}_{\mathrm{x}}$ emissions by 35 percent and holding VOC emissions constant, compared to estimated 1982 levels. The gray area shows where peak ozone concentrations were predicted to increase when $\mathrm{NO}_{\mathrm{x}}$ emissions were lowered. This area is centered on Los Angeles County, the portion of the region where $\mathrm{NO}_{\mathrm{x}}$ emission rates are highest. Downwind of this area, in San Bernardino and Riverside Counties, reducing $\mathrm{NO}_{\mathrm{x}}$ is predicted to reduce peak ozone.

For the case simulated, the highest ozone concentrations occurred in the eastern part of the Los Angeles basin, and reducing $\mathrm{NO}_{\mathrm{x}}$ emissions by 35 percent was predicted to lower the area-wide peak ozone concentration by slightly more than 10 percent. However, Los Angeles County is the most densely populated part of the basin, and a 35-percent reduction in $\mathrm{NO}_{\mathrm{x}}$ was predicted to lead to about a 5 -percent increase in population exposure to ozone concentrations above $0.12 \mathrm{ppm}$.

\section{Combined Volatile Organic Compound and Nitrogen Oxide Control in the Northeast}

EPA has used a regional-scale air pollution model, its Regional Oxidant Model (ROM), to study the effect of reducing $\mathrm{VOC}$ and $\mathrm{NO}_{\mathrm{x}}$ emissions in the Northeastern United States. The ROM modeling region is shown in figure 5-4. The region is divided into cells with horizontal dimensions of approximately 11.5 miles X 11.5 miles. Emissions, air quality and meteorological inputs and outputs are averaged within each cell. Averaging over this scale is necessary to keep computational requirements down, but can lead to underprediction of peak ozone concentrations in urban areas, and may also bias how ozone levels respond to changes in VOC and $\mathrm{NO}_{\mathrm{x}}$ emissions levels. Representation of such large point sources as utility and industrial boilers is especially problematic [13].

EPA has used ROM to examine control strategies involving both $\mathrm{VOC}$ and $\mathrm{NO}_{\mathrm{x}}$ control alone, and combinations of the two. In keeping with our premise that future efforts will focus first on reducing VOCs, but that $\mathrm{NO}_{\mathrm{x}}$ controls may also be imposed, we present results here for the following strategies [23]:

- VOC control alone-reductions of manmade VOC emissions by 42 percent, averaged over 
Figure 5-3-Change In Peak Ozone Concentrations in the Los Angeles Basin, Predicted to Result From Reducing NO Emissions by 35 Percent Below 1982 Levels

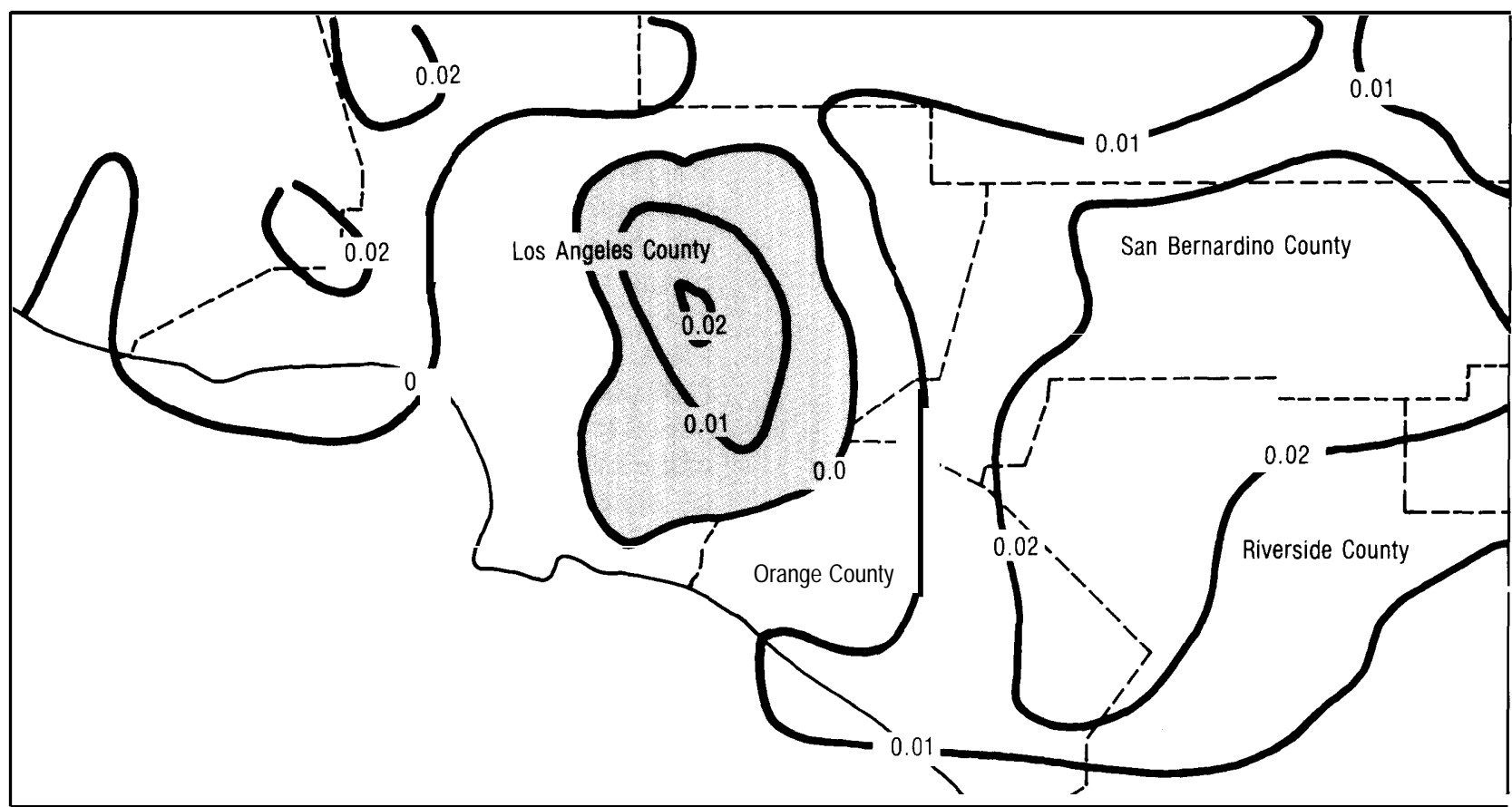

The gray area shows where ozone concentrations. are predicted to increase. Ozone concentrations are predicted to decrease throughout the rest of the region. The predictions were made using an urban-scale model, with emissions and meteorological conditions corresponding to the August 30-31, 1982 period.

SOURCE: J.B. Milford, A.G. Russell, and G.J. McRae, "Implications of Spatial Patterns in Pollutant Responses to Reductions in Nitrogen Oxides and Reactive Organic Gas Emissions," Environmental Science and Technology, accepted, 1989.

the entire ROM domain, with reductions in cells in nonattainment cities ranging from 27 to 70 percent and uniform 30-percent reductions outside of nonattainment areas.

- Combined VOC and $\mathrm{NO}_{\mathrm{x}}$ control-the same VOC reductions plus 27-percent reductions in $\mathrm{NO}_{\mathrm{x}}$ emissions, averaged over the entire modeling region.

The results reported here are for a 16-day period in July, 1980, when winds were generally from the west or southwest. ${ }^{4}$ Base case emissions estimates for manmade VOCs, $\mathrm{NO}_{x}$, and $\mathrm{CO}$ were from the 1980 National Acid Precipitation Assessment Program (NAP') inventory. VOC emissions from vegetation are also included.
ROM's development and evaluation are ongoing, so the results presented here should be considered preliminary. Uncertainties in the estimates of both manmade VOC emissions and VOC emissions from vegetation are significant. VOC emissions from both mobile sources and area sources were probably underestimated in the 1980 NAPAP inventory, since emissions associated with running losses and waste treatment, storage, and disposal facilities (TSDFs) were not included. Evaluations of the model conducted to date indicate a tendency to overpredict low concentrations and underpredict peaks, especially near major point sources; and to overpredict low concentrations in remote areas [14].

Table 5-1 shows the results for cities (Metropoli$\tan$ Statistical Areas or MSAs) in the ROM modeling

${ }^{4}$ Along the urbanizedeasternseaboard, during this period, surface winds often flowed from the southwest while winds at higher altitudes came frOm the west [22]. 
Figure 5-4-Region Covered by the U.S. Environmental Protection Agency's Regional Oxidant Model (ROM)



ROM is being used to study the effect of reducing VOC and NOx emissions.

SOURCE: W. Battye, L. Langstaff, M. Smith, N. Possiel, E. Meyer and K. Baugues, "Regional Ozone Modeling For Northeast Transport-Development of a "Regional Ozone Modeling For Northeast Transport-Development of a Meeting of the Air and Waste Management Association (Anaheim, CA: June 25-30, 1989).

region. Results for rural (non-MSA) areas of New York, Pennsylvania, and West Virginia are discussed below in the section on rural ozone. Two measures of the extent of possible exposure are tabulated for the base case and for the VOC-alone and combined VOC and $\mathrm{NO}_{\mathrm{x}}$ control strategies. The first is an area-weighted measure of the occurrence of ozone concentrations above specified levels-on each day, the number of grid cells where ozone exceeds a threshold concentration is counted, and then the daily totals are added up over the 16-day modeling period. The second measure is "populationweighted" - in this case the number of people living in those parts of a city where ozone exceeds a threshold concentration is added up for each day, and then the daily "potentially exposed" population numbers are totaled over the entire 16-day period. Two threshold levels are displayed in table 5-1: a peak daily l-hour average concentration of $0.12 \mathrm{ppm}$ (equivalent to the standard), and a peak daily 8-hour average concentration of $0.10 \mathrm{ppm}$ (a measure of multi-hour exposure).

Approximately 61 million people live within all the metropolitan areas included within the modeling region. The total metropolitan area covered is about 100,000 square miles. If the entire modeling region had been blanketed by ozone concentrations exceeding the standard for every day during the 16-day period modeled, the entries in table 5-1 would be about 976 million person-days (61 million people times 16 days) and 1.6 million square mile-days (100,000 square miles times 16 days). The 16-day period modeled represents one of the worst episodes of the 1980-88 period, with the base case occurrence of ozone concentrations above the thresholds in table 5-1 equal to about 10 percent of the theoretical maximum. This total represents a mix of conditionssome locations where the standard was never exceeded, and other locations such as New York City where the standard was exceeded on 11 of the 16 days modeled.

As shown in table 5-1, for the Northeast as a whole, the net effect of the combined VOC and $\mathrm{NO}_{x}$ control strategy is predicted to be an improvement over the strategy that would control VOCs alone, in terms of reducing both the urban area and population potentially exposed to elevated ozone concentrations. The large reductions in VOC emissions alone eliminate the majority of potential exposures, with the combined strategy eliminating 3 to 13 percent more, depending on the measure of exposure considered. Consistent with the explanation that ozone is most likely to be sensitive to VOC controls in densely populated, high-emissions areas, reducing VOC emissions alone is somewhat more effective for lowering population-weighted potential exposure than area-weighted exposure.

Despite the fact that the combined strategy is predicted to be beneficial overall, for urban areas in the Northeast, the modeling results suggest that $\mathrm{NO}_{\mathrm{x}}$ reductions may be counterproductive for individual locations within the region. In other places, though, adding $\mathrm{NO}_{\mathrm{x}}$ controls is predicted to be more effective than suggested by the regionwide totals shown in table 5-1. Table 5-2 presents results for the Pittsburgh, Hartford, and New York City areas. 
Table 5-I-Predicted Effect of VOC-Alone and Combined VOC and $\mathrm{NO}_{\mathrm{x}}$ Control Strategies In Northeastern Cities, Over a 16-Day Period in July 1980

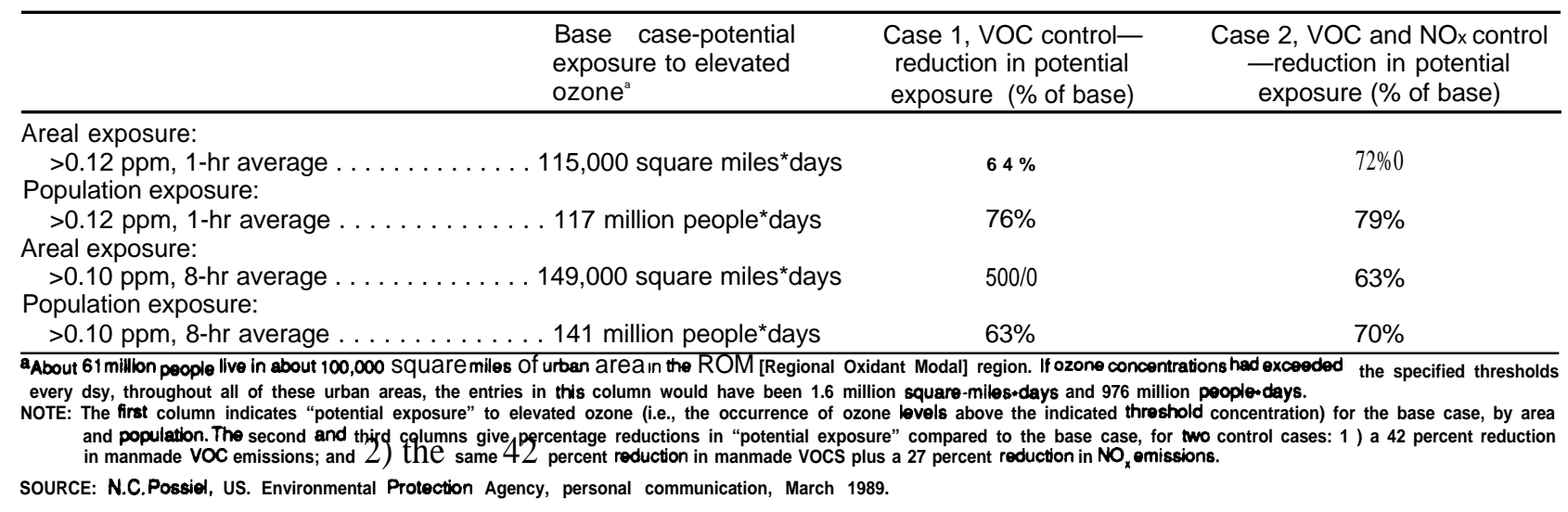

Table 5-2-Predicted Effects of VOC-Alone and Combined VOC and $\mathrm{NO}_{\mathrm{x}}$ Controls in the Hartford, New York City, and Pittsburgh Areas, Over a 16-Day Period in July 1980

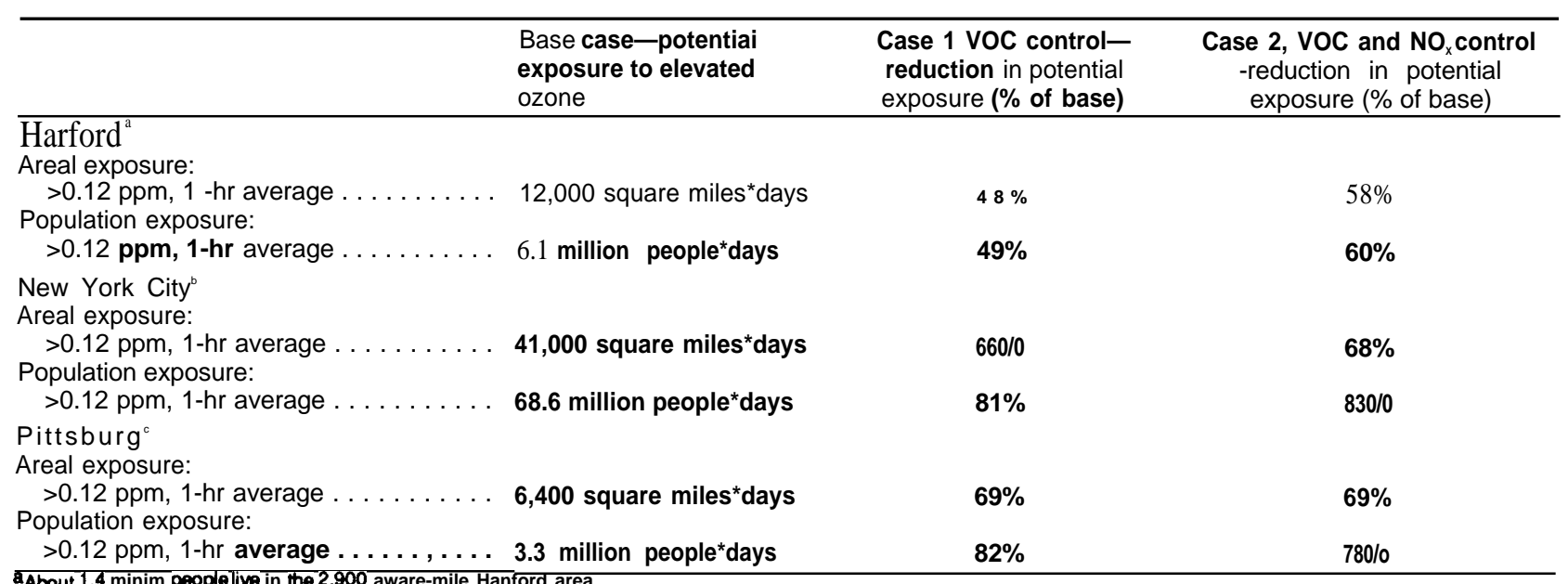

about 1.4 minim people live in the 2,900 aware-mile Hanford area.

-About 16.5 million people live in the 12,000 square-mile Now York City area.

CAbout 2.6 million people live in the 5,200 square-mile Pittsburgh area.

NOTE: See table 5-1 for a full explanation of the entries.

SOURCE: N.C.Possiel, U.S. Environmental Protection Agency, personal communication, March 1989.

Of the major urban areas in the Northeast, controlling $\mathrm{NO}_{\mathrm{x}}$ appears to be most counterproductive for Pittsburgh. As shown in the table, VOC control alone is predicted to reduce potential population exposure to concentrations above the standard by 82 percent; adding NO, control offsets some of those gains. For Pittsburgh, the net effect of combined controls is a 78-percent reduction in population exposure. In contrast to Pittsburgh, combining
$\mathrm{NO}_{\mathrm{x}}$ and VOC controls is predicted to be comparatively more effective for Hartford than for the urban Northeast overall. There, combining VOC and $\mathrm{NO}_{x}$ controls is predicted to reduce both the populationweighted and area-weighted exposure measures by about 60 percent, whereas 50-percent reductions are predicted with VOC-control alone.

Finally, in the base case, more than half of the total potential exposures in northeastern cities occur 
in the New York City area. Totaled over that 12,000 square mile area, the incremental effect of adding $\mathrm{NO}_{\mathrm{x}}$ control is predicted to be a relatively small improvement compared to controlling VOCs alone. VOC controls alone are predicted to reduce areaweighted exposures by 66 percent, and populationweighted exposures by 81 percent. Combined VOC and $\mathrm{NO}_{\mathrm{x}}$ controls yield additional reductions of 2 percent, by both measures.

Key limitations of these results need to be reiterated. First, they are specific to the meteorological conditions and emissions scenarios modeled. As discussed above, the emission reductions modeled are relative to an estimated 1980 baseline. Current emissions differ from those estimates due to actual changes in emissions since 1980, as well as methodological improvements in estimating emissions that have been made since 1980. The results also depend on the levels of control evaluated. Comparing a different combination of $\mathrm{VOC}$ and $\mathrm{NO}_{\mathrm{x}}$ control levels might have yielded different results in sign, as well as magnitude, from those presented here. In addition to the July episode, EPA has also used ROM to simulate an August 1980 episode of comparatively stagnant, recirculating flows. In that case the combined control strategy generally yielded more improvement over the VOC-alone case than for the episode considered here. Of the two, ozone episodes in the Northeast are more frequently similar to the July episode than the August episode [23]. Finally, the $11.5 \times 11.5$-mile resolution of the model precludes detailed analysis within cities and adds uncertainty about the effect of emissions from large sources.

\section{RURAL OZONE, TRANSPORTED OZONE, AND PRECURSORS}

\section{Transported Ozone and Precursors}

Even if local, manmade $\mathrm{VOC}$ and $\mathrm{NO}_{\mathrm{x}}$ emissions were eliminated completely, peak ozone concentrations would not be reduced to zero. A natural background concentration of $0.04 \mathrm{ppm}$ is generally assumed to contribute to peak (l-hour average) ozone concentrations. In most cases, emissions from upwind areas contribute additional ozone to observed peaks. For example, on days when the peak ozone concentrations measured downwind of Atlanta exceed $0.10 \mathrm{ppm}$, concentrations upwind of the city are typically only 0.02 to 0.04 ppm lower than the peak concentrations [15]. As another example, ozone concentrations approaching the standard are commonly observed upwind of east coast cities such as New York and Boston on days when the standard is violated downwind of these cities $[21,24]$.

Urban "plumes" with elevated ozone concentrations have been tracked over 200 miles downwind of some cities. Aircraft observations show that the New York City plume can extend to Boston, for example [21]. ozone formed from precursors emitted in urban areas within about 100 miles upwind may exacerbate nonattainment problems of cities along the Northeast corridor from Virginia to Maine (21 nonattainment areas); along the gulf coast of Texas and Louisiana (7 nonattainment areas); around Lake Michigan (5 nonattainment areas); and in California (8 nonattainment areas apparently affected by transport). Overall, of 74 consolidated metropolitan areas that did not attain the ozone standard for the 1983-85 period, 41 appear to lie within about 100 miles in directions commonly downwind of other nonattainment cities. In most of these cases, reducing both VOC and NOx emissions in the upwind nonattainment areas would probably help improve air quality in the downwind cities. Over the next 2 to 5 years, proposed or ongoing modeling studies in the four major transport areas listed above could provide quantitative information about the effect of alternative controI strategies in those areas.

\section{Regional Episodes}

In association with certain types of weather systems that cross the Eastern United States several times each summer, peak ozone concentrations in the range of 0.08 to $0.10 \mathrm{ppm}$ have been observed at rural locations throughout multi-state regions $[25,35]$.

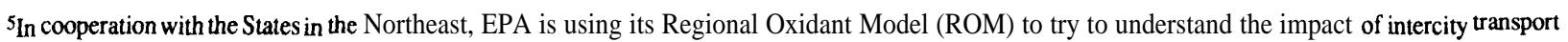
there, and to evaluate coordinated control strategies. The application should be completed by the end of 1990. The Agency has also applied ROM to the gulf coast region, but plans few additional applications to this area prior to 1991, due to limited resources. The California Air Resources Board, together with local governments in the San Joaquin Valley and California industries, has planned an $\$ 8$ to $\$ 10$ million field experiment and modeling study to investigate transport and control strategies for that area. The 6-week field experiment is planned for summer 1990. State air pollution control agencies of Michigan, Illinois, Indiana, and Wisconsin have proposed, but not yet found funding for a million-dollar field study and modeling effort for the southern Lake Michigan area.
} 
During the growing season, episodes of high ozone in rural areas are of concern due to potentially adverse impacts on crops and forests. Ozone formed during regional-scale episodes may also contribute to violations of the standard in urban areas, where additional ozone is formed from local emissions.

Based on modeling and analysis of spatial and temporal trends in ozone concentrations and air mass movement, some scientists have suggested that during multi-day episodes, pollutants emitted in major urban or industrial areas may contribute to high ozone concentrations observed several hundred miles away. In particular, they suggest that emissions from the industrial Midwest may contribute to high ozone concentrations over large areas of the South [15] and Northeast [27,8]. Carried aloft, it is plausible that slow-reacting VOCs and ozone could be carried several hundred miles. However, we are not aware of any analyses that have quantified the contributions that major urban or industrial areas make to ozone concentrations in either rural or urban areas several hundred miles away.

Rather than originating in distant urban or industrial areas, the ozone concentrations observed in regional-scale episodes could also build up over 2 or more days due to emissions from widely distributed sources, such as powerplants, or motor vehicles in rural areas or small towns. As an illustration, Trainer et al. [31] used a simple model to show that at levels estimated to occur during summer in rural Pennsylvania, manmade $\mathrm{NO}_{\mathrm{x}}$ emissions and VOCs emitted from vegetation alone (without any manmade VOC contribution) could produce peak ozone concentrations of almost $0.12 \mathrm{ppm}$, built up over a 4-day episode. (Adding manmade VOCs at levels observed in rural areas in the Northeast was predicted to increase the peak ozone concentration by less than 10 percent, as ozone production was predicted to be $\mathrm{NO}_{\mathrm{x}}$-limited.)

Within the next 2 years, EPA's modeling efforts should provide some information about the potential influence of emissions from urban and industrial areas in Ohio and Pennsylvania on ozone concentrations throughout the Northeast, including the nonattainment areas along the coast. The analysis could also provide information about the impacts of emissions from rural areas and small cities within this region. Regional-scale studies of these issues for the South and Midwest would also be useful.

\section{Reducing Rural Ozone}

Recent modeling studies that have simulated typical rural conditions suggest that outside of urban and industrial plumes, reducing $\mathrm{NO}_{\mathrm{x}}$ emissions will generally be a more effective strategy for lowering ozone than reducing VOC emissions [27,31]. Conditions in rural areas tend to be $\mathrm{NO}_{\mathrm{x}}$-limited $[1,10]$. In rural areas where vegetative VOC emissions are high, ozone production may be particularly insensitive to changes in manmade VOC emissions [31]. As discussed in the previous section, ozone and precursors transported from urban areas also contribute to elevated ozone levels in rural areas immediately downwind of cities, and some scientists suggest that impacts of transported pollutants may extend for hundreds of miles. In these cases, reductions in urban VOC and $\mathrm{NO}_{\mathrm{x}}$ emissions are likely to help reduce rural ozone. We cannot estimate the comparative contributions to rural ozone levels of local production versus transported pollution.

Table 5-3 shows results from the ROM simulations discussed above, for non-urban areas in Delaware, New Hampshire, New York, Pennsylvania, Vermont, Virginia and West Virginia. The total non-urban area included is about 83,000 square miles. For the non-urban results, the areal measure described above is tabulated, for 8-hour average concentrations exceeding 0.08 and $0.10 \mathrm{ppm}$, and for 1-hour average concentrations exceeding 0.10 and $0.12 \mathrm{ppm}$. Because the controls simulated were applied throughout the region, we cannot sort out the impacts of reducing precursors in rural areas versus cities.

As shown in the table, controlling $\mathrm{NO}_{\mathrm{x}}$ emissions in addition to VOCs (in both urban and rural areas) always reduced ozone in non-urban areas more than controlling VOCs alone, at the level of aggregation considered. This result is also true for each of these states individually. Comparing tables 5-1 and 5-3, shows that the incremental benefit of the combined strategy over reducing VOCs alone is larger in rural areas than in cities. This is consistent with the expectation that $\mathrm{NO}_{\mathrm{x}}$ controls would be more effective for reducing ozone in rural areas than in 
Table 5-3-Predicted Effect of VOC-Alone and Combined VOC and NQControl Strategies in Nonurban Areas of the Northeast, Over a 16-Day Period in July 1080

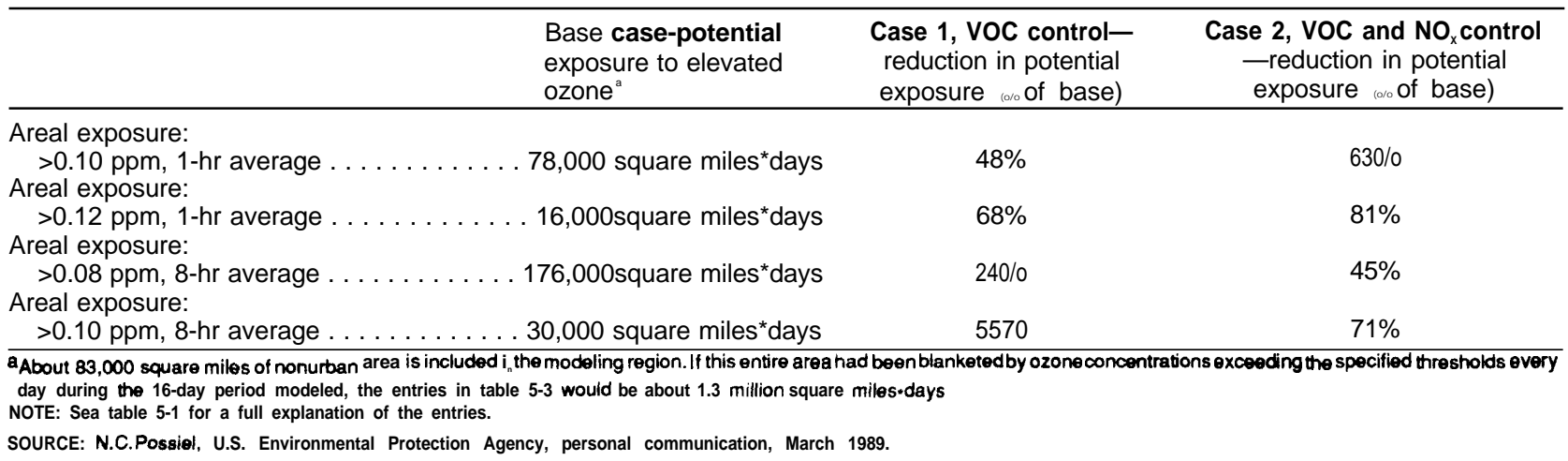

urban areas, and also with the fact that most of the VOC reductions occurred in cities, rather than rural areas.

\section{REFERENCES FOR CHAPTER 5}

1. Altshuller, A.P., "Review: Natural Volatile Organic Substances and Their Effect on Air Quality in the United States," Atmospheric Environment 17:2131$2165,1983$.

2. Altshuller, A. P., "Measurements of the Products of Atmospheric Photochemical Reactions in Laboratory Studies and in Ambient Air-Relationships Between Ozone and Other Products," Atmospheric Environment 17:2383-2427, 1983.

3. Baugues, K., A Review of NMOC, NO ${ }_{x}$ and NMOC/ NO Ratios Measured in 1984 and 1985, EPA-450/486-015 (Washington, DC: U.S. Environmental Protection Agency, September 1986).

4. Baugues, K., U.S. Environmental Protection Agency, personal communication, September 1988.

5. California Air Resource Board, Technical Support Document, prepared for the public hearing to consider a revision to the SIP for Kern County (Sacramento, CA: July 1986).

6. California Air Resources Board, California's Post1987 Motor Vehicle Plan for Continued Progress Toward Attainment of the National Ambient Air Quality Standards for Ozone and Carbon iklonoxidt+1988 Update, Appendix IV-F, Draft Air Quality Plan 1988 Revision (Sacramento, CA: September 1988).

7. Chameides, W. L., Lindsay, R. W., Richardson, J., and Kiang, C. S., "The Role of Biogenic Hydrocarbons in Urban Photochemical Smog: Atlanta as a Case Study," Science 241:1473-1475, 1988.

8. Clarke, J. F., and Ching, J. K. S., "Aircraft Observations of Regional Transport of Ozone in the North- eastern United States, " Atmospheric Environment 17:1703-1712, 1983.

9. Dodge, M. D., "Chemistry of Oxidant Formation: Implications for Designing Effective Control Strategies," Conference Proceedings, North American Oxidant Symposium (Quebec, Canada: Feb. 25-27, 1987).

10. Finlayson-Pitts, B. J., and Pitts, J. N., Jr., Atmospheric Chemistry (New York, NY: Wiley \& Sons, 1986).

11. Lamb, B., Guenther, A., Gay, D., and Westberg, H., "A National Inventory of Biogenic Hydrocarbon Emissions," Atmospheric Environment 21:16951705, 1987.

12. Lamb, B., Washington State University, personal communication, October 1987.

13. Lamb, R. G., "Design and Applications of the Regional Oxidant Model (ROM)," paper prepared for the North American Oxidant Symposium (Quebec, Canada: Feb. 25-27, 1987),

14. Lamb, R. G., "Diagnostic Studies of Ozone in the Northeastern United States Based on Applications of the Regional Oxidant Model (ROM), " in proceedings, The Scientific and Technical Issues Facing Post-1987 Ozone Control Strategies (Hartford, CT: November 1987).

15. Lindsay, R. W., and Chameides, W. L., "High-Ozone Events in Atlanta, GA, in 1983 and 1984, "Environmental Science and Technology 22:426-431,1988.

16. Logan, J. A., "Nitrogen Oxides in the Troposphere: Global and Regional Budgets, "J. Geophysical Research 88:10785, 1983.

17. Meyer, IL L., Jr., Review of Control Strategies for Ozone and their Effects on Other Environmental issues (Research Triangle Park, NC: U.S. Environmental Protection Agency, August 1986).

18. Meyer, E. L., Jr., U.S. Environmental Protection Agency, personal communication, September 1987. 
19. Milford, J. B., Russell, A. G., and McRae, G.J., "Implications of Spatial Patterns in Pollutant Responses to Reductions in Nitrogen Oxides and Reactive Organic Gas Emissions," Environmental Science and Technology, accepted, 1989.

20. Pierce, T., U.S. Environmental Protection Agency, personal communication, April 1989.

21. Possiel, N. C., Spicer, C. W., Sticksel, P.R., Sverdrup, G. M., Alkezweeny, A. J., and Davis, W. E., Northeast Corridor Regional Modeling Project, Ozone and Precursor Transport in New York City and Boston During the 1980 Field Program, EPA-450/4-84-Ol 1 (Research Triangle Park, NC: U.S. Environmental Protection Agency, August 1984).

22. Possiel, N. C., Tikvart, J. A., Novak, J. H., Schere, K. L., and Meyer, E. L., "Evaluation of Ozone Control Strategies in the Northeastern Region of the United States," paper presented at the Third U.S.Dutch International Symposium, Atmospheric Ozone Research and Its Policy Implications (Nijmegen, Netherlands: May 9-13, 1988),

23. Possiel, N. C., U.S. Environmental Protection Agency, personal communication, March 1989.

24. Rae, S. T., Application of the Urban Airshed Model to the New York Metropolitan Area, EPA 450/4-87-01 1 (Research Triangle Park, NC: U.S. Environmental Protection Agency, May 1987).

25. Samson, P. J., and Ragland, K. W., "Ozone and Visibility in the Midwest: Evidence for Large-Scale Transport," J. Applied Meteorology 16:1 101-1106, 1977.

26. Seinfeld, J. H., “Ozone Air Quality Models: A Critical Review," J. Air Pollution Control Association 38:616-645, 1988.

27. Sillman, S., Logan, J.A., and Wofsy, S. C., "The Sensitivity of Ozone to Nitrogen Oxides and Hydrocarbons in Regional Ozone Episodes," submitted for publication, 1989.

28. Singh, H. B., "Reactive Nitrogen in the Troposphere," Environmental Science and Technology 21:320-327, 1987.
29. South Coast Air Quality Management District, Draft Air Quality Managment Plan, 1988 Revision, App. V-S (El Monte, CÅ: September 1988).

30. Spicer, C. W., Joseph, D.W., Sticksel, P.R., and Ward, G.F., "Ozone Sources and Transport in the Northeastern United States," Environmental Science and Technology 13:975-985, 1979.

31. Trainer, M., Williams, E.J., Parrish, D. D., Buhr, M.P., Allwine, E.J., Westberg, H. H., Fehsenfeld, F. C., and Liu, S. C., "Models and Observations of the Impact of Natural Hydrocarbons on Rural Ozone\$" Nature 329:705-707, 1987.

32. U.S. Environmental Protection Agency, Environmental Criteria and Assessment Office, Air Quality Criteria for Ozone and Other Photochemical Oxidants, Volume II, EPA/600/8-84/020bF (Research Triangle Park, NC: August 1986).

33. U.S. Environmental Protection Agency, Federal Register, Nov. 17, 1987.

34. U.S. Environmental Protection Agency, National Emissions Data System, "Nationwide Emissions Report Summary, " computer printout, January 1988.

35. Vukovich, F. M., Bach, W. D., Jr.,Crissman, B. W., and King, W. J., "On the Relationship Between High Ozone in the Rural Surface Layer and High Pressure Systems," Atmospheric Environment 11:967-983, 1977.

36. Vukovich, F. M., Fishman, J., and Browell, E.V. "Reservoir of Ozone in the Boundary Layer of the Eastern United States and Its Potential Impact on the Global Tropospheric Ozone Budget," J. Geophysical Research 90:5687-5698, 1985.

37. Wolff, G.T., and Lioy, P.J., "Development of an Ozone River Associated With Synoptic Scale Episodes in the Eastern United States, "Environmental Science and Technology 14:1257-1260, 1980. 


\section{Chapter 6}

\section{Controlling Emissions of Volatile Organic Compounds}

\section{CONTENTS}

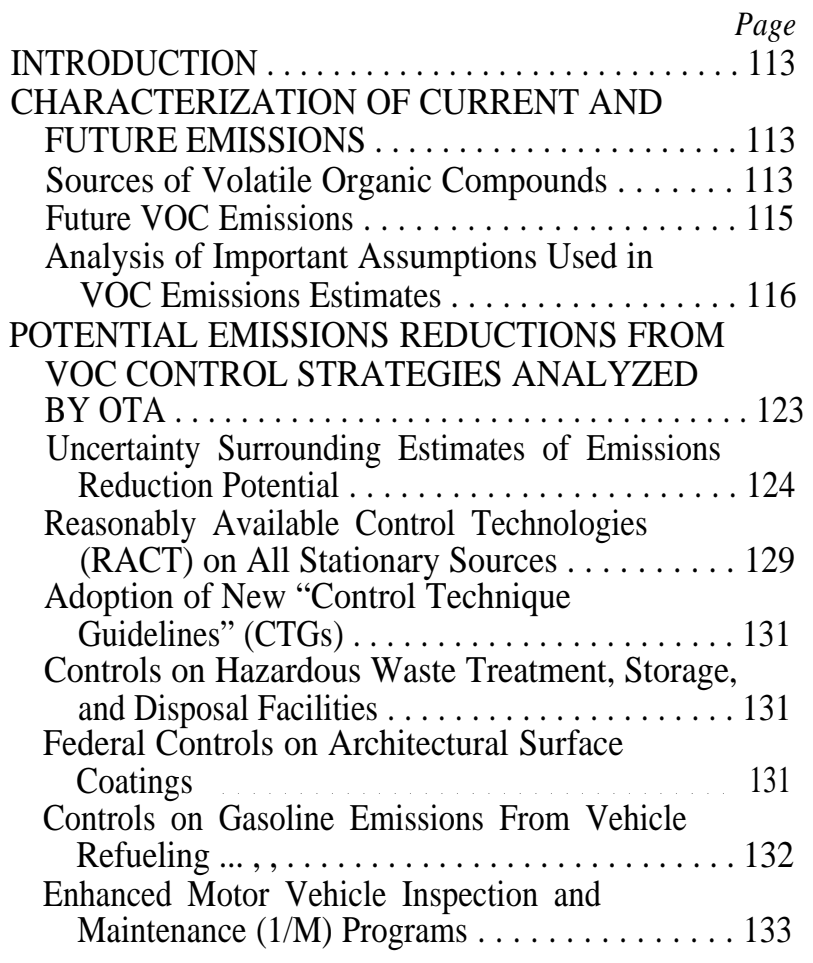

More Stringent Highway-Vehicle Emission

Standards . . . .. . . ., . . . . . . ....0 ... . . . . 133

Limits on Gasoline Volatility ............... 134

Methanol Fuels for Motor Vehicle Vehicles in the Worst Nonattainment Cities . . . . . . . . . . . . 134

COMPARISON OF POTENTIAL EMISSIONS

REDUCTIONS AND REDUCTIONS NEEDED

TO ATTAIN THE OZONE STANDARD . . . . . 135

Without Additional Controls . . . . . . . . . . . . . 135

With Additional Gasoline Volatility Limitations , 136

With All Control Strategies Analyzed by OTA . 137

Estimates of Possible Excesses and Shortfalls in Emissions Reductions Required To Attain the Ozone Standard , . . . . . . . . . . . . . . . . . . . 137

COSTS OF CONTROL STRATEGIES ANALYZED

BY OTA ........................... 139

Reasonably Available Control Technologies (RACT) on All Stationary Sources .......... 145

Adoption of New "Control Technique Guidelines" (CTGs) . . . . . . . . . . . . . . . . . 145

Controls on Hazardous Waste Treatment, Storage, and Disposal Facilities ................. 145

Federal Controls on Architectural Surface Coatings 


\section{CONTENTS-continued}

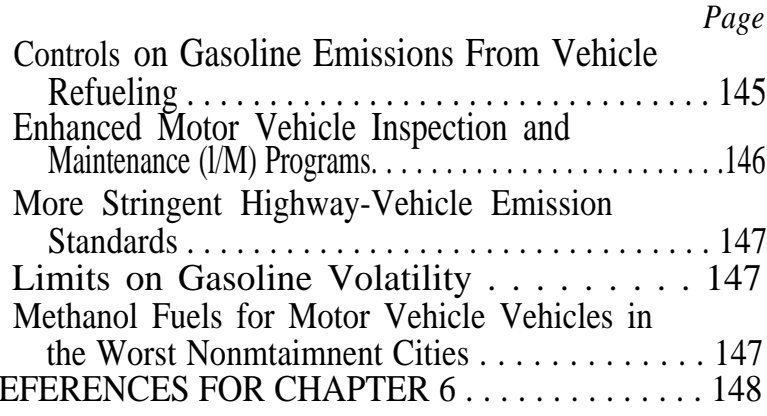

\section{Fiures}

Figure

6-1. VOC Emission in Nonattainment Cities, by Source Category, in 1985 . . . . . . . . . . . . 115

6-2. VOC Emissions From Mobile Sources in 1985 as a Percentage of Total Emissions in Nonattainment Cities . . . . . . . . . . . . . . . 115

6-3. Stationary Source Emissions of VOC in 1985 as a Percentage of thc Total Emissions Inventory, by Size of the Individual Source . . . . . . . . 116

6-4. Summary of Estimated Nationwide VOC Emissions by Source Category, by Year. . . . . 119

6-5. Uncertainty in Highway-Vehicle VOC Emissions in Nonattainment Areas in 1994.. 120

6-6. Uncertainty in Stationary-Source VOC Emissions in Nonattainment Areas in 1994.. 120

6-7. Effect of Running Losses on Passenger-Car Emission Rates in Nonattainment Cities in 1985 . ..

6-8. VOC Emissions Reductions in 1994 and 2004 Compared to 1985 Emissions, by Control Method

6-9. Potential VOC Emissions Reductions and Remaining Emissions in 1994 and 2004 as a Percentage of 1985 Emissions in Nonattainment Cities . . . . . . . . . . . . . . 129

6-10. VOC Emissions in Nonattainment Cities in 1994, by Source Category, After all Additional Control Methods Are Applied . . 129

6-11. Uncertainty in VOC Emissions Reductions From All Additional Controls in Nonattainment Cities in 1994 . . . . . . . . . . . . . . . . . . . . . 130

6-12, VOC Emissions Reductions Between 1985 and 1994, Assuming No Change From 1987 VOC Regulations and Assuming Additional Volatility Controls ................... 136

6-13. VOC Emissions Reductions Between 1985 and 1994, and 1985 and 2004, Including All
Additional Mobile and Stationary Source VOC

Control Methods ...................... 138

6-14. Estimates of Possible Excesses and

Shortfalls in Emissions Reductions Needed to

Attain the Ozone Standard in 1994 . . . . . . . . 138

6-15. Estimated Cost of VOC Emissions Control Methods in 1994 and 2004 in Nonattainment Cities . .

6-16. Estimated Cost-Effectiveness of VOC Emission Control Methods in 1994 in Nonattainment Cities . . . . . . . . . . . . . . . . . 144

6-17. Cumulative Annual Cost of, and Percent Emissions Reductions From VOC Control Methods ...................., . . . . . . . 14

\section{Tables}

Table

6-1. Summary of 1985 VOC Emissions in Nonattainment Cities and Attainment Regions ................., ......... 114

6-2, Summary of 1984 VOC Emissions in Nonattainment Cities and Attainment Regions .

6-3. Summary of 1989 VOC Emissions in Nonattainment Cities and Attainment Regions ., ........................ 117

6-4. Summary of 2004 VOC Emissions in Nonattainment Cities and Attainment Regions ............................... 118

6-5. Estimate of Uncertainty in Volatile Organic Compound Emissions in Nonattainment Cities ... . . . . . . . . . . . . . . . . . . . . 121

6-6. Potential Emissions Reductions in 1994 Compared to 1985 Emissions From SourceSpecific Control Strategies . . . . . . . . . . . . . . . 126

6-7. Potential Emissions Reductions in 1999 Compared to 1985 Emissions From SourceSpecific Control Strategies . . . . . . . . . . . . . . . 127

6-8. Potential Emissions Reductions in 2004 Compared to 1985 Emissions From SourceSpecific Control Strategies . . . . . . . . . . . . . 128

6-9. Estimate of Uncertainty in VOC Emissions Reductions After All Controls Are Applied in Nonattainment Cities in 1994 .... . . . . . . . . . . 130

6-10. Estimated Costs of Selected Control Strategies Analyzed by OTA ................... 141

6-11. Estimated Cost-Effectiveness of Selected Control Strategies Analyzed by OTA . . . . . . . 143 


\section{Controlling Emissions of Volatile Organic Compounds}

\section{INTRODUCTION}

Controlling emissions of volatile organic compounds (VOC) is the primary strategy used by the Environmental Protection Agency (EPA) and most States for reducing urban ozone. In this chapter, we discuss the sources of VOC emissions, our ability to control them, and the costs of control.

The first section describes the sources of VOC emissions and presents our estimates of the changes in emissions over the next several years. The next section analyzes the VOC emissions reductions from source-specific control methods that are currently available. We also compare these potential emissions reductions with estimates of the overall emissions reductions needed to attain the ozone standard in each nonattainment city. In the final section, we summarize the costs of each control method.

\section{CHARACTERIZATION OF CURRENT AND FUTURE EMISSIONS}

This section describes the man-made sources of VOC emissions and presents our estimates of the changes in emissions over the next 15 years due to the offsetting influences of economic growth and State and Federal regulations in place as of 1987. These estimates serve as a baseline for considering the effects of regulatory changes needed to attain the ozone standard. The focus of this section is on manmade emissions, since they are subject to control. VOC emissions from vegetation are discussed in chapter 5 .

\section{Sources of Volatile Organic Compounds}

Table 6-1 displays estimates of 1985 VOC emissions, number of cities, and population within each of five ozone design value categories. The EPA 1985 National Emissions Data System (NEDS) and the 1985 National Acid Precipitation Assessment Program (NAPAP) inventories are the sources of our emissions data and serve as the base inventory for all future year projections presented in this report. Three adjustments have been made to these data. First, highway-vehicle emissions contained in the 1985 NEDS inventory have been updated using EPA's most recent estimates of exhaust and evaporative emission rates. ${ }^{1}$ Vehicle emission rates were also adjusted to reflect a higher rate of gasoline evaporation during vehicle use. ${ }^{2}$ Highway vehicle emission rates were estimated for hot summer temperatures typical of days when the ozone standard is violated. Finally, VOC emissions from residential fuel combustion (primarily from wood burning) have been excluded from our analysis since these emissions occur primarily during the wintertime when ozone is not a problem. Thus, the estimates that we present are representative of the emissions on a typical nonattainment day, multiplied by 365 days per year, rather than estimates of true annual emissions. For convenience, throughout the report, we refer to these estimates as annual emissions rather than as "nonattainment-dayequivalent-annual-emissions."

Of the 25 million tons of VOCs emitted in 1985, nationwide, about 45 percent (11 million tons) were generated in 94 cities that exceeded the ozone standard during the 1983-85 period. For our analy -

\footnotetext{
${ }^{1}$ We use EPA's MOBLE 4 model to estimate highway vehicle emission rates. In a recent effort using MOBILE 4, EPA grouped nonattainment cities into five categories based on the Reid vapor pressure (RVP) of gasoline and ambient temperatures. These categories included:

$\begin{array}{ccccc} & \begin{array}{c}\text { \% of total VMT in } \\ \text { 61 selected cities }\end{array} & \begin{array}{c}\text { RVP } \\ \text { (psi) }\end{array} & \begin{array}{c}\text { Ambient } \\ \text { (min.) }\end{array} & \begin{array}{c}\text { temperature, OF } \\ \text { (max.) }\end{array} \\ \text { Group 1: } & 0.18 & 11.6 & 62 & 85 \\ \text { Group 2: } & 0.23 & 10.5 & 69 & 95 \\ \text { Group 3: } & 0.21 & 11.2 & 72 & 90 \\ \text { Group 4: } & 0.16 & 11.7 & 61 & 96 \\ \text { Group 5: } & 0.22 & 11.1 & 81 & 96\end{array}$

We used the vehicle-miles-traveled (VMT)-weighted average exhaust and evaporative emission rates of these five groups, assuming an average vehicle speed of 28 miles per hour.

'Preliminary EPA tests have shown that gasoline evaporation during vehicle operation on warm days (called "running loss") is significantly higher than previously thought. Details of this adjustment are discussed later.
} 
Table 6-I-Summary of 1985 VOC Emissions in Nonattainment Cities and Attainment Regions

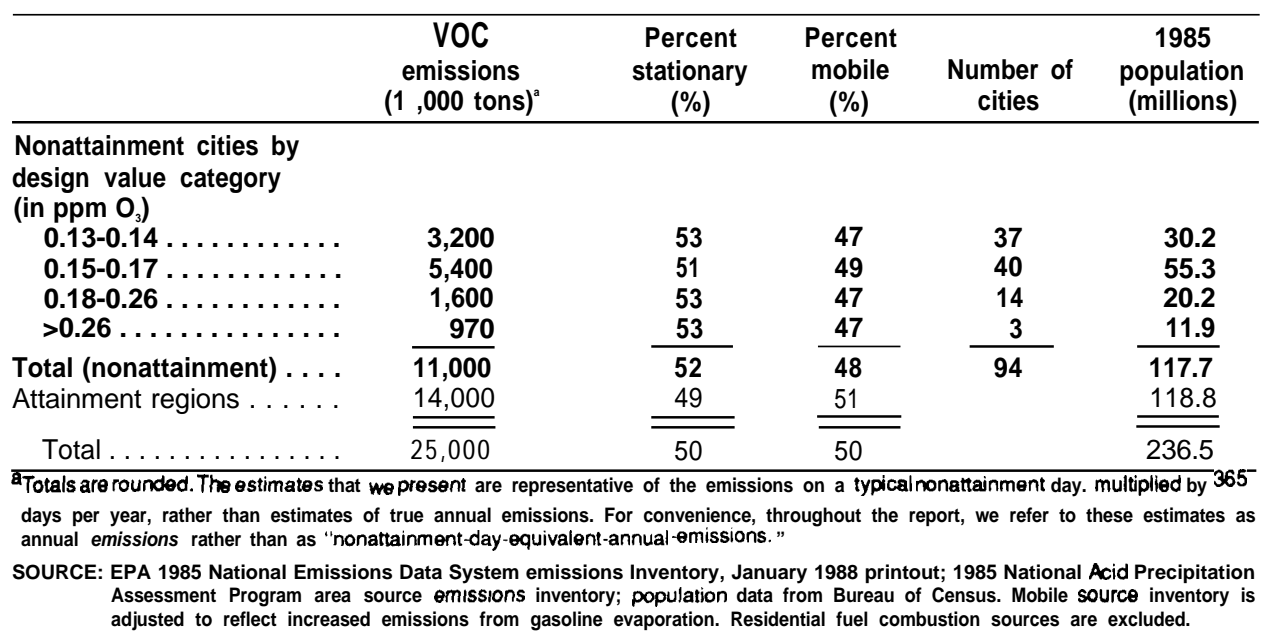

sis, an area is considered nonattainment if its design value is greater than 0.12 parts per million (ppm) ozone according to EPA-published 1983-85 ozone monitoring data. ${ }^{3}$ EPA's actual determination of nonattainment is based on a slightly different method, but the resulting number of nonattainment cities are essentially the same. Our number of nonattainment areas differs Ii-em EPA's count of 61 because, in several cases, EPA has used Consolidated Metropolitan Statistical Areas (CMSAs), rather than cities. Several of these CMSAs include two or more cities that we have considered separately. These regions contain about half of the Nation's population.

Our estimates of emissions throughout this analysis are subject to potentially significant uncertainty. We estimate that VOC emissions in nonattainment cities could be as low as 8 million or as high as 14 million tons per year in 1985 depending on several important mobile and stationary source assumptions. Uncertainties in the emissions inventory are discussed in more detail in a later section.

Figure 6-1 displays the percent contribution of various source categories to the total 1985 VOC emissions in nonattainment cities. About threequarters of the emissions are generated from three main categories: mobile sources, surface coating, and other organic solvent evaporation from stationary sources, About 43 percent of the 1985 emissions inventory is composed of highway vehicle emissions. A further breakdown of the data, shown in figure 6-2, reveals that passenger cars are the largest contributors within the highway vehicle category, with about one-third of the total 1985 nonattainment area VOC emissions, followed by light-duty gasoline trucks with 7 percent.

Surface coatings contributed about 9 percent of the total VOC emissions in 1985. Surface coatings are used in the manufacture of a wide variety of products including automobiles, furniture, large appliances, and other metal and plastic products; printing inks and many other applications are also included. Organic solvent evaporation from stationary sources other than from surface coatings contributed about 15 percent of the total VOC emissions in 1985. The sources within this category are extremely varied and include such activities as decreasing of metal parts and products, drycleaning, consumer and commercial products, and cutback asphalt paving.

The range of individual source sizes (as defined by their individual annual VOC emission rates) can also be quite wide, ranging from a small gas station

${ }^{3}$ The list of cities exceeding the standard during the 19116-88 period had not been released by EPA at the time of this analysis. We used the 1983-85 period in our analysis, rather than the most recent list available because we felt it is more representative of current nonattainment status. 
Figure 6-I-Volatile Organic Compound (VOC) Emissions in Nonattainment Cities, by Source Category, in 1985

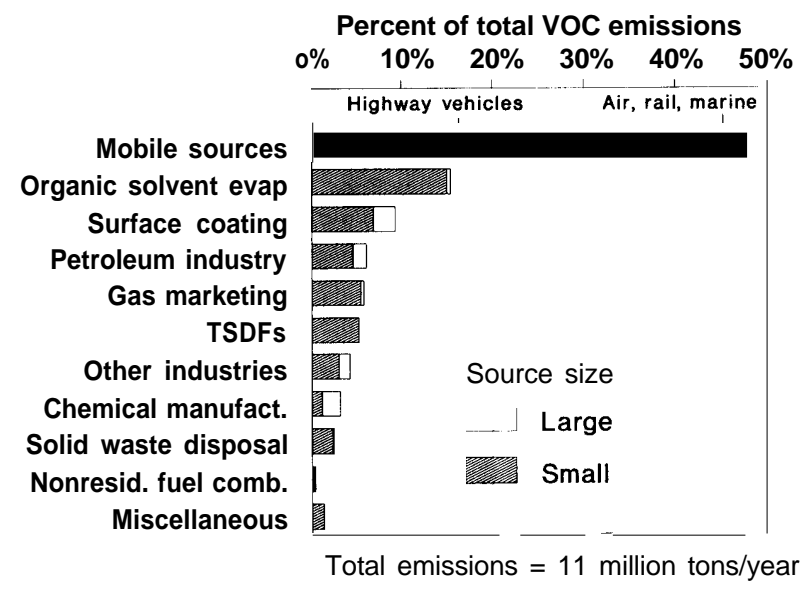

Stationary sources that emit more than 50 tons per year of VOC are included in the "Large" categories

SOURCE: OTA, from EPA's National Emissions Data System (NEDS) and National Acid Precipitation Assessment Program emissions inventories.

decreasing tank that emits less than a ton per year, to large industrial operations that contain evaporation sources emitting several hundred tons per year. Figure 6-1 shows that solvent evaporation (including surface coatings) from small stationary sources emitting less than 50 tons per year contributes about 20 percent of total VOC emissions.

Figure 6-3 displays the breakdown of stationary source emissions by source size. About 45 percent of the total 1985 VOC emissions originated from stationary sources that emit less than 50 tons per year. Because of the way EPA constructs the NEDS emissions inventory, it is not possible to show, with much certainty, a more detailed breakdown of the "less-than-50-tons-per-year" size class. ${ }^{4}$ However, we do know that at least 1 percent of the inventory comes from sources emitting between 25 and 50 tons per year, and that this contribution could be as high

\section{Figure 6-2-Volatile Organic Compound Emissions From Mobile Sources in 1985 as a Percentage of Total (mobile plus stationary) Emissions in Nonattainment Cities}

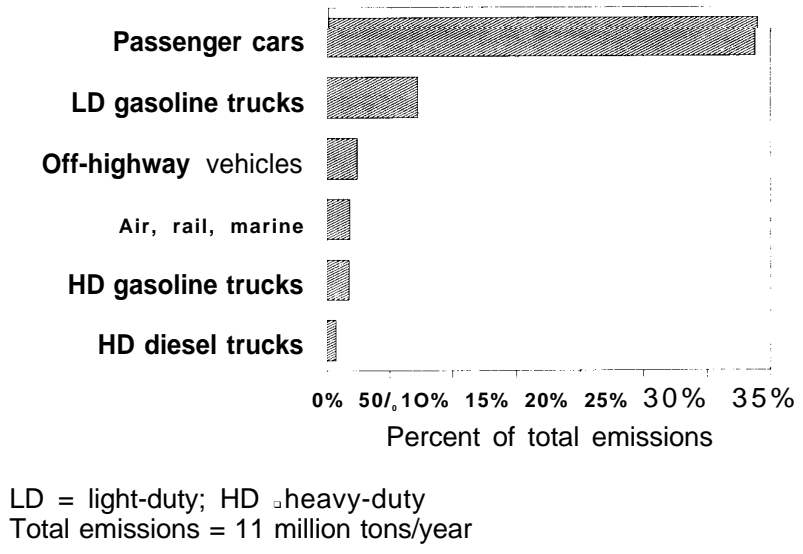

SOURCE: OTA, from EPA's National Emissions Data System (NEDS), National Acid Precipitation Assessment Program emission inventory, and MOBILE-4 modal.

as 30 to 35 percent. We have chosen 15 percent as a "rough guess," assuming that about a third of the small aggregated VOC stationary sources in the inventory (for which no source size can be identified) may, individually, emit more than 25 tons per years The uncertainty in actual sizes of the less-than50-ton sources does not diminish the significant contribution they make to total VOC emissions.

\section{Future VOC Emissions}

Tables 6-2 through 6-4 display our projections of VOC emissions in 5, 10, and 15 years-1994, 1999, and 2004-assuming that existing State and EPA regulations do not change. These projections serve as a baseline from which to gauge the effectiveness of future regulations; for example, the changes proposed in recent congressional bills or EPA's proposed post-1987 ozone policy. Under regulations in place as of 1987, total VOC emissions would decline approximately 6 percent by 1994 compared

${ }^{4}$ EPA requires States to report VOC emissions from individual sources that emit more than 50 tons per year. If a large "facility" (that contains more than one source) emits more than 100 tons per year of VOCs, each individual source emitting more than 25 tons per year within that facility must also be reported, EPA uses a "market-balance" approach to indirectly estimate the aggregate remaining emissions from small sources that are not required to report their emissions. Determination of individual source sizes is, therefore, not possible for these small size categories.

${ }^{5}$ The 25-ton-per-year size cutoff waschosen ${ }_{\star}$ thatwe could analyze (in a later section) the emissions reduction potential frOm stationary sources greater than 25 tons per year. The Clean Air Act currently requires that, at a minimum, all stationary VOC sources that emit more than 100 tons per year in nonattainment areas must adopt "reasonably available" control methods, though this cutoff is lower for some categories. 
Figure 6-3-Stationary Source Emissions of Volatile Organic Compounds (VOCs) in 1985 as a Percentage of the Total Emissions inventory, by Size of the individual Source

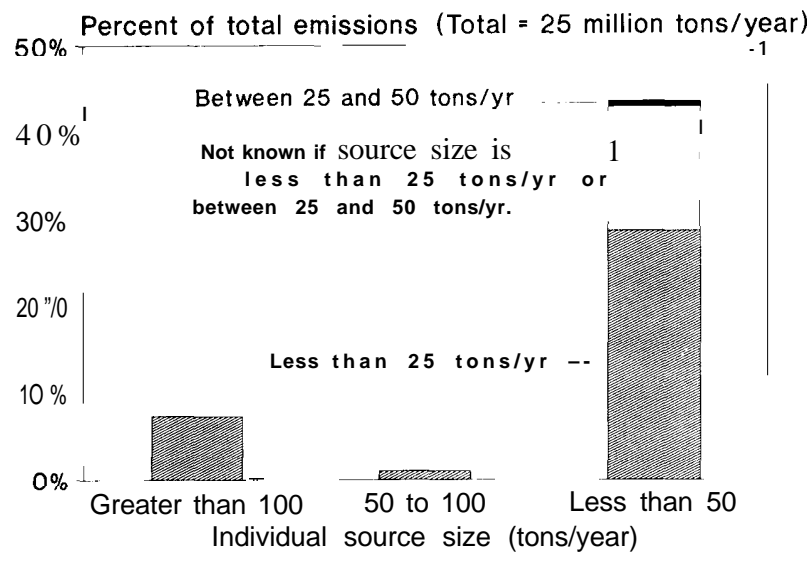

Each bar displays the percentage of total VOC emissions that are contributed by each source-size class. For example, about 45 percent of total emissions come from sources that emit less than 50 tons per year. Because of the way the 1985 emissions inventory is constructed, we are unable to give a more precise detailed breakdown within the "*Less-than-50 tons-per-year" category. We have assumed that sources that emit between 25 and 100 tons per year account for about 15 percent of the total VOC emissions; this percentage could be as high as 30 to 35 percent.

SOURCE: OTA, from EPA's National Emissions Data System (NEDS) and National Acid Precipitation Assessment Program emissions inventories.

to 1985 levels. Note that the baseline does not include reductions due to the recently promulgated limit on gasoline volatility of 10.5 psi Reid vapor pressure (RVP).

Total emissions are expected to start increasing again sometime after 1999, showing a net increase of 1 percent in 2004 compared to 1985 levels. Our estimates of future emissions depend on several key assumptions regarding stationary and mobile sources and are subject to potentially significant uncertainty. These assumptions, and their effects on total future emissions estimates, are discussed in more detail in a later section.
Total VOC emissions drop between 1985 and 1994 due to lower emission rates from cars and trucks. ${ }^{6}$ Although the number of vehicle-milestraveled is forecast to increase in many areas over this period, the gradual replacement of current vehicles with newer, cleaner ones will result in an overall decline in highway vehicle emissions. Figure 6-4 shows mobile and stationary source VOC emissions through time. VOC emissions from highway vehicles are projected to decline by about 25 percent between 1985 and 1999. Stationary source emissions, on the other hand, are forecast to increase steadily between 1985 and 2004, showing a 10percent increase by 1994 and a 23-percent increase by 2004, over 1985 levels. 'Growth of small (less than 50 ton-per-year) stationary VOC source emissions is one of the most important reasons why overall VOC emissions are not expected to decline more rapidly in the earlier years and why total emissions may show a net increase after 1999. This source category effectively offsets much of the emissions reductions realized from highway vehicles.

\section{Analysis of Important Assumptions Used in VOC Emissions Estimates}

In this section, we address some of the assumptions used in our emissions estimates presented above. The assumptions we tested include: 1) the rate of gasoline evaporation from in-use highway vehicles ("running losses"), 2) average highwayvehicle speeds, 3) exhaust emission rates from passenger cars after 50,000 miles of use, 4) level of compliance with existing stationary source VOC regulations, 5) emissions from organic solvent evaporation sources, and 6) emissions from hazardous waste treatment, storage, and disposal facilities (TSDFs). Figures 6-5 and 6-6 and table 6-5 display our estimates of uncertainty for these categories.

We estimate total VOC emissions in nonattainment cities would be about 10 million tons per year

${ }^{6}$ Future highway vehicle emissions were projected using EPA estimates of future highway vehicle VOC emission rates, combined with estimates of average yearly miles-traveled per person and Census Bureau population projections.

${ }^{7}$ Future large stationary source (greater than 50 tons per year) emissions were estimatedusing projections of industrial employment growth within various industrial categories, while small source growth was based either on industrial employment, estimates of population growth, or growth in the gross national product per capita [17] [22] [23]. 
Table 6-2-Summary of 1994 VOC Emissions in Nonattainment Cities and Attainment Regions (emissions in 1,000 tons per year) ${ }^{2}$

\begin{tabular}{|c|c|c|c|c|c|c|}
\hline & \multicolumn{3}{|c|}{ VOC emissions } & \multicolumn{3}{|c|}{ Change from 1985 emissions } \\
\hline & Total & Stationary & Mobile & Total & Stationary & Mobile \\
\hline 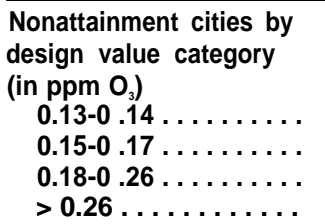 & $\begin{array}{r}3,000 \\
5,100 \\
1,500 \\
890\end{array}$ & $\begin{array}{r}1,800 \\
3,000 \\
940 \\
570\end{array}$ & $\begin{array}{r}1,100 \\
2,000 \\
590 \\
320\end{array}$ & $\begin{array}{l}-7 \% \\
-770 \\
-6 \% \\
-90 / 0\end{array}$ & $\begin{array}{r}8 \% \\
90 / 0 \\
8 \% \\
10 \%\end{array}$ & $\begin{array}{l}-24 \% \\
-23 \% \\
-22 \% \\
-30 \%\end{array}$ \\
\hline $\begin{array}{l}\text { Total (nonattainment) . . } \\
\text { Attainment regions . . }\end{array}$ & $\begin{array}{l}10,000 \\
13,000 \\
\end{array}$ & $\begin{array}{l}6,400 \\
7,500 \\
\end{array}$ & $\begin{array}{l}4,100 \\
\mathbf{5 , 6 0 0} \\
\end{array}$ & $\begin{array}{l}-770 \\
-5 \% \\
\end{array}$ & $\begin{array}{r}90 / 0 \\
11 \% \\
\end{array}$ & $\begin{array}{l}-24 \% \\
-20 \% \\
\end{array}$ \\
\hline Total . . . . . . . . & $\overline{24,000}$ & 14,000 & 9,700 & $-6^{\circ} \mathrm{A}$ & $10 “ l '$ & $-22 \%$ \\
\hline \multicolumn{7}{|c|}{$\begin{array}{l}\text { Totals are rounded. Assumes no regulations other thanthose in place in } 1987 \text {. The estimates that we present are representative of the } \\
\text { emissions on a typical nonattainment day, multiplied by } 365 \text { days per year, rather than estimates of true annual emissions. Fo } \\
\text { convenience, throughout the report, we refer to these estimates as annual emissions rather thanas "nonattainment-day equivalent-annual } \\
\text { emissions." Note that the baseline does not include reductions due to the recently promulgated limit on gasoline volatility of } 10.5 \text { ps Rei } \\
\text { vapor pressure (RVP). }\end{array}$} \\
\hline
\end{tabular}

Table 6-3-Summary of 1999 VOC Emissions in Nonattainment Cities and Attainment Regions (emissions in 1,000 tons per year) ${ }^{a}$

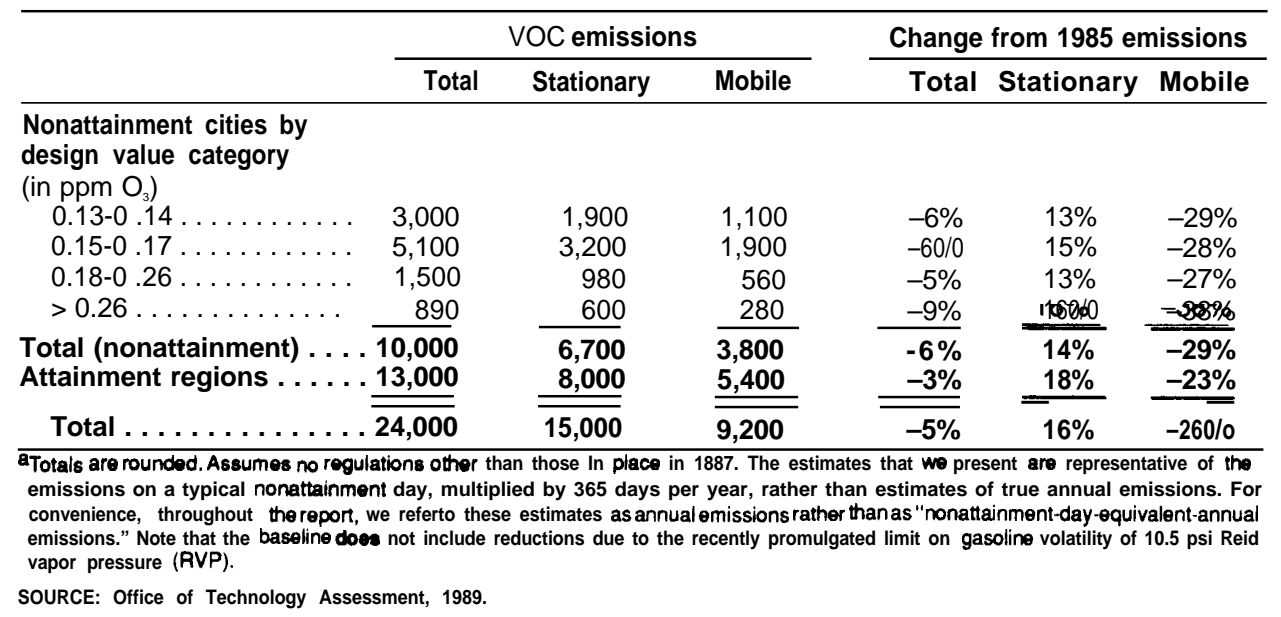

in 1994, again assuming the regulations in place as of $1987 .{ }^{8}$ This total could be as low as 7 million or as high as 13 million tons per year given a range of variability in all the assumptions listed above. Of all the assumptions we tested, running losses appear to have the most significant effect on total VOC emissions in nonattainment cities. The following discussion presents a more detailed account of our analysis of the five categories of uncertainty which we were able to analyze.

${ }^{8}$ This estimate assumes running losses equal to 1.5 grams per mile, average highway vehicle speeds equal to 28 miles per hour, 100 percent compliance with all existing stationary source VOC regulations, EPA's 1985 estimate of organic solvent use and TSDF emissions, and unadjusted in-use vehicle tailpipe emission rates. 
Table 6-4-Summary of 2004 VOC Emissions in Nonattainment Cities and Attainment Regions (emissions in 1,000 tons per year) ${ }^{2}$

\begin{tabular}{|c|c|c|c|c|c|c|}
\hline & \multicolumn{3}{|c|}{ VOC emissions } & \multicolumn{3}{|c|}{ Change from 1985 emissions } \\
\hline & Total & Stationary & Mobile & Total & Stationary & Mobile \\
\hline 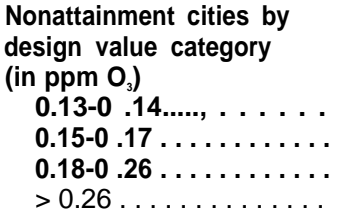 & $\begin{array}{r}3,100 \\
5,400 \\
1,600 \\
930 \\
\end{array}$ & $\begin{array}{r}2,000 \\
3,400 \\
1,000 \\
640 \\
\end{array}$ & $\begin{array}{c}1,100 \\
2,000 \\
590 \\
2 \\
\end{array}$ & $\begin{array}{r}-20 / 0 \\
-10 / 0 \\
0 \% \\
94 \% \\
\end{array}$ & $\begin{array}{l}20 \% \\
210 / 0 \\
19 \% \\
24 \% \\
\end{array}$ & $\begin{array}{l}-26 \% \\
-240 / 0 \\
-22 \% \\
-36 \%\end{array}$ \\
\hline $\begin{array}{l}\text { Total (nonattainment) . . . . } \\
\text { Attainment regions . . . . }\end{array}$ & $\begin{array}{l}11,000 \\
14,000 \\
\end{array}$ & $\begin{array}{r}7,100 \\
8,500 \\
\end{array}$ & $\begin{array}{l}4,000 \\
5,700 \\
\end{array}$ & $\begin{array}{r}-1 \% \\
3 \% \\
\end{array}$ & $\begin{array}{l}21 " / 0 \\
26 \%\end{array}$ & $\begin{array}{l}-250 / \\
-18 ? 40\end{array}$ \\
\hline Total . . . . . . . . . . . & 25,000 & 16,000 & 9,700 & $1 \%$ & $23 \%$ & $-21 \%$ \\
\hline \multicolumn{7}{|c|}{$\begin{array}{l}\text { a Totals are rounded. Assumes no regulations other than those in place in } 1967 \text {. The estimates that we present are representative of the } \\
\text { emissions on a typical nonattainment day, multiplied by } 365 \text { days per year, rather than estimates of true annual emissions. For } \\
\text { convenience, throughout thereport, wereferto these estimates as annual emissions rather than as "nonattainmentday-equivalent-annual- } \\
\text { emissions." Note that the baseline doee not include reductions due to the recently promulgated limit on gasoline volatility of } 10.5 \text { psi Reid } \\
\text { vapor pressure (RVP). }\end{array}$} \\
\hline
\end{tabular}

Rate of Gasoline Evaporation From In-Use Highway Vehicles

Preliminary results from EPA tests on 34 passenger cars and light-duty trucks [31] have shown that on hot summer days gasoline evaporation from the fuel system ("running losses") may significantly increase total vehicle emissions. The magnitude of additional emissions from running losses will vary from city to city depending factors such as ambient temperature and gasoline volatility. For example, in nonattainment cities with relatively moderate ambient summertime temperatures (e.g., 79 'F) and gasoline volatilities of around 11.5 pounds per square inch (psi) (e.g., Washington, DC), EPA's MOBILE-4 model estimates that fleet average running losses are about 1.5 grams of VOC emitted per mile driven in 1985. In cities with higher ambient temperatures $\left(87^{\circ} \mathrm{F}\right)$ and gasoline volatilities (1 1.7 psi), such as New York City, fleet average running losses are estimated to be about 2.9 grams per mile.

Figure 6-7 shows how varying running losses affects individual vehicle emission rates in nonat- tainment cities. ${ }^{9}$ A running loss of 1.5 grams per mile increases passenger car emission rates by about 34 percent; at 2.5 grams per mile, emission rates are about 58 percent higher than those which do not account for running losses. For passenger cars, gasoline evaporation contributes about 60 percent of the total in-use VOC emissions at a running loss of 1.5 grams per mile. Running losses represent a potentially large source of VOC emissions which are not included in EPA's 1985 NEDS mobile source inventory.

MOBILE-4 assumes that fleet average running losses will decline in the future as newer, cleaner vehicles replace older ones. However, because of the limited number of vehicles tested thus far, we believe it would be premature to predict future trends in running loss emission rates due solely to vehicle changes made for other reasons. Our estimates of current and future highway vehicle emissions presented above, and throughout our analysis, have been adjusted to reflect an additional 1.5 grams per mile emission rate due to running

${ }^{9}$ Exhaust emission rates shown in the figure do not include the effects of current motor vehicleinspection and maintenance (L/M) programs. We estimate that current $\mathbf{L} / \mathbf{M}$ programs reduce exhaust emissions by about 12 percent. Estimates of exhaust emission rates assume average vehicle speeds of 28 miles per hour, Emission rates for vehicles in Californiawill be lower since the State maintains a summertime gasoline volatility limit of 9 pounds per square inch. 


\section{Figure 6-4-Summary of Estimated Nationwide Voiltile Organic Compound Emissions by Source Category, by Year}

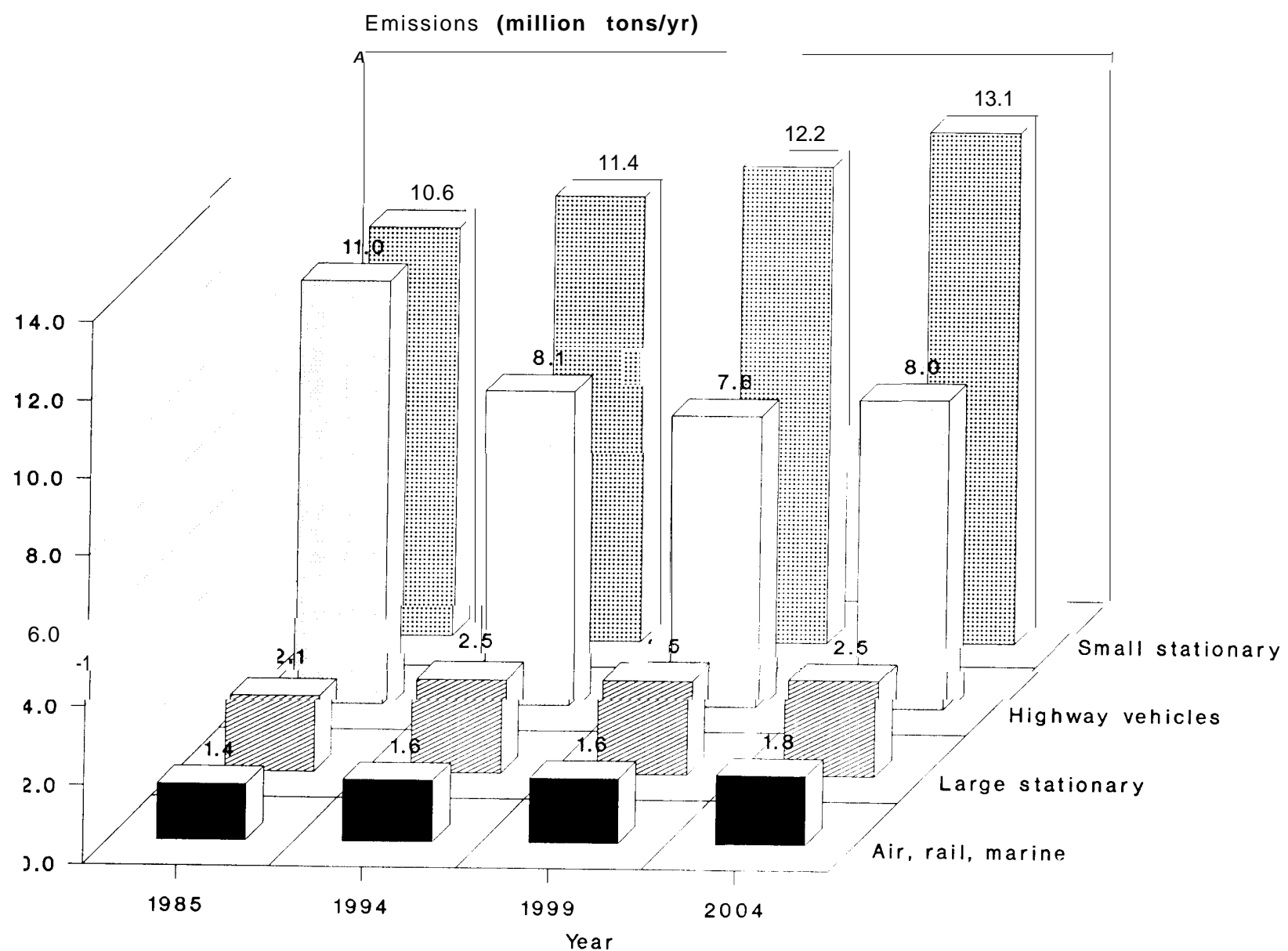

The numbers directly above the boxes are the total emissions within the source category. For example, emissions from highway vehicles in 1994 are 8.1 million tons per year, nationwide. "Small stationary" sources emit less than 5\%ons per year. Assumes no regulations other than those in place in 1987. The estimates that we present are representative of the emissions on a typical nonattainment day, multiplied by 365 days per year, rather than estimates of true annual emissions. For convenience, throughout the report, we refer to these estimates as annual emissions rather than as "nonattainment-day-equivalent-annual-emissions." Note that the baseline does not include reductions due to the recently promulgated limit on gasoline volatility of $\mathbf{1 0 . 5}$ psi Reid vapor pressure (RVP).

SOURCE: Office of Technology Assessment, 1989.

losses (0.5 gram per mile in California). ${ }^{10}$ If running losses are omitted from current highway vehicle emission rates (i.e., assumed to be zero grams per mile), we estimate that total VOC emissions in nonattainment cities decrease by about 10 percent in 1985 . At 2.5 grams per mile, total emissions increase by about 6 percent in 1985 . Although running losses add a potentially signifi-

10The VMT-weighted fleetwide average running loss for the five regional areas in 1985 (see footnote 1), as derived from EPA's MOBILE-4 model, is about 2 grams per mile, while after 20 to 25 years it is predicted to be about 1 gram per mile. For our analysis, we chose a fleetwide average estimate in the middle of this range-1.5 grams per mile-which, based on MOBILE-4 data, would be expected to occur sometime in the 1990s. In regions with relatively higher ambient summertime temperatures and gasoline volatilities, MOBILE-4 estimates that fleetwide average running losses are between about 2 and 3 grams per mile in 1985 . Therefore, we chose 2.5 grams per mile as a high estimate. MOBILE-4 data estimates that lowering gasoline volatility from 11.5 to 9.0 psi will reduce running losses by about two-thirds, In general, light-duty gasoline trucks probably have lower running losses than passenger cars. California emission rates are estimated assuming a gasoline volatility of $9.0 \mathrm{psi}$. 
Figure 6-5-Uncertainty in Highway-Vehicle VOC Emissions in Nonattainment Areas in 1904

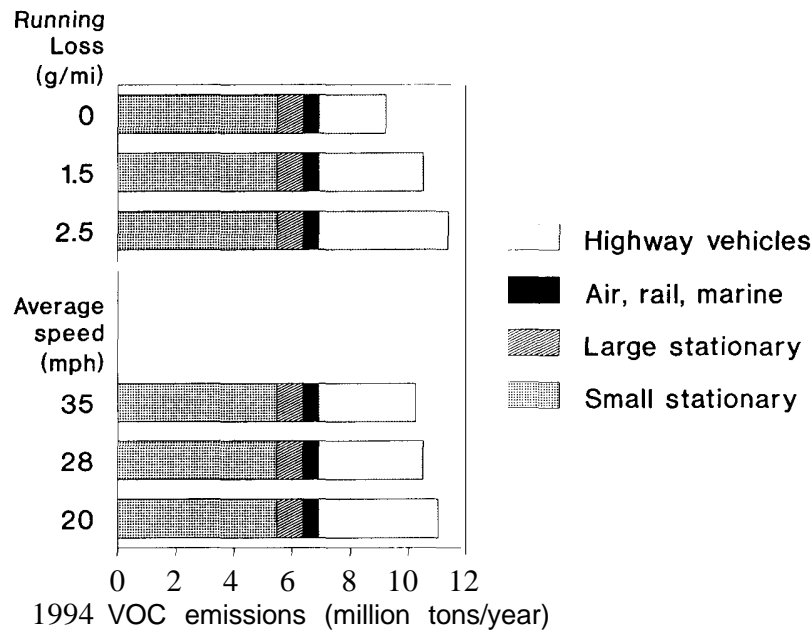

Throughout our analysis, we assume a 1.5 grams-per-mile running loss and average vehicle speeds of 28 miles per hour.

SOURCE: Office of Technology Assessment, 1989.

cant amount of emissions to existing inventones, these additional emissions, as we will show later, can be largely controlled by lowering current gasoline volatility limits.

\section{Average Highway-Vehicle Speeds}

Vehicle speed affects the rate at which pollutants are emitted from the tailpipe. VOC exhaust emissions generally increase with decreasing vehicle speed. A recent study found that the average automobile speed in 10 principal U.S. cities was about 27 miles per hour in 1980 [14]. In southern California, highway vehicle speeds are expected to decrease to about 19 miles per hour by 2010 if no further regional transportation improvements are adopted [16].

Our estimates of current and future highway vehicle emissions throughout our analysis are calculated assuming average speeds of 28 miles per hour for all cities [12,14]. If average speeds are reduced from 28 to 20 miles per hour, we estimate that total VOC emissions in nonattainment areas increase by about 7 percent, from about 11.2 million

\section{Figure 6-6-Uncertainty in Stationary-Source VOC Emissions in Nonattainment Areas in 1994}

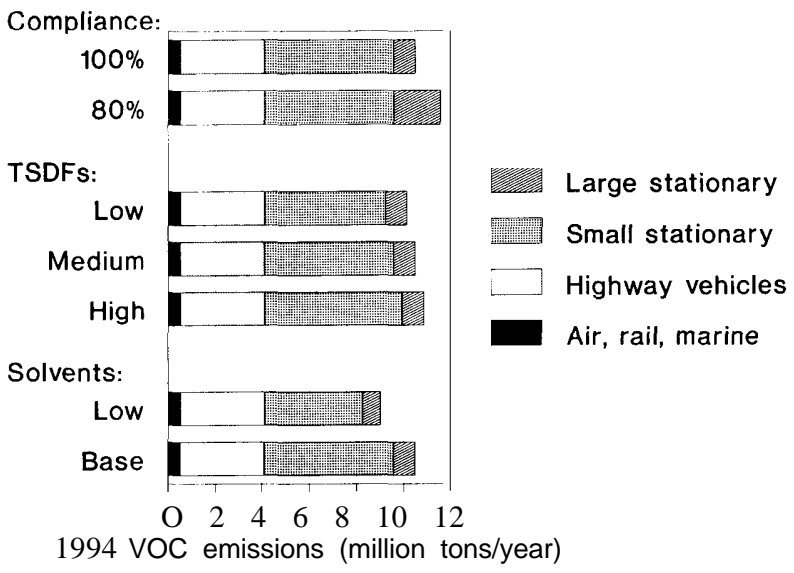

Throughout our analysis, we assume that: 1) stationary sources are in 100 percent compliance with existing VOC regulations, and 2) emissions from hazardous waste treatment, storage, and disposal facilities (TSDFs) (shown in the "medium" category) and organic solvent evaporation sources (shown in the "base") are the same as what is reported in the 1985 NAPAP inventory.

SOURCE: Office of Technology Assessment, 1989.

tons to about 12.1 million tons per year in 1985. If speeds increase from 28 to 35 miles per hour, nonattainment area total VOC emissions decrease by about 4 percent, to about 10.8 million tons per year in 1985 .

\section{Lower Passenger Car Tailpipe Emission Rates}

We have also analyzed one automobile manufacturer's assertion that cars built over the past several years emit at lower rates than EPA estimates. The manufacturer claims that improvements in passenger car emission control systems since 1981 were not reflected in the data used by EPA to estimate emissions from this vehicle class [10]. Test results on several hundred 1982-through-1986 model-year cars showed lower tailpipe VOC emissions after 50,000 miles of vehicle use compared to estimates used by EPA in compiling the 1985 mobile source inventory. If these new passenger car estimates are

\footnotetext{
${ }_{\text {EPA }}^{11}$ assumes that in-use exhaust emission rates for cars manufactured after 1982 are about 1 gram per mile. The test results showed emission rates about 0.6 gram per mile lower than EPA's estimate which would mean that these vehicles now meet the current 0.41 -gram-per-mile hydrocarbon standard after 50,000 miles of use.
} 
Table 6-5-Estimate of Uncertainty in Volatile Organic Compound Emissions in Nonattainment Cities

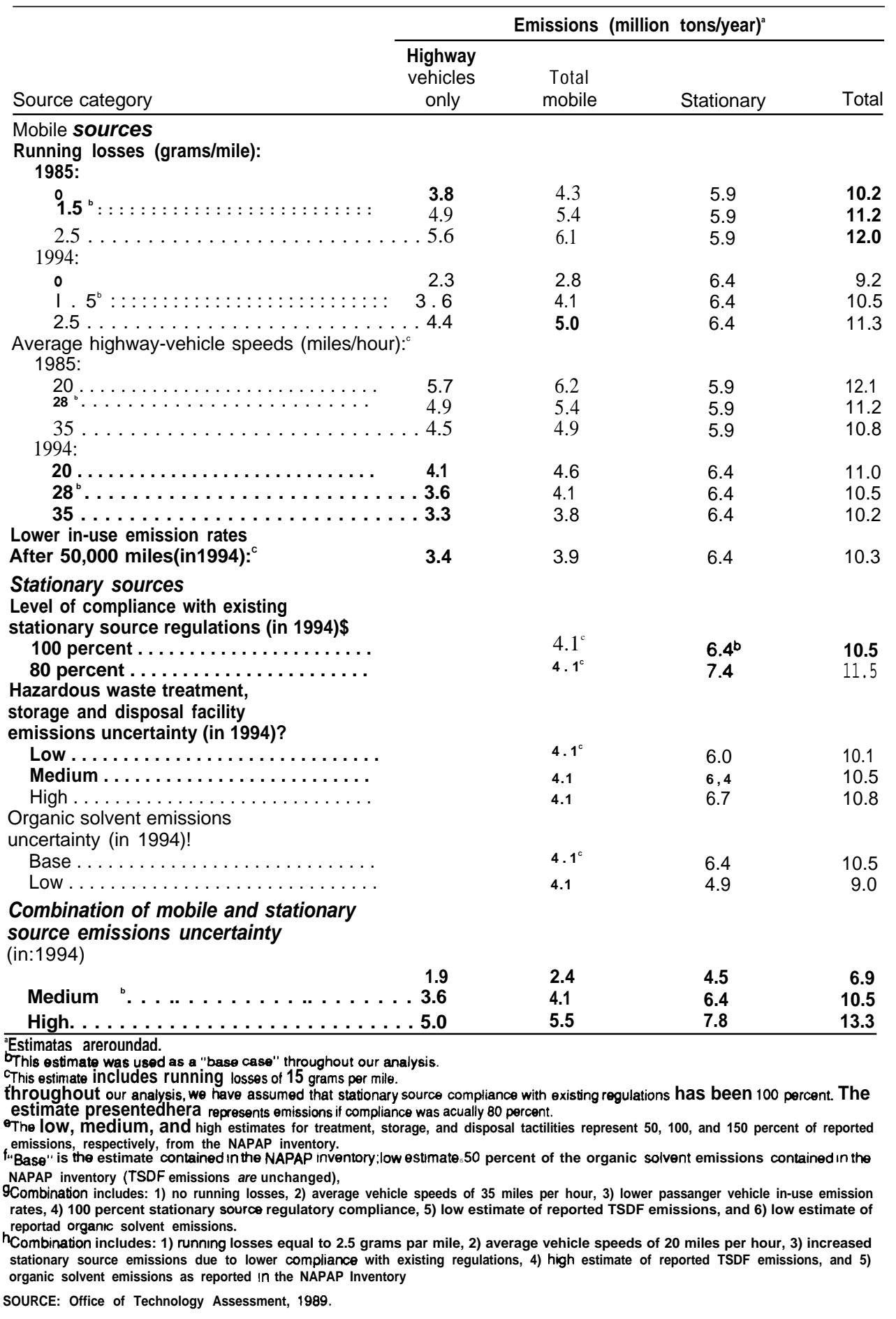




\section{Figure 6-7-Effect of Running Losses on Passenger- Car Emission Rates in Nonattainment Cities in 1985}

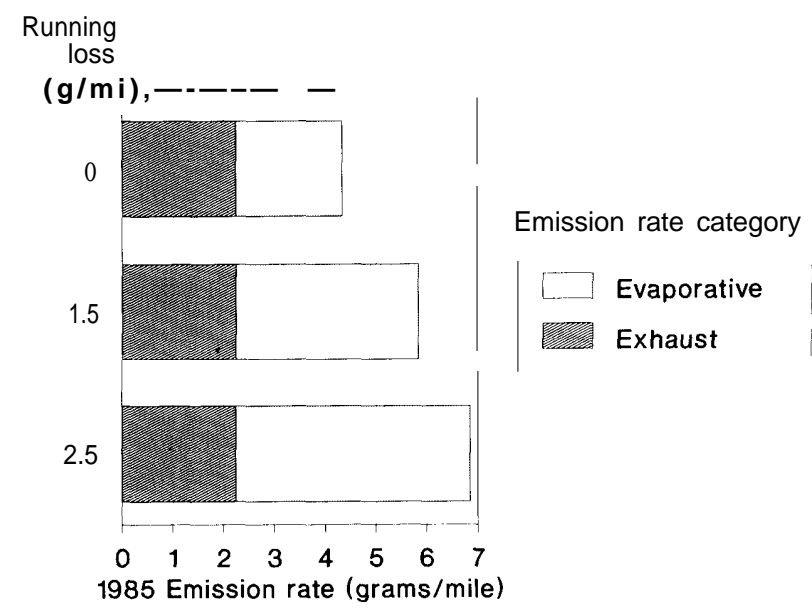

Exhaust emission rates do not include the effects of current motor vehicle inspection and maintenance $(\mathrm{l} / \mathrm{M})$ programs. We estimate that current I/M programs reduce exhaust emissions by about 12 percent. Estimates of exhaust emission rates assume average vehicle speeds of 28 miles per hour. Emission rates for vehicles in California will be lower since the State maintains a summertime gasoline volatility limit of 9.0 pounds per square inch.

SOURCE: Office of Technology Assessment, 1989.

substituted into the current emissions inventory, we estimate that total VOC emissions in nonattainment cities will be reduced by about 2 percent in 1994 .

\section{Level of Compliance With Existing Stationary Source VOC Regulations}

Each year, the States submit emissions data to EPA for inclusion in the NEDS inventory. Most States assume that all affected sources have complied fully with existing emission control rules and regulations. However, EPA no longer believes that rules are fully effective across all sources, all source categories, and over time. In fact, EPA recently proposed that States estimate their emissions based on an assumed compliance of no more than 80 percent [7]. Therefore, VOC emissions for some source categories in the 1985 NEDS inventory may be much higher than reported. ${ }^{12}$

We estimate that at least 1 million tons could be missing from 1985 stationary source totals for nonattainment cities, assuming that existing controls on selected stationary sources are only 80 percent as effective as reported. *3 Therefore, total nonattainment area emissions reported in 1985 may be 10 percent too low.

\section{Uncertainty in Hazardous Waste Treatment, Storage, and Disposal Facility Emissions}

VOC emissions data from hazardous waste TSDFs in the 1985 NAPAP inventory were derived from two EPA reports [30,34]. Because of discrepancies in total TSDF emissions between these two sources and local air pollution control agency emission inventories, we believe that the 1.4 million tons per year of emissions in the 1985 NAPAP inventory could be subject to significant uncertainty. If we assume that TSDF emissions are 50 percent higher than what is reported in the NAPAP inventory, our estimate of total VOC emissions in 1994 in nonattainment cities would increase by about 3 percent. Similarly, if we assume that TSDF emissions are 50 percent lower than what is currently reported, total emissions would decrease by about 3 percent.

\section{Uncertainty in Organic Solvent Emissions}

As figure 6-1 shows, organic solvent evaporation sources, including surface coatings, account for about one-quarter of total 1985 emissions in nonattainment cities. The majority of these emissions originate from sources that emit less than 50 tons per year. The uncertainty associated with the method that EPA uses to estimate emissions from these small sources (see footnote 4) may be quite significant. In particular, since many State and local regulations requiring emission controls on these

\footnotetext{
${ }^{12}$ For example, if the State reported that a control technology on a particular source was 75 percenteffective at reducing uncontrolled emissions, 'e may assume that the actual control efficiency was SO percent of this value. The resulting controlled emission would then be 60 percent higher than previously reported.

${ }^{13}$ This estimate includes only large stationary sources that reported using control equipment designed to trap or destroy excess emissions (e.g., carbon adsorber, incinerator).

${ }^{14} \mathrm{EPA}$ 's method assumes that all the organic solvent produced and consumed nationwide is emitted to the atmosphere. In fact, some Of the solvent used in various processes may be captured by control devices mandated by State or local regulations. Therefore, in some cases, solvent emissions may be less than solvent consumption.
} 
sources may not be factored into the estimates contained in the inventory, these emissions may be overestimated.

If we assume, as a lower bound estimate, that organic solvent emissions are 50 percent lower than what is reported in the inventory, total VOC emissions in nonattainment cities in 1994 would decline about 14 percent from 10.5 million to about 9 million tons per year.

Our projections for large stationary source emissions in all source categories (including organic solvents) could be somewhat high because we are unable to explicitly model all of the control requirements in the Clean Air Act pertaining to new and modified large VOC emission sources in nonattainment areas. ${ }^{55}$ However, the effect on our overall emissions estimates is small because, as illustrated in figure 6-4, small stationary source growth will have a much more significant impact on future estimates of total VOC emissions than large stationary sources. Inmost States, these more stringent new source regulations do not apply to small sources.

Finally, it is important to recognize that all emission inventories have an inherent, unquantified, level of uncertainty. Given this drawback, any interpretation of emissions inventory data, including those presented in this report, must be made with caution.

\section{POTENTIAL EMISSIONS REDUCTIONS FROM VOC CONTROL STRATEGIES ANALYZED BY OTA}

In this section we analyze the VOC emissions reductions from source-specific control strategies currently being considered by the Congress and EPA. We also show how these potential emissions reductions compare with estimates of the overall emissions reductions needed to attain the ozone standard in each nonattainment city. Discussion of the costs of these control strategies appears in the section Costs of Control Strategies.
We are able to analyze the following sourcespecific control strategies:

- adoption of "reasonably available control technologies" (RACT) on all existing stationary sources for which a regulation already exists in any State Implementation Plan;

- adoption of new Control Technique Guidelines (CTGs) - RACT-level controls for several existing stationary sources of VOC for which EPA has not issued control guidelines and not previously subject to regulation in any State Implementation Plan;

- emission controls on hazardous waste TSDFs;

- establishment of new federally regulated controls on architectural surface coatings;

- "Onboard" technology on motor vehicles to capture gasoline vapor during refueling;

- "Stage II" control devices on gas pumps to capture gasoline vapor during motor vehicle refueling;

- inspection and maintenance (I/M) programs for highway vehicles;

- more stringent exhaust emission standards for gasoline highway vehicles;

- new Federal restrictions on gasoline volatility; and

- the use of methanol instead of gasoline as a fuel for vehicles in centrally owned fleets in the worst nonattainment cities.

Transportation control measures that limit motor vehicle use are potentially important control strategies that we are unable to analyze. These measures are discussed in more detail in chapter 7 .

Throughout the analysis, emissions reductions reported apply to the change occurring between 1985 and the relevant future year. The emissions reductions reported in our analysis result from currently available control technologies that we believe can be applied in the near-term. We were able to analyze the emissions reduction potential and associated control costs for methods applicable to about 85 percent of current VOC emissions. The remaining 15 percent of $\mathrm{VOC}$ emissions come primarily from stationary sources for which we

\footnotetext{
${ }^{15}$ These regulations require that new stationary sources with the potential to emit more than 100 tons per year install the most stringent emission controls possible and that VOC emissions from other existing sources in the area be reduced so that there will be a net decline in emissions after new operations commence. These same control requirements apply to major modifications of existing sources that result in a VOC emissions increase of more than 40 tons per year.
} 
either could not find applicable control technologies or that we could not analyze because of a lack of suitable information. We believe that the large majority of emission reductions possible with currently available control technologies are accounted for in our analysis. This does not imply that additional VOC reductions beyond those analyzed here are not possible, but that they should not be counted on within the next 5 to 10 years.

All control methods listed above apply to nonattainment cities. Several control methods apply nationwide, not just in nonattainment cities, including: Federal controls on architectural surface coatings, Onboard controls, more stringent highwayvehicle emission standards and gasoline volatility limitations.

Figure 6-8 displays our estimates of emissions reductions resulting from each control category in 1994 and 2004, as a percentage reduction below total 1985 emissions in nonattainment cities. By 1994, total reductions average about 34 percent in nonattainment cities. The largest reductions come from limiting gasoline volatility and controls on hazardous waste TSDFs. ${ }^{16}$ The percentage reductions for most categories are about the same in 1994 and 2004, except for Onboard controls and new highwayvehicle standards which increase because more of the older vehicles will have been replaced by newer ones equipped with additional controls.

Tables 6-6 through 6-8 present estimates of emissions reductions achieved in 1994, 1999, and 2004, respectively, if the various control strategies listed above are applied. We estimate that VOC emissions in nonattainment cities can be reduced by 3.8 million tons per year in 1994, about 34 percent below 1985 levels. ${ }^{17}$ Due to uncertainty in the emissions inventory and the degree to which future emissions can be controlled, total emissions reductions from all the control measures we analyzed in 1994 may range between 1.5 million to 5.0 million tons per year in nonattainment cities, or about 18 to 37 percent of 1985 levels. (Emissions reduction uncertainties are discussed in more detail in a later section.) Because some measures are not restricted to nonattainment areas, about 6.5 million tons per year would be eliminated nationwide. Total emissions reductions in 2004 in nonattainment areas are about the same as those in $1994 .^{18}$

Again, we must stress that these estimates are for emissions reductions from the additional controls that we are able to analyze. Higher percentages may be possible, but they should not be counted on in the near term. In addition, the remaining 15 percent of the inventory for which we were unable to identify any controls may, in fact, be controllable to some extent. Therefore, actual emissions reduction potential available from these additional controls may be greater than represented here. Other potential control strategies, such as transportation control measures, are not included in our analysis.

Figure 6-9 displays potential emissions reductions and the percentage of emissions that remain after all of the reductions have been accounted for in 1994 and 2004. In 1994 and 2004, after all controls are applied, nonattainment area emissions are approximately two-thirds of the 1985 total. Most of the remaining emissions are from small stationary sources that emit less than 25 tons of VOCs per year. Figure 6-10 displays a more detailed breakdown of the nonattainment emissions inventory in 1994 after all controls have been applied. About 35 percent of the remaining emissions in 1994 are from surface coatings and other organic solvent evaporation sources. As stated earlier, we are unable to identify controls for approximately 15 percent of the emissions inventory. Over one-third of this (about 6 percent of the entire inventory) is emissions from small stationary sources.

\section{Uncertainty Surrounding Estimates of Emissions Reduction Potential}

In an earlier section, we analyzed the effects of various assumptions on our estimates of future VOC emissions before additional controls are applied. In

\footnotetext{
${ }^{16} \mathrm{As}_{\mathrm{e}}$ discuss in a later section, due to uncertainty in TSDF emissions reported in the 1985 NEDS inventory and the degree to which they can be controlled, the percentage reduction for this source category may range between 3 and 8 percent of total 1985 emissions.

${ }^{17}$ This estimate includes the 760,000 tons that would be eliminated as a result of the current Federal Motor Vehicle Control Program, which is equivalent to a 7-percent reduction based on 1985 emissions.

${ }^{18}$ Note that the total reductions are slightly lower than the sum of the component categories. This is because the emissions reductions achieved by: a) lowering gasoline volatility in combination with an $\mathbf{L} \mathbf{M}$ program, and b) combining a Stage 11 and Onboard control program, are slightly less than instituting each one alone.
} 


\section{Figure 6-8-Volatile Organic Compound (VOC) Emissions Reductions in 1994 and 2004 Compared to 1985 Emissions, by Control Method}
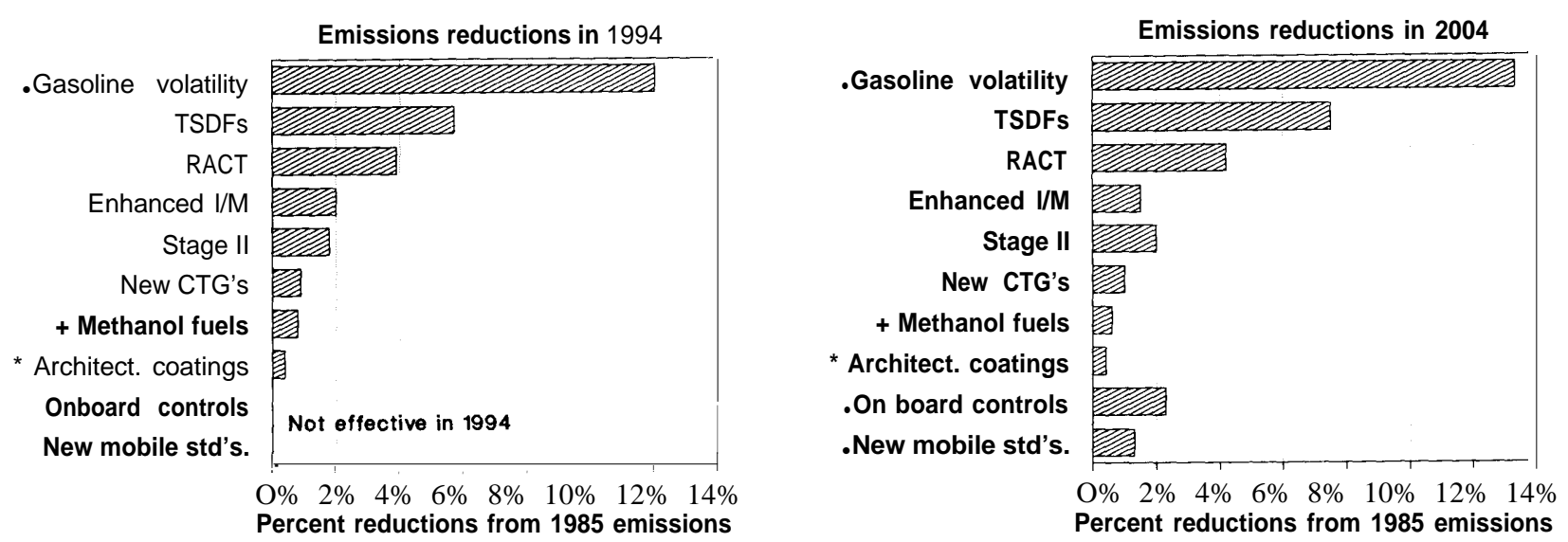

.Emissions redutions also achieved in attainment areas.

+ Percent reductions only in those cities in which it is adopted.

See text for description of control methods.

SOURCE: Office of Technology Assessment, 1989.

this section, we analyze how some of these same assumptions combined with the uncertainty associated with selected VOC control strategies affect our estimates of potential emissions reductions presented above. The assumptions we tested include: 1) the rate of gasoline evaporation from in-use highway vehicles ("running losses"), 2) average highwayvehicle speeds, 3) level of compliance with current and future stationary source VOC regulations, 4) emissions from organic solvent evaporation sources, and 5) emissions from hazardous waste TSDFs and the degree to which they can be controlled. Table 6-9 and figure 6-11 display our estimates of uncertainty for these particular categories.

We estimate that by applying currently available control methods, VOC emissions in nonattainment cities can be lowered by about 3.8 million tons per year in 1994, or about 34 percent of 1985 emis- sions. ${ }^{19}$ This total could be as low as 1.5 million or as high as 5.0 million tons per year given the variability in all the assumptions listed above. ${ }^{20} \mathrm{As}$ figure 6-11 shows, as running losses increase, total emissions reductions also increase. Although baseline highway vehicle emissions increase with increasing estimates of running losses (see figure 6-5), most of the additional emissions are controllable by lowering gasoline volatility. Also, as average highway vehicle speeds decrease, some of the resulting additional exhaust emissions are controllable through enhanced inspection and maintenance programs. If we assume that organic solvent emissions are 50 percent lower than what is reported in the 1985 inventory, total emissions reductions in 1994 are also slightly lowered. However, the total percent reductions compared to 1985 emissions after all controls are applied increase from 34 to 37 percent

${ }^{19}$ This estimate assumes running losses equal to 1.5 grams per mile, average vehicle speeds of 28 miles per hour, and 100 percent compliance with all current and future stationary source VOC regulations.

20Low estimate is calculated assuming: 1) no running losses from highway vehicles, 2) average vehicle speeds of 35 miles per hour, 3) the level of compliance with current and future stationary source regulations is 80 percent, and 4) emissions from organic solvent evaporation and TSDFs are 50 percent lower than totals reported in the 1985 NAPAPinventory, and that compliance with new TSDF regulations is only 80 percent. The high estimate assumes: 1) running losses of 2.5 grams per mile, 2) average vehicle speeds of 20 miles per hour, 3 ) both current and future regulatory compliance equals 100 percent, and 4) emissions from organic solvent evaporation and TSDFs are 50 percent higher than reported totals. 
Table 6-6-Potential Emissions Reductions in 1994 Compared to 1985 Emissions From Source-Specific Control Strategies (emissions reductions in 1,000 tons per year)

\begin{tabular}{|c|c|c|c|c|c|c|c|c|c|c|c|c|}
\hline RACT & $\begin{array}{l}\text { New } \\
\text { CTGs }\end{array}$ & TSDFs & $\begin{array}{c}\text { Architectural } \\
\text { coatings }\end{array}$ & Onboard & Stage II & $\begin{array}{l}\text { Combined } \\
\text { Stage II } \\
\& \text { Onboard }\end{array}$ & $\begin{array}{l}\text { Gasoline } \\
\text { volatility } \\
\text { controp }\end{array}$ & $\begin{array}{c}\text { Enhanced } \\
\text { I/M }\end{array}$ & $\begin{array}{c}\text { New highway } \\
\text { vehicle emission } \\
\text { standards } \\
\end{array}$ & $\begin{array}{l}\text { Methanol } \\
\text { fuels }\end{array}$ & $\begin{array}{l}\text { (Existing } \\
\text { controls) }\end{array}$ & $\begin{array}{c}\text { All } \\
\text { controls }\end{array}$ \\
\hline $\begin{array}{l}\text { Nonattainment cities by } \\
\text { design value category } \\
\text { (in ppm o) }\end{array}$ & & & & & & & & & & & & \\
\hline $\begin{array}{r}0.13-0.14 \ldots \ldots .120 \\
0,15-0.17 \ldots \ldots .230 \\
0.18-0.26 \ldots \ldots \\
>0.26 \ldots \ldots .\end{array}$ & $\begin{array}{l}29 \\
46 \\
11 \\
15 \\
\end{array}$ & $\begin{array}{r}280 \\
330 \\
31 \\
3 \\
\end{array}$ & $\begin{array}{r}15 \\
23 \\
8 \\
0 \\
\end{array}$ & $\begin{array}{l}0 \\
0 \\
0 \\
0 \\
\end{array}$ & $\begin{array}{r}64 \\
100 \\
31 \\
0\end{array}$ & $\begin{array}{r}64 \\
100 \\
31 \\
0 \\
\end{array}$ & $\begin{array}{r}430 \\
730 \\
190 \\
0 \\
\end{array}$ & $\begin{array}{r}68 \\
100 \\
31 \\
22 \\
\end{array}$ & $\begin{array}{l}0 \\
0 \\
0 \\
0 \\
\end{array}$ & $\begin{array}{l}0 \\
0 \\
8 \\
6 \\
\end{array}$ & $\begin{array}{r}220 \\
360 \\
99 \\
85 \\
\end{array}$ & $\begin{array}{r}1,200 \\
1,900 \\
480 \\
150 \\
\end{array}$ \\
\hline $\begin{array}{l}\text { Total (nonattainment) } 440 \\
\text { Attainment areas } .0\end{array}$ & $\begin{array}{c}100 \\
0\end{array}$ & $\begin{array}{r}640 \\
0\end{array}$ & $\begin{array}{l}47 \\
61\end{array}$ & $\begin{array}{l}0 \\
0\end{array}$ & $\begin{array}{r}200 \\
0\end{array}$ & $\begin{array}{r}200 \\
0\end{array}$ & $\begin{array}{l}1,300 \\
1,900\end{array}$ & $\begin{array}{r}220 \\
0\end{array}$ & $\begin{array}{l}0 \\
0\end{array}$ & $\begin{array}{r}14 \\
0\end{array}$ & $\begin{array}{l}760 \\
680\end{array}$ & $\begin{array}{l}3,800 \\
2,700\end{array}$ \\
\hline Total . . . . . . & 100 & 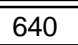 & 1110 & 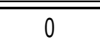 & 200 & 200 & 3,300 & 220 & $\overline{0}$ & 14 & $1,1,400$ & "6,500 \\
\hline
\end{tabular}

Totals are rounded.
bestimates are equivalent amual reductions, Actual reductions are required only 5 months out of the year.

cThese estimates assume the use of thel that is 85 percent methanol and 15 percent gasoline in light-duty cars and trucks in fleets of 10 or more.

e. All cons '" includes RACT new CTGs, TSDFs, architecturalcoatings, combined Stagelland Onboard, gasoline volatility controls, enhanced I/M, new highway-vehicle emission standards, methanol tuels, and exisung controls Note that total reductions are slightly lower than the sum of each component category This is because the reductions achieved by lowering gasoline volatility in combination with an enhanced I/M program, a combined Staga II and Onboard program, and methanol fuels, are slighty lower than instituting each one alone

Strategy Descriptions

RACT = "Reasonable Available Control Technology" on all existung stationary sources that emit more than 25 tons per year of Voc

CTGS = new Control Tectrique Guidelines for existing stationary sources that emit more than 25 tons per year of VOC

TSDFs = controls on hazardous waste treatment, storage, and disposal facilities

Onboard controls on motor vehicles to capture gasoline vapor during refuelin

Stage II control devices on gas pumps to capture gasoline vapor during motor vehicle refueling

Gasoline volatility controls which limit the rate of gasoline evaporation,

Enhanced inspection and maintenance (im) programs for cars and light-duty trucks

New highway-vehicle emission standards for passenger cars and light-duty gasoline trucks

Methanol fuels as a substitute for gasoline as a motor vehicle fuel.

SOURCE: Office of Technology Assessment, 1989 
Table 6-8-Potential Emissions Reductions in 2004 Compared to 1985 Emissions From Source-Specific Control Strategies (emissions reductions in 1,000 tons per year)

\begin{tabular}{|c|c|c|c|c|c|c|c|c|c|c|c|c|c|}
\hline & RACT & $\begin{array}{l}\text { New } \\
\text { CTGs }\end{array}$ & TSDFs & $\begin{array}{l}\text { Architectural } \\
\text { coatings }\end{array}$ & Onboard & Stage II & $\begin{array}{l}\text { Combined } \\
\text { Stage II } \\
\text { \& Onboard }\end{array}$ & $\begin{array}{l}\text { Gasoline } \\
\text { volatility } \\
\text { control }^{\circ}\end{array}$ & $\begin{array}{c}\text { Enhanced } \\
\mathrm{I} / \mathrm{M}\end{array}$ & $\begin{array}{l}\text { New highway } \\
\text { vehicle emission } \\
\text { standards }\end{array}$ & $\begin{array}{c}\text { Methanol } \\
\text { fuels }\end{array}$ & $\begin{array}{l}\text { (Existing } \\
\text { controls) }\end{array}$ & $\begin{array}{c}\text { All } \\
\text { Controls }\end{array}$ \\
\hline $\begin{array}{l}\text { Nonattainment cities by } \\
\text { design value category } \\
\text { (in ppm } \mathrm{O}_{3} \\
0.13-0.14 \ldots \ldots \\
0.15-0.17 \ldots \ldots \\
0.18-0.26 \ldots \ldots \\
>0.26 \ldots \ldots \ldots\end{array}$ & $\begin{array}{l}\ldots 130 \\
\ldots 250 \\
\ldots 78 \\
\ldots 19\end{array}$ & $\begin{array}{l}30 \\
49 \\
12 \\
16\end{array}$ & $\begin{array}{r}360 \\
440 \\
42 \\
4\end{array}$ & $\begin{array}{r}16 \\
25 \\
9 \\
0\end{array}$ & $\begin{array}{r}68 \\
120 \\
40 \\
27\end{array}$ & $\begin{array}{r}70 \\
120 \\
37 \\
0\end{array}$ & $\begin{array}{r}74 \\
130 \\
43 \\
27\end{array}$ & $\begin{array}{r}470 \\
820 \\
210 \\
0\end{array}$ & $\begin{array}{l}53 \\
80 \\
25 \\
17\end{array}$ & $\begin{array}{l}37 \\
68 \\
22 \\
17\end{array}$ & $\begin{array}{l}0 \\
0 \\
9 \\
7\end{array}$ & $\begin{array}{r}56 \\
40 \\
4 \\
39\end{array}$ & $\begin{array}{r}1,200 \\
2,000 \\
460 \\
150\end{array}$ \\
\hline $\begin{array}{l}\text { Total (nonattainment) } \\
\text { Attainment areas ., }\end{array}$ & $\begin{array}{l}.470 \\
\ldots 0 \\
\end{array}$ & $\begin{array}{r}110 \\
0 \\
\end{array}$ & $\begin{array}{r}840 \\
0 \\
\end{array}$ & $\begin{array}{l}50 \\
68 \\
\end{array}$ & $\begin{array}{l}260 \\
280 \\
\end{array}$ & $\begin{array}{r}220 \\
0 \\
\end{array}$ & $\begin{array}{l}280 \\
280 \\
\end{array}$ & $\begin{array}{l}1,500 \\
2,200 \\
\end{array}$ & $\begin{array}{r}170 \\
0 \\
\end{array}$ & $\begin{array}{l}140 \\
190 \\
\end{array}$ & $\begin{array}{r}16 \\
0 \\
\end{array}$ & $\begin{array}{l}140 \\
310 \\
\end{array}$ & $\begin{array}{l}3,700 \\
3,100 \\
\end{array}$ \\
\hline Total & 470 & 110 & 840 & 120 & 530 & 220 & 2550 & 3,700 & 170 & 330 & 16 & 450 & 6,800 \\
\hline
\end{tabular}

530

550

170

330

Estimates are equivalent annual reductions. Actual reductions are required only 5 morths out of the year

These estimates assume the use of fuel that is 85 percent methanol and 15 percent gasoline in light-duty cars and trucks in fleets of 10 or more.

e" Allions Note that total reductions are slightylower than ttre sum of each component category. This is because the reductions achieved by lowering gasoline volatility in combination with an enhanced I/M program, a combined Staga and Onboard program, and methanol fuels, are slighty lower than instituting each one alone.

Strategy Descriptions

RACT = "Reasonable Available Control Technology" on all existing stationary sources that emit more than 25 tons par year of VOC

Maw CTGs new Control Technique Guidelines for existing stationary sources that emit more than 25 tons per year of VOC.

TSDFs $=$ controls on hazardous waste treatment, storage, and disposal facilities

Federal controts on architecturel coattings

Onboard controls on motor vehicles to capture gasoline vapor during refueling

Stage II control devices on gas pumps to capture gasoline vapor during motor vehicle refuelin

Gasoline volatility controls which limit the rate of gasoline evaporation.

Enhanced inspection and mainonance (MM) programs for cars and light-duty trucks.

NeW highway-vehicie emission standards for passenger cars and light-duty gasoline truck

SOURCE: Office of Technology Assessment, 1989 


\section{Figure 6-9-Potential Volatile Organic Compound (VOC) Emissions Reductions and Remaining} Emissions in 1904 and 2004 as a Percentage of 1985 Emissions in Nonattainment Cities
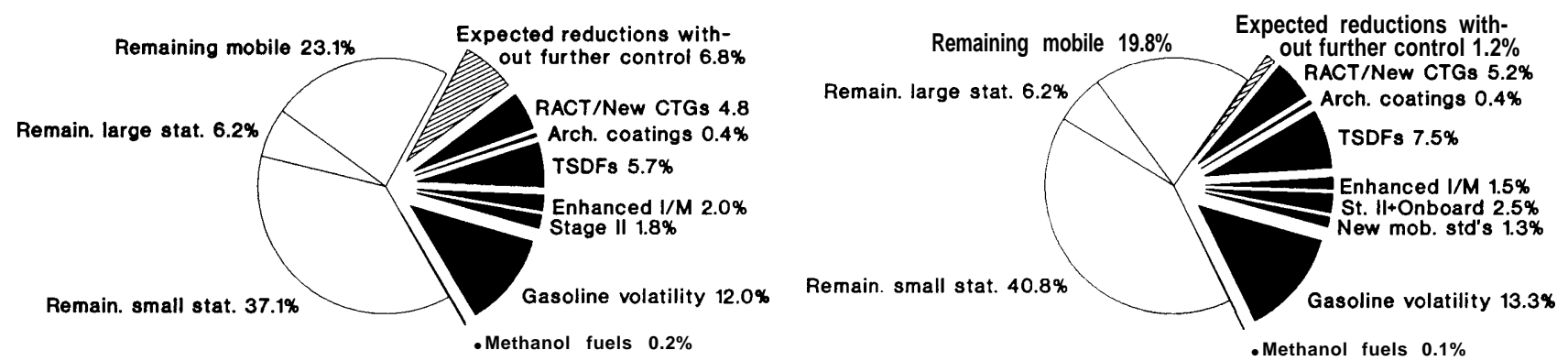

- Average percent reduction in cities in which it is required equals about 0.6 percent.

The pulled-out slices represent emissions that can be eliminated by each control method. The three connected slices represent emissions that remain after ail control methods are applied. The category "Expected Reductions without Further Control" represents reductions achieved from the existing Federal Motor Vehicle Control Program. "Remaining Small Stationary" represents emissions from stationary sources that emit less than 50 tons per year of VOC. See text for description of control methods.

SOURCE: Office of Technology Assessment, 1989.

Figure 6-10-Volatile Organic Compound (VOC) Emissions in Nonattainment Cities in 1994, by Source Category, After All Additional Control Methods Are Applied

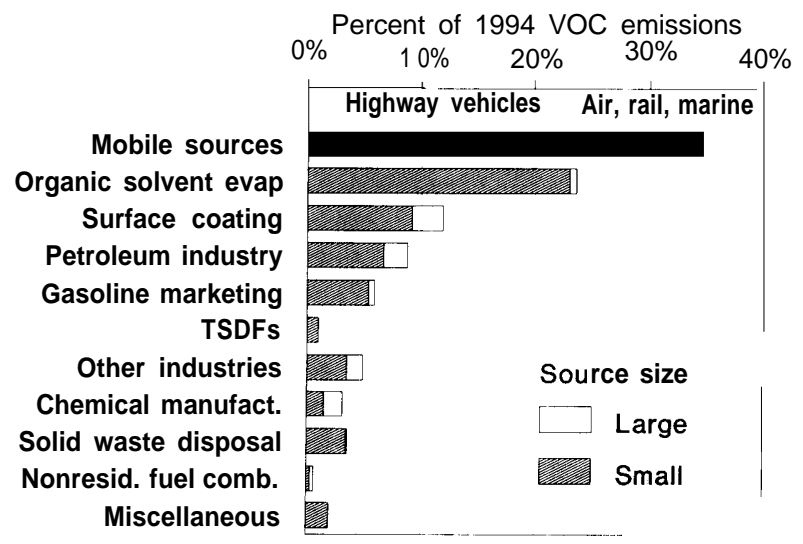

Total $=7.5$ million tons/year

Stationary sources that emit more than 50 tons per year of VOC are included in the "Large" categories. (See figure 6-1 for 1985 emissions in nonattainment cities before additional controls applied.)

SOURCE: Offce of Tehnology Assessment, 1989. in 1994. Percentage reductions increase because a large fraction of organic solvent use was not controllable given the measures we analyzed. Therefore lowering solvent emissions by 50 percent lowered total "baseline" emissions in 1985 while not changing future emissions reductions by much.

The following subsections summarize the emissions reduction potential of each individual control strategy.

\section{Reasonably Available Control Technologies (RACT) on All Stationary Sources}

The Clean Air Act requires that each State adopt, as part of its State Implementation Plan (SIP), "reasonably available control technologies" (RACT) regulations for existing stationary sources of VOC in nonattainment cities. In our analysis, we have applied RACT-level controls on 40 stationary source categories for which a regulation already exists in any SIP. These sources include petroleum refining, certain types of chemical manufacturing, paper surface coating, automobile surface coating, gasoline terminals, service stations, and drycleaning. 
Table 6-Estimate of Uncertainty in VOC Emissions Reductions After All Controls Are Applied in Nonattainment Cities In 1094

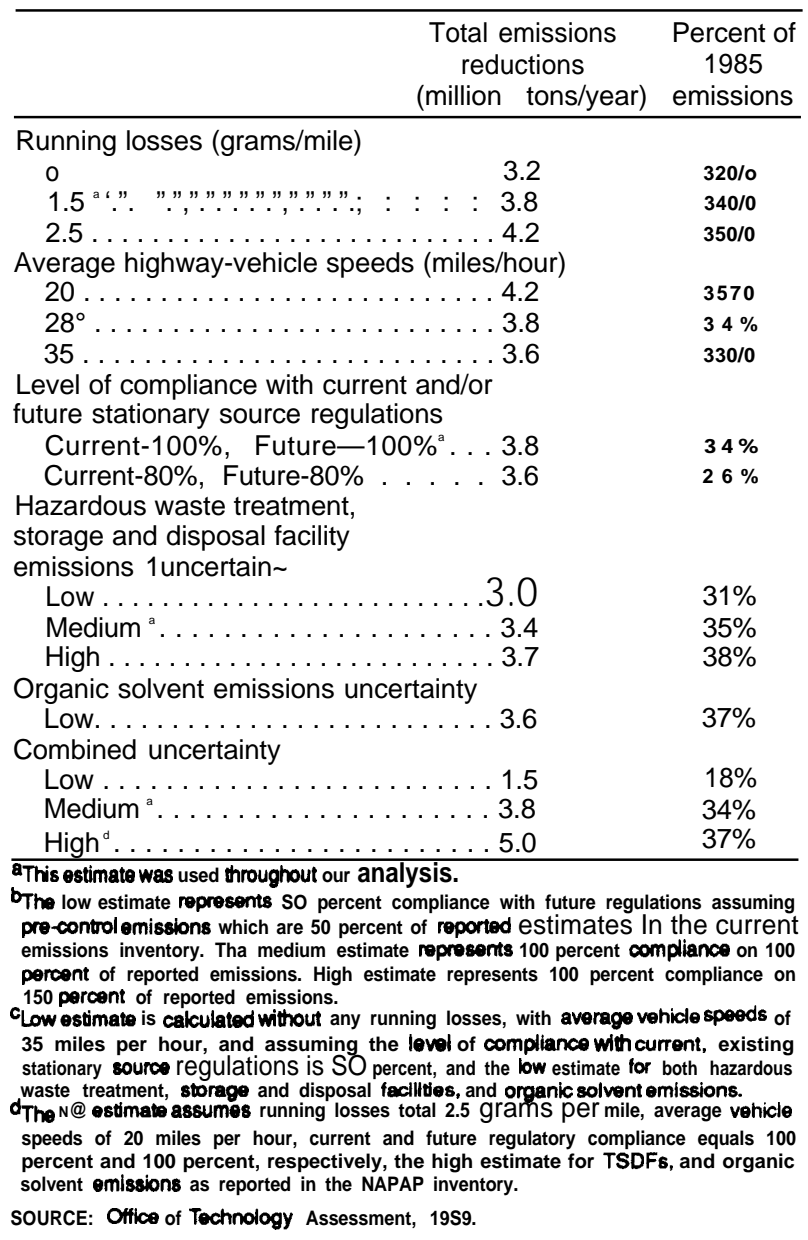

The sources of our estimates of the percentage reduction in VOC emissions from RACT and of the data we used to calculate the cost of these controls, are reports prepared for EPA by Alliance Technologies Corp. [3] and E.H. Pechan \& Associates, Inc. [4]. EPA made available to us a series of memos detailing the methods used, technical references, and economic assumptions used by Alliance, from which our estimates are drawn. A complete list of our control cost assumptions, including control efficiencies and associated costs for each source type, is included in an appendix.

Currently, many States require RACT-level controls only on existing sources which emit more than

\section{Figure 6-n-Uncertainty in VOC Emissions Reductions From All Additional Controls In Nonattainment Cities in 1994}

\author{
Uncertainty category: \\ Running losses \\ Average speeds \\ Level of compliance \\ Solvent emissions \\ TSDF emissions \\ Combined uncertainty \\ $15 \% \quad 20 \% \quad 25 \% \quad 30 \% \quad 35 \% \quad 40 \%$ \\ Percent reduction from 1985 emissions
}

The following assumptions were analyzed: 1) the rate of gasoline evaporation from in-use highway vehicles ("running losses"), 2) average highway-vehicle speeds, 3) level of compliance with current and future stationary source VOC control regulations, 4) emissions from organic solvent evaporation sources, and 5) emissions from hazardous waste treatment, storage, and disposal facilities (TSDFs).

SOURCE: Office of Technology Assessment, 1989.

100 tons of VOC per year in nonattainment areas. We estimated the emissions reductions achievable through RACT-level regulations by simulating controls on all existing stationary sources that emit more than 25 tons of VOCs per year in those nonattainment cities that did not have an existing RACT regulation for a particular source category in their SIP as of 1985. States are only required to provide EPA with emissions data from individual sources which emit more than 50 tons per year; emissions from sources less than 50 tons per year are calculated indirectly by EPA and then aggregated at the county level. Therefore, we had to make assumptions regarding the fraction of inventory that originates from sources which emit between 25 and 50 tons per year.

We estimate that applying RACT-level controls to all sources in nonattainment cities would lower VOC emissions by approximately 440,000 tons per year in 1994, representing a 4-percent decline based on 1985 levels. Reductions increase slightly over 
time, with total reductions in nonattainment cities in 2004 estimated to be about 470,000 tons per year, from 1985 levels.

\section{Adoption of New "Control Technique Guidelines” (CTGs)}

In the previous subsection, we analyzed the emissions reduction potential of applying all RACTlevel regulations currently in place in any State to all existing stationary VOC sources emitting more than 25 tons per year of VOC. Many States now are urging EPA to develop new RACT guidelines for several additional stationary source categories. These would be issued as "Control Technique Guidelines" (CTGs). Like the RACT controls analyzed in the previous section, nonattainment cities would be required to adopt these "new" RACT regulations on all existing stationary VOC sources that emit more than 25 tons of VOCs per year.

We are able to analyze the emission reduction potential from controls on: 1) wood furniture coating, 2) autobody refinishing, 3) plastic parts coating, 4) coke oven byproduct plants, 5) publicly owned treatment works, and 6) bakeries. (Hazardous waste treatment, storage, and disposal facilities is another category, but is discussed in the next subsection.) These six categories represent about 2 percent of the entire VOC inventory. The control efficiency assumptions we used for these sources are listed in an appendix.

Emissions reductions from applying RACT-level controls to these categories are estimated to be about 100,000 tons per year in 1994, or about a l-percent reduction based on 1985 emissions. This annual total is expected to increase by a few thousand tons in 2004.

\section{Controls on Hazardous Waste Treatment, Storage, and Disposal Facilities}

Hazardous waste TSDFs have recently been recognized as potentially significant sources of VOC, accounting for about 1.4 million tons per year, nationwide, and about 580,000 ton per year in nonattainment areas in 1985 (or about 6 percent of the total emissions) [34]. More recent data has shown that the nationwide total could be as high as 2 million tons per year [30]. By 2004, nonattainment area TSDF emissions are about 930 million tons per year. These totals are not based on emissions data from individual facilities, but are estimated indirectly on a nationwide basis and, therefore, are subject to potentially large, unquantified uncertainties.

We estimate that reasonably available controls on TSDFs can eliminate approximately 640,000 tons per year of VOCs in nonattainment cities in 1994, or about 6 percent of 1985 emissions. As mentioned earlier, if we account for potential uncertainty in reported TSDF emissions, the emissions reduction potential from this category may range between 3.1 and 8.4 percent from 1985 levels. Control technologies such as covers placed over TSDFs together with add-on emission control devices (e.g., carbon adsorbers, incinerators, etc.) and/or process modifications can reduce VOC emissions by about 90 percent [30].

\section{Federal Controls on Architectural Surface Coatings}

Many small sources of VOCs do not lend themselves to traditional forms of regulation (e.g., application of an add-on control device to reduce emissions). These sources individually emit small amounts of VOCs, but when aggregated over a region, they collectively contribute a significant portion of the VOC inventory. Such sources include consumer and commercial solvents, architectural surface coatings, agricultural pesticides, adhesives, and others. Although several categories have been proposed as candidates for new Federal controls in recent bills, we are only able to analyze architectural surface coatings. This category represents about 2 percent of the NAPAP emissions inventory as adjusted by OTA.

EPA control efficiency estimates range between 23 percent [25] and 65 percent [26] for architectural surface coatings. For our analysis, we assume a 25 percent control efficiency. Since this category would be federally regulated, emissions reductions would occur nationwide (in nonattainment and attainment areas).

In 1994, federally regulated controls on architectural surface coatings are estimated to reduce VOC emissions by 47,000 tons per year in nonattainment 
cities, and about 61,000 tons year in attainment areas. By 2004 in nonattainment cities, emissions reductions will reach about 50,000 tons per year.

Consumer and commercial products are also a potentially large source of VOC emissions, but because control technology information is lacking for this category we have excluded it from our overall emissions reduction potential and cost analyses. According to the 1985 NAPAP inventory, emissions from consumer and commercial products are about 860,000 tons per year in nonattainment cities, representing about 8 percent of total emissions. We must stress that the emission estimates for this category are subject to potentially large uncertainties. It is interesting to note that, on a per-capita basis, the 1985 NAPAP inventory contains about two times more VOC emissions from consumer products than local California emissions inventories such as the South Coast air basin [18].

Also, the degree to which VOCs can be eliminated from consumer products is not well understood at the present time. However, the South Coast Air Quality Management District estimates that VOC emissions from these products can be reduced by about 50 percent in the year 2000 through a ban of aerosols products containing VOCs and reformulation of other non-aerosol products [19]. Controlling emissions from consumer products is discussed further in chapter 7 .

\section{Controls on Gasoline Emissions From Vehicle Refueling}

Gasoline vapors that escape from vehicle fuel tanks during refilling can be controlled by two fundamentally different methods. One method involves installation of a vapor recovery system on service station gasoline pumps, referred to as 'Stage II" vapor recovery. The other method relies on a control device installed on each vehicle as part of the emission control system (referred to as "Onboard" controls) .21 Stage II programs can become fully effective within a few years. The emissions reduction benefits of an Onboard control program gradu- ally increase over time and achieve full potential after about 10 years, when most older, non-equipped vehicles have been replaced. In the following subsections, we describe the emissions reduction potential of each program individually, and in combination.

\section{"Onboard" Refueling Controls on Motor Vehicles}

For this analysis, we assume that Onboard controls are required on all new gasoline vehicles starting in 1994 and that by 2004, most gasoline vehicles on the road will be equipped with Onboard controls due to fleet turnover. Assumptions regarding fleet turnover and control efficiencies are obtained from EPA's recent gas-marketing regulatory impact analysis [28]. Because these controls apply to all new gasoline vehicles, emissions reductions will occur nationwide (in both nonattainment and attainment areas).

We estimate that in 1999, Onboard controls will eliminate about 180,000 tons per year of VOC emissions in nonattainment cities, and 370,000 tons per year nationwide, representing about a 1.6percent reduction, compared to 1985 emissions. In 2004, total nationwide VOC reductions increase to about 530,000 tons per year, or about a 2. 1-percent reduction based on 1985 levels. These results reflect only Onboard controls for vehicle refueling and do not include reductions from additional Stage II controls. An analysis of a combined Onboard and Stage II vapor recovery program is presented later.

\section{"Stage II" Refueling Vapor Recovery \\ Unlike Onboard controls, which are applied nationwide, we assume Stage 11 controls are only installed in nonattainment cities. Congressional proposals have generally limited the Stage 11 re- quirement to these areas. Emissions reductions in 1994 and 2004 are estimated to be about 200,000 and 220,000 tons per year, respectively, which amounts to about a 2-percent reduction in both 1994 and 2004, relative to 1985 emissions. We assume a control efficiency of 79 percent, which represents}

\footnotetext{
${ }^{21}$ There is a continuing debate between EPA, industry, and the National Highway Transportation Safety Administration, over possible safety concerns and in-use feasibility of Onboard controls.

${ }^{22}$ We assume that the percent reduction in refueling emissions from use of Onboard controls, as derived from EPA's gas marketing analysis [28,p. 3-18], is 28 percent, 58 percent, and 76 percent in 1994,1999, and 2004, respectively. EPA estimates that Onboard controls can reduce refueling emissions by about 93 percent $[28$, p. 2-9].
} 
EPA's average estimate for a Stage II program with annual enforcement [28]. ${ }^{23}$ Note that the percent emissions reductions ultimately achievable with Stage II and Onboard controls are roughly comparable. However, in 1999, Onboard is less effective than Stage II because complete fleet turnover will not have occurred yet.

\section{Combined Stage II and Onboard Controls}

If both Stage II and Onboard controls are adopted, the percent emissions reductions in nonattainment cities in 1999 and 2004 are estimated to be about 2 and 3 percent, respectively, relative to 1985 emissions. As the reduction benefits from Onboard controls increase through time (due to fleet turnover), the benefits from the combined strategy is only slightly greater than either method above. We assume a combined control efficiency of about 83 percent derived from EPA data [28].

\section{Enhanced Motor Vehicle Inspection and Maintenance (I/M) Programs}

For this analysis, we define an enhanced motor vehicle inspection and maintenance $(\mathrm{I} / \mathrm{M})$ program as one including all requirements of the existing California I/M program (among the most stringent in the Nation), plus the following improvements: annual testing for all pollutants $\left(\mathrm{VOC}, \mathrm{NO}_{\mathrm{x}}\right.$, carbon monoxide, and particulate) on all vehicles, improved visual inspection of the emissions control system to detect tampering and other functional defects, and a repair cost ceiling of $\$ 500$ per year. ${ }^{24}$ We have assumed that enhanced I/M programs are instituted in all nonattainment areas.

For cities without an existing I/M program as of 1987, the full emission reduction benefit of an enhanced I/M program is applied. If a city already had an I/M program as of 1987, then an incremental emission reduction benefit, representing the reductions achieved by going from an existing to an enhanced program, is applied. Estimates of the percentage reduction in emissions are taken from Sierra Research, Inc. [15]. We assume that the VOC emission reduction potential of existing I/M programs is about 12 percent. The full benefit of enhanced programs is about 29 percent, while the incremental benefit gained by switching from an existing to an enhanced program is about 17 percent. These control benefits apply only to the exhaust fraction of light-duty car and truck emissions, and do not affect emissions resulting from the gasoline evaporation.

We estimate that enhanced I/M programs in nonattainment cities will reduce VOC emissions by about 220,000 tons per year in 1994 and by 170,000 tons per year in $2004 .^{25}$ This represents about a 2 -and 1-percent reduction in 1994 and 2004, respectively, based on 1985 emissions. The emissions reduction benefits decline through time because average fleetwide exhaust emission rates also decline due the benefits from the existing Federal Motor Vehicle Control Program.

\section{More Stringent Highway-Vehicle Emission Standards}

This analysis includes the VOC emissions reduction potential of instituting more stringent tailpipe controls on new passenger cars and light-duty, gasoline-fueled trucks. The standards we analyzed were determined to be the most stringent technologically feasible, given currently "available" control technology, according to Sierra Research [15]. ${ }^{26}$ Sierra Research assumes that these standards can be met during 50,000 miles of controlled test driving (certification testing) for passenger cars, and 120,000 miles for light-duty trucks; however, VOC emission

\footnotetext{
${ }^{23}$ Under this scenario, stations which pump less than 10,000 gallons per month are not required to install controls.

${ }^{24}$ According t. Sierra Research, Inc. [ 16], if expensive major emission control systems were covered by a 10-year/100,000-mile manufacturer's warranty, the repair cost ceiling could be lowered to $\$ 200$ per vehicle per year.

${ }^{25}$ Nitrogen oxides, carbon monoxide, and particulate emissions reduction benefits are also gained by $\mathbf{L}$ M programs. Carbon monoxide and particulate reduction benefits are not calculated in our analysis; $\mathrm{NO}_{\mathbf{x}}$ benefits are calculated in a later chapter.

${ }^{26}$ The new emission standards used in our analysis are as follows: (in grams of pollutant emitted per mile traveled [g/mile] for 11011 -methane hydrocarbons $[\mathrm{NMHC}]$ and $\mathrm{NO}_{\mathrm{x}}$ )

Passenger cars- NMHC: $0.25 \mathrm{~g} /$ mile; $\mathrm{NO}_{\mathbf{x}}: 0.4 \mathrm{~g} /$ mile

Light-duty gasoline trucks (by truck weight)-

(less than 3,750lbs) NMHC: $0.34 \mathrm{~g} / \mathrm{mile} ; \mathrm{NO}_{\mathbf{x}}: 0.46 \mathrm{~g} / \mathrm{mile}$

(3,751 to $6,000 \mathrm{lbs})$ NMHC: $0.43 \mathrm{~g} / \mathrm{mile} ; \mathrm{NO}_{\mathrm{x}}: 0.80 \mathrm{~g} / \mathrm{mile}$

(6,000 to $8,500 \mathrm{lbs})$ NMHC: $0.55 \mathrm{~g} / \mathrm{mile} ; \mathrm{NO}_{\mathrm{x}}: 1.15 \mathrm{~g} / \mathrm{mile}$
} 
rates after 50,000 miles (for cars) and 120,000 miles (for trucks) of actual use by vehicle owners would likely exceed these standards. We assume that new standards go into effect in 1994 for both passenger cars and light-duty trucks.

We estimate that in 1999 new highway vehicle standards reduce VOC emissions by about 77,000 tons per year in nonattainment cities and 180,000 tons per year, nationwide, or about 0.7 percent compared to 1985 emissions. By 2004, reductions increase to about 140,000 tons per year in nonattainment cities and 330,000 tons per year, nationwide, or about 1.3 percent compared to 1985 levels. The slight increase in emissions reductions during this period is due to the gradual replacement of older vehicles with newer, cleaner ones.

As mentioned above, we assumed that the 0.25 gram-per-mile hydrocarbon emission standard for new passenger cars will be met during 50,000 miles of certification testing. Some congressional proposals have called for this standard to be met during 50,000 miles of actual driving use. If this more stringent "in-use" requirement was actually achieved by passenger cars, total emissions reductions from all new emission standards would increase from 140,000 to 210,000 tons per year in nonattainment cities in 2004. If passenger cars were required to meet a 0.25 gram-per-mile "in-use" standard during 100,000 miles of actual driving, if achieved, total reductions from new emission standards would increase to 250,000 tons per year in nonattainment cities in 2004 .

\section{Limits on Gasoline Volatility}

Lowering gasoline volatility (i.e., lowering the rate of evaporation) reduces emissions during refueling at the gas pump and during refilling of underground gasoline storage tanks, reduces evaporative emissions from vehicle fuel systems, and lowers exhaust emission rates. For this analysis, we assume that gasoline volatility is reduced to 9 pounds per square inch (psi) Reid Vapor Pressure (RVP) during the 5-month summertime period when ozone concentrations most often exceed the standard. Emissions reductions would occur only during the summer period and not year-round. However, for the purposes of comparison with other VOC control methods which are in effect over the entire year, we have scaled up seasonal emissions reductions fromI volatility control to an equivalent annual estimate. This scaled-up estimate should not be viewed as a year-round estimate, but as an equivalent annual tons-per-year estimate based on the highway-vehicle evaporative and running loss emissions which would occur on a typical summertime day in a nonattainment city. Data for the analysis comes from EPA [27].

We estimate that limiting gasoline volatility would lower VOC emissions in 1994 by about 12 percent in nonattainment cities, and about 14 percent in attainment areas. Equivalent annual emissions reductions in 1994 are about 3.3 million tons per year, nationwide, of which about 1.3 million tons per year are eliminated in nonattainment cities. Again, these estimates are based on highway-vehicle evaporative emissions occurring on a typical summertime day, when ozone concentrations exceed the standard, not on an average annual day.

The above estimates assume that gasoline evaporation from in-use highway vehicles (running losses) averages about 1.5 grams per mile on warm summer days with gasoline volatility at levels prevailing during 1985. It does not take into account the recently promulgated regulation requiring volatility limits of 10.5 psi during the summer months.

Given the uncertainty in running loss estimates, the percentage reduction, in 1994, due to gasoline volatility limits in nonattainment cities could be as low as 6 percent (assuming running losses equal zero) or as high as 16 percent (running loss equal to 2.5 grams per mile). We have assumed that running loss emissions can be reduced by 65 percent if gasoline volatility is reduced from levels prevailing in 1985 to 9.0 psi based on data from EPA's MOBILE 4 model.

\section{Methanol Fuels for Motor Vehicle Vehicles in the Worst Nonattainment Cities}

Methanol vehicles used within the next 10 years will probably operate on blends of methanol and gasoline (probably 85 percent methanol and 15 percent gasoline, by volume). EPA estimates that both exhaust and evaporative emission rates for light-duty vehicles operated on blends of methanol 
and gasoline would effectively ${ }^{27}$ be about 30 percent lower than for gasoline vehicles meeting current standards and operated on low-volatility gasoline $(9$ psi) $[1,29]$. Beyond the next 10 years, if vehicles can be produced to operate on 100 percent (straight) methanol and they are designed and adjusted to generate minimal VOC emissions, EPA suggests that rates for both exhaust and evaporative emissions could effectively be reduced by up to 90 percent [1 ]. However, significant advances in vehicle technology would be required to achieve such low VOC emission rates. EPA's proposed regulations for light-duty methanol vehicles would apply the same carbon monoxide and nitrogen oxides emissions standards for methanol as for gasoline [9], so no reductions in these pollutants would be expected.

In our analysis, we consider the use of alternative fuels in fleets of 10 or more vehicles, in areas with ozone design values of $0.18 \mathrm{ppm}$ or higher. In 1986, 6 million cars and 2 million light-duty trucks in centrally owned fleets of 10 or more vehicles accounted for about 13 percent of light-duty vehiclemiles-traveled nationwide [2]. ${ }^{28}$ Use in fleets is expected to be easier to promote or require than general use, because a less extensive network of refueling stations would be required. Because methanol is likely to be expensive, at least in the near term, we assume that its use would be limited to those areas with the most severe ozone problems.

For areas with design values of $0.18 \mathrm{ppm}$ or higher, if 30-percent reductions in VOC emission rates were obtained, we estimate that year-round operation of fleet vehicles on methanol would be equivalent to total annual reductions of VOC emissions of about 14 thousand tons per year in 1994, or about 0.5 percent of total 1985 emissions in these areas. An upper bound on the level of reductions that could ultimately be achieved with methanol is about 53,000 tons per year ${ }^{29}$ in 1994 , or about 2 percent of 1985 emissions in cities with design values of 0.18 ppm or higher. This estimate assumes that emission rates are reduced by 90 percent using straight methanol.

Use of methanol or compressed natural gas $(\mathrm{CNG})$ as fuel for light-duty vehicles is discussed in more detail in a later chapter.

\section{COMPARISON OF POTENTIAL EMISSIONS REDUCTIONS AND REDUCTIONS NEEDED TO ATTAIN THE OZONE STANDARD}

\section{Without Additional Controls}

The graph on the left-hand side of figure 6-12 shows the variability among nonattainment cities in the changes in VOC emissions predicted to occur between 1985 and 1994, assuming no change in State and EPA regulations in place as of 1987. For each city, at its design value, we have graphed the percentage change in emissions from the 1985 baseline expected to occur due to the regulations included in State Implementation Plans (SIP) as of 1985, the current Federal Motor Vehicle Control Program, and population and economic growth.

We have graphed cities by design value because it is a reasonable predictor of the emissions reductions needed to reach the standard. The graph also displays estimates of the reductions needed to reach the ozone standard of $0.12 \mathrm{ppm}$, as a function of design value. As discussed in chapter 5, the two curves arching across the graph represent high and low estimates of the percentage reduction in emissions that typical cities falling within a given range of design values need to attain the standard. The five vertical bars to the right of the two curves represent estimates of emissions reduction requirements for individual cities with design values above $0.19 \mathrm{ppm}$. We have omitted three cities with design values greater than $0.26 \mathrm{ppm}$ (all three are in southern California). As stated in chapter 5, control require-

${ }^{27}$ Under EPA'S proposed regulations [9] for methanol-fueled vehicles, total VOC emissions, i.e. the total mass of carbon emitted, would be the same as with gasoline, but the emissions would "effectively" be lower because methanol produces less ozone than the VOCS emitted with gasoline.

${ }^{28}$ Centrally owned fleets account for such a large fraction of VMT because on average, fleet vehicles are driven over two timesas many miles in a year as the vehicles in general use.

${ }^{29}$ Reductions $\mathrm{i}_{\mathrm{n}}$ Vehicle refueling from the use of straight methanol accounts for about 22 percent of this total. Reductions in vehicle exhaust and evaporative emissions account for the remaining 78 percent. No reductions in refueling emissions would be anticipated if gasoline were displaced by a methanol/gasoline blend. This is assuming that refueling controls would have been in place anyway, and that reductions in VOC emissions from refueling are proportional to the amount of gasoline displaced. 
Figure 6-12-Volatile Organic Compound (VOC) Emissions Reductions Between 1985 and 1994, Assuming No Change From 1987 VOC Regulations and Assuming Additional Volatility Controls

No additional controls

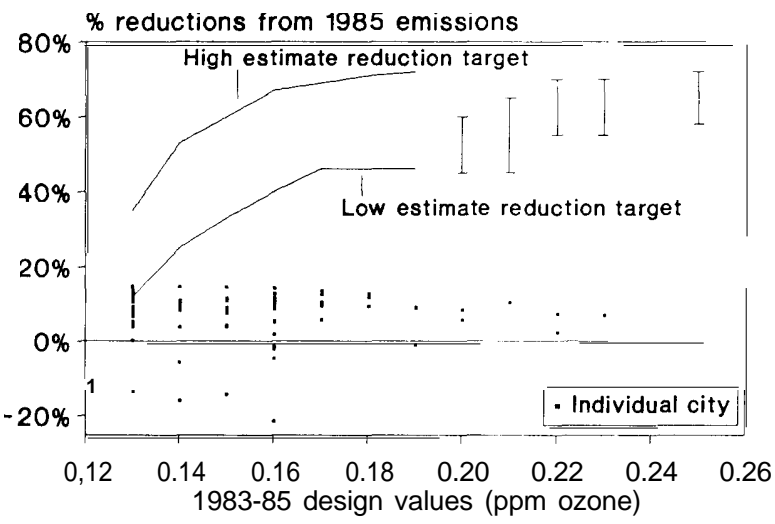

Existing controls plus additional volatility controls

Each square represents a nonattainment city. In the chart on the left, the location on the graph shows the Voc emissions reductions (as a percentage of 1985 levels) by 1994 given the local, State, and federal VOC regulations in place in 1987. The chart on the right shows the reductions each city can achieve by 1994 if gasoline volatility limits are adopted in addition to the local, State, and Federal VOC regulations in place as of 1987. Cities below the "O\%" line experience a net increase in emissions between 1985 and 1994 . The horizontal axis shows the "design value," a measure of peak ozone concentration used to determine the emissions reductions needed to attain the ozone standard. The two curves arching across the graph and vertical bars to the right of the curves show the upper and lower bounds of VOC reductions needed toattain the standard. The vertical bars show estimated control requirements explicitly for major urban areas with area-wide design values greater than $0.19 \mathrm{ppm}$.

SOURCE: Office of Technology Assessment, 1989.

ments for individual nonattainment areas could actually fall outside of the ranges presented here. In particular, areas with large contributions from transported pollutants or vegetative VOC emissions are not well represented. Moreover, the model used in the calculations is intended to provide only rough estimates of control requirements, based on a minimal amount of input information,

Summarizing how to read figure 6-12, the squares show the change in VOC emission in each nonattainment city projected for 1994 (assuming existing regulations) and the curves and vertical bars show the upper and lower bounds of the change needed, in each city, to attain the ozone standard by 1994.

As the graph on the left-hand side of figure 6-12 illustrates, the change in VOC emissions that would occur by 1994 without further control ranges from an increase of about 20 percent to a reduction of about 15 percent. Emissions in most cities are expected to decline, due to the replacement of today's cars with lower emitting, new cars. However, emissions may increase in some cities that are expected to experience high population growth.

Note that without additional controls only a few cities with design values of $0.13 \mathrm{ppm}$ maybe able to attain the ozone standard by 1994 . Most nonattainment areas will not be much closer to meeting the standard than they are today.

\section{With Additional Gasoline Volatility Limitations}

In the previous subsection, we analyzed the emissions reductions which would be expected in 1994 if only State and Federal regulations existing in 1985 were to be applied; these estimates represent a "no-further-control" scenario from which we can gauge the effectiveness of additional control measures. Recently, EPA announced proposals requiring limits on gasoline volatility [8]. Several States in the Northeast have already adopted regulations which would limit gasoline volatility to 9 pounds per 
square inch (psi) during the summer months [5]. Because this control method could become law, nationwide, in the near future, its exclusion from a baseline "no-further-control" scenario in a future year may not be appropriate. Therefore, this subsection shows how the adoption of volatility controls, alone, would affect future emissions reductions.

The graph on the right-hand side of figure 6-12 illustrates the percent reductions that would be achieved in 1994 from existing regulations plus gasoline volatility limits of 9 psi. On average, in 1994, gasoline volatility limits in nonattainment cities will lower emissions by about an additional 12 percent below 1985 levels. As noted earlier, this percentage represents emissions reductions that would likely occur on a typical day when ozone concentrations might exceed the standard and have been scaled up to equivalent annual reductions for the purposes of comparison with other year-round control methods. As illustrated in figure 6-12, when volatility controls are added, the percent reductions in many cities with design values of $0.13 \mathrm{ppm}$ fall between the two curves. These cities may be able to attain the ozone standard in 1994.

\section{With All Control Strategies Analyzed by OTA}

Figure 6-13 illustrates the percent reduction in VOC emissions that could be achieved by requiring all the control strategies listed in the beginning of this section. In most cities, emissions in 1994 would be lowered between about 20 and 50 percent, depending on the city. As the figure shows, emissions reductions do not substantially change between 1994 and 2004. This "flat" trend between 1994 and 2004 is due to the competing influences of population growth (which drives new emissions growth) and the effects of additional emission control measures. The emissions reduction benefits from these measures act to cancel out new emissions growth due to rising populations.

For typical cities with design values between 0.13 and $0.14 \mathrm{ppm}$, the VOC emissions reductions from all controls may be more than needed to attain the ozone standard. For other nonattainment cities with slightly higher design values, the reductions projected for 1994 fall within the range of reductions which might be needed. However, for most cities with design values of $0.16 \mathrm{ppm}$ or higher, projected reductions fall considerably below the amount needed to meet the standard. (Recall from chapter 5 that in each range of design values, the reduction requirements shown in the above figures may underestimate the reductions in local manmade VOC emissions that are needed in areas that have atypically large contributions from transported pollutants or vegetative VOC emissions.) In a later section, we discuss the extent to which the adoption of all control strategies in nonattainment cities achieves less than, or more than the emissions reductions required to attain the standard.

As stated earlier, the emissions reductions reported here represent control methods that we know can be applied in the near term. This does not imply that additional VOC reductions beyond those analyzed here are not possible, but that they should not be counted on within the next 5 to 10 years.

\section{Estimates of Possible Excesses and Shortfalls in Emissions Reductions Required To Attain the Ozone Standard}

In this section we estimate: 1) the extent of overcontrol in nonattainment cities with the lowest design values, and 2) the shortfall in nonattainment cities with higher design values, expected to occur after applying all of the VOC controls discussed earlier. Figure 6-14 displays our estimates of potential overcontrol and undercontrol from all VOC control strategies in 1994 expressed in tons of emissions reductions and as a percentage of 1985 emissions. The bars shown in the figure represent ranges of uncertainty associated with our method of estimating the VOC reductions needed to attain the standard in each city.

As discussed in an earlier section and in chapter 5 , because of the uncertainty associated with estimating the emissions reductions required to attain the ozone standard, the reduction target we chose for each city could be too low or too high. Therefore, the adoption of all additional controls in an individual city may result in either a shortfall or an excess in the emissions reductions required to meet the standard. For this reason, we present estimates for both undercontrol and overcontrol.

We estimate that adoption of all controls in all nonattainment areas might overcontrol VOC emission by about 160,000 to 920,000 tons per year in 
Figure 6-13-Volatile Organic Compound (VOC) Emissions Reductions Between 1965 and 1994, and 1985 and 2004, Including All Additional Mobile and Stationary Source VOC Control Methods

All additional mobile and stationary

source control methods in 1994

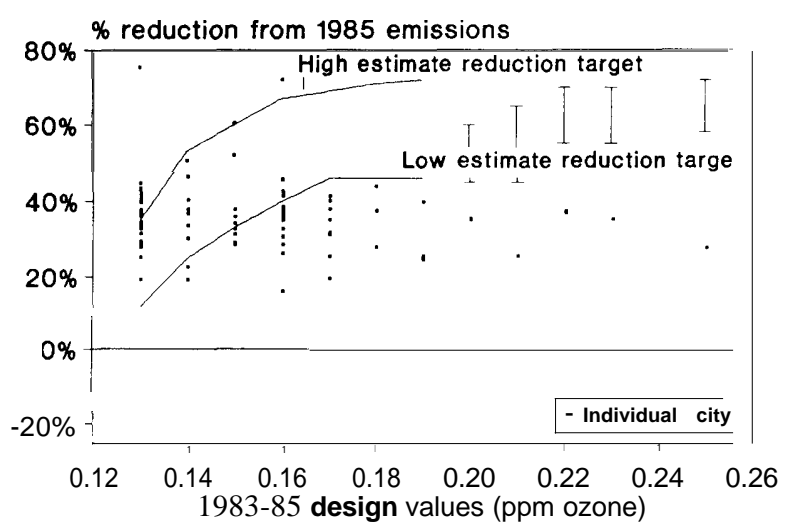

All additional mobile and stationary source control methods in 2004

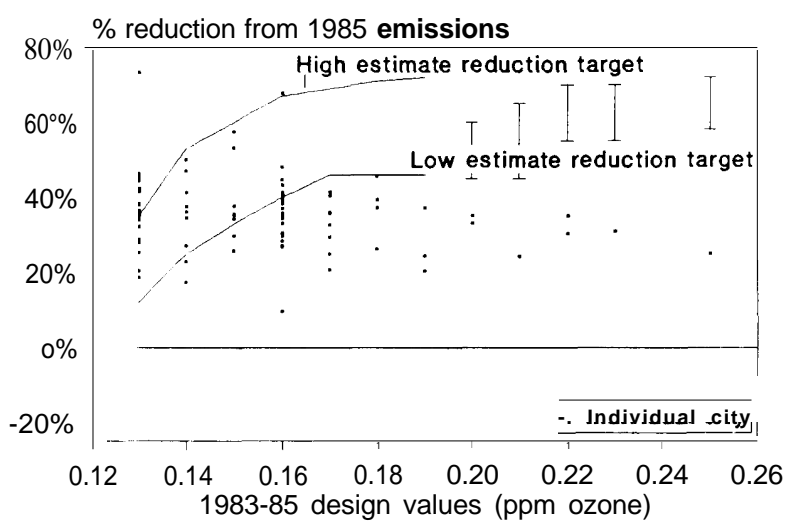

Each square represents a nonattainment city. The locatiolon the graph shows the projected VOC emissions reductions (as a percentage of 1985 levels) that each city can achieve by 1994 and 2004 if all additional mobile and stationary source control methods we analyzed are adopted in addition to the State and EPA VOC regulations in place in 1985. The horizontal axis shows the "design value," a measure of peak ozone concentration used to determine the emissions reductions needed to attain the ozone standard. The two curves arching across the graph and vertical bars to the right of the curves show the upper and lower bounds of VOC reductions needed to attain the standard. The vertical bars show estimated control requirements explicitlyor major urban areas with area-wide design values greater than $0.19 \mathrm{ppm}$.

SOURCE: Office of Technology Assessment, 1989.

\section{Figure 6-14-Estimates of Possible Excesses and Shortfalls in Emissions Reductions Needed to Attain the Ozone Standard in 1094}
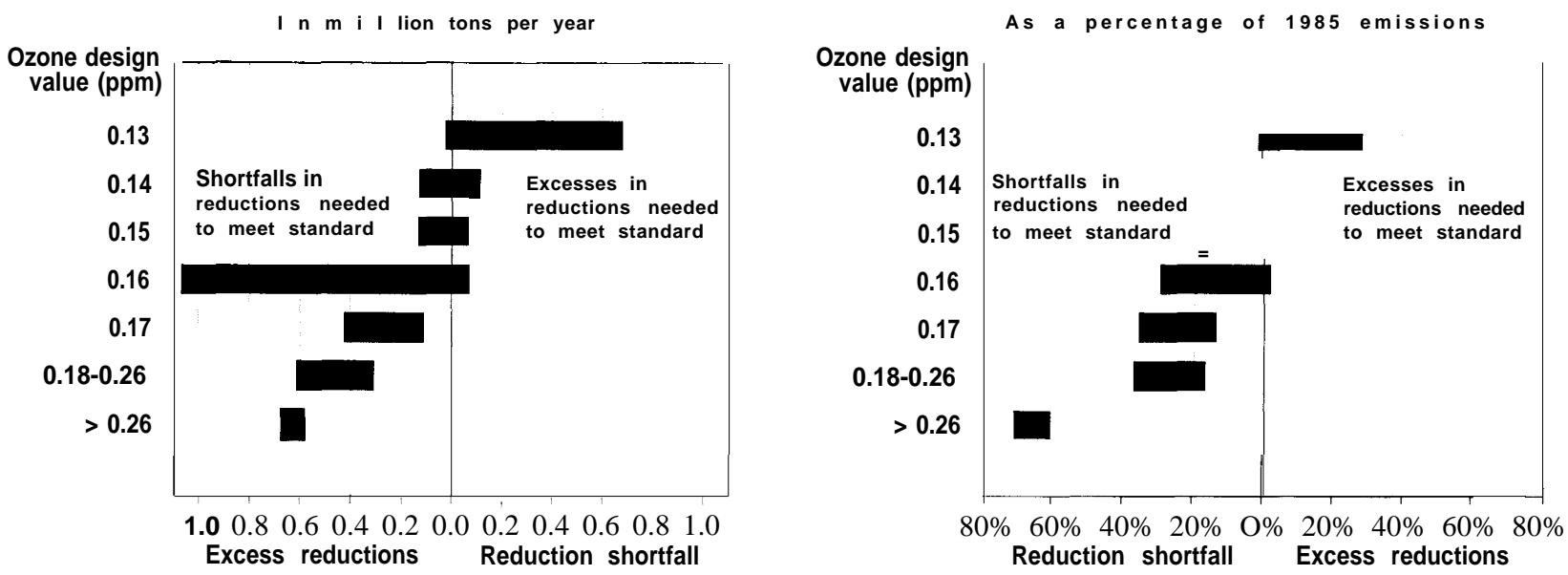

The graph on the left shows reductions and shortfalls expressed as tons of emissions in 1994 while the graph on the right displays these results as a percentage of 1985 emissions. The bars shown above represent ranges of uncertainty associated with our method of estimating the VOC reductions needed to attain the standard in each city. Because of the uncertainty associated with estimating the emissions reductions required to attain the ozone standard, the reduction target we chose for each city could be too low or too high. Therefore, the adoption of all additional controls in an individual city may result in either a shortfall or an excess in the emissions reductions required to meet the standard. For this reason, we present estimates for both undercontrol and overcontrol.

SOURCE: Office of Technology Assessment, 1989. 
1994, or about 1 to 8 percent of 1985 emissions in these cities. Figure 6-14 shows that the adoption of all VOC control strategies in cities with 1983-85 ozone design values equal to $0.13 \mathrm{ppm}$ (17 in all) will very likely result in excess emissions reductions of about 160,000 to 680,000 tons per year in 1994 , or about 7 to 29 percent of their total 1985 total emissions. Even given the uncertainty in estimating emissions reduction targets, these cities probably will not likely fall short of the reductions needed to meet the ozone standard. Potential overcontrol in cities with design values equal to 0.14 and $0.15 \mathrm{ppm}$ may average about 26,000 tons and 21,000 tons in 1994, respectively, or about 3 percent of their 1985 emissions. Overcontrol, therefore, may not be as much of a factor here compared to the cleaner cities. We estimate that undercontrol in cities with design values of 0.14 and $0.15 \mathrm{ppm}$ may be more of a problem, averaging about 37,000 and 58,000 tons in 1994 , or about 5 and 8 percent of their 1985 emissions, respectively.

VOC reductions in attainment areas are a potentially significant source of overcontrol in the sense that these areas do not need to reduce their emissions any further to meet the ozone standard locally. We know that there will be some benefit to nonattainment cities from controls in attainment areas, especially those in ozone transport regions, but we are not able to estimate how much. Moreover, even in cities that already meet the standard, lowering ozone concentrations even further will provide some benefit. The total emissions reduction in all attainment areas from application of the nationwide control measures only ${ }^{30}$ is about 2 million tons of VOCs per year, in 1994, or about 14 percent, based on 1985 emissions.

Figures 6-14 also presents our estimates of the additional VOC emissions reductions nonattainment cities must achieve to attain the ozone standard after all controls have been applied. Calculation procedures are similar to those discussed above. We estimate that after all controls are applied, nonattainment cities still fall about 1.2 to 3.1 million tons per year short of the emissions reductions needed to attain the standard in 1994, or about 11 to 27 percent of 1985 emissions. Given that the adoption of all additional controls will reduce total VOC emissions by about 34 percent in 1994, we estimate that nonattainment cities will still need an additional one-third more emissions reductions to attain the standard, based on 1985 levels. Of course, individual cities may require higher or lower percentage emissions reductions to achieve the standard depending on severity of the nonattainment problem. (Possible long-term strategies that cities could use to further reduce VOC emissions and measures to control $\mathrm{NO}_{\mathrm{x}}$ emissions are discussed in chapter 7.)

The shortfall of emissions reductions will be most significant in cities with design values greater than or equal to $0.16 \mathrm{ppm}$ (48 cities). In general, as the severity the ozone problem in individual cities increases, so too does the relative magnitude of the shortfall, measured as a percentage of 1985 emissions. Undercontrol will be most severe in cities with design values greater than 0.26 , with a possible shortfall of about 630,000 tons per year in 1994, or about two-thirds of 1985 emissions .31 The emissions reduction shortfall in cities with design values between 0.18 and $0.26 \mathrm{ppm}$ ( 13 cities) is estimated to be about 300,000 to 630,000 tons in 1994 , or about 18 to 38 percent of 1985 emissions. Therefore, given that the adoption of all control methods will reduce VOC emissions by about 29 percent in 1994, based on 1985 levels, an additional 50-percent reduction would be necessary to attain the standard in these cities. The reduction shortfall in cities with design values 0.16 and $0.17 \mathrm{ppm}$ is estimated to be, on average, about 880,000 tons per year, or about 18 percent of 1985 emissions.

\section{COSTS OF CONTROL STRATEGIES ANALYZED BY OTA}

This section summarizes the costs of the control strategies analyzed by OTA. Because we are unable to analyze the cost of additional emission controls required to make up the shortfall discussed above, we are not able to estimate the total costs of attaining the standard in all nonattainment cities.

\footnotetext{
${ }^{30}$ Includes Federal controls on architectural coatings and gasoline volatility limits. Emissions reductions from Onboard controls and more stringent tailpipe standards are also achieved in attainment areas but are assumed to go into effect after 1994.

${ }^{31}$ These cities have already adopted gasoline volatility limits, Stage 11 refueling controls, and architectural surface coatings regulations (a proposed federal control), and therefore, additional emissions reductions benefits for these controls were not assigned.
} 
We estimate that the total cost of all controls analyzed by OTA in nonattainment cities will be about $\$ 4.2$ billion to $\$ 7.1$ billion per year, in $1994 .{ }^{32}$ By 2004, costs will increase to about $\$ 6.6$ billion to $\$ 10$ billion per year in nonattainment cities, primarily because of the higher percentage of highway vehicles with more stringent controls. However, some controls that we considered apply nationwide. Total nationwide costs in 1994 and 2004 are about $\$ 4.4$ billion to $\$ 7.9$ billion per year and $\$ 8.8$ billion to $\$ 13$ billion per year, respectively. Again, this is total cost of achieving about two-thirds of the VOC reductions needed to attain the standard in all areas.

Some of the control methods we analyzed simultaneously reduce other air pollutants in addition to VOCS. Since enhanced motor vehicle inspection and maintenance $(1 / \mathrm{M})$ programs also reduce carbon monoxide, about \$1.2 billion of the total cost in 1994 is attributable to the control of this pollutant $(\$ 1.5$ billion per year in 2004)..$^{33}$ Also, both enhanced I/M programs and more stringent highway-vehicle standards reduce $\mathrm{NO}_{\mathrm{x}}$ emissions and, hence, we estimate that about $\$ 2.5$ billion per year of the total nationwide costs in 2004 are attributable to the control this pollutant.

Table 6-10 displays the costs in 1994, 1999, and 2004 by source category. Figure 6-15 displays the ranges of costs in nonattainment cities in 1994 and 2004. Table 6-11 presents the "cost-effectiveness" (the cost per ton of VOC eliminated) of specific control measures for the three forecast years. Figure 6-16 illustrates the cost-effectiveness of control measures in nonattainment cities in $1994 .{ }^{34}$ The solid bars represent the average cost-effectiveness in all nonattainment cities. Uncertainty in the costeffectiveness estimates is denoted by the thin horizontal lines. Note the wide range in average cost-effectiveness across control measures, from about $\$ 440$ per ton for limits on gasoline volatility to about $\$ 30,000$ per ton for methanol fuels.

We also analyzed the cost and emissions reduction impacts of excluding control methods that cost more than $\$ 5,000$ per ton of VOC reduced. We estimate that in 1994, by not requiring controls costing more than $\$ 5,000$ per ton, total costs would drop to about $\$ 2.7$ billion to $\$ 5.1$ billion per year in nonattainment areas, representing a 30 - to 35percent decline. Nationwide costs would drop to about $\$ 2.9$ billion to $\$ 4.7$ billion per year. In 2004 , total costs would drop to about $\$ 2.9$ billion to $\$ 3.3$ billion per year in nonattainment cities, representing a drop of about 56 to 67 percent. Nationwide costs would drop to about $\$ 5.1$ billion to $\$ 6.1$ billion per year in 2004, representing a decline of about 42 to 53 percent. The percentage decrease in total costs in 2004 is larger than in 1994 because the costeffectiveness of I/M programs is greater than $\$ 5,000$ by 2004 and, therefore, these programs would be excluded.

In 1994, about 190,000 tons per year of VOC emissions reductions would be lost in nonattainment cities if a $\$ 5,000$ cost-effectiveness cap is imposed, increasing total emissions from about 34 percent below, to about 32 percent below, 1985 levels. In 2004 , about 360,000 tons of the emissions reductions in nonattainment cities would also be lost, increasing emissions from about 33 percent below, to about 30 percent below, 1985 levels. Controls on many sources in the "RACT" and "New-CTGs" categories exceed the $\$ 5,000$ per ton cost ceiling; methanol fuels would be completely eliminated while enhanced I/M programs would be eliminated in 2004. Since I./M programs would not be required in 2004 under this scenario, the costs associated with carbon monoxide control no longer have to be considered when interpreting total costs.

Figure 6-17 shows the cumulative cost of achieving various levels of VOC emissions reductions in nonattainment cities in 1994 and 2004. This figure shows that in 1994, a 25-percent reduction in VOC emissions (from 1985 levels) will cost about $\$ 900$ million per year, while in 2004, the same reduction will cost about $\$ 1.6$ billion per year. The total cost of a 25-percent emissions reduction is somewhat

\footnotetext{
${ }^{32}$ In addition to VOC control costs, these estimates also include the cost of $\mathrm{NO}_{\mathrm{x}}$ and carbon monoxide control associated with enhanced $\mathrm{I} / \mathrm{M}$ programs, and $\mathrm{NO}_{\mathrm{x}}$ control associated with more stringent highway-vehicle standards.

${ }^{33}$ Motor vehicle inspection and maintenance programs reduce $\mathrm{VOC}, \mathrm{NO}_{\mathrm{X}}$, and carbon monoxide. Since many ozone nonattainment cities also violate tbe Federal carbon monoxide standard, we arbitrarily assume that about 50 percent of the cost are attributable to carbon monoxide control.

${ }^{34}$ In the figure, the cost-effectiveness of Onboard controls, combined Stage II and Onboard controls, and more stringent tailpipe standards are presented for 2004 since mobile source-related measures take effect after 1994.
} 
Table 6-1 0-Estimated Costs of Selected Control Strategies Analyzed by OTA (costs in million dollars per year)a

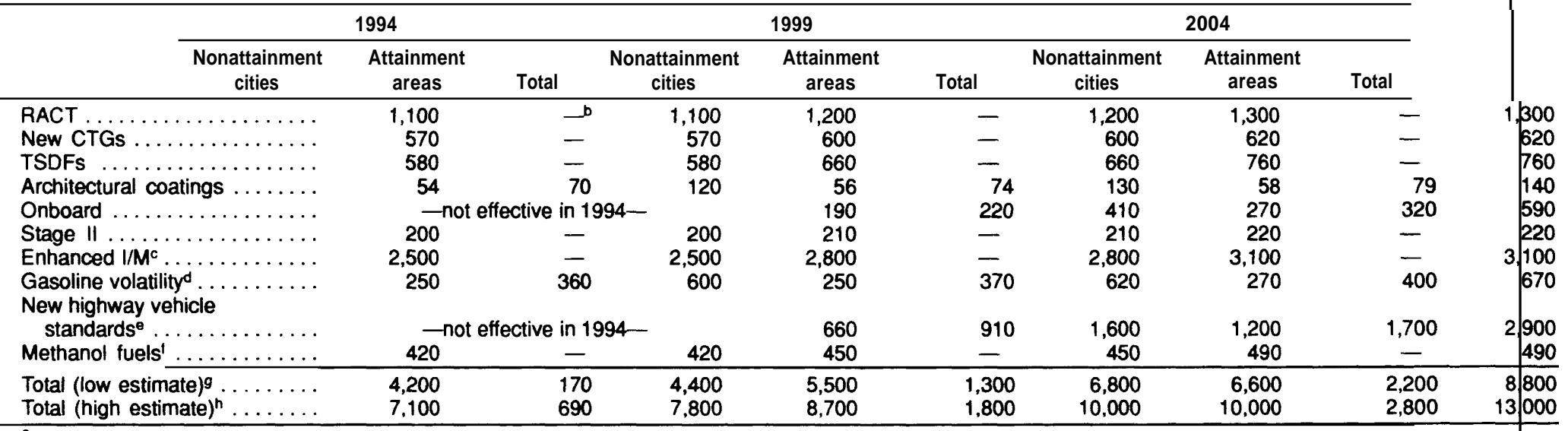

a Totals are rounded.
b."-" means control strategy applied only in nonattainment cities.

"We assume that half of the costs are attributable to the control of ozone and the other half to carbon monoxide. Totals include costs of VOC, NO, and carbon monoxide control. Total costs range between $\$ 1.5$ billion a d $\$ 3$ billion per year in 1994 .

dThese costs are accrued during the five-month summer period. Costs range

Indudes costs of both VOC and $\mathrm{NO}_{\mathrm{x}}$ control.

These controls are induded in nonatainment cities with ozone design values equal to 0.18 ppm or higher. Costs range berween $\$ 120$ million and $\$ 710$ million per year in 1994.

These estimales indude approximately $\$ 0.74$ billion, $\$ 0.83$ billion, and $\$ 0.93$ bilion per year for carbon monoxide control from enhanced $1 / M$ programs in 1994, 1999, and 2004, respectively.

These estimates include approximately $\$ 1.7$ billion, $\$ 1.9$ billion, and $\$ 2.2$ billion per year for carbon monoxide control trom enhanced IMM programs in 1994, 1999, and 2004, respectively.

Strategy Descriptions

RACT = "Reasonable Available Control Tecthology" on all existing stationary sources that emit more than 25 tons per year of VOC.

New CTGs = new Control Tectnique Guidelines for existing stationary sources that emit more than 25 tons per year of VOC.

TSDF = controls on hazardous waste treatment, storage, and disposal facilities.

Federal controls on architoctural coatings.

gasoline vapor during refueling.

Stage If control devices on gas pumps to capture gasoline vapor during motor vehicle refueling.

oline evaporation.

Enhanced inspection and mainenance (WW) programs for cars and light-duty trucks.

Now highway-vehiclo embselon standards for passenger cars and light-duty gasoline truck.

Methanot fuels as a substitute for gasoline as a motor vehicle fuel.

SOURCE: Office of Technology Assessment, 1989. 
Figure 6-15-Estimated Coat of Volatile Organic Compound Emission Control Methods in 1994 and 2004 in Nonattainment Cities



- Costs in attainment cities not shown.

In 1994 , total annual costs in nonattainment cities range between $\$ 4,2$ billion and $\$ 7.1$ billion per year. Total costs in nonattainment areas in 2004 range between $\$ 6.6$ billion and $\$ 10$ billion peryear. See text for description of control methods.

SOURCE: Office of Technology Aessessment, 1989.

more expensive in 2004 because additional reductions are needed to offset anticipated emissions growth over the intervening decade. A 30-percent reduction in nonattainment area VOC emissions will cost about $\$ 2$ billion per year in 1994 and about $\$ 3.4$ billion per year in 2004. Total annual costs begin to increase more sharply beyond a 30-percent reduction. A 33-percent reduction will cost about $\$ 4.6$ billion per year in 1994 and $\$ 8.4$ billion per year in 2004. Again, control costs are greater in the later years because greater reductions are required to offset emissions growth. Greater reductions are also possible because more stringent tailpipe standards and Onboard controls have become effective by the later year.

Control methods in figure 6-17 are ranked by cost-effectiveness; that is, the total cost of control per ton of VOC reduced. The most cost-effective controls are represented in the lower lefthand portion of the curve, while the less cost-effective controls appear farther up the curve, to the right. For this figure, the cost-effectiveness of enhanced I/M programs and new highway-vehicle standards includes the VOC control costs and the cost of $\mathrm{NO}_{\mathrm{x}}$ and 
Table 6-11-Estimated Cost-Effectiveness of Selected Control Strategies Analyzed by OTA (dollars par ton of VoC reduced) ${ }^{a}$

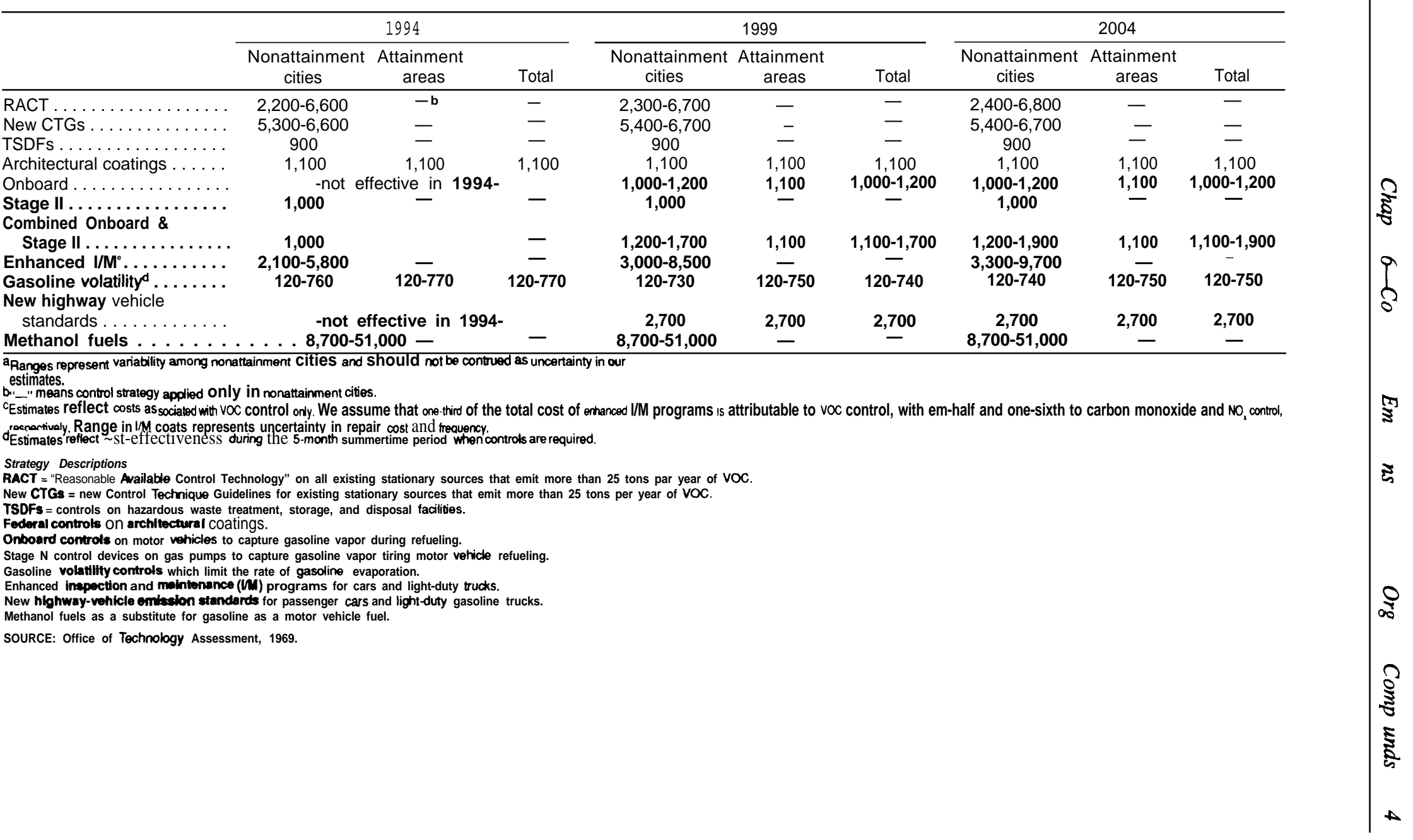


Figure 6-16-Estimated Cost-Effectiveness of Volatile Organic Compound Emission Control Methods in 1994 in Nonattainment Cities

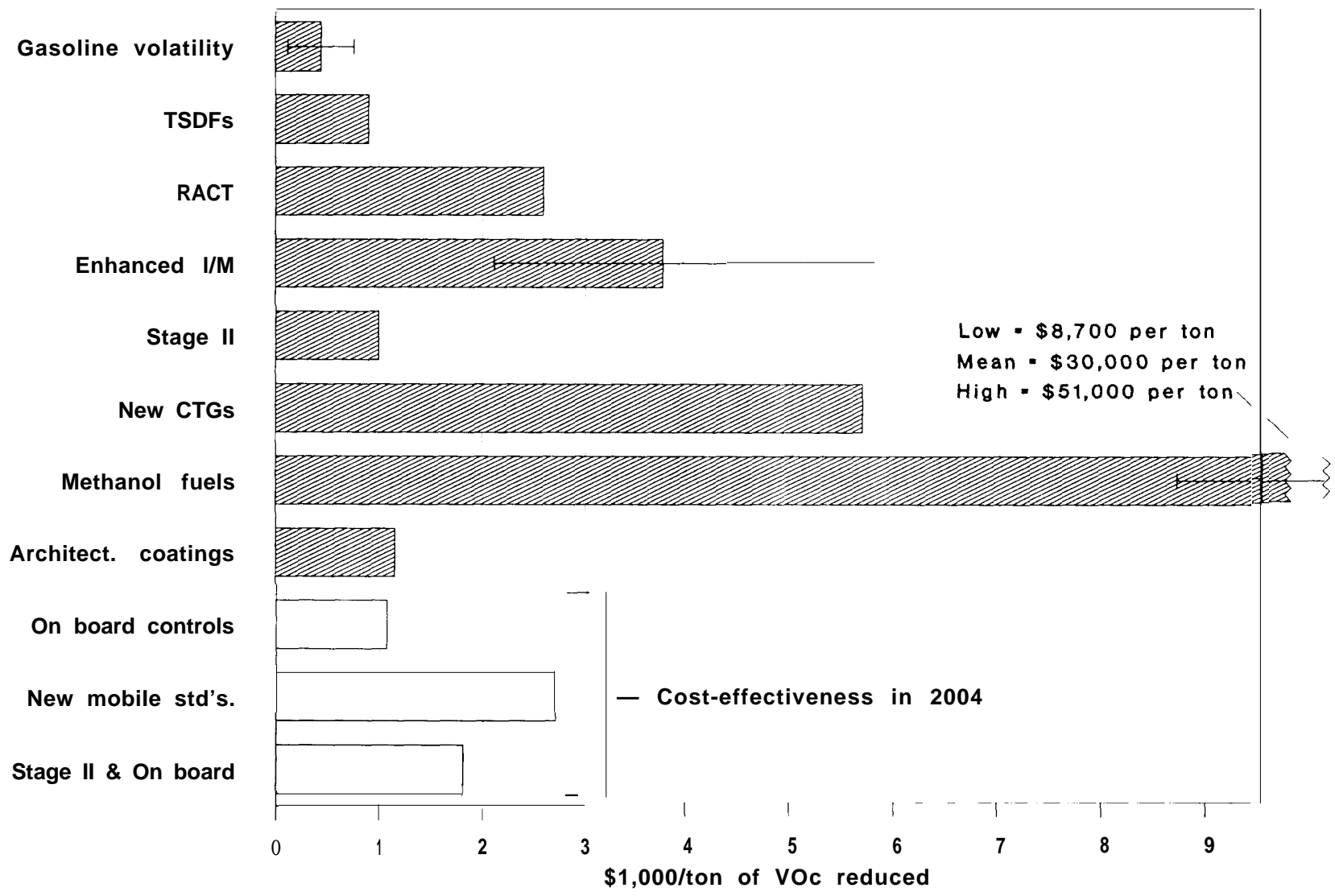

The cost-effectiveness of enhanced inspection and maintenance (I/M) programs and new mobile standards include only the cost of VOC control. Since Onboard controls and new mobile standards do not take affect until after 1994, we present the cost-effectiveness in 2004. The thick horizontal bars represent the average cost-effectiveness in nonattainment cities. The thin horizontal lines for gasoline volatility, methanol fuels, andl/M programs represent ranges of uncertainty associated with assumptions we used to estimate total annual costs. The very large uncertainty associated with the methanol fuels is due to the uncertainty of methanol prices relative to gasoline prices. We were unable to estimate cost-effectiveness uncertainty for other control methods. See text for a description of control methods.

SOURCE: Office of Technology Assessment, 1989.

carbon monoxide control (1/M programs, only). If the two least cost-effective control programs in 2004-enhanced I/M programs and methanol fuelsare eliminated, total costs would drop by approximately $\$ 3.6$ billion per year, representing a 40percent decline.

As described in an earlier section, the adoption of all additional control measures in nonattainment cities with design values of $0.13 \mathrm{ppm}$ may result in about 400,000 tons per year more emissions reductions than what is necessary to attain the ozone standard. If "New-CTGs, " hazardous waste TSDFs, and enhanced I/M programs are not required in these areas, excess emissions reductions could be cut by about 380,000 tons per year in 1994, representing a 30 -percent decline in emissions reductions. Total costs in these areas would drop from about $\$ 1.7$ billion per year to about $\$ 0.5$ billion per year, or about a 70-percent decline.

A brief discussion of the costs and costeffectiveness of each of the control strategies, 
Figure 6-1 7-Cumulative Annual Cost of, and Percent Emissions Reductions From, VOC Control Methods

Cumulative annual cost (in billion dollars per year)

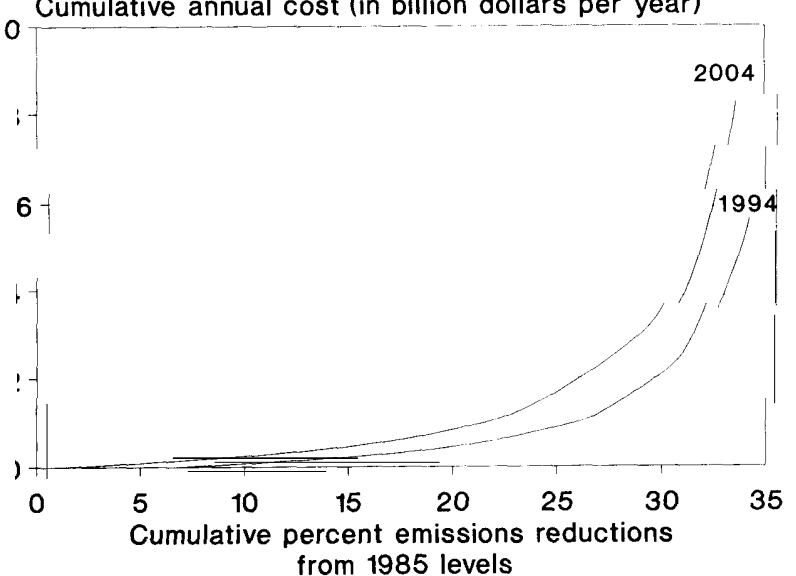

Control methods are ranked by cost-effectiveness; that is, the total cost of control per ton of VOC reduced. For example, the most cost-effective controls (e.g., gasoline volatility) are located in the lower left portion of the curve. In this figure, the costs of enhanced $\mathrm{I} / \mathrm{M}$ programs and new highway-vehicle standards includes the VOC control costs and the cost of $\mathrm{NO}_{x}$ and carbon monoxide control (1/M programs, only).

SOURCE: Office of Technology Assessment, 1989.

including the data sources from which the estimates are calculated, follows.

\section{Reasonably Available Control Technologies (RACT) on All Stationary Sources}

Total costs in nonattainment cities for this category are estimated to be about $\$ 1.1$ billion per year in 1994 , averaging about $\$ 2,200$ to $\$ 6,600$ per ton of VOC removed depending on city.

As mentioned in an earlier subsection, this control strategy applies to about 40 broad source categories such as petroleum refining, certain types of chemical manufacturing, gasoline stations, etc. A complete list, with our assumptions about control efficiencies and cost-effectiveness for each source type, is included in an appendix.

\section{Adoption of New "Control Technique Guidelines" (CTGs)}

As stated earlier, we analyzed six stationary source categories currently being considered as candidates for new CTGs: wood furniture coating, plastic parts coating, automobile refinishing, cokeoven byproduct plants, bakeries, and publicly owned treatment works. (Hazardous waste treatment, storage and disposal facilities are discussed in the next subsection.)

We estimate that new CTGs would cost about $\$ 570$ million per year in 1994, all of which would be incurred in nonattainment cities. The cost-effectiveness averages about $\$ 5,700$ per ton with a range of $\$ 5,300$ to $\$ 6,600$ per ton depending on the cities in which these controls are adopted.

\section{Controls on Hazardous Waste Treatment, Storage, and Disposal Facilities}

We estimate that emission controls on TSDFs will cost about $\$ 580$ million per year in nonattainment cities in 1994. This estimate is based on a costeffectiveness of $\$ 900$ per ton of VOC reduced for controls such as covered storage tanks and carbon adsorbers.

\section{Federal Controls on Architectural Surface Coatings}

The small amount of cost data available for architectural surface coatings revealed a wide range of estimates, from a net savings to default costs of $\$ 2,000$ per ton of reduction. We assume that controls for this source cost about $\$ 1,100$ per ton of VOC reduced. Commercial and consumer products are also potentially important sources of VOC emissions, but were excluded from our analysis because of a lack of adequate control technology information.

We estimate that, in 1994, Federal controls on architectural surface coatings would cost about $\$ 120$ million per year, nationwide, with about $\$ 54$ million per year incurred in nonattainment cities.

\section{Controls on Gasoline Emissions From Vehicle Refueling}

\section{"Onboard" Refueling Controls on Motor Vehicles}

We estimate the cost of Onboard controls by 1999 to be about $\$ 410$ million per year, nationwide, with about $\$ 190$ million per year incurred in nonattainment cities. By 2004, costs would total $\$ 590$ million per year, nationwide, because of the higher percent- 
age of Onboard-equipped vehicles on the road. The average nationwide cost-effectiveness is estimated to be about $\$ 1,100$ per ton in 1999 .

For this analysis, we assume that all gasoline vehicles manufactured in 1994 and later will be equipped with Onboard controls to capture gasoline vapors during refueling. By 2004, most gasoline vehicles on the road will be equipped with these controls. We assume that Onboard controls cost about $\$ 25$ per vehicle, which is close to EPA's upper bound estimate [28]. Note, however, that others conclude that the costs are higher. A study for the Motor Vehicle Manufacturers Association estimates that the average per-vehicle cost of Onboard controls for the first model year is about $\$ 80$ [13].

\section{"Stage $11^{99}$ Refueling Vapor Recovery}

We estimate the cost of Stage II controls to be about $\$ 200$ million per year in 1994, all of which is incurred in nonattainment cities. This estimate is based on a cost-effectiveness of $\$ 1,000$ per ton of VOC removed. This figure represents EPA's upper bound range as presented in the recent gasmarketing regulatory impact analysis [28]. EPA estimates that the total installed cost of Stage 11 controls, per station, ranges from $\$ 5,270$ for the smallest stations to $\$ 22,190$ for the largest [28].

\section{Combined Stage 11 and Onboard Controls}

We assume that the cost of a combined Stage 11 and Onboard program is the sum of the cost of each individual program. Therefore, in 1999, we estimate the cost to be about $\$ 610$ million per year, nationwide, with approximately $\$ 400$ million per year incurred in nonattainment cities. Nationwide costs increase to about $\$ 810$ million per year in 2004 . The combined cost-effectiveness in nonattainment cities in 1999 is estimated to be about $\$ 1,600$ per ton of VOC reduced and is expected to increase to about $\$ 1,800$ per ton by 2004 because of fleet turnover. The cost-effectiveness is higher than either Stage 11 and Onboard alone because the emissions reductions achieved from a combined system do not substantially increase compared to each one separately. The nationwide combined cost-effectiveness in 1999 and 2004 is estimated to be about $\$ 1,400$ and $\$ 1,500$ per ton, respectively. The cost-effectiveness is lower nationwide because we assume that Stage 11 controls are not required in attainment areas.

\section{Enhanced Motor Vehicle Inspection and Maintenance (I/M) Programs}

We estimate that enhanced I/M programs in nonattainment cities cost between about $\$ 1.5$ billion and $\$ 3.5$ billion per year in 1994. In 2004, costs are expected to rise to between $\$ 1.9$ billion and $\$ 4.3$ billion per year. About half of this total is for ozone control ( $\$ 0.74$ billion to $\$ 1.7$ billion per year in 1994 , and $\$ 0.93$ billion to $\$ 2.2$ billion per year in 2004), ${ }^{35}$ Of the portion that is assigned to ozone control, we estimate that about two-thirds would be for VOC control and one-third for $\mathrm{NO}_{\mathrm{x}}$ control. Thus, the cost-effectiveness for VOC reductions is estimated to be between $\$ 2,100$ and $\$ 5,800$ per ton in 1994. In 2004, the cost-effectiveness will increase to between $\$ 3,300$ to $\$ 9,700$ per ton; this rise is due to the fact that cars and trucks will be cleaner in 2004. Note that we have estimated the costeffectiveness of improving existing $\mathrm{I} / \mathrm{M}$ programs to the more stringent "enhanced" program described earlier.

Our estimates of enhanced I/M program costs are based on an analysis of the California I/M program, prepared for the California Air Resources Board by Sierra Research, Inc. [15]. We use Sierra Research's finding that an enhanced I/M program costs about $\$ 34$ to $\$ 55$ per vehicle per year. About $\$ 20$ of this cost is for the inspection fee and program administration. The remainder is for repair costs, which we assume to range between $\$ 70$ and $\$ 100$ per vehicle. We also assume that 20 and 35 percent of the vehicles tested will fail. ${ }^{36}$ Sierra Research's analysis concludes that an enhanced I/M program can reduce VOC emissions from cars and light-duty trucks by about 30 percent. This is about 17 percent higher than current I/M programs. For those cities that already have an I/M program in place, we credit $\$ 20$ per vehicle as the cost of the existing program.

These costs are quite a bit higher than EPA estimates [11]. The major difference seems to be

\footnotetext{
${ }^{35}$ The other half of the costs are assigned to carbon monoxide control.

${ }^{36}$ The low $/ \mathrm{m}$ cost estimate assumes that a repair cost of $\$ 70$ per vehicle will be levied on the 20 percent of the vehicles whiclfail; the h@ estimate assumes $\$ 100$ repair cost on 35 percent of the vehicles,
} 
assumptions about whether repair costs drop after the program has been operating a few years.

\section{More Stringent Highway-Vehicle Emission Standards}

We estimate that the total cost of tighter emission standards for highway vehicles in 1999 will be about $\$ 1.6$ billion per year, nationwide, of which about $\$ 0.66$ billion per year will be incurred in nonattainment cities. By 2004, costs will total about $\$ 2.9$ billion per year, nationwide, because a higher percentage of vehicles on the road will be equipped with new controls. These totals include the costs attributed to both $\mathrm{VOC}$ and $\mathrm{NO}_{\mathrm{x}}$ control on new passengers cars and light-duty gasoline trucks. Costs are based on an OTA contractor report by Sierra Research, Inc., that estimated new emission control costs of about $\$ 140$ per vehicle for combined VOC and $\mathrm{NO}_{\mathrm{x}}$ control [15]. Reductions of VOC in nonattainment cities in 1999 and 2004 are estimated to cost about $\$ 2,700$ per ton of VOC reduced. As described earlier, we analyzed more stringent standards that can be met up to 50,000 miles of driving under controlled conditions for cars, and 120,000 miles for light-duty trucks; tailpipe VOC emissions may exceed these standards after 50,000 miles (for cars) and 120,000 miles (for trucks) of actual use by individual vehicle owners.

\section{Limits on Gasoline Volatility}

We estimate that reducing gasoline volatility (i.e., the rate of evaporation) during the 5-month summertime period costs between about $\$ 0.17$ billion and $\$ 1.0$ billion per year nationwide in 1994. During the 5-month summer period, costs are between about 0.5 and 3.2 cents per gallon of gasoline. The lower cost estimate is derived from a recent EPA analysis of proposed nationwide limits on gasoline volatility [27], while the high estimate was obtained from a petroleum industry analysis [20,33] .37 In 1994, the cost-effectiveness ranges between $\$ 120$ to $\$ 800$ per ton of VOC reduced. Our estimates of costeffectiveness are lower than EPA's because we have increased the emissions reduction potential from highway vehicles by including a 1.5 gram-per-mile running loss to the existing inventory.

\section{Methanol Fuels for Motor Vehicle Vehicles in the Worst Nonattainment Cities}

In the near term, use of blends of methanol and gasoline could easily be several times more expensive per ton of VOCs reduced than any other measure we have considered. If advances in vehicle technology yielded reductions in emissions rates on the order of 90 percent, the estimated costs of using straight methanol could be more in line with other control measures we have evaluated. In all cases, the costs are extremely sensitive to prices assumed for gasoline and methanol.

Automobile manufacturers estimate that in production runs of fewer than about 100,000 vehicles, cars and light-duty trucks designed to operate on methanol would cost $\$ 500$ to $\$ 1,000$ more than gasoline-fueled vehicles [32]. In larger runs, methanol and gasoline-fueled vehicle production costs could be comparable [32]. For centrally owned fleets, assuming a vehicle life of 6 years $(150,000$ miles) and an 8 percent discount rate, the annualized added cost of a methanol vehicle could thus range from $\$ 0$ to about $\$ 215$.

Based on a range of 40 to 60 cents per gallon as the wholesale price of methanol, we estimate that straight methanol would be sold to consumers at $\$ 0.64$ to $\$ 0.84$ per gallon, or $\$ 1.15$ to $\$ 1.51$ per gasoline-gallon equivalent, adjusting for the difference in the energy content and thermal efficiency of the two fuels. ${ }^{38}$ These estimates can be compared to current national average prices for regular and premium unleaded gasoline of $\$ 0.95$ and $\$ 1.10$ per gallon, respectively [24]. Assuming that fleet vehicles average 26,000 miles per year and get the energy equivalent of 26.5 miles per gallon of gasoline, use of a blend of 85 percent methanol and 15 percent gasoline would increase annual fuel costs by about $\$ 130$ to $\$ 480$ per vehicle.

In the near term, assuming methanol is blended with 15 percent gasoline and yields VOC emissions

\footnotetext{
${ }^{37}$ The study by Turner, Mason \& CO. for the American Petroleum Institute (API) estimated that EPA's volatility proposal would cost about $\$ 1.5$ billion per year. The standard we analyzed was somewhat less stringent than EPA's original proposal and, hence, total costs, as evaluated by API, were estimated to be about $\$ 1.0$ billion per year.

${ }^{38}$ See ch. 7 for details.
} 
rates that are 30 percent lower than gasoline-fueled vehicles, we estimate that using methanol in fleets would cost about $\$ 120$ million to $\$ 710$ million per year in 1994 , or about $\$ 8,700$ to $\$ 51,000$ per ton of VOC reduced. The low estimate assumes vehicle and fuel costs most favorable to methanol, while the high estimate represents costs which are least favorable.

Use of methanol or compressed natural gas (CNG) as fuel for light-duty vehicles is discussed in more detail in the next chapter.

\section{REFERENCES FOR CHAPTER 6}

1. Alson, J. A., 'The Emission Characteristics of Methanol and Compressed Natural Gas in Light Vehicles," paper 88-99.3, presented at the 81st Annual Meeting of APCA, Dallas, TX, June 19-24, 1988.

2. Automotive Fleet 1987 Fact Book, Volume 26 Supplement (Bobit Publishing Co., 1987).

3. Battye, W. H., Smith, M. G., and Deese, M., Cost Assessment of Alternative National Ambient Air Quality Standards For Ozone, Draft Report, prepared by Alliance Technology Corp., contract No. 68-02-4317 (Research Triangle Park, NC: U.S. Environmental Protection Agency, October 1987).

4. E.H.Pechan \& Associates, Inc., National Assessment of VOC, CO, and $\mathrm{NO}_{x}$ Controls, Emissions, and Costs, Contract No. 68-W8-0038 (Washington, DC: Office of Policy, Planning and Standards, U.S. Environmental Protection Agency, September 1988).

5. Environment Reporter, "Most Northeast States To Have Final Rules on Fuel Volatility Before 1989 Ozone Season," Current Developments 19(37):1835, Jan. 13, 1989.

6. Jack Faucett Associates, Methanol Prices During Transition (U.S. Environmental Protection Agency, September 1986).

7. 52 Federal Register 45060 (Nov. 24, 1987).

8. 52 Federal Register 31274 (Aug. 19, 1987).

9. 54 Federal Register 14425 (Apr. 11, 1989).

10. Leonard, Samuel A., Director, Automotive Emission Control, General Motors Corp., letter to Charles L. Gray, Director, Emission Control Technology Division, U.S. Environmental Protection Agency, Mar. 7, 1988.

11. Lorang, P., "Further OMS Reflections on the Cost of Mobile Source Provisions of the Mitchell Bill" (Ann Arbor, MI: U.S. Environmental Protection Agency, Office of Mobile Sources, Sept. 10, 1987).

12. Lorang, Phil, Office of Mobile Sources, U.S. Environmental Protection Agency, personal communication, April 1989.
13. Multinational Business Services, Inc., Costs and Cost-Effectiveness of Stage II and Onboard Refueling Vapor Controls (Motor Vehicle Manufacturers Association of the United States, Inc. and the Automobile Importers of America, Inc., April 1987).

14. Newman, P. W. G., and Kenworthy, J. R., "Gasoline Consumption and Cities: A Comparison of U.S. Cities With a Global Survey, "Journal of the American Planning Association 55:24-37,1989.

15. Sierra Research, Inc., "The Feasibility and Costs of More Stringent Mobile Source Emission Controls," contractor report for Office of Technology Assessment, Jan. 20, 1988.

16. Southern California Association of Governments, Regional Mobility Plan, Draft (Los Angeles, CA: October 1988).

17. South, David, et al., "Industrial voc Model: Regionalized Forecasts of Uncontrolled Emissions by Source Category, Draft Discussion Paper No. 19 for Task Group B of the Interagency Task Force on Acid Precipitation" (Washington, DC: U.S. Department of Energy, Office of Planning and Environment, June 1985).

18. South Coast Air Quality Management District, Draft Air Quality Management Plan, 1988 Revision, Appendix III-A, 1985 Emissions Inventory, South Coast Air Basin (E1 Monte, CA: March 1988).

19. South Coast Air Quality Management District, Draft Air Quality Management Plan, 1988 Revision, Addendum to Appendix IV-A, Tier I and Tier II control Measures (El Monte, CA: August 1988).

20. Turner, Mason \& Co., "U.S. Gasoline RVP Reduction Capabilities and Costs, " Comments of the American Petroleum Institute, Volume III, Concerning EPA's August 19, 1987 Proposed Regulation of Fuels and Fuel Additives and Regulation of Refueling Emissions (Washington, DC: American Petroleum Institute, Feb. 11, 1988).

21. U.S. Department of Commerce, Bureau of the Census, Statistical Abstracts of the United States, 1982 (Washington, DC: U.S. Government Printing Office, 1987).

22. U.S. Department of Commerce, Bureau of Economic Analysis, Survey of Current Business (Washington, DC: U.S. Government Printing Office, October 1985).

23. U.S. Department of Commerce, Bureau of Economic Analysis, Survey of Current Business (Washington, DC: U.S. Government Printing Office, July 1987),

24. U.S. Department of Energy, Monthly Energy Review (Washington, DC: U.S. Government Printing Office, September 1988).

25. U.S. Environmental Protection Agency, Office of Air, Noise, and Radiation/Office of Air Quality 
Planning and Standards, Control of Organic Emissions From Architectural Surface Coating, Preliminary Draft (Research Triangle Park, NC: March 1981).

26. U.S. Environmental Protection Agency, Office of Air Quality Planning and Standards, "Implications of Federal Implementation Plans (FIPs) for Post-1987 Ozone Nonattainment Areas" (Washington, DC: March 1987).

27. U.S. Environmental Protection Agency, Office of Air and Radiation, Office of Mobile Sources, Draft Regulatory Impact Analysis: Control of Gasoline Volatility and Evaporative Hydrocarbon Emissions From Motor Vehicles (Research Triangle Park, NC: July 1987).

28. U.S. Environmental Protection Agency, Office of Air and Radiation, Draft Regulatory Impact Analysis: Proposed Refueling Emission Regulations for GasolineFueled Motor Vehicles—Volume I, Analysis of Gasoline Marketing Regulatory Strategies, EPA-450/6-87OOla (Research Triangle Park, NC: July 1987).

29. U.S. Environmental Protection Agency, Guidance on Estimating Motor Vehicle Emission Reductions From the Use of Alternative Fuels and Fuel Blends, EPA-AA-TSS-PA-87-4 (Research Triangle Park, NC: January 1988).
30. U.S. Environmental Protection Agency, Hazardous Waste TSDF-Background Information for Proposed RCRA Air Emission Standards, Volume 1-Chapters, Preliminary Draft EIS (Research Triangle Park, NC: March 1988).

31. U.S. Environmental Protection Agency, Office of Mobile Sources. Preliminary data presented at the MOBILE4 Workshop, Ann Arbor, Michigan, Nov. 30, 1988.

32. Vice President's Task Force, "Cost and Cost Effectiveness of Alternative Fuels" (Washington, DC: July 1987).

33. Yosie, Terry, Vice President, American Petroleum Institute, memorandum to Robert Friedman, Office of Technology Assessment, Mar. 31, 1989.

34. Zimmerman, D., Tax, W., Smith, M., Demmy, J., and Battye, R., Anthropogenic Emissions Data for the 2985 NAPAP Inventory EPA-600/7-88-022, prepared by Alliance Technologies Corporation (Research Triangle Park, NC: U.S. Environmental Protection Agency, Air and Energy Engineering Research Laboratory, November 1988). 
Chapter 7

\section{New Opportunities for Controlling Ozone}




\section{CONTENTS}

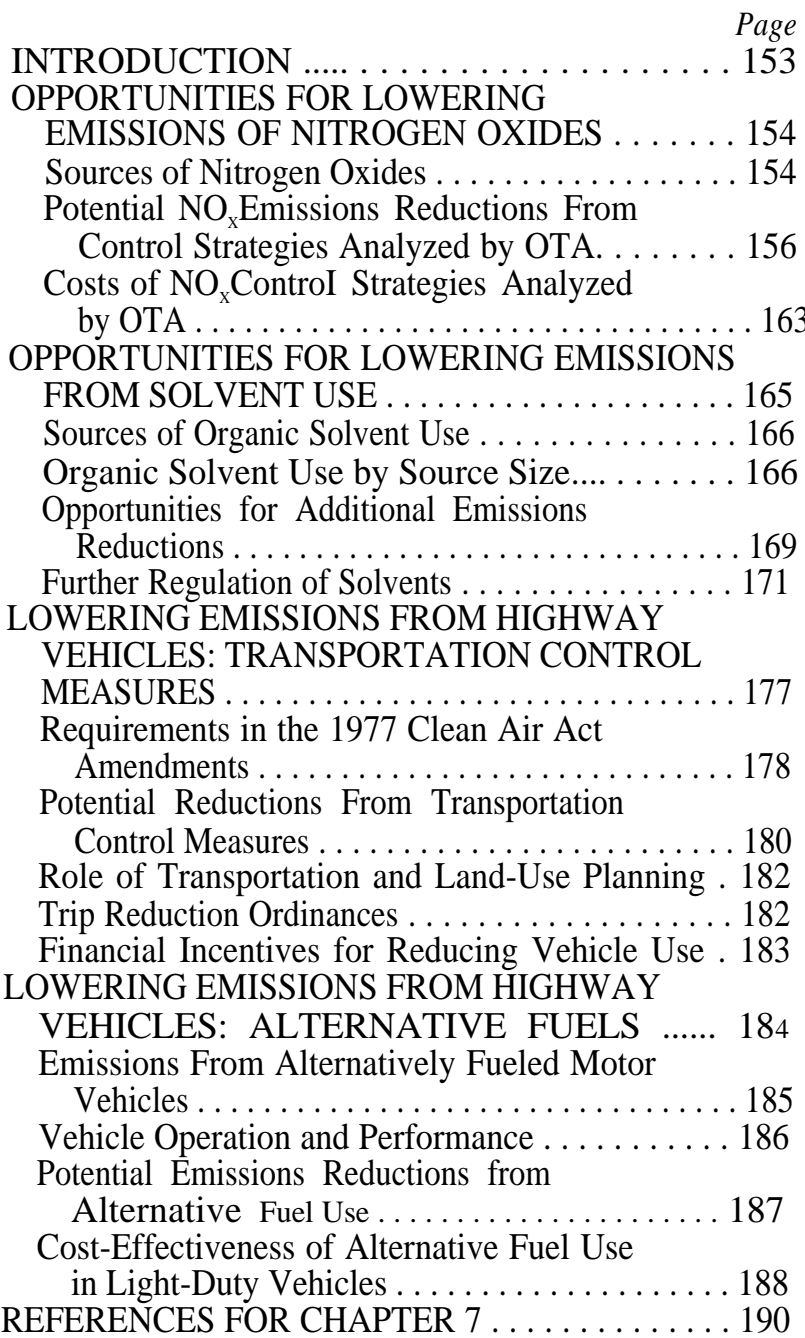

\section{Figures}

Figure Page

7-1. $\mathrm{NO}_{\mathrm{x}}$ Emissions in 1985, by Source Category. 156

7-2. $\mathrm{NO}_{\mathrm{x}}$ Emissioms from Mobile Sources in1985 as a Percentage of Total (Mobile plus Stationary)

Emissions ........................... 156

7-3. Summary of Estimated Nationwide $\mathrm{NO}_{\mathrm{x}}$ by Source Category, by Year ............ . . 158

7-4. $\mathrm{NO}_{\mathrm{x}}$ Emissions Reductions in 1994 and 2004 Compared to 1985 Emissions, by Control Method

7-5. Potential $\mathrm{NO}_{\mathrm{x}}$ Emissions Reductions and Remaining Emissions in 1994 and 2004 as a Percentage of 1985 Emissions in Nonattainment Cities . . . . . . . . . . . . . . ............. 161

7-6. Estimated Cost of $\mathrm{NO}_{\mathrm{x}}$ Emission Control Methods in 1994 and 2004 in Nonattainment Cities . . . 164
7-7. Estimated Cost-Effectiveness of $\mathrm{NO}_{\mathrm{X}}$ Emission Control Methods in 1994 in Nonattainment Cities ........................... 165

7-8, Total Solvent Use as a Percentage of 1985 Total VOC Emissions in Nonattainment Areas . . . . 166

7-9. Total 1985 Solvent Use in Nonattainment Areas, by Source Size ........................ 167

7-10. Industrial Solvent Use in 1985 by Four Source-Size Cutoffs in Nonattainment Cities . . . . . . . . . . . 168

7-11. Total Solvent Use Covered by Existing Regulations in 1985 in Nonattainment Cities . . . . . . . . . . . 169

7-12. Total Solvent Use Covered by Existing Regulations in 1985, by Source Category in Nonattainment

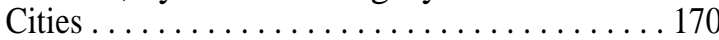

7-13. Identifiable Industrial Solvent Use Covered by Existing Regulations; and the Number of Firms by Source Size . . . . . . . . . . . . . ... ....... 171

\section{Tables}

Table Page

7-1. Summary of $1985 \mathrm{NO}_{\mathrm{x}}$ Emissions in Nonattainment Cities and Attainment Regions . . . . . . . . . . 155

7-2. Summary of 1994 NOX Emissions in Nonattainment Cities and Attainment Regions . . . . . . . . . . 157

7-3. Summary of $1995 \mathrm{NO}_{x}$ Emissionsin Nonattainment Cities and Attainment Regions . .. . ........ 157

7-4, Summary of $2004 \mathrm{NO}_{\mathrm{x}}$ Emissions in Nonattainment Cities and Attainment Regions . . . . ........ 157

7-5. Potential NO Emissions Reductions in 1994 Compared to 1985 Emissions from SourceSpecific Control Strategies . . . . . . . . . . . . . 159

7-6. Potential NO Emissions Reductions in 1999 Compared to 1985 Emissions from SourceSpecific Control Strategies

7-7. Potential $\mathrm{NO}_{\mathrm{x}}$ Emissions Reductions in 2004 Compared to 1985 Emissions from SourceSpecific Control Strategies

7-8. Estimated Costs of Selected $\mathrm{NO}_{\mathrm{x}}$ Control Methods in Nonattainment Cities in 1994 and 2004 ....

7-9. Estimated Cost-Effectiveness of Selected $\mathrm{NO}_{\mathrm{x}}$ Control Methods in Nonattainment Cities in 1994 and 2004 . . . . . . . . . . . . . . . . . . . . . . . 164

7-10. Effective VOC Reductions in 2004, From Use of CNG and Methanol as Light-Duty Motor Vehicle Fuels in Areas with Design Value of 0.15 ppm or Higher . . . . . . . . . . . . . . . . . . . . . . . . . 168

7-11. Cost-Effectiveness of Alternative Fuel Use.. 169 


\section{INTRODUCTION}

In the previous chapter, we examined progress that could be made towards attaining the current ozone standard by applying currently available control measures. We predicted that most of the cities with design values of 0.16 parts per million (ppm) or higher and some of the cities with design values of 0.14 and $0.15 \mathrm{ppm}$ would still fall short of attainment after implementing all of the measures we could identify.

As shown in figure 6-10, after all controls have been applied, two categories of sources-organic solvent evaporation, and highway vehicles (and associated gasoline marketing) - acount for over two-thirds of the volatile organic compound (VOC) emissions remaining in nonattainment cities in 1994. This chapter addresses the possibility of further controlling emissions from these source categories, using new regulatory approaches or technology that is not yet ready for application.

As discussed in chapter $5, \mathrm{NO}_{\mathrm{x}}$ reductions in addition to VOC controls would be counterproductive for some cities, actually increasing ozone concentrations compared to levels that would have resulted if just VOC emissions had been reduced. However, other cities may need to control NO, emissions in addition to VOCs in order to meet the ozone standard. Although we assume that the primary strategy for reducing urban ozone will continue to be controlling VOCs, in this chapter we also discuss measures that are currently available for reducing $\mathrm{NO}_{\mathrm{x}}$ emissions.

The first section of this chapter examines opportunities for controlling nitrogen oxides. Of the 20 million tons of $\mathrm{NO}_{\mathrm{x}}$ emitted per year, nationwide, approximately 35 percent were generated in ozone nonattainment areas. Without additional controls, $\mathrm{NO}_{\mathrm{x}}$ emissions are projected to increase by almost 30 percent by 2004 , with most of the increase coming from stationary sources. We analyzed potential $\mathrm{NO}_{\mathrm{x}}$ emissions reductions from highway vehicles and stationary sources including electric utility boilers, industrial boilers, stationary engines, gas turbines, and process heaters. We estimate that by
2004, application of controls to all of these categories would result in reductions in nonattainment areas of about 28 percent, compared to 1985 levels, and would cost about $\$ 3.7$ to $\$ 6.2$ billion per year in nonattainment cities, and about $\$ 5.4$ to $\$ 7.9$ billion per year, nationwide.

The second section focuses on emissions from organic solvent evaporation. We first describe categories of organic solvent use, and identify which categories provide opportunities for further control. We estimate that only about one-fourth of total solvent use is covered by existing regulations, and that an additional one-fourth could be covered by broader application of these rules. Of the remaining, "unregulated" solvent uses, the majority of emissions come from very small sources such as consumer and commercial products and miscellaneous surface coating uses. To suggest approaches for reducing emissions from these sources, we present examples of innovative State programs, and discuss the alternative of market-based controls.

Addressing motor vehicles, the third section looks at transportation control measures (TCMs)----such as encouraging use of mass transit or carpooling-that attempt to reduce vehicle use. TCMs have to be tailored to individual cities, and the emissions reductions that could be obtained from them will vary significantly from one city to another. However, to suggest the magnitude of reductions that could be achieved from an aggressive program, we review the assessment of TCMs that was recently completed for the Los Angeles area. With full funding and authority, it is hoped that the proposed measures will reduce highway-vehicle VOC emissions by a total of 30 percent by 2010 , compared to projected baseline emissions for that year. Growth management measures aimed at matching new jobs with nearby housing account for almost 50 percent of the reductions.

In the final section on alternative fuels, we first discuss their effect on motor vehicle emission rates and other aspects of vehicle operation and performance. We then present estimates of total emissions impacts of using alternative fuels, and the costs per ton of VOC emissions effectively eliminated. We 
conclude that in the near term, effective VOC emission rates with alternative-fueled vehicles will be only moderately lower than rates that could be obtained with gasoline vehicles meeting current standards. Using either methanol blends or dualfueled compressed natural gas $(\mathrm{CNG})$ vehicles would be an extremely costly means of reducing ozone. With significant advances in vehicle technology, greater and more cost-effective reductions may eventually be possible.

\section{OPPORTUNITIES FOR LOWERING EMISSIONS OF NITROGEN OXIDES}

Ozone is produced in the atmosphere from reactions involving two "precursor" pollutants: volatile organic compounds and nitrogen oxides. The focus of efforts to reduce ozone has historically been on controlling local VOC emissions. This focus is expected to continue. In some cities, controlling $\mathrm{NO}_{\mathrm{x}}$ emissions in addition to VOCs would be counterproductive, increasing ozone concentrations compared to levels that would have resulted if just VOC emissions had been reduced. In other cities, however, controlling $\mathrm{NO}_{\mathrm{x}}$ emissions in addition to VOCs might help reduce ozone.

At present, our ability to make reliable predictions about whether or not $\mathrm{NO}_{x}$ controls will be helpful is limited. For most cities, the data gathering and modeling needed to assess the impact of $\mathrm{NO}_{\mathrm{x}}$ emissions reductions have not been done. In the best-studied area, Los Angeles, the issue is clouded by the fact that reducing $\mathrm{NO}_{\mathrm{x}}$ emissions would apparently lower peak ozone concentrations at some locations but increase them at others, compared to VOC controls alone. Such mixed outcomes might occur in other cities, as well.

The effect of reducing $\mathrm{NO}_{x}$ emissions in the Northeastern United States has been studied using EPA's Regional Oxidant Model. The analysis should be considered preliminary, and consideration of different meteorological conditions or levels of control might change the conclusions. The results suggest that totalled over all of the urban areas in the region, reducing $\mathrm{NO}_{\mathrm{x}}$ emissions by 27 percent and VOC emissions by 42 percent below estimated 1980 levels would improve air quality more than reducing VOC emissions alone. However, for a few individual cities, the $\mathrm{NO}_{\mathrm{x}}$ reductions were predicted to be counterproductive. In all of the northeastern States, the $\mathrm{NO}_{\mathrm{x}}$ reductions were predicted to be beneficial for nonurban areas, supporting the theoretically based expectation that $\mathrm{NO}_{\mathrm{x}}$ control would help reduce ozone in most rural areas.

Modeling calculations comparable to those performed for the Northeast have not been done for the South. However, measurements of VOCs and $\mathrm{NO}_{\mathrm{x}}$ in urban air, and estimates of VOC emissions from vegetation, give a very preliminary suggestion that cities in the South are even more likely to benefit from $\mathrm{NO}_{\mathrm{x}}$ control than cities in the Midwest or Northeast.

This next section describes the sources of $\mathrm{NO}_{x}$ emissions and presents our estimates of the changes in emissions over the next 15 years due to the offsetting influences of economic growth and State and Federal regulations in place as of 1987. These estimates serve as a baseline for considering the effects of regulatory changes that could be required to attain the ozone standard. We analyze potential $\mathrm{NO}_{\mathrm{x}}$ emissions reductions and control costs for highway vehicles, and stationary sources including electric utility boilers, industrial boilers, stationary engines, gas turbines, and process heaters.

\section{Sources of Nitrogen Oxides}

Table 7-1 displays estimates of $1985 \mathrm{NO}_{\mathrm{x}}$ emissions, number of cities, and population within each of five ozone design value categories. The EPA 1985 National Emissions Data System (NEDS) inventory is the source of our emissions data and serves as the base inventory for all future year projections presented in this report. Residential fuel combustion sources have been excluded from our analysis since these emissions occur primarily during the wintertime when ozone is not a problem. Of the 20 million tons of $\mathrm{NO}_{\mathrm{x}}$ emitted per year, approximately 35 percent were generated in cities that exceeded the ozone standard during the 1983-85 period.

\footnotetext{
${ }^{1}$ For our analysis, an area is considered in nonattainment if its design value is greater than 0.12 ppm ozone according to EPA-published 1983-85 ozone monitoring data. EPA's actual determination of nonattainment is based on a slightly different method, but the resulting number of nonattainment cities are essentially the same. Our number of nonattainment areas differs from EPA's count of 61 because, in several cases, EPA has used Consolidated Metropolitan Statistical Areas (CMSAs), rather than cities. Several of these CMSAS include two or more cities that we have considered separately.
} 
Table 7-I-Summary of $1985 \mathrm{NO}_{\mathrm{x}}$ Emissions in Nonattainment Cities and Attainment Regions

\begin{tabular}{|c|c|c|c|c|c|}
\hline & $\begin{array}{c}\mathbf{N O}_{\mathbf{x}} \\
\text { emissions } \\
(1,000 \text { tons })^{\mathrm{a}} \\
\end{array}$ & $\begin{array}{c}\text { Percent } \\
\text { stationary } \\
(\%)\end{array}$ & $\begin{array}{l}\text { Percent } \\
\text { mobile } \\
(\%)\end{array}$ & $\begin{array}{l}\text { No. of } \\
\text { cities }\end{array}$ & $\begin{array}{c}1985 \\
\text { population } \\
\text { (millions) }\end{array}$ \\
\hline \multicolumn{6}{|l|}{$\begin{array}{l}\text { Nonattainment cities by } \\
\text { design value category } \\
\text { (in ppm } \mathrm{O}_{3} \text { ) }\end{array}$} \\
\hline $0.13-0.14 \ldots \ldots \ldots \ldots$ & 2,300 & $5 a$ & 42 & 37 & 30.2 \\
\hline $0.15-0.17 \ldots \ldots \ldots$ & 3,300 & 49 & 51 & 40 & 55.3 \\
\hline $0.18-0.26 \ldots \ldots \ldots \ldots$ & 970 & 51 & 49 & 14 & 20.2 \\
\hline$>0.26 \ldots \ldots \ldots \ldots$ & 490 & 25 & 75 & 3 & 11.9 \\
\hline Total (nonattainment) . . & 7,100 & 50 & 50 & 94 & 117.7 \\
\hline Attainment regions . . . . & $\underline{13,000}$ & 60 & 40 & & 118.8 \\
\hline Total . . . & $\overline{20,000}$ & 56 & 44 & & 236.5 \\
\hline
\end{tabular}

Figure 7-1 displays the percent contribution of various source categories to total $1985 \mathrm{NO}_{\mathrm{x}}$ emissions. About three-quarters of the emissions are generated from two main categories: mobile sources and electric utility boilers. About a third of the 1985 emissions inventory is composed of highwayvehicle emissions. A further breakdown of the data, shown in figure 7-2, reveals that passenger cars are the largest contributors within the highway-vehicle category, with about 17 percent of the total 1985 $\mathrm{NO}_{\mathrm{x}}$ emissions, followed by heavy-duty diesel trucks with 9 percent. It is interesting to note that in cities with ozone design values greater than 0.26 ppm (southern California), mobile sources account for almost three-quarters of the total $\mathrm{NO}_{\mathrm{x}}$ emissions. In other nonattainment cities, mobile sources contribute between about 42 and 49 percent of total $\mathrm{NO}_{x}$ emissions.

Tables 7-2 through 7-4 display our projections of $\mathrm{NO}_{\mathrm{x}}$ emissions in 1994, 1999, and 2004, assuming that existing State and EPA regulations do not change. Under current regulations, total $\mathrm{NO}_{\mathrm{x}}$ emissions increase steadily between 1985 and 2004, showing an increase of about 7 percent between 1985 and 1994, and 27 percent between 1985 and 2004.
Although the number of vehicle-miles traveled is forecast to increase in many areas through 2004, the gradual replacement of current vehicles with newer, cleaner ones will result in an overall decline in highway-vehicle emissions by 1994. However after 1994, total highway-vehicle emissions will begin to increase because of the dominant influence of increasing vehicle-miles traveled. Stationary source emissions, on the other hand, are forecast to increase continuously between 1985 and 2004, showing an 18-percent increase by 1994 and a 45-percent increase by 2004, over 1985 levels. ${ }^{2}$ About 60 percent of the stationary source growth between 1985 and 1994 is contributed by electric utility boilers. These sources are estimated to increase about 18 percent by 1994, and 38 percent by 2004, from 1985 levels. Figure 7-3 shows mobile and stationary source $\mathrm{NO}_{\mathrm{x}}$ emissions through time. The net increase in total emissions from 1985 to 1994 would be much greater were it not for the 12-percent decline in highway-vehicle emissions by 1994 .

Our emissions projections for large stationary sources other than utility boilers may be somewhat high because we do not model the effect of New Source Performance Standards (NSPS), control requirements that apply to new and modified large

${ }^{2}$ Future emissions from electric utility boilers were estimated based on growth in electricity demand per capita. We assume that between 1985 and 1994 expansion of existing sources will account for all the growth in utility boiler emissions; after 1994, growth is assumed to come from new sources (which have lower $\mathrm{NO}_{\mathrm{x}}$ emission rates). For industrial boilers, gas turbines, process heaters, and stationary engines, estimates were based on growth in Gross National Product per capita. Population growth rates were used for all other stationary source categories.

${ }^{3}$ Future highway vehicle emissions were projected using EPA estimates of future highway vehicle VOC emission rates, combined with estimates of average yearly miles-travelled per person, and Census Bureau population projections. 
Figure 7-1-NO Emissions in 1985, by Source Category

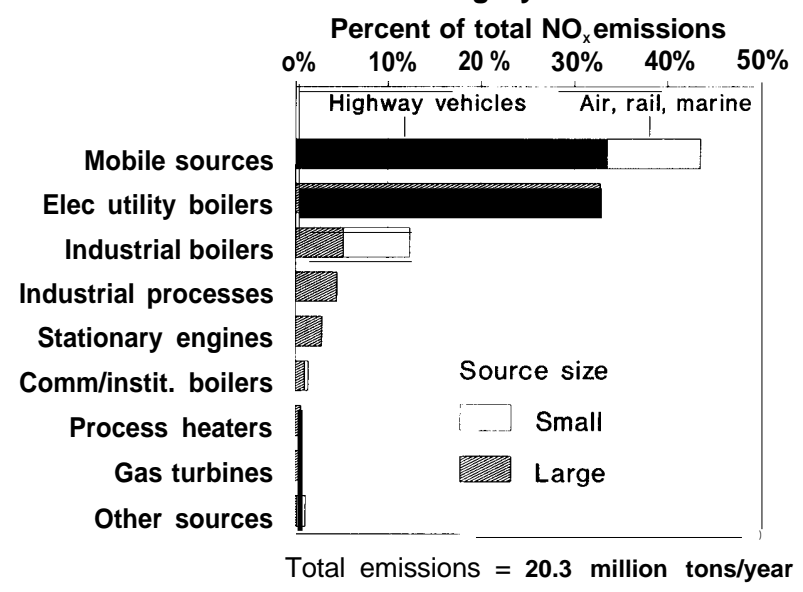

Stationary sources that emit more than $\mathbf{5 0}$ tons per year of $\mathrm{NO}$, are included in the "Large" categories.

SOURCE: OTA, from EPA's National Emissions Data System (NEDS) and National Adid Precipitation As sessment Program emissions inventories.

NO, emission sources. ${ }^{4}$ However, the effect on our overall emissions estimates is small because, as illustrated in figure 7-3, utility boiler emissions (which do factor in NSPS requirements) will have a much more significant impact on future estimates of total $\mathrm{NO}_{\mathrm{x}}$ emissions than other large stationary sources.

\section{Potential NO $\mathrm{N}_{X}$ Emissions Reductions From Control Strategies Analyzed by OTA}

In this section we analyze the $\mathrm{NO}_{\mathrm{x}}$ emissions reductions from, and costs of, the following sourcespecific control strategies:

- controls on major existing stationary sources;

- inspection and maintenance $(1 / \mathrm{M})$ programs for highway vehicles; and

. more stringent exhaust emission standards for gasoline highway vehicles.

Throughout the analysis, emissions reductions reported apply to the change occurring between 1985 and the relevant future year. The emissions
Figure 7-2-NO Emissions from Mobile Sources in 1985 as a Percentage of Total (Mobile plus Stationary) Em is sions

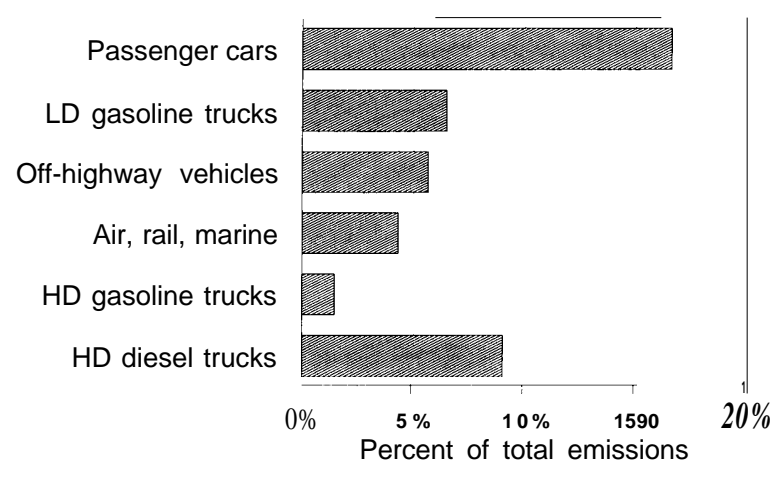

LD = light-duty; HD = heavy-duty

Total $\mathrm{NO}_{\mathrm{x}}$ emissions $=20.3 \mathrm{MM}$ tons/year

SOURCE: Office of Technology Assessment, 1989.

reductions reported in our analysis result from currently available control methods that we know can be applied in the near-term. We were able to analyze the emissions reduction potential and associated control costs for strategies applicable to about 86 percent of current NO, emissions. Source categories for which we had emission control information include electric utility and large industrial boilers, gas turbines, stationary engines, process heaters, and highway vehicles. The remaining 14 percent of $\mathrm{NO}_{\mathrm{x}}$ emissions for which we did not have control information include commercial and institutional boilers, industrial processes, and miscellaneous small sources.

All control strategies listed above can be restricted to ozone nonattainment cities if desired, except for more stringent tailpipe standards which would apply nationwide. Tables 7-5 through 7-7 present estimates of emissions reductions achieved in 1994, 1999, and 2004, respectively, if the various control strategies listed above are applied. We estimate that $\mathrm{NO}_{\mathrm{x}}$ emissions in nonattainment cities can be reduced by 1.2 million tons per year in 1994, about 17 percent below 1985 levels. By 2004, total

\footnotetext{
${ }^{4}$ These regulations require that new stationary sources with the potential to emit more than 100 tons per year install stringent emission controls. These same control requirements apply to major modifications of existing sources that result in $\mathrm{NO}_{\mathrm{x}}$ emissions increase of more than 40 tons per year. More stringent controls are required in nitrogen dioxide nonattainment areas; as of 1986, the Los Angeles metropolitan area was the only region in the Nation that exceeded this standard,
} 
Table 7-2--Summary of $1994 \mathrm{NO}_{x}$ Emissions in Nonattainment Cities and Attainment Regions (emissions in 1,000 tons per year) ${ }^{\mathrm{a}}$

\begin{tabular}{|c|c|c|c|c|c|c|}
\hline & \multicolumn{3}{|c|}{$\mathrm{NO}_{\mathrm{x}}$ emissions } & \multicolumn{3}{|c|}{ Change from 1985 emissions } \\
\hline & Total & Stationary & Mobile & Total & Stationary & Mobile \\
\hline 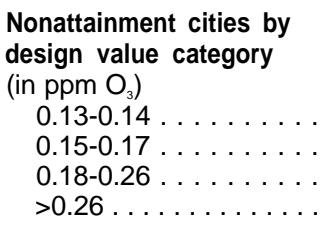 & $\begin{array}{r}2,400 \\
3,500 \\
.1,100 \\
-490\end{array}$ & $\begin{array}{r}1,500 \\
1,900 \\
620 \\
150 \\
\end{array}$ & $\begin{array}{r}880 \\
1,600 \\
450 \\
340 \\
\end{array}$ & $\begin{array}{r}5 \% \\
4 \% \\
10 \% 0 \\
1 \% \\
\end{array}$ & $\begin{array}{l}16 \% \\
18 \% \\
250 \% \\
21 \% \\
\end{array}$ & $\begin{array}{r}-10 \% \\
-870 \\
-6 \% \\
-6 \% \\
\end{array}$ \\
\hline $\begin{array}{l}\text { Total (nonattainment) } . \\
\text { Attainment regions '. .. }\end{array}$ & $\begin{array}{r}7,400 \\
14,000 \\
\end{array}$ & $\begin{array}{l}4,200 \\
9,400 \\
\end{array}$ & $\begin{array}{l}3,200 \\
5,000 \\
\end{array}$ & $\begin{array}{l}5 \% \\
80 / 0 \\
\end{array}$ & $\begin{array}{l}18 \% \\
180 / 0 \\
\end{array}$ & $\begin{array}{l}-8 \% \\
-6 \% \\
\end{array}$ \\
\hline Total . ...........2 & 2,000 & 14,000 & $\overline{8,200}$ & $7 \%$ & $180 / 0$ & $-7 \%$ \\
\hline
\end{tabular}

Totals are rounded.

SOURCE: Office of Technology Assessment, 1989.

Table 7-3-Summary of $1999 \mathrm{NO}_{\mathrm{x}}$ Emissions in Nonattainment Cities and Attainment Regions (emissions in 1,000 tons per year) ${ }^{2}$

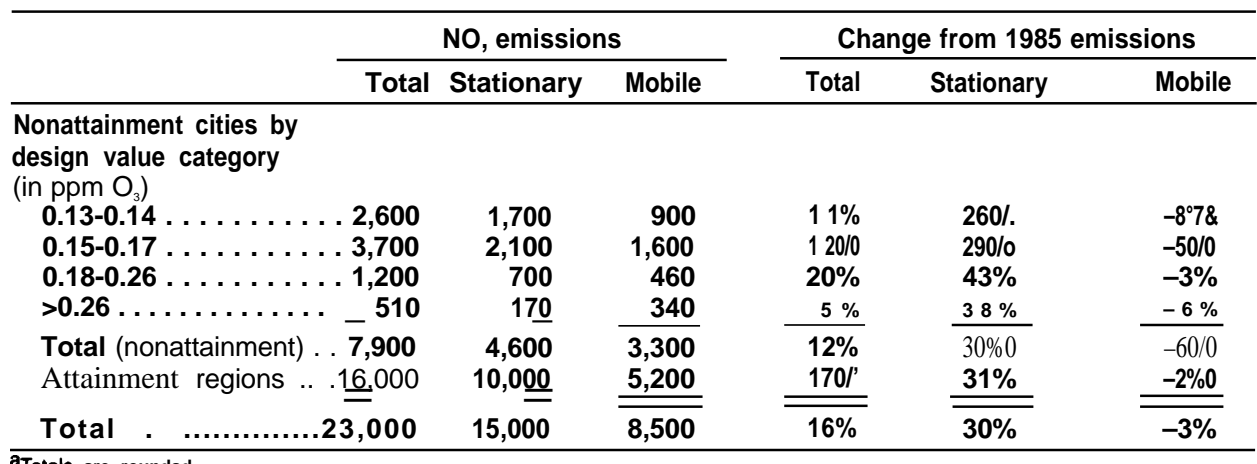

Totals are roundad.

SOURCE: Office of Technology Assessment, 1989.

Table 7-Summary of $2004 \mathrm{NO}_{\mathrm{x}}$ Emissions in Nonattainment Cities and Attainment Regions (emissions in 1,000 tons per year) ${ }^{a}$

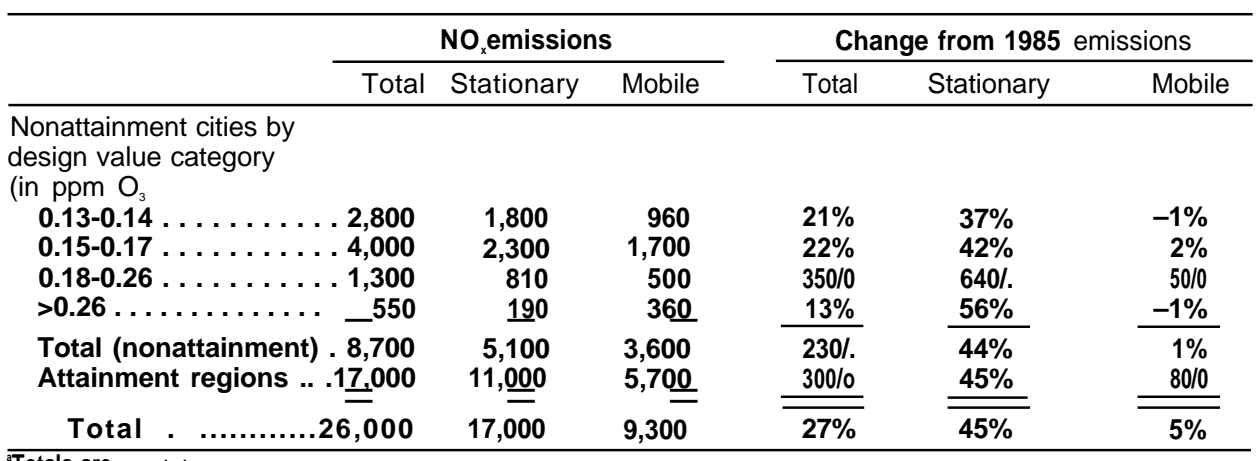

${ }^{\mathrm{a}}$ Totals are rounded.

SOURCE: Office of Technology Assessment, 1989. 
Figure 7-Summary of Estimated Nationwide $\mathrm{NO}_{x}$ by Source Category, by Year

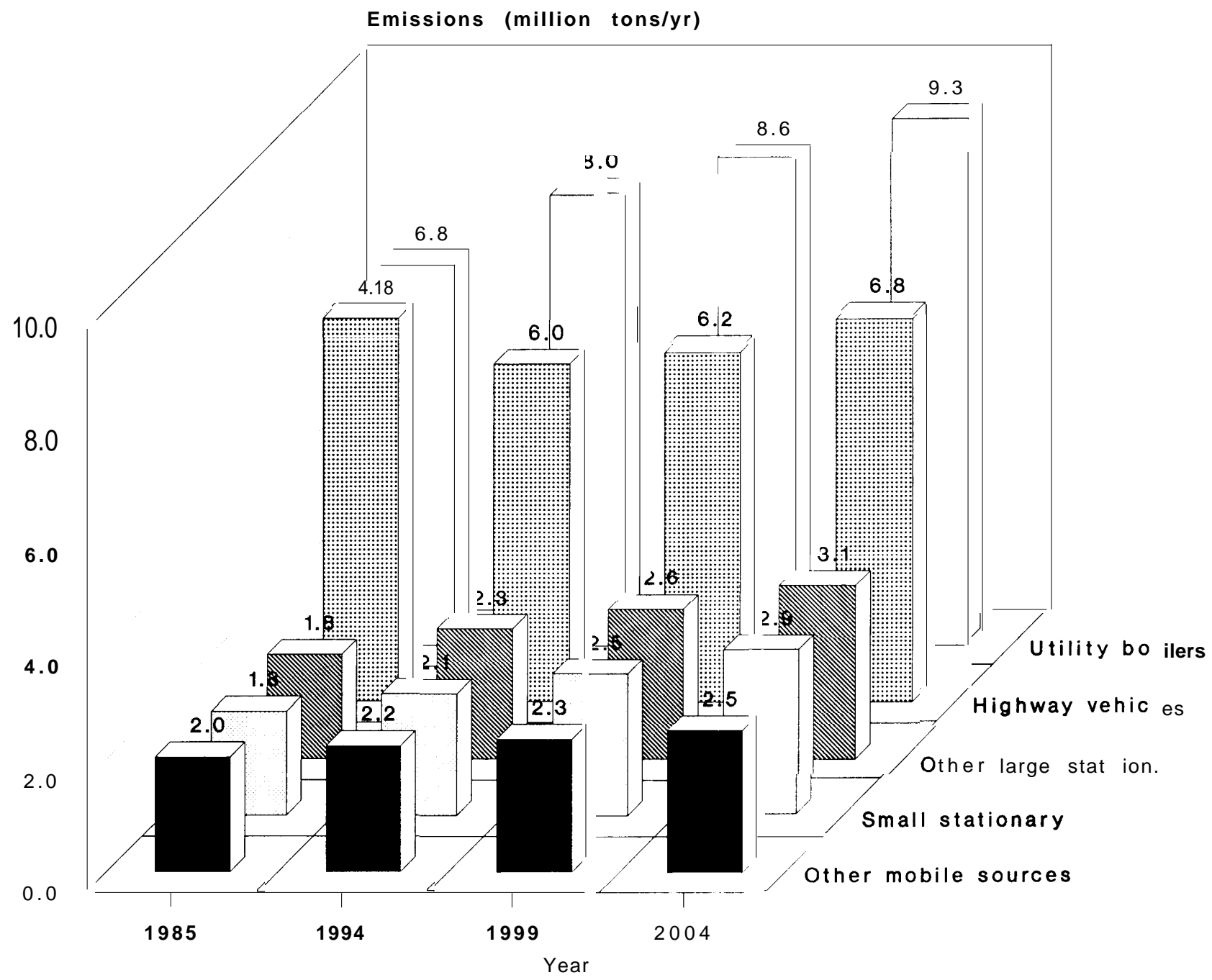

The numbers directly above the boxes are the total emissions within the source category. For example, emissions from highway vehicles in 1994 are 6.0 million tons per year, nationwide. Assumes no regulations other than those in place in 1987.

SOURCE: Office of Technology Assessment, 1989.

emissions reductions from these control measures in nonattainment areas increase to about 2 million tons per year, about 28 percent below 1985 levels. An additional 810,000 tons per year would be eliminated in attainment areas by 2004 due to new highway-vehicle emission standards.
Figure 7-4 displays our estimates of emissions reductions resulting from each control strategy in 1994 and 2004, as a percentage reduction below total 1985 emissions in nonattainment cities. The largest reductions come from instituting controls ${ }^{5}$ on electric utility boilers. The percentage reductions are

5For these estimates we assume the use of moderately stringent control techniques which we consider to be reasonably available control technologies (RACY). Controls include boiler combustion modifications such as the installation of low $\mathrm{NO}_{\mathrm{x}}$-emitting fuel burners, reducing air flow through the boiler, and other techniques. 
Table 7-5-Potential NO Emissions Reductions in 1994 Compared to 1985 Emissions From Source-Specific Control Strategies (emissions reductions in 1,000 tons par year)

\begin{tabular}{|c|c|c|c|c|c|}
\hline & \multicolumn{2}{|c|}{ Stationary source controls } & \multirow[b]{2}{*}{ Enhanced I/M } & \multirow[b]{2}{*}{$\begin{array}{c}\text { New highway- } \\
\text { vehicle emission } \\
\text { standards } \\
\end{array}$} & \multirow[b]{2}{*}{$\begin{array}{c}\text { Total } \\
\text { reductions }\end{array}$} \\
\hline & $\begin{array}{c}\text { Utility } \\
\text { boilers }\end{array}$ & $\begin{array}{l}\text { Industrial boilers, } \\
\text { gas turbines, } \\
\text { stationary engines } \\
\text { process heaters }\end{array}$ & & & \\
\hline \multicolumn{6}{|l|}{$\begin{array}{l}\text { Nonattainment cities by } \\
\text { design value category } \\
\left(\text { in } \mathrm{ppm}_{3} \text { ) }\right.\end{array}$} \\
\hline $0.13-0.14 \ldots \ldots$ & 440 & 83 & 54 & 0 & 570 \\
\hline $0.15-0.17 \ldots \ldots \ldots \ldots$ & 290 & 110 & 86 & 0 & 480 \\
\hline $0.18-0.26 \ldots \ldots \ldots \ldots$ & 63 & 48 & 27 & 0 & 140 \\
\hline$>0.26 \ldots \ldots \ldots \ldots$ & 5 & 12 & 19 & 0 & 37 \\
\hline Total (nonattainment) . . . & 790 & 250 & 190 & 0 & 1,200 \\
\hline Attainment areas . . . . . . & 0 & 0 & 0 & 0 & 0 \\
\hline$\ldots \ldots \ldots$ & 790 & 250 & 190 & 0 & 1,200 \\
\hline
\end{tabular}

Totals are roundad.

Strategy descriptions;

Stationary source controls = moderately stringent controls on all existing stationary sources that emit more than 100 tons par year of NO,. considered to be "reasonably available control tochnologies."

Enhanced inapection and maintenance (IM) programs for cars and light-duty trucks.

New highway-vehkfa emiaclon standards for passenger cars and light-duty gasoline trucks.

SOURCE: Office of Tectuology Assessment, 1969.

Table 7-6-Potential NO Emissions Reductions in 1999 Compared to 1985 Emissions From source-specific Control Strategies (emissions reductions in 1,000 tons per year)

\begin{tabular}{|c|c|c|c|c|c|}
\hline & \multicolumn{2}{|c|}{ Stationary source controls } & \multirow[b]{2}{*}{ Enhanced I/M } & \multirow[b]{2}{*}{$\begin{array}{l}\text { New highway- } \\
\text { vehicle emission } \\
\text { standards }\end{array}$} & \multirow[b]{2}{*}{$\begin{array}{l}\text { Total } \\
\text { reductions }\end{array}$} \\
\hline & $\begin{array}{l}\text { Utility } \\
\text { boilers }\end{array}$ & $\begin{array}{l}\text { Industrial boilers, } \\
\text { gas turbines, } \\
\text { stationary engines } \\
\text { process heaters }\end{array}$ & & & \\
\hline $\begin{array}{l}\text { Nonattainment cities by } \\
\text { design value category } \\
\text { (in } \mathrm{ppm} \mathrm{O}_{3} \text { ) }\end{array}$ & & & & & \\
\hline $\begin{array}{l}0.13-0.14 \ldots \ldots \ldots \ldots \\
0.15-0.17 \ldots \ldots \ldots \ldots \\
0.18-0.26 \ldots \ldots \ldots \ldots \\
>0.26 \ldots \ldots \ldots\end{array}$ & $\begin{array}{r}460 \\
300 \\
69 \\
6 \\
\end{array}$ & $\begin{array}{r}97 \\
120 \\
57 \\
14\end{array}$ & $\begin{array}{l}55 \\
88 \\
27 \\
19 \\
\end{array}$ & $\begin{array}{r}100 \\
170 \\
43 \\
0 \\
\end{array}$ & $\begin{array}{r}710 \\
680 \\
200 \\
38 \\
\end{array}$ \\
\hline $\begin{array}{l}\text { Total (nonattainment) . . . } \\
\text { Attainment areas . . . . . . }\end{array}$ & $\begin{array}{r}840 \\
0 \\
\end{array}$ & $\begin{array}{r}290 \\
0 \\
\end{array}$ & $\begin{array}{r}190 \\
0 \\
\end{array}$ & $\begin{array}{l}310 \\
470 \\
\end{array}$ & $\begin{array}{r}1,600 \\
490 \\
\end{array}$ \\
\hline Total . & 840 & $\overline{290}$ & $\overline{190}$ & 780 & 2,100 \\
\hline
\end{tabular}

a Totals are rounded.

Strategy descriptions:

Stationary source controle = moderately stringent controls on all existing stationary sources that emit more than 100 tons par year of NO,. considered to be "reasonably available control technologies."

Enhanced inepection and maintenance (I/W) programs for cars and light-duty mucks.

Now highway.vehkfe emleclon standarde for passenger cars and light-duty gasoline trucks,

SOURCE: Ottice of Technology Assessment, 1989.

about the same for each category between 1994 and 2004, except for new highway vehicle standards, which increase over time due to the gradual replacement of older cars with newer ones equipped with additional controls,
Figure 7-5 displays potential emissions reductions and the percentage of emissions that remain after all of the reductions have been accounted for by 1994 and 2004. In 1994, after all controls are applied, emissions are approximately 83 percent of 
Table 7-7-Potential $\mathrm{NO}_{\mathrm{x}}$ Emissions Reductions in 2004 Compared to 1985 Emissions From Source-Specific Control Sttategies (emissions reductions in 1,000 tons per year)

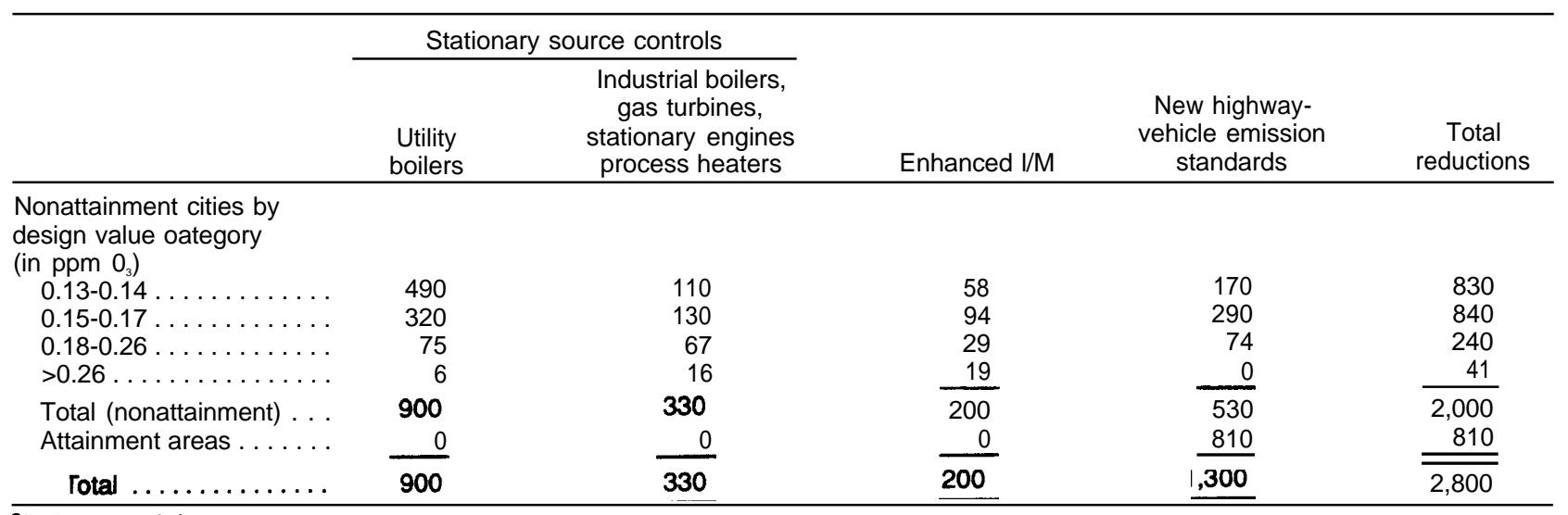

aTotals am rounded. Strategy descriptions: c on trol inológiès."

Enhanced inapection end mulntenance (I/N) programs for cars and light-duty trucks.

Now highway-vohkle eminion tandiands for passenger cars and light-duty gasoline trucks.

SOURCE: Office of Technology Assessment, 1959.

Figure 7-4-NO Emissions Reductions in 1994 and 2004 Compared to 1985 Emissions, by Control Method
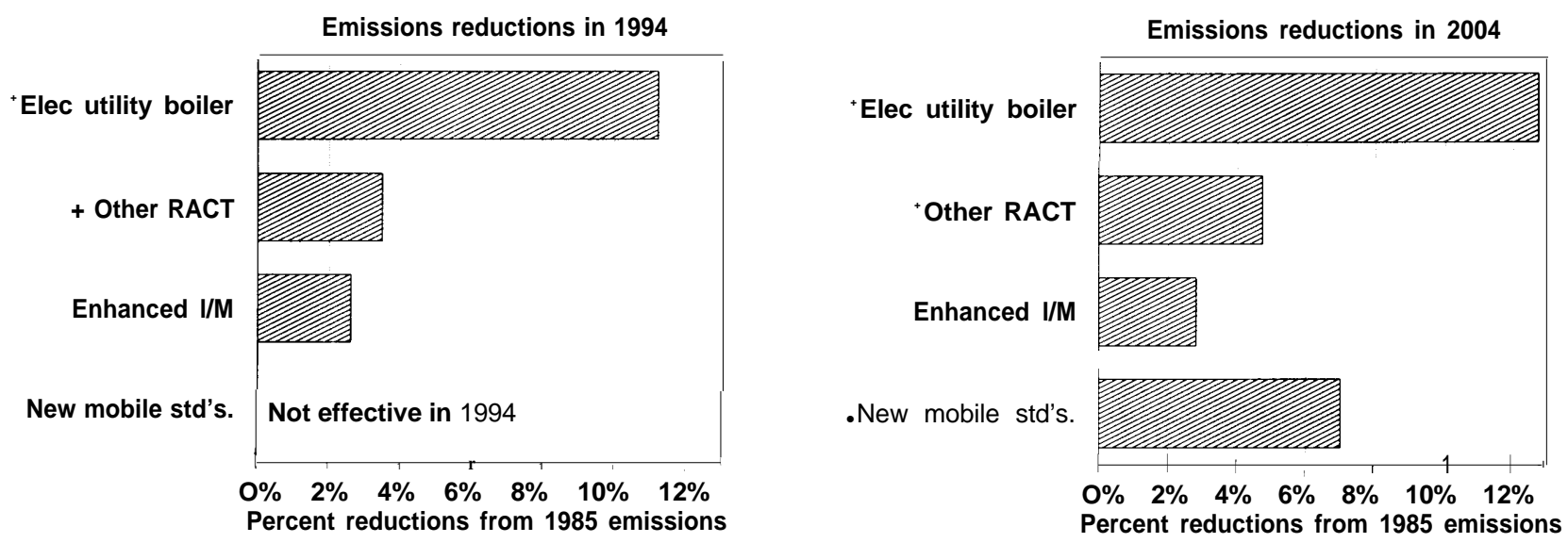

+ Controls o $\mathrm{n}$ sources emitting more than 100 tons per year.

-Reductions are also achieved in attainment areas.

See text for description of control methods.

SOURCE: Office of Technology Assessment, 1989.

the 1985 total. By 2004, the emissions that remain after all controls are applied declines to about 72 percent of 1985 levels. The drop in remaining emissions between 1994 and 2004 is due to the increased effectiveness of more stringent highwayvehicle emission standards. 


\section{Figure 7-5-Potential $\mathrm{NO}_{x}$ Emissions Reductions and Remaining Emissions in 1994 and 2004 as a Percentage of 1085 Emissions in Nonattainment Cities}
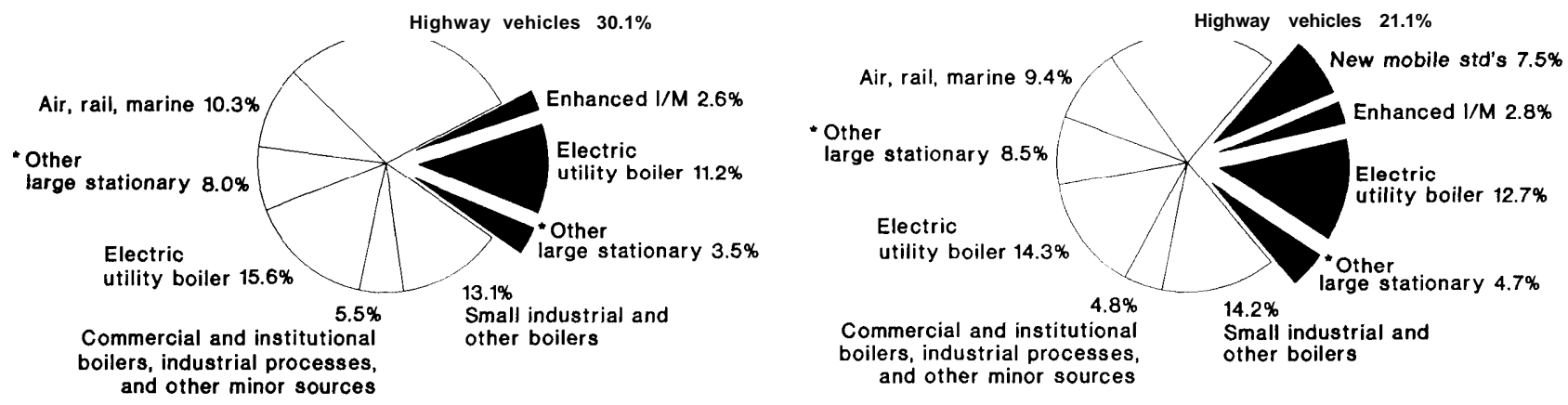

Emissions reductions

Remaining emissions

\footnotetext{
.Other large stationary includes: industrial boilers,

stationary engines, gas turbines, and process heaters.
}

The pulled-out slices represent emissions that can be eliminated by each control method. The six connected slices represent emissions that remain after all control methods are applied. "Large" emission sources are defined as those which emit more than $\mathbf{5 0}$ tons per year $\mathrm{NO}_{x}$. See text for description of control methods.

SOURCE: Office of Technology Assessment, 1989.

Approximately 22 percent of the remaining emissions in 1994 comes from two categories (shown in figure 7-5): 1) commercial and institutional boilers, and industrial processes, and 2) small industrial and other boilers. The 14 percent of the inventory for which we were unable to identify control methods is composed entirely of these two categories. Although controls were applied to utility boilers, this category still accounts for about 16 percent of the inventory after control in 1994 (based on 1985 emissions). As we will discuss later, these estimates do not reflect the most stringent level of control possible for existing stationary sources.

The following subsections summarize the emissions reduction potential of each individual control strategy.

\section{Controls on All Major Stationary Sources}

The following subsection presents estimates of emissions reduction potential after applying $\mathrm{NO}_{\mathrm{x}}$ controls at two levels of stringency. The first level represents control techniques of moderate stringency, or what we may consider reasonably available control technologies (RACT). This is the control level used in the estimates discussed in the previous section. The second level represents the most stringent level of control achievable given current technology.

In our analysis, we have applied controls on five source categories: electric utility boilers, industrial boilers, stationary engines, gas turbines, and process heaters. ${ }^{6}$ Data on the emissions reduction potential

${ }^{6}$ For example, $\mathrm{NO}_{\mathrm{x}}$ emissions from utility and industrial boilers can be reduced by installing devices which alter the way fuel is combusted inside the boiler. 
and associated costs of the control technologies used in our analysis were supplied by E.H. Pechan \& Associates, Inc., and were used in a recent report to EPA [34].

Moderately Stringent Controls. We estimate emissions reductions achievable through RACT-level regulations by simulating controls on all existing stationary sources that emit more than 100 tons of $\mathrm{NO}_{\mathrm{x}}$ per year in those cities that did not have an existing regulation for a particular source category

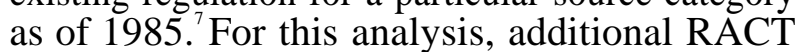
controls are applied only in nonattainment cities.

We estimate that applying RACT to all sources would lower $\mathrm{NO}_{\mathrm{x}}$ emissions by approximately 1 million tons per year in 1994, representing a 15-percent decline based on 1985 levels. Electric utility boilers, alone, account for about threequarters of this total reduction. By 2004, RACT reductions are estimated to increase to about 1.2 million tons per year, from 1985 levels.

Most Stringent Controls. If the most stringent control technologies are required on sources that emit more than 100 tons of $\mathrm{NO}_{\mathrm{x}}$ per year, about 2.1 million tons per year could be eliminated from nonattainment cities in 1994, more than double the amount achieved through RACT-level control. Lowering the source size cutoff from 100 to 25 tons per year while requiring the most stringent controls adds about an additional 100,000 tons per year of emissions reductions to this total.

\section{Enhanced Motor Vehicle Inspection and Maintenance (I/M) Programs}

The definition and scope of our analysis of an enhanced I/M program were outlined in chapter 6. Emissions reduction benefit assumptions were taken from Sierra Research, Inc. [37]. We assume that the $\mathrm{NO}_{\mathrm{x}}$ emissions reduction potential from existing $\mathrm{I} / \mathrm{M}$ programs is about 4 percent. The full benefit from enhanced programs is about 14 percent, while the incremental benefit gained by switching from an existing to an enhanced program is about 10 percent.

We estimate that enhanced $\mathrm{I} / \mathrm{M}$ programs in nonattainment cities will reduce $\mathrm{NO}_{\mathrm{X}}$ emissions by about 190,000 tons per year in 1994 and by 200,000 tons in $2004 .{ }^{9}$ This represents about a 3-percent reduction in both 1994 and 2004, based on 1985 emissions.

\section{More Stringent Highway-Vehicle Emission Standards}

This analysis includes the $\mathrm{NO}_{\mathrm{x}}$ emissions reduction potential of instituting more stringent tailpipe controls on new passenger cars and light-duty gasoline-fueled trucks. The standards we analyzed were determined to be the most stringent technologically feasible, given currently "available" control technology, according to Sierra Research, Inc. [37] .10 Sierra Research, Inc., assumes that these standards can be met after 50,000 miles of controlled test driving for passenger cars, and 120,000 miles for light-duty trucks. These standards are discussed in more detail in chapter 6 . We assume that new standards go into effect in 1994 for both passenger cars and light-duty trucks.

We estimate that new highway-vehicle standards will reduce $\mathrm{NO}_{\mathrm{x}}$ emissions in 1999 by about 4 percent, both nationwide and in nonattainment cities. By 2004, reductions increase to about 7 percent in both nonattainment and attainment areas, based on 1985 emissions. Again, the increase in emissions reductions over time is due to the gradual

\footnotetext{
${ }^{7}$ If a source already had a control device that resulted in an emissions reduction of more than 10 percent, aregulation was assumed to exist for that source and no further controls were applied.

${ }^{8}$ We assume ${ }^{\text {tihe }}$ highest level of $\mathrm{NO}_{\mathbf{x}}$ control could\& achieved through a process called selective catalytic reduction which eliminates nitrogen oxides from fuel combustion exhaust gases.

${ }^{9}$ Volatile organic compound emissions reductions from enhanced $\mathrm{I} / \mathrm{M}$ programs are discussed in chapter 6 . Carbon monoxide and particulate emissions reduction benefits are also gained, but are not calculated in this analysis.

${ }^{10}$ According to Sierra Research, Inc., more stringent $\mathrm{NO}_{\mathrm{x}}$ standards for he a v y-d u ty diesel-fueled trucks were not considered to be technologically feasible given current technology and, thus, were not analyzed.

${ }^{11}$ The $\mathrm{ne}_{w} \mathrm{NO}_{\mathbf{x}}$ emission standards used in our analysis are as follows: (in "grams ofNO ${ }_{\mathrm{x}}$ emitted per mile traveled," $\mathrm{g} / \mathrm{mile}$ ) Passenger cars: $0.4 \mathrm{~g} / \mathrm{mile}$

Light-duty gasoline trucks (by weight)

(less than 3,750 pounds): $0.46 \mathrm{~g} / \mathrm{mile}$

(3,75 1 to 6,000 pounds): $0.80 \mathrm{~g} / \mathrm{mile}$

(6,001 to 8,000 pounds): $1.15 \mathrm{~g} / \mathrm{mile}$
} 
replacement of older vehicles with newer, cleaner ones. Since California has already adopted standards to those we analyze here, further emissions reduction credits due to this control strategy are not assigned to cities in this State. ${ }^{12}$

\section{Costs of $\mathrm{No}_{X}$ Contol Strategies Analyzed by OTA}

This section summarizes the costs of the three $\mathrm{NO}_{\mathrm{x}}$ control strategies discussed previously. Of the three, only one-RACT-level controls on stationary sources emitting more than 100 ton per year-was not included in the cost of more "traditional" controls presented in chapter 6 . Thus, the costs of the $\mathrm{NO}_{\mathrm{x}}$ controls that we considered, over and above the VOC control costs presented earlier, are about $\$ 550$ million per year in 1994 and about $\$ 670$ million per year in 2004. We have assumed that stationary source controls are applied in all nonattainment areas, regardless of their effectiveness for lowering ozone concentrations.

The costs for all three programs, of course, is quite a bit higher. We estimate that, in 1994, the total cost of all controls is about $\$ 2.0$ to $\$ 4.0$ billion per year in nonattainment cities, and about $\$ 2.8$ to $\$ 4.8$ billion per year, nationwide. By 2004, costs will increase to about $\$ 3.7$ to $\$ 6.2$ billion per year in nonattainment cities, and to about $\$ 5.4$ to $\$ 7.9$ billion per year, nationwide. This increase is primarily because of the higher percentage of highway vehicles equipped with more stringent controls. Again, two of the programs will provide multiple emissions reduction benefits. In addition to reducing $\mathrm{NO}_{\mathrm{x}}$ emissions, enhanced $\mathrm{I} / \mathrm{M}$ programs and more stringent highway-vehicle standards also reduce VOC emissions. Furthermore, I/M programs also reduce emissions of carbon monoxide. Table 7-8 displays the ranges of costs in nonattainment in 1994 and 2004 by source category. Figure 7-6 displays the ranges of costs in nonattainment cities in 1994 and 2004.

Table 7-9 presents the "cost-effectiveness" of specific control measures for 1994 and 2004. Figure 7-7 illustrates the cost-effectiveness of control measures in nonattainment in 1994. The solid bars represent the average cost-effectiveness in all nonat-
Table 7-8--Estimated Costs of Selected NO $\mathrm{N}_{\mathrm{x}}$ Control Methods in Nonattainment Cities in 1994 and 2004 (In million dollars per year)

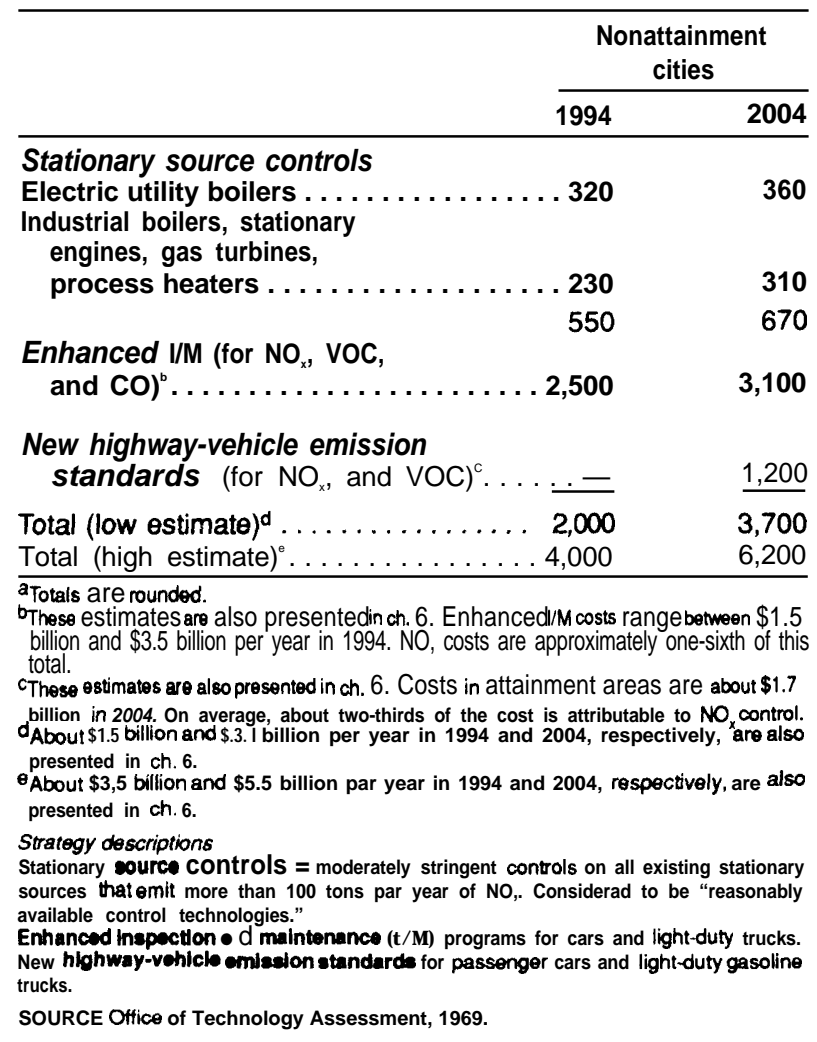

tainment cities. Uncertainty in cost-effectiveness estimates is denoted by the thin horizontal lines. The average cost-effectiveness for control strategies varies between $\$ 400$ per ton of $\mathrm{NO}_{\mathrm{x}}$ reduced (for electric utility boilers) to about $\$ 2,200$ per ton (enhanced I/M programs). Note that for cities with ozone design values greater than $0.26 \mathrm{ppm}$ (southern California), the cost of controls on electric utility boilers is much higher than the average nonattainment city estimate. Since this region has already adopted measures to control $\mathrm{NO}_{\mathrm{x}}$ emissions from these, and other, sources (e.g., use cleaner burning fuels), each dollar spent on further $\mathrm{NO}_{\mathrm{x}}$ controls yields relatively less emissions reductions.

A brief discussion of the costs and costeffectiveness of each of the control strategies,

\footnotetext{
${ }^{12}$ California's adoption of similar highway-vehicle emission standards is reflected in our estimates of future emissions that will occur with existing controls as presented in tables 7-2 through 7-4.
} 


\section{Figure 7-6-Estimated Cost of $\mathrm{NO}_{x}$ Emission Control Methods in 1994 and 2004 in Nonattainment Cities}

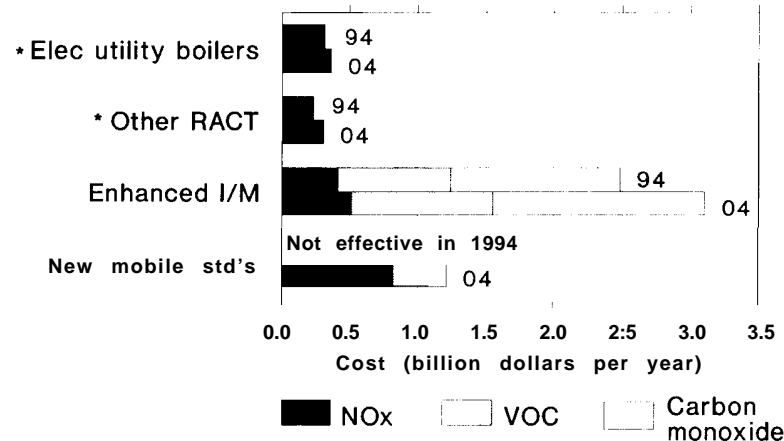

-Assumes sources emitting greater than 100 tons/year are subject to RACT controls.

Of the four control methods shown above, only two-controls on electric utility boilers and RACT-level controls on other stationary sources emitting more than 100 ton per year-were not included in the cost of more "traditional" controls presented in Chapter 6. Thus, the costs of the $\mathrm{NO}_{\mathrm{x}}$ controls that we considered, over and above the VOC control costs presented earlier, are about $\$ 550$ million per year in 1994 and about $\$ 670$ million per year in 2004 . See text for description of control methods.

SOURCE: Office of Technology Assessment, 1989.

including the data sources from which the estimates are calculated, follows.

\section{Controls on All Major Stationary Sources}

If moderately stringent controls ${ }^{13}$ are required, total costs in nonattainment cities for this category are estimated to be about $\$ 550$ million per year in 1994 , averaging about $\$ 240$ to $\$ 1,100$ per ton of $\mathrm{NO}_{x}$ removed. ${ }^{14}$ Controls on electric utility boilers account for about 58 percent of this total ( $\$ 320$ million per year).

If the most stringent level of control ${ }^{15}$ is required, the total cost for this category increases dramatically to about $\$ 8.3$ billion per year in 1994 . As mentioned earlier, these controls buy about an extra 15 percent more emissions reductions than RACT-level controls. While lowering the source-size cutoff from 100 to 25 tons per year adds an additional 2 percent
Table 7-9-Estimated Cost-Effectiveness of Selected $\mathrm{NO}_{\mathrm{x}}$ Control Methods in Nonattainment Cities in 1994 and 2004 (in dollars per ton of $\mathrm{NO}_{x}$ reduced) ${ }^{\mathrm{a}}$



onto the reductions achieved using the most stringent level of control, it does so at an additional cost of $\$ 1.7$ billion per year.

\section{Enhanced Motor Vehicle Inspection and Maintenance (I/M) Programs}

We estimate that enhanced $\mathrm{I} / \mathrm{M}$ programs in nonattainment cities cost between about $\$ 1.5$ billion and $\$ 3.5$ billion per year in 1994. In 2004, costs are expected to rise to between about $\$ 1.9$ billion and $\$ 4.3$ billion per year. We assume that about half of the costs are attributable to carbon monoxide control and the other half to ozone control. Of the ozone fraction, we assign about one-third of the cost to NO, and the other two-thirds to VOC. Assuming that one-sixth of the total cost of $\mathrm{I} / \mathrm{M}$ programs is for $\mathrm{NO}_{\mathrm{x}}$ reductions, the cost-effectiveness in 1994 is estimated to be between $\$ 1,200$ and $\$ 3,300$ per ton of $\mathrm{NO}_{x}$, eliminated.

\footnotetext{
${ }^{13} \mathrm{We}$ define moderately stringent control techniques to include boiler combustion modifications such as the installation of low $\mathrm{NO}_{\mathrm{x}}$-emitting fuel burners, reducing air flow through the boiler, and other techniques.

${ }^{14}$ Average cost-effectiveness excludes estimates for the three southern \&Ii fomia cities with ozone design values greater than $0.26 \mathrm{ppm}$. The average cost-effectiveness for electric utility boiler controls in these areas is about $\$ 5,500$ per ton. The cost-effectiveness is higher in these regions because measures to control $\mathrm{NO}_{\mathbf{x}}$ emissions have already been adopted, so that each dollar spent buys leas emissions reductions.

${ }^{15}$ We define most stringent control techniques to include selective catalytic reduction which eliminate $\mathrm{NO}_{\mathrm{x}}$ from fuel combustion exhaust gases.
} 
Figure 7-7-Estimated Cost-Effecttveness of NO Emission Control Methods in 1994 in Nonattainment cities

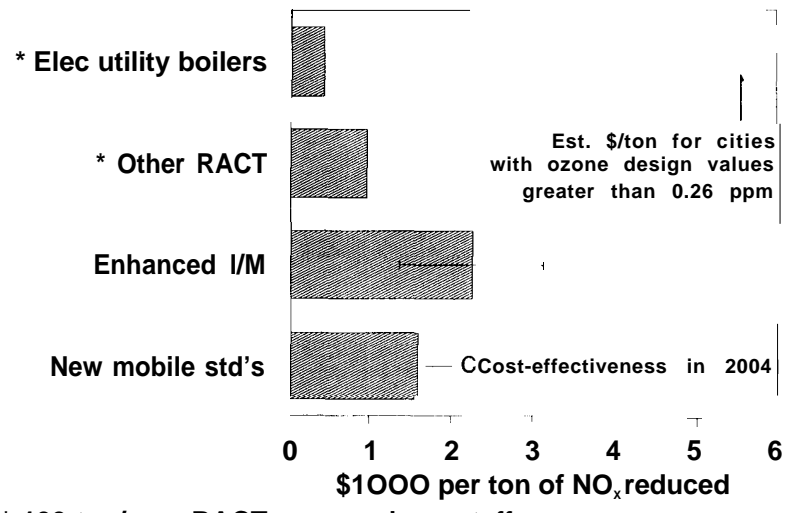

* 100-ton/year RACT source-size cutoff

The cost-effectiveness of enhanced inspection and maintenance (I/M) programs and new mobile standards include only the cost of $\mathrm{NO}_{x}$ control. The thick horizontal bars represent the average cost-effectiveness in nonattainment cities. The thin horizontal line for I/M programs represents the range of uncertainty associated with assumptions we used to estimate total annual costs. We were unable to estimate cost-effectiveness uncertainty for other control methods. See text for a description of control methods.

SOURCE: Office of Technology Assessment, 1959.

Our estimates of enhanced $\mathrm{I} / \mathrm{M}$ program costs are based on an analysis of the California I/M program, prepared for the California Air Resources Board by Sierra Research, Inc. [37]. We use Sierra Research's finding that an enhanced I/M program costs about $\$ 34$ to $\$ 55$ per vehicle per year. About $\$ 20$ of this cost is for the inspection fee and program administration. The remainder is for repair costs, which we assume to range between $\$ 70$ and $\$ 100$ per vehicle. We also assume that 20 and 35 percent of the vehicles tested will fail. ${ }^{16}$

\section{More Stringent Highway-Vehicle Emission Standards}

We estimate that the total cost of more stringent VOC and $\mathrm{NO}_{\mathrm{x}}$ exhaust standards for highway vehicles in 1999 will be about $\$ 1.6$ billion per year, nationwide, of which about $\$ 0.66$ billion per year will be incurred in nonattainment cities. By 2004, costs increase to about $\$ 2.9$ billion per year, nationwide, because a higher percentage of vehicles on the road will be equipped with new controls. About 70 percent of the costs are for controlling $\mathrm{NO}_{\mathrm{x}}$.

The cost-effectiveness of these controls in 2004 is about $\$ 1,600$ per ton of $\mathrm{NO}_{\mathrm{x}}$ reduced. As discussed in an earlier section, our cost estimates are based on a Sierra Research, Inc. report which concluded that more stringent emission standards would cost about $\$ 140$ per vehicle (combined cost for $\mathrm{NO}_{\mathrm{x}}$ and VOC emissions control) [37].

\section{OPPORTUNITIES FOR LOWERING EMISSIONS FROM SOLVENT USE}

To find the additional VOC emissions reductions needed to meet the ozone standard, many nonattainment cities may want to consider new ways of controlling emissions from organic solvent use. Although some State and Federal regulations controlling organic solvent emissions already exist, most have traditionally focused on larger sources. Much of the emissions from organic solvent use, however, originate from smaller sources (which vastly outnumber their larger counterparts). Because controls on some of the smaller organic solvent emission sources have been considered to be either technically, economically, or administratively infeasible, many of these sources are exempt from current regulations.

This section characterizes several aspects of organic solvent use in nonattainment areas that may be of interest when developing new control strategies. The first part describes: a) the relative contribution of various solvent end uses to total VOC emissions in nonattainment areas, b) the distribution of solvent emissions by source size, c) the fraction of solvent emissions that are currently covered by existing Federal and State regulations, and d) source categories where future significant emissions reductions may be possible. The section continues with a description of how various States are planning to capture uncontrolled organic solvent emissions. The section concludes with a discussion of market-based approaches to controlling solvent emissions.

\footnotetext{
${ }^{16}$ The low I/M cost estimate assumes that a repair cost of \$70 per vehicle will be levied on the 20 percent of the vehicles which fail; the hi@ estimate assumes $\$ 100$ repair cost on 35 percent of the vehicles.
} 


\section{Sources of Organic Solvent Use}

Solvents are used in such diverse applications as surface coatings, cleaning agents, decreasing, and drycleaning, and in many other industrial applications. Solvents are also used in a wide variety of commercial and consumer products such as insecticides, various household cleaners, nail polish and remover, underarm deodorants, hair spray, window cleaners, spot removers, automotive products, adhesives and sealants, pesticides, and many others. In 1985, VOC emissions from organic solvent evaporation in nonattainment areas were about 2.7 million tons per year, or about 27 percent of total emissions.

The above estimate assumes that 100 percent of the solvent purchased in 1985 is eventually emitted to the atmosphere. However, in response to existing regulations, some sources may recycle or destroy excess solvent emitted from their operations. Therefore we may have overestimated actual emissions. Figure 7-8 displays organic solvent emissions as a percentage of total emissions in nonattainment areas. We use the same end use categories, and solvent purchased therein, as EPA used in the 1985 National Acid Precipitation Assessment Program (NAPAP) inventory. Industrial solvent use ${ }^{18}$ accounts for about 14 percent of total nonattainment area VOC emissions, followed by commercial and consumer solvents, and architectural coatings at 8 and 2 percent, respectively.

\section{Organic Solvent Use by Source Size}

The Clean Air Act currently requires existing stationary sources in nonattainment areas that emit more than 100 tons per year of VOC to adopt "reasonably available" control technologies. Since bills from the 100th Congress have proposed lower-
Figure 7-8-Total Solvent Use as a Percentage of 1985 Total VOC Emissions in Nonattainment Areas

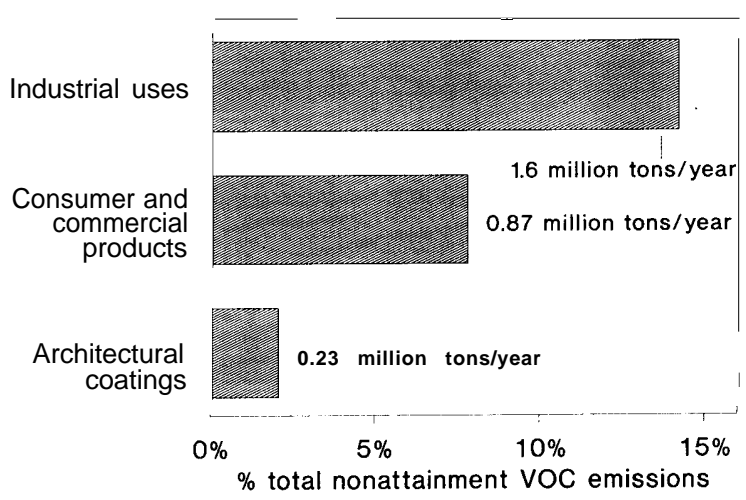

Total VOC emissions in nonattainment areas $=11 \mathrm{MM}$ tons/year

See text for description of sources included in the "industrial uses" category.

SOURCE: OTA, from EPA's National Acid Procipitation Assessment Program emission inventory.

ing the 100-ton-per-year cutoff, it is useful to see what fraction of total solvent use in nonattainment areas originates from sources of various sizes.

Because the 1985 NAPAP emissions inventory does not contain source-by-source emissions data for sources that emit less than 50 tons per year, we had to estimate the breakdown of emissions by type of application and by source size using a method developed by EPA [18] based on the relationship between solvent use and employment. By using the number of employees ${ }^{19}$ as surrogates for solvent use we were able to apportion EPA estimates of solvent use [19] to three source sizes: greater than 100, 50, and 25 tons per year. ${ }^{20}$ Since we had no employment data for architectural coating, consumer and commercial products, and miscellaneous surface coating, we assumed that these sources all individually emit less than 25 tons per year. [59].

${ }^{17}$ Solvent use data used throughout this section ${ }_{\text {was calculated }}$ based on the 1985 National Acid Precipitation Assessment Program emissions inventory

18The industrial solvent use category includes the following 15 subcategories as defined $b_{y}$ EPA for the 1985 NAPAP emissions inventory: automobile refinishing, new motor vehicle manufacturing, furniture and fixtures, fabricated metal products, machinery and equipment, paper coating, factory-finished wood products, non-automobile transportation equipment, electrical insulation, shipbuilding, metal cleaning (decreasing), dry cleaning, printing, rubber and plastics production and other miscellaneous surface coatings.

${ }^{19}$ Data on the number of employees and firms are from U.S. Department of Commerce, Bureau of the Census [44].

${ }^{20}$ We assume that the ratio of solvent use to the number of employees in a particular solvent category is the same (i.e., each employee uses the same amount of solvent) for all three source size categories. The ratio of emissions (rather than solvent use) to employment will be smaller if individual sources choose to comply with existing State or Federal regulations by incinerating or recycling excess solvent. 
Figure 7-9-Total 1085 Solvent Use In Nonattainment Areas, by Source Size
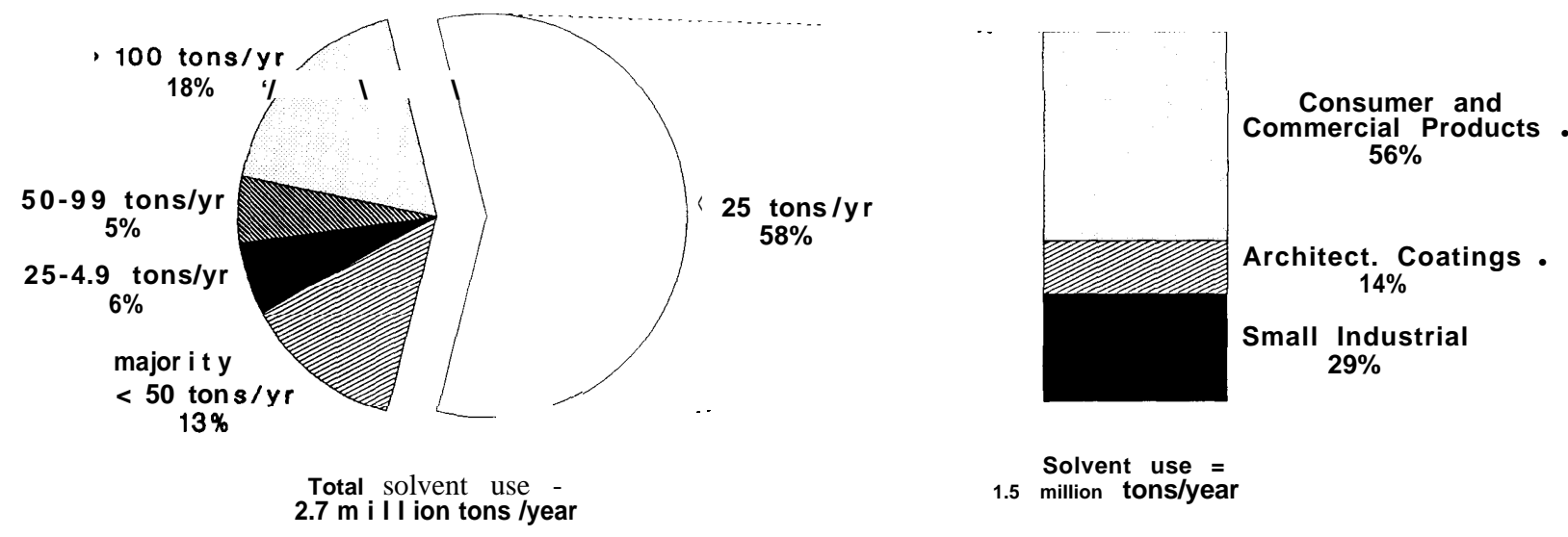

. These sources em $\mathrm{i} t$ much less $t$ ha. 25 tons per year.

Solvent use in the "less-than-25-tons-per-year" category is probably understated since an unknown fraction in the "majority less-than-50-tone-per-year" category may actually originate from sources using lees than 25 tons per year. The latter category contains solvent use that EPA has identified as miscellaneous surface coatings. Because of the way EPA constructs this category, we were unable to disaggregate solvent use below 50 tons per year.

SOURCE: Ofilice of Tochnology Assossment, 1969.

Figure 7-9 displays the contribution of different source sizes to total solvent use in nonattainment areas. Note that about three-quarters of the total solvent use (2.1 million tons per year) originates from sources that emit less than 50 tons per year. Sources less than 25 tons per year account for about 1.5 million tons per year, or about 60 percent of the total. ${ }^{21}$ About one-quarter of the solvent used came from sources greater than 50 tons per year.

Figure 7-10 displays a more detailed breakdown of 1.6 million tons per year of industrial solvent use in nonattainment areas presented in figure 7-8. About 480,000 tons originate from sources greater than 100 tons per year. As mentioned earlier, this is the size category that existing State and Federal VOC regulations have traditionally targeted. ${ }^{22}$ As we will discuss later, not all sources in this size class have been subject to regulations.
Figure 7-10 also shows that at least $\mathbf{3 0}$ percent of the industrial solvent use, or nearly 450,000 tons, originate from sources emitting less than 25 tons per year, mostly in the decreasing, printing, and drycleaning categories. This estimate should be considered a lower bound since an unknown fraction of use from miscellaneous surface coatings may also come from less-than-25-ton sources. Therefore, if we include all miscellaneous surface coatings in our estimates, sources less than 25 tons per year may contribute as much as 810,000 tons per year, or about 50 percent of total nonattainment industrial solvent use.

Figure 7-11 displays the breakdown of total solvent use, by source size, that is covered by State and Federal regulations as of 1985. Information on the regulatory status of various source categories was obtained from EPA summaries of State VOC regulations $[57,58]$. We estimate that approximately

${ }^{21}$ This percentage is probably underestimated since some of the solvent use in the majority-less-than-50-tons slice shown in the figure may belong in\& less-than-25-ton category. The former category contains solvent use that EPA has identified as miscellaneous surface coatings, and could include sources that are both less thanand greater than $\mathbf{5 0}$ tons per year. Since we were unable to determine employee fractions associated with this category, we chose not to disaggregate the solvent use below 50 tons per year.

${ }^{22}$ Some State regulations, however, require controls on sources in nonattainment areas that emit less than 100 tons per year. 
Figure 7-10-industrial Solvent Use in 1985 by Four Source-Size Cutoffs in Nonattainment Cities

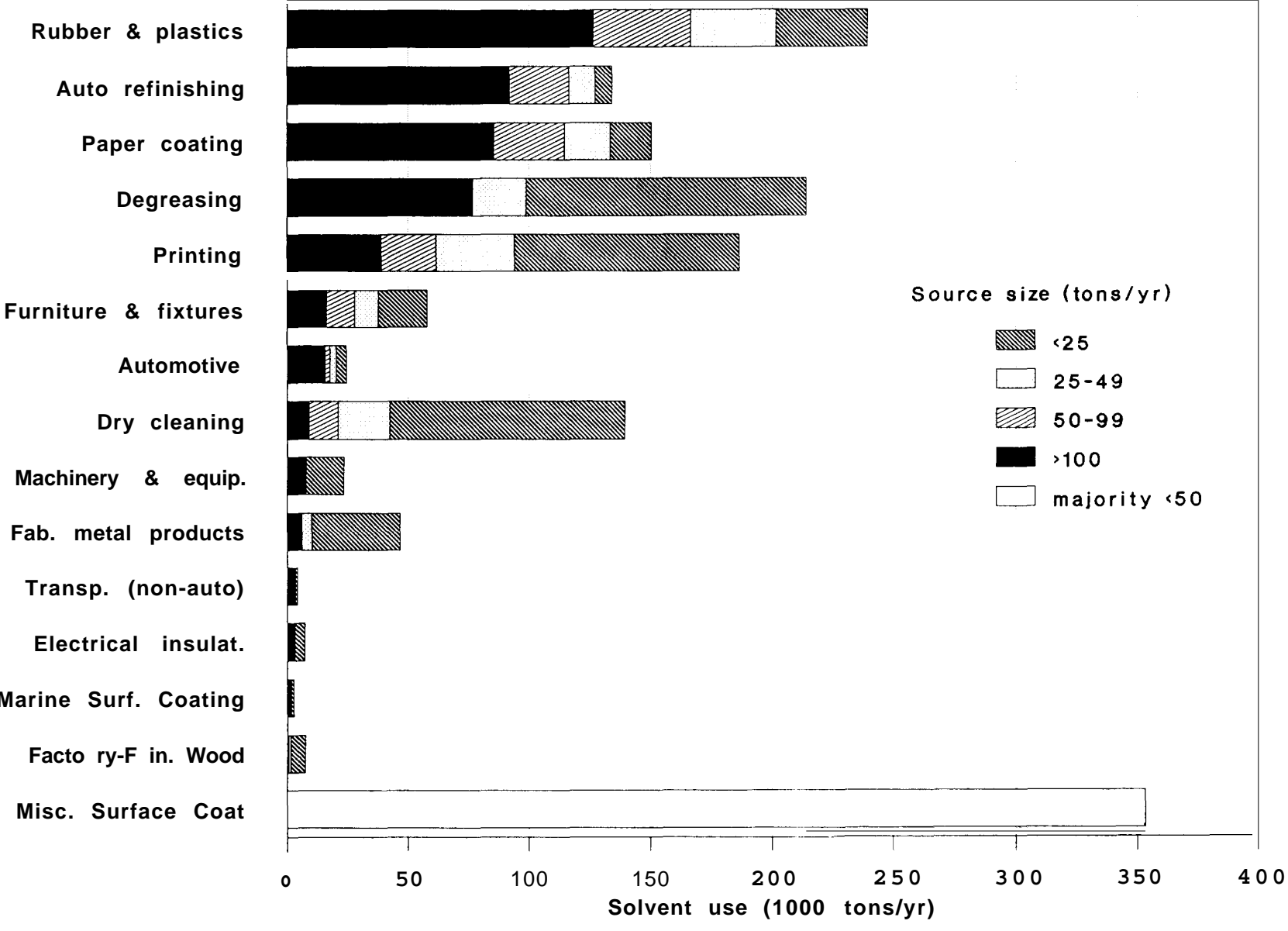

Because of the way EPA constructs the miscellanous surface coating category, we were unable to disaggregate solvent use below 50 tons per year.

SOURCE: Office of Technology Assessment, 1989.

one-quarter of all the solvent used in nonattainment areas in 1985 was subject to VOC emission regulations. About 45 percent of the solvent used by sources greater than 50 tons per year was covered by regulations, while 20 percent of the solvent used by sources emitting less than 50 tons per year was covered. Overall, there is about four times as much unregulated solvent use from less-than-50-ton sources than by sources emitting more than 50 tons per year.

Our estimates of solvent use may overestimate actual solvent emissions since many sources which are subject to solvent regulations (especially those emitting more than 50 tons per year) may use control devices which capture or destroy excess solvent emissions. Hence, solvent use is not always synonymous with solvent emissions.

Because many State VOC regulations are applied on the basis of the amount of solvent used by a source (e.g., gallons of solvent used, pounds of clothes cleaned, etc.) rather than on the amount of VOC emitted to the atmosphere during a year, it is difficult to know the precise source-size cutoff for which a particular regulation applies. Therefore, the estimates presented here should be considered only rough approximations. 
Figure 7-11-Total Solvent Use Covered by Existing Regulations in 1985 in Nonattainment Cities

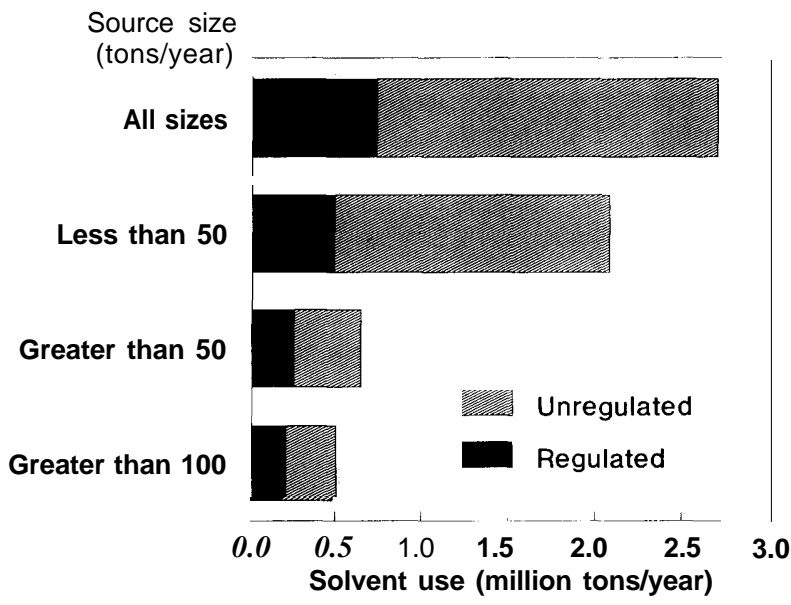

Determinations of the regulatory status of solvent use categories in nonattainment cities were made using EPA summaries of State and local VOC regulations in place as of 1985 [57,58]. The estimates presented here should be considered only rough approximations. See text for explanation.

SOURCE: Office of Technology Assesment, 1989,

\section{Opportunities for Additional Emissions Reductions}

Figure 7-12 displays a detailed breakdown of solvent use, by end-use and source size, that is covered by existing regulations. We show solvent use that is: 1) covered by existing regulations, 2) not covered, but for which applicable regulations exist, and 3) not covered and for which no regulations exist. The "Regs-Not-Applied" category refers to solvent use that could be covered: a) if existing regulations for larger sources were applied to smaller sources in the same end-use category, orb) if existing regulations in some nonattainment areas were applied to the same end-use categories in all other nonattainment areas. The "No-Regs-Exist" category contains solvent use for which no regulations exist anywhere in the Nation.
Figure 7-12 shows that an additional 550,000 tons of solvent use in nonattainment cities, or about 20 percent, could be covered if regulations currently applied in some areas are adopted in all other areas. This category is important because it highlights solvent use that has the most immediate potential for additional emissions reductions.

Of the 2.7 million tons per year of total solvent use shown in figure 7-12, about 1.2 million tons of solvent were used by identifiable industrial sources $^{23}$ in nonattainment cities. Figure 7-13 presents a slightly different breakdown of this category together with the number of firms that contain sources of various sizes. We estimate that about 650,000 tons per year of solvent is used by about 150,000 identifiable industrial sources that are already covered by control requirements. About 580,000 tons per year of solvent is used by about 90,000 sources in nonattainment areas that are not covered by control requirements.

About 270,000 tons of unregulated solvent use in this category, or about 45 percent, could be covered by targeting the small number of unregulated firms that contain sources emitting more than 100 tons per year. The emissions reductions achieved will be lower than our estimated solvent use and will depend on the type of control technique required by new regulations. ${ }^{25}$ If unregulated sources emitting 50 tons per year or more are targeted, we estimate that about 60 percent of the total unregulated solvent use among identifiable industrial sources could be covered. At this source-size cutoff, roughly 3,000 firms in nonattainment cities would need to be identified. If the source-size cutoff is lowered from 50 to 25 tons per year, about 10 percent more solvent use-about 410,000 tons per year-could be covered, but about two-thirds more firms would then have to be identified. Finally, we estimate that the addition of sources emitting less than 25 tons per year would require the identification of about 86,000 more firms. Although including these smaller sources would allow about 40 percent more solvent use to be covered, about 20 times as many firms

\footnotetext{
${ }^{23}$ See footnote 18 for a list of the 14 sources included in the identifiable industrial category.

${ }^{24}$ In this figure we do not show solvent use from other less-than-50-ton sources including consumer products, architectural coatings and other miscellaneous coatings because we were unable to determine the number of firms associated with their use.

${ }^{25}$ For example, control devices such as incinerators can reduce emissions from organic solvent use by about 90 percent. Therefore the emissions reductions achieved by targeting unregulated I00-ton-per-year sources would be about 240,000 tons per years.
} 
Figure 7-12-Total Solvent Use Covered by Existing Regulations in 1985, by Source Category in Nonattainment Cities

Solvent use (m ill ion tons/year)

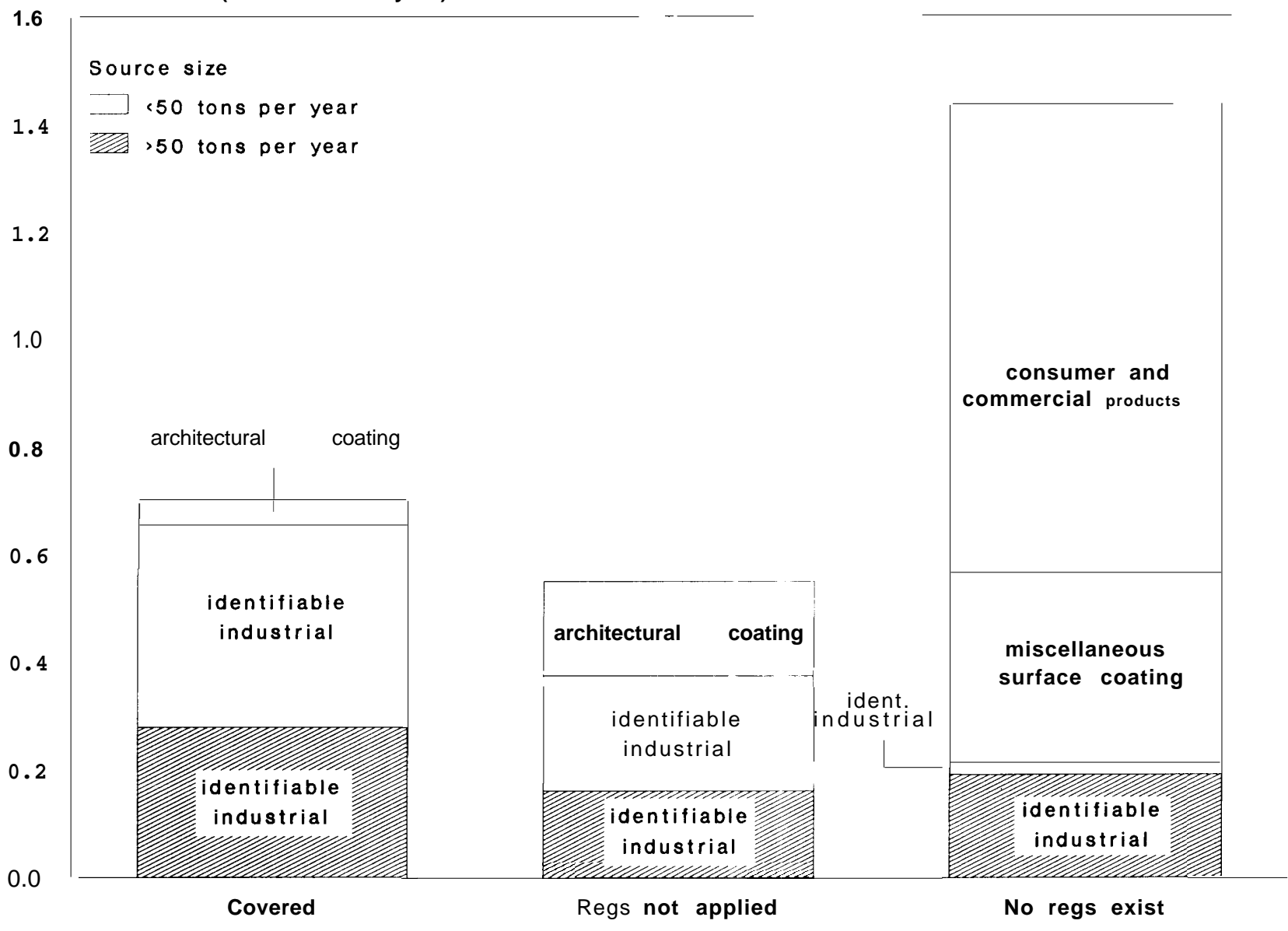

The Identifiable industrial category includes the same sources as those in figure 7-10, except for miscellaneous surfacecoatings which is a seperate category in the figure shown above. We show solvent use that is (1) covered by existing regulations in place as of 1985, (2) not covered in a particular nonattainment area, but for which regulations do exist in other areas, and (3) not covered and for which no regulations exist as of 1985 . See text for further explanation.

SOURCE: Office of Technology Assessment, 1989.

would have to be identified compared to a strategy which targeted sources emitting more than 25 tons per year.

Figure 7-13 shows that solvent use from sources greater than either 25 or 50 tons per year offers regulators a relatively attractive target for future emissions reductions. While including sources that emit less than 25 tons per year would offer a somewhat greater potential for emissions reduc- tions, regulators would be faced with the difficult task of locating and keeping track of a much larger number of fins.

While some identifiable industrial sources present a good opportunity for capturing unregulated VOC emissions (at least from an administrative efficiency standpoint), figure 7-12 shows that consumer and commercial products and miscellaneous surface coatings accounted for about 1.2 million tons, or about 60 percent, of total unregulated solvent use in 
Figure 7-13-Identifiable Industrial Solvent Use Covered by Existing Regulations; and the Number of Firms by Source Size

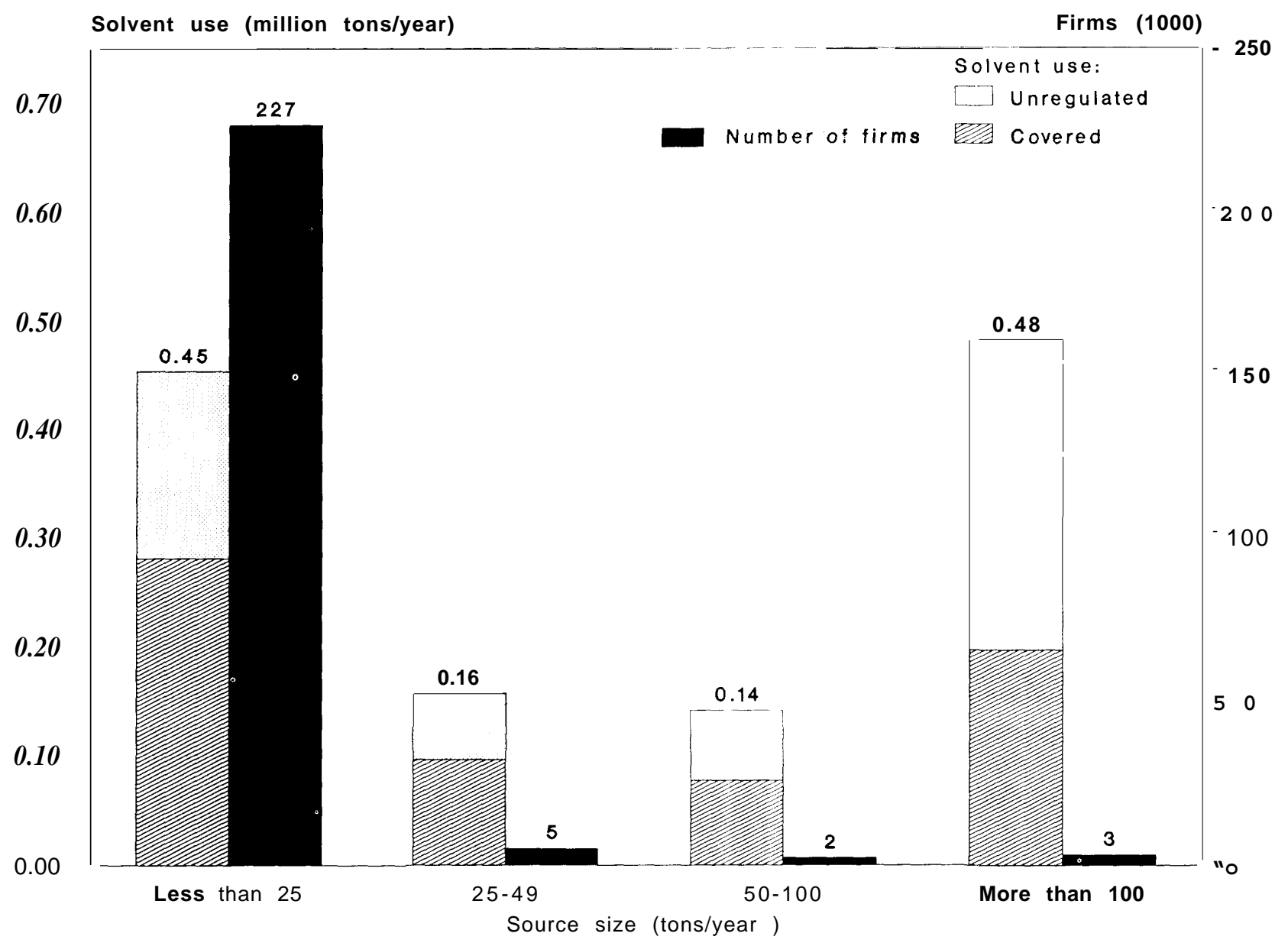

The identifiable Industrial category includes the same sources as those in figure 7-10, except for miscellaneous surface coatings which Is excluded.

SOURCE: Office of Technology Assessment, 1989

nonattainment cities. $^{26} \mathrm{~A}$ large fraction of this solvent use originates from sources emitting less than 50 tons of VOC per year; and in some cases, these sources emit very much less than 25 tons per year per source (e.g., consumer products). Because these solvent uses originate both in the home and from a large number of small commercial, institutional, and industrial establishments, traditional forms of "command-and-control" regulations may be difficult to administer and enforce. In the next section, we review how some States are planning to control this fraction of solvent use.

\section{Further Regulation of Solvents}

As the preceding analysis indicates, only about one-quarter of total solvent use is covered by

${ }^{26}$ Some States and localities have general solvent use regulations that may apply to some uses contained in the miscellaneous surface coating category, however we were unable to identify these particular uses. 
existing regulations. Most of this is from industrial solvent use by both large and small sources. At most, we believe that another one-quarter of total solvent use could be controlled (to some extent) given more widespread application of current regulations. Much of these additional reductions would come from use of industrial solvents and architectural coatings by predominantly small sources, although some emissions reductions could be realized from controlling selected large sources. Of the remaining ' "unregulated" solvent use, we believe that small sources offer the greatest opportunity for additional emissions reductions. These sources are mainly consumer and commercial products, miscellaneous surface coating uses, and some industrial solvent use.

While it is conceivable that a "command-andcontrol" approach could be devised to reduce part of the remaining uncontrolled emissions, the large number, small size, and diversity of sources might make this approach costly and difficult to administer. For these reasons, some have proposed alternative, market-based strategies to controlling emissions. In the following section, we will present some examples of innovative State programs designed to capture uncontrolled solvent emissions and will discuss some market-based alternatives to the traditional "engineering" approach.

\section{State Efforts To Capture Uncontrolled Solvent Emissions}

The solvent end uses that are currently subject to some form of regulation are listed in appendix A. Here we see that most industrial solvent use categories have some form of regulatory requirements. However, regulation of some surface coating uses, as well as architectural surface coatings and consumer and commercial products, is limited. A recent national ozone control strategy proposed by STAPPA-ALAPCO also identified these three solvent end use categories as being the least wellregulated at this time and as having significant emissions reduction potential [43].

Although very few Federal controls have been issued for these uses of solvents, a few States have begun to devise ways to control their emissions, as well as ways to get further reductions from end uses already subject to some control. The following policy options represent the major approaches that States have either already taken or are proposing at this time:

1. lowering source-size exemption cutoffs of existing regulations to capture smaller sources within particular end use categories;

2. developing new regulations directed towards specific end uses, in some cases bringing in all sources in the category irrespective of size (e.g., lithographic printing, consumer solvents, architectural coatings);

3. placing limits on the VOC content of certain products or processes to encourage reformulation of solvents or use of non-solvent-based alternatives; imposing bans on the sale of products that fail to meet these control requirements by a specified date; and

4. establishing emissions fees or marketable permit systems to discourage the use of products with high VOC content.

Generally, States have been inconsistent in their degree of VOC emissions control requirements for solvent uses. While some have stringent regulations applicable to a broad range of end uses, others are less far-reaching in their requirements. For example, Massachusetts allows very few exemptions from its requirements for surface coating sources, whereas Rhode Island has no regulations for many of the same types of sources. In some cases, States are developing their own "allowable limits" on VOC emissions from source categories for which EPA has not yet issued any Control Technique Guidelines (CTGs) (e.g., New York is developing regulations for wood furniture coating). Most States follow EPA's lead in applying RACT requirements mostly to greater than 100-ton" sources, although some have begun to lower control requirements to apply to smaller sources. A few States are eliminating applicability limits altogether, so as to capture all VOC sources within an end use category. Others are issuing exemptions from certain regulatory requirements for using alternative, 1ow-VOC products in place of traditional solvents (e.g., North Carolina exempts waterborne inks with low VOC content for use in graphic arts).

One reason many States give for having resisted lowering the source-size cutoffs in their regulations is a lack of resources. Because States already have 
resource limitations in trying to enforce existing regulations, they are wary about their ability to account for and monitor additional sources. Some States or nonattainment areas, such as Illinois, Philadelphia, and the San Francisco Bay area, have used their source permitting systems to improve their inventories. These areas have been able to maintain inventory data on sources as small as 10 tons per year for many categories. However, most areas do not keep records on such small sources.

With regard to consumer and commercial product regulation, many of the regulators from States that have attempted or proposed some form of this regulation stated that such efforts would perhaps best be done on a national basis. Because most of these products are being sold across State lines, they believe it will be a very difficult strategy to enforce on a State-by-State basis. Inconsistencies in the stringency of such regulations from State to State may cause manufacturers to abandon some markets and relocate to other regions of the country.

Two nonattainment areas in particular have been at the forefront in developing innovative or stringent approaches to controlling VOC emissions: the South Coast Air Quality Management District (AQMD) of California and the New York City metropolitan area. Many of their requirements apply to solvent-related activities and cover the range of the four policy options presented above. The control approaches designed by these two areas provide examples of some of the options available to policy makers for reducing VOC emissions from solvents.

The South Coast AQMD has proposed a threetiered approach to controlling VOC emissions from solvent uses that would make its regulations the most stringent in the country. More rigorous requirements are phased-in with each new tier. The first two tiers consist mainly of limiting the reactive solvent content of products and establishing a minimum transfer efficiency requirement for several coating categories. Tier I requires application of existing technologies. Tier 11 aims to cut in half the remaining emissions by improving and refining the applicability of these technologies. The third tier aims to almost eliminate VOC emissions from solvents in the Basin, by fostering "technological breakthroughs" to process changes that do not rely on solvents, new product formulations, and substitute products. The proposed third tier would culminate with a Basinwide ban on noncompliant products and processes.

Tier I of the South Coast's strategy requires the application of all currently known technologies to existing sources. State regulators have listed 22 control measures directed at controlling VOC emissions from various categories of solvent use, including selected surface coating uses, architectural coatings, graphic arts operations, metal cleaning and decreasing, plastics manufacturing operations, drycleaning operations, and underarm and other domestic products. The AQMD estimates that VOC emissions from solvents could be reduced by approximately 45 percent of projected levels for the year 2000 by implementing Tier I controls. The greatest reductions are expected to come from regulations on domestic products ( 33 percent of total reductions in solvent emissions expected from Tier I controls), automobile refinishing (19 percent) and wood furniture coating (14 percent). Tier I is to be implemented over the next 5 years. Most of the measures included are expected to be "reasonably available" at the time the regulations take effect. However, at least for the domestic products category, the efforts necessary to bring about the anticipated reductions (e.g., total phaseout of aerosol propellants) seem more extraordinary than 'reasonably available."

Three forcing mechanisms are set up to ensure that the objectives established under Tier I are met: 1) compliance schedules with interim dates for progressively reducing the VOC content of products and limiting process emissions; 2) emissions charges for architectural coatings to discourage purchase of coatings with high VOC content; and 3) the threat of a ban on the sale or limitations on the use of a product if its manufacturer fails to comply with regulations.

The goal of Tier II is to obtain a reduction of 50 percent of the emissions remaining from solvent evaporation after Tier I has been implemented, for cumulative reductions with Tiers I and II of about 70 percent compared to projected emissions levels in the year 2000. While categories for reduction are only generally described, controls on surface coating and consumer products are targeted. The South Coast hopes to reduce VOC emissions from coating 
operations by one-half through the use of alternative coating technologies, more efficient application of coatings, and the use of low- or non-solvent-based coating products and processes. They hope to cut, in half, emissions from consumer products through further development and widespread application of such controls as product reformulation and alternative propellant or dispensing mechanisms. The time frame for implementing Tier II is within the next 10 years. In addition to broader application of technologyforcing compliance schedules and emissions charges, the following actions have been proposed by the AQMD to facilitate achieving Tier II goals: 1) a cooperative effort with the State, product manufacturers and end users, to fully assess obstacles to and options for reducing solvent evaporation; 2) a Basin-wide program to disseminate information and educate business owners or operators about alternative products and processes; and 3) a program to increase public awareness, to enhance the marketability of newly formulated or packaged products.

Tier 111 sets forth the ambitious goal of "near-total phase-out" of VOC emissions from solvents by the year 2007. At present, no detailed strategy for achieving this goal has been proposed. However, Tier III does appear to rely on more full application of efforts begun in the earlier two tiers, such as adoption of alternative, non-solvent products or processes. The underlying assumption is that Tiers I and 11 will pave the way. As proposed, Tier 111 culminates with a ban on products that cannot comply with restrictions on solvent content, and processes that cannot meet emissions limitations.

A variety of impacts could result from the South Coast's three-tiered strategy. Sources may be moved out of the area or forced out of business because of the regulatory burden. In some cases, greater use of exempt solvents such as chlorinated solvents, would increase air toxic emissions. In other cases, as with controls on solvents used in drycleaning, emissions of potentially toxic air contaminants would be reduced. Also, additional liquid or solid waste could be produced from some add-on control devices. There would also be some administrative burden due to increased source permitting and additional enforcement needs.

While New York's approach is perhaps less ambitious and far-reaching than the South Coast's, it also aims to significantly reduce VOC emissions from solvents. Rather than exempting sources that emit VOCs below a certain level, all users of VOC-based solvents in some end use categories (e.g., all lithographic printers) will be required to meet limitations on the use of products with certain VOC contents. This approach is also designed to bring the supplier of such products into the regulatory loop, so that both the user and supplier are held accountable.

Two types of new regulations are being issued by the State: 1) regulations that bring in all sources in categories that are already regulated, and 2) regulations that apply to new, previously unregulated end use categories. By removing exemptions from RACT for selected categories-e.g., EPA's 100-ton source exemption for graphic arts facilities, and the exemption for surface coating sources using less than 5 gallons per day-the State is making all sources in a particular end use category subject to control requirements. And, because EPA has issued little or no technical guidance to States for regulating some categories, New York is developing its own control requirements independent of the Agency. For example, the State has recently issued final regulations for the following previously unregulated categories: graphic arts, surface coating uses (wood, plastic, glass and leather coating, auto refinishing), architectural coatings, and consumer and commercial products.

With the eventual goal of controlling all emissions from selected solvent categories, many of New York's regulations place strict limits on the VOC content in paints, inks, and other surface coatings. By 1990, new regulations are expected to reduce emissions from these three categories by about 40 percent compared to 1987 levels. This will constitute a 20-percent reduction in VOC emissions from all solvent uses. Eighty percent of these emissions reductions are expected to be from graphic arts facilities. The remainder of the anticipated reductions would come from limits on the VOC content of eight surface coating categories, autobody refinishing shops, and architectural paints. Regulations prohibit the sale (in the New York City metropolitan area) of architectural coatings that exceed a specified VOC content after July 1, 1989. Manufacturers of some consumer products (air fresheners, disinfectants, and insecticides) are required to study ways of 
reducing VOC emissions from these products. There is an accompanying ban on the sale of these products if the manufacturer has not registered them with the New York Department of Environmental Protection (DEP) and if a study protocol has not been submitted and approved by specified dates. While actual emissions reductions are not specified, projected schedules for implementation of measures proposed in the study are not to go beyond January 1, 1997.

In implementing these new regulations, the major issue as far the DEP is concerned seems to be how previously unregulated sources are going to be notified of the new regulatory requirements. The State plans to notify major manufacturers that their products are now subject to regulations, and let them tell their distributors, who in turn can notify the end users. Both users and manufacturers will be considered liable if users are found to be using nonapproved products.

\section{Alternatives to Traditional Methods of Controlling Solvent Emissions}

Solvent emissions can be lowered in many ways. In some instances it is possible to switch to alternative products that use no solvent (e.g., using water-based rather than oil-based paints). Products can be reformulated using low-solvent technologies or using solvents which are not involved in ozone formation. Manufacturing methods can be changed so that less solvent is emitted per unit manufactured. And finally, emissions can be captured or destroyed through control methods such as incineration so that VOCs are not released to the atmosphere.

Most regulation under the Clean Air Act follows a traditional "engineering control" approach. Pollution control engineers within EPA or the States define "reasonably available control technology" (RACT) or the "lowest achievable emission rate" (LAER) for many different types of sources, and then source-specific regulations are issued. However, for many products and processes, this traditional approach may not produce the desired emissions reductions. Low- or non-solvent alternatives may not be available, and alternative manufacturing methods may not deliver the desired quality end product. Congress, EPA, and the States must find new ways to force the development of new products, manufacturing processes, and control methods.
The California Air Resources Board (CARB) is currently looking at alternatives to the traditional engineering approach to help reduce VOC emissions from solvent use in cases where new products or processes are needed. CARB has examined three basic options: 1) setting limits on solvent content or VOC emissions, together with deadlines for compliance and penalties for failure to meet the deadlines; 2) setting fees or taxing products that contain solvents or are manufactured using solvents; and 3) allocating permits to emit VOCs, and gradually phasing out allowable emissions by reducing the number or value of permits. CARB has not completed its evaluation of these options, and we have not analyzed them in detail. However, we attempt to provide a broad description of each, in this section, along with examples of how they might apply to solvents.

Compliance Schedules and Penalties-When Congress directed EPA in 1970 to develop regulations to lower motor vehicle emission rates by 90 percent, the technology to achieve this target was not available. Congress decided to force development of technology by choosing a percentage reduction target and a date by which it was to be reached, and by adopting penalties to give manufacturers incentives to develop the technologies needed to comply. Deadlines slipped many times, and several have yet to be reached, but tailpipe emissions of VOCs, nitrogen oxides, and carbon monoxide have been lowered considerably.

A similar framework could conceivably be developed for solvents. For domestic products, for example, increasingly stringent limits on solvent content could be set, along with compliance schedules and penalties for noncompliant products. Emissions reduction targets and deadlines could also be established for specific categories of sources, and flexibility provided for meeting them through process changes that eliminate or reduce solvent use, or add-on devices to control emissions.

Although it might work for large manufacturers of solvent-containing products or large businesses that use solvents, a potential problem with this approach is that numerous small businesses that one would like to cover through such regulations lack the resources to develop new products, processes, or control methods needed to comply. Furthermore, 
State or local regulatory agencies may lack the resources needed to enforce such an approach on the large number of small end users. Market-based strategies, that allow sources to "trade" emissions reductions, might help to ease this problem.

Marketable Emissions Permits-EPA'S proposed regulations for chlorofluorocarbons (CFCs and Halons- two chemicals that deplete stratospheric ozone $^{27}$ - combine technology forcing with a marketbased approach to minimize the costs of cutting back production of these chemicals [52]. After considering the traditional engineering approach to control, EPA opted for a regulatory scheme that allocates production rights to CFC manufacturers based on their production in a historical year (1986), and gradually cuts back production rights from that level over a 12-year period.

In EPA's proposal, manufacturers are given the rights to produce 100 percent of their baseline levels each year through 1993. Manufacturers that produce less can sell their extra rights to produce CFCs to other firms. Any firm wishing to produce more than the amount they produced in 1986 must purchase rights from another manufacturer. In 1993, firms will be allowed to either produce--or sell the rights to produce- 80 percent of their baseline levels. Each firm must return 20 percent of their rights to produce CFCs to EPA. In 1998, firms will be allowed to produce, or sell the rights to produce, 50 percent of the amount they produced in 1986 . Theoretically, allowing trades should minimize the costs of cutting back production, as those firms for which reductions are most economical reduce more than necessary, and sell their unused production rights to other firms for whom reductions are more expensive.

Regulating CFC use and VOC emissions has one striking similarity: engineers cannot at this moment sit down and list all the control methods that one would need to achieve the desired reductions. A market-based approach has the advantage of actively involving industry in the search for new control methods. There are enough differences between the characteristics of the two control problems, however, so that one cannot just substitute the word "VOC" for "CFC" throughout the EPA regulations and expect a market-based program to work.
(For example, CFC control applies nationwide, while VOCs are controlled primarily in nonattainment areas.)

In the case of CFCs, EPA preferred to regulate producers because there are far fewer of them than users, thus lowering EPA's record keeping burden. For solvents, there are reasons why it might be preferable to regulate users. First, VOCs are of concern primarily in nonattainment areas, and it might not be desirable to limit solvent production and hence restrict their availability everywhere. Second, it might be desirable to allow solvent users the option of destroying or capturing VOCs before they are released to the atmosphere. Because some record of emissions by end users is required for States' emission inventories anyway, EPA might choose to allocate solvent emission rights directly to users in nonattainment areas. The phase-out and trading provisions of the CFC proposal would still apply.

One controversial issue associated with a marketable permit system is how the permits will be initially allocated. In the case of emissions permits, allocation based on a historical year could be considered to place sources that have controlled stringently in the past at an unfair disadvantage. An alternative approach would be to require initial controls on some source types and then allocate production rights from this new, "post-control" baseline. While rejected for CFCs, this approach might be useful for regulating solvent use. Unlike CFCs, emissions from solvent use are already regulated, to some extent. Some States stringently regulate some types of solvent use, some do not. Defining a "fair baseline" for allocation of permits would be an important, if difficult frost step in implementing a market-based strategy.

Emission Fees or Taxes- In addition to marketable permits, EPA also considered placing fees on production of CFCs, with the intent that a high enough fee would discourage production. Agency staff rejected this approach because they felt they could not ensure that the required control levels would be reached by specified date. Manufacturers could opt to continue producing CFCs and pay the fees rather than lower production. Through trial and error the agency would eventually determine the

${ }^{27}$ Ozone in thestratosphere, 6to 30 milesabove the Earth's surface, shields plants and animals from harmfully high levels of ultraviolet radiation. 
level of the fee necessary to achieve the required production limit, but it would be difficult to meet a target date. In considering the approach for solvents, the California Air Resources Board similarly notes that political difficulties associated with setting and subsequently adjusting emissions fees could be a major drawback.

One place where a fee or tax system seems particularly useful is in giving consumers incentives to purchase products with low solvent content. While it would be difficult to project how much emissions would be reduced by taxing spray deodorants to make them more expensive than stick deodorants, it might be one way to significantly reduce VOC emissions from consumer products that are sold on the national market, without banning them from nonattainment areas altogether.

A final problem with fees is that it is unclear whether the Clean Air Act gives EPA the authority to set fees for purposes other than recovering the cost of regulation. Congress needs to clarify its intent on this matter if market-based approaches are to be given full consideration.

\section{LOWERING EMISSIONS FROM HIGHWAY VEHICLES: TRANSPORTATION CONTROL MEASURES}

Of the VOC emissions remaining in nonattainment cities in 1994 after all of the controls we analyzed in chapter 6 are applied, highway vehicles account for about 28 percent, and gasoline marketing contributes 6 percent. Especially in fast-growing areas, efforts to further reduce emissions associated with highway vehicles involve a race between tighter controls that reduce emissions per vehicle mile, and increases in the number of vehicles on the road. Averaged nationwide, motor vehicle exhaust emissions are projected to decline through the late 1990s as an increasing percentage of vehicles on the road meet new standards, but rise after that due to growth in vehicle use.
Based on current trends in population and travel, and trends in age and income distributions, the number of vehicle-miles traveled (VMT) nationwide is projected to increase by 2 to 3 percent per year from now through 2005, resulting in a cumulative increase of about 40 to 60 percent [23]. The national average projections understate the increase expected in some cities: for example, 3.5 and 4 percent per year increases are projected for Houston and Phoenix, respectively, compared to increases of 1.5 and 2 percent per year in Detroit and Philadelphia.

Obviously, VMT growth could have a major impact on traffic flow in urban areas, as well as on air pollution. According to the Federal Highway Administration [23], traffic volumes in 1985 equalled or exceeded 80 percent of capacity on over 40 percent of the Interstate highways in the Nation's 45 largest metropolitan areas, indicating "extensive congestion during peak-traffic periods. " Coping with, or limiting future growth in motor vehicle use presents major challenges to both air quality and transportation planners, who face the twin problems of congestion and air pollution.

To address motor vehicle use, the 1977 Amendments to the Clean Air Act required some urban areas $_{28}$ to implement transportation control measures. ${ }^{28}$ TCMs are a set of interrelated measures that have the general objective of reducing emissions by reducing driving or improving traffic flow. ${ }^{29}$ Examples include improved public transit, exclusive highway lanes for buses and carpools, bicycle lanes, modified schedules for work, parking management, and road use charges or tolls. Because they try to change the behavior of large segments of the public (e.g., getting people to use mass transit or share rides to work), public awareness of congestion and air quality problems is a key to the success of TCMs. In most cases in which these measures have been used, they have been justified on broad grounds of improving urban mobility as well as air quality.

In this section, we first review the TCM requirements in the 1977 Amendments, including requirements for integrating air quality and transportation

\footnotetext{
${ }^{28} \mathrm{Sec} .110(\mathrm{c})(5)(\mathrm{B})$ of the Clean Air Act, as amended.

${ }^{29} \mathrm{VOC}$ emission rates decline as "chic.e speeds increase, especially up to about 35 to $40 \mathrm{mph}$. Also, emission rates are lower when speeds are held constant, than under stop/start conditions,
} 


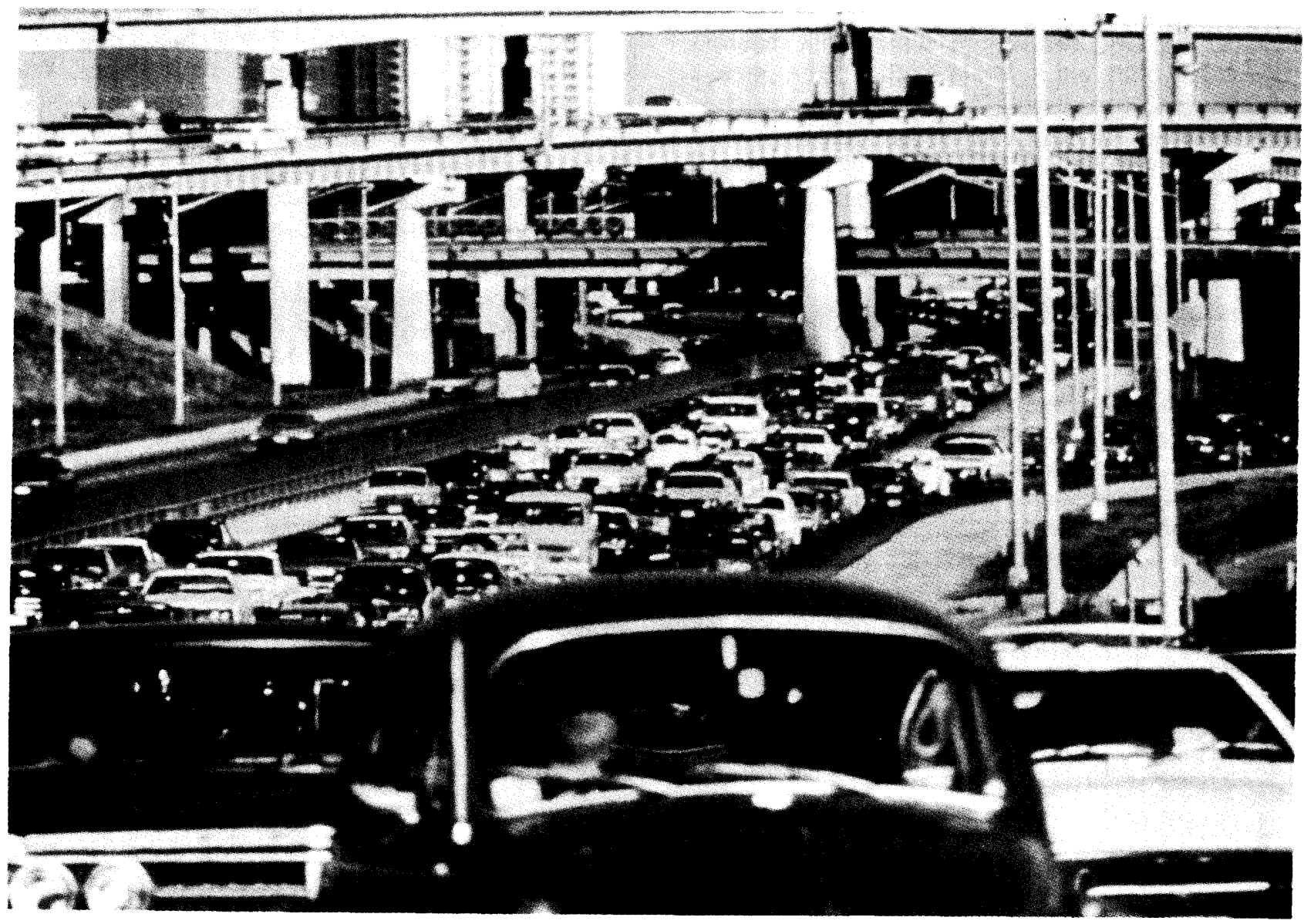

Photo credit: South Coast Air Quality Management District, EI Monte, CA

The number of miles traveled on our Nation's highways is projected to increase by about 40 to 60 percent by 2005. The adoption of transportation control measures, such as ridesharing, carpool lanes, alternative work schedules, and transit improvements could help reduce congestion and the accompanying increased highway vehicle emissions by improving traffic flow.

planning. We then provide estimates of the magnitude of reductions that can be expected from TCMs, based on the 1988 Air Quality Maintenance Plan for the Los Angeles area. In addition to "traditional" measures that focus on the transportation system of roads and mass transit facilities, measures that seek to reduce driving by managing land-use are also considered. Finally, we discuss key implementation issues, including transportation and land-use planning and policy, and strategies to ensure participation.

\section{Requirements in the 1977 Clean Air Act Amendments}

The 1977 Amendments to the Clean Air Act required urban areas that would not be able to meet the ozone or carbon monoxide standards by 1982 to implement transportation control measures (TCMs) as necessary to attain the ozone and carbon monoxide standards. ${ }^{30}$ The Act specified that development of TCM programs had to be coordinated with the transportation planning process that the Department of Transportation requires as a condition for receipt

${ }^{30}$ Secs.110(a)(3)(D) and $110(\mathrm{C})(5)(B)$ of the Clean Air Act, as amended. 
of Federal highway and mass transit assistance. ${ }^{31}$ One-time-only grants to Metropolitan Planning Organizations (MPOs) for integrated air quality and transportation planning were authorized. ${ }^{32}$ About $\$ 50$ million was awarded. The Amendments also tried to provide a check on the air quality impacts of all projects supported by Federal highway and mass transit finds, by requiring the Secretary of Transportation to ensure that federally funded projects "conform" to State Implementation Plans (SIPS) .33

Some transportation control measures were included in most States' 1979 and 1982 SIP revisions. In most cases the TCM programs were not very aggressive, and accordingly, expectations of VOC emissions reductions from TCM programs were generally modest. Many of the TCMs included in the 1979 and 1982 SIPS were adopted primarily to help reduce carbon monoxide emissions, or even to ease congestion or meet other transportation or developmentrelated goals [51]. For example, a review of a few 1982 SIP submittals found that in the two from Louisville and St. Louis, TCMs such as transit improvements, ridesharing programs, parking controls and traffic flow improvements were expected to yield 6 to 7 percent of the VOC reductions anticipated through 1987. In SIPs from two other areasBaltimore and Chicago-expected reductions from transportation control measures amounted to 1 percent or less of the anticipated VOC reductions [22].

Unfortunately, we cannot evaluate whether previous SIP projections generally overestimated or underestimated the effect of transportation control measures, because the impact of the measures that have been implemented has not been systematically monitored by EPA or the States. EPA's Office of Transportation and Land Use Policy was eliminated in 1982 due to budget constraints and shifted priorities, and the Agency has not subsequently required detailed program evaluations and reports from the States. Moreover, it is generally difficult to evaluate the impact of individual TCMs on air quality, due to errors and uncertainty in baseline estimates of vehicle use, and confounding factors such as local economic conditions, fuel prices, and unrelated changes in the local transportation system (e.g., freeway construction).

Several key generalizations about TCMs can be drawn from interviews and reports on programs in various cities [27,1 1]:

- TCM programs have to be tailored to each individual area. Critical local characteristics that need to be considered in developing TCM programs include population and employment distributions and densities, city layout and transportation routes, highway system capacity and level of congestion; access to mass transit; and parking availability and costs.

- The success of many transportation control measures depends to a large degree on public acceptance and participation. In the absence of widespread public concern about air pollution and/or traffic congestion problems, past experience indicates that political resistance to involuntary restrictions on people's modes or amount of travel will be insurmountable. From a political standpoint, it is apt to be much easier to initiate voluntary TCM programs than mandatory ones. However, the ultimate success of voluntary programs can also depend critically on public awareness. And, due to turnover in participation, promotional efforts for strictly voluntary programs have to be sustained over time. For example, carpools typically have turnover rates of 1 to 2 years. Two approaches other than promotional campaigns that attempt to give people incentives to participate in TCM programs are discussed below: "trip reduction ordinances" directed at employers, and financial incentives and disincentives.

- Long leadtimes and sustained efforts are required to implement TCMs. Major capital projects such as development of mass transit obviously require long lead times. Other measures may be directed at new employers or

\footnotetext{
${ }^{31}$ Federal aidfor highways and mass transit totals about $\$ 16$ billion, annually, most of which is supported through Federal motor fuels taxes. To be eligible for Federal highway and mass transit assistance, metropolitan areas are required to coordinate transportation plans and transportation improvement programs across local jurisdictions within the area. Metropolitan Planning Organizations (MPOs) with elected representatives from each local jurisdiction, perform this function. MPOs typically do not have authority to implement or enforce transportation plans.

${ }^{32} \mathrm{Sec} .175$ of the Clean Air Act.

${ }^{33} \mathrm{Sec} .176(\mathrm{c})$ of the Clean Air Act.
} 
commercial developments, and thus take effect only gradually. Ordinances requiring new employers to encourage employees to share rides, use transit, or otherwise collectively reduce their driving are one example. Ridesharing programs and parking restrictions could help reduce emissions within a very short time, although their continuing impact may depend on long-term land use and transportation policies.

- The effectiveness of one transportation control measure may depend substantially on concurrent implementation of another. For example, ridesharing programs and mass transit are likely to be more successful if some highway lanes are restricted to buses and carpools, or if parking in business districts is restricted or expensive. A recent comparison of the business districts of San Francisco, Portland, Seattle and Denver found that transit shares were highest in the cities with the highest parking prices and most limited parking [28]. In general, larger reductions in emissions are likely to be achieved if TCM programs are coordinated throughout an area and over an extended time horizon, than if measures are developed on a piecemeal or sporadic basis.

- For TCMs to be effective, air quality has to be considered a priority in urban transportation and land-use planning. Because TCMs involve highway and transit facilities and operations, it is obvious that State and local organizations with responsibility for transportation system operations, maintenance and improvements have to be involved in their development and implementation. Since TCMs can also involve zoning laws and requirements for new developments, the participation of local organizations with authority over landuse policies is also needed. Land-use policies that affect VMT are discussed further in the next section,

The planning grants made under the 1977 Amendments were judged to have been effective in getting MPOs to examine transportation control measures (many of them for the first time). The grants also enabled areas to obtain local data on mobile sources that were needed to evaluate potential TCM impacts. However, the one-time-only grants apparently fell short of convincing transportation planners in most areas to give continuing priority to improving air quality [51].

The requirement that federally funded projects conform to SIPS also failed to institute improvement or maintenance of air quality as a goal in urban transportation planning. The U.S. Department of Transportation (DoT), which distributes Federal highway and mass transit assistance, has sought to equate "conformance" with a narrow finding that a transportation plan or project does not interfere with transportation control measures included in SIPS [50]. EPA has suggested a broader requirement that transportation plans and projects "should not cause or contribute to existing or new standard violations, or delay attainment" [12]. While DoT and EPA have debated the meaning of "conformance," transportation plans, projects and programs have not generally been required to address air quality concerns proactively.

\section{Potential Reductions From Transposition Control Measures}

One of the most up-to-date and comprehensive assessments of transportation control measures is the review that the South Coast Air Quality Management District (AQMD) and the Southern California Association of Governments recently completed for the Los Angeles area [38,40]. For each of the transportation control measures listed below, the AQMD estimated the VOC reductions that would be possible using existing authority and funds (the low end of the range) as well as reductions dependent upon additional funding or new legislative initiatives (the upper end of the range). Reductions are estimated for the period 2000-10.

Without the measures listed below, VMT in the Los Angeles area is projected to increase by almost 70 percent by the year 2010 , as the population living in the area increases by 35 percent, to 18.3 million. Due to congestion, the average vehicle speed on area freeways is predicted to fall from 47 to $24 \mathrm{mph}$ [41]. In 2010 total VOC emissions from highway vehicles are projected to be reduced by about 40 percent from 1985 levels, to about 320 tons per day, despite increased VMT and without the measures listed below [40]. 
With full funding and authority, the proposed measures are expected to reduce highway-vehicle VOC emissions by a total of 30 percent, by 2010 , compared to levels projected without them. Note that under these circumstances, growth management measures that are aimed at matching new jobs with nearby housing account for over 40 percent of these reductions. (Total reductions in highway vehicle emissions of $\mathrm{NO}_{\mathrm{x}}$, sulfur oxides, carbon monoxide, and particulate matter from the set of measures listed below are also expected to be about 30 percent, compared to emissions levels projected for 2010 without the TCMs listed below.)

. strategies to reduce the number of singleoccupancy car trips, including: employer ride share and mass transit incentives, parking management (increase parking meter fees, eliminate peak-period on-street parking, eliminate employer-subsidized parking, etc.), vanpool purchase incentives, auto use restrictions, and high-occupancy vehicle (HOV) lanes. Businesses in the Los Angeles area with more than 100 employees are already required to encourage ride sharing and transit use; requirements for employers would be strengthened and expanded. New laws would regulate commercial parking and eliminate parking subsidies. New funding is sought for transit improvements and HOV lanes. Federal legislation is called for to restore tax credits for vanpool purchases. The South Coast AQMD estimates that all such measures will reduce highway vehicle emissions by about 0.2 to 3 percent, compared to levels projected without TCMs.

- traffic flow improvements, including: metering on highway ramps, synchronized traffic signals, and intersection improvements. Making these improvements is primarily a matter of obtaining funds for roadway modifications and installation and maintenance of metering and synchronization technology. The South Coast AQMD estimates that these measures will reduce highway vehicle emissions by about 0.5 to 1.5 percent.

. rescheduling and rerouting of truck deliveries away from congested areas during peak commute hours. Truck delivery routes and schedules were altered voluntarily during the 1984 Olympic Games. To implement these measures on a wider scale, local ordinances such as those that restrict night deliveries might have to be modified. The AQMD estimates reductions of about 0.3 to 3 percent from this measure.

. alternative work schedules (e.g., work weeks consisting of 10-hour days), and telecommuting. As examples, businesses would be required to adopt alternative work scheduling as a condition for permit renewal, and new employment developments in business or industrial districts with more jobs than available housing would be required to establish satellite work centers in predominantly residential areas. Employers in the Los Angeles area have some experience with alternative work schedules, which were adopted voluntarily to help reduce traffic congestion and air pollution during the 1984 Olympic Games. Although the State of California is currently conducting a pilot project on telecommuting, the idea of requiring new businesses to have satellite work centers is unprecedented, and would require changes in zoning, licensing, tax and possibly labor laws to implement. Highway-vehicle emission reductions of about 0.5 to 7 percent are estimated to be available from these measures.

. freeway capacity enhancements. The AQMD estimates that by building an additional 880 lane miles, highway vehicle emissions can be reduced by about 1.5 to 4 percent. This step constitutes an extremely ambitious highway construction program, and AQMD acknowledges that obtaining sufficient funding will be a major challenge. The projection that net reductions in emissions would result from freeway expansion means that in the Los Angeles area, lower emissions due to reduced congestion are expected to offset increased travel that might be encouraged by new roads.

- growth management. The population in the South Coast is projected to grow to 18.3 million by the year 2010, almost a 50-percent increase since 1984. This measure proposes to use land-use management measures to help match new jobs with nearby housing, and vice versa. Specific measures include assessing development fees, modifying zoning rules, and strategically locating new public facilities and infrastructure. Though growth management is likely 
to be politically contentious, it is becoming more common for fast-growing municipalities to use zoning laws, development fees, etc. to try to do so. However, the scale of the AQMD proposal, which entails coordination over dozens of municipalities, is unprecedented. The AQMD estimates that shifting 10 percent of new jobs to housing-rich areas, and 4 percent of new housing to job-rich areas, would reduce highway vehicle emissions by 0.6 to 14 percent.

\section{Role of Transportation and Land-Use Planning}

Land-use patterns play an important role in either tying people to their cars or facilitating other modes of transportation. As an illustration, people who live within a few miles of work might choose to walk or bike. But where urban areas consist of sprawling residential suburbs and separate business districts or industrial parks, few people have these options. A recent comparison of ten U.S. cities found that per capita gasoline consumption (which we assume to be a reasonable surrogate for VMT) is relatively low in cities with high population and job density, and relatively high in cities with abundant roads and parking. Per capita gasoline consumption is 10 times higher for residents of suburbs outside of Denver than for residents of Manhattan [32].

Between 1980 and 1986, about 85 percent of the population growth in the United States was in metropolitan areas. About three-fourths of that growth occurred in the suburbs of those areas. According to a task force formed to advise the Federal Highway Administration (FHWA), this pattern of growth is expected to continue [23]. However, growth in the suburbs does not necessarily have to mean more and longer commutes in private cars. The FHWA's task force anticipates that the density of residential development in the suburbs will increase as rising housing costs and declining household sizes necessitate construction of apartments and compact townhouses rather than expansive subdivisions [23]. This increase in density could facilitate transit service. And, some analysts have suggested, land-use policies could guide development to limit reliance on driving,
Land-use planning and regulation are traditionally activities carried out by local governments, whereas transportation planning is more apt to be a State or regional responsibility. Land-use policies are implemented through local zoning laws and permit requirements for subdivision and commercial site development. Permit reviews typically ensure that public works (e.g., water, sewers, roads, interchanges, and parking) are adequate to support the development. Interaction between transportation and land-use planning agencies usually takes the form of assessing the impacts of new developments. The number of trips that would be generated by a proposed development is estimated and compared with the capacity of nearby roads and intersections.

If a transportation system is inadequate to support new development, it maybe expanded, sometimes at a developer's expense. Increasingly, where funds are limited or congestion is already an issue, developers are being required to take steps such as providing convenience stores on site, or providing transit shelters or bike paths, in order to reduce potential transportation impacts. Downtown developers in several cities have been faced with caps on the number of parking spaces they can provide. As mentioned above for Los Angeles, area-wide landuse regulations can also be modified to help reduce traffic congestion and air pollution. The guiding principles include: promoting development in areas with existing mass transit services; encouraging development within developed areas to increase population density and thus make transit services easier to provide; and promoting housing construction in job-rich areas or employment opportunities in residential areas. Due to the links between land-use policies, jobs, and tax revenues, local political resistance is apt to be the major problem in trying to modify land-use regulations [15].

\section{Trip Reduction Ordinances}

To circumvent problems in getting people to accept and participate in transportation control measures, some areas have passed "trip reduction ordinances" requiring companies to provide services, facilities, or incentives to encourage their employees not to drive to work alone. Companies are required to promote transportation alternatives, but the participation of individuals is voluntary. Some companies have increased the proportion of 
their employees who do not drive alone to more than 80 percent [11]. Services and incentives provided include preferential parking, shuttle services, on-site sale and subsidies of mass transit passes, and subsidized vanpools.

Examples of trip reduction ordinances include a regulation passed in 1987 in the Los Angeles area that is designed to increase average ridership from the current level of 1.13 to 1.5 people per vehicle during peak periods. The ordinance applies to all employers of 100 or more people and thus affects more than 8,000 businesses. Employers are required to prepare comprehensive trip reduction plans for their companies. Failure to submit a plan or annual update, or offer any incentive included in the plan is a violation of the ordinance; failure to meet ridership goals is not. The regulation is expected to reduce the number of private motor vehicle trips made each day by about 10 percent, resulting in VOC emissions reductions of about 4 percent of current highway vehicle emissions [25].

An ordinance passed in Pleasanton, CA in 1984 set a goal of reducing peak hour commuting traffic by 55 percent, from a baseline that assumes everyone drives alone. Employers are expected to achieve a 15-percent reduction in the first year, and additional reductions of 10 percent each of the next 4 years. In the second year of the program, only three companies failed to achieve the targeted 25 percent reductions, and twelve companies had already exceeded the fourth year target of 45 percent. Companies are fined for failing to provide required survey data, but not for failing to meet goals [24].

\section{Financial Incentives for Reducing Vehicle Use}

Because the cost of driving influences the number of miles per year that people travel, another approach to reducing VMT involves the use of fees to make driving more expensive, and subsidies to encourage use of alternative modes of transportation. Financial incentives have the potential to affect a greater fraction of urban travel than trip reduction ordinances, because less than 30 percent of local travel is work-related [49]. Targets that have been proposed for fees or taxes include gasoline, parking, and road-use (i.e., tolls).

Ironically, Federal income tax policy currently provides a financial incentive that encourages driving to work alone over using mass transit or ride sharing. Employers' provision of free or subsidized parking is a tax free benefit, worth up to $\$ 300$ per month if valued at commercial rates charged in the business districts of some cities. In contrast, provision of more than $\$ 15$ per month worth of mass transit passes is a taxable benefit. The amount by which the market value of vanpool trips exceeds what employees are charged to participate is also taxable under current law [31].

Although many studies have looked at the relationship between the price of and demand for gasoline, only a few have explicitly estimated the effect of gasoline price on automobile travel. ${ }^{34} \mathrm{Of}$ these, most have concentrated on the effect over the first few years of a price change, not on changes that might persist over many years. When estimating the effect of gasoline price on travel from historical data, several factors must be considered simultaneously. Income, average fuel economy, and the cost of more fuel-efficient cars must all be taken into account as factors that influence how a consumer will respond to changing gasoline prices. Data from different time periods and countries indicate that the likely response to a $\$ 0,50$ per gallon tax is a reduction in automobile travel of between 5 and 25 percent, for the first few years the tax is imposed..$^{35}$ Thus a reasonable assumption is that a 15-percent reduction in automobile travel would result from a $\$ 0.50$ per gallon tax. Similarly, one would expect about an 8-percent reduction in automobile travel from a $\mathbf{\$ 0 . 2 5}$ per gallon tax.

The effect of a gasoline tax over the long term is quite a bit more uncertain. Some studies have found that the effectiveness of a gas tax increased through time. Others found that it dropped. In many cases, the latter trend seems most likely. Rather than reducing travel, consumers will respond by purchasing more fuel-efficient cars when it is time to replace their old ones. However, this is not the only response

\footnotetext{
${ }^{34}$ Two recent reviews of the relationship between gasoline price and automobile travel are Dahl,1986 [14] and Bohi and Zimmerman, 1984 [6].

${ }^{35}$ These studies estimate the "elasticity" of miles traveled to changes in the price of gasoline, that is the ratio of the change in miles traveled to the change in the price of gasoline, Short-term elasticities of -0.1 to -0.5 have been reported in the literature and summarized by Dahl [14],
} 
possible. If a gasoline taxis combined with improvements in mass transit, for example, consumers may permanently shift their mode of transportation.

If the only benefit from a gasoline tax that is considered is the reduction in VOC emissions, the cost-effectiveness of a gasoline taxis quite high. We estimate that emissions reductions from a gasoline tax would cost about $\$ 35,000$ to $\$ 75,000$ per ton of VOCs over the first few years. Over the long term, costs might rise to about $\$ 100,000$ to $\$ 200,000$ per ton. Of course, other benefits would also result, including lower emissions of carbon monoxide, nitrogen oxides, and carbon dioxide, reduced highway congestion, and less reliance on imported oil.

\section{LOWERING EMISSIONS FROM HIGHWAY VEHICLES: ALTERNATIVE FUELS}

Two motor vehicle fuels, methanol and compressed natural gas $(\mathrm{CNG}),{ }^{36}$ are currently being considered as alternatives to gasoline, to help reduce urban ozone. Roughly 1,000 vehicles in the United States, mostly in demonstration fleets in California, are currently operated on methanol blended with a small amount of gasoline [47,1]. About 30,000 vehicles in the United States have been retrofit to run on either CNG or gasoline [47].

Based on experience in the United States and elsewhere, it appears feasible to modify or design light-duty vehicles (i.e., cars and light trucks) to operate on either CNG or methanol, and give performance that is generally comparable to that of vehicles running on gasoline. The limited distance that can be driven on CNG before refueling is currently a disadvantage for it, compared to gasoline. Problems that still need to be addressed with methanol vehicles include starting them on straight (100 percent) methanol in cold weather, and safety concerns related to the fuel's acute toxicity and invisible flame. Partly because of these limitations, methanol vehicles used within the next 10 years will probably operate on blends of methanol and gaso-



Photo credit: South Coast Air Quality Management District, EI Monte, CA

Methanol-fueled vehicles emit less ozone-forming pollutants than traditional gasoline-fueled vehicles. The use of compressed natural gas also represents a promising alternative to gasoline.

line. CNG vehicles will most likely be dual-fueled, operating on CNG part of the time, and gasoline part of the time.

The potential for reducing ozone when methanol or CNG are substituted for gasoline stems from the fact that methanol and natural gas (methane) are VOCs that react more slowly in the atmosphere and consequently lead to less ozone production than the complex mixture of VOCs emitted from the combustion and evaporation of gasoline. In the near term, "effective" VOC emission rates with alternatively fueled vehicles will be only moderately lower than rates that could be obtained with gasoline vehicles meeting current standards ${ }^{37}$ In the short term, using either methanol blends or dual-fueled CNG vehicles is likely to be an extremely costly means of reducing ozone. With major advances in vehicle technology over the next 10 years, and use of straight methanol (rather than a blend) or exclusive use of CNG (rather than dual-fuel operation) greater and more costeffective reductions may be possible.

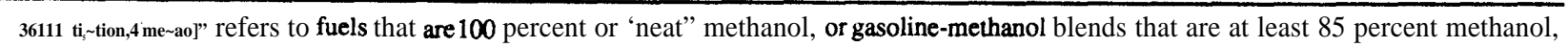
by volume. "Compressed natural gas" is natural gas that is stored on a vehicle under high pressure-typically at 2,400 psi or higher.

37We use the phrase "effective VOC emissions" throughout this section to indicate relative ozone-forming potential, as opposed to the actualamount of VOCs (i.e., tons of carbon) emitted. Because different organic compounds are emitted from methanol or CNG versus gasoline-fueled vehicles, alternative fuel use can "effectively" lower emissions in terms of how much ozone is produced when various compounds react, even if the total amount of VOCs emitted is unchanged. 
In the sections that follow, we first discuss estimates of the effect of alternative fuel use on emission rates and other aspects of motor vehicle operation and performance. We then present estimates of total emissions impacts of using alternative fuels in: 1) fleets of 10 or more light-duty vehicles, and 2) light-duty vehicles in general use. Finally, we present a range of estimates of the costs per ton of VOC emissions effectively eliminated by using methanol or CNG. Throughout the analysis, we adopt estimates of effective emissions reductions attainable with methanol blends or dual-fueled CNG vehicles as our best estimates. We use projections of reductions that might be obtainable with advanced technology and use of straight methanol or exclusive use of CNG, to get upper bound estimates of the potential benefits of alternative fuels.

\section{Emissions From Alternatively Fueled Motor Vehicles}

Estimates of emissions rates for methanol-fueled vehicles are speculative because the vehicles tested to date have been versions of vehicles originally designed to operate on gasoline, which were retrofit or modified in limited production runs. Massproduced vehicles could have different emissions characteristics. Moreover, most methanol vehicles tested had not accumulated much mileage, and it is not known how much emissions rates would deteriorate in use. Our best estimate is that vehicles likely to be available in the next 10 years, which would be operated on blends of 85 percent methanol mixed with 15 percent gasoline (by volume), would have total rates of evaporative and exhaust VOC emissions that are effectively 30 percent lower (in terms of ozone-forming potential) than those of light-duty vehicles meeting current standards and operating on low volatility gasoline (9.0 psi Reid Vapor Pressure (RVP)) [3,47].

Estimates of emission rates that might eventually be obtainable with technological advances and with operation on straight methanol are very speculative. As an upper bound, we adopt EPA's assumption that effective reductions of up to 90 percent may be possible, compared to gasoline vehicles meeting current standards [56]. A major advance needed before such large reductions could be obtained is to improve engine and catalyst designs to control emissions of formaldehyde, a highly reactive, toxic VOC produced when methanol is burned. Some engineers and analysts are skeptical that formaldehyde emissions can be controlled well enough to reduce overall ozone-forming potential by 90 percent $[33,4]$.

Emissions reductions that could be achieved using CNG are even more speculative than those for methanol vehicles, because emissions have only been measured for a few dual-fuel CNG vehicles, and the results have varied significantly from one test to another [3,7]. EPA has preliminarily estimated that while operated on $\mathrm{CNG}$, dual-fuel vehicle exhaust emissions would effectively be 40 percent lower, and evaporative emissions 100 percent lower, than emissions from vehicles meeting current emission standards and operating on low volatility gasoline [56]. Adding up the exhaust and evaporative impacts, total emissions would be reduced by about 75 percent. ${ }^{38}$ As an upper bound for CNG, we assume that if vehicles are designed and adjusted for minimal emissions with exclusive operation on CNG, total effective reductions of up to 90 percent might be realized.

It is important to emphasize that the relative ozone-producing potential of vehicles operated on gasoline versus alternative fuels will depend on future regulations, including volatility limits set for gasoline, and exhaust and evaporative emissions limits imposed on both gasoline and alternativefueled vehicles. With any fuel, considerable leeway exists in trading off emission rates for engine performance, starting and warm-up characteristics, and vehicle costs. EPA has promulgated emissions standards for methanol-fueled vehicles that allow the same levels of exhaust and evaporative VOC emissions for methanol as for current gasoline-

\footnotetext{
${ }^{38}$ Based on EPA's model of motor vehicle emissions, MOBILE4, for a vehicle meeting current exhaust standards and operating on 9.0 psi RVP gasoline, and for atypical hot summer day, we assume in-use exhaust, evaporative and 'running loss" emissions are 42,21 , and 37 percent, respectively, of total emissions.
} 
fueled vehicles. ${ }^{39}$ Under the proposed regulations, the improvement in air quality anticipated with methanol would be due solely to the reduced ozone-forming character of the emissions, rather than reduced emissions, per se. To date, EPA has not proposed standards for CNG vehicles.

Switching to alternative fuels could affect levels of several air pollutants besides ozone. In addition to VOCs, gasoline vehicles also emit nitrogen oxides, benzene and other toxic organic compounds, carbon monoxide, and particulate. In theory, methanol and CNG have the potential to reduce emissions of all of these pollutants, although the reductions that actually occur will depend on regulations, and on vehicle design and operation. Replacing diesel with methanol or CNG might be especially helpful in allowing heavy-duty buses and trucks to obtain concurrent reductions in emissions of both particulate and nitrogen oxides. ${ }^{40}$ For light-duty vehicles, EPA applies the same carbon monoxide and nitrogen oxides emissions standards for methanol as for gasoline [52], so potential reductions in these pollutants would probably not be realized. A critical problem that needs to be addressed with methanol vehicles is emissions of formaldehyde. With catalyst designs tested to date, methanol vehicles cannot meet the in-use standards California has proposed for formaldehyde emissions [33].

One final air quality consideration associated with the use of motor vehicle fuels other than gasoline is their comparative emissions of "greenhouse" gases that trap heat in the atmosphere, such as carbon dioxide $\left(\mathrm{Co}_{2}\right)$ and natural gas (methane). Considering production of the fuels as well as combustion in motor vehicles, and assuming that on an energy equivalent basis the fuel economy is the same, use of
CNG would be expected to reduce greenhouse gas emissions by about 20 percent, compared to gasoline [16]. Greenhouse gas emissions from methanol produced from natural gas would be about the same as emissions from gasoline [16]. However, use of methanol produced from coal could increase emissions of greenhouse gases by 50 to 100 percent, depending on the efficiency of the process of producing methanol $[16,25]$. At present, methanol is produced almost exclusively from natural gas, because production from coal is not economically viable [46].

\section{Vehicle Operation and Performance}

Because methanol is incompatible with some metals and polymers currently used in automotive fuel systems, straight methanol cannot be used in vehicles designed to run on gasoline. However, in California tests, vehicles that were built to run on methanol have given comparable performance and maintenance records and equal or improved fuel economy (on an energy equivalent basis ${ }^{41}$ ) compared to gasoline-fueled vehicles of the same model [1]. Gasoline was generally added to the methanol used in these demonstration programs for safety, so that in case of an accident the fuel would burn with a visible flame, and because cars run on straight methanol are difficult to start in cold weather [1]. Theory suggests that if these two problems can be overcome, vehicles that are modified to operate on straight methanol could get 10 to 15 percent higher fuel economy (energy equivalent basis) and give improved performance (due to methanol's high octane rating) than gasoline-fueled vehicles [1]. Finally, methanol is much more toxic than gasoline.

39U.S. EPA's standards for light-duty-methanol-fueled vehicles are exhaust emissions of $0.41 \mathrm{~g} / \mathrm{mi}$ hydrocarbon(HC), and evaporativeemissions of $2.0 \mathrm{~g}$ /test HC [52]. The State of California's standards for methanol-fueled passenger vehicles are similarly equivalent to their proposed gasoline-fueled vehicle standards (California has proposed a new exhaust emissions limit for 1992 and subsequent model year passenger vehicles of $0,25 \mathrm{~g} / \mathrm{mi}$ ) except that limits on formaldehyde in exhaust are specified explicitly $(0.015 \mathrm{~g} / \mathrm{mi}$ at certification and $0.023 \mathrm{~g} / \mathrm{mi}$ in-use for the 1993 to 1995 period, and 0.015 $\mathrm{g} / \mathrm{mi}$ at certification and in-use after 1995) [9].

${ }^{40}$ In 1990 , the $\mathrm{NO}_{\mathrm{x}}$ emissions standard for all heavy duty vehicles will be reduced from the current Standard of $10.7 \mathrm{~g} / \mathrm{bhp}-\mathrm{hr}$ to $6.0 \mathrm{~g} / \mathrm{hhp}-\mathrm{hr}$ and to $5.0 \mathrm{~g} / \mathrm{hhp}$-hr in 1991. in 1991 the particulate standard for urban transit buses will be reduced from $0.6 \mathrm{~g} / \mathrm{bhp}$-hr to $0.1 \mathrm{~g} / \mathrm{bhp}$-hr and for other heavy duty vehicles to $0.25 \mathrm{~g} / \mathrm{bhp}$-hr. In 1994, all heavy duty vehicles will be required to meet a $0.1 \mathrm{~g} / \mathrm{bhp}$-hr particulate emissions standard, The particulate and $\mathrm{NO}_{\mathbf{x}}$ standards may be difficult to meet concurrently with the add-on control technology anticipated to be available for heavy-duty diesel vehicles. In a demonstration program in California, transit buses with either spark or compression ignition engines that were designed or significantly modified to run on methanol emitted lower levels of $\mathbf{N O}_{\mathbf{x}}$ and particulate than diesel-fueled buses. However, methanol buses have had problems with limited durability of parts and restricted range between refueling [1]. Several heavy-duty engine manufacturers have research underway to develop spark ignition engines to operate on CNG [35].

${ }^{41}$ The energy content of a gallon of gasoline is approximately 2.0 times greater than that of a gallon of methanol. 
Ingestion can cause permanent blindness or death. ${ }^{42}$ Widespread use of methanol would require safety precautions that have not been taken with gasoline.

The advantages of CNG include its very high octane rating, high combustion efficiency, and good characteristics for starting in cold weather. The main disadvantages of the fuel are related to its low volumetric energy content. The distance that current CNG vehicles can be driven without refueling is currently limited to about 200 miles, whereas a typical light-duty vehicle has a range of up to 350 miles on 15 gallons of gasoline. In providing a 200-mile range, current CNG-fueled vehicles carry extra weight and displace about five times the space that gasoline tanks providing the same range would require. The most commonly used steel tanks weigh up to 400 pounds, while more recently developed fiberglass-wrapped aluminum tanks weigh about 200 pounds [17]. For comparison, the average weight of current passenger cars is about 3,000 pounds, including a 25-pound gasoline tank.

Most of the CNG vehicles that are currently in operation in the United States have been retrofitted for dual CNG or gasoline use. Adjustments made to allow dual fuel operation affect performance and fuel efficiency. Dual-fuel vehicles have generally given poorer performance and had worse fuel economy on both gasoline and CNG than comparable gasoline vehicles [46,7]. Some experience with $\mathrm{CNG}$ vehicles that operate exclusively on CNG has been gained with 27 light-duty trucks built by the Ford Motor Company. The truck tested by U.S. EPA gave performance and fuel efficiency comparable to an equivalent gasoline-fueled truck [3].

\section{Potential Emissions Reductions from Alternative Fuel Use}

In the following sections, we consider the total emissions impacts of alternative fuel use in the year
2004, in: 1) fleets of 10 or more light-duty vehicles (e.g., vehicles owned by corporations or police departments), and 2) light-duty vehicles in general use. We also estimate the costs per ton of VOC emissions effectively eliminated. ${ }^{43}$ Emissions impacts are calculated assuming that refueling emissions and gasoline volatility have already been controlled, and that light-duty vehicles are subject to current standards. Because of the potentially high cost of using methanol and natural gas, it may be desirable to limit their use to those areas with the most severe ozone problems. Therefore we only consider alternative fuel use in areas with design values of $0.15 \mathrm{ppm}$ or higher. The other control measures OTA has identified are projected to be insufficient to bring most of these areas into attainment by the year 2004 (see chapter 6).

In the sections that follow, as our best estimates, we assume that emission rates with methanol blends would effectively be 30 percent lower than those of gasoline vehicles; and that emissions from dual-fuel vehicles operated on CNG would effectively be 75 percent lower. We assume full-time use of methanol blends, but that dual-fuel vehicles are only operated on CNG 75 percent of the time. ${ }^{44}$ As an upper bound for exclusive use of either CNG or methanol in vehicles incorporating technological advances, we use an effective reduction in emission rates of 90 percent, compared to gasoline.

In addition to motor vehicle exhaust and evaporative emissions, refueling emissions would also be reduced if gasoline were displaced by straight methanol or by CNG. Negligible reductions in refueling emissions would be anticipated if gasoline were displaced by a methanol/gasoline blend. With straight methanol or CNG use, we assume that refueling controls would have been in place anyway, and that reductions in VOC emissions from refueling are proportional to the amount of gasoline displaced.

\footnotetext{
${ }^{42} \mathrm{Just}$ over 2 ounces of methanol could potentially be lethal if swallowed by a 150-pound adult. This amount could readily be ingested accidentally by someone siphoning fuel. Swallowing less than half an ounce of methanol could be lethal to a young child [30].

${ }^{43}$ Note that in estimating VOC control cost-effectiveness, we have used the full cost differentialbetween gasoline and the alternatives.If, compared to gasoline, use of alternative fuels also reduced emissions of other pollutants such as carbon monoxide, the costs associated with fuel substitution should be distributed across pollutant control programs.

${ }^{44}$ We assume that some operation on gasoline would be necessary for dual-fuel CNG vehicles, because the distance they can be driven on CNG without refueling is limited, and because CNG would not be available everywhere. Nationwide, about 15 percent of vehicle males are driven on trips that cover more than 75 miles in distance, one-way [48].

${ }_{45}$ VOC emissions from petroleum refining could also be reduced, assuming that they are tied to gasoline ales. However, we cannot be sure where such reductions would occur, so we do not count them in the totals for the areas where alternative fuels are used.
} 


\section{Light-Duty Fleet Vehicles}

In 1986,6 million cars and 2 million light trucks in centrally owned fleets of 10 or more vehicles accounted for about 13 percent of light-duty vehicle miles traveled (VMT) nationwide [5]. Centrally owned fleets account for such a large fraction of VMT because on average, fleet vehicles are driven over two times as many miles in a year as vehicles in general use. Use of alternative fuels in centrally fueled fleets is expected to be easier to promote or require than general use, because the latter would have to be preceded by development of a much more extensive network of refueling stations than the former. ${ }^{46}$

In 2004, in areas with design values of $0.15 \mathrm{ppm}$ or higher, about 4.5 million light-duty vehicles are expected to be operating in centrally owned fleets of 10 or more. About 7.9 billion gallons of methanol per year would be required to operate these 4.5 million vehicles. ${ }^{47}$ This amount is about equal to the worldwide capacity for production projected for $1990[21]^{48}$ About 520 billion cubic feet of natural gas (approximately 3 percent of current U.S. production) would be required annually to operate 4.5 million light-duty vehicles exclusively on CNG.

Table 7-10 summarizes the effective VOC reductions that could be obtained with $\mathrm{CNG}$ or methanol use in areas with design values of $0.15 \mathrm{ppm}$ or higher. Our best estimate is that by 2004, use of methanol in fleets would be equivalent to reducing emissions by 0.7 percent of total 1985 levels. Using CNG in fleets ( 75 percent of the time) is estimated to be equivalent to reducing VOC emissions by 1.3 percent of 1985 levels. As an upper bound, with technological advances and exclusive use of either CNG or straight methanol, we estimate that emissions might be reduced by 2.1 percent.

Vehicles in General Use

By 2004, it might be possible to expand the supply and distribution of alternative motor vehicle fuels to satisfy a large portion of the general market. To illustrate the magnitude of potential VOC emissions reductions and fuel consumption involved, we consider the impacts of using alternative fuels in 25 percent of the light-duty vehicles in general use in 2004, in nonattainment areas with current design values of $0.15 \mathrm{ppm}$ or higher.

About 15 billion gallons of methanol are estimated to be needed to fuel 25 percent of the general population of light-duty vehicles in nonattainment areas with design values of $0.15 \mathrm{ppm}$ or higher. About 1 trillion cubic feet of natural gas (5 percent of U.S. production in 1987) is estimated to be needed if $\mathrm{CNG}$ is used.

As shown in table 7-10, our best estimate is that if 25 percent of the light-duty vehicles in areas with design values of $0.15 \mathrm{ppm}$ or higher used methanol or CNG, emissions would be effectively reduced by 1.3 or 2.5 percent, respectively, compared to 1985 levels. Our upper bound estimate is that emissions might be effectively reduced by up to 4.1 percent, again with technological advances and exclusive use of either CNG or straight methanol.

\section{Cost-Effectiveness of Alternative Fuel Use in Light-Duty Vehicles}

\section{Methanol}

One automobile manufacturer has estimated that in production runs of fewer than about 100,000 vehicles, cars and light-duty trucks designed to operate on methanol would cost $\$ 500$ to $\$ 1,000$ more than gasoline-fueled vehicles; whereas in larger runs, methanol and gasoline-fueled vehicle production costs could be comparable [53]. For centrally owned fleets, assuming a vehicle life of 6 years (150,000 miles) and an 8-percent discount rate, the annualized cost differential for a methanol vehicle could thus range from $\$ 0$ to about $\$ 215$. For a vehicle in general use, with a 10 -year $(100,000$ mile) life and again assuming an 8-percent discount rate, the annualized added cost could range from $\$ 0$ to $\$ 150$.

\footnotetext{
${ }^{46}$ Because of data limitations, we focusour analysis on centrally owned fleet vehicles, rathethan on centrally fueled fleet vehicles.

${ }^{47}$ This assumes that cars average 27.5 miles per gasoline gallon equivalent fuel, and that light duty trucks average 20 miles per gallon. About 690 billion cubic feet of natural gas would be required to produce 7.9 billion gallons of methanol.

${ }^{48}$ U.S. production capacity $i_{n} 1990$ is projected tobeabout 2 billiongallons. The principal use of methanol is currently as a chemical feedstock.
} 
Table 7-10-Effective VOC Reductions in 2004, From Use of CNG and Methanol as Light-Duty Motor Vehicle Fuels in Areas with Design Value of $0.15 \mathrm{ppm}$ or Higher

\begin{tabular}{|c|c|c|c|c|c|}
\hline & \multirow{2}{*}{$\begin{array}{l}\text { New vehicle } \\
\text { reduction } \\
\text { (percent) }\end{array}$} & \multicolumn{2}{|c|}{ Area-wide total fleets ${ }^{c}$} & \multicolumn{2}{|c|}{ Area-wide total general ${ }^{d}$} \\
\hline & & (tons) & (percent) & (tons) & (percent) \\
\hline $\begin{array}{l}\text { Methanol blends ................ } \\
\text { (best estimate) }\end{array}$ & 30 & 54,000 & 0.7 & 102,000 & 1.3 \\
\hline $\begin{array}{l}\text { Straight methanol } \ldots \ldots \ldots \ldots \ldots \\
\quad \text { (upper bound) }\end{array}$ & 90 & 173,000 & 2.1 & 328,000 & 4.1 \\
\hline $\begin{array}{l}\text { Dual-fuel } \mathrm{CNG}^{\mathrm{e}} \ldots \ldots \ldots \ldots \ldots \ldots \\
\quad \text { (best estimate) }\end{array}$ & 75 & 108,000 & 1.3 & 205,000 & 2.5 \\
\hline $\begin{array}{l}\text { Exclusive } \text { CNG } \ldots \ldots \ldots \ldots \ldots \ldots \\
\quad \text { (upper bound) }\end{array}$ & 90 & 173,000 & 2.1 & 328,000 & 4.1 \\
\hline
\end{tabular}

aThe reduction totals for straight methanol and exclusive CNG use include refueling emissions reductions of 11,000 tons for fleets, and 21,000 tons for general-use vehicles. For dual-fuel CNG vehides, 75 percegt of those reductions are colınted Beductions in refueling emissions are expected to be negligible, with methanol blends.

CAlternative tuel use in centrally owned fleets of 10 or more light-duty vehicles.

Aiternative tuel use in 25 percent of all light-duty vehicles.

-Assumes 75 percent operation on CNG, 25 percent operation on gasoline.

SOURCE: Office of Technology Assessment, 1989.

Based on a range of 40 to 60 cents per gallon as the wholesale price of methano $1^{49}$ we estimate that methanol would be sold to consumers at $\$ 0.64$ to $\$ 0.84$ per gallon, or $\$ 1.15$ to $\$ 1.51$ per gasolinegallon equivalent, adjusting for the difference in the energy content of the two fuels. ${ }^{50}$ These estimates can be compared to national average prices for regular and premium unleaded gasoline of $\$ 0.95$ and $\$ 1.10$ per gallon, respectively [47]. Assuming that fleet vehicles average 26,000 miles per year and get the energy equivalent of 26.5 miles per gallon of gasoline, straight methanol use would increase annual fuel costs by about $\$ 130$ to $\$ 480$ per vehicle. Annual fuel costs would be about $\$ 50$ to $\$ 180$ higher for a vehicle in the general population averaging 10,000 miles per year and 26.2 miles per gallon.

Table 7-11 summarizes our cost-effectiveness estimates for methanol-fueled vehicles. In the near term, assuming that methanol is blended with 15 percent gasoline and yields effective VOC emissions rates that are only 30 percent lower than gasoline-fueled vehicles, we estimate that using methanol would cost $\$ 9,000$ to $\$ 66,000$ per ton of
VOCs eliminated. If the equivalent of 90-percent reductions in VOC emissions can be achieved through advanced technology, we estimate that using straight methanol would cost $\$ 3,000$ to $\$ 22,000$ per ton. In each case, the low estimate assumes both vehicle and fuel costs that are most favorable to methanol, and the high estimate assumes costs that are least favorable.

\section{Compressed Natural Gas}

Retrofitting a gasoline vehicle to operate on both CNG and gasoline costs about $\$ 1,000$ to $\$ 1,500$ [53]. Because a special fuel tank is required, a cost differential of about $\$ 500$ is expected between $\mathrm{CNG}$ and gasoline-fueled vehicles even in large production runs. The annualized added cost of a vehicle that would be run on CNG is expected to fall between $\$ 110$ and $\$ 325$, for a fleet vehicle, and between $\$ 75$ and $\$ 218$, for a vehicle in general use.

Based on 1987 national average commercial natural gas prices of $\$ 4.76$ per thousand cubic feet [47], or $\$ 0.56$ per gasoline-gallon equivalent, and $\$ 0.20$ to $\$ 0.30$ per gasoline-gallon equivalent com-

${ }^{49}$ Wholesale methanol prices in summer, 1988 , were $\$ 0.60$ per gallon, delivered to the Gulf Coast [29]. Methanol used in demonstration fleets in California is supplied at $\$ 0.59$ per gallon, but tbe State has new commitments for delivery of 9 million gallons at $\$ 0.45$ per gallon [10]. With new plants and sufficient demand to ship methanol by tanker, various analysts estimate long-run costs for methanol ranging from less than $\$ 0.35$ to more than $\$ 0.70$ per @ on $[13,21,20,10,42,2]$. Relatively cheap methanol is expected to come from countries such as Trinidad or Saudi Arabia, where it could be retie from natural gas that is recovered in the process of oil production and would otherwise be vented or flared. U.S. methanol production costs would be relatively high due to the high cost of U.S. natural gas. Because of the dominance of feedstock costs, the cost of producing methanol domestically would increase with demand.

50We have added $\$ 0.24$ per gallon for taxes, distribution to refueling stations, and retail markup. The gasoline-gallon equivalent price is estimated by assuming that a gallon of methanol is equivalent to 1.8 gallons of gasoline, based on the 2:1 ratio of gasoline to methanol energy content and a 10-percent improvement in energy efficiency with methanol. 
Table 7-II+Xet-Effectiveness of Alternative Fuel Use

\begin{tabular}{|c|c|c|c|c|}
\hline & $\begin{array}{l}\text { Fuel price } \\
\text { (\$/gas. } \\
\text { gal. equiv.) }\end{array}$ & $\begin{array}{l}\text { New vehicle } \\
\text { differential } \\
(\$)\end{array}$ & $\begin{array}{c}\text { Fleet cost- } \\
\text { effectiveness } \\
(\$ / \text { ton })\end{array}$ & $\begin{array}{c}\text { General cost- } \\
\text { effectiveness } \\
(\$ / \text { ton })\end{array}$ \\
\hline $\begin{array}{l}\text { Methanol blends .. } \\
\text { Straight methanol . } \\
\text { Dual-fuel CNG }{ }^{\mathrm{a}} . . \\
\text { Exclusive CNG . . }\end{array}$ & $\begin{array}{l}.1 .15-1.51 \\
.0 .85-0.95\end{array}$ & $\begin{array}{c}0-1,000 \\
500-1,500\end{array}$ & $\begin{array}{c}8,700-51,000 \\
3,200-18,000 \\
400-12,000 \\
0-7,400\end{array}$ & $\begin{array}{l}8,700-66,000 \\
3,200-22,000 \\
3,900-22,000 \\
1,600-14,000\end{array}$ \\
\hline
\end{tabular}

${ }^{3}$ Assumes 75 percent operation on CNG, 25 percent operation on gasoline.

NOTE: A retail gasoline price of $\$ 1.025$ per gallon is used to calculate fuel cost differentials.

SOURCE: Office of Techology Assessment, 1989.

pression costs $[46,17,36]$, we estimate that $\mathrm{CNG}$ would be sold to consumers at about $\$ 0.89$ to $\$ 0.99$ per gasoline-gallon equivalent. ${ }^{51}$ At these prices, use of CNG in fleet vehicles could save from $\$ 35$ to $\$ 130$ per vehicle per year. In general, light-duty vehicles' use of CNG could save $\$ 10$ to $\$ 50$ annually per vehicle.

As shown in table 7-11, if three-quarter time use of CNG in dual-fuel vehicles resulted in 56-percent reductions in VOC emissions overall (averaged over operation on gasoline and $\mathrm{CNG}$ ), the cost of using CNG would be $\$ 400$ to $\$ 22,000$ per ton of VOCs removed, depending on vehicle and fuel costs, and distance traveled (which determines how much fuel cost savings offset vehicle purchase costs). If 90-percent reductions could be realized with advanced vehicles operated exclusively on $\mathrm{CNG}$, use of CNG in fleets could result in a net savings, compared to gasoline, or cost up to $\$ 7,000$ per ton of VOCs removed; in the general population, costs would be $\$ 1,600$ to $\$ 14,000$ per ton.

\section{REFERENCES FOR CHAPTER 7}

1. Acurex Corp., California's MethanolProgram. Evaluation Report, Volume II: Technical Analyses, report P500-86-012A prepared for the California Energy Commission (Mountain View, CA: June 1987).

2. Acurex Corp., "Discussion Review of Draft Final Report and Findings, AB234 Economics Committee," presentation to the Advisory Board on Air Quality and Fuels (Sacramento, CA: Apr. 19, 1989).

3. Alson, J. A., 'The Emission Characteristics of Methanol and Compressed Natural Gas in Light Vehicles," paper 88-99.3, presented at the 81st Annual Meeting of the Air Pollution Control Association, Dallas, TX, June 19-24, 1988.
4. Austin, T. C., Sierra Research, letter to Richard Rapoport, Office of Technology Assessment, Mar. 17, 1989.

5. Automotive Fleet 1987 Fact Book, Volume 26 Supplement (Bobit Publishing Co., 1987).

6. Bohi, D.R., and Zimmerman, M. B., "An Update on Econometric Studies of Energy Demand Behavior," Ann, Rev. Energy 9:105- 154, 1984.

7. Bruetsch, R. I., Emissions, Fuel Economy, and Performance of Light-Duty CNG and Dual-Fuel Vehicles (Ann Arbor, MI: U.S. Environmental Protection Agency, June 1988).

8. California Air Resources Board, California's Post1987 Motor Vehicle Plan for Continued Progress toward Attainment of the National Ambient Air Quality Standards for Ozone and Carbon Monoxide1988 Update, Appendix IV-F, Draft Air Quality Plan 1988 Revision (El Monte, CA: September 1988).

9. California Air Resources Board, "Notice of Public Hearing to Consider the Adoption of Regulations Regarding Certification of Methanol-Fueled Motor Vehicles and Motor Vehicle Engines for Sale in the State of California" (El Monte, CA: March 1989).

10. California Energy Commission, Cost and Availability of Low-Emission Motor Vehicles and Fuels, Draft AB234 report (Sacramento, CA: April 1989).

11. Cambridge Systematic, Inc., Improved Air Quality in Maricopa and Pima Counties - the Applicability of Transportation Measures (Cambridge, MA: November 1986).

12. Clay, D.R., and Wilson, J. J., U.S. Environmental Protection Agency, letter to R.E. Farris, Nov. 8,1988.

13. Cohen, L.H., and Muller, H. L., "Methanol Cannot Economically Dislodge Gasoline," Oil and Gas Journal,83:1 19-124, 1985.

14. Dahl, C. A., "Gasoline Demand Survey," The Energy Journal 7:67-82, 1986.

15. Deakin, E., "Land Use and Transportation Planning in Response to Congestion: A Review and Critique, "

${ }^{51}$ Current forecasts project that natural gas prices will roughly track gasoline pricesthrough the year 2000 [45]. 
paper no. 880586, presented at the 68th Annual Meeting of the Transportation Research Board (Washington, DC: Jan. 22-26, 1989).

16. DeLuchi, M. A., Johnston, R. A., and Sperling, D., Transportation Fuels and the Greenhouse Effect, Universitywide Energy Research Group report UER182 (Davis, CA: University of California, December 1987).

17. DeLuchi, M.A., Sperling, D., and Johnson, R.A., A Comparative Analysis of Future Transportation Fuels, Research Report UCB-ITS-RR-87-13 (Berkeley, CA: Institute of Transportation Studies, University of California, October 1987),

18. Demmy, J.L., Tax, W. M., and Warn, T.E., Area Source Documentation for the 1985 National Acid Precipitation Assessment Program Inventory, pp. 55-59, B-107 to B-110, prepared for the U.S. Environmental Protection Agency, Office of Research and Development, EPA Contract 68-02-4274, Work Assignment Nos. 2 and 23 (Alliance Technologies Corporation, November 1987).

19. Demmy, J. L., Alliance Technologies Corporation, letter to Robert Friedman, Office of Technology Assessment, Aug. 19, 1988.

20. Energy and Environmental Analysis, Inc., Methanol's Potential as a Fuel for Highway Vehicles, draft contractor report prepared for the Office of Technology Assessment February 1987.

21. Jack Faucett Associates, Methanol Prices During Transition, report prepared for the U.S. Environmental Protection Agency (Bethesda, MD: September 1986).

22. Federal Highway Administration, Transportation and Air Quality: A Review of the 1982 State Implementation Plans (U.S. Department of Transportation, June 1983).

23. Federal Highway Administration, America's Challenge for Highway Transportation in the 21st Century, interim report of the Future National Highway Program Task Force, FHWA-PL-89-020 HPP-1-1188(2M)E (U.S. Department of Transportation, November 1988).

24. Flynn C.P., and Glazer, L., "Ten Cities' Approach to Transportation Demand Management," paper no. 880640, presented at the 68th Annual Meeting of the Transportation Research Board (Washington, DC: Jan. 22-26, 1989).

25. Guensler, R., "Compliance Perspectives on Transportation Control Measures: South Coast AQMD Regulation XV," presented at the 68th Annual Meeting of the Transportation Research Board (Washington, DC: Jan. 22-26, 1989).

26. Gushee, D.E., Carbon Dioxide Emissions from Methanol as a Vehicle Fuel, CRS report for Congress,
88-407 S (Washington, DC: Congressional Research Service, June 1988).

27. Gushee, D. E., and Sieg-Ross, S., The Role of Transportation Controls in Urban Air Quality, CRS 88-101 S (Washington, DC: Congressional Research Service, January 1988).

28. Higgins, T., "Parking Management and Traffic Mitigation in Six Cities: Implications for Local Policy," paper no. 880396, presented at the 68th Annual Meeting of the Transportation Research Board (Washington, DC: Jan. 22-26, 1989).

29. Information Resources, Inc., Alcohol Update (Washington DC: July 1988).

30. Litovitz, T., "Acute Exposure to Methanol in Fuels: A Prediction of Ingestion Incidence and Toxicity, " submitted, October 1988.

31. Martin, R. E., Transit and Parking: Public Policy, Report prepared for Senators Bradley, Lautenberg, D'Amato and Moynihan (Urban Mass Transportation Administration, U.S. Department of Transportation, February 1989),

32. Newman, P. W. G., and Kenworthy, J. R., "Gasoline Consumption and Cities: A Comparison of U.S. Cities With a Global Survey," J. American Planning Association 55:24-37, 1989.

33. Nichols, R.J., Clinton, E.L., King, E.T., Smith, C. S., and Wineland, R. J., "A View of Flexible Fuel Vehicle Aldehyde Emissions," SAE Technical Paper Series no. 881200 (Warrendale, PA: Society of Automotive Engineers, August 1988).

34. Pechan, E.H. and Associates, Inc., National Assessment of VOC, CO, and $\mathrm{NO}_{x}$ Controls, Emissions, and Costs, prepared for the Office of Policy Planning and Evaluation, U.S. Environmental Protection Agency, Contract No. 68-W8-0038 (Washington, DC: September 1988).

35. Seisler, J., American Gas Association, presentation at the Alternative Fuels for Vehicles Outlook Conference (Ames, IA: Iowa State University, June 15, 1988).

36. Seisler, J., American Gas Association, personal communication, April 1988.

37. Sierra Research, Inc., The Feasibility and Costs of More Stringent Mobile Source Emission Controls, contractor report prepared for the Office of Technology Assessment, Jan. 20, 1988.

38. South Coast Air Quality Management District and the Southern California Association of Governments, The Path to Clean Air: Attainment Strategies (El Monte, CA: December 1987).

39. South Coast Air Quality Management District, Draft Air Quality Management Plan, 1988 Revision, Appendices IV-A (incl. Addendum) and IV-C (El Monte, CA: May 1988). 
40. Southern California Association of Governments, Draft Air Quality Management Plan, 1988 Revision, Appendix IV-G, "Transportation, Land Use, and Energy Conservation Measures" (Los Angeles, CA: September 1988).

41. Southern California Association of Governments, Regional Mobility Plan, draft report (Los Angeles, CA: October 1988).

42. SRI International, "The Economics of Alternative Fuels and Conventional Fuels," presentation to the Advisory Board on Air Quality and Fuels (Sacramento, CA: Feb. 2, 1989).

43. State and Territorial Air Pollution Program Admininis tratorsAssociation of Local Air Pollution Control Officials, The STAPPA-ALAPCO National Ozone Control Strategy, Executive Summary, May 1988.

44. U.S. Department of Commerce, Bureau of the Census, County Business Patterns 1985-United States, CBP-85-1 (Washington, DC: U.S. Government Printing Office, November 1987).

45. U.S. Department of Energy, Annual Energy Outlook 1987, DOE/EIA-0383(87) (Washington, DC: March 1988).

46. U.S. Department of Energy, Assessment of Costs and Benefits of Flexible and Alternative Fuel Use in the U.S. Transportation Sector. Progress Report One: Context and Analytical Framework (Washington, DC: January 1988).

47. U.S. Department of Energy, Monthly Energy Review (Washington, DC: September 1988).

48. U.S. Department of Transportation, Personal Travel in the U.S., Volume I (Washington, DC: August 1986).

49. U.S. Department of Transportation, Personal Travel in the U.S., Volume II (Washington, DC: November 1986).

50. U.S. Department of Transportation, Federal Register 53:35178-35185, notice of proposed rulemaking, Sept. 9, 1988.

51. U.S. Environmental Protection Agency, Office of Transportation and Land Use Policy, Transportation and Air Quality (Washington, DC: July 1981).
52. U.S. Environmental Protection Agency, Federal Register 54:14425-14612, Apr. 11, 1989.

53. U.S. Environmental Protection Agency, Cost and Cost Effectiveness of Alternative Fuels, prepared for the Vice President's Task Force on Alternative Fuels, July 1987.

54. U.S. Environmental Protection Agency, Federal Register, Nov.17, 1987.

55. U.S. Environmental Protection Agency, Federal Register 53:30566-30602, Aug. 12, 1988.

56. U.S. Environmental Protection Agency, Guidance on Estimating Motor Vehicle Emission Reductions from the Use of Alternative Fuels and Fuel Blends, EPA-AA-TSS-PA-87-4 (Research Triangle Park, NC: January 1988).

57. U.S. Environmental Protection Agency, Office of Air Quality Planning and Standards, Summary of State VOC Regulations, EPA-450/2-85-O03 (Raleigh, NC: April 1985).

58. U.S. Environmental Protection Agency, Office of Air Quality Planning and Standards, Summary of State VOC Regulations-Volume 2, Group III CTG and Greater Than 100 Ton Per Year Non-CTG VOC Regulations, EPA-450/2-88-004 (Raleigh, NC: May 1988).

59. U.S. Environmental Protection Agency, Office of Research and Development, Anthropogenic Emissions Data for the 1985 NAPAP Inventory - Final Report, prepared for the National Acid Precipitation Assessment Program, EPA-600/7-88-022 (Springfield, VA: National Technical Information Service, November 1988). 
Chapter 8

\section{Policy Options}




\section{CONTENTS}

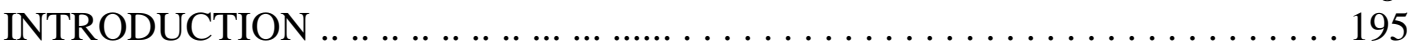



Deadlines ....................................................... 195

Interim Requirements. ........................................... 201

Penalties and Corrective Actions in the Event of Failure . . . . . . . . . . . . . . . . . . . 204

State and Local Planning Requirements . . . . . . . . . . . . . . . . . . . . . . . . . . 206

Research ............................................... 210

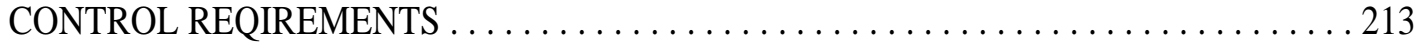

Federally Implemented, Nationwide Control Requirements . . . . . . . . . . . . . . 213

Control Requirements To Be Implemented by States in Nonattainment Areas . . . . . . 216

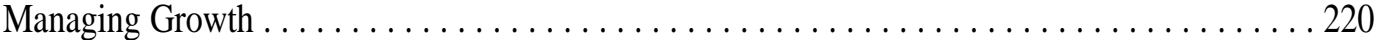

NEW DIRECTIONS FOR THE CLEAN AIR ACT . . . . . . . . . . . . . . . . . 221

Controls on Emissions of Nitrogen Oxides in Nonattainment Areas . . . . . . . . . . . . . . 222

Controls in Upwind AReas . . . ..................................... 224

Reducing Ozone in Rural Attainment Areas. . . . . . . . . . . . . . . . . . . ..... 227

Long-Term Control Strategies for Chronic Nonattainment Areas . . . . . . . . . . . . . 228

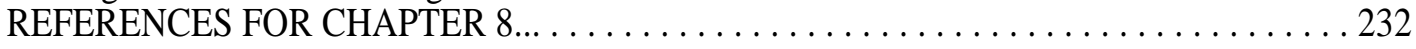

\section{Tables}

Table Page

8-1. Options for Amending the Clean Air Act: Overall Requirements . . . . . . . . . . 196

8-2. Options for Amending the Clean Air Act: Currently Available Control Methods . 197

8-3 Options for Amending the Clean Air Act New Directions . . . . . . . . . . . . . . . . . 197

8-4 Time Requirements for SIP Process Under the 1977 Clean Air Act Amendments . 198

8-5 Sanctions for Failure To Meet the Requirements of the Clean Air Act . . . . . . . . . . . 204

8-6 VOC Sources For Which Nationwide Regulations Exist.. . . . . . . . . . . . . . . . . . . . . . 214

8-7 Options for New Car and Light-Duty Truck Exhaust Standards . . . . . . . . . . . . . . . . . 215

8-8 VOC Sources For Which EPA Has Issued Control Technique Guidelines . . . . . . . 217 


\section{INTRODUCTION}

More than 10 years have gone by since the passage of the last major set of amendments to the Clean Air Act. While some progress has been made in reducing $\mathrm{VOC}$ emissions and lowering ozone concentrations, most major metropolitan areas still do not meet the ozone standard. Ozone has been the most difficult of the major air pollutants to control over the almost 20-year history of the Clean Air Act. The Nation has failed several times to meet the attainment deadlines set by Congress in the Clean Air Act-first in 1975 and again in 1982 and 1987.

One of the most important findings of our assessment is that about half of the nonattainment cities will still not be able to attain the standard with currently available VOC control measures. According to our calculations, most areas with peak ozone concentrations above $0.16 \mathrm{ppm}$ will not be able to attain the standard with existing VOC controls. Some areas with even lower peak concentrations may have great difficulty, as well. These include: cities that are heavily affected by pollution transported from neighboring areas, cities that have already implemented most of the available VOC control measures, and cities where ozone levels are more sensitive to $\mathrm{NO}_{\mathrm{x}}$ emissions, for example, southern cities that are surrounded by areas with high emissions of VOCs from natural sources.

If Congress once again sets ambitious near-term targets for the next decade, but ignores the decade that follows, we will likely fail one more time. An effective ozone strategy must incorporate two components: 1) measures to address near-term VOC reductions possible with currently available control methods and 2) measures to ensure that we can continue to make progress after the year 2000, when many areas will still exceed the standard even after substantial emissions reductions are made in the next 5 to 10 years.

In this final chapter, we present options for Congress in three broad categories. First we present options for overall requirements, including deadlines for attaining the standard; interim requirements to ensure continuing progress towards attainment; and penalties in the event of failure. We also present options for State planning, and for further research. Table 8-1 outlines these more general policy decisions facing Congress and the options that we present.

We then provide options for the near-term VOC reductions that are possible using currently available control methods. Because air pollution control under the Clean Air Act relies on a partnership between EPA and the States, these fall naturally into two categories: a list of federally implemented, nationwide control requirements and control requirements to be implemented by the States. The section concludes with options for managing emissions growth in nonattainment areas. An outline of these options is found in table 8-2.

Because many areas will not be able to attain the ozone standard by relying solely on currently available VOC control measures, we discuss some new directions for the Clean Air Act in the final section. These include controls on nitrogen oxides in nonattainment areas, controls on both nitrogen oxides and VOCs in upwind areas, and several alternatives for long-term strategies for the worst nonattainment areas. We also present options for lowering ozone concentrations in rural areas to protect crops and forests. Table 8-3 summarizes the options discussed in this final section.

\section{OVERALL REQUIREMENTS}

\section{Discussion}

\section{Deadlines}

The 1977 Amendments established two major categories of nonattainment areas, each with its own attainment deadline. Areas with less severe problems were to attain the standard within 5 years, by the end of 1982. Those areas that could not attain the standard by the end of 1982 by adopting all reasonably available control measures were given an additional 5 years. However, by December 1987, the deadline for all areas to attain the standard, more than 60 areas were still not in compliance.

Congress is once again faced with the problem of setting new deadlines. An important finding of our 
Table 8-I-Options for Amending the Clean Air Act:Overall Requirements

\section{Deadlines:}

Decision 1: How many categories of nonattainment areas, each with its own deadline and other requirements, should be established?

Option 1: Two categories-those that can attain the standard with currently available controls and those that cannot.

- Option 2: Three or more categories, including more than one category of areas that cannot attain with currently available controls.

Decision 2: What deadline should be set for those areas that can attain the standard with currently available contro methods?

Option 1: Maintain the Act's current 5-year schedule from start of planning to attainment.

Option 2: Require detailed inventories, modeling, and planning and allow 5 to 7 years.

Decision 3: What deadline(s) should be set for those areas that cannot attain the standard with currently available control methods?

Option 1: 8 to 10 years for the "best" of the areas that cannot attain with currently available control measures; at least 20 years for the "(worst" (Los Angeles).

Option 2: Eliminate deadlines.

\section{Interim Requirements:}

Decision: What interim requirements are needed to ensure continuing progress towards attainment?

Option 1: Interim air quality targets.

Option 2: Areawide emission reduction schedules.

Option 3: Source-specific controls.

- Option 4: Some combination of the above options.

Penalties and corrective actions in the event of failure:

Decision 1: For what kinds of failures should States be penalized?

Option 1: Sanctions for failing to make "sufficient" efforts.

Option 2: Sanctions for failing to identify enough controls to meet a congressionally specified reduction schedule.

- Option 3: Sanctions for failing to attain the standard by the required date or to meet an interim requirement.

SOURCE: Office of Technology Assessment, 1989.

assessment is that many areas will not be able to attain the standard with the adoption of "currently available" control methods. Thus when considering potential attainment deadlines, Congress must once again address two separate questions:

. What is an appropriate deadline for those areas that are now close enough to meeting the standard that they can do so using currently available control methods?
Decision 2: What types of sanctions should be adopted?

. Option 1: Sanctions that limit growth in nonattainment areas, fo example, a ban on construction of new sources of pollution or a moratorium on hookups to publicly owned drinking water distribution systems or sewage treatment systems.

-Option 2: Limits on Federal assistance, for example, withholding Federal highway funds (except those for safety, mass transit, and transportation improvement projects related to air quality) or sewage treatment grants.

Decision 3: What types of corrective actions should be adopted? Option 1: Planning requirements.

Option 2: Source-specific controls.

- Option 3: Market-based control programs, for example, emissions fees or marketable emissions permits.

State and local planning requirements:

Decision 1: What types of planning should be required and where?

Ž Option 1: Minimal requirements for all nonattainment areas.

Option 2: Enhanced efforts in areas with the worst ozone problems or atypical conditions.

Decision 2: Who pays for enhanced State and local planning activities?

Option 1: Increase funding for section 105 grants or make special, separate appropriations for ozone nonattainment area planning.

-Option 2: Develop a nationwide user-fee program (administered by EPA) or a fee requirement (administered by the States) on nonattainment area emissions.

Research:

Decision 1: What areas of research deserve increased funding?

- Improving the planning process, developing new control methods, and further evaluating the risks from ozone.

Decision 2: Who pays for the research?

- Option 1: General revenues.

. Option 2: User fees.

'These are control methods that are well enough understood that weare able to estimate their emission reduction potential ancosts. While we are certain that some additional controls are possible, we believe that the large majority of VOC emissions reductions possible with currently available control methods are accounted for in our analysis.

. What is an appropriate deadline or set of deadlines for areas that cannot meet the standard with currently available control methods?

Both EPA and STAPPA/ALAPCO (the State and Territorial Air Program Administrators, which represents State-level air pollution regulators, and the Association of Local Air Pollution Program Administrators, representing local regulators) have stated that about 5 years is an appropriate timeframe for areas that can meet the standard with currently 
Table 8-2-Options for Amending the Clean Air Act: Currently Available Control Methods

\author{
Federally implemented, nationwide \\ control requirements: \\ . Option 1: Limits on gasoline volatility. \\ . Option 2: More stringent tailpipe exhaust standards for cars and \\ trucks. \\ . Option 3: "Onboard" technology for cars and trucks to control \\ refueling emissions. \\ . Option 4: Federal solvent regulations, for example, for architec- \\ tural coatings.

\section{Control requirements to be implemented by States} \\ in nonattainment areas: \\ - Option 1: Lowered source-size cutoff for requiring "reasonably \\ available control technology" (RACT). \\ Option 2: Require EPA to define RACT for additional source \\ categories. \\ - Option 3: More stringent requirements for motor vehicle \\ inspection and maintenance programs. \\ - Option 4: Required use of alternative fuels by centrally owned \\ fleets. \\ - Option 5: Transportation control measures. \\ - Option 6: Tax on gasoline.

\section{Managing growth:} \\ - Option 1: Lower the cutoff for new source control requirements. \\ Option 2: Eliminate "netting" out of new source control \\ requirements. \\ - Option 3: Areawide emission ceilings. \\ SOURCE: Office of Technology Assessment, 1989.
}

available control measures to both plan and implement emissions reductions [15,22]. For those areas where currently available controls will not be sufficient, EPA has proposed to require a 3 percent per year reduction in VOC emissions. Under the resulting schedule, some of the worst areas might take over 20 years to attain the standard.

When addressing the question of timing, there are several factors that Congress might wish to consider. First, sufficient time must be allowed for planning and other administrative requirements under the Clean Air Act. The amount of time Congress allowed for planning in the 1977 Amendments turned out to be about half the time required. Once controls are mandated, sufficient time must be allowed for them to be implemented. For those areas that cannot meet the standard with currently available measures, Congress must allow time for new methods to be developed. Finally, Congress must weigh the urgency of the problem against the difficulty of the task. Allowing more time for development and implementation of control measures might reduce their cost or facilitate their
Table 8-3-Options for Amending the Clean Air Act: New Directions

\section{Controls on emissions of nitrogenoxides in}

nonattainment areas:

. Option 1: Congressionally mandated $\mathrm{NO}_{x}$ controls.

- Option 2: Presumptive $\mathrm{NO}_{x}$ controls on stationary sources, with

EPA authority to exempt areas under specified situations

- Option 3: Requirements to analyze $\mathrm{NO}_{x}$ controls under certain situations.

Controls in upwind areas:

- Option 1: Enlarge nonattainment areas to include the entire extended metropolitan area.

Option 2: Congressionally specified $\mathrm{NO}_{x}$ controls in designated "transport regions" or nationwide.

- Option 3: Strengthen the interstate transport provisions of the Clean Air Act.

- Option 4: Provide EPA with clear authority to develop regional control strategies based on regional-scale modeling.

Reducing ozone in attainment (rural) areas:

- Option 1: Specify a deadline for EPA reconsideration of the ozone secondary standard and a schedule for Option by the States.

Option 2: Congressionally specified $\mathrm{NO}_{x}$ controls.

Long-term VOC control strategies:

. Option 1: Lowering emissions from solvents, either through traditional engineering approaches or through market-based mechanisms.

- Option 2: Transportation control measures.

- Option 3: Requirements for widespread use of alternative fuels in nonattainment areas that are far from meeting the standard.

SOURCE: Office of Technology Assessment, 1989.

acceptance. However, allowing more time also means that more people will be exposed to concentrations above the standard. Each of these factors is discussed in greater detail below.

\section{Factors to Consider When Choosing Deadlines}

How Much Administrative Lead Time Is Necessary?-History is probably the best guide to the amount of time required to complete the process of State planning for emissions reductions and for subsequent EPA approval. Under the 1977 Clean Air Act Amendments, EPA was to identify and list nonattainment areas by early 1978. The States had to revise plans for each of their nonattainment areas and submit SIPS to EPA by January 1, 1979, about 16 months after enactment. EPA was required to approve or disapprove these plans by June 30, 1979, 6 months after the States submitted them.

EPA and the States did not succeed in meeting many of the deadlines established in the 1977 Amendments. By April 1980, 15 months after they 
were due, SIPS had been submitted for only about 20 percent of the areas. Half of these were either incomplete or considered deficient by EPA [9]. This failure to have SIPs developed and approved in the time allotted continued through the 1980s.

Table 8-4 displays the SIP actions required of the States and EPA, and compares the amount of time allowed by Congress in the 1977 Amendments with the amount of time it actually took to complete these actions. As the table shows, the time frame specified by Congress was substantially exceeded by the States and EPA, Rather than taking a little under 2 years from enactment to approval or disapproval of a SIP, as required under the 1977 Amendments, the entire process took about 3 to $4 \frac{1}{2}$ years.

Three years seems to be a reasonable allowance for the time needed between EPA's call for revision of a SIP to EPA approval, assuming the type of planning undertaken is similar to that followed under the 1977 Amendments. An extra year or two should be added if more detailed inventorying, modeling, and planning are required. The advantages and disadvantages of enhanced planning requirements are discussed in a later section.

How Quickly Can Emissions Be Lowered?Once the planning process is complete, time must be allowed for controls to be implemented. For control methods that are well understood and can be applied to existing sources, a year or two could be sufficient. For example, the San Francisco Bay Area Air Quality Management District allowed gas stations 7 months to install devices to capture gasoline vapors lost during refueling. Large drycleaners were given 21 months to install control devices, once regulations were issued. Smaller facilities were given an additional 1 or 2 years. Most available controls fall into this category-of the emissions reductions we were able to identify, about 35 percent are available now and could be implemented and effective within a few years.

Other controls, however, require a much longer lead time. Lowered exhaust emission standards for

Table 8-4-Time Requirements for SIP Process Under the 1977 Clean Air Act Amendments

\begin{tabular}{|c|c|c|c|}
\hline Action & Required time & Actual time & Difference \\
\hline $\begin{array}{l}\text { 1. Designation of } \\
\text { a State's attainment } \\
\text { status }\end{array}$ & $\begin{array}{l}6 \text { months } \\
\text { (from promulgation } \\
\text { of Amendments) }\end{array}$ & 8 months & 2 months \\
\hline $\begin{array}{l}\text { 2. States' development } \\
\text { of technical database }\end{array}$ & & $\begin{array}{l}3 \text { to } 6 \text { months minimum } \\
15 \text { to } 24 \text { months maximum }\end{array}$ & \\
\hline $\begin{array}{l}\text { 3. State submission } \\
\text { of revised SIP } \\
\text { (development of new } \\
\text { ozone control strategy } \\
\text { and adoption of regulations } \\
\text { by State or local agency) }\end{array}$ & $\begin{array}{l}\text { By January 1, } \\
1979 \text { (10 months } \\
\text { from attainment } \\
\text { designation) }\end{array}$ & 19 to 33 months ${ }^{b c d}$ & 9 to 23 months \\
\hline $\begin{array}{l}\text { 4. EPA review and } \\
\text { approval or disapproval } \\
\text { of SIP }\end{array}$ & $\begin{array}{l}\text { Act allows } 6 \text { months } \\
\text { between date SIPS } \\
\text { were due }(1 / 79) \text { and } \\
\text { date construction } \\
\text { ban was to have } \\
\text { been imposed }(6 / 79)\end{array}$ & 9 to 24 months $^{\text {be }}$ & 3 to 18 months \\
\hline Total time & $\begin{array}{l}22 \text { months } \\
\text { (1.8 years) }\end{array}$ & $\begin{array}{l}36 \text { to } 53 \text { months } \\
\text { ( } 3.0 \text { to } 4.4 \\
\text { years) }\end{array}$ & $\begin{array}{l}14 \text { to } 43 \text { months } \\
\text { (1.2 to } 3.6 \\
\text { years) }\end{array}$ \\
\hline
\end{tabular}

"Study of the 1979 State Implementation Plan Submittals: An overview of the SIP Review Process at the State Level and the SIPS for Particulate Mattar, Sulfur Dioxide and Ozone,"

Pacific Environmental Services, ho., for the National Commission on Air Quality, December 1980.
bpacific Envirommental Services, $l_{l}$ e., Study of the 1979 State Implementation Plan Submittals (Washington, DC: National Commission on Air Quality, December 1980)

CNational Commission on Air Quality, To Breathe Clean Air (Washington, DC: March 1981).

d Many States started working on SIP revisions as early as 1975 or 1976, about 12 t. 26 months before the 1977 Clean Air Act Amendments. This time was not included In the 19- to

"Comments of particlpant in OTA" listed for Action \#3.

SOURCE: Office of Technology Assessment, 1969. 


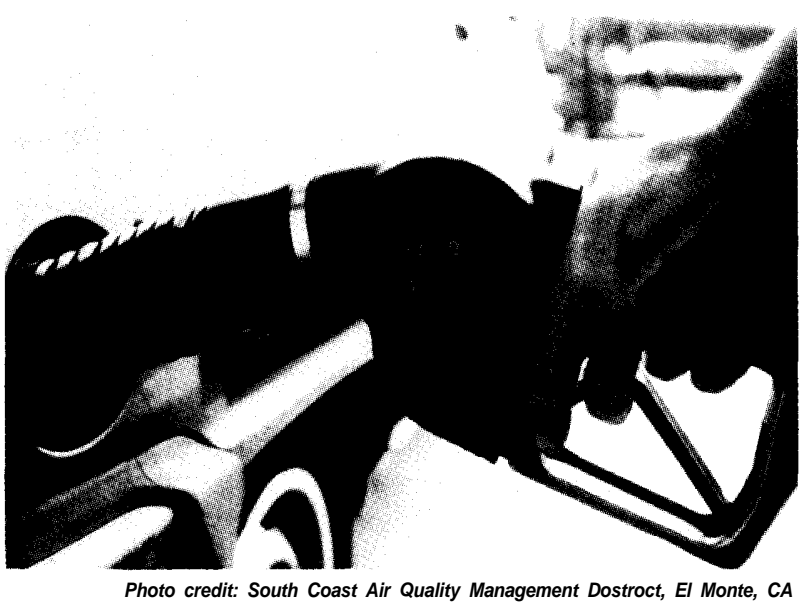

Stage II control devices installed on service station pump nozzles help control the release of gasoline vapors during motor vehicle refueling, Such devices can be installed and working in under a year from the time regulations are promulgated. Another method of controlling refueling emissions, installing canisters directly "onboard" cars, requires about a decade to take full effect.

new cars require over a decade to take full effect. About 4 years of lead time is needed for manufacturers to bring cars equipped with additional controls to market. After another 5 years, enough new cars will have been purchased so that about half the cars on the road will have the new controls. Replacement of the second half will take even longer.

The greatest uncertainty, of course, surrounds the time needed to develop new control methods. For example, close to 20 percent of VOC emissions come from a variety of solvent uses. For many of these uses, reformulated products, substitutions, or process changes might be used to lower emissions. We have no way of anticipating how long it will take to develop these alternatives. The deadlines that Congress sets will certainly influence the rate of development of new control methods, but Congress cannot be assured that any deadline can be met.

How Urgent is the Problem?-Human exposure to ozone primarily affects the lungs. Ozone has been shown to cause immediate, short-term changes in lung function and increased respiratory symptoms, and is suspected of playing a role in the long-term development of chronic lung diseases. The immedi- ate or "acute" effects may include some breathing difficulty and coughing, but such effects appear to be reversible, usually disappearing after a few hours.

Although the short-term effects are important, many health professionals appear to be more concerned that repeated exposure to ozone over a lifetime may result in permanent respiratory impairment. Since ozone damages the tissues lining the airways of the lung, ozone could play a role in accelerated aging of the lung, retardation of lung development in children, or the development of pulmonary fibrosis, a chronic lung disease. We are not yet able to confirm or dismiss many of the concerns about these effects.

The Clean Air Act has set a societal goal of achieving air quality necessary "to protect the public health ... with an adequate margin of safety. "The Administrator of EPA is responsible for setting national ambient air quality standards based on health effects information alone, with no consideration of the difficulty of achieving them. While there is certainly some disagreement about the precise concentration at which the standard should be set, ozone concentrations in many major U.S. cities are well above the range of controversy on at least a few days each year.

Without explicit direction from Congress that avoiding the types of effects described above is no longer a societal goal-and there are few indications that society as a whole feels that this is the case-the ozone standard is unlikely to be relaxed. Rather, since recent studies point to health effects at concentrations below the standard when exposure occurs over several hours, if the standard is changed it is likely to be tightened.

However, Congress sets not only the level of protection that the standard is to achieve, but the date by which it is to be met. In this latter decision Congress cannot avoid some balancing of the magnitude of the health problem with the costs and difficulty of achieving the standard. At issue is not just how quickly areas must install well-understood control technology, but also how quickly new technology can be developed and whether too short a schedule will result in wasted resources or less efficient or socially acceptable control methods. An 
understanding of how many people are affected by ozone, and how seriously they are affected, can help with this decision.

No doubt, most Members and staff have heard many conflicting statements about the seriousness of the ozone problem. Some people have characterized it as a problem that affects a few asthmatic joggers who do not have the good sense to avoid running on a few hot, smoggy afternoons each year. Others state that it is a major public health problem adversely affecting over 100 million Americans.

While it is true that over 100 million people live in U.S. cities that do not meet the ozone standard, not everyone is in the right place at the right time to be exposed to concentrations above the standard. Taking into account when and where people are outdoors, we estimate that about 25 percent of people who live in these cities are actually exposed to ozone concentrations above the standard. Even then, ozone is thought to be a problem primarily when people are exercising. We estimate that about 20 million people are exposed to concentrations above the standard while exercising at moderate levels of exertion and that on average, these people are exposed about 9 hours per year. Of course, the number of hours of exposure varies considerably by region.

In chapter 3 , we attempt to quantify many of the health improvements one can expect from lowering ozone levels. We estimate that if ozone concentrations were lowered enough to meet the standard in all areas, about 110 to 350 million cough incidents each year, and about 60 to 200 million incidents each of shortness of breath and chest pain, might be avoided each year. About 8 to 50 million "restricted activity days" might also be eliminated. These are days when someone feels ill enough to disrupt most of the day's activities, but generally not to spend the day in bed or stay home from work. About 2 million days of asthma attacks would also be eliminated.

These health benefits become more meaningful when expressed on a per person basis. For example, among every 100 people, averaged across all nonattainment areas, meeting the standard would eliminate about 100 to 300 cough episodes per year. However, the average improvement varies considerably from nonattainment area to nonattainment area, depending on the severity of the ozone problem. In those areas where peak ozone concentrations are close to the standard (between 0.12 and $0.14 \mathrm{ppm}$ ), meeting the standard would eliminate about 15 to 55 cough episodes per year and about 3 days of restricted activity among every 100 people. In those areas with the worst ozone problems, meeting the standard would eliminate 400 to 1,400 cough episodes per year and about 120 days of restricted activity, among every 100 people.

Unfortunately, we cannot similarly add up the longer term, chronic effects of exposure to ozone that would be avoided if ozone levels were lowered. Whether there are chronic effects from exposure over many years and, if so, their magnitude, is still unknown. This too, must be factored into the congressional decision on setting attainment deadlines.

\section{Options}

\section{Decision 1: How many categories of nonattain- ment areas and associated deadlines should be established?}

\section{Option 1: Two categories.}

At a minimum, Congress must establish two categories of nonattainment areas, recognizing that while many areas will be able to attain the standard with currently available control methods, many will not. Congress could directly specify the dividing line, for example, based on each area's "design value" (a measure of peak ozone concentrations), which is a reasonable predictor of the reductions necessary to attain the standard. OTA estimates that the dividing line falls somewhere between design values of 0.15 and $0.16 \mathrm{ppm}$, that is, most cities with design values of $0.16 \mathrm{ppm}$ or greater will not be able to attain the standard with currently available VOC control methods. Alternatively, Congress could require EPA to make a determination of the likelihood of each area being able to attain the standard using known control methods.

\section{Option 2: Three or more categories.}

Congress may want to divide nonattainment areas that cannot attain the standard with known technology into three or more categories, based on the severity of the problem. 


\section{Decision 2: What deadline should be set for those areas that can attain the standard with currently available control methods?}

Option 1: Maintain the Act's current 5 year schedule from start of planning to attainment.

Under the 1977 Clean Air Act Amendments, Congress allowed 5 years for those areas that were able to meet the standard with the "application of reasonably available control measures." Though many areas took longer than 5 years to achieve the reductions specified in their SIPS, the timeframe seems reasonable, assuming that the planning process remains about as complex as is currently required. As mentioned above, both EPA and STAPPA/LAPCO, the associations of State and local air program administrators, have proposed timeframes of about 5 years.

Option 2: Require detailed inventories, modeling and planning and allow 5 to 7 years.

Allowing additional time for detailed inventories, modeling and planning will help identify those areas that at first might appear to be able to meet the standard by applying currently available technology, but because of atypical conditions (e.g., areas with unusually predominant sources of one type or significant emissions from vegetation) will need to identify additional VOC controls, controls in upwind areas, or possibly undertake $\mathrm{NO}_{\mathrm{x}}$ reductions. While a simpler planning process will be adequate for many nonattainment areas with low design values, the simpler process can yield overly optimistic results in some atypical nonattainment areas.

In those areas that actually can meet the standard using currently available controls, allowing additional time for detailed planning and modeling might prevent some overcontrol in some areas or identify more cost-effective emissions reductions. The disadvantage of such an approach is that ozone concentrations could remain high longer. The benefits and costs of detailed planning exercises are discussed in a later section of this chapter.

Decision 3: What deadline(s) should be set for those areas that cannot attain the standard with currently available control methods?

Under the 1977 Amendments, Congress chose 10 years as the appropriate timeframe for meeting the standard in those nonattainment areas that could not do so with control measures "reasonably available" in 1977. Assuming appropriate incentives exist so that new control methods will be developed, the additional 5 years over and above the time needed for basic planning and implementation should allow some areas to attain the standard. However, in many areas the shortfall between emissions reductions needed and currently available is so large that considerably longer time may be needed. For example, the Los Angeles region, the worst nonattainment area in the country, anticipates that at least 20 years are needed to develop and implement the control measures necessary for it to attain the standard.

Option 1:8 to 10 years for the "best" of the areas that cannot attain with currently available control measures; at least 20 years for the "worst."

The amount of time necessary to develop new control methods is simply not known. Shorter time frames might be achieved with additional Federal $\mathrm{R} \& \mathrm{D}$ funds (discussed in a later section) and careful attention to the penalties of missing the deadline. The very real possibility of missing these deadlines must be accepted, however.

\section{Option 2: Eliminate deadlines.}

In its 1981 report, the National Commission on Air Quality (established by Congress under the 1977 Clean Air Act Amendments to analyze strategies for achieving the goals of the Act) recommended that deadlines be eliminated. In their place, they recommended a technology driven process. Every 3 years, EPA would identify additional reasonably available control technologies. Remaining nonattainment areas would be required to adopt those controls or measures that would lead to equivalent reductions.

The advantages and disadvantages of available substitutes for deadlines are discussed below under the section on "Interim Requirements."

\section{Interim Requirements}

\section{Discussion}

As described above, the 1977 Clean Air Act Amendments required nonattainment areas to attain the standard within 5 or 10 years. Though the Amendments also included some requirements for 
annual increments of emissions reductions, in practice, this requirement seems to have had little effect. There were few Federal requirements that the States had to meet between the time plans were submitted and the eventual 5- or 10-year deadline.

Many of the recent proposals to amend the Act have specified "interim" requirements. Because many of the proposals would allow more time to meet the standard than the 1977 Amendments, the need for some type of interim milestone is greater.

There are two distinct purposes for interim requirements: 1) to establish the minimum level of effort towards attaining the standard and 2) to establish a mechanism for tracking progress and taking early corrective action. Both the form of the interim requirements and the types of sanctions applied for failure to meet them depend on which of these two goals one is trying to achieve.

Congress could choose among three types of interim requirements: 1) air quality targets, for example, lowering ozone concentrations half of the way between current levels and the standard by a specified date, 2) areawide emission reduction requirements, for example, requiring a 10 or 15 percent reduction in VOC emissions every 3 years, and 3) source-specific technology or performance standards. The advantages and disadvantages of the three approaches are discussed below.

\section{Options}

\section{Option I: Interim air quality targets.}

Rather than setting only one air quality targetattaining the standard by a specified date-Congress could establish one or more additional air quality levels that must be met by earlier dates. These might be specified in the same form as the standard-i. e., peak concentrations must be lower than a specified target - or by using a different indicator of air quality, for example, number of exceedances of the standard each year.

Air quality measurements are the most direct way to determine whether progress is being made towards meeting the goal of the Act. If fewer exceedances of the standard or lower peak ozone concentrations are measured-and enough years have been averaged to have overcome year-to-year climatic variability-one can be confident that an increment of progress has been made. Uncertainties about emissions inventories, air quality models, and implementation effectiveness are all avoided.

Unfortunately, feedback about whether progress is being made can be delayed by several years. Several years of monitoring data must be averaged to be assured that the progress observed is not due to a somewhat cooler summer or similar, natural fluctuation. It may be possible to correct for such variation, but the approach would lose some of its attractiveness-its direct relationship to what is measured at an air quality monitor.

If one of the purposes of adopting an interim requirement is to have a yard stick against which to judge each State's performance-and penalize those that are not moving quickly enough-an air quality target may be an inappropriate choice. Success meeting the target depends on efforts of both State and Federal regulators and an accurate understanding of the science of ozone formation. Thus some feel it is unfair to penalize a State in the event of failure to meet the target if the fault is not clearly identified as the State's.

However, if the purpose for adopting an interim requirement is to identify that something is not working as planned and to signal the need for an examination of the cause of failure, an air quality target is highly appropriate. Thus rather than linking a failure to achieve the target to a sanction, Congress might consider linking it to a requirement to reopen the planning process.

Option 2: Areawide emission reduction schedules.

A second option for an interim requirement is a schedule of areawide total emission reductions. In 1977, Congress added a provision to the Act that required areas to achieve "annual incremental reductions in emissions ... sufficient in the judgment of the Administrator" to attain the standard within 5 or 10 years. A somewhat different approach has been proposed by both EPA and several bills introduced in the 100th Congress. Directly specified rates of progress -3 percent to 5 percent per year, depending on the proposal-are required of most areas. Rather than "back calculating" the rate of progress needed to attain the standard by a specified date, the new proposals opt for a rate of progress 
based on a judgment of a reasonable rate to implement (and in many cases, both develop and implement) new emission controls.

One of the reasons for the popularity of this approach is that it is not affected by the uncertainties inherent to modeling future air quality. States are given an identifiable target over which they feel they have direct control. Success or failure to meet the target is judged by whether the State achieved the reductions stated in their plan, not whether the air quality model used in the plan proves to be scientifically accurate.

Moreover, the approach retains considerable flexibility for the States. Assuming enough control alternatives exist for a State to have a choice, source categories that might be particularly difficult or expensive to control in a given nonattainment city could be left alone. This type of requirement is well suited to a market-based approach to reducing emissions, should Congress or the States decide to adopt one.

There are, however, some disadvantages to this approach, as well. Some State agencies may not have sufficient expertise to design the regulations needed to meet their emission reduction schedule. Others may not have the political clout necessary to require the new regulations. For such States, a list of federally prescribed regulations would be preferable.

In addition, emissions inventories can be "gamed," that is, reductions can be exaggerated by using overly optimistic assumptions about the level of control actually achieved. Gaming of SIPS submitted after the Clean Air Act Amendments of 1977 is often given as one reason for the failure of some areas to achieve the reductions they needed to attain the standard.

\section{Option 3: Source-specific controls.}

A third option for an interim requirement is for Congress to directly specify controls for specific source categories, and to direct the Administrator of EPA to issue appropriate regulations. States would be required to adopt the specified controls, for example, inspection and maintenance programs for motor vehicles, by a specified date.
STAPPA/ALAPCO, the associations of State and local air pollution regulators, is one of the foremost advocates of this approach. Federal assignment of the source categories that must control their emissions and the degree of control removes the burden of making these assignments from the States. This would be most helpful in those States with minimal expertise in designing regulations and in States where legislatures have been hesitant to approve regulations not specifically required by EPA. In addition, under this option, States know exactly what they are required to do. Failures to achieve the interim target are relatively easy for EPA to identify, and clearly the responsibility of the State, not the fault of a modeling error.

Industry often prefers this approach as well, especially if the control requirements are specified by EPA through agency rule-making rather than directly by Congress. The rule-making process provides greater protection that the controls are feasible.

From another point of view, however, this approach imposes a very large burden on EPA to come up with new methods of lowering emissions. There are no incentives for industry to actively develop new control methods, as there would be if they were required to meet a progressively tightened schedule of emissions reductions.

Possible candidates for congressionally specified controls are included in a later section, "Control Requirements."

Option 4: Some combination of the above options:

Congress might choose to combine some or all of the interim requirements discussed above to take advantage of the strengths of each. For example, Congress might require several particularly costeffective, source-specific controls to be implemented by an early date. A congressionally specified percentage reduction in emissions might apply until attainment. For the worst nonattainment areas, Congress might also add an interim air quality target, to keep the program firmly linked to identifiable improvements in air quality. 


\section{Table 8-5-Sanctions for Failure To Meet the} Requirements of the Clean Air Act

1. For failure of a state to submit inadequate SIP by the required date:

a. Section 110 requires the Administrator of EPA to prohibit the construction of major stationary sources in nonattainment areas if a SIP revision is inadequate.

b. Section 176(a) requires the EPA Administrator to withhold Federal highway funds, except those for safety, mass transit, and transportation improvement projects related to air quality. EPA interprets this sanction to be dependent upon a discretionary finding by the Administrator that an area both failed to submit and failed to make a reasonable effort to submit a plan meeting Part D requirements. Under this interpretation, an area which made a reasonable effort to submit a plan by the deadline but failed to do so would not have its highway funds withheld. EPA's interpretation was recently upheld in Court. ${ }^{a}$

2. For failure of a State or local area to adequately implement their SIP:

a. Section 176(b) enables the EPA Administrator to halt Federal air program grants. EPA has interpreted this sanction to apply only to areas that it "finds" not to have implemented requirements under its SIP. Without this formal finding by EPA, the Agency believes it has the discretion not to impose this sanction. Others disagree, however, and believe this sanction to be nondiscretionary.

b. Section 316 allows the EPA Administrator discretion to withhold, condition, or restrict Federal grants for sewage treatment plant construction.

3. For failure to attain the standard by the required date: Section lo requires the Administrator of EPA to prohibit the construction of major stationary sources. There is some difference of interpretation with regard to this sanction. Some believe that a construction moratorium should be imposed if a State fails to meet the standard by the deadline. EPA believes that the sanction should not apply to areas with approved plans that predicted attainment by the deadline but failed to actually attain the standard by the deadline.

aMcCarthy v. Thomas, District Court, Arizona, Aug. 10,1987.

SOURCE: Office of Technology Assessment, 1989.

\section{Penalties and Corrective Actions in the Event of Failure}

\section{Discussion}

The Clean Air Act includes a series of sanctions for the EPA Administrator to impose on States if certain requirements are not met. As detailed in table 8-5, the Act includes different penalties for failing to submit a revised plan for how each nonattainment area intends to lower emissions, penalties for failing to implement the requirements of the plan, and penalties for failing to attain the standard by the required date.

Few would disagree that some type of penalty is appropriate for failing to submit a revised plan or for adequately implementing that plan. At issue is whether a State should be penalized for failures that are in some ways beyond its control. For example, if Congress sets a 10-year deadline for an area that needs greater emissions reductions than current control methods can provide, should the area be penalized for not being able to find as-yetundeveloped control methods to meet the standard?

Congress must match appropriate penalties or corrective actions to the different types of possible failures. When considering what types of sanctions are appropriate to impose on States, it is helpful to understand the possible causes of failure. These include:

1. Failure that is primarily the fault of the State, including poor planning, implementation, and enforcement.

2. Failure that is due to reasonable scientific or technical errors, for example, uncertainties inherent in air quality modeling.

3. Failure due primarily to poor EPA performance.

4. Failure to maintain a congressionally specified reduction schedule or attain by the deadline because progress in developing new control methods turn out to be slower than hoped for.

Again, sanctions such as those included in the current Act may be appropriate for the first type of failure-those primarily the fault of the State. But many consider it unfair to sanction the State for failures due to poor scientific understanding. Corrective actions may be more appropriate for those failures that are beyond a State's control. Such corrective actions might include instructions to revise implementation plans or requirements to adopt source-specific controls that previously were left to the State's discretion.

\section{Options}

\section{Decision 1: For what kinds of failures should States be penalized?}

Congress may wish to penalize the States for only certain types of failures. The options listed below are not mutually exclusive.

Option 1: Sanctions for failing to make "sufficient" efforts. 
Few would disagree that penalties are appropriate for States that violate requirements of the Act over which they have complete control. For example, States should be required to submit revised SIPS by a reasonable date and implement and enforce the control measures included in their plan.

Option 2: Sanctions for failing to identifiy enough controls to meet a congressionally specified reduction schedule.

Congress faces a difficult choice deciding whether to penalize areas that need greater emissions reductions than can be expected from currently available control methods. These areas cannot specify the details of their plan to attain the standard by the required date or how they will meet interim reduction requirements.

If Congress decides not to penalize States for these failures, it must provide some guidance to EPA about what should be considered an available control method. Congress must indicate whether the dividing line should be "reasonably available" control methods, "lowest achievable" emission rates, or some similar descriptor of what constitutes a "sufficient" effort on the States' part.

Arguments against imposing sanctions for failure to identifiy enough controls center on concerns for fairness. Should States be penalized for the limits of current technology? Arguments for imposing sanctions under these conditions rest on the idea behind "technology forcing" requirements. How can one expect to rapidly develop new technology if there are no incentives to do so?

Option 3: Sanctions for failing to attain the standard by the required date.

Last, Congress must decide whether States should be penalized for not meeting their attainment deadline, even if they meet all other requirements of the Act. States that have fulfilled all the requirements of their plans might still fail to attain the standard due to uncertainty inherent in predicting future air quality or to failures on EPA's part. STAPPAALAPCO, in particular, has objected to penalizing States for failing to attain by a specified date.

Arguments against imposing sanctions for failure to attain the standard again center on concerns for fairness. Should States be penalized for failures beyond their control? Others argue that deadlines without sanctions will not be taken seriously.

Decision 2: What types of sanctions should be adopted?

Option 1: Sanctions that limit growth in nonattainment areas.

The current Act includes as one of its sanctions a ban on the construction of major stationary sources (sources that have the potential to emit greater than 100 tons per year). In a series of workshops held by OTA, there was general agreement that in low- or no-growth areas, the construction ban has had little effect. One of the participants noted that a construction ban has been in effect in Chicago for over five years, but "no one cares". As a remedy, some have suggested lowering the threshold to 50 tons per year or lower.

However the construction ban, or a variant, might be quite influential in areas experiencing higher growth. One participant at our workshops commented that the Michigan State legislature did not improve an automobile inspection and maintenance program until auto manufacturers complained that they could not construct new facilities under the construction ban.

Variants on a construction ban might be almost as effective, but allow a bit more flexibility. Rather than imposing an outright construction ban, new sources would be allowed to locate only if they offset their emissions with 2, 5 or more times the emissions reductions at existing facilities. After additional controls have been imposed, however, obtaining the necessary offsets should in theory be extremely difficult and available only for priority projects.

Recent congressional proposals have also included two additional types of sanctions that would serve to limit growth in nonattainment areas. These include a proposal for a moratorium on hookups to publicly owned drinking water distribution systems and a somewhat similar proposal for a moratorium on hookups to publicly owned sewage treatment systems.

Of course, sanctions that limit growth can have undesirable economic consequences if they have to 
be imposed. One participant at our workshops noted that for a sanction to be effective, nonattainment areas must believe that EPA and the Congress will be willing to impose the sanction if need be. Thus, as discussed above, Congress must consider what types of failures merit sanctions that limit growth, and whether it will allow them to actually be imposed. When EPA was considering implementing construction bans against 144 nonattainment areas in 1983, Congress added a provision to an appropriations bill to prohibit EPA from imposing sanctions during fiscal year 1984 [23].

\section{Option 2: Limits on Federal assistance.}

The Clean Air Act allows the EPA Administrator to withhold three types of Federal assistance: 1) Federal highway funds, except those for safety, mass transit, and transportation improvement projects related to air quality, 2) sewage treatment grants, and 3 ) grants to State air pollution control agencies.

Some have questioned the wisdom of the last of these provisions. An under-funded agency is less able to remedy the failure that led to the imposition of sanctions.

Decision 3: What types of corrective actions should be adopted?

For failures to meet certain types of interim requirements, corrective actions may be more appropriate than sanctions. Requirements for additional source-specific controls or further planning can serve, in part, as incentives not to fail, but more importantly, can help remedy the failure before the attainment deadline has once again passed. A discussion of the types of interim requirements Congress might adopt can be found earlier in this chapter.

\section{Option I: Planning requirements.}

If Congress chooses to adopt interim air quality requirements, Congress could require States that fall behind their schedules to reexamine the premises behind their SIP. States could be required to redo their emissions inventory, collect additional air quality information, or undertake a detailed modeling exercise to understand the reasons for the failure. The details of such a program are discussed below.

Option 2: Source-specific controls.
For areas that fall behind interim emission reduction schedules, Congress may choose to require additional source-specific controls that otherwise might be optional. Several of the proposals of the 100th Congress adopted this approach. Areas that cannot meet their deadlines are reclassified to a category that has more federally prescribed controls.

Option 3: Market-based control programs.

Another option for areas that fall behind interim reduction schedules is for Congress to require market-based control programs, such as emissions fees or marketable emissions permits. Depending on the stringency of the reduction schedules specified, areas might miss interim milestones because regulators cannot identify additional control measures to require. In such cases, the only alternative may be to provide economic incentives to industry and individuals to identify ways to lower emissions through market-based control programs. Clearly, there are no guarantees that such programs will achieve the desired reduction schedule, but the pace of reductions would most likely quicken.

EPA could be required to develop model regulations for the States to adopt. A program based on emissions fees might include fees on stationary sources larger than a specified size, a gasoline tax to lower highway vehicle usage, and a fee on products containing high solvent content. In a program relying on marketable emissions permits, permits are first distributed to VOC emitters, and then cut back gradually according to a specified schedule. Sources must then figure out ways to lower emissions or purchase permits from other sources on the open market.

\section{State and Local Planning Requirements}

\section{Discussion}

To fulfill its requirement that by 1987 the ozone standard was to be met everywhere in the country, the 1977 Clean Air Act Amendments relied on the State Implementation Planning (SIP) process, in combination with several mandatory control programs. Under the SIP process, the States were to determine how much they would need to reduce emissions in order to meet the ozone standard, and then set up control programs (including those mandated in the Act) to achieve the required 
reductions. The information required for this planthe States two years to develop, adopt and submit ning process included air quality and meteorologicaState Implementation Plans, including updated emisdata, an emissions inventory, estimates of growth insions inventories, identification and evaluation of emissions, and estimates of reductions that could beontrol measures, and air quality modeling to achieved through the available control measures. demonstrate attainment [22]. For the worst nonat-

The SIP approach used last time has been tainment areas, where enhanced planning exercises criticized for having depended too much on inaccu- will be needed, EPA has proposed five years for final rate estimates of cording to this criticis many areas failed to

the ozone standard by the 1987 deadline because EPA has estimated that nationwide, State and they underestimated the amount of control theylocal agencies would need to increase the resources needed. ${ }^{2}$ Errors in projected control requirementsthey devote to ozone and carbon monoxide control stemmed from uncertainties in emissions inventoprograms by about 50 percent, or about $\$ 40$ million, ries, under prediction of growth in emissions, to comply with the proposed new requirements [24]. inadequate monitoring of ambient $\mathrm{NO}_{x}$, VOC and The additional funds would cover efforts to refine ozone concentrations, and limitations of computermissions inventories, plan for implementation of models used to estimate needed reductions.

complex control measures such as use of alternative

For the next round of control efforts, EPA has fuels, and review the effectiveness of control measFor the next the most elaborate planning process proposed [22] to require planning exercises similarikely to be undertaken anywhere, the South Coast to those performed last time, with updated, refined Air Quality Management District began work on its and expanded emissions inventories, slightly ex-new Air Quality Maintenance Plan in June 1987, and panded air quality monitoring, and some evaluation expects to spend three years on it. The District of the effectiveness of specific control measures. budgeted $\$ 6.2$ million for the first two years of the More detailed exercises would be left to the discre-effort [6]. tion of the States.

Planning activities can help States in several ways. First, when done correctly, they can improve predict the effect of emissions reductions on air ways. First, when done correctly, they can improve quality, costs will be higher. Starting with a special estimates of what level of control will ultimately benitoring program, and including a concurrent needed to meet the standard. In areas where controleffort to refine emissions estimates, an urban grid measures beyond those needed to attain the standardmodeling study "would typically take one to three are available, they can identify the most cost-years and cost on the order of $\$ 500,000$ to complete effective control measures and prevent over control. In areas with the worst ozone problems, they can be used to assess whether $\mathrm{NO}_{\mathrm{x}}$ emissions should be controlled in addition to VOCs and whether regional control measures might be necessary.

The reliability of such information will depend on the time and resources devoted to refining emissions inventories, monitoring, modeling, and investigating control alternatives. EPA has proposed to allow $[17,18,26]$. In some situations, however, costs could go much higher. For example, the anticipated cost of a four-year air quality study being planned for California's San Joaquin Valley is $\$ 8$ to 10 million [4].

\section{Options}

\section{Decision 1: What types of planning should be required and where?}

\footnotetext{
${ }^{2}$ As the Clean Air Act was interpreted by EPA, sanctions were to be imposed for failure to submit SIPS that "demonstrated attainment" by specified deadlines, and for failure to implement SIPS, but not for failure to attain the standard when an acceptable SIP had been implemented in good faith.

${ }^{3}$ The proposal requires that States submit an updatedemissionsinventory 12 monthsafter the Agency calls for it, and subsequently update the inventory every three years. Previously, process and emissions data were only required for individual sources emitting more than 100 tons per year, with smaller stationary sources treated as area sources. The requirement for data from individual sources would now be extended to include all sources emitting 10 or more tons per year. As before, the proposal requires that the States usc computer modeling to estimate emissions reductions needed for attainment. States would be allowed to use the widely criticized "Empirical Kinetics Modeling Approach" (EKMA) model, but the more detailed and expensive "Urban Airshed Model" (UAM) is recommended. To monitor each area's attainment status and provide data for computer modeling, EPA's proposal recommends that at least five ozone monitors and two collocated $\mathrm{NO}_{\mathrm{x}}$ and $\mathrm{VOC}$ montors be operated in each nonattainment area.
} 
Option 1: Minimal requirements for all nonattainrnent areas.

The modest planning exercise proposed by EPA would be beneficial in all nonattainment areas. Air quality monitoring and an updated emissions inventory are necessary whether control measures are identified locally or specified at the Federal level. Modeling is the only way to predict the impact of emissions reductions on air quality, and thus to project (at least roughly) progress toward the ultimate goal of attaining the standard.

Option 2: Enhanced efforts in areas with the worst ozone problems or atypical conditions.

In general, nonattainment areas that have the highest design values or exceedance rates need to abate emissions the most to meet air quality standards. Ultimate control costs are likely to be highest in these areas. Enhanced air quality modeling (with supporting monitoring and emissions inventory refinement) and comprehensive assessment of control options would be particularly useful in these areas to ensure that the controls imposed will be effective, to target the most cost-effective measures first, and to recognize and begin to address shortfalls in needed reductions as early as possible.

In some urban areas, atypical emission sources, meteorology, topography, or geographical location may warrant enhanced air quality modeling or special consideration of certain control options. For example, special efforts might be warranted in areas with significant emissions from vegetation, pollutant transport from outside the area, unusually predominant sources of a specific type, or preliminary indications that $\mathrm{NO}_{\mathrm{x}}$ controls might be particularly helpful or harmful.

State-of-the-art air quality models (such as the Urban Airshed Model) are the best means available for predicting the effect of emissions reductions on air quality. They are especially preferred for examining the impacts of reducing $\mathrm{NO}_{\mathrm{x}}$ emissions, or the effect of emissions reductions that are unevenly distributed within an area. Application of such models typically requires a short-term but intensive pollution and meteorological monitoring program. New information about the composition of emissions and how they are distributed within the area may also be needed, In many areas, estimates of
VOC emissions, especially emissions from area sources, need to be refined if models are to give reliable results.

Enhanced local efforts to identify and evaluate control options would help States design control strategies tailored to local conditions. Such efforts might improve the cost-effectiveness, political viability, and administrative tractability of controls. In many nonattainment areas, exhaustive exploration of potential control measures will be required to identify reductions to attain (or come as close as possible to) the standard. In areas where transportation control measures are needed, State and local agencies involved in transportation and land-use planning, as well as air quality, need to be involved.

As an example, in developing its 1988 Air Quality Maintenance Plan (AQMP), the Los Angeles area South Coast Air Quality Management District attempted to identify "all the potential control measures that could be available by the year 2000." The District included all currently available control technologies as well as measures ranging from development of non-reactive solvents to "clean" motor vehicle fuels. Major transportation and landuse planning studies were conducted in conjunction with the AQMP.

In chapter 6 we concluded that cities with design values of $0.16 \mathrm{ppm}$ or higher will probably not be able to meet the air quality standard for ozone with currently available VOC control measures. Congress could direct the EPA Administrator to require these areas to carry out a comprehensive analysis of potential control measures.

A design value cutoff of $0.16 \mathrm{ppm}$ would also be appropriate for delineating areas where enhanced modeling is required. However, because of the limited availability of people at EPA or State and local agencies who could perform or oversee enhanced modeling, Congress could allow the Administrator to consolidate efforts across areas, where appropriate (e.g., New York City and parts of Connecticut); exempt cities where enhanced modeling would not be useful due to the impact of upwind areas (e.g., Atlantic City, NJ); or set priorities for the order in which the analyses are completed.

Decision 2: Who pays for enhanced State and local planning activities? 
State and local planning activities are supported by general State and local revenues, grants from the Federal Government (authorized under section 105 of the Clean Air Act), and fees assessed by State and local agencies on pollution sources. ${ }^{4}$ In addition, private groups have supported special air quality modeling and monitoring studies and assessments of control options that have contributed to official planning efforts.

In 1986, State air agency budgets ranged from $\$ 270,000$ (Nevada) to $\$ 54.8$ million (California), with the 50-state average at $\$ 4.1$ million ( $\$ 3.1$ million excluding California). Of 32 local air agencies reporting, 1986 budgets ranged from $\$ 65,000$ (Madera, CA) to \$29 million (South Coast Air Quality Management District, CA).

Federal grants under section 105 contributed about one-third of State and local air agencies' budgets in 1987. On average, 50 percent of the Federal funds received by State and local agencies are budgeted for administration and planning activities (including monitoring, SIP revisions, development and maintenance of emissions inventories, air quality modeling, and development of new programs). Permitting and enforcement activities and other minor categories account for the other 50 percent.

EPA has estimated that altogether, State and local agencies would need increases in revenues totaling about $\$ 40$ million per year, to fulfill all of the new requirements contained in its proposed "Post1987" ozone and carbon monoxide policy [24].

Option 1: Increase funding for section 105 grants or make special, separate appropriations for ozone nonattainment area planning
Congress could increase appropriations for section 105 grants. Federal appropriations for State and local air programs under section 105 totaled $\$ 94.6$ million, in fiscal year 1987. Appropriations were reduced to $\$ 93.3$ million in fiscal year 1988 , and increased to $\$ 101.5$ million for fiscal year $1989 .{ }^{6} \mathrm{In}$ 1986, Federal contributions to State agencies ranged from $\$ 180,000$ (Nevada) to $\$ 5.9$ million (New York). Federal contributions to local air agencies ranged from no funding for some to $\$ 1.5$ million.

In addition to grants allowed under section 105, the 1977 Amendments authorized grants for planning transportation control measures. A total of $\$ 50$ million was appropriated. Most of the grants, which were administered through the Department of Transportation (DoT), went to Metropolitan Planning Organizations (MPOs) responsible for developing urban transportation plans, rather than to air agencies. While it lasted (through 1982), the grants program was considered successful in introducing air quality considerations into urban transportation planning. Congress could consider new authorizations targeted specifically for grants for joint air quality/transportation planning.

Option 2: Develop a nationwide user-fee program (administered by EPA) or a fee requirement (administered by the States) on nonattainment area emissions.

The Clean Air Act requires States to assess fees to cover the costs of processing, implementing and enforcing permits. ${ }^{7}$ In 1986, 31 States assessed permit fees. Some of these States covered more than half of their air agency budgets through extensive

${ }^{4}$ The information on State and local air agency budgets and fee programs presented in this section is frorreference [16].

${ }^{5}$ Section 105(a)(1)(A-C) defines the maximum Federal share of funding for State and local air pollution control as 60 percent for maintaining an established program and 75 percent for planning or developing an air quality program for those recipients carrying out a SIP. A major requirement for receipt of Federal funding is that the agencies' nonfederal support for 'recurrent expenditures" cannot be reduced unless the reduction is a nonselective reduction in expenditures of all executive agencies at the same level of government.

$6 \mathrm{D}_{\text {uс }}$. relatively flat funding levels over the past few years, in the face of increasing responsibilities and new priorities, EPA officials note a decline in Federal support for several fundamental State and local activities including: enforcement, emission inventory maintenance, ambient monitoring, and preventive activities such as new source review.

${ }^{7}$ Section 1 lo(a)(2)(K) of the Clean Air Act requires States to charge owners/operators of major stationary sources for "the reasonable costs of reviewing and acting upon" applications for permits; and for "the reasonable costs of implementing and enforcing the terms and conditions" of permits that are given out.

${ }^{8}$ Eleven other States had authority $t$. collect fees but did not. Agencies that did not collect fees cited lack of a strong signal from EPA that fee programs were required; lack of a national policy or regulation that would ensure that fee programs were not perceived as a local disincentive to industry; and concern that they would not benefit from the revenues generated (because revenues were diverted elsewhere or because other funding sources would be reduced accordingly). 
user-fee programs. ${ }^{9}$ About half of the State air agencies collecting fees retained the revenues; the other half put them into State general funds. In 60 percent of the States collecting fees, the revenues were at least reflected in the air agencies' budgets. On average, revenues raised by assessing fees equaled about 10 percent of agency budgets (irrespective of whether or not they retained the fees). ${ }^{10}$

Congress could shift more responsibility for funding State and local planning efforts to State and local governments, encouraging or requiring them to assess user fees to support their own activities. Agencies that do not now have permit fee programs have suggested that a Federal directive would bean important factor in their ability to obtain local authorization to assess fees. In addition to or instead of State and local assessments, Federal user fees could be instituted, with some portion turned over to State and local air agencies through EPA.

As discussed above, EPA estimates that in order to undertake the planning requirements that they have proposed, State agencies will require an additional $\$ 40$ million per year. Adding requirements for state-of-the-art modeling in many areas might increase this by another 50 percent or more. Using \$100 million per year as an upper bound, we can get a feel for the magnitude of the fees that would have to be imposed.

Assuming that fees are to be related to emissions, fees of about $\$ 10$ per ton of VOC would be needed to raise $\$ 100$ million in nonattainment areas. Identifying and imposing fees on all sources, however, would be quite difficult. Three source categories, emitting over half of nonattainment area VOC emissions, are probably the easiest to locate: large stationary sources, highway vehicles, and solvents. Roughly assigning a fee to these sources according to their contribution to emissions produces a fee schedule of about: \$15 to \$20 per ton of VOC emissions from stationary sources emitting more than 50 tons per year, about 0.1 to 0.15 cents per gallon of gasoline, and about 15 to 20 cents per gallon of the most commonly used solvents (such as special naphthas).

\section{Research}

\section{Discussion}

Ozone is probably the least-well understood of the six "criteria" air pollutants, those for which air quality standards have been set. This lack of understanding is one of the reasons why ozone is the criteria pollutant that we have had the least success controlling.

The next reauthorization of the Clean Air Act will include the third major change in the way we have attempted to control ozone. If, when the second major initiatives were taken following the 1977 Amendments, we had also launched an aggressive research program, our task might be easier today. Research begun today can help the States implement the changes made during this round of amendments and help Congress when it considers the fourth major set of changes 5 or 10 years from now.

We have identified three areas where research seems most pressing: 1) research to improve the planning process, 2) development of new control methods, and 3) research to better understand the magnitude of the risks posed by ozone. Each of these is discussed below.

Research To Improve Planning-Two areas are prime candidates for increased Federal research funds: 1) methods to allow States to improve estimates of VOC emissions; and 2) air quality models that are more accurate than the current generation of tools used by most States, and at the same time are easier to use than research-level models.

VOC Emissions Inventories-Air pollutant emissions are rarely measured, but rather are estimated using emissions models. The models used for estimating VOC emissions are far less accurate than, for example, those used to estimate either sulfur dioxide or nitrogen oxide emissions.

\footnotetext{
${ }^{9}$ In addition to permitting, some State or local agencies assess fees for other services suchas source testing, banking and bubble applications, and motor vehicle inspections. Some agencies also assess fees on emissions.

${ }^{10}$ Fees collected $b_{y}$ over 50 percent of the States were equal t. less than 3 percent of their air agency budgets. Fees amount to about 30 percent or more of the budgets of State air agencies in Kansas, Louisiana, Texas, and Ohio. Fees contribute about 30 to 80 percent of the annual budgets of local air agencies in Arizona and California.
} 
About 10 to 20 percent of VOC emissions come from large stationary sources for which a location is identified in an inventory, for example, a petroleum refinery or a factory that manufactures chemicals. These sources can be surveyed individually and emissions can be estimated reasonably well based on production levels.

About 40 percent of VOC emissions come from highway vehicles. Emissions are estimated using a model called Mobile-4. Mobile-3, the previous version of the model, was based on data collected from about 11,000 vehicles manufactured before 1982 (with about half of these manufactured before 1976). Though Mobile-3 was widely criticized as not able to adequately simulate emissions under road conditions, data from fewer than 500 vehicles were used to update the model [25]. Given the changes in vehicle design that have occurred over the last several years-and the importance of highway vehicle emissions-additional funds to EPA to test newer vehicles and improve the performance of Mobile-4 would be well spent.

Another 25 to 30 percent of VOC emissions come from a diverse range of solvent uses, including drycleaning, consumer products, and coatings for everything from furniture to cars to houses. While nationwide emissions can be estimated from published statistics of total solvent produced, emissions in any given nonattainment area can only be crudely guessed. The method currently being used was developed in 1975 and has been modified little since that time. Improvements are sorely needed.

The magnitude, distribution, and role of "biogenie" emissions-natural hydrocarbon emissions primarily from forests - are also poorly understood and characterized. Nationwide, summertime VOC emissions from natural sources are estimated to be greater than man-made emissions. Natural-source VOCs are emitted primarily in forested areas, that is, outside of nonattainment areas where man-made emissions of VOCs generally predominate. Nevertheless, in some parts of the country (especially the Southeast), VOC emissions from vegetation may contribute substantially to ozone nonattainment problems. Improved understanding of biogenic emissions will help such areas determine how best to control ozone-in particular, whether emphasis needs to be placed on reducing $\mathrm{NO}_{\mathrm{x}}$ emissions if a significant fraction of VOCs are not subject to control.

Air Quality Models - A wide disparity exists between the accuracy of the best available air quality models and those commonly used by the States to prepare their SIPS. The best available tools are expensive to use, require extensive data collection, and require highly trained personnel to be used effectively. Thus, state-of-the-art models are beyond the capabilities of many of the State air pollution control agencies that might make use of them.

Though the best models may be beyond the States' reach, better models are not. More EPA attention to the operational aspects of modelingdeveloping tools for the average rather than the expert modeller-could improve the States' abilities to understand the effectiveness of alternative emission controls.

New Control Methods-As discussed previously, OTA estimates that controls sufficient to achieve about two-thirds of the reductions needed to attain the standard will cost about $\$ 10$ billion per year. We cannot estimate the costs of the remaining third because we do not know how it can be achieved. Yet EPA's total research budget for new and cheaper VOC control measures totals about $\$ 1.5$ million per year-much less than one-tenth of a percent of the projected costs of control.

Once currently available controls are in place, the remaining emissions will come primarily from small (less than 50 tons per year) stationary sources and highway vehicles. High-priority research and development areas include methods to trap or destroy VOCs from small sources emitting VOCs in low concentrations, non-ozone producing solvent substitutes, and cleaner vehicle fuels, such as methanol and compressed natural gas.

Better Understanding of the Problem-The current regulatory program is focused mainly on one of ozone's effects, acute health effects resulting from exposure to short-term peaks. Other effects are also of concern, including possible chronic health effects from long-term exposure to ozone and effects on crops and forests. Additional research is needed in each of these areas. 
Chronic Health Effects-Although the short-term effects of ozone are important, many health professionals appear to be more concerned that repeated exposure to ozone over many years may result in permanent impairment of the lung. Unfortunately, the limited research that has been conducted to date has been unable to either confirm or dismiss this concern.

Most of EPA's health effects research focuses on ozone exposures of one to several hours. Information about the chronic effects of exposure to ozone over longer time periods-days to years-must come from a combination of animal studies and carefully planned epidemiologic studies.

Welfare Effects-For decades we have known that ozone can harm plants. Just how much damage is occurring in specific agricultural and forested regions, however, is not well understood. In chapter 4 we estimate that if seasonal, daytime average ozone concentrations could be lowered by 25 percent of the amount by which they exceed natural background, about $\$ 0.5$ billion to $\$ 1$ billion per year of agricultural benefits would be gained. We are not yet able to estimate the amount of forest damage that might be avoided.

While a fair amount of research on the effects of ozone on crops and forests is currently underway, major information gaps remain. Much has already been learned about crop damage through the EPA sponsored National Crop Loss Assessment Network (NCLAN), but many scientists feel that the research effort was ended prematurely. We are still uncertain whether productivity declines are due primarily to intermittent peak concentrations or the accumulated ozone dose over a growing season. Forest effects are being studied under the National Acid Precipitation Assessment Program (NAPAP) and under the new 10-year research program established at the end of the 100th Congress by the Forest Ecosystems and Atmospheric Pollution Research Act.

A goalof both research efforts should be to enable EPA to set a secondary "welfare" standard based on crop and forest effects. The current secondary standard is identical to the health-based primary standard. Many feel that the form of the primary standard (i.e., a peak one-hour standard, not to be exceeded more than once per year) is inappropriate for a secondary standard to protect vegetation.
Additional monitoring of ozone and its precursors in non-urban environments is needed to better characterize the magnitude of the problem. Moreover, it is not well understood how to lower regional ozone concentrations, if Congress or EPA were to pursue this goal. The VOC reductions needed to lower peak ozone concentrations in nonattainment cities may have little effect in less populated areas; reductions in nitrogen oxide would probably be necessary to reduce ozone in most non-urban areas. Additional field studies and modeling are needed to better understand how to lower ozone concentrations in non-urban areas.

\section{Options}

\section{Decision 1: What areas of research deserve increased funding?}

In the discussion above, we outlined three general research areas that Congress should consider for increased funding. These include: 1) research to help the States analyze the emissions reductions needed to meet the standard, 2) research on new control methods, and 3) research to better understand other effects of ozone, including possible chronic health effects from exposure over many years and crop and forest productivity declines.

Current research expenditures in each of these areas is quite modest. EPA gives the States about \$3 million per year for improved inventories, monitoring, and air quality modeling. In fiscal year 1990, EPA's Office of Air Quality Planning and Standards will itself spend about $\$ 3$ million, including staff time, on developing improved ozone models and a better emissions data management system. Fiscal year 1989 expenditures were closer to \$1 million [5]. The Mobile-4 model, used by the States to estimate emissions from highway vehicles, is the responsibility of the Office of Mobile Sources (OMS). In fiscal year 1989, OMS spent about $\$ 2.8$ million testing cars for data needed to build the model, up from about $\$ 0.8$ million in fiscal year 1987. Even at the higher level, about 900 vehicles per year can be tested (compared to a peak of about 5000 vehicles tested in 1979) [2].

About $\$ 1.5$ million per year is spent by EPA's Office of Research and Development (ORD) on the "Regional Oxidants Model" (ROM), a highly sophisticated model capable of simulating multi-day 
ozone episodes in the Northeast. Similar efforts in the Southeast, Gulf Coast region, and the area surrounding Lake Michigan would help cities in each those regions to better understand how to solve their nonattainment problems. In addition, such efforts are needed to understand how to lower rural ozone concentrations.

OMS spent about \$2.8 million in fiscal year 1989 on research on alternatively fueled vehicles, primarily methanol vehicles [2]. ORD spends about $\$ 1$ million per year on research on mobile source emissions. About $\$ 0.6$ million is devoted to use of alternative fuels [8]. The Air and Energy Engineering Research Laboratory of ORD spends about $\$ 0.4$ million per year on research to develop new control methods for stationary sources of VOC. Most of the emphasis is on developing technology appropriate for small stationary sources, and on developing environmental impact guidance for manufacturers reformulating VOC-containing products [7].

ORD spends close to $\$ 7$ million per year on ozone effects research. Of this, the single largest component is now research to determine the long-term health effects from ozone, about $\$ 3.6$ million in fiscal year 1989. Given the importance of knowing whether there are chronic effects from exposure to ozone and if so, of what magnitude, this level of research seems extremely modest. ORD also spends about $\$ 2$ million per year on forest effects research and about $\$ 1$ million on continuing research on the short-term health effects of ozone [8].

\section{Decision 2: Who pays for the research?}

Traditionally the Federal Government has funded air pollution related research out of general tax revenues. While this has been generally true for most pollution related research, there have been a few exceptions. For example, in the Nuclear Waste Policy Act of 1982 (Public Law 97-425), Congress established a fee on electricity generated by civilian nuclear power reactors to be used to pay for the costs of radioactive waste disposal. While most of the fee will be used to pay for the construction and operation of a waste repository, the costs of research, development, and demonstration activities and the costs of administering the program are also covered.

Under the Superfund Amendments and Reauthorization Act of 1986 (SARA), Congress established four hazardous substances research centers, each with funding of $\$ 5$ million per year from Superfund. Though Superfund is jointly funded by industry and general tax revenues, well over half of the funds come from industry.

In the discussion above on additional requirements for State planning, we presented several alternatives for raising revenues for these activities. If Congress decides to fund these activities through a fee or tax mechanism, it might also consider allocating a portion of the revenues raised to ozone-related research activities.

\section{CONTROL REQUIREMENTS}

In addition to the more generic options discussed above, Congress might want to consider requiring specific types of controls directly in the Act. We have organized our discussion of the specific options available to the Congress in the near term into three categories. Air pollution control under the Clean Air Act relies on a partnership between EPA and State and local governments. Therefore, our first two categories present: 1) federally implemented controls that apply nationwide and 2) controls to be implemented by the States in nonattainment areas. A final category includes options for managing emissions growth due to population increase and expanding economic activity in nonattainment areas

All of the control options presented in this section are available today and fall, more or less, within the traditional regulatory bounds of the Clean Air Act. The last section in this chapter presents some "New Directions for the Clean Air Act" that Congress should also consider to augment the more traditional control strategies presented here.

\section{Federally Implemented, Nationwide Control Requirements}

\section{Discussion}

Two major categories of regulations currently apply nationwide. These include emission standards for highway vehicles and a series of "new source performance standards" (NSPS) that apply to certain categories of new facilities locating in attainment areas. While NSPS regulations also apply to new facilities in nonattainment areas, they are often superseded by more stringent regulations. Note also 
that highway vehicle emission standards are more stringent in California, the State with the most severe nonattainment problems.

Part of the philosophy behind uniform nationwide car and truck standards is that people as well as vehicles are mobile. Obviously, it would be extremely difficult to implement and enforce a set of highway vehicle regulations that applied only to cars and trucks in nonattainment areas. For pollutants such as nitrogen oxides and carbon monoxide, the only source categories that move around are transportation related-cars, trucks, buses, trains, airplanes, and ships - and certain off-highway vehicles such as construction equipment. For VOCs, however, there are significant sources that do move around and which are not transportation related. Paints and other solvent-containing products release VOCs at the point of end-use. Since controlling the movement of certain kinds of house paints, pesticides, and similar products with high VOC content would be difficult, nationwide regulations have been proposed for these products as well.

Nationwide control requirements under current law and regulations are listed in table 8-6. Additional controls that Congress might want to specify are discussed below.

\section{Options}

Chapter 6 presented our estimates of the emission reduction potential and costs of additional pollution controls. Those regulations that would be federally implemented are summarized below.

\section{Option 1: Limits on gasoline volatility.}

Limiting the volatility (i.e., rate of evaporation) of gasoline sold during warm weather months would substantially reduce transportation-related VOC emissions. On a warm summer day, twice as much VOC comes from gasoline evaporation than from the tailpipe of a car. Limiting the volatility of gasoline to 9 pounds per square inch (psi) Reid Vapor Pressure (RVP) from levels of between about 11.0 and 11.5 psi would lower VOC emissions about 3,700 tons per day on hot summer days in nonattainment cities in 1994. (This is equivalent to an annual reduction of about 1.3 million tons per year, or about 12 percent). An additional 5,200 tons per day would be eliminated in attainment areas (equivalent to annual reductions of about 1.9 million tons).

\section{Table 8-6-VOC Sources For Which Nationwide Regulations Exist}

Current law and regulations include the following controls for highway vehicles:

1. Tailpipe exhaust standards for passenger cars:

a. $0.41 \mathrm{~g} / \mathrm{mi} \mathrm{HC}$ and $1.0 \mathrm{~g} / \mathrm{mi} \mathrm{NO}_{\mathrm{x}^{*}}$

b. Vehicles must be able to meet these standards for at least 5 years or 50,000 miles.

2. Tailpipe exhaust standards for light-duty trucks (less than $8,500 \mathrm{lb}$ gross vehicle weight rating [GVWR]):

a. $0.8 \mathrm{~g} / \mathrm{mi} \mathrm{HC}$ and $1.2 \mathrm{~g} / \mathrm{mi} \mathrm{NO}_{\mathrm{x}}$ for trucks with loaded vehicle weights up to $3,750 \mathrm{lbs}$.

b. $0.8 \mathrm{~g} / \mathrm{mi} \mathrm{HC}$ and $1.7 \mathrm{~g} / \mathrm{mi} \mathrm{NO}_{\mathrm{x}}$ for trucks with loaded vehicle weights over $3,750 \mathrm{lbs}$. Standards must be met for 120,000 miles.

3. Tailpipe exhaust standards for heavyduty engines and vehicles (over 8,500 lb GVWR):

a. 1.1 grams per brake-horsepower-hour (ghhp-hr) ${ }^{\mathrm{a}} \mathrm{HC}$ and $10.6 \mathrm{~g} / \mathrm{hp}-\mathrm{hr} \mathrm{NO}_{\mathrm{x}}$ for gasoline vehicles less than $14,000 \mathrm{lb}$ GVWR.

b. $1.9 \mathrm{~g} / \mathrm{bhp}-\mathrm{hr} \mathrm{HC}$ and $10.6 \mathrm{~g} / \mathrm{bhp}-\mathrm{hr} \mathrm{NO}_{\mathrm{x}}$ for gasoline vehicles over 14,000 lb GVWR.

c. $1.3 \mathrm{~g} / \mathrm{bhp}-\mathrm{hr} \mathrm{HC}$ and $10.6 \mathrm{~g} / \mathrm{bhp}-\mathrm{hr} \mathrm{NO}_{\mathrm{x}}$ for diesel vehicles.

d. For all vehicles, $\mathrm{NO}_{\mathrm{x}}$ standards drop to $6 \mathrm{~g} / \mathrm{bhp}-\mathrm{hr}$ in 1990 and $5 \mathrm{~g} / \mathrm{bhp}-\mathrm{hr}$ in 1991.

Standards must be maintained for 110,000 to 290,000 miles, depending on fuel and truck weight.

4. Limits on gasoline evaporation from highway vehicles.

Currant law and regulations include the following controls for stationary sources:

New source performance standards (NSPS) requiring the "best available control technology" on certain new stationary sources of VOC and $\mathrm{NO}_{\mathrm{x}}$. (Note that the "lowest achievable emission rates" for VOC required for new sources in nonattainment areas are more stringent than the nationwide NSPS limits.)

1. Surface coating regulations, including NSPS for coating large appliances, metal furniture, cars and light-duty trucks, beverage cans, metal coils, magnetic tape, pressure sensitive tapes and labels, and flexible vinyl coating.

2. Petroleum-related regulations, including NSPS for petroleum refining, refinery wastewater, bulk gasoline terminals, storage vessels, and natural gas production.

3. Synthetic organic chemical industry (SOCMI) related regulations, including NSPS for air oxidation equipment, distillation operations, reactors, and other equipment.

4. Others including NSPS for drycleaning, graphic arts, synthetic fiber production, and rubber tire manufacture.

a To convert g/bho-hr to $g / \mathrm{mi}$, multiply by approximately 0.9 for gasoline vehicles and 2.0

for diesel vehicles.

SOURCE: Otfice of Technology Assessment, 1989.

EPA estimates that the costs for lowering gasoline volatility during the 5 summer months would be about $\$ 0.2$ billion per year nationwide; the American Petroleum Institute estimates that the costs would be closer to $\$ 1$ billion per year nationwide. The resulting cost-effectiveness ranges between about $\$ 120$ and $\$ 800$ per ton of VOC during the 5 summer month period. 
Note that the reduction estimates and costs above assume as a baseline gasoline volatility in the range of 11.0 to $11.5 \mathrm{psi}$, which prevailed throughout most of the United States during the summer months between 1985 and 1988. They do not use as a baseline the recently promulgated EPA regulations requiring gasoline volatility of 10.5 psi beginning during the summer of 1989 or several northeastern state regulations requiring $9.0 \mathrm{psi}$, also beginning in 1989.

\section{Option 2: More stringent exhaust standards for} cars and trucks.

Table 8-7 displays OTA's estimates of the most stringent car and truck emission standards that are feasible with currently identifiable technology. About 4 years lead time might be needed for manufacturers to design, test, and certify vehicles meeting these lower standards. We feel that the emission rates listed can be met as "certification standards, " that is, emission rates after 50,000 miles on a test track. The emission rates might also be met by well-maintained vehicles after 50,000 miles in customer service. However, vehicle emissions could easily be higher after 50,000 miles in normal customer service.

As these are estimates of emission rates from vehicles not yet designed, they should be viewed with some caution. On reviewing the contractor work on which the table is based, the auto and truck manufacturers felt that the OTA contractor's estimates of feasible emission standards were too optimistic. Both EPA and the California Air Resources Board, however, felt that the standards were too conservative. They felt that the numerical standards could be met not only during certification but after 50,000 miles in customer service. Though they could not identify the particular technology mix that would assure meeting the standards in customer service, they believed that the manufacturers have the technical capability to develop such a system if forced by law.

Assuming these new highway vehicle standards go into effect in 1994, costs would total about \$2.9 billion dollars per year nationwide and lower VOC emissions by 330,000 tons per year and $\mathrm{NO}_{\mathrm{x}}$,
Table 8-7-Options for New Car and Light-Duty Truck Exhaust Standards

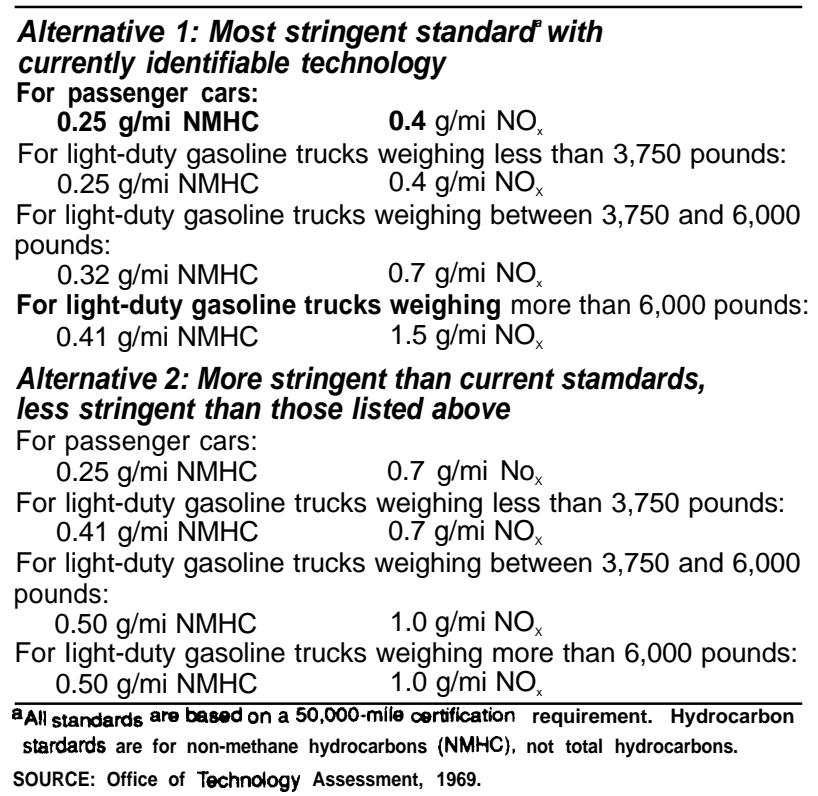

emissions by 1.3 million tons per year by 2004 (when most older vehicles will have been replaced). About 45 percent of the emission reductions would be in nonattainment areas.

Table 8-7 also presents a second possible set of standards that are more stringent than those in place today, but not quite as difficult or expensive to achieve than those discussed above [11]. These new standards would cost about $\$ 1.3$ billion per year by 2004 and achieve about 65 percent of the VOC reductions and 55 percent of the $\mathrm{NO}_{\mathrm{x}}$ reductions of the more stringent standards discussed above.

Option 3: "Onboard" technology for cars and trucks to control refueling emissions.

Gasoline vapors that escape from vehicle fuel tanks during refilling can be controlled by two different methods. The first, "stage-II" vapor recovery devices on gas pumps, was discussed above as an option that can be limited to nonattainment areas only. Control devices can also be installed "onboard" cars and trucks that can lower refueling emissions by about 90 percent. VOC emissions

${ }^{1}$ These options are based on a report to OTA by Sierra Research [11], a consulting firm that provides services to a variety of auto industry, oil industry, and regulatory agency clients. 
could be lowered by about 530,000 tons per year nationwide, at a cost of about $\$ 600$ million per year by 2004 . This nationwide cost is based on a per vehicle cost of $\$ 25$, the upper bound of EPA's estimates. The Motor Vehicle Manufacturers' Association estimates that the cost would be $\$ 80$ per vehicle.

In August 1987, EPA published a notice of proposed rulemaking in requiring all gasolinefueled cars and trucks manufactured after 1990 to have onboard technology to control refueling emissions. A final rule has not yet been issued.

\section{Option 4: Federal solvent regulations.}

STAPPA/ALAPCO, the associations of State and local air regulatory agencies, has recommended that Congress require EPA to develop and implement a set of Federal regulations for the following solvent categories: 1) commercial solvents, 2) consumer solvents, 3) architectural coatings, 4) pesticide application, 5) traffic-marking coatings, and 6) metal-parts coatings for military applications and aerospace-industry applications [15].

STAPPA/ALAPCO's reason for advocating nationwide requirements, rather than requirements for nonattainment areas only, is that such products are "manufactured and marketed regionally and nationally (rather than by individual States)." STAPPA/ ALAPCO states only that they believe that control measures are technologically feasible, but does not state the reductions that might be achieved or the cost.

The emissions reductions from, and costs of, regulations on the solvent content of architectural coatings are discussed in chapter 6 . Emissions could be lowered by about 0.5 percent per year at a nationwide cost of about $\$ 0.13$ billion. Regulations on other categories of solvent use are discussed in a later section on "New Directions for the Clean Air Act."

\section{Control Requirements To Be Implemented by States in Nonattainment Areas \\ Discussion}

The Clean Air Act divides the responsibility for air pollution control programs between EPA and State and local governments. EPA is responsible for setting emission standards for new motor vehicles.
The States are responsible for implementing inspection and maintenance programs in nonattainment areas to ensure that motor vehicles continue to operate properly.

The States are responsible for applying emission controls to existing stationary sources. While EPA issues regulations for new stationary sources that apply nationwide, States are required to apply more stringent requirements in nonattainment areas, that is, the "lowest achievable emission rates" from new stationary sources.

In 1985, about half of all VOC emissions came from stationary sources, and therefore were the responsibility of the State to control. In the absence of further regulations, within a decade the percentage could rise to about 60 percent. Thus the importance of State-implemented, as opposed to federally implemented, controls will increase.

We will first review the controls that States are already required to implement in nonattainment areas under the Clean Air Act, and then present additional controls that Congress could add to the Act.

The 1977 Amendments created two categories of nonattainment areas. The following Stateimplemented controls were required under regulations issued by EPA:

- In areas that could demonstrate attainment by December 1982:

— "Reasonably available control technology" (RACT) for all stationary sources of VOC emitting more than 100 tons per year, for which EPA issued 'control technique guidelines" (CTGs) prior to 1979. (Source categories are listed in table 8-8.)

In areas that received extensions of the attainment deadline to December 1987 ('extension" areas):

-RACT for all stationary sources of VOC for which CTGs have been issued. (Source categories are listed in table 8-8.)

- RACT for all stationary sources of VOC emitting greater than 100 tons per year for which CTGs have not been issued.

-Inspection and maintenance $(1 / \mathrm{M})$ program for highway vehicles. 
Table 8-8-VOC Sources For Which EPA Hss Issued Control Technique Guidelines

EPA has issued "control technique guidelines" (CTGs), which presumptively determine RACT, for the following source categories:

1. Prior to 1979 :

a. Surface coating regulations, including CTGs for coating cans, coils, paper, fabrics, autos and light-duty trucks, metal furniture, magnet wire, large appliances, flatwood paneling, and miscellaneous metal parts.

b. Other solvent-related regulations, including CTGs for graphic arts, metal decreasing, and drycleaners using perchloroethylene.

c. Petroleum-related regulations, including CTGs for bulk gasoline plants and terminals, liquids in fixed- and floatingroof tanks, miscellaneous sources in petroleum refineries, gasoline tank trucks, and delivery of gasoline to service stations.

d. Several additional regulations, including rubber tire manufacture, pharmaceutical manufacture, and cutback asphalt.

2. 1979 and later:

a. Large petroleum drycleaners.

b. Synthetic organic chemical industry (SOCMI) related regulations, including CTGs for high-density plastic resins, air oxidation processes, volatile organic storage tanks, and leaks.

C. Leaks from natural gas and gas processing plants.

SOURCE: Office of Technology Assessment, 1989.

— "Lowest achievable emission rate" (LAER) of VOC for new stationary sources emitting more than 100 tons per year or modified stationary sources emitting more than 40 tons per year.

\section{Options}

Chapter 6 presented our estimates of the emissions reductions potential and costs of currently available currently methods. Those measures from chapter 6 that can be implemented by States, as well as a few additional ones, are discussed below:

Option 1: Lowered source-size cutoff for requiring "reasonably available control technology" (RACT).

EPA currently requires RACT-level controls for stationary sources that emit, or have the potential to emit, over 100 tons per year of VOC. (The Act currently requires all reasonably available control measures, but is silent on the source size cut-off.) Congress could lower this cutoff to, for example, 50-or 25-ton-per-year sources in all nonattainment areas or require progressively lower cutoffs depend-

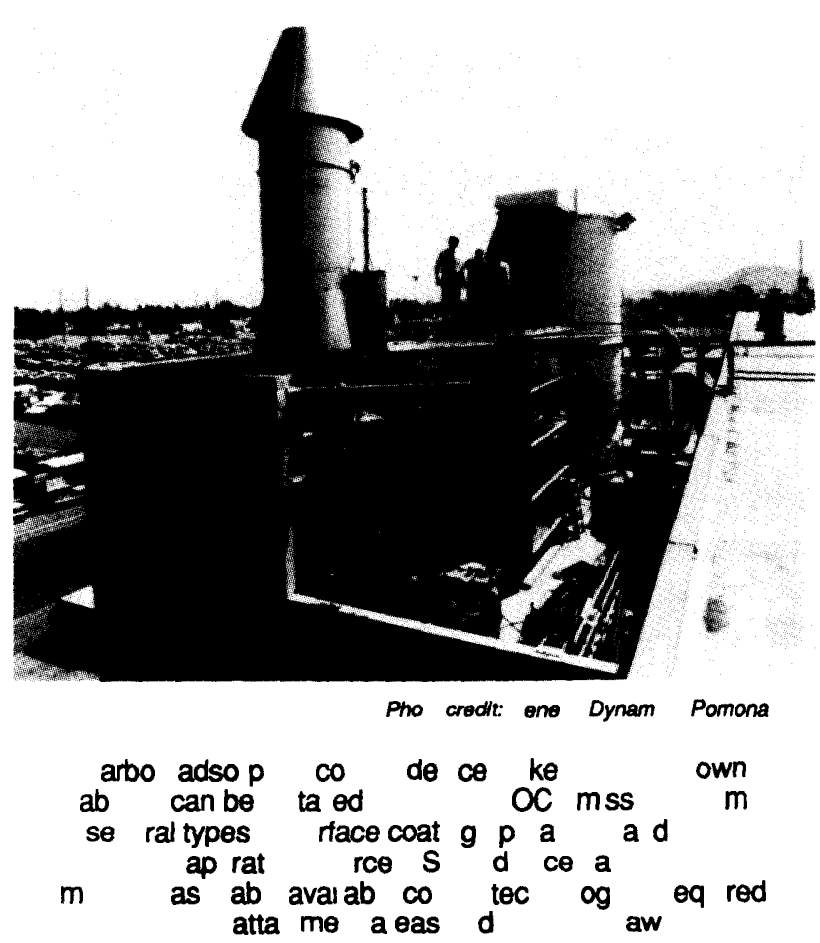

ing on design value. For example, Congress might maintain the current 100-ton-per-year cutoff in areas with design values close to the standard (e.g., 0.13 ppm or lower), require a 50-ton-per-year cutoff for most nonattainment areas, and require a 25 -ton-peryear cutoff for the worst areas. Estimating the reductions from such a change is quite difficult because the nationwide emissions inventory maintained by EPA does not include detailed information on sources that emit less than 50 tons per year of VOC. In chapter 6 , we estimate that emissions in nonattainment cities could be lowered by about 4 percent by requiring RACT-level controls for all sources that emit more than 25 tons per year.

Option 2: Require EPA to define RACT for additional source categories.

EPA has issued "control technique guidelines" (CTGs), which presumptively determine RACT for about 30 source categories. State and local agencies are able to use these documents as a basis for regulations in their nonattainment areas. EPA has not issued any new CTGs for several years. 
State regulatory agencies have been particularly strong advocates of requiring EPA to issue additional CTGs, both in OTA sponsored workshops and in a position paper by STAPPA/ALAPCO [15]. State air program administrators have stated that it is difficult for many agencies to impose controls on source categories for which EPA has not issued CTGs, even though the Act clearly states that all stationary sources in nonattainment areas must apply RACT-level controls.

STAPPA/ALAPCO recommends that EPA issue CTGs for at least the following source categories: hazardous waste treatment, storage, and disposal facilities; stage II vapor recovery; wood furniture coating; autobody refinishing; coke oven byproduct plants; bakeries; sewage treatment plants; synthetic organic chemical industry (SOCMI) batch process; SOCMI distillation; web offset lithography; metal rolling; plastic parts coating; and marine vessels.

We estimate that RACT-level controls on the frost seven source categories listed above could lower nonattainment area VOC emissions by about 8 percent in 1994. Note, however, that most of the reductions-about 68 percent-come from one source category, hazardous waste treatment, storage, and disposal facilities. Costs to implement these controls would total about $\$ 1.3$ billion per year in 1994.

Option 3: More stringent requirements for motor vehicle inspection and maintenance programs.

Improper maintenance, tampering with emissions control systems, and component defects all result in vehicle emissions in customer service at rates higher than the standard. To correct these deficiencies, Congress, in the 1977 Clean Air Act Amendments, required motor vehicle inspection and maintenance (I/M) programs in nonattainment areas that could not meet the standard by 1982 . Thirty States, plus the District of Columbia, have I/M programs in place. However, the effectiveness of the program varies considerably from State to State. A wellimplemented 1/M program, such as California's, can lower VOC emissions by about 12 percent and $\mathrm{NO}_{\mathrm{x}}$ emissions by about 4 percent [11]. Poorly implemented programs may achieve very little emissions reductions.
Obviously, for an I/M program to succeed, improperly functioning vehicles must be both identified and then repaired. Some programs employ test methods that allow many poorly functioning vehicles to pass; a few programs do not test tailpipe emissions at all but only perform a visual inspection. Other programs may identify poorly functioning vehicles but only require that repairs costing $\$ 50$ or less be made.

In a study of ways to improve California's existing I/M program, Sierra Research, Inc. identified a series of measures that could increase VOC reductions from $\mathrm{I} / \mathrm{M}$ from 12 percent of motor vehicle emissions (current effectiveness) to about 30 percent [10]. Such an "enhanced" I/M program would include: 1) more stringent emission standards, 2) centralized inspections or private garage inspections using computer-controlled analyzers with data recording, 3) visual and functional inspection of the emission control system, 4) repair cost ceilings high enough to ensure that most vehicles that fail the inspection will be completely repaired (about \$500), and 5) adequate inspection fees to cover the cost of doing the inspection properly [11].

Such a program would cost about $\$ 50$ per vehicle per year-\$20 per year for the inspection fee and program administration and repair costs averaging $\$ 70$ to $\$ 100$ for an estimated 20 to 35 percent of the vehicles that might fail. The program would lower total VOC emissions by about 1 percent and $\mathrm{NO}_{\mathrm{x}}$ emissions by about 3 percent by 1994. Total costs of an enhanced I/M program in all nonattainment areas would be about $\$ 1.5$ billion to $\$ 3.5$ billion per year.

Option 4: Required use of alternative fuels by centrally owned fleets.

In chapter 7, we discuss the emissions reductions that could be achieved by requiring centrally owned fleets of vehicles to use either methanol or compressed natural gas instead of gasoline. Methanol vehicles used within the next 10 years would probably be operated on blends of methanol and gasoline. CNG vehicles would probably be "dualfueled," operating part time on CNG and part time on gasoline, Although current projections of VOC reductions that could be realized are uncertain, our best estimate is that total (exhaust and evaporative) emission rates would effectively be about 30 percent lower for these alternatively fueled vehicles than for 
gasoline vehicles meeting current standards and operated on low volatility gasoline (Reid Vapor Pressure [RVP] of 9.0 pounds per square inch [psi]) $[1,20]$

Based on experience in the United States and elsewhere, it appears feasible to modify or design vehicles to operate on either CNG or methanol, with performance that is generally comparable to that of gasoline vehicles. The limited distance that can be driven on CNG without refueling is currently a disadvantage, compared to gasoline or methanol. Safety concerns related to the toxicity of methanol still need to be addressed before methanol/gasoline blends are widely utilized. Safety, emissions, and fuel economy standards are needed for CNG and methanol vehicles, and fuel storage and handling standards are needed for methanol.

Our analysis for the period through 2004 considered use of alternative fuels by vehicles that are owned and operated as fleets of 10 vehicles or more (e.g., by businesses or local governments) in areas with peak ozone concentrations of $0.18 \mathrm{ppm}$ or higher. We limit the requirement to the worst areas for two reasons: 1) at least over the next decade, the costs of switching to either methanol or CNG would be quite high; and 2) if methanol is the fuel of choice, demand for the fuel from the 17 areas considered would about equal upper bound estimates of current excess production capacity worldwide. Additional demand would increase the cost of the option further, and could not be met in the near term.

There are several advantages to requiring vehicles operated in fleets to use alternative fuels, rather than applying the requirements to vehicles in general service. Especially for vehicles that are refueled at a central location, the network of stations needed would be limited. And, although only about 6 percent of vehicles are in centrally owned fleets, they account for over 12 percent of the total mileage traveled each year, improving the cost effectiveness of conversion. Finally, fleet vehicles are currently replaced every 3 years, on average, compared to a 10 -year turnover rate for vehicles in general use, suggesting that benefits would accrue more rapidly with fleets.

We estimate that fleets in the areas we considered currently purchase about 500,000 vehicles per year. Subsidies might be needed to dissuade businesses from simply disbanding their fleets to avoid extra costs. In addition to requiring that fleets purchase alternative-fueled vehicles, manufacturers may have to be provided incentives or required to produce them.

Our best estimate is that use of methanol blends would lower in emissions in the areas in which it is required by about 0.5 to 0.7 percent per year, after full conversion of fleets of 10 or more vehicles. Use of $\mathrm{CNG}$ in fleets 75 percent of the time would lower emissions by about 1.3 percent.

Assuming that methanol blended with 15 percent gasoline is used, these reductions would cost from $\$ 8,700$ to $\$ 51,000$ per ton of VOCs eliminated, totaling $\$ 120$ million to $\$ 710$ million per year in areas with design values of $0.18 \mathrm{ppm}$ or higher. For dual-fueled CNG vehicles using CNG 75 percent of the time and gasoline the remaining 25 percent, the cost would be from $\$ 400$ to $\$ 22,000$ per ton. In both cases, the costs are extremely sensitive to fuel prices.

Use of alternative fuels in vehicles in general service is discussed under "Long-Term Control Strategies," below.

\section{Option 5: Transportation control measures.}

Under the general heading of "transportation control measures" (TCMs), people refer to a set of interrelated approaches that either reduce highway vehicle use or lower emissions per trip by increasing average vehicle speed. Examples of the former include improved public transit, highway lanes for the exclusive use of buses and carpools, bicycle lanes, parking management, and road-use restrictions or tolls. Measures such as traffic flow improvements and modified schedules for work do not lower highway vehicle use but can reduce emissions by reducing congestion, thus cutting the numbers of hours vehicles are on the road. Transportation control measures were included in most States' 1979 and 1982 SIP revisions, typically with only modest emissions reductions expected from them.

Since transportation control measures have to be tailored to local conditions, and since different programs will be most effective in different areas, States need to be allowed some flexibility in applying them. Tying the implications of failing to meet interim emissions reduction requirements to growth restrictions or limitations on Federal high- 
way funds could encourage local officials involved in transportation and land-use planning to participate in the development and implementation of TCMs.

The benefits of some programs, such as requiring companies to give their employees incentives for ride sharing, designating high occupancy vehicle lanes, and synchronizing traffic signals, can be realized fairly quickly. Experience in the Los Angeles area during the 1984 Olympics illustrated that some TCMs, for example, modified work and delivery schedules and increased transit service and usage, can yield substantial benefits with little lead time [14]. On the other hand, although the TCMs contained in the 1988 Air Quality Maintenance Plan for the Los Angeles area are expected to reduce highway vehicle VOC emissions by 30 percent in 2010 , only a 3 -percent reduction is expected from them in 1994 [13]. Because the potential for reducing emissions appears greatest if TCMs are viewed as long-term measures, further discussion of this option is presented in the section discussing "New Directions for the Clean Air Act."

\section{Option 6: Tax on gasoline.}

The cost of using one's car influences the number of miles per year that people travel. As the price of gasoline goes up, vehicle miles traveled go down, at least in the short term. A gasoline tax, therefore, is another available option for lowering emissions from highway vehicles in nonattainment areas. For the first few years of a tax set at about $\$ 0.25$ per gallon, automobile travel would be expected to drop about 8 percent. If a tax were set at about $\$ 0.50$ per gallon, automobile travel would be expected to drop about 15 percent during the first few years. Over the longer term, per capita travel might remain at the lower level, might drop even further if economical and convenient mass transit were made available, or most likely, per capita travel would begin to rise again as people compensated for the gasoline price hike by buying more fuel efficient cars.

If the only benefits one counts from a gasoline tax is the reduction in VOC emissions, the costeffectiveness of a gasoline tax is quite high. We estimate that the emissions reductions from a gasoline tax would cost about $\$ 35,000$ to $\$ 75,000$ per ton of VOC over the first few years, possibly
$\$ 100,000$ to $\$ 200,000$ per ton over the long term. Of course, there are additional benefits, including lower emissions of carbon monoxide, nitrogen oxides, and carbon dioxide; reduced highway congestion; and less reliance on imported oil.

\section{Managing Growth}

\section{Discussion}

Underestimating emissions growth is one of the most often cited reasons for the failure to meet the 1987 attainment deadline of the current Clean Air Act Amendments. In particular, few areas accurately forecast the increase in automobile use that occurred, offsetting much of the gains made by the lower motor vehicle emission standards required under the Act. This illustrates a problem with the present Clean Air Act. Most regulations control emission rates (e.g., grams of pollutant per mile traveled) rather than limiting the total amount of pollutant emitted throughout a nonattainment area. Thus, emission trends are the result of a race between declining emission rates and increasing use of goods and services.

In chapter 6, we presented our estimates of VOC emissions trends over the next 15 years, assuming no change in existing regulations. The projections serve as a baseline against which to gauge the effectiveness of future regulations, including a way to judge how well current regulations will manage future emissions growth. We estimate that total VOC emissions will continue to drop a few percent through about 1995 but then return to 1985 levels by 2004.

We project that the current motor vehicle control program will continue to lower highway vehicle emissions to about 30 percent below 1985 levels by 1999 and then emissions will begin to rise again. Without tighter standards or limits on vehicle use, gains from replacement of older vehicles by newer, cleaner ones will out pace emissions increases due to increased vehicle use by the mid to late 1990s in most nonattainment areas.

In contrast, stationary source emissions in nonattainment areas are forecast to increase steadily, showing a 10-percent increase by 1994 and about a 20-percent increase by 2004, over 1985 levels. 
Growth in emissions from small stationary sources (i.e., those emitting less than 50 tons of VOC per year) is the primary contributor to this increase.

Under the current Act, in nonattainment areas, new stationary sources emitting more than 100 tons per year or modified stationary sources emitting more than 40 tons per year must install controls that achieve the "lowest achievable emission rate" (LAER) for VOC. Moreover, emissions increases must be offset by emission reductions elsewhere in the nonattainment area. However, about 14 percent of stationary source VOC emissions originate from sources larger than 100 tons per year. Somewhere in the range of 55 to 80 percent of stationary source emissions originate from sources smaller than 25 tons per year. Thus, while the stationary source requirements of the current Act limit growth to some degree, a large majority of emissions are not affected by these regulations.

\section{Options}

Option 1: Lower the cutoff for new source control requirements.

As discussed above, current regulations require that in nonattainment areas, new stationary sources emitting more than 100 tons per year, or modified stationary sources emitting more than 40 tons per year, install controls that achieve the "lowest achievable emission rate" (LAER) for VOC. Lowering this threshold, for example to 25 or 50 tons per year for new sources and 10 or 20 tons per year for modified sources, would further control future emissions growth. Requirements to offset emissions increases should also apply to these smaller sources.

Option 2: Eliminate "netting out" of new source control requirements.

Current regulations allow sources to avoid the new source control requirements described above by lowering emissions at one place in a facility to keep the total facility-wide increase below 100 tons per year. For example, anew source that emits 120 tons per year in a larger facility does not have to install controls that achieve LAER if reductions of at least 20 tons per year are made elsewhere in the facility, keeping net emissions increases below 100 tons per year. Concern over this provision stems from the belief that in many cases, the reductions that are made elsewhere in the facility would have happened regardless of whether the new source was installed or not. Allowing netting, therefore, eliminates the reductions that might be achieved through normal operation improvements or retirement. We cannot estimate how often this loophole is exploited.

Eliminating netting would hold down emissions growth somewhat, but it is difficult to estimate the magnitude of reductions or costs from such a change. EPA has estimated that reductions of about 400,000 tons per year might be possible through tighter new source control requirements, including adoption of both this option and option 1 above [21]. A "back-of-the-envelope" calculation using our estimates of the distribution of source sizes and expected growth rates yields a considerably lower reduction estimate, about 100,000 to 150,000 tons per year.

\section{Option 3: Areawide emission ceilings.}

Most regulations under the Clean Air Act limit emission rates, not areawide emissions. increased motor vehicle use or growth in the number of, and therefore emissions from, small sources will eliminate some of the gains made from stringent emission regulations. In the section above on "Interim Requirements" we discuss the advantages and disadvantages of specifying areawide emission reduction schedules in addition to setting a deadline for attaining the standard. Such interim requirements might apply to total areawide emissions or apply only to a subset of sources that are particularly difficult to control. For example, areas might be limited to a specified rate of increase in vehicle miles traveled or might have limits on total solvent use within the area.

Though implementation of areawide emission limits would require an extensive and detailed inventory, the advantage is that nonattainment areas would be made accountable for all emissions increases on a continuing basis, rather than only by the attainment deadline, as is currently the case.

\section{NEW DIRECTIONS FOR THE CLEAN AIR ACT}

Controlling local VOC emissions will not be sufficient in many nonattainment areas to comply with the ozone standard. Part of the problem, of course, is that currently available control measures 
are inadequate to achieve the reductions that would be necessary. In some areas, though, it may be especially difficult to attain the standard if local $\mathrm{NO}_{x}$ emissions and/or VOC and $\mathrm{NO}_{\mathrm{x}}$ emissions in upwind areas are not reduced concurrently with local VOC emissions.

The starting point for this section is the assumption that the primary strategy for reducing urban ozone that is followed by EPA and most States will continue to be controlling VOC emissions in nonattainment areas. Focusing on the objective of reducing urban ozone, this section presents options for additional controls, including: 1) controlling NO, emissions in nonattainment areas, 2) controls on $\mathrm{NO}_{\mathrm{x}}$ and VOCs in areas upwind of nonattainment areas, and 3) several long-term strategies to attain and maintain compliance with the standard.

In a fourth section, we present options for reducing ozone in rural areas to prevent damage to crops and trees.

\section{Controls on Emissions of Nitrogen Oxides in Nonattainment Areas}

\section{Discussion}

Ozone is produced via chemical reactions involving both VOCs and NO,. In the past, EPA has encouraged exclusive reliance on control of VOC emissions to achieve compliance with the ambient air quality standard for ozone.

The effect of controlling $\mathrm{NO}_{\mathrm{x}}$ emissions in nonattainment areas will be mixed. If $\mathrm{NO}_{\mathrm{x}}$ emissions are controlled, peak ozone concentrations will be lower in some areas but higher in others, compared to levels that would have been obtained with VOC controls alone. Our ability to make reliable predictions about whether or not $\mathrm{NO}_{x}$ controls will be helpful is limited, at present, because the modeling and data gathering needed to do so have not been done for most cities. Even in the most well-studied area, Los Angeles, the issue is not clear cut: modeling studies suggest that the effects of $\mathrm{NO}_{\mathrm{x}}$ control differ across locations within the LA basin, and that they may change from day to day depending on meteorological conditions.

EPA has used its "Regional Oxidant Model" (ROM) to investigate the effect of reducing VOC and $\mathrm{NO}_{\mathrm{x}}$ emissions in the Northeast. Totaled overall of the urban areas in the modeling region, reducing $\mathrm{NO}_{\mathrm{x}}$ emissions by 27 percent and VOC emissions by 42 percent below 1980 levels is predicted to yield an improvement compared to controlling VOC emissions alone. However, underlying the overall improvement are impacts of $\mathrm{NO}_{x}$ control that vary from city to city. For example, in the Pittsburgh area, $\mathrm{NO}_{x}$ controls are predicted to increase potential population exposures to ozone concentrations above the standard, whereas in Hartford, they are predicted to be especially helpful in lowering them. These results should be considered preliminary, because ROM's development and evaluation are not complete. Moreover, changes in base emissions levels since 1980, and consideration of other control strategies or meteorological episodes might alter these conclusions.

Based on measurements of the balance in urban air between VOCs and $\mathrm{NO}_{\mathrm{x}}$, a very preliminary judgment can be drawn that in general, Southern cities are more likely to benefit from $\mathrm{NO}_{\mathrm{x}}$ controls than cities in the Midwest or Northeast. However, modeling calculations similar to those done for the Northeast would need to be done for the South before much confidence could be assigned to such a generalization.

As with VOC controls, two broad categories of $\mathrm{NO}_{\mathrm{x}}$ controls are possible: 1 ) federally implemented controls that apply nationwide and 2) controls implemented by the States in individual nonattainment areas. Given the characteristics of the problem, Congress may choose to treat the two categories differently. Congress may wish to allow the States or EPA to decide where to require those $\mathrm{NO}_{\mathrm{x}}$ control measures that can be implemented in some nonattainment areas without being imposed in others. For those controls that are difficult to implement area by area-in particular more stringent motor vehicle standards-Congress must judge whether the reductions will, overall, do more good or harm.

Complicating the decision about whether to mandate $\mathrm{NO}_{x}$ controls is our understanding that $\mathrm{NO}_{\mathrm{x}}$ emissions affect more than just nonattainment area ozone concentrations. $\mathrm{NO}_{\mathrm{x}}$ emissions contribute to acid deposition and are a major determinant of elevated ozone concentrations in agricultural and forested regions. Thus, Congress' decision about how to treat $\mathrm{NO}_{\mathrm{x}}$ emissions depends on the goals it 
is trying to achieve: 1) lowering peak ozone concentrations in urban areas, 2) lowering exposure of crops and forests to ozone over the growing season, and/or 3 ) reducing acid deposition levels. NO, reductions can have either a beneficial or detrimental effect on peak ozone concentrations in nonattainment areas, depending on city-specific conditions. NO, reductions will most likely lower both acid deposition and regional ozone concentrations.

In 1985, total $\mathrm{NO}_{\mathrm{x}}$ emissions in nonattainrnent areas were about 7.1 million tons. On average, mobile and stationary sources contribute about equally to $\mathrm{NO}_{\mathrm{x}}$ emissions in nonattainment areas, although the split varies from city-to-city. Without new controls, $\mathrm{NO}_{\mathrm{x}}$ emissions in nonattainment areas in 2004 are projected to be 8.7 million tons (a 23 -percent increase), with about 30 percent of the total from highway vehicles and about 45 percent from large stationary sources. Almost no growth is anticipated in highway vehicle emissions between now and 2004, as increased vehicle miles are expected to be offset by lower $\mathrm{NO}_{\mathrm{x}}$ emissions per vehicle.

\section{Options}

Option 1: Congressionally mandated $\mathrm{NO}_{\mathrm{X}}$ controls.

By imposing a package of more stringent lightduty vehicle exhaust standards, ${ }^{13}$ nonattainment area $\mathrm{NO}_{\mathrm{x}}$ emissions could be reduced by about 0.5 million tons (about 7 percent of 1985 levels) in 2004. Nationwide, a total of 1.3 million tons of $\mathrm{NO}_{z}$ would be eliminated, at a cost of $\$ 2.9$ billion (combined cost for both more stringent VOC and $\mathrm{NO}_{\mathrm{x}}$ controls). New standards have already been adopted in California, to take effect in 1990, so no reductions there are attributed to this option (i.e., 1.3 million tons are reduced outside of California).

Since 1977, California has had more stringent $\mathrm{NO}_{\mathrm{x}}$ standards for motor vehicles than the rest of the United States. As an alternative to legislating a more stringent standard nationwide, Congress could choose to continue having two sets of motor vehicle $\mathrm{NO}_{\mathrm{x}}$ standards, but extend the applicability of the stricter standard beyond California. For example, cars sold in States with ozone nonattainment areas might be subject to more stringent standards than cars sold in other States. About 10 States do not have any nonattainment areas.

Option 2: Presumptive NO controls, with EPA authority to exempt areas under specified situations.

In chapter 7, we estimate emissions reductions from applying "reasonably available" control technology (RACT) for nitrogen oxides to five stationary source categories: electric utility boilers, industrial boilers, stationary engines, gas turbines and process heaters. Imposing RACT-level controls on electric utility boilers that are located in nonattainment areas and emit more than 100 tons per year of $\mathrm{NO}_{\mathrm{x}}$ would result in emissions reductions in 2004 of about 0.9 million tons (about 13 percent of the 1985 nonattainment area total), at a cost of $\$ 360$ million per year. RACT-level controls for the other four source categories would result in reductions of 0.3 million tons (about 5 percent) in the year 2004, and cost about $\$ 310$ million per year. Control technology also exists that would reduce $\mathrm{NO}_{\mathrm{x}}$ emissions from electric utility boilers by approximately twice as much as RACT. Application of this technology in all nonattainment areas would cost over $\$ 8$ billion.

As discussed in the section above on nonattainment area-specific controls, an "enhanced" inspection and maintenance (I/M) program for highway vehicles could lower total VOC emissions in nonattainment areas by about 2 percent, and $\mathrm{NO}_{\mathrm{x}}$ emissions by about 3 percent. Most of the currently operating I/M programs focus on VOCs, carbon monoxide, or both. If $\mathrm{NO}_{x}$ requirements were added in all nonattainment areas, reductions of about 200,000 tons could be obtained in 2004 from enhanced I/M programs. Attributing one-sixth of the

\footnotetext{
${ }^{12}$ Current exhaust standards for $\mathrm{NO}_{\mathbf{x}}$ were listed in the earlier section on federally implemented controls.

${ }^{13}$ The new emission standards used in our analysis are as follows:

(in grams of pollutant emitted per mile travelled [g/mile] for non-methane hydrocarbons $\left[\mathrm{NMHC}\right.$ ] and $\mathrm{NO}_{\mathbf{x}}$ )

Passenger cars- NMHC: $0.25 \mathrm{~g} /$ mile; $\mathrm{NO}_{\mathbf{x}}: 0.4 \mathrm{~g} /$ mile

Light-duty gasoline trucks (by truck weight)-

(less than 3,750lbs) NMHC: $0.34 \mathrm{~g} / \mathrm{mile} ; \mathrm{NO}_{\mathbf{x}}: 0.46 \mathrm{~g} /$ mile

(3,751 to $6,000 \mathrm{lbs})$ NMHC: $0.43 \mathrm{~g} /$ mile; $\mathbf{N O}_{\mathbf{x}}: 0.80 \mathrm{~g} / \mathrm{mile}$ (6,000 to 8,500 lbs) NMHC: $0.55 \mathrm{~g} /$ mile; $\mathrm{NO}_{\mathrm{x}}: 1.15 \mathrm{~g} / \mathrm{mile}$
} 
total cost of enhanced $\mathrm{I} / \mathrm{M}$ programs to $\mathrm{NO}_{\mathrm{x}}$, these reductions would cost about $\$ 500$ million. We assume that enhanced $\mathrm{I} / \mathrm{M}$ programs would not be required for the sake of $\mathrm{NO}_{\mathrm{x}}$ reductions alone, but to reduce VOC and in some cases $\mathrm{CO}$ emissions as well.

Because both stationary source control measures and highway vehicle I/M programs are implemented at the State or local level, Congress can be selective about where to require them. For example, Congress might limit imposition of these $\mathrm{NO}_{\mathrm{x}}$ control requirements to nonattainment areas with design values above a specified cutoff (e.g., $0.16 \mathrm{ppm}$ and higher). Congress could also allow the Administrator to exempt areas where he or she determines that stationary source $\mathrm{NO}_{\mathrm{x}}$ controls would be ineffective or counterproductive.

\section{Option 3: Requirements for evaluating $\mathrm{NO}_{x}$} controls.

Rather than presumptively requiring $\mathrm{NO}_{\mathrm{x}}$ controls, Congress could require some States to assess their likely impact on air quality, and require them if they appear beneficial. ${ }^{14}$ Areas in which available VOC controls were not sufficient to enable them to meet the standard by a specified deadline could be targeted for this requirement. Based on our analysis, this would include most areas with design values of $0.16 \mathrm{ppm}$ or higher. $\mathrm{NO}_{\mathrm{x}}$ controls could be mandated in these areas if analysis indicates that, for example, peak ozone concentrations or some measure of exposure to concentrations above the standard, would be lower with $\mathrm{NO}_{\mathrm{x}}$ controls than with the available VOC controls alone. Note that it might also be useful for areas with high ratios of VOC to $\mathrm{NO}_{\mathrm{x}}$ concentrations (greater than about 12 to 1 ) to be included in this requirement, as theory suggests that controlling $\mathrm{NO}_{\mathrm{x}}$ is likely to be especially effective for reducing ozone in these areas. Enhanced air quality modeling efforts are needed to produce a full evaluation of the impact of $\mathrm{NO}_{\mathrm{x}}$ controls. However, as discussed in an earlier section on planning requirements, the limited number of people who know how to run state-of-the-art air quality models may pragmatically limit the number of areas that can be required to use them.

\section{Controls in Upwind Areas}

\section{Discussion}

Both ozone and its precursors, VOCs and $\mathrm{NO}_{x}$, can be transported into nonattainment regions from upwind areas. Thus, some fraction of the ozone found in nonattainment areas is not subject to local regulatory authority. If the upwind area is also a nonattainment region, further control will take place to bring the area into attainment with the standard. However, if the upwind region already meets the standard, the only controls that can be expected are those that are federally mandated nationwide.

Thus, two issues may have to be addressed by Congress. First, current law does not provide an adequate mechanism to implement additional controls in selected areas that currently attain the standard, but contribute to ozone nonattainment problems in areas downwind. A similar limitation applies to requiring reductions in nonattainment areas. Current law does not include an adequate mechanism to force nonattainment areas to undertake emission reductions in excess of the amount required to attain the standard, even though the area might still be contributing to the nonattainment problem of another area downwind.

In chapter 5 we discuss which areas seem most likely to be significantly affected by pollutant transport from outside their region. The Eastern Seaboard, from Richmond to Maine, is the clearest situation of an interstate region that might require coordinated management. In the central part of the country, interstate transport is likely around Lake Michigan, and possibly between Cleveland and Erie, PA. In the South, transport appears likely in the coastal areas of Texas and Louisiana, and may also be contributing to nonattainment problems in parts of the Southeast. Finally, though within State borders, pollutant transport from one city to another is also a problem in central California.

Certainly some of these transport-related problems will be helped by the imposition of further controls in nonattainment cities. However, given the limits on the emissions reductions feasible with currently known control measures, many areas will

\footnotetext{
${ }^{14}$ If this option is chosen, it is important to be explicit about what is meant by the term "beneficial," because controlling $\mathrm{NO}_{\mathrm{x}}$ can give mixed results. As a hypothetical but plausible example of the kinds of contrary outcomes that are possible $\mathrm{NO}_{\mathbf{x}}$ controls could help lower peak ozone concentrations in a city from $0.18 \mathrm{ppm}$ to $0.15 \mathrm{ppm}$, but at the same time increase the number of areas within a city where concentrations reach $0.13 \mathrm{ppm}$.
} 
not be able to attain the standard in the near term. Moreover, in some regions (for example, the Southeast) much of the ozone transported into nonattainment cities may be originating from areas that meet the standard.

Unfortunately, it is easier to identify that a transport problem might exist than it is to identify solutions to the problem. The first question is which pollutant should be controlled, VOCS or $\mathrm{NO}_{x}$ ? Next, one must attempt to define an appropriate control region size-e. g., 50 miles around nonattainment cities significantly affected by transport, whole States, or multi-State regions?

Theoretical considerations suggest that in most situations reducing $\mathrm{NO}_{x}$ emissions in attainment areas would either reduce ozone in nonattainment areas or have negligible effect, but would usually not be counterproductive. $\mathrm{NO}_{\mathrm{X}}$ reductions in attainment areas would affect ozone concentrations in nonattainment areas by reducing ozone produced upwind. $\mathrm{NO}$, controls in attainment areas would be expected to help reduce ozone in rural areas, as well as acid deposition.

$\mathrm{NO}_{\mathrm{x}}$ itself is unlikely to be transported further than about 100 miles. However, our best guess of an upper bound to the distance over which major point sources of $\mathrm{NO}_{\mathrm{x}}$ could have more than a negligible influence on downwind ozone is on the order of 300 miles-a distance over which ozone produced from the $\mathrm{NO}_{\mathrm{x}}$ could be transported. We guess that aggregate emissions from mobile or area sources could have a similar scale of impact.

The relative amounts of $\mathrm{NO}_{\mathrm{x}}$ emitted in attainment areas versus nonattainment areas varies significantly by region. In the Northeast, about 40 percent of the region's $\mathrm{NO}_{\mathrm{x}}$ is emitted in attainment areas. In the South and Midwest, attainment areas contribute about 70 percent of regional $\mathrm{NO}_{\mathrm{x}}$ emissions.

In 1985, about 60 percent of $\mathrm{NO}_{\mathrm{x}}$ emissions in attainment areas came from stationary sources and 40 percent from mobile sources. By 2004, without further controls, we project the relative contributions to be about 65 percent from stationary sources and 35 percent from mobile sources.

Reducing manmade VOC emissions in attainment areas will either reduce ozone in nonattainment areas or have negligible effect. VOC emissions in attain- ment areas would affect nonattainment area ozone primarily by reducing VOCs transported into the area from upwind. Theory suggests that VOC controls in attainment areas could help reduce ozone in some rural areas, but would generally be less effective than $\mathrm{NO}_{\mathrm{x}}$ controls. VOC controls would have a negligible effect on region-wide acid deposition levels. Note that in some parts of the country, less than half of the total VOC emissions in attainment areas are subject to control, as VOC emissions from vegetation exceed manmade emissions. As discussed in chapter 5, emissions from vegetation are especially high in the Southeast, but are also high in forested areas of the Northeast, Southwest, and Northwest.

Distances over which various volatile organic compounds can be transported range from a few miles to several hundred miles, depending on how quickly the individual compounds react away. However, the VOCs that travel farthest tend to be least efficient at producing ozone-so fresh emissions not only are more concentrated but are also likely to be more reactive than transported emissions. Our best guess of an upper bound distance over which VOCs from attainment areas would have an observable impact on ozone in downwind cities is on the order of 100 miles.

As with $\mathrm{NO}=$, the proportion of VOCs emitted in attainment areas versus nonattainment areas varies by region. In the Northeast, about 40 percent of manmade VOCs are emitted in attainment areas. In the South, attainment areas contribute about 70 percent of manmade emissions. In the Midwest, attainment areas contribute about 60 percent of the region's manmade VOC emissions.

In 1985, about 50 percent of the manmade VOC emissions in attainment areas were from stationary sources and $\mathbf{5 0}$ percent were from mobile sources. By 2004, without further control, we estimate that about 60 percent will come from stationary sources and 40 percent from mobile sources.

\section{Options}

Option 1: Enlarge nonattainment areas to include the entire extended metropolitan area.

In its proposed post-1987 policy, EPA suggested that ozone nonattainment areas be defined as including (at least) the entire "metropolitan statistical 
area" (MSA) or "consolidated metropolitan statistical area" (CMSA) in which the ozone standard is violated. ${ }^{15}$ The Washington, DC MSA, for example, extends over 100 miles, from the Pennsylvania border north of Frederick, MD; south and east to Solomons, VA on the Chesapeake Bay; and west to Middleburg, VA. In the past, some designated areas only encompassed the central urbanized city or county of the metropolitan area. Our analysis of emissions reductions has used MSA boundaries to define nonattainment areas.

Congress could adopt EPA's suggested new definition of an ozone nonattainment area. Or, Congress could further expand nonattainment areas out beyond MSA or CMSA boundaries. For purposes of reducing VOC emissions that may affect peak ozone concentrations within an urbanized area, an upper bound on how far nonattainment areas should be expanded is about 100 miles. Specified control requirements could automatically be applied throughout expanded areas. Alternatively, the States could be required to determine whether controls in these areas would be beneficial, with imposition left to their discretion.

Option 2: Congressionally specified $\mathrm{NO}_{\mathrm{X}}$ controls in designated "transport regions" or nationwide.

Congress could require "reasonably available" control technology (RACT) for large stationary sources of $\mathrm{NO}_{\mathrm{x}}$ in attainment areas as well as nonattainment areas. Again, Congress can be selective about where to require stationary source control measures. If the goal is to lower nonattainment area ozone concentrations, stationary source $\mathrm{NO}_{\mathrm{x}}$ control requirements could be limited to States with or adjacent to nonattainment areas. Rural ozone impacts (discussed below) and acid deposition might also be considered in determining where stationary source $\mathrm{NO}_{\mathrm{x}}$ controls should be required. Congress could allow the Administrator to exempt areas where he or she determines that stationary source $\mathrm{NO}_{\mathrm{x}}$ controls would be ineffective.

Excluding States that do not have nonattainment areas, imposition of RACT-level standards for utility boilers in attainment areas would result in $\mathrm{NO}_{\mathrm{x}}$ emissions reductions of about 15 percent below 1985 levels. RACT for other stationary sources in attainment areas would reduce emissions by an additional few percent.

Nationwide imposition of more stringent lightduty vehicle exhaust standards (discussed above) could result in about a 5-percent reduction in attainment area $\mathrm{NO}_{\mathrm{x}}$ emissions.

Option 3: Strengthen the interstate transport provisions of the Clean Air Act.

Section 110(a)(2)(E) of the Clean Air Act requires that SIPS "prohibit any stationary source within the State from emitting any air pollutant in amounts which will prevent attainment or maintenance [of standards] by any other State. "Section 126 allows States or local areas to petition the Administrator for a finding that any major source violates section 110, and allows the Administrator 60 days after receipt of the petition to make the finding. Once such a finding is made, proposed sources are prevented from being constructed and existing sources must be brought into compliance within 3 years. ${ }^{16}$

To date, EPA has not issued regulations to establish what constitutes compliance with section 110 , and has not granted any petitions under section 126, although some of the petitions filed have been resolved through the SIP or permit review processes. EPA has required petitioners to establish that an actual violation of an applicable standard has occurred, and that the out-of-state source is a "significant" contributor to the violation. Claims have been required to be supported by monitoring data or modeling studies. But EPA has not considered the modeling techniques used to predict violations to be sufficiently reliable to demonstrate the connection between emitting and receiving regions or to distinguish local from interstate contributions.

Sections 110 and 126 of the Clean Air Act could be amended to define more clearly how much of an impact of one State's emissions on

\footnotetext{
${ }^{15}$ In addition, EPA has suggested that it will require that emissions from major point sources ofVOC and $\mathrm{NO}_{\mathrm{x}}$ located within 25 miles of the MSA or CMSA boundaries be included in the area's emissions inventory. This implies that these sources would be included in the agency's proposed area-wide average 3 percent per year VOC emissions reduction requirements.

${ }^{16}$ Section 126 \&SO requires notification if a major proposed or existing source in one State may "significantly contribute" to levels of air pollution in excess of the NAAQS in another State.
} 
another State's air quality is prohibited; to clarify where the burden lies in proving that an impact is or is not significant enough to take action against; and to specify factors that EPA should consider in determining what measures to require of the offending sources. Congress could broaden the applicability of the prohibition in section 110 from "any stationary source" to include groups of sources-such as an upwind MSA or State-and then amend Section 126 accordingly. If Congress chooses to rely on mechanisms similar to those provided by sections lo and 126 , the question of whether $\mathrm{NO}_{\mathrm{x}}$ controls could be required when they might be counterproductive in the emitting State should be addressed explicitly.

Option 4: Provide EPA with clear authority to develop regional control strategies based on regionalscale modeling.

Over the past several years EPA has developed, and is currently working jointly with Northeastern States to apply, a regional-scale atmospheric model for the entire Northeast called the Regional Oxidant Model, or ROM. EPA proposes to use ROM, by the end of 1990, to test whether the independently developed, local attainment strategies of nonattainment areas in that region are adequate, or whether further emissions reductions are necessary. If the modeling analysis indicates that further controls are needed, EPA has proposed to use its authority to require SIP revisions to obtain them. While EPA "does not anticipate the need for a regional model in areas outside the northeast region at the present time" [22], interstate transport may also be complicating the nonattainment problems of areas in the southern Lake Michigan and Gulf Coast regions.

Affirming EPA's proposed policy for the Northeast, Congress could require the Agency to apply regional-scale modeling in specified regions to ensure compliance with an amended section lo. The modifications to section 110 specified above would be applicable. Moreover, Congress could specify that once the modeling is completed, EPA is required to review all applicable SIPS. (A recent court interpretation of section lo holds that the section does not require reevaluation and revision of existing SIPS, unless the SIP is being revised for another reason. ${ }^{17}$ )

Several years and several million dollars would be required to develop programs for regions other than the Northeast. As mentioned above, the Gulf Coast, Southeast, and Great Lakes regions are potential candidates.

\section{Reducing Ozone in Rural Attainment Areas}

\section{Discussion}

Elevated concentrations of ozone occur in rural areas throughout the southern and eastern halves of the United States. Nationwide, reducing daytime, growing-season-average ozone concentrations by about 25 percent $^{18}$ in crop-producing areas is estimated to result in annual benefits from increased crop yields in the range of $\$ 0.5$ billion to $\$ 1.0$ billion per year. Reducing ozone concentrations outside of urban areas would also reduce damage to trees in national parks as well as commercial timberlands. However, the impacts of ozone on trees and on forest ecosystems are not understood well enough to support evaluation of the forest-related benefits of reducing ozone.

Rural ozone essentially has two sources, either of which could be a target for control-pollution that is transported from urban areas, and pollution that is produced locally. At present, there are no estimates of the comparative contributions of these two sources. Controls imposed in nonattainment areas (for VOC or VOC and $N O_{x}$ ) will help reduce ozone at rural sites impacted by urban "plumes" of elevated ozone concentrations. Such plumes have been observed to extend more than 200 miles downwind of some cities.

For reducing ozone produced locally, outside of urban areas, theory (including modeling exercises with hypothetical "typical" rural conditions) suggests that $\mathrm{NO}_{\mathrm{x}}$ control will generally be more beneficial than VOC control. Although they do not allow us to sort out benefits of urban versus nonurban controls, results from EPA's ROM sug-

171852 F.2d 574 (D.C. Cir. 1988)

${ }^{18}$ In our analyses, we lower ozone concentrations by 25 percent of the difference between current levels and natural background. 
gest that either controlling VOC emissions alone or controlling both $\mathrm{VOC}$ and $\mathrm{NO}_{\mathrm{x}}$ emissions would help reduce ozone in rural areas in the Northeast.

\section{Options}

Option 1: Specify a deadline for EPA reconsideration of the ozone secondary standard for ozone and a schedule for adoption by the States.

The Clean Air Act establishes two types of air quality standards. "Primary" air quality standards are set by EPA to protect against adverse health effects. "Secondary" standards are established to protect against adverse impacts on human comfort and welfare, including impacts on visibility, vegetation, animals, wildlife, materials, and property. The States, together with EPA, are responsible for ensuring that the primary air quality standards are met "as expeditiously as practicable," within the deadlines specified in the Act. The secondary standards are to be attained in a' "reasonable" period of time.

The secondary standard for ozone is currently set as a one-hour average concentration of $0.12 \mathrm{ppm}$, i.e., identical to the primary standard set to protect human health. The standard is under review by EPA, as it is generally thought to be poorly designed for protecting vegetation.

To date, definition of an appropriate secondary standard for ozone has been hampered by: 1) the preliminary status of assessment of its impact on forests; and 2) uncertainty about whether peak or long-term concentrations are most important in determining impacts on vegetation. Implementation of secondary standards for all of the criteria pollutants has been neglected, as evidenced by the scarcity of air quality monitors located in rural areas. Congress could direct EPA to put more effort into developing and enforcing a secondary standard for ozone.

Option 2: Congressionally specified $N O_{x}$ controls.

We estimate that imposing more stringent lightduty vehicle exhaust standards nationwide would reduce $\mathrm{NO}_{x}$ emissions by a total of 1.3 million tons (7 percent of 1985 levels) in 2004, at a cost of $\$ 2.9$ billion (for both $\mathrm{NO}_{\mathrm{x}}$ and VOC controls).

Nationwide imposition of RACT-level standards for utility boilers in both attainment and nonattainment areas would result in $\mathrm{NO}_{\mathrm{x}}$ emissions reductions of 3.7 million tons (about 20 percent of the nationwide 1985 total) in 2004. Nationwide RACT for other stationary sources would reduce emissions in 2004 by about 800,000 tons ( 4 percent).$^{19}$

\section{Long-Term Control Strategies for Chronic Nonattainment Areas}

\section{Discussion}

About half of the current nonattainment cities may require greater emissions reductions to attain the standard than are achievable with near-term control methods. Figure 6-12 displays our estimate of VOC emissions in 1994, after all of the controls discussed in chapter 6 have been applied. Note that emissions from solvents-surface coatings and many other sources of organic solvent evaporation-will account for about 35 percent of the remaining inventory. Highway vehicles and the gas stations that fill them will account for an additional 35 percent.

Longer term strategies to bring the remaining nonattainment areas into compliance with the standard will have to include one or both of these emissions categories-and in some cities, progress in other categories as well. Within this section we consider three possible targets of opportunity for post-2000 emission reductions. These include: ways to lower organic solvent emissions, long-term transportation control measures, and use of alternative motor vehicle fuels such as methanol and compressed natural gas (CNG). Each of these was discussed in detail in chapter 7 .

\section{Options}

\section{Option 1: Lowering emissions from solvents.}

As described in chapter 7, organic solvents are used in a myriad of products and manufacturing processes. They are used to clean many types of products, from decreasing metals to drycleaning fine

\footnotetext{
${ }^{19}$ The majority of these reductions ( 56 percent) would occur in the South;17 percent would occur in the Midwest;and 9 percent would occur in the Northeast.
} 
clothing; to deliver surface coatings, including house paints, printing inks, and coatings on many manufactured products from cans to furniture to magnetic tape; and in consumer products such as pesticides and deodorants.

Solvent emissions can be lowered in many ways. In some instances it is possible to switch to alternative products that use no solvent (for example, using water-based rather than oil-based paints). Products can be reformulated so that less solvent is used or solvents that are not photochemically reactive are substituted for those that are involved in ozone formation. Manufacturing methods can be changed so that less solvent is emitted per unit manufactured. And finally, emissions can be captured or destroyed through control methods such as incineration, preventing release to the atmosphere.

However, for many products and processes, low or no-solvent alternatives are not available and alternative manufacturing methods may not deliver the desired quality end product. Thus, unlike for many other source categories for which significant reductions can be achieved by applying "reasonably available control methods" or "best available control methods," the problem of solvent emission reduction faced by Congress, EPA, and the States is to force the development of new products, manufacturing processes and control methods.

This problem is not without precedent. When Congress directed EPA in 1970 to develop regulations that lowered motor vehicle emissions by 90 percent, the technology to achieve this was not available. Congress decided to force development of technology by choosing a percentage reduction target and a date by which it was to be reached, and by adopting penalties to provide additional incentives for manufacturers to develop technologies that would comply with the new law. Deadlines were slipped many times and several have yet to be reached, but tailpipe emissions of VOC, nitrogen oxides, and carbon monoxide have been lowered considerably.

We have identified three basic approaches that Congress can take to facilitate reductions in solventrelated emissions and promote innovative approaches to achieve these reductions:
1) Direct EPA to issue "reasonably available control measures" for specified solvent uses and source sizes. Some categories for which Federal guidance or regulations could be issued in the near future were discussed in earlier sections of this chapter. Under this option, EPA would be directed to continue developing control technique guidelines (CTGs) for new categories of sources or develop Federal regulations that apply nationwide. In some instances, size cutoffs could be lowered from current levels or eliminated altogether.

2) Direct EPA or the States to issue regulations to lower solvent-related emissions by a specified percentage by a certain date. Rather than specifying particular solvent uses, Congress could specify the desired emissions reduction schedule and leave the choice of solvent uses to be regulated to either EPA or the States.

3) Provide clear authority in the Clean Air Act for EPA or the States to use a market-based approach for controlling emissions and, in the latter case, direct EPA to provide model regulations as guidance for the States. Two basic approaches would either: 1) impose fees or surcharges on emissions or products with high solvent content, making the fees high enough so that it is cheaper to control emissions or find substitutes than to pay them; or 2) distribute permits to producers or users that allow them to emit a specified amount of VOCs, and then cut back gradually on the permitted levels. Trades would be allowed among sources so that those who could reduce emissions at the least cost could reduce more than required, and "sell" their extra reductions to others for whom reductions were more expensive.

Of the three options listed above, the marketbased strategy deviates most from traditional control approaches. We did not evaluate whether fees or permits or some variation of these approaches would be best suited to VOC or solvent regulation. Nor did we analyze in detail the advantages and disadvantages of market-based approaches compared to more traditional regulatory systems in which EPA or State engineers identify available control technology for specific source categories and require those sources either to use them or match the reductions obtained with them by using other measures. However, market-based approaches seem to offer enough promise for cutting costs and promoting develop- 
ment of new ways to reduce emissions that Congress might choose to direct EPA to seriously evaluate their use for lowering solvent-related emissions.

Though the Clean Air Act does not preclude the use of market incentives, most of the Act is devoted to establishing a regulatory system based on the traditional "engineering" approach. By clearly stating its intent that market-based approaches are acceptable, Congress could at least allow them to be considered on their merits. If Congress decides that a market-based strategy is the preferred approach, then EPA could be required to develop model regulations for the States to adopt.

Option 2: Long-term transportation control measures.

The 1988 Air Quality Maintenance Plan for Los Angeles estimates that by 2010, highway vehicle emissions could be reduced by 30 percent below where they otherwise are projected to be, by using a suite of complementary transportation control measures ranging from parking management to highway expansion to telecommuting. Total daily reductions anticipated in 2010 are 10 times higher than those expected from the program in 1994, as measures focused on new businesses or developments take effect, and as freeway expansion projects are completed. Growth management measures aimed at matching new jobs with nearby housing account for about 40 percent of the reductions projected for 2010, but have negligible impact in 1994. These measures entail assessing development fees, modifying zoning rules, and policies for location of new public facilities and infrastructure. An additional 15 percent of the expected reductions would come from freeway capacity enhancements to reduce congestion.

Of the remaining measures, about 30 percent of the reductions come from a series of measures aimed at lowering highway vehicle usage. These are primarily strategies to reduce the number of singleoccupancy car trips, including employer ride share and mass transit incentives, parking management (increase parking meter fees, eliminate peak-period on-street parking, eliminate employer-subsidized parking, etc.), van pool purchase incentives, auto use restrictions, and high-occupancy vehicle (HOV) lanes. About 15 percent of the reductions come from measures that do not lower vehicle usage but rather reduce congestion. Reducing congestion decreases the number of hours that vehicles are on the road and thus lowers emissions. These include such measures as traffic flow improvements (e.g., metering on highway ramps, synchronized traffic signals, and intersection improvements) and rescheduling and rerouting of truck deliveries away from congested areas during peak commute hours.

For Los Angeles, such reductions would occur at a crucial period. Highway vehicle emissions are forecast to drop over the next 10 years due to the replacement of older cars and trucks with more stringently controlled ones. After 2000, however, emissions are forecast to rise again due to population growth. The hoped for 30-percent reduction due to transportation control measures is enough to more than offset the expected emissions growth between 2000 and 2010, keeping highway vehicle emissions on a slight downward trend.

The potential for reducing emissions appears greatest if TCMs are viewed as long-term programs. To guide SIP revisions likely to be required in the interim, areas could be required to develop TCM programs over 15 - to 20 -year time horizons and include them in urban transportation and land-use plans. Periodic updates would accommodate changes in development patterns and transportation requirements, etc.

In addition to requiring that States use TCMs, Congress may want to require that air quality objectives are given higher priority in federally funded urban transportation projects. Section 176(c) of the 1977 Amendments was an attempt to provide a check on the air quality impacts of all projects supported by Federal highway and mass transit funds by requiring that federally funded projects "conform" to State Implementation Plans. However, DOT, which distributes Federal highway and mass transit assistance, has sought to equate "conformance" with a narrow finding that a transportation plan or project does not interfere with transportation control measures included in SIPs [19]. EPA has suggested a broader requirement that transportation plans and projects "should not cause or contribute to existing or new standard violations, or delay attainment" [3]. Congress could clarify or strengthen the conformance requirements of section 176(c) to support EPA's interpretation. 
Option 3: Requirements for widespread use of alternative fuels in nonattainment areas that are far from meeting the standard.

We estimate that for every 25 percent of light-duty vehicles using alternative fuels in 2004, VOC emissions would effectively be reduced by 1.5 to 4 percent, compared to 1985 levels. The lower level of reductions is our best estimate. Achieving greater reductions from alternative fuels would require exclusive use of methanol or compressed natural gas in each vehicle, as opposed to use of methanol/ gasoline blends or vehicles that could run on gasoline or alternative fuels. Achieving the greater reduction levels would also require significant advances in vehicle technology, and vehicle designs and operating parameter adjustments to ensure minimal emissions.

Assuming that methanol blended with 15 percent gasoline is used, and the lower levels of reductions cited above are achieved, we estimate that costs would be $\$ 8,700$ to $\$ 66,000$ per ton of VOCs reduced. Assuming use of CNG 75 percent of the time and use of gasoline for the remaining 25 percent, cost-effectiveness would fall in the range of $\$ 3,900$ to $\$ 22,000$ per ton. If the upper bound level of reductions can be achieved, the cost of using straight methanol could be as low as $\$ 3,200$ to $\$ 22,000$ per ton. Exclusive use of CNG could result in costs between $\$ 1,600$ to $\$ 14,000$ per ton. In each case, costs are extremely sensitive to fuel prices.

Obviously, for vehicles in general use to operate on CNG or methanol, both vehicles and fuel have to be made available. Establishing fuel production capacity, fuel distribution networks, and motor vehicle production lines entails major investments, and simultaneous and appropriately scaled commitments are needed in each area. Current estimates of the economics of using alternative fuels, compared to gasoline, suggest that either subsidies or mandates from Federal or State government will be needed if alternative fuels are to be used in general service in the next 10 to 15 years.

Using California as an example, a fixed percentage of each major automobile manufacturer's new vehicle sales in the State might be required to be either CNG or methanol fueled. Vehicle registration fees or tax credits could be used to equalize the cost of alternative and gasoline-fueled vehicles. Similarly, fuel retailers could be required to offer alternative fuels at a fixed percentage of their stations, and gasoline taxes could be set to about $\$ 0.25$ to $\$ 0.50$ per gallon to allow methanol to compete with gasoline on a cents per mile basis.

Flexibly fueled vehicles that can run on methanol or gasoline or any combination of the two, and dual-fueled CNG vehicles that can run on gasoline or $\mathrm{CNG}$, would be easier to introduce into general service than vehicles operated exclusively on CNG or methanol, because they could be operated out of range of refueling stations that supplied the alternative fuels. Where improvements in air quality are the major motivation for using alternative fuels, however, these vehicles have two disadvantages: low emissions that might be possible with the alternative fuels would be compromised to provide for satisfactory operation on multiple fuels; and consumers might simply choose not to operate them on the alternative fuel. The second problem could be addressed by using taxes or subsidies to encourage alternative fuel use. The first problem suggests that flexibly or dual-fueled vehicles should only be viewed as a transition measure.

In addition to developing the necessary infrastructure, government intervention may be needed to increase the likelihood that low emission rates can be realized, so that from an air quality standpoint, alternative fuels will be worth the investment. This could take the form of government-funded research and development efforts. Alternatively, manufacturers could be required to produce a fixed percentage of vehicles meeting new, technology forcing emissions standards, but be given the flexibility of meeting them using any vehicle technology they choose. EPA would be given the task of defining equivalent emission rates-based on ozone forming potential-of gasoline-, methanol- and CNG-fueled vehicles.

The Los Angeles area Air Quality Management District has already adopted the goal that by the year 2000, at least 15 to 30 percent of the motor vehicles in the area should be "clean fuel" vehicles [12]. To date, however, the district has not set forth its strategy for meeting that goal. 


\section{REFERENCES FOR CHAPTER 8}

1. Alson, J.A., "The Emission Characteristics of Methanol and Compressed Natural Gas in Light Vehicles," paper 88-99.3, presented at the 81st Annual Meeting of the Air Pollution Control Association (Dallas, TX: June 19-24, 1988).

2. Bockh, L., U.S. Environmental Protection Agency, personal communication, May 11, 1989

3. Clay, D.R., and Wilson, J.J., letter to R.E. Farris, Nov. 8, 1988.

4. Croes, B., California Air Resources Board, personal communication, December 1988.

5. Meiburg, M., U.S. Environmental Protection Agency, personal communication, Apr. 10, 1989

6. Nazemi, M., South Coast Air Quality Maintenance District, personal communication, December 12, 1988.

7. Princiotta, F., U.S. Environmental Protection Agency, personal communication, Oct. 4, 1988

8. Principe, P., U.S. Environmental Protection Agency, personal communication, April 1989

9. Pacific Environmental Services, Inc., Study of the 1979 State Implementation Plan Submittals (Washington, DC: National Commission on Air Quality, December 1980).

10. Sierra Research, Inc., Evaluation of the California Smog Check Program, Technical Appendix (April 1987).

11. Sierra Research, Inc., The Feasibility and Costs of More Stringent Mobile Source Emission Controls, contractor report prepared for the Office of Technology Assessment, Jan. 20, 1988.

12. South Coast Air Quality Management District Board, "Recommendation to Adopt a Five-Year Clean Fuels Program," December 1987.

13. Southern California Association of Governments, Draft Air Quality Management Plan, 1988 Revision, Appendix IV-G, "Transportation, Land Use, and Energy Conservation Measures" (Los Angeles, CA: September 1988).

14. Southern California Association of Governments, Transportation Policy Recommendations: The Olympic Legacy, Let's Keep It Moving (Los Angeles, CA: January 1986).
15. State and TerritoriálAir Pollution Program AdministratorsAssociation of Local Air Pollution Control Officials, The STAPPA-ALAPCO National Ozone Control Strategy, Executive Summary (May 1988).

16. Sullivan, M., Air Permit and Emissions Fees (Washington DC: State and Territorial Air Pollution Program Administrators/Association of Local Air Pollution Control Officials, April 1987).

17. Tesche, T., Radian Corp., personal communication, July 1986.

18. Twaddell, R., New York Department of Environmental Conservation, personal communication, $\mathrm{Au}-$ gust 1986.

19. U.S. Department of Transportation, Notice of Proposed Rulemaking, 53 FR 35178, Sept. 9, 1988.

20. U.S. Environmental Protection Agency, Guidance on Estimating Motor Vehicle Emission Reductions from the Use of Alternative Fuels and Fuel Blends, EPA report number EPA-AA-TSS-PA-87-4 (Research Triangle Park, NC: January 1988).

21. U.S. Environmental Protection Agency, Office of Air Quality and Standards, Implications of Federal Implementation Plans (FIPs) for Post-1987 Ozone Nonattainment Areas (March 1987).

22. U.S. Environmental Protection Agency, Federal Register, 52 F.R. 45044, Nov. 24, 1987.

23. U.S. Government Accounting Office, Ozone Attainment Requires Long-Term Solutions to Solve Complex Problems, GAO/RCED-88-40 (Washington, DC: January 1988).

24. U.S. Government Accounting Office, EPA's Ozone Policy is a Positive Step but Needs More Legal Authority, GAO/RCED-89-28 (Washington, DC: November 1988).

25. Walsh, Michael P., Critical Analysis of the Federal Motor Vehicle Control Program, report prepared for the Northeast States for Coordinated Air Use Management, July 1988.

26. Wojcik, M., Wojcik, J., Bareford, P., Havelock, M., Geraghty, M., Haupt, S. E., "Cost Analyses of Proposed Changes to the Air Quality Modeling Guidelines," EPA 450/4-82-014 (U.S. Environmental Protection Agency, February 1982). 
Appendix 
Appendix A

Parameters Used To Calculate Volatile Organic Compound Emissions Reduction Potential and Associated Costs of Control for Stationary Sources

The equation used to calculated total annual cost is given by:

Annual cost $=\left(\left(\mathrm{A}^{*} \mathrm{CC} * \mathrm{U}^{\mathrm{CE}}\right)+\left(\mathrm{OC} * \mathrm{U}^{\mathrm{OE}}\right)-(\mathrm{RI}+\mathrm{U} * \mathrm{RS})\right\}$

where, $\mathrm{A}=$ annualization factor (assume 10\% annual interest; incineration-15-year equipment life, others-10-year life),

$\mathrm{U}=$ uncontrolled VOC emissions, and other parameters defined in the column headings below. 


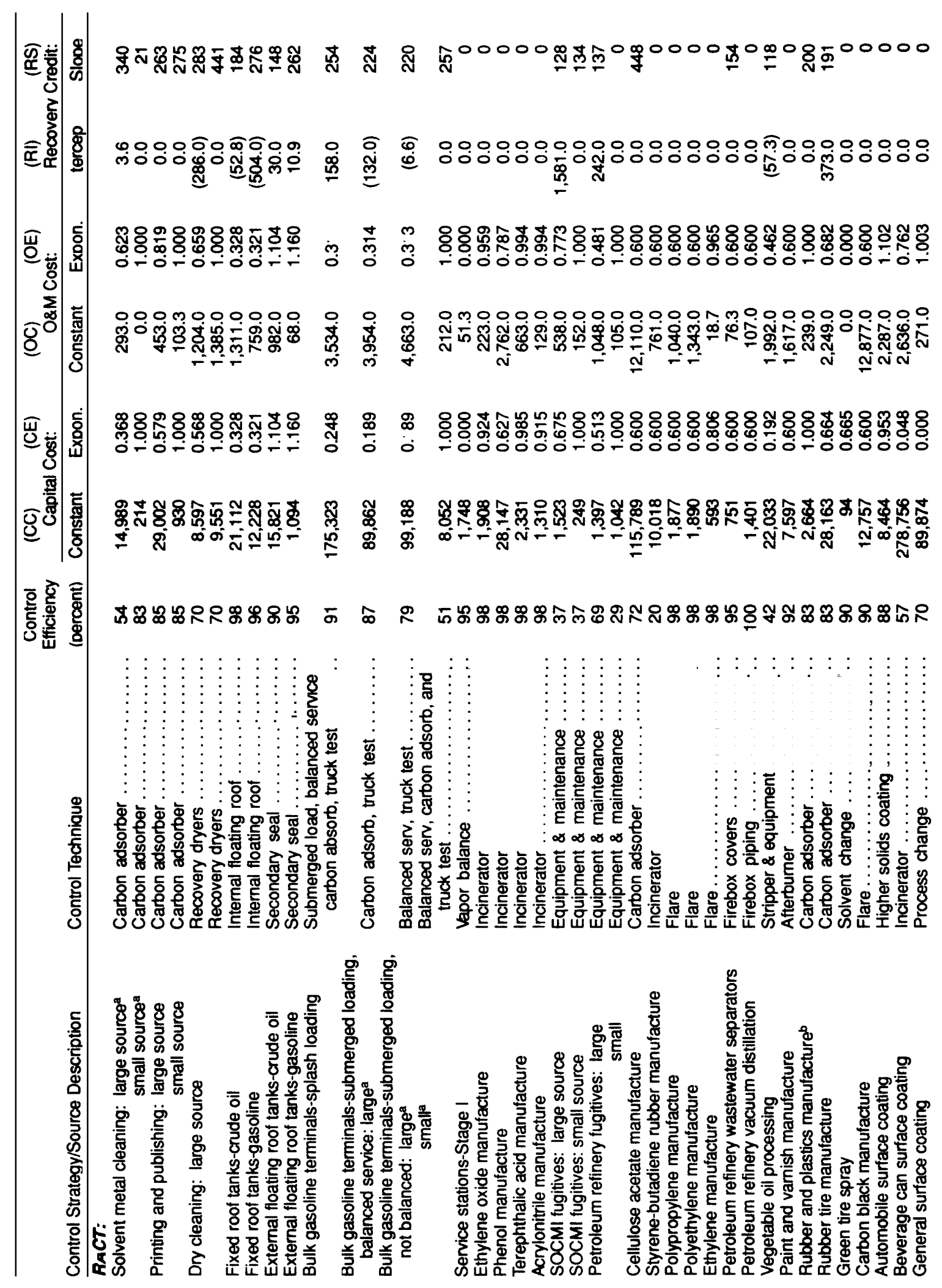




\section{Related OTA Report}

-Acid Rain and Transported Air Pollutants: Implications for Public Policy. OTA-O-204, 6/84; 324 pages. GPO stock \#052-003-00956-1; \$9.50.

NTIS order \#PB 84-222 967/AS.

NOTE: Reports are available from the U.S. Government Printing Office, Superintendent of Documents, Washington, D.C. 20402-9325 (202-783-3238); and the National Technical Information Service, 5285 Port Royal Road, Springfield, VA 22161 -O(X) I (703-4874650). 